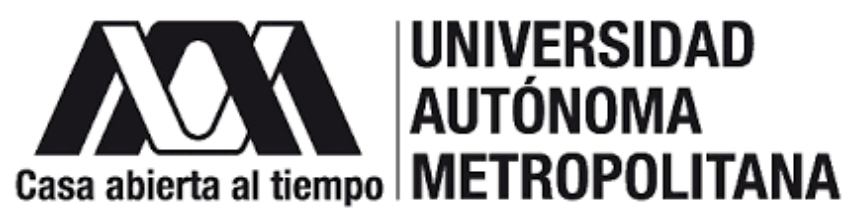

DIVISION DE ARTES Y CIENCIAS PARA EL DISEÑO

Especialización, Maestría y Doctorado en Diseño

\title{
LA MODERNIZACIÓN URBANA DE LIMA A FINALES DEL SIGLO XIX Jessica Esquivel Coronado
}

Tesis para optar el título de Doctor en Diseño Línea de Investigación Estudios Urbanos

Miembros del Jurado:

Dr. Armado Cisneros Sosa

Director de tesis

Dr. Gerardo Sánchez Ruíz

Co-Director de tesis

Dra. Teresita Quiroz Ávila

Dr. Manuel Carmona Lerdo de Tejada

Dr. Elías Huamán Herrera

Ciudad de México

Agosto, 2020 


\section{DEDICATORIA}

A mis padres Aurea y Víctor (+)

A mi familia Coronado Palma

A mi esposo Omar 


\section{AGRADECIMIENTOS}

Agradezco al Consejo de Ciencia y Tecnología por el apoyo recibido para la realización de este proyecto de Investigación. A la Universidad Autónoma Metropolitana por haberme brindado la oportunidad de continuar mi educación es este país.

A mi director de Tesis Dr. Armando Cisneros Sosa y a mí Co director Dr. Gerardo Sánchez Ruíz por el apoyo recibido durante el proceso de elaboración de mí proyecto de Investigación. A mis compañeros de estudio.

A la Biblioteca Nacional del Perú y al Archivo General de la Nación por brindarme todas las facilidades para poder acceder a la información requerida. A la Srta. Fiorella Margarita Mechato Lara por su apoyo en la digitalización de los documentos. 


\section{Índice General}

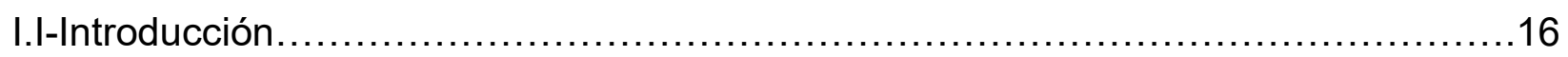

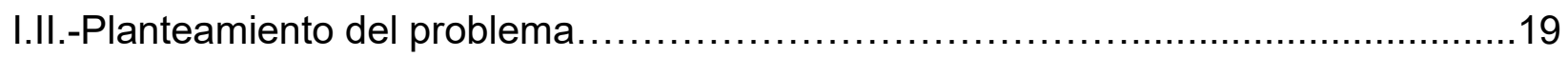

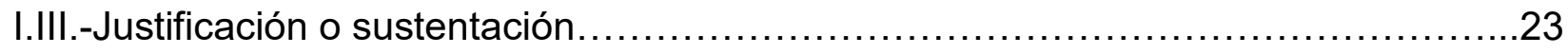

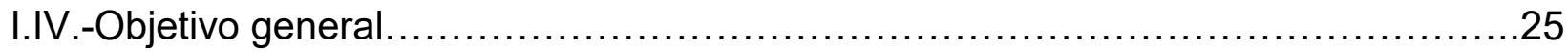

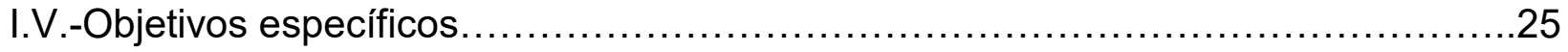

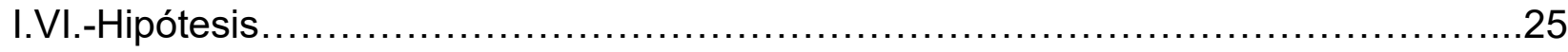

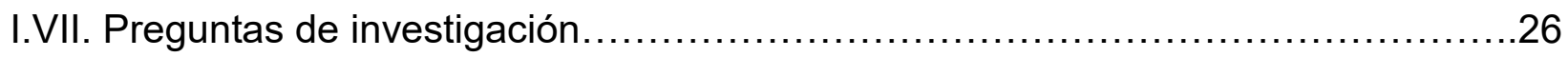

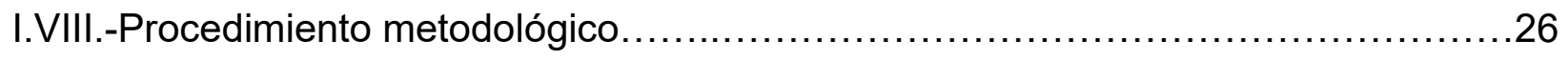

I.XIX.- Aportaciones al diseño en la línea de investigación en Estudios Urbanos.........28

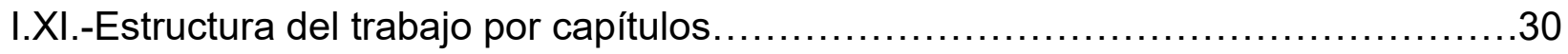

Capítulo I Desenvolvimiento social, la defensa de la ciudad de Lima y

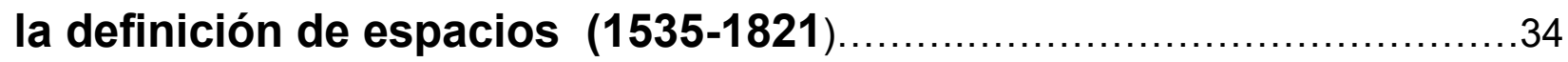

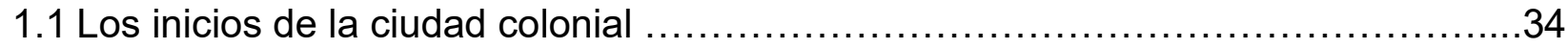

1.2 Determinantes del crecimiento de la ciudad en el siglo XVII: La centralidad y la construcción de muralla de Lima.................................................42

1.2.1 La centralidad de la ciudad Lima .............................................. 42

1.2.2 El debate, gestión y construcción de la muralla de Lima.........................44

1.3 El sismo de 1687 y el crecimiento urbano de la ciudad............................53

1.4 Las nuevas disposiciones para la ciudad de la Casa Borbón en el siglo XVIII........60 $1.5 \mathrm{El}$ terremoto de 1746 y la reconstrucción de Lima en un contexto de reformas Borbónicas.

1.5.1 Los planes para la reconstrucción de Lima: Las propuestas de los cosmógrafos Pedro de Peralta y Barrionuevo y Louis Godin. 
1.5.1.1 El proyecto del cosmógrafo Pedro Peralta y Barrionuevo: Lima la inexpugnable $(1740)$ 63

1.5.1.2 La propuesta del cosmógrafo Louis Godin y el Plan de Ensanche de calles.....65

1.5.1.3 El apogeo de Lima durante el reinado de la Casa Borbón en el siglo XVIII y la nueva demarcación territorial (1769-1785).

1.5.1.3.1 La implementación del "libre comercio" y su efecto en la ciudad (1778). .75

1.6 La formación del discurso ilustrado peruano ..................................... 81

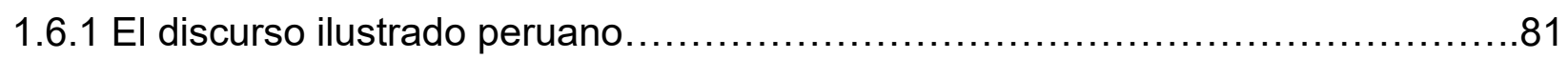

Comentarios generales del capítulo................................................ 86

\section{Capítulo II La nueva nación y la utopía de la modernización: la transformación de la ciudad con los ingresos del}

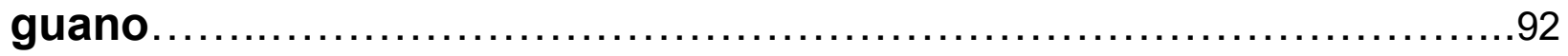

2.1 La construcción de la nueva nación peruana y la ciudad............................93

2.1.1 La subdivisión de las manzanas en las casas de vecindad y la aparición de los

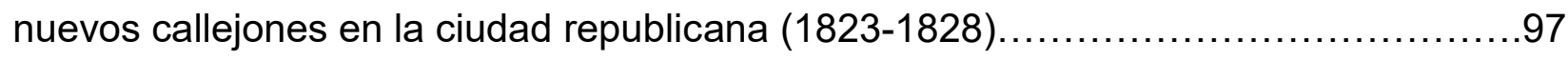

2.1.2 Los cambios en la ciudad a partir de la nueva demarcación: La salubridad, el

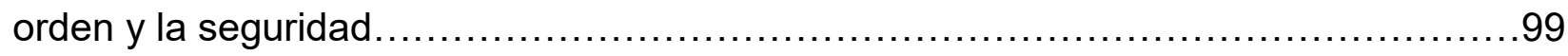

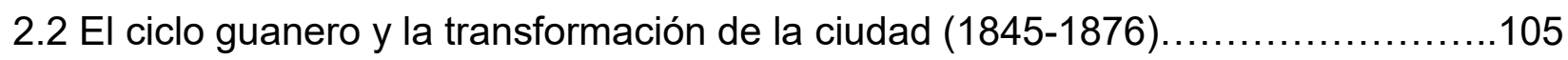

2.2.1. Un intento modernizador en la ciudad a cargo del presidente Ramón Castilla

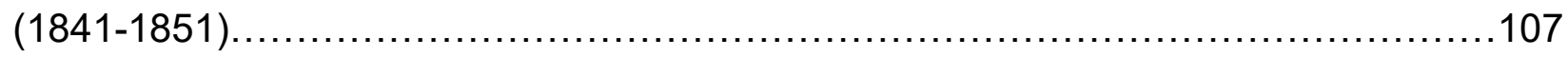

2.2.2 El segundo periodo de gobierno del presidente Ramón Castilla de rasgos

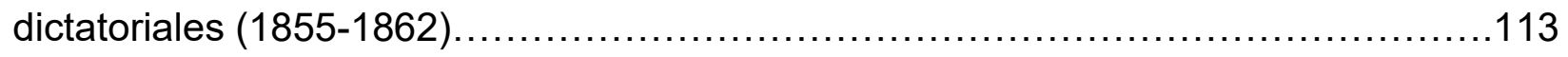

2.2.2.1 La urbanización de la periferia a cargo de la inversión privada: La urbanización "La Chacrita". 113 
2.2.2.2 La cartografía, la estadística, la continuidad de obras y el nuevo financiamiento

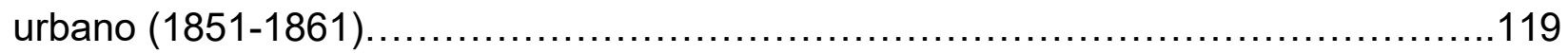

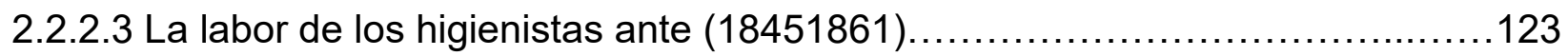

2.2.2.4 La utopía de la urbanización. Lima: un laboratorio urbano con obras de

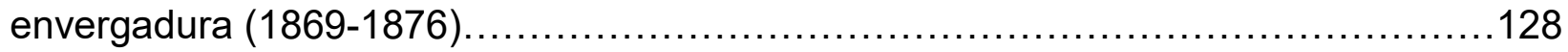

2.2.3 El gobierno del presidente José Balta y la ejecución de las obra de envergadura

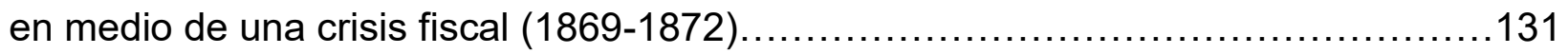

2.2.3.1 El discurso para la demolición de la muralla de Lima (1869-1877) .............134

2.2.4 El gobierno del presidente Manuel Prado y la república práctica (1872-1876)...142

Comentarios generales del capítulo ................................................. 146

Capítulo III la estructura de precios de la ciudad y la urbanización en la periferia: modernización inmobiliaria y bancaria (1872-1876).......150

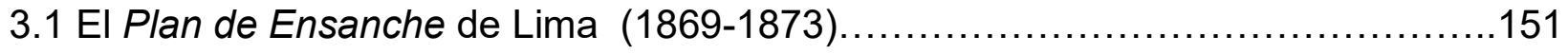

3.2 El Plano topográfico de Lima elaborado por Enrique Meiggs (1875)...............158

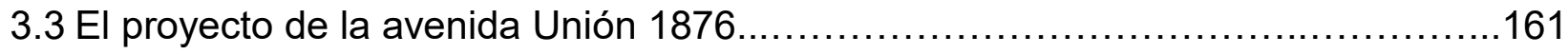

3.4 El mercado de suelo y la oferta de vivienda en la periferia al demolerse la muralla de

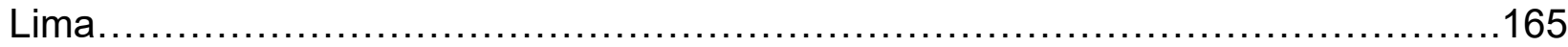

3.5 Los Bancos Hipotecarios y la Ley de Expropiación en apoyo a los fraccionadores

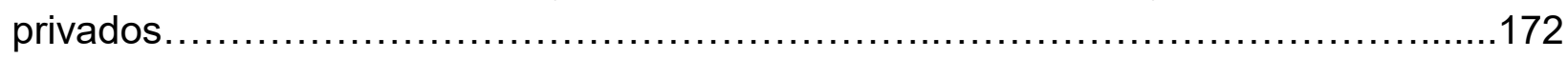

3.5.1. Créditos hipotecarios a favor de la redistribución de la propiedad.................173

3.5.2 Expropiación, permutas, enajenaciones forzadas y expropiaciones de

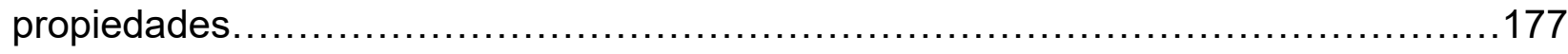

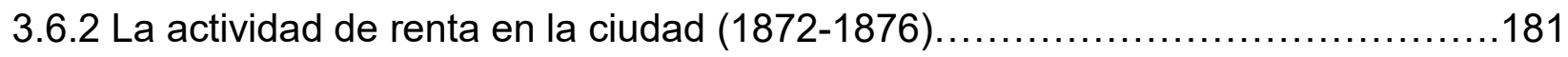

3.7 La estructura de precios en el centro y la periferia entre los años (1872-1876)....185

3.8 El diseño del mercado de suelo para la periferia según Enrique Meiggs

(1872-1876)

3.8.1 La urbanización al sur de la ciudad y la unión del tejido colonial con la periferia195 
3.8.1.1 La oferta inmobiliaria para la élite que se quedó a vivir en la ciudad 199

3.8.2 El trazado al este de la ciudad y la Plaza de la Guardia Nacional..................199

3.8.3 El registro de tenencia de propiedades en la tercera sección.......................199

3.8.4 La urbanización cerca a los óvalos Dos de Mayo y Unión..........................203

3.8.4.1 La oferta de lotes de vivienda y comercio para los inmigrantes.................204

3.8.5 El diseño de la Avenida Unión y la quinta sección..............................207

3.9 Los trabajos que ejecutó Enrique Meiggs del Plan de Ensanche (1872-1876).....209

3.10 La urbanización de la periferia a la ciudad.......................................215

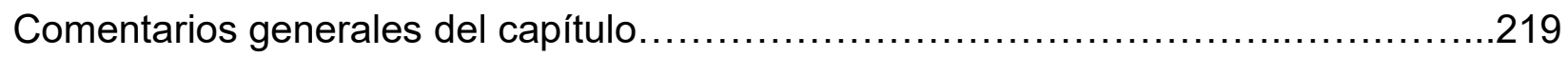

Capítulo IV El discurso modernizador civilista: La reubicación del centro y la expansión de la ciudad al sur-oeste (1878-1908) .............222

4.1 La ciudad durante la ocupación de las tropas chilenas y el periodo de

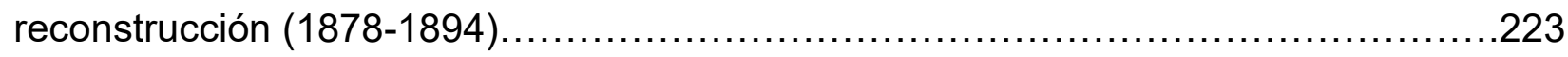

4.1.1 El gobierno del presidente Miguel Iglesias y los inicios de la reconstrucción de la

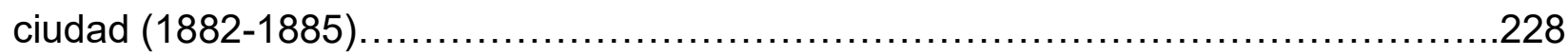

4.1.2 El primer gobierno del presidente Andrés Avelino Cáceres y la recuperación

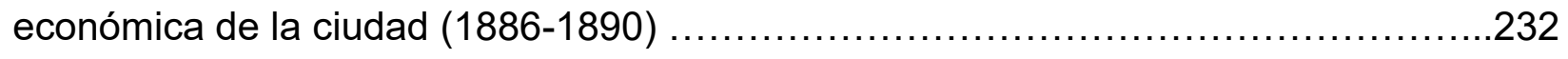

4.1.2.1 El proyecto de canalización del río Rímac elaborado por el ingeniero Felipe

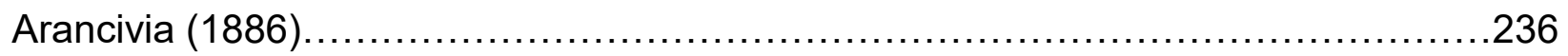

4.1.3 El gobierno del presidente Remigio Morales Bermúdez y la mejora de los servicios

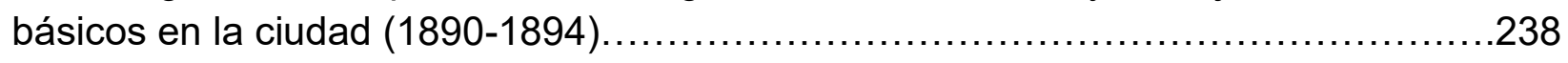

4.1.3.1 La intervención en la margen izquierda del río Rímac (1890) ...................241

4.2 La materialización del discurso civilista de modernidad y progreso urbano (1896-

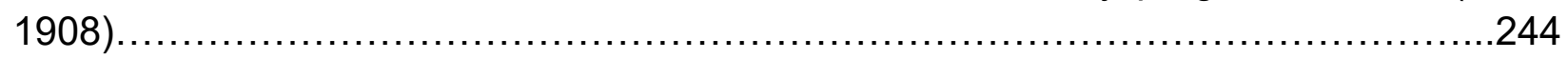

4.2.1 El segundo gobierno del presidente Nicolás de Piérola. Retomando la

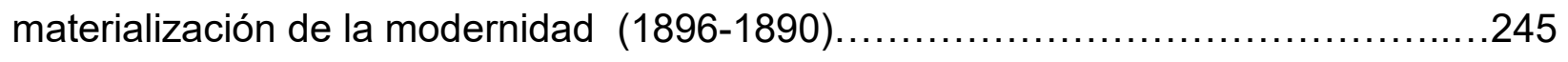

4.2.1.1 Regularización de la propiedad en la periferia $(1896-1897) \ldots \ldots \ldots \ldots \ldots \ldots \ldots . \ldots 247$ 
4.2.1.2 La matrícula de predios rústicos y la distribución de la propiedad en la ciudad el

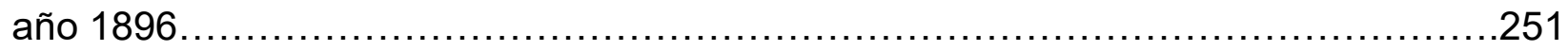

4.2.1.3 Retomando el proyecto del nuevo centro en la ciudad (1896-1899) ............253

4.2.1.4 El proyecto de la Avenida de La Magdalena (1899)..........................257

4.2.2 El gobierno de Eduardo López de Romaña y la inversión privada en la

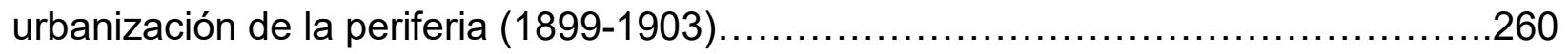

4.2.2.1 La ley de Expropiación de 1900 y la urbanización de la periferia con el apoyo de

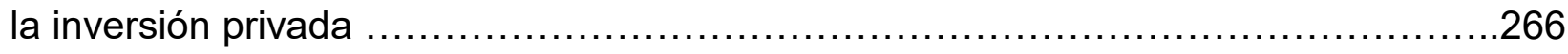

4.2.2.2 El caso de la avenida Interior o La Colmena (1901) ..........................267

4.2.3 El gobierno del presidente Manuel Candamo y la nueva Ley de Expropiación

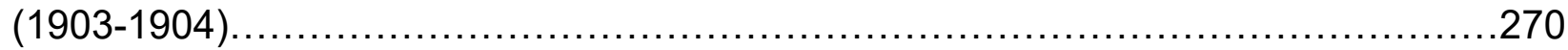

4.2.4 El gobierno del presidente José Pardo y Barreda y el problema de la salubridad en

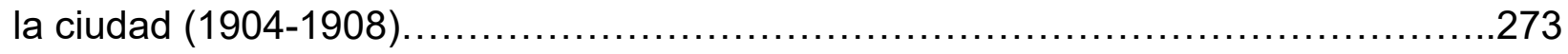

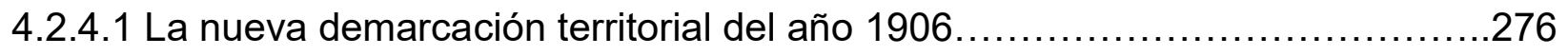

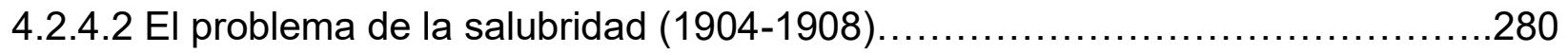

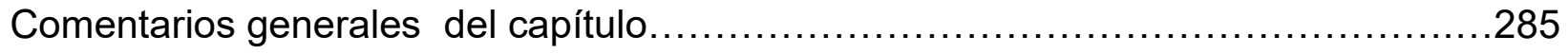

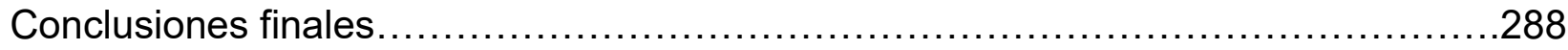

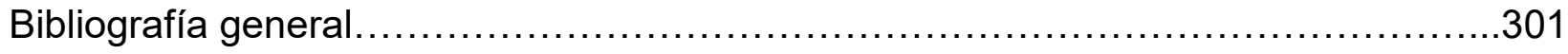




\section{Índice de planos, fotos y figuras}

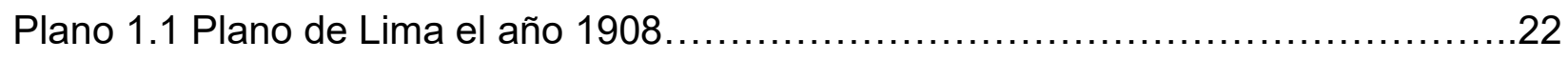

\section{Capítulo I}

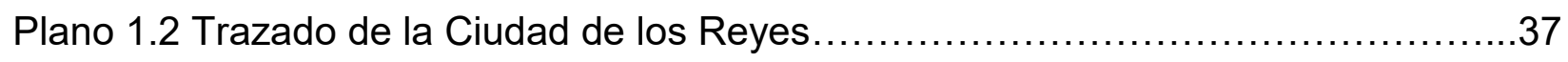

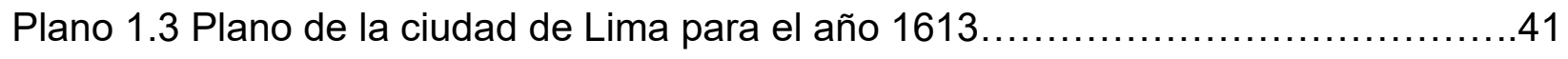

Plano 1.4 El proyecto de amurallar Lima a cargo de Juan Ramón Connick...............45

Plano 1.5 Ubicación de las portadas de la muralla....................................47

Plano 1.6 Ubicación de los barrios del Cercado y San Lázaro en el siglo XVII...........58

Plano 1.7 Ciudadela amurallada según Pedro de Peralta en $1740 \ldots \ldots \ldots \ldots \ldots \ldots \ldots . . \ldots 5$

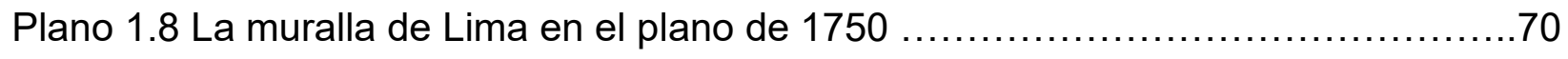

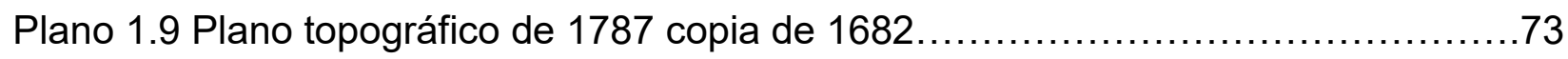

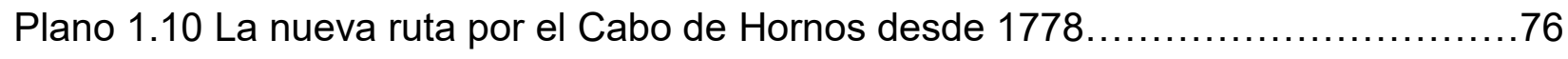

\section{Capítulo II}

Plano 2.1Demarcación territorial de 1828 en cinco cuarteles ...........................100

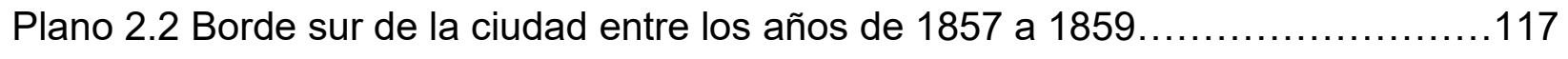

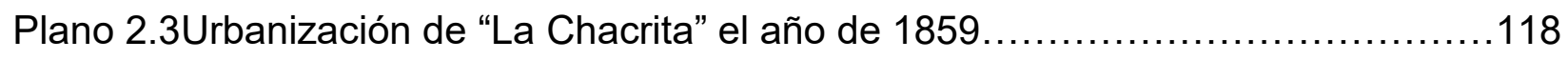

Plano 2.4 Plano de Lima elaborado por el ingeniero José María Dupard el año 1859120

Plano 2.5 Plano de Lima elaborado por Mariano Bolognesi el año 1862 ................121

Plano 2.6 Lima el año 1872 según J.P. Jouanny...................................130

\section{Capítulo III}

Plano 3.1 Plano topográfico de Lima en 1872 elaborado por Luis Sada di Carlo........152

Plano 3.2 Plano topográfico de Lima versión Enrique Meiggs año $1875 \ldots \ldots \ldots \ldots \ldots \ldots . . .159$ 
Plano 3.3 Plano de Lima y Callao y sus alrededores 1876 163

Plano 3.4Huertas ubicadas en la periferia de Lima para finales del siglo XIX y principios del XX. 171

Foto 3.1Precios arancelarios de la ciudad de Lima entre (1839-1944)..... 187

Plano 3.5 Estructura de precios en la ciudad (1870-1876). 189

Plano 3.6 Limites de las cinco secciones según Enrique Meiggs 195

Plano 3.7 Primera sección lado norte. 197

Plano 3.8 Primera sección lado sur. 197

Plano 3.9 Fragmento de la propuesta en la primera sección entre las calles Maipiri, Bogotá y Montevideo. 198

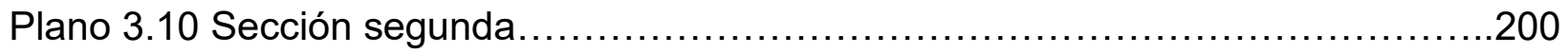

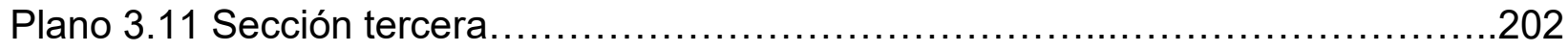

Foto 3.2 Baluarte $\mathrm{N}^{\circ} 2$ de la antigua muralla ubicado en Barrios Altos..................202

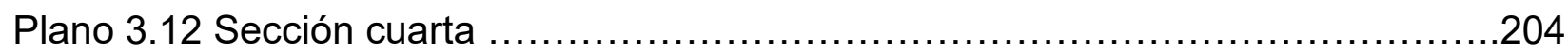

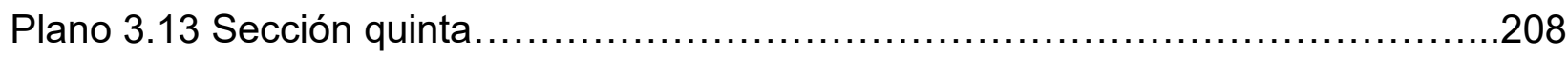

Plano 3.14 Fragmento de la quinta sección según el Sr. Aranibar.......................208

Plano 3.15 Detalle de la demolición del muro primera sección en la Avenida de

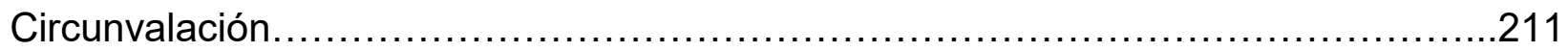

Plano 3.16 Detalle de demolición del muro en la calle Santiago........................214

Plano 3.17 Plano de la testamentaria de Enrique Meiggs.............................217

\section{Capítulo IV}

Plano 4.1 Ferrocarriles eléctricos de Lima, Callao, La Magdalena y Chorrillos por el

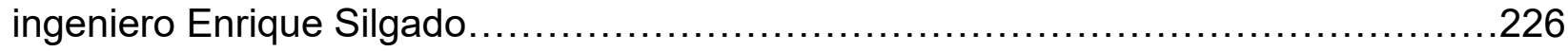

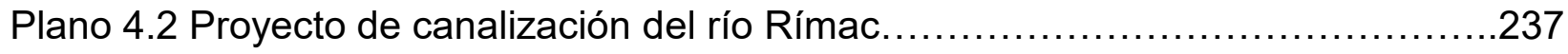


Plano 4.3 Lima el año 1896.

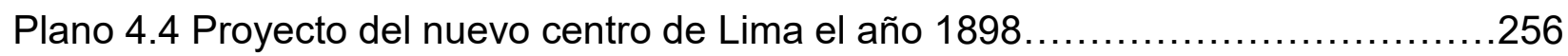

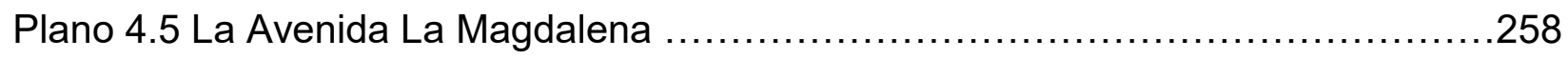

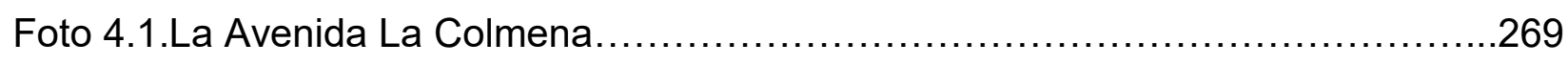

Plano 4.6 La demarcación territorial de Lima elaborada por Carlos Fabbri

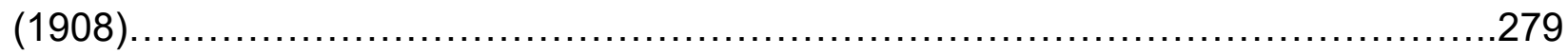

Figura 4.1 Intervención en el callejón de Petateros el año de $1906 \ldots \ldots \ldots \ldots \ldots \ldots \ldots . . \ldots 283$

\section{Índice de cuadros}

\section{Capítulo I}

Cuadro $1.1^{\text {a }}$ Proceso de gestión, evaluación y construcción de la muralla de Lima (1673-

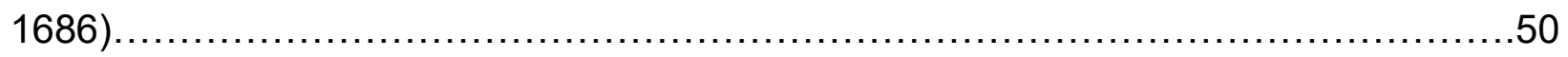

Cuadro 1.1b Proceso de gestión, evaluación y construcción de la muralla de Lima

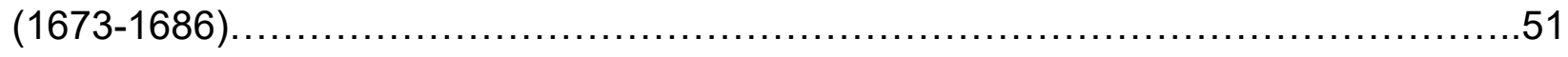

Cuadro 1.2 Edificaciones dañadas en el núcleo central de la ciudad el año $1687 \ldots \ldots . .55$

Cuadro $1.3^{\mathrm{a}}$ Edificaciones dañadas en la periferia de la ciudad el año $1687 \ldots \ldots \ldots \ldots . . .56$

Cuadro1.3b Edificaciones dañadas en la periferia de la ciudad el año $1687 \ldots \ldots \ldots \ldots . .57$

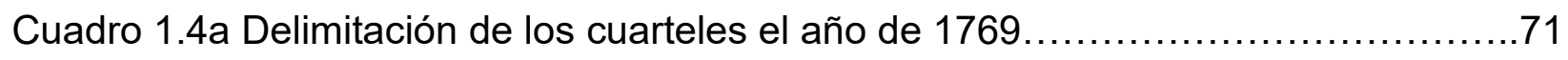

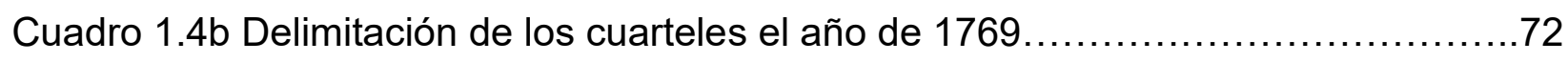

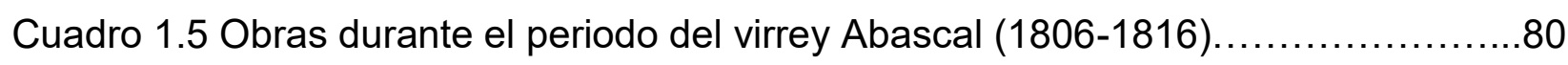




\section{Capítulo II}

Cuadro 2.1 Demarcación de los diez distrito según José María Urrutia el año 1828...102

Cuadro 2.2 Obras públicas durante el primer gobierno del presidente Ramón Castilla (1845-1851). 109

Cuadro 2.3 Obras públicas durante el segundo gobierno del presidente Ramón Castilla (1855-1862).

Cuadro 2.4 Obras públicas durante el gobierno del presidente José Balta (18691871).

Cuadro 2.5 Acciones ejecutadas para la demolición de la muralla (1868-1876)..... 138

Cuadro 2.6 Obras públicas durante el gobierno del presidente Manuel Pardo (1872).145

\section{Capítulo III}

Cuadro 3.1 Obras a ejecutar para materializar el Plan de Ensanche (18701876). 154

Cuadro 3.1b Obras a ejecutar para materializar el Plan de Ensanche (18701876). 155

Cuadro 3.2 Proceso general del Plan de Ensanche (1869-1876). 157

Cuadro 3.3 Variantes propuestas del plano topográfico al plano de Ensanche (18721875). 160

Cuadro 3.4 Proyectos y obras ejecutadas en el trayecto de Lima al Callao (18691872) 164

Cuadro 3.5 Huertas ubicadas en la periferia de Lima a finales del siglo XIX. 168

Cuadro 3.6 Hipotecas en la ciudad de Lima entre los años (1873-1875). 176

Cuadro 3.7 Expropiaciones, ventas forzosas y permutas en Lima entre (18721876) 179

Cuadro 3.8 Arrendamientos en la ciudad entre los años (1874-1875). 183

Cuadro 3.9 Compras ventas en la ciudad entre (1872-1873). 186 
Cuadro 3.10 Estructura del precios en la ciudad de Lima $(1870-1876) \ldots \ldots \ldots \ldots \ldots \ldots \ldots . . . \ldots 190$

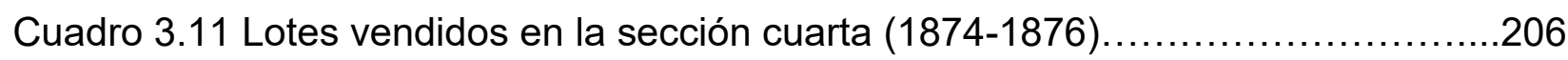

Cuadro 3.12 Obras a ejecutar del Plan de Ensanche primera sección (1872-1876)...210

Cuadro 3.13 Obras a ejecutar del Plan de Ensanche segunda sección (18721876).

Cuadro 3.14 Obras a ejecutar del Plan de Ensanche tercera sección (1872-1876)...212

Cuadro 3.15 Obras a ejecutar del Plan de Ensanche cuarta sección (1872-1876)....213

Cuadro 3.16 Resumen económico del negocio de Enrique Meiggs en la periferia de

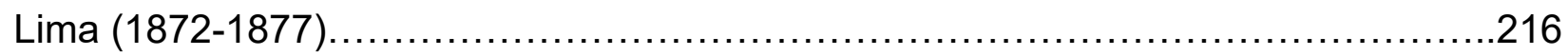

\section{Capítulo IV}

Cuadro 4.1 Obras públicas durante el gobierno municipal del alcalde Rufino Torrico el año 1881. 227

Cuadro 4.2 Políticas urbanas y obras públicas durante el gobierno del presidente Miguel Iglesias (1884-1885). 231

Cuadro 4.3 Obras públicas durante el primer gobierno del presidente Andrés Avelino Cáceres (1886-1887). 235

Cuadro 4.4 Obras públicas durante el gobierno del presidente Remigio Morales Bermúdez (1890-1893).................................................................240

Cuadro 4.5 Obras a ejecutar por la empresa de Ferrocarriles del Perú en la margen izquierda del río Rímac 242

Cuadro 4.6 Obras durante la guerra civil el año 1895. .243

Cuadro 4.7 Obras durante el segundo gobierno del presidente Nicolás de Piérola (18961897). 246

Cuadro 4.8 Acciones para el saneamiento legal en la periferia a cargo del Estado (1896-1897) 249

Cuadro 4.9 Catastro de Lima y poblaciones cercanas el año 1896. .252 
Cuadro 4.10 Avenidas y calles aperturadas (1896-1899).

Cuadro 4.11Acciones ejecutadas durante la obra de la Avenida de La Magdalena (1899-1901) 259

Cuadro $4.12^{\mathrm{a}}$ Obras públicas durante el gobierno del presidente Eduardo López de

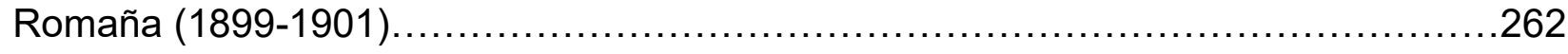

Cuadro 4.12b Obras públicas durante el gobierno del presidente Eduardo López de

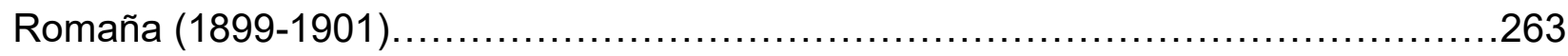

Cuadro 4.13 Obras públicas durante el periodo del presidente Manuel Candamo y el gobierno provisional a cargo del presidente Serapio Calderón (1903-1904). 271

Cuadro 4.14 Cuadro de obras públicas durante el gobierno del presidente Manuel Pardo

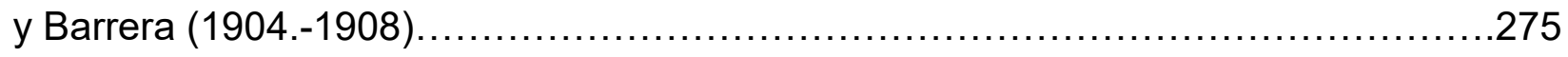

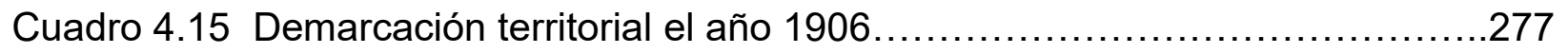




\section{Introducción}




\section{I.I-Introducción}

Esta tesis tuvo por objeto el conocimiento de la modernización urbana en la ciudad Lima a finales del siglo XIX. Para ello ha sido necesario realizar un análisis histórico que nos ha permitido conocer el pasado para comprender los problemas urbanos que en la actualidad tiene la ciudad de Lima de allí la importancia de realizar un análisis historiográfico. A través de un estudio multidisciplinario, fue posible conocer las particularidades del proceso de urbanización de Lima en el siglo XIX, que como muchas capitales de Latinoamérica, buscaron alcanzar el progreso.

En el caso de la ciudad de Lima, el proceso de modernización se dio a partir de la demolición de la muralla; cuando inició su crecimiento urbano en la primera mitad del siglo XIX y principios del siglo XX. Para ese entonces, el Estado buscó materializar la modernización urbana a base de la mercantilización de suelo, por esa razón, propició dos procesos especulativos de suelo. En un primer momento, el Estado entregó para su ejecución el Plan de Ensanche al fraccionador Enrique Meiggs generando un monopolio inmobiliario en la periferia. En un segundo momento, el Estado mediante la puesta en vigencia de la Ley de Expropiación de los años 1900 y 1903 facilitó la compra de suelo en la periferia a los inversionistas privados generando procesos especulativos de suelo. A continuación, algunas características del proceso de urbanización por el que atravesó la ciudad de Lima que serán analizadas en cada uno de los capítulos de la presente investigación.

En el año de 1535, con su fundación, dio inicio el proceso de urbanización de Lima colonial. A partir, de ese momento, el factor de localización, respecto a su ubicación central frente al océano Pacífico, comenzó a tener especial ventaja e importancia para el desarrollo de la ciudad. La ubicación y su carácter de sede del virreinato del Perú contribuyeron a hacer de Lima un espacio de conexión estratégica con la corona española y, paradójicamente, de atractivo para la piratería de la época.

Entre las amenazas piratas que sufrió la ciudad estuvo la del inglés Francis Drake. En el año 1579, quien atacó los puertos del Callao y Paita (Augustín, 2011:26). Así como la 
intervención del pirata Jois van Spielbergen, que llegó a las costas del Callao el año de 1615 (Augustín, 2011:33). Poco después, el $1^{\circ}$ de agosto de 1618, el provincial de la Compañía de Jesús, Diego Álvarez de Paz, solicitó al virrey Francisco de Borja y Aragón ${ }^{1}$ la construcción de defensas para el resguardo de la ciudad de Lima. A esa propuesta se sumaron las demás órdenes religiosas debido a que ellas guardaban una parte importante de las riquezas de la ciudad (Augustin,2011:92). Fue así como se produjo una discusión entre las autoridades del Cabildo y las autoridades religiosas, lo que dio como resultado el levantamiento, entre 1684-1687 de la muralla, recurso para la protección de la población y sus riquezas. Este hecho generó que la ciudad limitara su crecimiento urbano a la estructura artefacto muralla.

En 1687 la ciudad sufrió un sismo dañando la muralla y se inició un proceso de reconstrucción urbana. (Angulo, 1939:7) Para aquel entonces, mientras en el centro se ordenaba en base al damero, los barrios periféricos que rodeaban la ciudad, ocupados por indígenas, habían tenido un proceso de crecimiento desordenado, que fue puesto en vigencia como consecuencia de las pugnas de los propietarios, después de la distribución de tierras, según las Leyes de Indias $^{2}$. Un siglo más tarde, el terremoto de 1746 (Odriozzola,1863:36), generó la oportunidad de introducir las reformas borbónicas en la ciudad, entre ellas, recaudar dinero proveniente de los impuestos y restarle poder a la Iglesia. No obstante, la reconstrucción de la ciudad estuvo a cargo del virrey Manso de Velasco que con una visión más racional decidió intervenir y, para ello, convocó al cosmógrafo francés Louis Godin que diseño el primer Plan de Ensanche de Calles (Walker,2012:131-135). Esta propuesta, junto con la propuesta de nueva ciudadela amurallada para Lima, la cual nunca se construyó, estuvo a cargo de Pedro Peralta y Barrionuevo (Eguiguren,1966:10-17), significando la llegada de las ideas de la ilustración a la ciudad.

En el año de 1821, con la firma del acta de la independencia (Ávila, 2013:241-274), la ciudad inició su etapa republicana y atravesó por un proceso de transición política

\footnotetext{
${ }_{1}^{1}$ Francisco de Aragón segundo Conde de Mayalte y Príncipe de Esquilache fue virrey del Perú en el periodo de 1615-1622

2 Ley VI “Que las tierras se repartan con ayuda del procurador (Roix, 1841:119).
} 
administrativa. A partir de 1845, con el inicio de las exportaciones del guano y la aplicación del discurso liberal, los gobiernos (conservadores, intervencionistas y liberales) intentaron la modernización de la ciudad. En el año de 1870, el estado decidió la demolición de la muralla de Lima. Este hecho, inició un cambio en la ciudad bajo las ideas de modernizar, expandir, embellecer y mejorar la salubridad. Sin embargo, en el año de 1879, al producirse la guerra del Pacífico, las actividades de la ciudad se paralizaron y fue hasta la retirada de las tropas chilenas cuando las autoridades locales iniciaron la reconstrucción de la ciudad. Con la llegada de la república aristocrática durante el gobierno del presidente Nicolás de Piérola (1895-1898) se retomó la modernización de la ciudad y se planteó la refuncionalización del centro. En este momento la élite limeña continúo su éxodo hacia los suburbios del sur pero ante la necesidad de conectar estas nuevas urbanizaciones ubicadas en la zona de expansión con el centro surgieron las avenidas centrales generándose un nuevo trazado urbano entre el centro y la periferia.

Para inicios del siglo XX la ciudad había crecido hacia el sur y las autoridades se encontraban con el reto de intervenir la nueva periferia, terminar con los problemas de insalubridad y planificar el crecimiento de las nuevas poblaciones ubicadas al sur. En 1908, la ciudad seguiría el curso de una economía liberal y un intenso proceso de metropolización. 


\section{I.II-Planteamiento del problema}

Esta investigación busca conocer el proceso de modernización urbana de Lima a finales del siglo XIX y principios del siglo XX. Se trata de un fenómeno que requiere ser estudiado desde diversos ángulos $\mathrm{y}$, por tanto, es posible estudiarlo desde la historia urbana, que es una disciplina, que tiene por objetivo la investigación histórica de la ciudad con una mirada multidisciplinaria que la vincula en términos generales al campo de los Estudios Urbanos (Martínez, 2020:06) ${ }^{3}$. La ciudad es entendida como un objeto urbano, producto de los procesos sociales y, a la vez, influyendo en los mismos.

En esta investigación, se busca analizar los procesos de trasformación urbana por los cuales transitó la ciudad de Lima a cargo de la élite y los gobiernos de turno durante el siglo XIX. El papel de estos actores, en el proceso de modernización ocasionó transformaciones en los ámbitos sociales, políticos (Berman, 1989:121-122) ${ }^{4}$ que produjeron fragmentos de espacios modernos al interior de la ciudad. En el caso de Latinoamérica "la modernidad fue un camino para alcanzar la modernización, (e) intentó presentar la voluntad ideológica de una cultura para producir un determinado tipo de transformación estructural" (Gorelik,2003:15), lo que se tradujo en transformaciones en la ciudad. En el caso de Lima, la primera modernidad se dio a partir del periodo de la ilustración. La materialización de la modernidad ${ }^{5}$ fue producto del binomio ilustraciónmodernidad. Como explica Jorge Larraín la modernidad, se dio sobre la base de: "ideas clave como libertad, tolerancia, ciencia, progreso, y razón en oposición a la metafísica,

\footnotetext{
3 Gerardo Martínez Delgado nos dice “La historia urbana en primer lugar, como historia general debería renovar permanentemente su dialogo con otras disciplinas; pero, aun más debía abrir un diálogo sostenido con el presente, con los problemas urbanos contemporáneos y con las formas en que se estudian". "Derribar muros. De la historia urbana a los estudios urbanos con perspectiva histórica: propuestas teóricas metodológicas desde un dialogo interdisciplinar". En: Revista Eure Vol.46 $N^{\circ} 137$ Enero 2020, pp.23.

${ }^{4}$ Según Berman "Específicamente, se puede clarificar la relación entre la cultura modernista y la economía de la sociedad burguesa "_ el mundo de la modernización__ de que aquella emano. Veremos que tienen mucho en común lo que tanto los modernistas y la burguesía les gustaría pensar" "Los solido se desvanece en el aire- La experiencia moderna" Marshall Berman, México, Ed. Siglo XXI, pp.84

${ }^{5}$ Según Bibiana Cicutti, "Sí convenimos que la modernidad se encuentra circunscrita por una serie de acontecimientos tales como: la Revolución Industrial, los cambios políticos en Inglaterra en el siglo XVIII, las revoluciones francesas y americanas, los procesos de urbanización y democratización consecuentes, así como el surgimiento de una concepción empírica y analítica del acontecimiento etc. Advertimos prontamente que se trata de fenómenos desiguales, dispersos en el tiempo y en el espacio, y que no siempre se desarrollan en forma simultánea"."Registros Urbanos de una modernidad periférica: Representaciones y transformaciones materiales en el frente costero de Rosario 1920 y 1940", Ed. Nobuko, Buenos Aires, pp.43.
} 
la superstición y la religión. Tenían especial importancia las ideas de libertad y autonomía individual en todos los niveles" (Larrain,2004,29). Como parte de ese proceso, para la primera mitad del siglo XIX, los gobiernos liberales y la élite limeña emprendieron un nuevo intento de modernización urbana, pero esta vez, sobre la base del discurso político denominado discurso ilustrado peruano que fusionaba ideas e ideales que vinieron de Europa a finales del siglo XVIII y que fueron discutidas y asimiladas a la realidad peruana por un grupo de intelectuales de la clase criolla. En este caso, se trató de una modernidad en un contexto revolucionario. Desde mediados del siglo XIX, con los ingresos del recurso guano, fue posible la materialización de la modernización urbana. La modernización fue un objeto de reforma para alcanzar el ideal civilizador y de progreso que condujera a dejar atrás el pasado y buscar un mejor futuro (Gorelik,2003:16 ${ }^{6}$ ) a cargo de la oligarquía. La idea era satisfacer las demandas de las clases acomodadas con espacios modernos en fragmentos de la ciudad, como en el centro, cerca al Palacio de la Exposición.

En la ciudad de Lima, la muralla de la ciudad y los diferentes ensanches a lo largo del siglo XIX definieron momentos importantes de la ciudad en busca del deseo de modernizar, que en este caso, se dio en medio un procesos especulativos con el aval del Estado con la intención de activar la economía de la ciudad y generar un crecimiento económico. Por ello, este trabajo, trata de mostrar que el proceso especulativo en Lima tuvo dos momentos importantes. El primero, cuando se encontraba en proceso de demolición la muralla de Lima el año 1870 y Enrique Meiggs ejecutaba el ensanche y urbanizó de manera privada. Un segundo, momento fue la aplicación de la Ley de Expropiación, dándole el control de la urbanización a la empresa privada.

El objetivo general nos llevó a la necesidad de conocer las políticas que implementaron los gobiernos liberales de turno y saber cuáles fueron las consecuencias de la reglamentación de la ciudad. También a observar cómo los gobiernos centralistas

\footnotetext{
${ }^{6}$ Gorelik Adrian “Ciudad, modernidad, modernización, Revista Universitas Humanística, Núm. 56 junio 2003,pp.11-27 Universidad Javeriana, Bogotá, Colombia.
} 
decidieron utilizar el dinero del guano para emprender obras de modernización en la ciudad. Sin embargo, la guerra del Pacífico con Chile significó una interrupción en el proceso de ensanche de la ciudad. La ciudad ingresó en un proceso de reconstrucción. A principios del siglo XX, la falta de un diagnóstico sobre el problema de insalubridad del centro llevó a la Municipalidad a intervenir algunas manzanas donde se presentaban los problemas más críticos.

La zona de estudio comprende lo que se conoce actualmente como Centro Histórico de Lima y llega hasta la actual avenida 28 de julio siguiendo el catastro del Registro de Predios de 1897 (Junta Departamental,1897) y el plano elaborado por Ricardo Tizón y Bueno el año 1908 (Ver plano 1.1). Durante los distintos periodos de su historia, a medida que Lima experimentó un cambio de administración y crecimiento urbano, las demarcaciones se fueron transformando desde cinco cuarteles o distritos hasta siete distritos a inicios del siglo $\mathrm{XX}$, todo ello en medio de problemas de insalubridad, tugurización y hacinamiento en el centro. Sin embargo, el Estado buscó complacer a la élite modernizando la ciudad y construyendo nuevas vialidades que permitieran la conexión del centro con los balnearios del sur. 


\section{Plano 1.1 Plano de Lima año 1908}

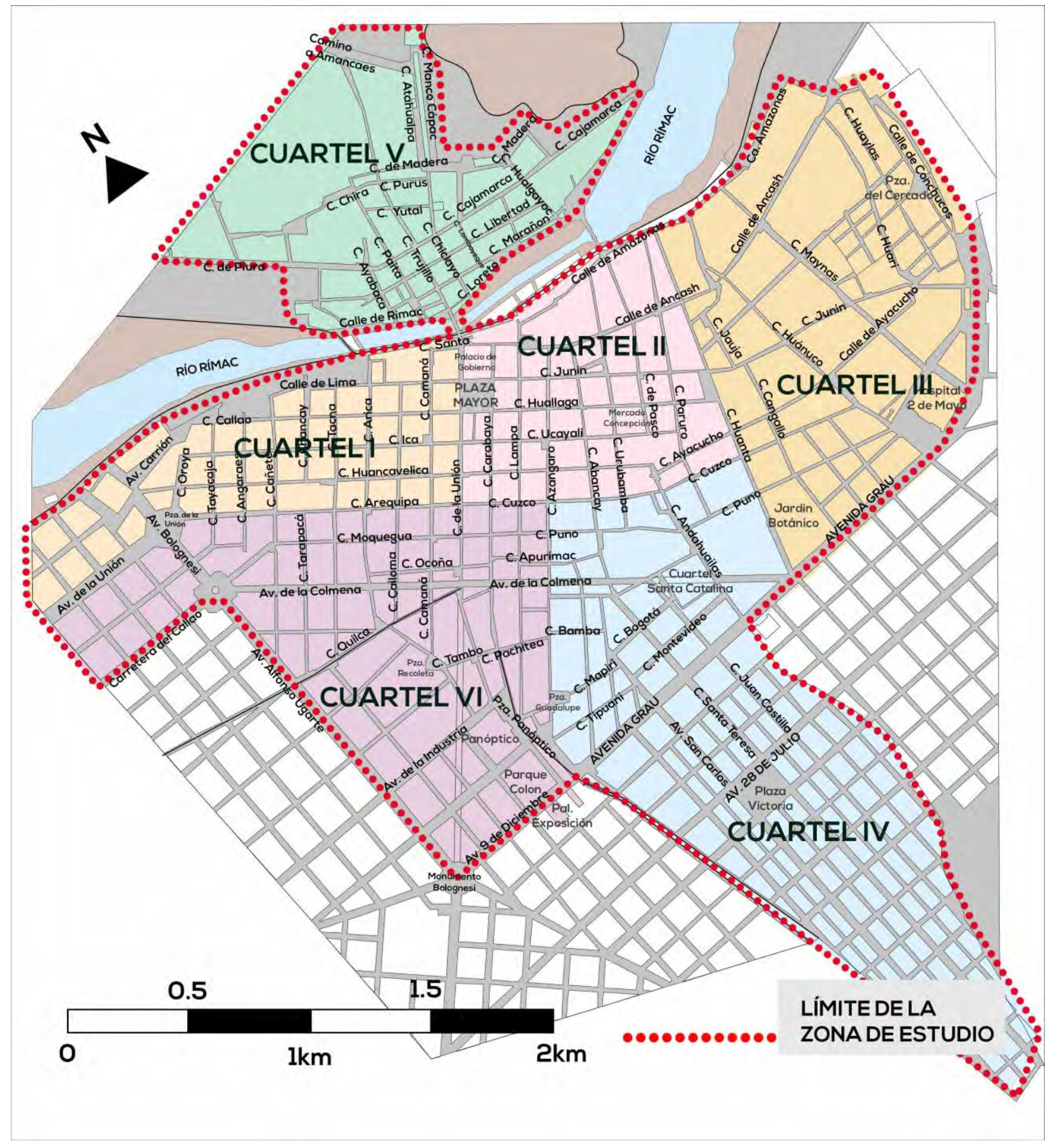

Fuente: Junta Departamental (1897), Tizón y Bueno (1908), Fabbri (1908) 


\section{I.III.- Justificación o sustentación}

Para poder entender las características de la modernización de la ciudad de Lima, es necesario conocer los principales procesos de urbanización que atravesó la ciudad desde su fundación española y que constituyeron antecedentes directos de la modernización del XIX. Por esa razón, nos sentimos en la necesidad de construir una historia urbana ${ }^{7}$ de la ciudad de Lima, para conocer qué tipo de procesos urbanos aparecieron durante la colonia y el siglo XIX, en particular con vínculos espaciales con la muralla. Esto bajo el entendimiento de la ciudad como una sucesión de capas de tejido urbano que pertenecen a distintos momentos de su historia como son: el periodo colonial, el republicano y principios del siglo XX.

Consideramos que la muralla de Lima, marcó un momento importante para la ciudad, debido a que los gobiernos liberales de esta época decidieron que la inversión privada urbanizara la periferia del espacio histórico. Fue una forma de interpretar y ejecutar la modernidad. Se produjo así un proceso especulativo de suelo cuyo resultado fue el desorden en la urbanización, lo que trajo como consecuencia que en la actualidad existan colonias que funcionan como islas desarticuladas dentro del Centro Histórico de Lima, ocasionando desorden urbano, deterioro de las edificaciones, servicios y equipamiento, resultado de materializar la modernidad en la ciudad de Lima.

En esta investigación fue necesario conocer las razones por las cuales la ciudad fue amurallada y como este hecho afectó la vida de la ciudad y su crecimiento urbano en el periodo colonial. Adicionalmente, buscamos ver cómo las ideas de la ilustración que llegaron de Europa influyeron en la construcción del discurso ilustrado peruano que seguirían los gobiernos de turno para materializar la modernidad en la ciudad. Así

\footnotetext{
7 Según Liliana Rueda el concepto de historia urbana es "un forma de conocimiento caracterizado por las implicaciones decididamente dialécticas que se producen entre fenómenos socio-económicos y las necesarias repercusiones espaciales que los exteriorizan y lo expresan (Álvarez, 1996 p.30) en la que la ciudad es el objeto de estudio como "producto social". Para Álvarez Mora la historia urbana debe de contener como necesidad epistemológica componentes espaciales y propone los siguientes puntos fundamentales como "presupuesto metodológicos"; primero, el componente espacial pasa a primer plano; segundo, que los componentes que participan en la construcción física de la ciudad hagan parte de los componentes metodológicos de investigación y análisis; y tercero, que el conocimiento del plano de la ciudad permita reflexionar sobre el tipo de ciudad que ha producido" "Hacia un estado del arte de la historia urbana en Colombia: el caso de Bogotá" En Revista Apuntes, Vol. 29 Núm. 02, 2016, Bogotá, pp.56-67.
} 
también, cómo su destrucción en el periodo republicano permitió el ensanche de la ciudad. Las fuentes primarias de documentos ubicados en el Archivo General de la Nación y en la Biblioteca Nacional han sido útiles para esta investigación. Con su revisión hemos entendido el debate sobre la construcción de la muralla. De la misma manera, los documentos oficiales de la gestión de los gobiernos liberales, las Actas de la municipalidad de Lima, así como el Boletín de Salubridad y La Crónica Médica, nos describen los esfuerzos del gobierno local por solucionar el problema de la salubridad. Todos estos documentos, junto con los estudios de investigadores de la historia colonial, republicana y contemporánea nos ayudaron a conocer el proceso de modernización urbana de la ciudad de Lima.

Con la finalidad de establecer algunas coincidencias en los procesos de urbanización entre Lima y México, incluimos algunos trabajos de teóricos latinoamericanos que han estudiado los procesos desde una mirada del urbanismo, la planificación, la historia, las ciencias sociales, permitiendo el dialogo con otras disciplinas para entender de manera más integral la construcción de la ciudad de Lima y de esta manera vincular el pasado con el presente (Martinez,2020:23).

Al buscar coincidencias buscamos que las investigaciones sobre México nos brinde una forma de analizar nuestra investigación. De esta forma hemos tratado de abordar esta investigación buscando un análisis de las transformaciones que tuvo la ciudad y las repercusiones en su espacialidad y forma urbana ${ }^{8}$. Para ello hemos recogido las investigaciones de: "Modernidad e ilustración" de Jorge Larraín (1996), "Los precursores del urbanismo" de Gerardo Sánchez (2013), "El contratista de don Porfirio obras pública, deuda y desarrollo desigual” Priscilla Conolly (1997), "La traza del poder: historia de la política y los negocios urbanos en el Distrito Federal: De sus orígenes a la

\footnotetext{
${ }^{8}$ Según Arturo Almandoz "Puede entenderse el urbanismo como una disciplina que por su naturaleza es primordialmente practica sin excluir componentes técnico-artísticos, así como tampoco un corpus teórico en el proceso de formación. Por lo que concierne a su objeto, el urbanismo se ocupa de la explicación analítica y sintética de la forma urbana principalmente a la ciudad como una manifestación histórica, aunque también de la región o el territorio, pero primordialmente se encarga de la ordenación de tales objetos, distinguiéndose la ordenación practico-política sobre las actividades económicas y la organización social de esa forma urbana, así como la ordenación técnico constructiva y ambiental sobre su espacio y territorio". "Reconsideraciones epistemológicas y conceptuales sobre el urbanismo", En: Revista EURE, vol. 46 Núm. 137, enero 2020, Santiago de Chile, pp. 282-283.
} 
desaparición del ayuntamiento (1824-1928)" de Jorge Jiménez (1993), "La ciudad que hoy es centro" de Oscar Terrazas (2010) y "Antologías-Ensayos urbanos La ciudad de México en el siglo XIX" María Dolores Morales (2011) entre las investigaciones que hemos revisado.

\section{I.IV.-Objetivo general}

Conocer las principales características del proceso de urbanización de Lima en el siglo XIX, tratando de explicitar la manera en que ese proceso constituyó una parte importante de su modernización.

\section{I.V.-Objetivos específicos}

-Conocer cómo influenció la construcción de la muralla de Lima en el crecimiento y desenvolvimiento del urbanismo durante los siglos XVII y XVIII, como parte de una etapa premoderna, y cómo, durante el siglo XIX, con la destrucción de la muralla, inició una serie de transformaciones en la ciudad por parte de los gobiernos de turno en busca de la modernización.

-Analizar las obras públicas ejecutadas por los gobiernos de turno desde mediados del siglo XIX para conocer las particularidades del proceso de expropiación, como parte de la modernización.

-Entender las causas y consecuencias de mercado de suelo en la periferia de Lima, como consecuencia de la demolición de la muralla de Lima.

-Identificar las causas que influenciaron a la élite a salir del núcleo central a la periferia.

-Entender hasta qué punto intervino la inversión privada en la urbanización de la ciudad en la zona de expansión, lo que provocó el desorden en la urbanización de la zona de expansión. 


\section{I.VI.-Hipótesis}

La modernización urbana de la ciudad de Lima tuvo como uno de sus pilares la expansión de la ciudad, lo que incluyó la destrucción de la muralla, proceso en el que participaron las decisiones políticas de los gobiernos liberales de turno.

\section{I.VII.-Preguntas de investigación}

¿Qué factores influenciaron en la construcción de la muralla de Lima y, por consiguiente determinaron, su espacialidad?

¿Fue la reorganización de las instituciones de Estado y la Municipalidad un factor decisivo para que los gobiernos de turno emprendieran la modernización de la ciudad de Lima?

¿La demolición de la muralla de Lima puso al descubierto los intereses económicos, y políticos de la élite y los gobiernos de turno para materializar la modernidad urbana, y hasta qué punto, estas intervenciones favorecieron a la población para evitar un enfrentamiento entre los distintos sectores de la sociedad?

¿La falta de un adecuado intervencionismo Municipal en los procesos de expropiación de suelo por parte los inversionistas privados generó un desorden en la urbanización en la periferia?

\section{I.VIII.-Procedimiento metodológico}

La metodología utilizada para estudiar la transformación urbana fue básicamente el análisis de documentos y bibliografía histórica. Este es un proceso común en los Estudios Urbanos. Vemos como los arquitectos analizan la ciudad y la arquitectura en un determinado espacio y tiempo, lo que los lleva a utilizar el discurso histórico como una metodología para entender la ciudad. Por ejemplo, la propuesta metodológica de Marina Waisman del libro "La estructura histórica del entorno" utiliza el discurso histórico, no solo, para analizar la arquitectura sino el entorno de ciudad. Según su 
enfoque, el análisis de un objeto está relacionado a su contexto físico y social (Rueda, 2016:59) y de esta manera relaciona la arquitectura con la ciudad. Al respecto nos dice "La visión histórica se conforma del presente, desde las urgencias de los problemas presentes y se estrecha o se amplía con respecto a la visión del pasado de acuerdo con el pensamiento presente" (Waisman,1972:60). Para entender el desorden urbano de la actual periferia del centro histórico de Lima, es necesario entender el proceso histórico por el cual atravesó y lo llevó a ese desorden. En su caso, el arquitecto Rem Hoolhaas también hace uso del discurso histórico para explicar el desenvolvimiento de la ciudad y la arquitectura en Nueva York desde la ocupación de las primeros habitantes hasta 1940, (Hoolhaass, 2004) lo que le permite analizar cómo se relaciona la arquitectura con la ciudad en un espacio y tiempo determinado haciendo uso de un discurso histórico en el libro "Delirio de New York". Por su parte, el arquitecto Aldo Rossi en su libro "La arquitectura de la ciudad" vincula la ciudad con la arquitectura donde analiza los hechos y los integra en un espacio y tiempo" (Rossi,1995:7). Para Aldo Rossi el uso del método histórico le permite comparar realidades y de esta manera comprender como las ideas se convierten en formas urbanas y en otros casos solo quedan en utopías ${ }^{9}$. Estos casos nos demuestran que es posible utilizar el discurso histórico para estudiar la ciudad y la arquitectura.

Nuestro abordaje del discurso histórico urbano (Landa,2020:268) ${ }^{10}$ nos permitió estudiar la ciudad según su historicidad y realizar una explicación de la ciudad (Mejía ,1999:1) ${ }^{11}$. Para ello fue necesario recurrir a ciencias auxiliares como la planificación, el urbanismo, la sociología entre otras que nos ayuden a analizar sus transformaciones.

En una primera etapa, se ha realizado una búsqueda de fuentes primarias como manuscritos, planos de Lima, documentos hemerográficos, mapas y planos, documentos de gobiernos e investigaciones históricas de distintos autores de cada una de los distintos periodos. De manera simultánea, se inició la reconstrucción histórica en

\footnotetext{
9 Según Rossi "ve la ciudad como manufactura, como obra de arquitectura o ingeniería que crece en el tiempo" (Rossi, 1995:15).

10 IzasKun Landa "Una aproximación a la historiografía urbana: algunos aspectos epistemológicos y históricos" En Revista Eure Vol. 36 Núm. 139, setiembre 2020,.Santiago de Chile. pp.259-276

11 "La pregunta por la existencia de la Historia Urbana" Conferencia de Germán Rodrigo Mejía Pavony. Universidad. Javeriana conferencia marzo 1999. Bogotá pp.1-14.
} 
cada uno de los periodos de la urbanización de la ciudad, identificando los momentos más importantes que definieron transformaciones en la ciudad de Lima como la construcción y la demolición de la muralla.

En una segunda etapa, debido a los hallazgos de más documentos de archivo y planos de cada uno de los periodos, fue posible definir la estructura interior de cada uno de los capítulos y cómo estos nos llevaron a poder analizar de mejor manera la investigación. Podemos destacar, documentos como "El Registro Único de Hipotecas" y la "Ley de Hipotecas" que nos permiten mostrar el apoyo al sistema financiero por parte del Estado Peruano y como este tuvo el objetivo de la activar del mercado de suelo y su reestructuración en la ciudad y en la periferia. Así también las Leyes de Expropiación de 1900 y 1903 que nos demuestran el apoyo del Estado a la élite con la finalidad de reactivar la economía.

En una tercera etapa, se elaboraron cuadros para identificar la teoría necesaria desde una mirada multidisciplinaria que incluyera urbanismo, planificación, ordenamiento del territorio, mercado de suelo y centralidades, buscando que nos ayudara a analizar el proceso de urbanización de la ciudad y los intentos de modernización de los gobiernos de turno. La idea fue elaborar inferencias que nos ayuden a identificar las particularidades del proceso de modernización urbana de Lima y poder aportar con nuestra investigación.

Finalmente, cada uno de los hallazgos a lo largo de esta investigación y los resultados del análisis fueron divididos en conclusiones de: urbanización, modernización, salubridad, mercado de suelo, ordenamiento del territorio como los principales indicadores que muestran la materialización de modernidad urbana en la ciudad. 


\section{I.IX. Aportaciones al diseño en la línea de investigación de Estudios Urbanos}

1) Aportar al conocimiento del proceso de modernización Latinoamericano, mediante la reconstrucción de la historia urbana de Lima, con énfasis en el siglo $\mathrm{XIX}$ y principios del siglo $\mathrm{XX}$. En este periodo se dieron transformaciones producto del crecimiento urbano, la especulación inmobiliaria, la densificación del centro que transformaron la morfología urbana.

2) Poner en evidencia, como los ideales por modernizar, higienizar e industrializar en la ciudad de Lima a finales del siglo XIX y principios del siglo XX dieron como resultado la intervención y transformación de los espacios públicos y privados en la ciudad a cargo de los gobiernos de turno y transformaron la forma urbana como una manifestación estudiada desde el campo de los Estudios Urbanos.

3) Mostrar como el deseo de modernización de la ciudad de Lima está vinculado con las ideas de planificación de la ciudad de los gobernantes especialmente entre 1870 a 1876 periodo de la demolición de la muralla de Lima, en el cual, se produjeron las mayores transformaciones urbanas.

4) El abordaje historiográfico nos ha permitido mostrar las transformaciones urbanas que tuvo la ciudad en: mercado de suelo, demarcación territorial, modernización, crecimiento urbano, salubridad y urbanización aportando elementos al conocimiento de los Estudios Urbanos.

5) Podemos observar como el ensanche transformó la forma urbana de la ciudad de Lima a partir de los sucesos económicos, sociales y políticos. 
6) Destacar el problema de la especulación inmobiliaria en la ciudad y como esta generó una serie de transformaciones en la periferia de Lima a finales del siglo XIX y principios del siglo XX.

\section{I.X. Estructura del trabajo por capítulos}

\section{Capítulo I}

En este capítulo, se describe el proceso de urbanización desde 1535 hasta 1821 cuando inició el periodo republicano. Se señala como Lima inició su proceso de urbanización influenciada por el factor de localización y centralidad respecto a los puertos ubicados hacia el Pacífico, lo que permitió su crecimiento económico, convirtiéndola en una de las ciudades más importantes del Nuevo Mundo. Entre los años de 1568 a 1570 durante el gobierno del virrey Toledo se crearon las reducciones que fueron ubicadas en la periferia como la de Santiago del Cercado en el año 1570 (Coello, 2006:69) que generaron el desplazamiento de la población indígena hacia afuera de la ciudad colonial y que trajo como consecuencia la repartición de tierras en la periferia.

A mediados del siglo XVII, se discutió la necesidad de construir una defensa para la ciudad que serviría para proteger a la población y a las riquezas que la ciudad poseía. La aparición de la muralla de Lima delimitó el crecimiento urbano de la ciudad y a partir de entonces, su proceso de urbanización se adecuo a sus límites. También la aparición de una mole de barro, rodeando la ciudad, generó una sensación de seguridad en la población. El sismo de 1687 ocasionó graves daños en la estructura de templos y viviendas en el núcleo central, motivo por el cual, el Cabildo destinó fondos para su reconstrucción. En el siglo XVIII, con el cambio de la Casa Borbón se produjo una modernización administrativa con la finalidad de aumentar los ingresos, modernizar, controlar, ordenar y embellecer la ciudad siendo el terremoto de 1746 la oportunidad para que el virrey Conde de Superunda decidiera implementar un Plan de Ensanche de Calles (Walker,2012:131-135). Al mismo tiempo, el cosmógrafo Pedro de Peralta propuso la construcción de una nueva ciudadela amurallada (Eguiguren, 1966:12-27). 
La implementación de la Ley de "Libre Comercio" por la ruta del Cabo de Hornos el año 1778 benefició económicamente la ciudad generando una mayor actividad comercial que dio como resultado la urbanización de la ciudad hasta los límites con la muralla y generó la urbanización al otro lado del río Rímac para la élite colonial.

\section{Capítulo II}

La independencia del Perú el año 1821 (Ávila, 2013:241-274) dio inicio al periodo republicano en medio de la inestabilidad política. La necesidad de las élites de generar una economía para la subsistencia generó la subdivisión de muchas casas en el centro, lo que inició concentración poblacional. Entre los años de 1842-1866 periodo conocido como Prosperidad Falaz (Basadre, 2014,tomolV: 5) el comercio del guano generó recursos al Estado y permitió a los gobernantes, entre dictatoriales e intervencionistas, la posibilidad de concretar el tan ansiado progreso. Sin embargo, debido a la excesiva burocracia y el deseo constante de los cambios de reglamentación en las instituciones del Estado Peruano, fue muy poco el presupuesto destinado a la ejecución de obras públicas. En el año de 1869, como parte de la modernización, surgió el discurso para demoler la muralla, destacando seis razones esgrimidas: altas rentas, saneamiento, aumento poblacional, adelanto de la "Industria Pública", remover obstáculos de desarrollo y bienestar, por lo tanto: destruir la muralla.

\section{Capítulo III}

En el año de 1870 (Diario oficial El Peruano, 1869 á, 02 diciembre: 451) el gobierno del presidente Balta decidió demoler la muralla de Lima para ofrecer vivienda a la población y descongestionar el centro, para ello puso en ejecución el Plan de Ensanche elaborado por el ingeniero Luis Sada Di Carlo, cuyo ejecutor fue el fraccionador Enrique Meiggs quién inició un proceso especulativo de suelo. El proyecto de la Avenida Unión y el Plano Topográfico de Lima convirtieron a la ciudad en un laboratorio urbano, pero al no ser concluidos, convirtieron a la materialización de la modernidad en una utopía. Hacia 1877 al fallecimiento de Meiggs la urbanización de la periferia quedó inconclusa e inició 
un proceso de urbanización espontanea que dio como resultado un mercado ilegal de suelo.

\section{Capítulo IV}

En 1881 (Guerra, 1991:102-103) cuando la ciudad fue ocupada por las tropas chilenas, las actividades de la ciudad se vieron paralizadas y la ciudad fue controlada por Chile. Muchas familias tuvieron que mudarse a otros sectores de la ciudad por seguridad, generándose una urbanización espontanea al interior de los barrios ubicados en la periferia. En el año de 1886 la ciudad ingresó a un periodo de reconstrucción. Desde el año 1896 tomaron el control del Estado de manera sucesiva presidentes del partido "civil" quienes buscaron materializar la modernidad en la ciudad. Para el año 1900 el presidente Eduardo López de Romaña buscó el apoyo de la inversión privada para urbanizar la periferia de la ciudad, estableciendo la Ley de Expropiación (Diario oficial El Peruano, 17 noviembre, 1900:298) lo que dio como resultado la rápida urbanización del sur-poniente de la ciudad e intensificó el proceso de especulación de suelo en la periferia de Lima. Hacia el año de 1904 se habían aperturado las avenidas, las líneas del tranvía que permitieron la conexión entre la ciudad y los balnearios donde la élite se mudó a vivir. Para 1906 el gobierno implementó una nueva demarcación territorial que incluyó los barrios al sur de la ciudad con la finalidad de implementar equipamiento básico y evitar problemas de salubridad en la zona (Portella, 1923:262-263). Para entonces, el problema de la insalubridad en el centro (Basurco, 1907:54-83) aún no había sido resuelto, aunque el Instituto de Higiene contaba con un registro que les permitió cuantificar el problema. El gobierno únicamente intervino los callejones de Petateros y Otaiza (Tizón y Bueno, 1906:12-13) donde se encontraban los casos más críticos. Para 1908 el rápido crecimiento urbano de la ciudad fuera del perímetro de la antigua muralla y el crecimiento de la urbanización en los balnearios del sur daban indicios de que la ciudad había pasado por una etapa de modernización urbana y se encontraba camino a su metropolización en las próximas décadas. 
CAPITULO I
"Creo que la importancia del rito y su naturaleza colectiva, su carácter esencial de elemento conservador del mito constituyen una clave para la comprensión del valor de los monumentos y, para nosotros, del valor de la fundación de la ciudad y de la transmisión de las ideas en la realidad urbana

(Aldo Rossi, 1993:07) 


\section{Capítulo I Desenvolvimiento social, la defensa de la ciudad de Lima y la definición de espacios $(1535-1821)$}

\subsection{Los inicios de la ciudad colonial}

En el año de 1535, con su fundación, dio inicio el proceso de urbanización de Lima colonial. A partir, de ese momento, el factor de localización, respecto a su ubicación central frente al océano Pacífico, comenzó a tener especial ventaja e importancia para el desarrollo de la ciudad. La ubicación privilegiada cerca al puerto del Callao y el carácter de Lima de sede del virreinato del Perú, contribuyeron a hacer de esta ciudad un espacio de conexión estratégica con la corona española y, paradójicamente, de especial atractivo para la piratería de la época.

Entre las amenazas piratas que sufrió la ciudad estuvo la del inglés Francis Drake. En el año 1579, quien atacó los puertos del Callao y Paita (Augustín, 2011:26). Así como la intervención del pirata Jois van Spielbergen, que llegó a las costas del Callao el año de 1615 (Augustín, 2011:33). Poco después, el $1^{\circ}$. de agosto de 1618, el provincial de la Compañía de Jesús, Diego Álvarez de Paz, solicitó al virrey Francisco de Borja y Aragón la construcción de defensas para el resguardo de la ciudad de Lima. A esa propuesta se sumaron las demás órdenes religiosas debido a que ellas guardaban una parte importante de las riquezas de la ciudad (Augustin,2011:92). Fue así como se produjo una discusión entre las autoridades del Cabildo y las autoridades religiosas, lo que dio como resultado el levantamiento, entre 1684-1687 de la muralla, recurso para la protección de la población y sus riquezas. El carácter apremiante que tuvo la muralla para la ciudad puede reconocerse por el hecho de que fue construida antes de que el rey Carlos II aprobara el proyecto, rompiendo los cánones tradicionales de autoridad de la corona. Por otra parte, este hecho generó que la ciudad limitara su crecimiento urbano a la estructura artefacto muralla. 
En el año de 1687 un fuerte sismo sacudió a la ciudad y puso en evidencia el desorden de la urbanización de las parroquias que rodeaban al núcleo central debido a los problemas de repartición de tierras por parte de los españoles que vivían en el centro que adquirieron tierras en la periferia. Por otro lado, las órdenes religiosas que tenían sus propiedades en la periferia habían generado cierta urbanización espontanea cercana a sus propiedades, sobre todo, viviendas para los indígenas que estaban a su cuidado que fueron destruidas con el sismo. La reconstrucción buscó una mejor evacuación de la población a través de las calles reales que conducían a las portadas de la muralla y un ordenamiento de la urbanización en la periferia y la reconstrucción del equipamiento y edificaciones en el centro.

A mediados de 1750 con la ascensión de la casa Borbón al poder se dio inicio a una serie de reformas que tuvieron como objetivo mejorar la recaudación, materializar la grandeza de la Corona Española e introducir las ideas de la ilustración en las ciudades coloniales. Por estos años, la ciudad atravesó por un periodo de apogeo económico y crecimiento poblacional. Sin embargo, la bonanza económica producto de la llegada de mercancías a la ciudad por la nueva ruta mercantil por El Cabo de Hornos provocó la urbanización de la ciudad hasta el borde urbano. No obstante, con el terremoto de 1746 se discutió un Plan de Ensanche de Calles para la ciudad que no se llegó a ejecutar porque requería el consenso de la población, pero puso en evidencia, el control que tenía la Iglesia sobre la propiedad de las tierras en la ciudad. El terremoto, fue la oportunidad para que las autoridades decidieran poner en vigencia una nueva demarcación que produjo una reorganización del territorio para un mayor control del crecimiento urbano y la seguridad en la ciudad.

Producto de los acontecimientos en el viejo mundo y con la llegada de las ideas de la ilustración a la ciudad a mediados del siglo XVIII llegaron a la ciudad ideas e ideales a través del intercambio de la correspondencia entre los intelectuales locales con los del viejo mundo y publicaciones locales que permitieron la maduración del discurso político impulsado por los criollos denominado discurso ilustrado peruano que sirvió como base ideológica a la nueva nación. 
Desde su fundación, la Ciudad de los Reyes, como se le llamó a Lima ${ }^{12}$, siguió la traza que impuso la urbanización colonial. Fue así que el trazado reticulado conocido como damero se convirtió en la base planimetríca del desarrollo de la nueva ciudad, asentada sobre los asentamientos prehispánicos en el valle de Lima. Según el acta de fundación de Lima, el valle cumplía con los requerimientos de abundancia de alimento, agua para una mediana población colonial, terrenos para cultivar y espacios para construir los nuevos edificios públicos y privados. (Archivo de Cabildo de la Municipalidad de Lima, 18 enero de 1535, p.s/n).

El siguiente bosquejo fue el utilizado como plantilla para el trazado, mismo que sirvió a todas las nuevas poblaciones de la Metrópoli y que al ajustarla al terreno, denominado asiento o paraje, se superpuso al territorio prehispánico y dio inicio a la urbanización de la ciudad. El trazado significó el control sobre el territorio conquistado y la materialización del poder. Fue el inició de la construcción espacial de la nueva ciudad, el resultado de la conjunción de lo social, lo teórico, lo ideal y lo real (Lefvebre, 1976,28) $)^{13}$.

\footnotetext{
12 Según María Dolores Crespo "La fundación de la Ciudad de los Reyes fundada en Enero de 1535 de la mano de Francisco Pizarro. Su lugar fue el valle del Rímac uno de los mejores del mundo, muy ancho abundante, de muchas y buenas tierras, todas de riego pobladas de chácaras. Según escribiera el religioso Lizárraga sin querer hacer agravio a otro. Ciertamente, la fundación de la ciudad respondía a unas necesidades específicas de las poblaciones colonizadas americanas tuvieron a la hora de tomar asiento" En: Arquitectura doméstica en la Ciudad de los Reyes (1535-1570), Ed. Universidad de Sevilla, Sevilla, 2006, pp.20.

${ }^{13}$ En el caso de Lima se inició la construcción del espacio ciudad "Dado que la lógica construye espacios. de atributos de configuraciones con un cierto número de variables y parámetros, el espacio se presenta como coherencia y modelo de coherencia, articula lo social, lo mental, lo teórico y los practico, lo ideal y lo real" En: “Espacio y Política” H. Lebfebvre. Ed. Península, 1976, pp.18.
} 


\section{Plano 1.2 \\ Trazado de la Ciudad de los Reyes - 1534}

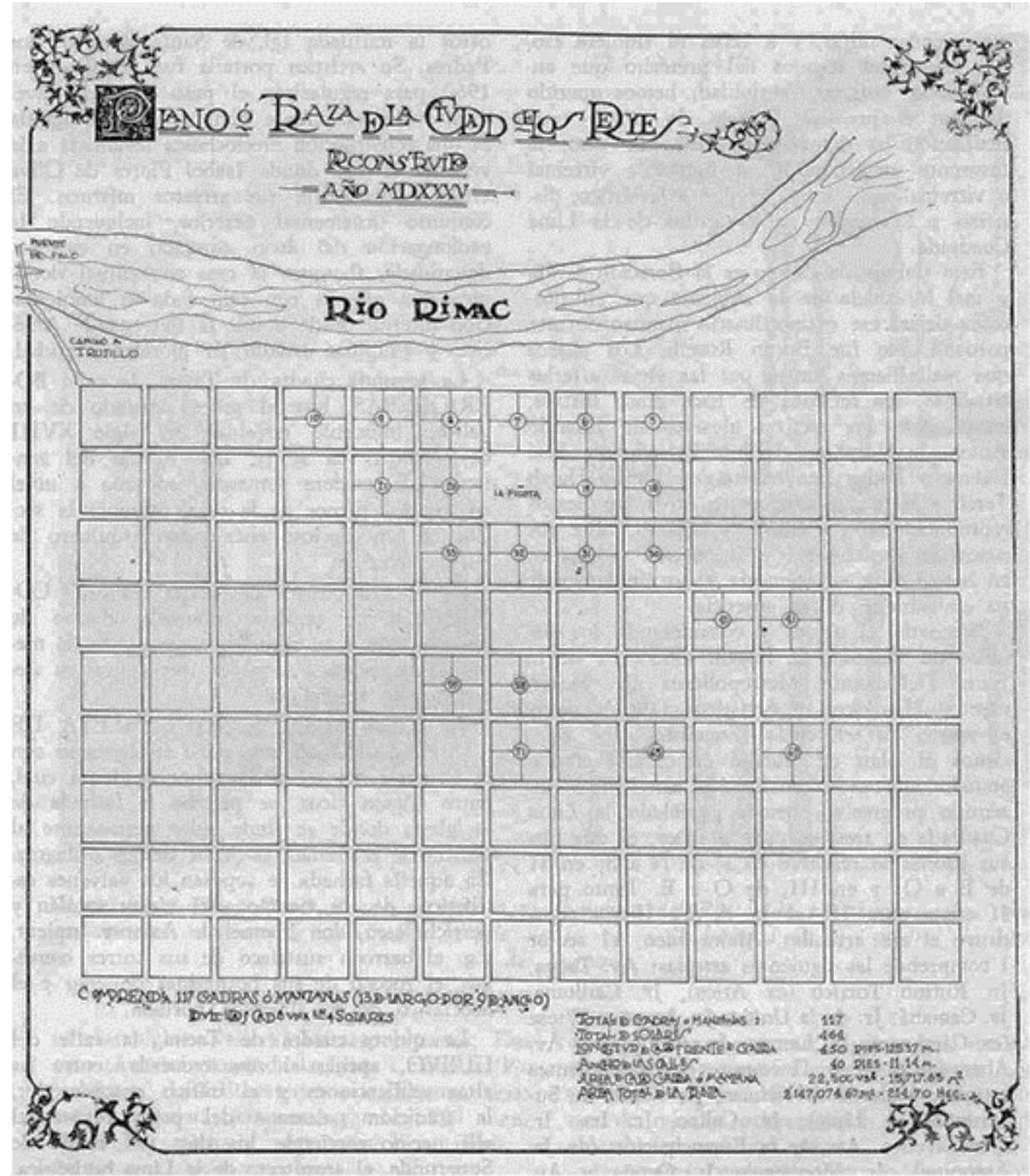

Fuente: Bromley (1945)

El reparto de solares a los primeros conquistadores y la llegada de las órdenes religiosas dieron inicio al proceso de urbanización de la ciudad colonial ${ }^{14}$. A partir del año 1550 llegaron a la ciudad las órdenes de los Franciscanos, Dominicos, Agustinos, Mercedarios y Jesuitas) (Tibesar, 1991:193) iniciando la construcción de grandes templos en los terrenos asignados. De esta manera, la

\footnotetext{
${ }^{14}$ Según Lockhart "el año 1538 Garcí Pérez en compañía de un artesano compró una hilera de tiendas en la Plaza Mayor y el año 1540 construyó una carretera de Lima al Callao mediante una concesión de carreteras con el Cabildo de la ciudad. "El Mundo Hispano peruano 1532-1560" Ed. Fondo de Cultura Económica, México, 1982, pp.190.
} 
Iglesia inició el proceso de acumulación de propiedades con los conventos y templos religiosos aparecieron las primeras plazuelas como micro-espacios para la conversión y el recogimiento. Fue así, que hicieron su aparición las plazas de: Santa Ana, Santo Oficio, María Escobar y Santiago que pasaron a ser las segundas en jerarquía después de la Plaza Mayor debido a su ubicación fuera del núcleo central. De esta manera, se fueron estructurando los espacios parroquiales, confiriéndole a Lima un conjunto de plazuelas que la caracterizarían hasta nuestros días. Por otro lado, los indígenas ocuparon encomiendas en los límites de la ciudad (Augustín, 2016:56) como una política urbana que aún se encontraba en proceso de organización donde aún había vestigios de construcciones de los asentamientos prehispánicos que paulatinamente serían destruidos y arrasados por la nueva urbanización colonial $^{15}$.

Para el año de 1553 la Recopilación de Leyes de los Reinos de Indias, sobre nuevas poblaciones permitieron una mejor organización y administración de la ciudad como: la repartición de los solares Ley $I_{16}$ (Roix,1841:107), la ubicación de las edificaciones Ley XIV (Roix,1841:107), el tamaño de las plazas según Ley IX (Roix,1841:106,). En este periodo se configuró la ciudad en núcleo central y barrios periféricos como las parroquias de Santa Ana, Pachacamilla y San Lázaro al otro lado del río (Gunther, 1983) y se inició con la construcción de las primeras edificaciones siguiendo el trazado de damero en el centro y la periferia.

Para finales del siglo $\mathrm{XVI}$, el trazado de damero tuvo la siguiente distribución social: en el centro para las autoridades administrativas y eclesiásticas. La periferia fue el hogar de indios pobres, mulatos y personas marginales (Coello, 2001:80). En todo momento las autoridades coloniales buscaron controlar el orden en la ciudad. Sin embargo, durante la administración del virrey Francisco de Toledo de 1568 a 1570 se produjo la organización de las reducciones de

\footnotetext{
${ }^{15}$ Según Gutiérrez para 1549 la Audiencia de Lima promulgó unas ordenanzas por las que disponía que todos los indios que vivían en los alrededores de la dicha ciudad se juntaran con orden y policía tarea encomendada a don Antonio cacique de la provincia de Huarochirí y a don Gonzalo cacique de la provincia de Lima. "Pueblos de Indios: otro urbanismo en la región andina" Ed. Abya Ayala, Quito, 1993, pp.275.

${ }^{16}$ Según Augustín las ordenanzas de Felipe II para 1573 constituyen una serie de principios urbanos que se había venido asentando varias décadas antes de su promulgación, y que derivan de constatar que ofrecía para la organización, protección del Damero y sirvió para crear el aparato de extirpación de idolatrías como un modelo de orden y vida “Ceques y Dameros-La reducción indígena de Santiago del Cercado” Ed. URP, Lima, 2016 pp.23.
} 
indios según el modelo de Matienzo (Gutiérrez, 1993:282) para realizar las correcciones del trazado de la periferia que siguió el curso de los riachuelos y controlar la urbanización del damero ante la resistencia de la población indígena. Este modelo reticulado fue aplicado en Lima siendo la primera reducción experimental la del Cercado de indios de Santiago fuera del núcleo central fundada el año 1570 (Coello, 2006:69) con la finalidad de establecer un modelo de urbanización para las reducciones de indios ${ }^{17}$. De esta manera, se establecía, la configuración del espacio urbano de la ciudad $(Z a m b r a n o, 2014: 25)^{18}$ en centro y la periferia que significó un nuevo proceso de ocupación de tierras que permitió la creación de nuevos espacios al interior que, de manera paulatina, se consolidarían.

En este caso, el barrio de Santiago del Cercado ocupó un espacio periférico con una población indígena que trabajaba durante las mañanas en las casas de los españoles en la ciudad y estaban obligados por las noches a regresar a este barrio donde vivían en ranchos o barracas, en otros casos, podían vivir con el empleador español (Lockhart, 1982:275). No obstante, esta normativa permitió controlar a la población flotante de indígenas que ingresaban a la ciudad e impedir la formación de rancherías de indios ${ }^{19}$. Además, estas medidas evitaron posibles rebeliones, disturbios en la ciudad y controlar la seguridad de la población española y de esta manera se produjo la separación entre ciudad de españoles y ciudad de indígenas.

Al retiro de la población indígena de la ciudad el año 1549 debido a que la Audiencia de Lima promulgó una Ordenanza para que esta viviera en los alrededores de la ciudad en pueblos de indios (Gutiérrez, 1993:275). Se produjo la separación de la población indígena y española que permitió organizar no solo la morfología sino también el trazado de las calles reales, calles secundarias y callejones que llegaban al centro desde la periferia. Para

\footnotetext{
17 Según Gutiérrez "las reducciones formarían un Cabildo análogo que existía en los pueblos de españoles, siendo todos sus miembros indios" "Pueblos de Indios: otro urbanismo en la región andina" Ed. Abya Ayala, Quito, 1993, pp.294.

${ }^{18}$ Según Zambrano "un nuevo núcleo significó la posesión de tierras y la sujeción de los pueblos que las habitaban. Desde la ciudades se organizaba la explotación de las regiones conquistada y se administraba las unidades económicas En: "El poblamiento durante la colonia, ciudad y territorio: proceso de territorio en Colombia". Ed. IFEA, Lima, Año 1993. pp.25-61.

19 Según Goya "una ranchería de indios era una forma de ocupar un territorio de manera provisional de los indígenas del siglo XVII". "Asentamientos y pueblos de indios desaparecidos en el alto Jalisco durante el virreinato". En: Revista Scielo Nro.30 Vol. 15 julio-diciembre 2013. pp-1-7.
} 
finales de 1590 los indios que vivían en el barrio de San Lázaro de manera desordenada y en malas condiciones fueron trasladados al barrio de Santiago del Cercado (Coello, 2001:160-161). Este incidente, puso al descubierto el carácter colonial excluyente de las autoridades de Cabildo ante la repartición de tierras en la periferia como consecuencia de la reubicación de la población indígena al barrio de Santiago del Cercado.

Hacia inicios del siglo XVII, en la ciudad se construyeron los primeros edificios institucionales representativos como: el Cabildo de la ciudad, la Casa de la Moneda, la Universidad Pontificia de San Idelfonso, el Colegio Seminario de Santo Toribio, el Colegio del Real Felipe, el Colegio Real de San Martín. Los hospitales de: Santa Ana, San Andrés, San Diego, San Cosme y San Damián (Bromley:1613). Todas estas edificaciones de equipamiento urbano otorgaron cierta identidad a la ciudad favoreciendo la construcción de viviendas y establecimientos de comercio próximos a ellas. 
Plano 1.3 Plano de la ciudad de Lima para el año 1613

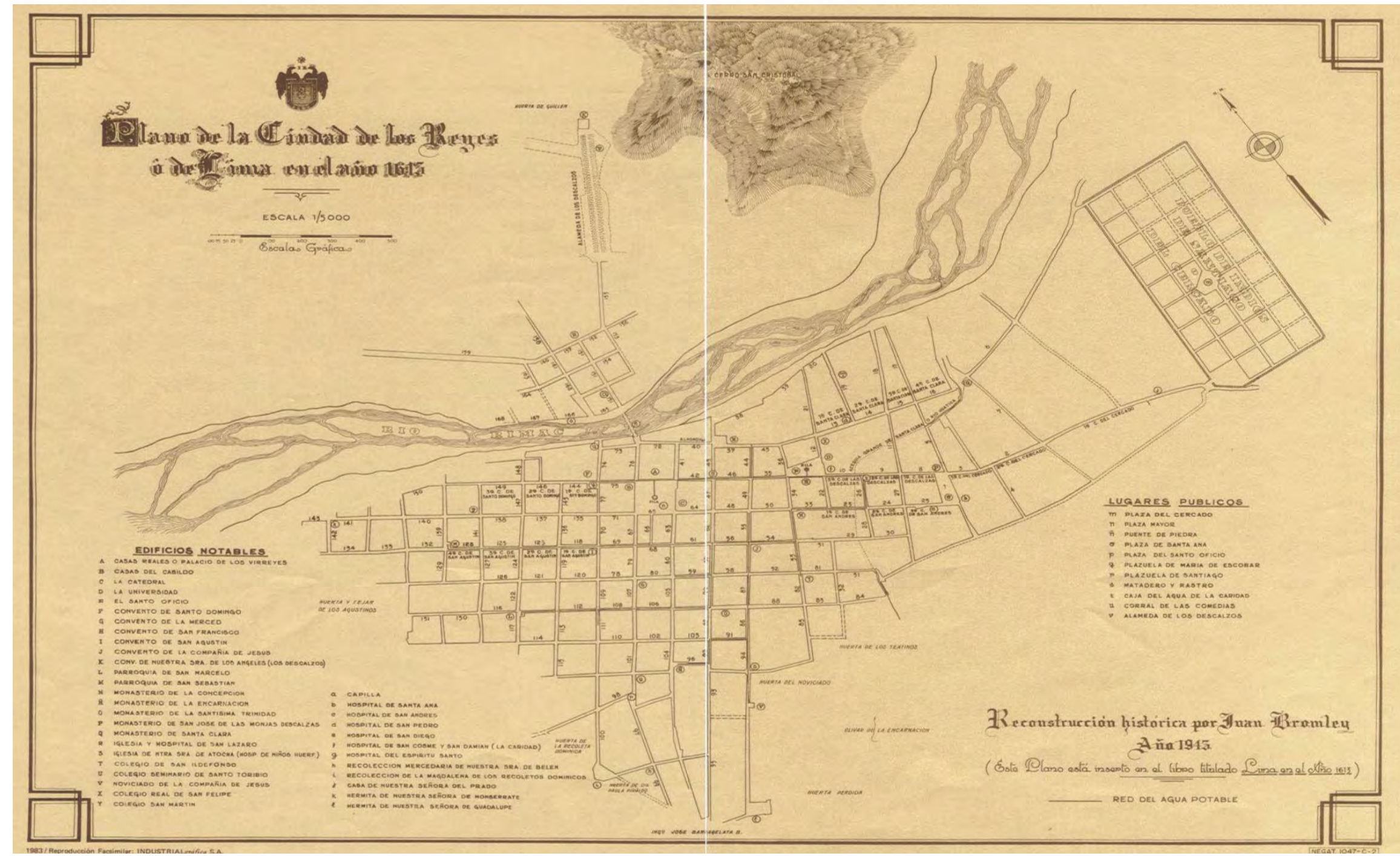

Fuente: Bromley J (1945). Reconstrucción histórica en base al padrón de indios levantado por el escribano real Miguel de Contreras por encargo del virrey. 


\section{2.-Determinantes de crecimiento de la ciudad en el siglo XVII: La centralidad de la ciudad y la construcción de una muralla para Lima}

El año 1600 se realizó el primer censo de población a cargo de virrey Marqués de Salinas que dio como resultado de 14,262 habitantes (Diario El Mercurio Peruano ,1791 á, 03 febrero: 91-92). Por estos años, la ciudad había crecido y convertido en un espacio central como consecuencia del aumento de la afluencia de embarcaciones que llevaban mercancía desde el puerto del Callao al puerto de Cádiz que provocó una mayor actividad comercial y puso a discusión la construcción de una defensa para la ciudad.

\subsubsection{La centralidad de la ciudad de Lima}

En el siglo XVI el puerto del Callao se convirtió en un enclave importante y parte de la red de puertos del lado del Océano Pacifico entre los que se encontraban Guayaquil, Valparaíso y Santiago. Por aquel entonces, el puerto del Callao y Veracruz eran los únicos autorizados para el comercio con la Metrópoli (Sáenz, 2004:132) que les confirió una mayor jerarquía respecto a los otros puertos ${ }^{20}$ convirtiéndola en una centralidad (Paris,2013:41). Siendo la ciudad el centro de actividades de intercambio de mercaderías, comercio de productos que venían de otras partes del virreinato, el centro administrativo del virreinato del Perú y que concentraba al poder eclesiástico. Es decir, la concentración de actividades sociales en este centro urbano le confería este atributo. Por ello, se establecieron en la ciudad una nueva élite de comerciantes que junto con la concentración de los tributos indígenas que llegaban a Lima y la carga de plata que llegaba de Potosí fueron convirtieron a la ciudad en prospera y poseedora de riquezas.

Por otro lado, el proceso de urbanización del puerto del Callao, se dio de manera espontánea debido a que se vendieron paulatinamente terrenos cercanos al puerto autorizado por una comisión específica para usos de

\footnotetext{
20 En el caso de Lima podemos decir que es un espacio central "Al mismo tiempo sus usuarios habitantes perciben estos espacios como verdaderos lugares, y por ello, esta centralidades adquieren un papel determinante en el territorio, tanto a escala humana como escala regional. Estos espacios son dotados de una identidad y una urbanidad específica. En: "El centro en otro lugar, centralidades urbanas polaridades territoriales" Mario Paris, Revista del Instituto de Urbanística de Valladolid - ciudades N 16, Año 2013, pp.41.
} 
almacenamiento, administrativo y residencial. Sin embargo, debido a que el puerto del Callao generó una vinculación con Lima por ser el primer punto de contacto de las mercaderías (Sáenz,2004:132) condicionó su crecimiento urbano y poblacional a la capital durante todo el periodo colonial se produjo una subordinación del puerto del Callao respecto a la ciudad de Lima.

Estos años se había establecido una compleja red de ciudades puerto, capitales de virreinato y capitanías a este lado del océano Pacífico donde la ciudad con mayor jerarquía fue Lima que junto con el doble atributo de ser capital de virreinato, el factor de localización, una mayor dinámica y acumulación de riqueza que el resto de las ciudades la habían convertido en un área central.

La ciudad de Lima atrajo una importante población flotante proveniente de otras partes del virreinato del Perú para realizar inversiones que permitieron su crecimiento económico y la convirtieron en una centralidad. Como consecuencia de esta bonanza, fue posible un mayor presupuesto para la ejecución de la obra pública, mayores oportunidades de trabajo y una mayor actividad comercial. Por ejemplo la calle Mercaderes (actual cuadra 4 del jirón de la Unión) albergó actividades comerciales de la ciudad. Sin embargo, esta característica inició una desigualdad del crecimiento económico en el centro y la periferia que se materializó en la urbanización y que fue puesta en evidencia con el sismo de 1687.

Como consecuencia de esta característica de la ciudad de ser espacio central la ciudad se organizó en el núcleo central existían palacios y casas principales (Bernales,1972:193) rodeados de nuevas edificaciones como el corral de comedias (1637), el hospital de San Bartolomé para negros (1659) (Sifuentes, 2004:70), los hospitales de La Caridad, San Pedro, Santa Ana, San Andrés y San Diego. Los templos los Colegios, Monasterios y Conventos de las órdenes religiosas. Mientras en la periferia existían casas de vecinos, casas de campo, rancherías y haciendas (Bernales, 1972:193) y obras públicas viales como el puente de Piedra (1610), la alameda de los Descalzos (1610), la Caja de agua de la Caridad, los tajamares del río Rímac (1637) (Romero, 1976:102) que 
muestran las diferencias entre la urbanización del centro y la periferia. La ciudad vivía una bonanza económica que hacía necesaria su defensa.

\subsubsection{El debate, gestión y construcción de la muralla de Lima}

Durante la administración del virrey Montesclaros entre los años de 1607 a 1615 se realizó un censo en la ciudad de Lima que dio como resultado 25,454 habitantes (Diario El Mercurio Peruano, 1791 á, 03 febrero: 91-92) que demuestra lo atractivo que se había vuelto vivir en Lima debido principalmente a la actividad económica existente. Esta fue la principal causa que se discutiera su defensa ${ }^{21}$ debido a la aparición de amenazas externas e internas que afectaban su estabilidad política, administrativa y social. Habría que anotar los ataques de los guerreros incas de Kusi Yupanqui (Augustin,2011:21) y la rebelión de Almagro El Mozo en 1542 contra los pizarristas para sustituir al oidor Cristóbal Vaca de Castro (Augustin,2011:22), pero especialmente las amenazas de los piratas y corsarios por apoderarse de las riquezas de la ciudad y el cargamento que transportaban los navíos que salían de Lima o llegaban al puerto de Cádiz en el viejo mundo. Fue el caso de cómo la flota del pirata ingles Francis Drake el año 1579 que atacó los puertos del Callao y Paita (Augustín, 2011:26) y el pirata Joris van Spielbergen que llegó a las costas del Callao el año 1615 (Augustín, 2011:33). En ese momento la defensa construida en el Callao sirvió para replegar al enemigo.

Ante estas amenazas las autoridades del Cabildo de la ciudad, las órdenes religiosas y la ciudadanía de Lima discutieron la posibilidad de construir una defensa para la ciudad que ayudara a su defensa y resguardo. No obstante, dentro de todas estas amenazas la de mayor impacto en la población fue la incursión de los piratas que produjo inseguridad e inestabilidad en las instituciones políticas, religiosas ante posibilidad que la ciudad fuera saqueada. A partir de entonces, el virrey Melchor de Navarra y Rocafull o Duque de Palata gobernante de 1681 a 1689 convocó a los especialistas más renombrados para que presenten propuestas para la construcción de la muralla de Lima.

\footnotetext{
21 Según Gutiérrez "la defensa estaba concebida como la idea de reforzar las defensas de Atlántico y del Pacífico, asegurar el dominio de los mares del Caribe, controlar los puntos de contacto y los pasos marítimos y las plazas fuertes de la región" En: "Fortificaciones Iberoamericanas" Ramón Gutiérrez .Ed. Fundación, EI VISO, 2006 pp.28
} 
Por aquel entonces, presentaron sus propuestas los cosmógrafos Juan Jiménez, Cosme Céspedes y Juan Ramón Coninck (Augustín, 2011:110). Según estos estudiosos el desembarque podría darse en los puertos de Chilca, Conchan, Chorrillos, Bocanegra, Ventanilla y Ancón, siendo insuficiente el contingente armado de la ciudad para protegerla y por lo disperso del territorio en esta zona hizo necesario un muro que rodeara la ciudad para su defensa (Augustín,2011:111). De las propuestas presentadas fue aceptada por el Cabildo el proyecto del jesuita Juan Ramón Coninck $^{22}$ debido a que presentó tres expedientes: primero la justificación de la construcción de la muralla, segundo especificaciones técnica y el tercero de financiamiento (Augustín, 2011:110). El presupuesto para la ejecución de esta obra fue calculado en 618,360 pesos (Augustín,2011:117). Sin embargo, para cubrir el costo fue necesario un mes de impuesto de la propiedad rústica y urbana de la ciudad, aumentar el impuesto de sisa de carne y recibir donativos voluntarios de la élite limeña permitido en la Ley IV "Que las audiencias puedan dar licencia para repartimientos en gastos de pleitos y obras públicas a los pueblos que no tuvieren propios" (Roix, 1841:128).

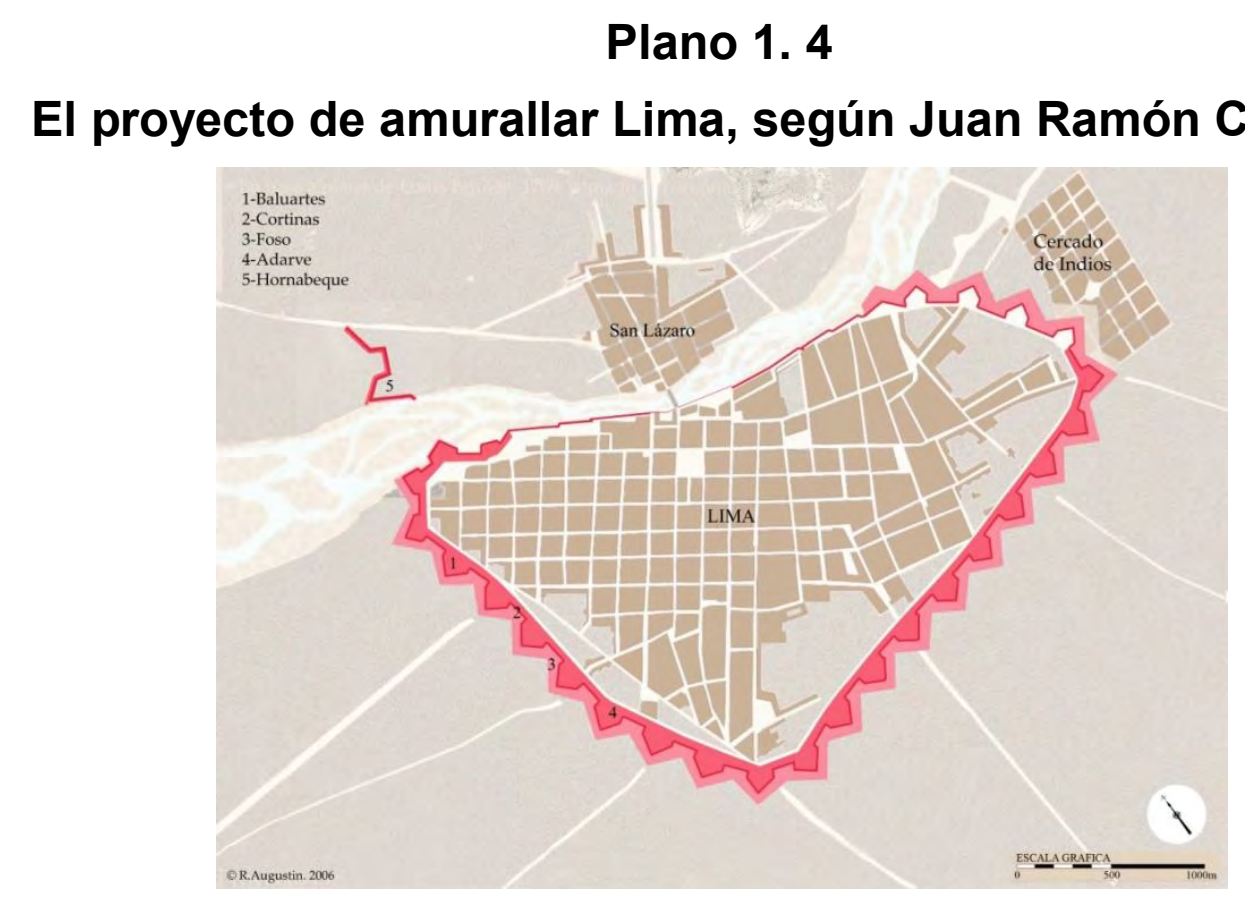

Fuente: Augustín (2011. pp.114).

\footnotetext{
22 Según Sifuentes "Juan Ramón Coninck nació en Malinas y vino al Perú el año 1655 en Compañía del Conde de Alba del Liste, ejerció durante años la cátedra de matemáticas en la Universidad Mayor de San Marcos de Lima". "Las Murallas en el Proceso Histórico del Perú: Ensayo acerca de la Historia y Evolución Urbana de la ciudad de Lima entre los siglo XVII y XIX", Ed. CONCYTEC, Lima, 2004, pp.96-97.
} 
La muralla de Lima fue concebida como una protección para la seguridad de la población y las riquezas que poseía. En este caso, Juan Ramón Coninck argumentó las razones por las cuales era necesaria una defensa para la ciudad que demuestran su conocimiento en tácticas de guerra, características del terreno para la futura construcción y elaboración de un plan de contingencia ante un ataque terrestre de la siguiente manera:

Según Coninck, el muro a construir no se encontraría próximo a la zona edificada de la ciudad, sino que se dejaría un espacio entre la ciudad y la muralla para el futuro crecimiento de la ciudad. Según la visión del cosmógrafo:

"la muralla no ocuparía muchas huertas ni edificaciones cercanas para lograr el apoyo de la Iglesia que se vería afectada por no contar con esos ingresos por concepto de censos o hipotecas para las obras de caridad. Las zonas cercanas a la muralla para uso agrícola permitirían continuar estas actividades intramuros que servían para abastecer a la ciudad" (Augustin,2011:113-114).

El cosmógrafo, propuso que el barrio denominado Santiago del Cercado de indios quedara fuera del recinto amurallado para reducir considerablemente el costo de la obra. Además, por su ubicación, no era conveniente incluirlo por hallarse cerca a montículos importantes como los cerros de El Agustino y San Cosme posiciones que podían ser tomadas por el enemigo para dominar y dirigir un ataque sobre la ciudad (Augustín, 2011:114) y por ser un tema de costos. Sin embargo, las Leyes de Indias consideraban por vecino de la nueva población al hijo o hija del nuevo poblador español y sus parientes en cualquier grado. Según la Ley VI "Que los pobladores principales y sus hijos y descendientes legítimos sean hijodalgo en las Indias" (Roix, 1841:104) que incluía a esta población como parte de la ciudad. Fue por esta razón que este punto siguió en debate hasta el proyecto definitivo.

El cosmógrafo pensó en todos los detalles en su proyecto no solo de resguardar la ciudad sino que esta cumpliera con los requisitos de un artefacto de la época.

"La planta de la muralla formaría un triángulo irregular de ocho mil cuatrocientos metros de perímetro, con veinticinco baluartes cerrados por muros o cortinas de ciento treintaicuatro metros de longitud cada una. Por otra parte, la estructura interna de la muralla estaría conformada por dos paramentos de adobe entre los que se acumularía tierra, piedras y cascajo extraídos del foso proyectado, para formar un terraplén de 11 metros. La forma de la muralla en 
triangulo se adecuaría al valle y permitiría resguárdalo desde el lado del río reforzando con tajamares. Sobre las medidas que uso para el diseño de la muralla se tienen: La cara exterior de cada muro propuestas era de 3.10 metros, con una cara interior o contramuro de 1.20 metros. El espacio entre ambas sería 6.10 metros y estaría relleno con lo extraído del foso. Este foso tendría 15.12 metros de ancho por 3.36 de profundidad en el encuentro del foso con el parapeto del muro se colocaría un cimiento de cal y piedra colocado en "tizón" de 2.52 metros de altura, por 0.84 metros de espesor, sumados a los 0.42 de este cimiento que quedaban por debajo de este nivel del fondo del foso, el cual quedaba ligado a la capa maciza subterránea del cascajo. Sobre este cimiento se colocaría un sobre cimiento de adobe de 1.26 metros de altura por 1.68 de espesor sobre el que descansaría el muro de parapeto, el cual quedaba trabado el cimiento "(Augustin, 2011:115).

La muralla contaba con diez portadas que arquitectónicamente tenían una estética propia. Los nombres estaban en función de su localización en la ciudad cerca de un barrio, parroquia, puente o camino como: Barbones, Maravillas, Santa Catalina, Cocharcas, Guadalupe, San Jacinto, San Juan Simón, Martinete, Monserrate, Callao (Sifuentes, 2004:123-126). Complementan las portadas fuera de la muralla Piedra Lisa y Guía (Fuentes, 1866:632). Sin embargo, la ubicación de las portadas, tenían la función de garitas de control del tráfico de personas, mercaderías a la ciudad y permitieron la recaudación de los respectivos peajes de entrada y salida para posibles reparaciones (Ramón, 1999:75). Además la Ley II de Indias "Que se procure labrar la tierra alrededor del sitio donde hubiere fábrica" (Roix,1841:36).

\section{Plano 1. 5}

\section{Ubicación de las portadas en la muralla}

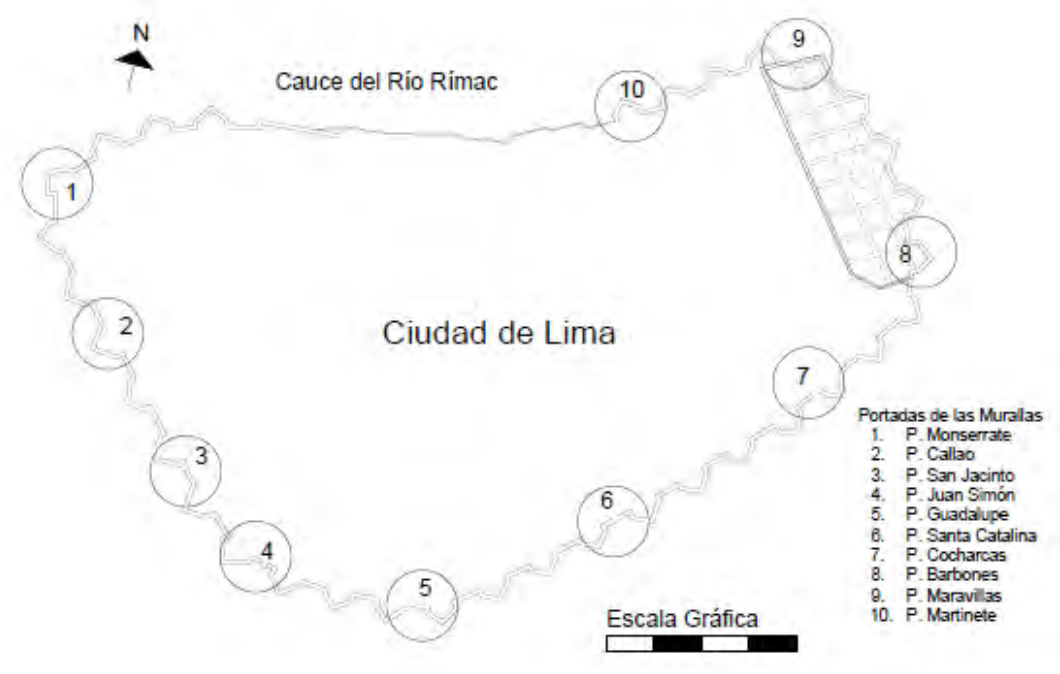

Fuente: Elaboración propia en base a Sifuentes (2004, pp.124) 
Antes de iniciar la obra, se discutió sobre el territorio que debía defender la muralla. En primer lugar, la inclusión o no dentro del perímetro del barrio de indios de Santiago conocido como el barrio de Santiago del Cercado y el de San Lázaro al otro lado del río. En este caso, las autoridades del Cabildo, la Junta de Guerra y el virrey en turno decidieron incluir al barrio de Santiago del Cercado al interior de la muralla realizando esta modificación en el plano final. En este caso, la muralla defendió la ciudad de los españoles y la de los indígenas. Sin embargo, no fue así con el barrio de San Lázaro por encontrarse al otro lado del río. En segundo lugar decidieron dejar unos terrenos libres entre la muralla y la ciudad para tener mayor resguardo y cumplir con las leyes de indias que decían:

"ordenamos que cerca de las murallas o estacadas de las nuevas poblaciones en distancia de trescientos pasos, no se edifiquen casas, que así conviene a nuestro servicio, seguridad y defensa de las poblaciones como esta proveído en castillos y fortaleza" (Roix, 1841:107).

De esta manera, se dio cumplimiento a las Leyes de Indias en el caso de la ciudad de Lima.

El proyecto elaborado por Juan Ramón Coninck, que con las correcciones fue aprobado y enviado a España para su revisión siguiendo el mandato de Leyes Indias para su aprobación (Roix, 1841:36). En el caso de la muralla de Lima el encargado de evaluar el proyecto fue el Duque Alejandro de Bournaville ${ }^{23}$, quien envió sus observaciones a Juan Ramón Coninck (Augustín, 2011:134) pero como la obra ya se encontraba en ejecución no fueron tomadas en cuenta (Augustín, 2011:140). Sin embargo, muestran el control que tuvo la Corona sobre la ejecución de la obra pública en las ciudades del virreinato y hasta qué punto la autoridades locales tenían autonomía para realizar obras en la ciudad por su cuenta.

El proceso de construcción del proyecto iniciado el año 1683 demoró casi trece años, debido a varias causas como: la burocracia que existía en la época, la distancia entre el virreinato del Perú y la Metrópoli, el momento político que vivía la ciudad cuando el virrey asumía un cargo por un periodo y la importancia de la aprobación de la Iglesia en la decisiones políticas de la ciudad. En este

\footnotetext{
${ }^{23}$ Duque Alejandro de Bournaville experto en fortificaciones nombrado por el Consejo de Indias. En el siglo XVII. Boletín instituto Riva Agüero, Nro. 24, Lima -Perú Ed. PUCP, 1997, pp.383.
} 
caso, se trataba de lograr un consenso entre las autoridades civiles, religiosas y la élite para conseguir dinero y poder financiar la obra a nivel local y que esta continuara hasta su culminación. En el caso de Lima, el ataque a Cartagena y saqueo de Veracruz en el año 1683 (Augustín, 2011:38) ayudó para que los vecinos notables y sobretodo la Iglesia entraran en razón que se debía construir una muralla para Lima a pesar que la ocupación de terrenos para su construcción afectaría sus rentas. En el siguiente cuadro vemos el proceso de gestión evaluación y construcción de la muralla de Lima: 


\section{Cuadro 1. 1a}

\section{Proceso de gestión, evaluación y construcción de la muralla de Lima (1673-1686)}

\begin{tabular}{|c|c|c|}
\hline Año & Acción realizada & $\begin{array}{l}\text { Periodo del } \\
\text { gobernante }\end{array}$ \\
\hline 1673 & $\begin{array}{c}\text { Agosto de } 1673 \text { evaluación de los tres proyectos presentados } \\
\text { y selección del proyecto de Coninck para la construcción de la } \\
\text { muralla a cargo de Diego Matos maestre del Campo del } \\
\text { Batallón de Lima, Francisco de Cueva y Guzmán maestre de } \\
\text { campo del Callao y Antonio Sancho Dávila. }\end{array}$ & $\begin{array}{l}\text { Baltasar de la } \\
\text { Cueva y } \\
\text { Enríquez } \\
\text { Cabrera } \\
(1673-1678)\end{array}$ \\
\hline 1673 & $\begin{array}{c}\text { Envió del proyecto de Coninck a la Audiencia de Lima tras ser } \\
\text { aprobado por la Junta de Guerra remitido al Consejo de Indias } \\
\text { en Madrid y encarpetado. }\end{array}$ & $\begin{array}{l}\text { Baltasar de la } \\
\text { Cueva y } \\
\text { Enríquez } \\
\text { Cabrera } \\
(1673-1678) \\
\end{array}$ \\
\hline 1680 & $\begin{array}{c}\text { Encargo al ingeniero Mayor Venegas Osorio la situación y } \\
\text { defensa de las zonas costeras del virreinato y propuesta para } \\
\text { su reforzamiento la propuesta fue rechazada por el virrey al } \\
\text { arzobispo. }\end{array}$ & $\begin{array}{l}\text { Arzobispo de } \\
\text { Lima, Melchor } \\
\text { Liñan Cisneros } \\
(1678-1681)\end{array}$ \\
\hline 1681 & $\begin{array}{l}\text { Asume el virreinato del Perú y busca un argumento para la } \\
\text { realización de la construcción de la muralla de Lima. }\end{array}$ & $\begin{array}{l}\text { Melchor de } \\
\text { Navarra y } \\
\text { Rocafull } \\
(1681-1689)\end{array}$ \\
\hline 1682 & $\begin{array}{c}\text { Se inició la gestión para la construcción de la muralla el } 29 \text { de } \\
\text { octubre de } 1683 \text {. Se inició la recaudación de fondos. }\end{array}$ & $\begin{array}{l}\text { Melchor de } \\
\text { Navarra y } \\
\text { Rocafull } \\
(1681-1689)\end{array}$ \\
\hline 1683 & $\begin{array}{l}\text { Gestión del virrey del proyecto de la muralla ante el rey Carlos } \\
\text { II para su aprobación. Justifica la introducción de impuesto y } \\
\text { plan para generar fondos. }\end{array}$ & $\begin{array}{l}\text { Melchor de } \\
\text { Navarra y } \\
\text { Rocafull } \\
(1681-1689)\end{array}$ \\
\hline 1683 & $\begin{array}{l}\text { Construcción de la muralla de Lima sin la aprobación de la } \\
\text { Corona. Se inició el trazado de la muralla. Expuso el Ing. } \\
\text { Venegas Osorio la forma de administrar la obra. }\end{array}$ & $\begin{array}{l}\text { Melchor de } \\
\text { Navarra y } \\
\text { Rocafull } \\
(1681-1689)\end{array}$ \\
\hline 1684 & $\begin{array}{c}\text { El virrey convocó a Junta de Guerra el } 2 \text { de mayo de } 1684 \\
\text { aplazar el inicio de los trabajos hasta concluir los trabajos de } \\
\text { Venezuela y enviar el proyecto de Coninck a revisión por el } \\
\text { Duque Bournonville. }\end{array}$ & $\begin{array}{l}\text { Melchor de } \\
\text { Navarra y } \\
\text { Rocafull } \\
(1681-1689)\end{array}$ \\
\hline 1684 & $\begin{array}{l}\text { Joseph y Francisco Mugaburu en el Diario de Lima publicaron } \\
\text { el inicio de las obras de la muralla el } 30 \text { de junio de } 1684 \text {. La } \\
\text { supervisión de la obra quedó en manos de Coninck. }\end{array}$ & $\begin{array}{l}\text { Melchor de } \\
\text { Navarra y } \\
\text { Rocafull } \\
(1681-1689)\end{array}$ \\
\hline
\end{tabular}

Fuente: Elaboración propia en base a Augustín (2011, pp.89-144) 


\section{Cuadro 1. 2b}

\section{Proceso de gestión evaluación y construcción de la muralla de Lima (1673-1686)}

\begin{tabular}{|c|c|c|}
\hline Año & Acción realizada & $\begin{array}{l}\text { Periodo del } \\
\text { gobernante }\end{array}$ \\
\hline 1684 & $\begin{array}{l}02 \text { de noviembre de } 1684 \text { el virrey convoca para dejar sentado } \\
\text { las opiniones sobre la construcción de la muralla. Ante el } \\
\text { General de la Armada del Mar del Sur Antonio Vea. Ante el } \\
\text { maestre de Campo del Batallón de Lima Francisco Cueva y } \\
\text { Guzmán. Ante el Teniente Capitán del Virreinato Tomas } \\
\text { Palavicino. Ante el General de Artillería Juan Enríquez. Ante } \\
\text { el Sargento Mayor de la Guarnición del Callao, Francisco } \\
\text { Méndez de Anaya. Ante el Militar Luis Antonio de Oviedo. Ante } \\
\text { el sargento mayor Corbera de Ocampo. }\end{array}$ & $\begin{array}{l}\text { Melchor de } \\
\text { Navarra y } \\
\text { Rocaful } \\
(1681-1689)\end{array}$ \\
\hline 1685 & $\begin{array}{l}\text { Aprobación del Consejo de Indias. Aprobación por Real } \\
\text { Cédula, emitida en Madrid el } 15 \text { de Junio de } 1685 .\end{array}$ & $\begin{array}{l}\text { Melchor de } \\
\text { Navarra y } \\
\text { Rocafull } \\
(1681-1689)\end{array}$ \\
\hline 1685 & $\begin{array}{l}\text { En Junio de } 1685 \text { junto con la aprobación Real del proyecto } \\
\text { llegan las observaciones del Duque de Bournonville, que } \\
\text { fueron sustentadas por Coninck pero la muralla ya se } \\
\text { encontraba en construcción y el Duque no conocía el terreno } \\
\text { por eso no fueron tomadas en cuenta. }\end{array}$ & $\begin{array}{l}\text { Melchor de } \\
\text { Navarra y } \\
\text { Rocafull } \\
(1681-1689)\end{array}$ \\
\hline 1686 & $\begin{array}{l}\text { El virrey no quedo conforme con algunas partes del } \\
\text { documento negadas por el Rey Carlos II, dirigiéndose el } 02 \text { de } \\
\text { abril de } 1686 \text { fundamentando los métodos para generar } \\
\text { fondos. }\end{array}$ & $\begin{array}{l}\text { Melchor de } \\
\text { Navarra y } \\
\text { Rocaful } \\
(1681-1689)\end{array}$ \\
\hline 1686 & $\begin{array}{l}15 \text { de diciembre de } 1686 \text { llega a Lima la autorización de } \\
\text { España para ampliar los medios de recaudación para construir } \\
\text { la muralla de Lima. }\end{array}$ & $\begin{array}{l}\text { Melchor de } \\
\text { Navarra y } \\
\text { Rocafull } \\
(1681-1689)\end{array}$ \\
\hline 1687 & $\begin{array}{l}\text { Se le acepta al virrey la creación de un estanco de papel en } \\
\text { Lima para recaudación de fondos para la muralla. }\end{array}$ & $\begin{array}{l}\text { Melchor de } \\
\text { Navarra y } \\
\text { Rocafull } \\
(1681-1689) \\
\end{array}$ \\
\hline 1687 & Conclusión de las obras de la muralla. & $\begin{array}{l}\text { Melchor de } \\
\text { Navarra y } \\
\text { Rocafull } \\
(1681-1689)\end{array}$ \\
\hline
\end{tabular}

Fuente: Elaboración propia en base a Augustín (2011, pp.144-148) 
Como vemos en el cuadro 1.1a y 1.1b, la construcción de la muralla de Lima fue posible gracias al compromiso y la capacidad de gestión del virrey Melchor de Navarra y Rocafull para lograr el consenso de todos los actores involucrados como: El rey Carlos II, el Consejo de Indias, el Cabildo, el Arzobispo de Lima, las autoridades religiosas y la Junta de Guerra de Lima y Callao. No obstante, el prestigio y la calidad del proyecto elaborado por el jesuita Juan Ramón Coninck permitieron que el virrey pudiera generar un plan de gestión y recaudación de fondos en cada una de las etapas de su construcción con el apoyo de los ingenieros de la Junta de Guerra y las autoridades de El Cabildo.

Fue un riesgo del virrey de turno Melchor de Navarra y Rocafull iniciar la obra sin tener la aprobación del Consejo de Indias debido a que las leyes prohibían a los gobernantes locales tomar decisiones sin el consentimiento de la Metrópoli (Roix, 1841:36). Por esta razón, la construcción de la muralla fue una decisión local que requirió de la aprobación de la ciudad y sobretodo de la Junta de Guerra para lograr su posterior aprobación por el Consejo de Indias y el rey Carlos II. El proceso de gestión y construcción de la muralla de Lima, muestra que debido a la lejanía con la Metrópoli las autoridades asumían las decisiones para obras en la ciudad de manera autónoma, pero para ello, debían lograr el apoyo de todos los niveles de población sobre todo de la élite y la Iglesia donde se concentraba el poder económico.

La aparición de la muralla el año 1687 (Augustín, 2111:144-147), reorganizó el territorio en: núcleo central, parroquias circundantes al centro y periferia o bordes de la ciudad y definió la forma física de la ciudad y sus límites. Así también, la aparición de las portadas generó un cambio de uso de suelo. Por ejemplo las calles principales que conducían a las salidas por las nuevas portadas generaron una actividad comercial en lugares donde antes eran terrenos de cultivo. La ciudad se tuvo que adaptar a la aparición del artefacto con el que se había logrado una defensa física, pero a su vez, se había delimitado sus confines físicos a los cuales debía adecuar su crecimiento. 


\subsection{El sismo de 1687 y el crecimiento urbano de la ciudad}

El 20 de octubre de 1687 ocurrieron dos temblores en Lima que afectaron la ciudad y siguió un tsunami en las localidades hacía la costa que afectó la zona del litora ${ }^{24}$ dejó incomunicada a la ciudad y destruyó la infraestructura marítima que paralizó el comercio en la ciudad por un tiempo. Además, el sismo puso en evidencia lo frágil de las construcciones de adobe, quincha y el crecimiento urbano que tuvo la ciudad a finales del siglo XVII con el aumento de la actividad comercial y la construcción de la muralla y como la Iglesia con la escusa de evangelización indígena había logrado que un buen porcentaje de esta población se encontrara viviendo en la periferia de la ciudad a pesar de la prohibición existente. Unos días después del sismo, los alarifes mayores de reales fábricas como: Fray Diego Maroto junto con Manuel Escobar, Pedro Ascensio y Pedro Fernando de Valdez alarife mayor de la ciudad relataron el estado de la ciudad después del sismo de 1687:

"El día 20 de octubre del año pasado de mil seiscientos ochenta y siete sobrevinieron dos temblores, el primero a las cuatro de la mañana y el segundo a las seis tan horribles que espantosos que arruinaron la santa iglesia catedral y todas las demás de las perroquias y monasterios y el Palacio Real, y las casas particulares de sus vecinos y moradores "(Angulo, 1939:7).

Según el último censo del año 1613 la población de Lima era 25,954 habitantes (Pérez, 1985:384) que fueron afectados con el terremoto. Gracias al informe sobre el sismo, fue posible conocer el estado de las edificaciones en el núcleo central habitado por las autoridades civiles, religiosas, comerciantes españoles y criollos. Mientras que en la periferia fueron afectadas las reducciones de indios y barrios habitados por españoles, religiosos y mulatos. En el siguiente párrafo, vemos como la destrucción de los templos, iglesias y parroquias fue total en el núcleo central que tenía alrededor de cuatro mil quinientas casas (Angulo, 1939:08) como describe el siguiente texto:

"Si saben que la ciudad está ynhabitable por la rruina de sus edificios, y sus calles las mas ynpenetrables, pues algunas, y las más principales no se pueden andar ni a caiillo y, que no está capaz de rodar coche ni en muchos años, y que no se pueden conseguir quitar los desmontes de las calles, sin gastar infinito dinero, y que todos los moradores de esta ciudad estén viviendo en los campos, plazas, muladares y huertas, en ranchos de cañas y esteras, barracas y pauellones, con suma incomodidad, de la qual y la falta de mantenimiento ha sobrevenido la común enfermedad de tabardillo y tercianas malignas, que dizen los médicos

24 Según M. Gasco el sismo provocó el inició de las importaciones de trigo desde Chile "Vientos, terremotos, tsunamis y otras catástrofes naturales- historia y casos latinoamericanos". Buenos Aires, Argentina: Editorial Biblos, 2005. pp.74. 
hay más de catorze mil enfermos, y desde el día veinte de octubre hasta hoy día a la fecha han muerto de la dicha enfermedad hasta dos mil y seiscientas personas" (Angulo,1939:13.).

El costo de la reedificación de casi todos los edificios públicos fue tasado en seis millones de pesos por el alarife mayor de la Catedral de Lima (Angulo, 1939:09). No obstante, el panorama de la ciudad después del sismo era personas que se encontraban viviendo en los espacios públicos; por ejemplo en la Plaza Mayor se encontraba viviendo el virrey con su familia en casas con carrizos (Angulo, 1939:10). En esta oportunidad, el virrey tuvo que ejecutar un plan de salubridad para evitar la propagación de las enfermedades y atender a los enfermos. Así también, un plan de seguridad para resguardar los bienes de la Corona, particulares y de las órdenes religiosas.

La reconstrucción quedó a cargo del virrey Melchor Portocarrero Lazo de la Vega o Conde Monclova que gobernó de 1689 a 1705 (Sifuentes, 2004:311) que tuvo que planificar, ejecutar y controlar un plan de reconstrucción. La visión que tenía de la ciudad era mantener el trazado de damero en el núcleo central, mejorar la accesibilidad de los barrios periféricos al centro y reconstruir las edificaciones que tendrían un nuevo planteamiento en su estructura para resistir futuros movimientos sísmicos. Esta tarea quedó en manos de los alarifes de la ciudad (Crespo, 2005:50). Para lograr este objetivo se emprendieron las acciones como buscar mayores recaudaciones de impuestos por parte de El Cabildo y donaciones. En el siguiente cuadro se resumen las edificaciones dañadas por el sismo en el núcleo central que tuvieron que ser reconstruidas. 


\section{Cuadro 1.2}

\section{Edificaciones dañadas en el núcleo central de la ciudad el año 1687}

\begin{tabular}{|c|c|}
\hline Tipo de edificación & $\begin{array}{c}\text { Número de } \\
\text { edificaciones } \\
\text { dañadas }\end{array}$ \\
\hline $\begin{array}{c}\text { Templos o iglesias entre grandes y pequeñas. } \\
\text { cuatro parroquias }\end{array}$ & 76 \\
\hline $\begin{array}{c}\text { Conventos de religiosas y religiosos } \\
\text { Dos hospederías de Monserrate y Francisco } \\
\text { de Paula }\end{array}$ & 20 \\
\hline Monasterios de Monjas & 02 \\
\hline Hospitales y convalencias & 11 \\
\hline Beaterios & 11 \\
\hline La iglesia y casa de niños huérfanos y \\
recogimientos de amparadas de la Purísima & 02 \\
\hline Dos capillas & 02 \\
\hline La Santa Inquisición & 01 \\
\hline Total & 146 \\
\hline
\end{tabular}

Fuente: Elaboración propia en base a documentos del terremoto de 1687 Angulo (1939, pp.10-45).

El cuadro nos muestra que fueron los templos e iglesias los más dañados, seguidos de los conventos por lo que la Iglesia tuvo que intervenir en el Plan de Reconstrucción de la ciudad. También se dañaron los hospitales que implicó atención ambulante a los heridos durante la reconstrucción. El daño a los Colegios y Universidades paralizó la enseñanza superior a cargo de la Iglesia por un periodo. El siguiente cuadro nos muestra el estado en el que quedaron las edificaciones en la periferia después del sismo. 


\section{Cuadro 1.3a}

\section{Edificaciones dañadas en la periferia de la ciudad con el sismo de 1687}

\begin{tabular}{|c|c|c|}
\hline Lugar & Descripción del lugar & Ubicación \\
\hline $\begin{array}{l}\text { Huerta Cuero (cerca a } \\
\text { Monserrate) propiedad del } \\
\text { Mayorazgo de Juan de } \\
\text { Aliaga }\end{array}$ & Pueblo con esteras y carrizos & Monserrate \\
\hline Paraje Remanga Naguas & Fábricas portátiles, pequeña población & Monserrate \\
\hline $\begin{array}{l}\text { Huerta San Nicolás de los } \\
\text { religiosos de San Agustín }\end{array}$ & Personas resguardadas & Monserrate \\
\hline $\begin{array}{l}\text { Hospicio, huerta de los } \\
\text { religiosos de San } \\
\text { Francisco de Paula en la } \\
\text { esquina de la salida al } \\
\text { Callao }\end{array}$ & Iglesia y celda caídas y cerca demolida & San Francisco de Paula \\
\hline $\begin{array}{l}\text { Huerta del maestre de } \\
\text { campo Don Diego y } \\
\text { Manrique y Lara y pueblo } \\
\text { numeroso }\end{array}$ & $\begin{array}{l}\text { Iglesia de Santo Cristo de los Milagros } \\
\text { arruinada cerca había un pedazo de muralla. }\end{array}$ & $\begin{array}{l}\text { Santo Cristo de los } \\
\text { Milagros }\end{array}$ \\
\hline $\begin{array}{l}\text { Chacarilla de los padres } \\
\text { Agustinos }\end{array}$ & Brecha de muralla & $\begin{array}{l}\text { Santo Cristo de los } \\
\text { Milagros }\end{array}$ \\
\hline $\begin{array}{l}\text { Chacarilla de San Jacinto } \\
\text { de los padres de Santo } \\
\text { Domingo }\end{array}$ & Brecha de muralla que la atraviesa & San Jacinto \\
\hline $\begin{array}{l}\text { Huerta de los religiosos de } \\
\text { Magdalena }\end{array}$ & Convento y pequeñas poblaciones & $\begin{array}{l}\text { Chacarilla de San } \\
\text { Jacinto }\end{array}$ \\
\hline $\begin{array}{l}\text { Religiosos de nuestra Sra. } \\
\text { de Belén, recolección de } \\
\text { nuestra Sra. de Merced }\end{array}$ & Huerta de cercas caídas & $\begin{array}{l}\text { Chacarilla de San } \\
\text { Jacinto }\end{array}$ \\
\hline $\begin{array}{l}\text { Chacarilla San Jacinto de } \\
\text { Antonio Jiménez }\end{array}$ & Población con colegio & $\begin{array}{c}\text { Chacarilla de San } \\
\text { Jacinto }\end{array}$ \\
\hline $\begin{array}{l}\text { Santa Rosa de Santa } \\
\text { María }\end{array}$ & $\begin{array}{l}\text { Bajando por el muladar el molino del maestre } \\
\text { de Campo Fernando de Pastriana y Espinoza }\end{array}$ & $\begin{array}{l}\text { Santa Rosa de Santa } \\
\text { María }\end{array}$ \\
\hline Parroquia de San Lázaro & $\begin{array}{l}\text { Barrio de Malambo, puente de Romero y rastro } \\
\text { de Grande Vaca }\end{array}$ & $\begin{array}{l}\text { Santa Rosa de Santa } \\
\text { María }\end{array}$ \\
\hline $\begin{array}{l}\text { Por la orilla del rio en la } \\
\text { otra banda }\end{array}$ & $\begin{array}{l}\text { Molino de Pólvora de doña Isabel Castillo al pie } \\
\text { del Cerro de San Cristóbal , la alameda }\end{array}$ & $\begin{array}{l}\text { Santa Rosa de Santa } \\
\text { María }\end{array}$ \\
\hline $\begin{array}{l}\text { Capilla de la señora de } \\
\text { Copacabana }\end{array}$ & $\begin{array}{l}\text { Calle de Amancaes, molino de Piedra de } \\
\text { Francisca Calderón viuda de Ximenez que está } \\
\text { en el puente de la Sauceda }\end{array}$ & $\begin{array}{l}\text { Santa Rosa de Santa } \\
\text { María }\end{array}$ \\
\hline $\begin{array}{l}\text { Huerta Pedregal de la } \\
\text { calle ancha de Malambo }\end{array}$ & Iglesia de nuestra señora del Socorro & Nuestra señora Guía \\
\hline
\end{tabular}

Fuente: Elaboración propia en base a documento del terremoto de 1687 Angulo (1939, pp.10-45). 


\section{Cuadro 1.3b}

\section{Edificaciones dañadas en la periferia de Lima con el sismo de 1687}

\begin{tabular}{|c|c|c|}
\hline Lugar & Descripción del lugar & Ubicación \\
\hline Huerta la Venturosa & Población & $\begin{array}{l}\text { Chacarilla de } \\
\text { San Jacinto }\end{array}$ \\
\hline Huerta Belén religiosos de la Merced & Casa parroquial & $\begin{array}{l}\text { Chacarilla de } \\
\text { San Jacinto }\end{array}$ \\
\hline Casa Huerta de Juan Simón & Muchos ranchos edificados & Guadalupe \\
\hline Chacra Matamandinga & $\begin{array}{l}\text { Iglesia de Nuestra señora de } \\
\text { Guadalupe de los religiosos de San } \\
\text { Francisco caída la iglesia }\end{array}$ & Guadalupe \\
\hline $\begin{array}{l}\text { Huerta Perdida de Don Miguel de los } \\
\text { Ríos }\end{array}$ & Dos huertas con varias casas & Guadalupe \\
\hline $\begin{array}{c}\text { Plazuela de las monjas de Santa } \\
\text { Catalina }\end{array}$ & Claustro de monjas & Santa Catalina \\
\hline $\begin{array}{l}\text { Monjas de la Concepción en Santa } \\
\text { Catalina }\end{array}$ & Convento & Santa Catalina \\
\hline Huerta de Pedro Solano & Ranchos & Santa Catalina \\
\hline $\begin{array}{c}\text { Huerta Breten de doña María Morante y } \\
\text { Aguilar }\end{array}$ & Ranchos & Santa Catalina \\
\hline $\begin{array}{l}\text { Huerta de las monjas del capitán Alonso } \\
\text { Ximenez de Vela y Lara }\end{array}$ & Capilla y huertas & Santa Catalina \\
\hline Plazuela de Guaquilla de Santa Ana & Tambo de la Estrella & Santa Catalina \\
\hline Huerta de Juan de Cueva & Ranchos & Santa Catalina \\
\hline $\begin{array}{l}\text { Huerta del señor Thomas Berjon de } \\
\text { Cabiedes oidor de la Real Audiencia }\end{array}$ & Iglesia de Cocharcas demolida & Cocharcas \\
\hline Convento del Carmen & $\begin{array}{c}\text { Plaza de la iglesia muchos ranchos y } \\
\text { casas }\end{array}$ & $\begin{array}{l}\text { Convento del } \\
\text { Carmen }\end{array}$ \\
\hline Nuestra señora del Prado & Nuestra señora del Prado & $\begin{array}{l}\text { Nuestra señora } \\
\text { del Prado }\end{array}$ \\
\hline Convalensencia de indios & Hospital & Cercado \\
\hline Beatas de la Merced & Casa & Cercado \\
\hline Santiago del Cercado & Plaza y plazuela muchos ranchos & Cercado \\
\hline Convalecencia de Pedro Alcántara & $\begin{array}{c}\text { Por la calle que sale a Santa Clara, } \\
\text { rancherías }\end{array}$ & Cercado \\
\hline Santa Clara & Población cerca al río & Santa Clara \\
\hline Soledad & Iglesia arruinada & Soledad \\
\hline Beaterio de Santa Rosa de Viterbo & Arriba de la cerca de San Francisco & Viterbo \\
\hline $\begin{array}{l}\text { Rastro grande donde se mata carne de } \\
\text { Castilla }\end{array}$ & $\begin{array}{l}\text { Plazuela y barrancas con muchas } \\
\text { casas cerca al río, Saliendo de la } \\
\text { iglesia de Desamparados }\end{array}$ & Desamparados \\
\hline
\end{tabular}

Fuente: Elaboración propia en base a documento del terremoto de 1687 Angulo (1939, pp.10-45) 


\section{Plano 1.6}

\section{Ubicación de los barrios de Santiago del Cercado y San Lázaro en el siglo XVII}

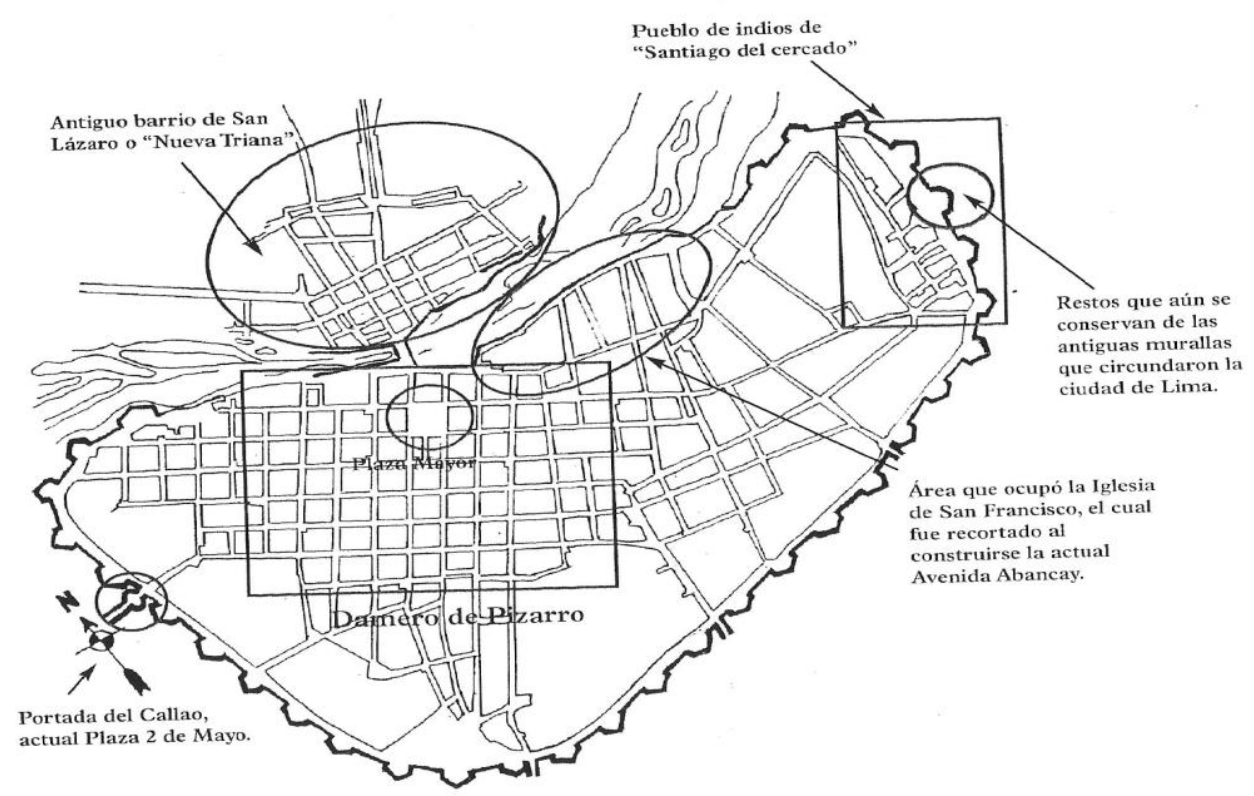

Fuente: Sifuentes.L (2004, pp.130)

Gracias a la información de los cuadros $1.2,1.3^{\mathrm{a}}$ y $1.3 \mathrm{~b}$ podemos decir que los barrios con edificaciones dañadas que rodeaban al núcleo central fueron: El Cercado, Santa Rosa de Santa María, Nuestra Señora Guía, Desamparados, Soledad, Viterbo, Cocharcas, Santa Catalina, Guadalupe, San Jacinto y Monserrate que se habían urbanizado desde finales del siglo XVII. Además cerca de las portadas de Callao, Cocharcas, Guadalupe, Monserrate y Guía se puede observar urbanización espontanea junto a las iglesias del Socorro y Cocharcas alrededor de las cuales existía una infraestructura educativa y actividad comercial.

También se dañaron edificaciones al interior de las huertas y chacras que pertenecían a las órdenes religiosas y particulares que albergaban pequeñas poblaciones indígenas a su cuidado como fue el caso de la casa huerta de San Simón donde existieron varios ranchos edificados. El sismo puso en evidencia 
la urbanización espontanea cerca a las iglesias de Desamparados en los bordes ribereños generado por la población a pesar las Leyes prohibían que esta población indígena viviera en la ciudad. En este momento, en la ciudad de Lima se produjo un proceso de subordinación de la periferia respecto al centro (Ramírez, 2007:69-89) $^{25}$ debido a factores políticos y económicos que influyeron en la organización del suelo urbano y en el desarrollo de estos dos espacios.

Gracias al sismo, la urbanización espontanea fue destruida paulatinamente y El Cabildo prohibió esta práctica en la periferia para que el trazado de damero de orden y control fuera respetado en toda la ciudad. Debido a estas disposiciones fue posible reubicar a la población indígena fuera de la ciudad y organizar mejor los espacios en la periferia de la ciudad. El sismo puso al descubierto la actividad del mercado de suelo en la periferia que, para ese entonces, ya no era la ubicación de los españoles pobres, indígenas y mulatos como en el siglo XVI e inicios de XVII sino los principales propietarios eran las órdenes religiosas y españoles de la élite ${ }^{26}$ como don Thomas Berjon de Cabiedes oidor de la Real Audiencia dueño de una huerta en el distrito de Cocharcas que sufrió daños con el sismo que era utilizada para uso comercial y de servicios cerca a las portadas de la muralla. La ciudad había experimentado un crecimiento y la periferia se había convertido en un espacio hibrido rural-urbano que incluía tierras de cultivo, molinos de trigo, actividad comercial, hospedaje y vivienda.

La reconstrucción de la ciudad, llevó diez años en materializarse y puso en evidencia aspectos sociales, económicos, políticos y espaciales de la ciudad como: el desorden urbano en la periferia por una falta del control del Cabildo,

\footnotetext{
25 Según Ramírez V. Blanca "Cuando analizamos la manera como los teóricos del proceso de urbanización introducen el tema de la periferia urbana se identifican con dos posiciones que, desde los parámetros antes expuestos pueden ser considerados como modelos como referentes teóricos. En primer lugar se presenta la postura que prioriza la centralidad como un elemento clave para identificar por contraposición la periferia. Otras posiciones subordinan a la periferia a lo urbano, mientras que otros marginal a los agentes de la periferia adoptando procesos de crecimiento ecológico de la ciudad" En: Revista Leirdinarie Latino Americain, 2007, http://www.scielo.org.co/scielo.php?script=sci_nlinks\&ref=000282\&pid=S0121215X201400010000300048\&lng=es, pp.69-89.

26 Según Augustín "para 1540 el derecho de los españoles de poseer tierras estuvo limitado solo pro la prohibición de expropiarlas a los indígenas, de vender propiedades a la Iglesia o eclesiásticos y la obtener terrenos o inmuebles en una jurisdicción distintas a sus residencias "Ceques y Dameros - La reducción de Santiago del Cercado" Ed. URP,2016,Lima", pp.57
} 
la urbanización espontanea del borde ribereño, el control del mercado de suelo de la Iglesia, las desigualdades entre el centro y periferia, la capacidad del virrey de administrar y ejecutar un plan de reconstrucción que involucre a la Iglesia y la élite, el crecimiento poblacional cerca a las portadas de la muralla, la necesidad de vivienda de las poblaciones cerca a las parroquias periféricas y la necesidad de ordenar la urbanización espontanea cerca a las portadas y las iglesias de la periferia. Se produjo un proceso de regeneración urbana del centro y de la periferia con un control de los usos de suelo principalmente de vivienda-comercio en la periferia y se continúo con el reparto de tierras.

\subsection{Las nuevas disposiciones para la ciudad de la Casa Borbón en el siglo XVIII}

Para inicios de 1700 el virrey Conde de Monclova mandó a realizar un censo de población de la ciudad que dio como resultado 37,259 habitantes (Diario El Mercurio Peruano á, 03 febrero, 1791:92-93) ${ }^{27}$ que demuestra un crecimiento poblacional después del último sismo producto de la actividad económica en la ciudad gracias principalmente al comercio marítimo.

Las nuevas disposiciones de la Casa Borbón generaron cambios en la administración virreinal en todas las colonias que también afectó la vida en la ciudad como: desaparecieron las reducciones indígenas que fueron absorbidos por la ciudad y se produjo la reducción de los criollos en la administración colonial. El endurecimiento del sistema fiscal a favor de la Metrópoli generó una menor inversión en la ciudad por parte de los comerciantes (Fisher, 2000:6370). El libre comercio al interior de las colonias provocó una mayor actividad por el puerto del Callao. La introducción de las intendencias descentralizaron el poder que tenían las capitales de virreinato restándole poder político a Lima. La aparición del clero secular que permitió disminuir el poder a la lglesia en las decisiones políticas de la ciudad. Por último, la aparición de la libertad de

\footnotetext{
27 Según Pérez Cantó nos da referencia de un segundo censo realizado en 1700 ubicado en la Biblioteca de Nacional de Madrid titulado "Numeración General de todas las personas de sexos, edades y calidades que se ha hecho en la ciudad de Lima. Año 1700" al respecto nos dice que las cifras no son muy exactas por la disparidad de criterio en su confección y errores de recuento. Este censo se realizó con la finalidad de conocer el número de personas que podían portar armas en caso de un ataque," Población de Lima en el siglo XVIII", Madrid, Universidad Autónoma de Madrid, 1985, pp. 384-386.
} 
imprenta que permitió la introducción de las ideas de la ilustración (Barreiro:2001:278) ${ }^{28}$, la difusión de la ciencia y la política en la ciudad.

Aunque estas reformas tuvieron por objetivo materializar la grandeza de la Casa Borbón, controlar el desarrollo urbano en la ciudad y las actividades de la población, también permitieron que la población modifique sus actividades y se produzca una reestructuración de los barrios con una nueva demarcación territorial en cuatro cuarteles y se pusiera en vigencia el Reglamento de Policía. Con estas disposiciones se construyeron en el núcleo central edificaciones suntuosas de arquitectura civil y religiosa. No obstante, se produjo también, el crecimiento urbano al otro lado del río que convirtió esta zona en una de las más exclusivas de la ciudad. El terremoto de 1746 se convirtió en la oportunidad de introducir estas reformas administrativas, tributarias y reconfigurar el territorio en nuevas unidades administrativas.

\subsection{El terremoto de 1746 y la reconstrucción de Lima en un contexto de reformas borbónicas}

El año 1746 nuevamente un terremoto había destruido la ciudad y arruinado casi todas las edificaciones civiles y eclesiásticas. Pero en esta oportunidad, la discusión de reconstruir la ciudad y lograr una recaudación de fondos giró en torno a la figura del virrey de turno Manso de Velasco o Conde de Superunda que gobernó de 1745 a 1761 debido a la ineficacia de El Cabildo de Lima (Walker, 2012:107) para asumir un plan de reconstrucción para la ciudad. Desde inicios del siglo XVIII, se habían incorporado nuevas castas en la ciudad como: asiáticos llegados de Filipinas y europeos que habían vuelto la ciudad multirracial y cosmopolita (Walker,2012:84-86), fue por esta razón, que en esta oportunidad la reconstrucción de la ciudad debía satisfacer también a estos nuevos grupos sociales.

\footnotetext{
28 Según José Luis Barreiro "Sí algo ha caracterizado a esta época moderna, que ahora parece declinar, fue la propuesta de emancipación del hombre: emancipación de Dios, emancipación de la naturaleza y emancipación de los demás hombres. El protagonista de esta libre liberación religiosa, económica y social, tenía que ser la razón. Decir modernidad, es decir ilustración, confianza ciega en el poder de la razón humana para construir una humanidad más fraternal e igualitaria...Decir modernidad, es decir, también, racionalización de todo aquello que abarca nuestra vida: racionalización de la vida pública y privada, de lo económico y los político, de los económico y de los estético. Para esta tarea racionalizadora no se eligió, como saben, una razón teórico filosófico, sino una razón nacida con la modernidad: la razón científica. Porque la razón científica, era la que encarnaba mejor los ideales de individuo" "llustración y modernidad los avatares de la razón", 2001, Ed. Universidad de Santiago de Compostela, pp.277-301.
} 
Según el documento "Relación del terremoto que arruinó a Lima e inundó el Callao" el 28 de octubre de 1746 escrita por el padre Lozano de la Compañía de Jesús" el panorama fue desolador.

"El 28 de octubre de 1746 como a las diez y media de la noche, se sintió en Lima un temblor de tierra, tan violento, que en menos de tres o cuatro minutos de duración ha sido arruinada la ciudad. Fue tan repentino el mal, que nadie tuvo tiempo de ponerse en seguro: y fue tan universal el estrago, que nadie pudo evitar el peligro de la huida. Han quedado solo de pie veinticinco casas; y sin embargo, por una protección particular, de la providencia, sesenta mil personas que se componía la ciudad, no pereció más que la duodécima parte, sin saber los que se vieron libres de peligro, y sin mirar la conservación de sus vidas, como una especie de milagro " (Odriozola,1863:36).

La devastación fue total pero gran parte de la población se salvó de morir. No obstante, el virrey tuvo que pensar en un plan de contingencia para el abastecimiento de alimentos y servicios a la población afectada así como resguardar los bienes de la Iglesia y la población. En este caso, mando arreglar los hornos de pan, molinos y limpiar los acueductos y fuentes para restablecer el servicio de agua en la ciudad (Odriozzola, 1863:44) y el Cuerpo de Policía resguardo la ciudad. Así también, el virrey implementó un plan de salubridad para el levantamiento de los cadáveres cerca a las iglesias que estuvo a cargo del Cuerpo de Policía y la Cofradía de la Caridad (Odriozola, 1863:40).

La visión del virrey después de la reconstrucción era una ciudad más racional. Para lograr este objetivo, no se permitieron la construcción de edificaciones ostentosas en la ciudad, esta restricción significó un cambio del estilo de barroco al neoclásico. También buscó fortalecer la diferencia entre espacios públicos y religiosos (Walker, 2012:159) para así mantener separados el mundo religioso del secular. Otro objetivo fue lograr que la reconstrucción ayudara a implementar las nuevas normativas de la administración Borbón de modernizar y embellecer la ciudad. Sin embargo, debido al crecimiento espontaneo en el borde ribereño y la periferia se buscó controlar el proceso de urbanización en estos espacios.

En esta oportunidad, ante un panorama de reconstrucción en un periodo de introducción de ideas de la ilustración en la ciudad surgieron propuestas para la reconstrucción total de la ciudad o su ensanche que muestran hasta qué punto la sociedad limeña y la Iglesia podían apoyar las transformaciones en la ciudad 
propuestas por los cosmógrafos y como las ideas de la llustración habían transformado la forma de pensar de la población como veremos a continuación.

\subsubsection{Los planes para la reconstrucción de Lima: Las propuestas de los cosmógrafos Luis Godin y Pedro de Peralta y Barrionuevo (1740-1746)}

La reconstrucción de la ciudad coincidió con un momento de apogeo de la ingeniería militar en la Metrópoli (Gutiérrez, 2005:32-34). Muchos cosmógrafos hicieron uso de esta ciencia para realizar proyectos tanto en Europa como en América que no solo se limitaron a diseñar fortificaciones sino obras civiles y planes que comprendieran la reconstrucción parcial o total de la ciudad. El sismo fue la oportunidad de introducir a miembros de la Real Academia e ingenieros militares en Lima que permitió la modernización de los gremios de Alarifes o Maestros Mayores que llevó al uso de materiales más resistentes ante los frecuentes sismos en Lima.

La reconstrucción de Lima no solo implicó un plan de reconstrucción de las edificaciones civiles y religiosas sino también la implementación de primer Plan de Ensanche de las calles, delimitación de las alturas de las edificaciones, prohibición de torres con arcos, reemplazar la estructura de piedra por quincha en los segundos pisos de las edificaciones y adecuar espacios públicos para que sirvieran de refugio en caso de sismo (Odriozola, 1863:46-47). Con todos estos requerimientos los cosmógrafos elaboraron los siguientes planes.

\subsubsection{El proyecto del cosmógrafo Pedro de Peralta y Barrionuevo: Lima inexpugnable (1740)}

Este planteamiento buscó un cambio de ubicación de la ciudad y la idea de la ciudadela amurallada. Al respecto, los ciudadanos y la élite pensaron que la ciudad podría cambiar de lugar porque requería de más espacio (Moreno, 1983:70) y apoyaron el proyecto del cosmógrafo Pedro Peralta y Barrionuevo publicado en el libro titulado Lima la Inexpugnable el año 1740 donde describía a la muralla como una cerca que quitaba el paso de la ciudad débil e insalubre más que una edificación que defendía a la ciudad (Ramón, 1999:75). La 
propuesta del cosmógrafo buscó crear un espacio amurallado para la defensa que implicó seguridad de las riquezas que tenia la ciudad (Eguiguren, 1966:1012). Sin embargo, para Pedro de Peralta el discurso de la defensa significó poner en práctica la arquitectura militar en la construcción de una ciudadela amuralla. Por ejemplo, el cosmógrafo pensó que la falta del terraplén en la muralla la hacía inútil para defenderla con artillería y hombres. Pero además, la convirtió en una cerca que cerraba a la ciudad y que iba en contra la salubridad más que ser una defensa (Eguiguren, 1966:14). Ante este análisis de la actual muralla el cosmógrafo pensó que debería aplicarse el concepto de ciudad de guerra en Lima debido a la importancia de Lima como capital del virreinato y porque si se defendía esta ciudad se estaba defendido todo el virreinato. Dentro de los argumentos para la construcción de la ciudadela amurallada se encontraban: los contingentes de soldados y pertrechos eran más costosos que construir una ciudadela amurallada (Eguiguren, 1966:27). Otro argumento que dio el cosmógrafo fue que sí alguna parte de la muralla fuera derribada o se encontraba deteriorada esta ya no serviría para la defensa mientras en un ciudadela amurallada era posible mantener la defensa. Por último, la propuesta de ciudadela amurallada representaba una defensa mucho más segura que la muralla y remediaba la debilidad de una ciudad con un mejor refugio donde se podía retomar estrategias para una mejor defensa (Eguiguren, 1966:16-17).

Para el cosmógrafo, la ciudadela amurallada era un modelo militar de ciudad cuyo objetivo era la absoluta defensa que permitiría el resguardo de las riquezas y la fácil evacuación ante sismos (Sáenz, 2008:04-05). Aunque este nuevo planteamiento mostró una gran diferencia iba en contra de los intereses de la Iglesia que ya tenía el control del mercado de suelo de la ciudad. 


\section{Plano 1.7}

\section{La ciudadela amurallada de Pedro de Peralta y Barrionuevo} (1740)

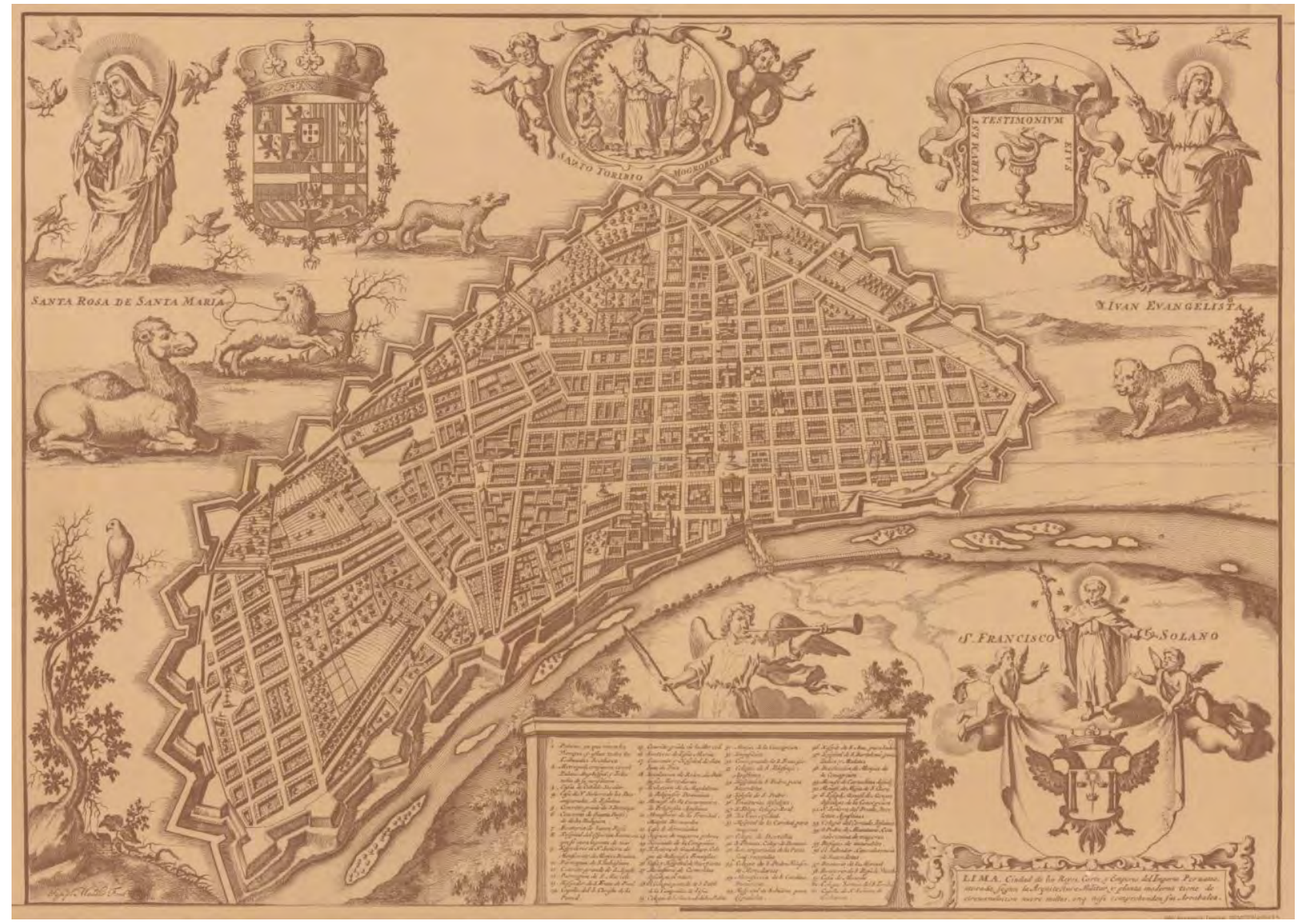

Fuente: Gunther (1983) Lámina 5

\subsubsection{La propuesta de Louis Godin y el Plan de Ensanche de Calles el año (1746)}

El planteamiento del cosmógrafo francés Luis $\operatorname{Godin}^{29}$ miembro de la Academia Real de Ciencias de Paris para elaborar un Plan de Ensanche de Calles a pedido del virrey de Superunda buscó cambiar el trazo de la ciudad, arquitectura y uso de materiales con el objetivo de salvaguardar a la población a diferencia de la anterior propuesta. Sin embargo, como esto afectaba directamente los bienes de la Iglesia tampoco fue posible su ejecución total en la ciudad a pesar que era la propuesta oficial apoyada por el virrey de turno.

\footnotetext{
${ }^{29}$ Louis Godin cosmógrafo Francés miembro de la Real Academia de París.
} 
El Plan tuvo como idea cambiar de lugar a la ciudad argumentado por el cosmógrafo que el estado de los baluartes de la muralla estaban deteriorados así como la mayoría de las edificaciones civiles y religiosas que reconstruir facilitaban el cambio de ubicación de la ciudad desde la ribera del río hasta la hacienda la Pólvora. La propuesta, propuso la idea que una nueva muralla fuera edificada para recuperar la capacidad defensiva de Lima (Sáenz, 2008:04).

En este caso, las Leyes de Indias no especificaban el ensanchamiento de las calles únicamente debía ser estrechas por el calor con algunas concesiones para ampliarlas en caso de defensa según Ley de Indias X "Forma de calles" (Roix, 184:107). Sin embargo, el planteamiento buscó aumentar el ancho a 12 varas promedio (10.26 metros) (Walker, 212:127) para permitir la rápida evacuación de las personas. Este Plan también incluyó la demolición de los muros de más de 4.5 varas (3.28 metros) aunque las Leyes de Indias no determinaban una altura de edificación solo exigía la construcción de viviendas ventiladas, patios y corrales anchos para la salubridad y limpieza según Ley de Indias XVII "Que las casas se dispongan conforme a esta Ley" (Roix, 1841:107). Uno de los principales aportes de este Plan fue la prohibición de construcciones de más de dos pisos para prevenir desastres ante otro sismo que sí tuvo el apoyo de la población.

Sin embargo, la idea de demoler los segundos pisos de las casas en la ciudad generó un rechazo de los ciudadanos sobre todo de la élite que siguió un juicio por este cambio ante la Corte de Lima representados por el abogado Salvador Jerónimo de Portalanza. Logrando después de una serie de sustentaciones y presiones de miembros de El Cabildo y la Iglesia que el virrey desistiera de esta idea (Walker, 212:131). La discusión sobre la demolición de las casas de más de dos pisos demostró la libertad de ideas de la sociedad organizada limeña a partir de la administración Borbón y como las ideas de la ilustración del bien común y la razón se habían introducido en la población. Por otro lado, el debate del abogado Portalanza para evitar la demolición de los segundos pisos de las casas puso en evidencia el poco espacio que quedaba en la ciudad encerrada en la muralla y el alto precio de las propiedades a demoler (Walker,2012:134-135). Esto nos demuestra que, la idea de crecimiento urbano 
se encontraba en debate, pero aún, no con un suficiente sustento y aprobación de las autoridades y la población para lograr la demolición de la muralla.

Aunque ambas propuestas no fueron materializadas debido principalmente porque afectaba el monopolio del mercado de suelo de la Iglesia, motivo por el cual, tuvo una fuerte oposición por parte de La Junta de Tribunales y El Cabildo (Walker,2012:129). Esta decisión, hubiera significado construir un nuevo sistema financiero en base a nuevas propiedades con una pérdida económica para la Iglesia. Al final los alarifes y el Cabildo Secular reunidos el 6 de enero de 1747 en la ciudad decidieron reconstruir la ciudad en el mismo lugar porque significaba un menor costo (Moreno, 1983:70).

El sismo puso en evidencia el control de la Iglesia sobre el mercado de suelo en la ciudad que con los años el proyecto Borbón trató de disminuir introduciendo el clero secular restándole poder en las parroquias. Para ese año, la Iglesia era la propietaria del 75 por ciento del total de las propiedades urbanas (Walker, 2012:146). Al respecto, el virrey Manso de Velasco con el apoyo de El Cabildo y la Real Audiencia gestionó que los propietarios pagaran las hipotecas a la mitad y bajo las tasas de interés de 5 por ciento a 2 (Moreno, 1983:71). Aunque al final bajaron de 3 por ciento a 2 por ciento este incentivo permitió a los propietarios de las casas reconstruir sus edificaciones y renegociar los censos o hipotecas con la Iglesia (Moreno, 1983:71). De esta manera, la Iglesia se convirtió en la principal institución crediticia de la ciudad que hizo posible la reconstrucción en la ciudad.

El sismo posibilitó al virrey observar cambios y necesidades de la ciudad que para este periodo era multirracial y cosmopolita (Diario El Mercurio Peruano, 1791á, 02 enero:02-03). Sin embargo, la principal necesidad de esta población era contar con una vivienda en las parroquias que rodeaban el núcleo central que habían crecido y desarrollado desde la última reconstrucción (Moreno, 1983:71) que provocó la especulación inmobiliaria por parte de las órdenes religiosas y la élite que eran los grandes propietarios de la ciudad. Esto fue evidente, con el alza de las rentas en las zonas de la periferia. Para solucionar el problema de la vivienda ocasionada por el sismo y evitar la especulación el virrey permitió que los pobres arrendaran propiedades en la periferia a bajo 
costo beneficiando a los propietarios de los barrios de Acho, Cocharcas y Naranjos (Moreno, 1983:266). De esta manera, reordeno el mercado de suelo sin densificar el centro acertadamente y cubrió la necesidad de vivienda de esta población.

Entre los años de 1746 a 1748 la ciudad de Lima atravesó un proceso de reconstrucción a cargo de El Cabildo y del Virrey Manso de Velasco. Es muy posible que el ensanche de calles se diera en la periferia cerca a espacios en construcción que aun no se habían consolidado. Sin embargo, la política de reconstrucción acelerada no benefició a los propietarios sino a las órdenes religiosas para quienes estaban hipotecadas las casas vía censo. En los últimos años de la reconstrucción, las nuevas obras públicas dieron un nuevo rostro a la ciudad y mostraron el absolutismo en el que se vivía. No obstante, la estética de la ciudad había cambiado pasó de una arquitectura barroca a una neoclásica que mostraba. El cambio en la ciudad, aportaba alamedas y espacios afrancesados producto de la influencia de los europeos que ya vivían en la ciudad. La ciudad iniciaba su periodo de apogeo.

Fue la oportunidad para materializar la modernidad, extenderla materializarla y producirla (Gorelik,2003:13) con la ejecución de obras públicas. Para ello se recaudaron fondos de arbitrios municipales y donaciones que sirvieron para realizar las siguientes obras: el arreglo de la Casa de El Cabildo, el acondicionamiento de la Cárcel, la construcción de un nuevo arco a la entrada del puente, una nueva caja de agua a la que se adicionó una nueva fuente pública, se arregló la fuente de la Plaza Mayor, un pilar del puente del río Rímac y los tajamares de la ciudad. Se construyeron, El Tribunal del Santo Oficio de la Inquisición y La Real Universidad (Odriozola, 1863:38). Todas estas obras cumplieron el objetivo de materializar la grandeza de la administración Borbón en la ciudad en medio de un proceso de reconstrucción de la ciudad y que atravesara por un proceso de modernización urbana. En esta oportunidad, el sismo mostró la autonomía que tenían las autoridades para la ejecución de planes y proyectos en beneficio de la población. 


\subsubsection{El apogeo de Lima durante el reinado de la Casa Borbón en el siglo XVIII y la nueva demarcación territorial (1769-1785)}

El plano de Lima del año 1750 muestra una ciudad urbanizada hasta los bordes de la muralla por el norte. Por el sur las huertas de particulares llegaban hasta calle que rodeaba a la muralla. Por el este existían huertas y chacras cercanas al barrio de Santiago del Cercado (Plano, 1750). Debido al crecimiento de la ciudad ya no se estaba cumpliendo con las Leyes de Indias que exigían trescientos pasos entre las edificaciones y la muralla (Roix, 1841:107). La urbanización hasta el borde generó un desequilibrio ambiental debido a que se eliminó espacios verdes que se encontraban cerca a la muralla que servían a la ciudad para evitar la contaminación en un clima húmedo. Sin embargo, un aspecto positivo de la urbanización cerca a la muralla fue la eliminación de los basurales cerca a algunas portadas deterioradas.

Para 1755 la población de Lima era de 54,000 habitantes (Diario El Mercurio Peruano, 1791:93) la ciudad había crecido desde el último sismo pero las edificaciones quedaron en dos pisos. Sin embargo, existía una necesidad de vivienda que inició la densificación en el centro y en la periferia que trajo como consecuencia una especulación en el precio de la renta.

Según Cédula Real de 19 de noviembre de 1769 se realizó una nueva demarcación de la ciudad en cuatro cuarteles y 36 barrios a cargo del urbanista Jorge Escobedo el documento fue publicado el año 1785 (Escobedo, 1785:1). De esta manera, las demarcaciones parroquiales quedaron sin efecto y con ello la Iglesia perdió el poder económico y administrativo que tenía. Se produjo una reorganización del territorio y una modernización administrativa de la ciudad dividida en nuevas unidades administrativas o cuarteles $^{30}$ a cargo de un alcalde e intendente.

\footnotetext{
30 La distribución de los cuarteles fue una práctica militar heredada de la administración de la Metrópoli que era reformas administrativas y no judiciales. Los nombramientos de alcaldes eran a personas que vivían en la zona.
} 
Plano 1.8 La muralla de Lima en un plano del año 1750

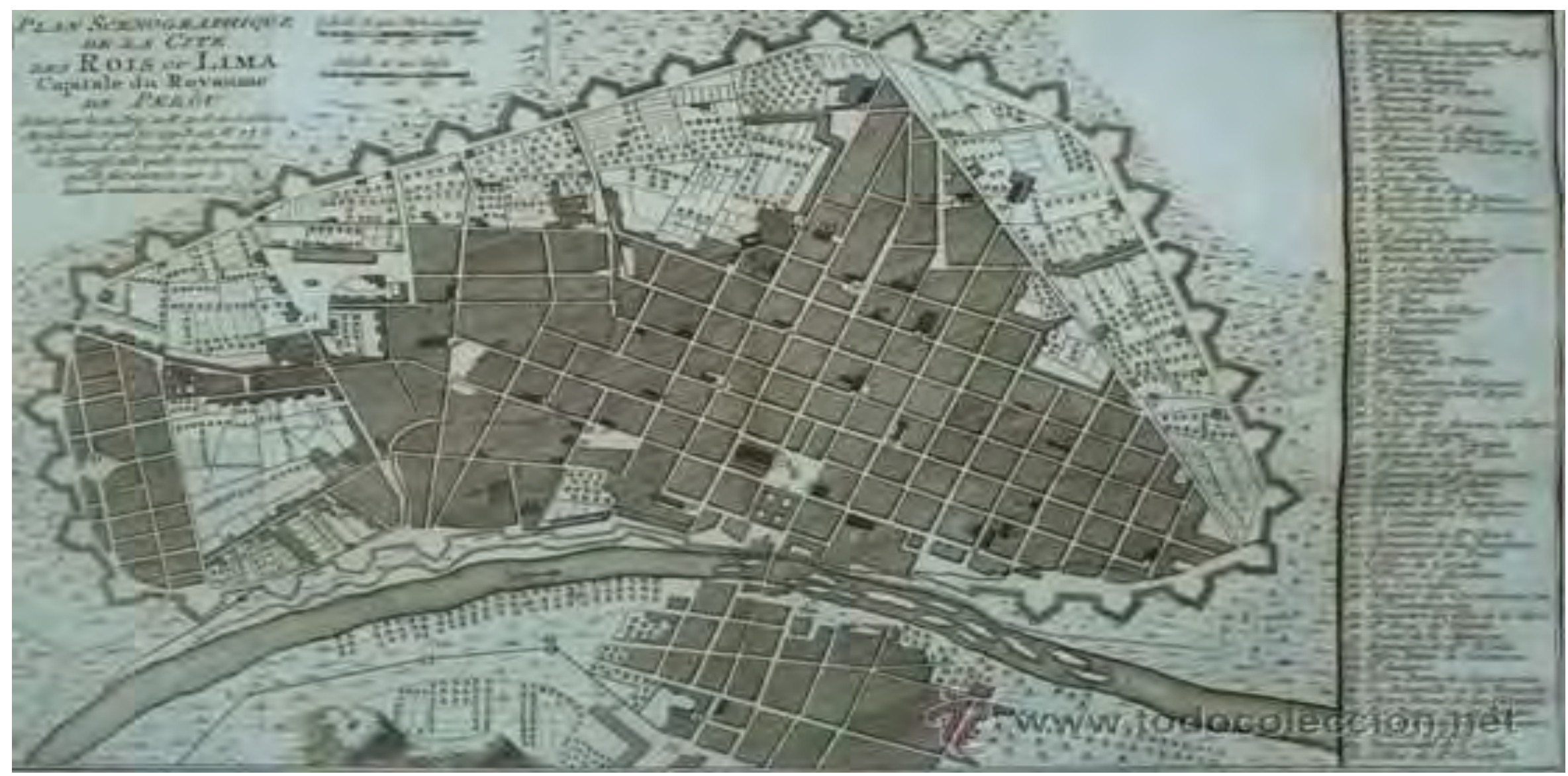

Fuente: Las murallas de Lima en un plano de 1750. https://medium.com/@culturaparalima/las-murallas-ribere\%C3\%B1as-de-lima-1508decb 


\section{Cuadro 1.4a}

\section{Delimitación de cuarteles el año 1769}

\begin{tabular}{|c|c|}
\hline Cuartel & Límites \\
\hline 1 & $\begin{array}{l}\text { Desde las portadas de Martinette hasta la Maravillas hasta la Nievería y Rincón de Polvos } \\
\text { Azules. Comprende Diez barrios 1.-Desde Martinette hasta la esquina de Viterbo con las } \\
\text { cuadras inmediatas que atraviesan a la izquierda.2.-Desde Viterbo hasta la Nieveria, con } \\
\text { las cuadras inmediatas que atraviesan a la izquierda.3.-Desde la portada desde las } \\
\text { Maravillas hasta el puente de Santa Clara con las cuadras inmediatas que atraviesan a la } \\
\text { izquierda. 4.-Desde el puente de Santa Clara hasta el esquina de la calle Tigre con todas } \\
\text { las cuadras que atraviesan a la izquierda.5.-Desde la esquine de la calle Tigre hasta la } \\
\text { plazuela de San Francisco hasta las cuadras que atraviesan a la izquierda. 6.-Desde la } \\
\text { plazuela de San Francisco inclusive hasta el Rincón de Polvos Azules con las cuadras que } \\
\text { atraviesan a la izquierda.7.-Desde la plazuela de Desamparados, hasta la Iglesia de San } \\
\text { Lázaro, con todas las cuadras que atraviesan a la derecha.8.-Desde la plazuela de San } \\
\text { Lázaro hasta Guía, Herbao, las Cabezas, el baratillo con todas las cuadras hasta el } \\
\text { puente del Baratillo.9.-Desde el fin del callejón de Romero hasta la esquina de la calle } \\
\text { Miranda, con todas las cuadras que atraviesa a la derecha, la almea vieja, el Acho, Plaza } \\
\text { de Toros, Pampilla de Leones y plazuela de Otero. 10.-Desde la plazuela de San Lázaro } \\
\text { siguiendo en línea derecha hasta el Pedregal, Santa Liberata y Descalzos con las calles } \\
\text { que atraviesan por la izquierda, hasta las casas del Sacramento, callejón de la puerta } \\
\text { falsa de San Francisco de Paola y la huerta Monigote y Guisado; y por la derecha hasta } \\
\text { Copacabana Molino de Portillo y Cerro de San Cristóbal, con todas las cuadras rectas o } \\
\text { atravesadas en este recinto. }\end{array}$ \\
\hline 2 & $\begin{array}{l}\text { En el segundo cuartel, se forma de todas las cuadras que se comprenden en línea recta, y } \\
\text { en travesía a la izquierda desde la portada de Betlemitas, e iglesia de Santa Ana, hasta la } \\
\text { calle de Matienzo y la plazuela de Monserrate.1.- Desde la portada de los Betlemitas } \\
\text { hasta la calle Vergara inclusive con las cuadras a la izquierda 2.-Desde el fin de la calle } \\
\text { Vergara hasta la esquina de la Caridad, con las cuadras que atraviesan a la izquierda.3.- } \\
\text { Desde la esquina de la Caridad hasta la del Arzobispado, ó plaza Mayor con las cuadras } \\
\text { que atraviesan a la izquierd.4.- desde la esquina del Arzobispado hasta la puerta falsa de } \\
\text { Santo Domingo con las cuadras que atraviesan a la izquierda 5.-Desde la esquina de la } \\
\text { puerta falsa de santo Domingo hasta la calle de Matienzo, con las cuadras que atraviesan } \\
\text { a la izquierda.6.-Desde Santa Ana hasta la esquina de la lglesia de la Concepción con las } \\
\text { cuadras que atraviesan a la izquierda. 7.-Desde la esquina de Mercaderes o plaza Mayor, } \\
\text { con las cuadras que atraviesan a la izquierda- } 8 \text {.-Desde la esquina de Mercaderes hasta } \\
\text { el Mármol de Bronce, con las cuadras que atraviesan a la izquierda. 9.-Desde la esquina } \\
\text { de Mármol e Bronce hasta la calle Villanueva, que sigue a la del Espíritu Santo, inclusive } \\
\text { con las cuadras que atraviesan a la izquierda. 10.-Desde la calle de las Lamillas inclusive } \\
\text { al final de la plazuela de Monserrate, con las cuadras que atraviesan a la izquierda. }\end{array}$ \\
\hline
\end{tabular}

Fuente: Escobedo (1785, pp-1-37) 


\section{Cuadro 1.4b}

\section{Delimitación de cuarteles el año 1785}

\begin{tabular}{|c|c|}
\hline Cuartel & Límites \\
\hline 3 & $\begin{array}{l}\text { Atraviesa por la izquierda por la calle Capón. Los naranjos, la Pampa de Lara } \\
\text { hasta el Molino de Arévalo, Torrecilla y Pampilla.1.-Desde el Capón hasta la } \\
\text { plazuela de San Pablo, con todas las cuadras que atraviesan a la izquierda. } 2 \text {-- } \\
\text { Desde la plazuela de San Pablo hasta la Iglesia de San Agustín hasta la calle } \\
\text { de San Sebastián inclusive con todas las cuadras que atraviesan a la } \\
\text { izquierda.3.-Desde la plazuela de San Agustín hasta la calle de San Sebastián } \\
\text { inclusive con todas las cuadras que atraviesan a la izquierda 4.-Desde la calle } \\
\text { de Orejuela hasta el Molino de Arévalo con las cuadras que atraviesan a la } \\
\text { izquierda.5.-Desde los Naranjos hasta la Aduana con las cuadras que } \\
\text { atraviesan a la izquierda. 6.-Desde la puerta falsa de San Pablo hasta la } \\
\text { plazuela de la Merced, con las cuadras que atraviesan a la izquierda. 7.- Desde } \\
\text { la plazuela de Monserrate la Torrecilla con las cuadras que atraviesan a la } \\
\text { izquierda.8.-desde la pampa de Lara hasta la puerta falsa de la Aduana con las } \\
\text { cuadras que atraviesan a la izquierda. 9.-Desde la calle de Mascaron hasta la } \\
\text { alcantarilla de la Merced, con las cuadras que atraviesan a la izquierda.10.- } \\
\text { Desde la alcantarilla de la Merced hasta la Pampilla con las cuadras que } \\
\text { atraviesan a la izquierda. }\end{array}$ \\
\hline 4 & $\begin{array}{l}\text { El cuarto cuartel se forma de todas las cuadras que se comprenden en línea } \\
\text { recta, y travesía a la izquierda desde Ollería de Cocharcas, Chacarilla puerta } \\
\text { falsa de San Juan de Dios, Pileta del Noviciado, y Guadalupe hasta la Portada } \\
\text { del Callao, Callejón de San Jacinto, Recoleta Dominica y callejón de la } \\
\text { Venturosa 1.-Desde la Ollería y el Pilón de Santa Catalina con las cuadras que } \\
\text { atraviesan a la izquierda. 2.-Desde el Pilón de Santa Catalina hasta la plazuela } \\
\text { de Santa Teresa y las cuadras que atraviesan a la izquierda.3.-Desde la } \\
\text { plazuela de Santa Teresa y las cuadras que atraviesan a la izquierda 4.-Desde } \\
\text { la calle costado de la casa Bosa hasta la del Villar, inclusive con las cuadras } \\
\text { que atraviesan a la izquierda. 5.-Desde la calle de Carboda inclusive hasta la } \\
\text { portada del Callao, con las cuadras que atraviesan a la izquierda. } 6 \text {.-Desde la } \\
\text { Chacarilla hasta la puerta falsa de la Encarnación con las cuadras que } \\
\text { atraviesan a la izquierda. 7.-Desde la puerta falsa de la Encarnación hasta la } \\
\text { calle de Seguro inclusive, con las cuadras a la izquierda.8.-Desde Juan de } \\
\text { Medina hasta el Callejón de San Jacinto con las cuadras que atraviesan a la } \\
\text { izquierda. 9.-Desde la puerta falsa de San Juan de Dios con las cuadras que } \\
\text { atraviesan a la izquierda 10.-Desde la Pileta del Noviciado y Guadalupe hasta } \\
\text { la Recoleta Dominica y Callejón de la Venturosa, con las cuadras que } \\
\text { atraviesan a la izquierda. }\end{array}$ \\
\hline
\end{tabular}

Fuente: Escobedo (1785, pp.1-37) 


\section{Plano 1.9}

\section{Plano topográfico 1787 copia de 1862}

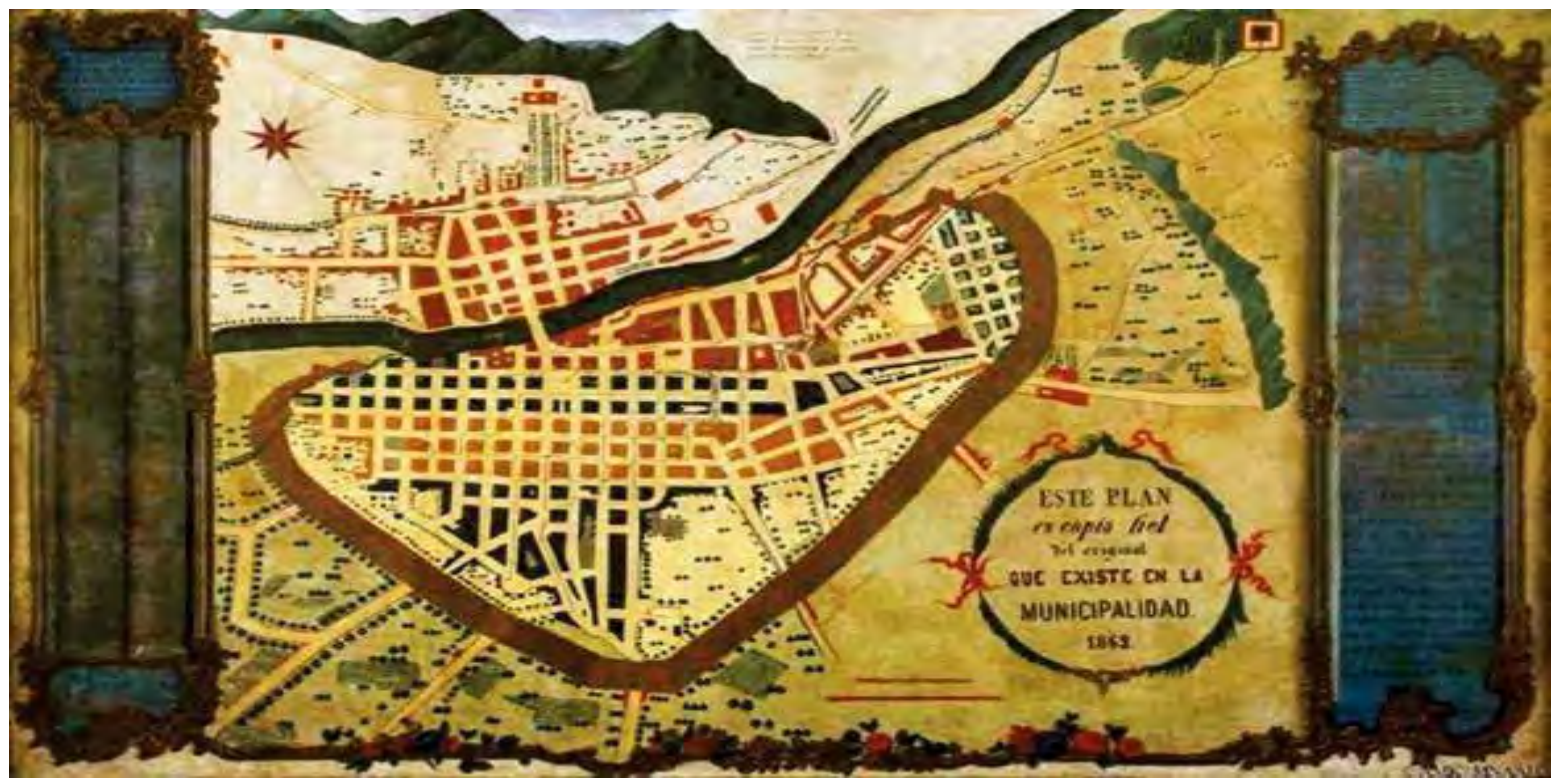

Fuente: Plano topográfico 1787 copia de 1862. Colección del Museo de Historia y

Antropología de Lima. Fotografía de Antonio Manrique.

https://www.researchgate.net/figure/Figura-1-Plano-Topografico-1787-Copia-de-1862-

Coleccion-Museo-Nacional-de_fig1_321129616

La sub-división administrativa en barrios, significó la construcción de demarcaciones menores autónomas donde se recaudaban los fondos necesarios para la limpieza de las calles y acequias por medio del pago de arbitrios en el que contribuían cada uno de los vecinos con el dinero que contaban (Escobedo,1875) esta acción permitió una cohesión social y desarrollo de la identidad de los barrios al interior de los cuarteles. Así también, se trató de eliminar a la población de vagos en la ciudad incorporándolos a las tareas de limpieza de las acequias y calles en la ciudad. De esta manera, estas personas se incorporaron a los barrios como parte de su población.

La demarcación del territorio se dio como una necesidad de: controlar el territorio, tener una administración de la ciudad más eficiente, un buen gobierno, tener un control de la población y sus actividades, mejorar la recaudación de impuestos e iniciar el proceso de restarle poder a la Iglesia sobre el mercado de suelo y modernizar la ciudad. Como resultado de este proceso se realizó la expulsión de la orden Jesuita el año 1767 (Vargas 
Ugarte, 1956:198) confiscándose todas sus propiedades. Este hecho fue una advertencia al resto de órdenes religiosas para acatar las reformas de la administración Borbón como la demarcación en curso para no sufrir la confiscación de sus bienes. Además, las transformaciones territoriales tuvieron las siguientes consecuencias: permitieron un mayor desarrollo de las actividades comerciales y agrícolas en cada una de las nuevas demarcaciones, propiciaron la construcción de una identidad propia. Se produjo un proceso de reconstrucción del tejido social y construcción de una nueva identidad en función de las nuevas demarcaciones.

De manera paralela desde 1785 se puso en vigencia "La división de cuarteles y barrios e Instrucción para el establecimiento de alcaldes de barrio en la capital de Lima" (Escobedo,1785:1-37) que significó la modernización de la administración de la ciudad, la búsqueda de la acción y la puesta en vigencia del Sistema Policial en la ciudad que tuvo como finalidad gestionar los espacios, reglamentación económica, control de la circulación de mercaderías y la ejecución de obras públicas. No obstante, muchas de las normas de salubridad fueron incorporadas en el Reglamento de Policía gracias a los análisis de los proto médicos ${ }^{31}$ Hipólito Unanue y Manuel Asencio Segura, Cosme Bueno y Ambrosio Cerdán que veían como problema en la ciudad la necesidad de la limpieza de calles, acequias, alcantarillado como una medida de controlar la propagación de las epidemias en la población. Con estas acciones se intentó modernizar la ciudad una búsqueda de dejar lo antiguo por lo nuevo (Velasco,2015:90-93) ${ }^{32}$.

Durante los gobiernos de los virreyes Amat y Juniet y Teodoro de Croix de 1761 a 1790 se continuó la implementación de la colocación de nomenclatura de calles, numeración de casas, división de cuarteles, barrios y puso en vigencia el Reglamento de Policía. Para este periodo la administración de la ciudad a cargo del virrey y El Cabildo habían logrado controlar a la población.

\footnotetext{
31 Según Lossio el proto médico Hipólito Unanue publicó Observaciones del clima de Lima (1806) y el médico Manuel Asencio Segura (1759) y Cosme Bueno publicaron Disertación Físico Experimental (1759) y el médico Ambrosio Cerdán publicó Tratado Esencial sobre Aguas (1792) “Acequias y Gallinazos salud ambiental en Lima en el siglo XIX" Lima, Ed. IEP,2002, pp.31.

32 Adrei Velasco Julian "Reseña de las Reformas Borbónicas 1750-1808 coordinado por Clar García Aluardo. Memoria y sociedad $19 \mathrm{~N}^{\circ} 38$ (2015) pp.90-93.
} 
"Ya hemos dicho que Lima en su actual estado contiene 209 cuadras: están abrazan 8,222 puertas de casas y tiendas. 366 calles para la vigilancia de la policía y el buen orden público se dividen toda la ciudad en cuatro cuarteles y 36 barrios en cada uno de los cuales hay un Alcalde escogido entre todos los vecinos de distinción que lo habitan "(Diario El Mercurio Peruano, 1791 á, 03 febrero,:94).

Se había aplicado la nueva demarcación y se tenía un control de la población flotante y residente. En la ciudad se había materializado el poder de la Casa Borbón con obras de envergadura y materializar la modernidad pero debido a la lejanía de esta a la realidad de la ciudad en muchos casos habían sido aceptados por la sociedad y en otros habían sido rechazados. Sin embargo, como muestra de la materialización de la modernidad en la ciudad en el centro aparecieron las primeras fondas, cafés y peluquerías como una influencia directa de la inmigración europea a la ciudad (Diario El Mercurio Peruano, 1791:95)

\subsection{La implementación del "libre comercio" y su efecto en la ciudad (1778)}

Entre los años de 1777 a 1785 se dieron reformas tributarias por parte de la Metrópoli que tuvieron por objetivo la recuperación económica de la Corona después de la guerra de los Siete Años. El año 1778 se implementó la Ley de "libre comercio" (Fisher, 2000:102) que permitió un crecimiento económico en las colonias y evitó el excesivo contrabando por el Cabo de Hornos. Paralelamente se reestructuró el territorio al interior de virreinato dividiéndolo en capitanías e intendencias con la finalidad de redistribuir la red portuaria en Sudamérica y así evitar las ambiciones navales británicas. Por ejemplo, en el Alto Perú se incorporó al virreinato de Rio de la Plata, el reino de Chile pasó a ser Capitanía General y se aperturaron los puertos de Buenos Aires y Valparaíso como nuevos enclaves marítimos (Fisher, 2000:69). Sin embargo, estas medidas no afectaron a Lima, muy por el contrario, favorecieron su crecimiento económico debido al aumento de tráfico a esta ciudad por el libre comercio manteniendo su centralidad. 
Plano 1.10

La nueva ruta por el Cabo de Hornos desde 1778

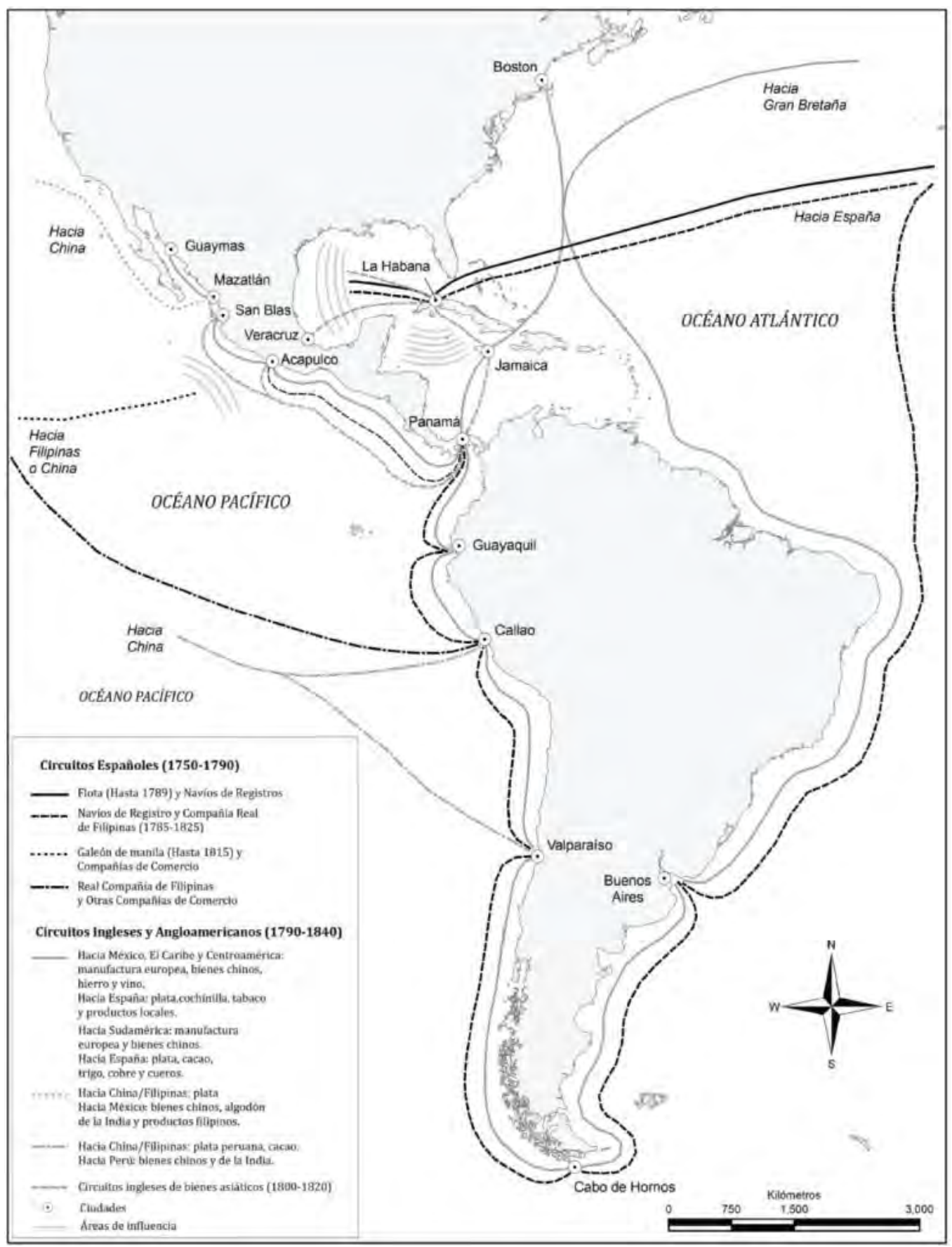

Fuente: México de epicentro a periferia. La desintegración del modelo seminformal del comercio hispano americano (17501840) Mariano Bonialian.

https://www.google.com.pe/search?q=La+nueva+ruta+por+el+Cabo+de+Hornos+desde+1778\&tbm=isch\&ved= 2ahUKEwjI57DMnubnAhVJY60KHdWNDHoQ2- 
En un artículo titulado "Reflexiones Históricas y Políticas sobre el estado de la población de esta capital", se describe la opinión de la población limeña acerca del libre comercio.

\begin{abstract}
"El libre comercio, ese beneficio nunca agradecido del Ministerio, ha reparado todo el vacío que podía haber cuando en los intereses y la población de esta capital, aquella desmembración política. En efecto desde que se hizo libremente, de esa franquicia, especialmente de esa primitiva y libre venida de los navíos por el Cabo de Hornos, Lima ha crecido en la quinta parte de su grandeza local. Testimonio de esta son las nuevas posesiones, que últimamente se han librado el Señor Don Manuel Lorenzo de León y Encalada regidor perpetuo de este Cabildo ha poblado todo el terreno abandonado de la huerta de Pitti y terrenos de la huerta del Hacho: Ha fabricado dos Manzanas enteras de casa y cerca de la otra con 240 varas cada una. Todas ellas contiene una casa grande 207 puertas á la calle y 4 callejones con 53 cuartos habitables, La Pampa el jirón de los Naranjos, el que va a la Alameda de los Descalzos parte de esta Venturosa son fábricas de nuestros día" (El Mercurio Peruano, 1791 á, 3 febrero,:94).
\end{abstract}

La riqueza producto del libre comercio marítimo por el Cabo de Hornos influyó positivamente en la urbanización de la ciudad. Debido a que la ciudad se encontraba urbanizada hasta los bordes se produjo la urbanización de la zona al otro lado del río Rímac ${ }^{33}$ que antiguamente fue ocupado por mulatos e indígenas que fueron reubicados en la periferia. La mayor parte de las obras se habían ejecutado al otro lado del río en la zona conocida como el Rímac o nueva Triana que se convirtió en la zona más cara de la ciudad. En este periodo de gobierno del virrey Manuel Amat y Juniet (1761-1776) se ejecutaron las siguientes obras: En el año 1760 se construyó la Quinta Presa y el año 1776 el Paseo de las Aguas (Sifuentes,2004:131), en el año 1766 se construyeron la Plaza y la Alameda de Acho (Sifuentes,2004:131). Durante el periodo del virrey Teodoro de Croix (1784-1790) se construyó el Jardín Botánico $(1787)^{34}$ que consolidó a la ciencia como uno de las principales formas de conocimiento desplazando a las ideas de la Iglesia. También se construyó el Cementerio General el año de 1791 (Diario El Mercurio Peruano, 1791á, 02 enero:127).

Así también la construcción del Cementerio General puso en evidencia la modernización de la ciudad y la mejora de la salubridad. A partir de entonces,

\footnotetext{
33 Según Rubén Vargas Ugarte "Lima había crecido en una extensión de una quinta parte y las nuevas urbanizaciones como Acho, Pampa de Lara, Jirón de los Naranjos, la Venturosa y La Alameda (al otro lado del río) eran parte de la demostración del mayor número de pobladores ". "Historia del Perú virreinato siglo XVIII, Ed. Librería e imprenta Gil, 1956, pp.13.

${ }^{34}$ Según el doctor Gómez Carrión en uno de los números de la Gaceta Medica de San Marcos indica que el jardín Botánico fue fundado el 18 de marzo de 1787 por Carlos III, Rey de España. https://jardinbotanicoffybb.jimdofree.com/.
} 
los difuntos ya no serían enterrados cerca a las Iglesias. Así también la aparición del Paseo de las Aguas y la Alameda de Acho muestran los primeros espacios públicos de reunión de los políticos y las élites ubicados hacia el otro lado del río ${ }^{35}$. La ciudad continuaba su periodo de apogeo bajo un control de la administración Borbón y con la implementación de la Ley de libre comercio.

Debido a la falta de terrenos disponibles en la ciudad se aplicó la Ley de Indias XXXII que prohibían apropiación de bienes hasta en cuarto grado de consanguinidad $^{36}$. De un total de 3,941 casas de las cuales, 969 pertenecieron a manos muertas y 157 a cofradías que tenían un gravamen a una orden religiosa o cofradías que impedía su venta (El Mercurio Peruano, 1791 á, 03 febrero: 95). No obstante, la aplicación de estas acciones permitió la redistribución de la propiedad en la ciudad, reactivaron el mercado de suelo y encarecieron los precios de los terrenos en el centro.

Para finales del siglo XVIII en el informe que redacto José Ignacio de Lecuanda por orden del virrey titulado "Idea sucinta del comercio del Perú y medios de prosperarlo con una noticia general de sus producciones" (Vargas Ugarte,1968:19) describe la prosperidad de la ciudad a causa del libre comercio y sus consecuencias como: la abundancia de la burocracia para administrar el Estado Virreinal moderno, el crecimiento de la población, la urbanización de la ciudad hasta la periferia y la necesidad de vivienda debido al crecimiento de la ciudad y el aumento de las rentas debido a la escasez de propiedades.

Para 1791 el periodo de gobierno Virrey Conde de Lemos la población disminuyó a 52,627 habitantes (El Mercurio Peruano,1791 á, 03 febrero,:92.94) debido a las epidemias y pestes que diezmaron a la población el gobierno implementó mejoras en la salubridad de la ciudad como: la aparición de lazaretos para aislar a los enfermos, se construyó el hospital de Incurables (hospital de mujeres) el año 1804 (Ramón,1999:73) y se mejoró la salubridad

\footnotetext{
${ }^{35}$ Aun no existía la idea de espacio público eran lugares de reunión de la élite colonial.

${ }^{36}$ Según Roix en Recopilación de las Leyes de Indias Ley XXXII "Que ningún pariente o allegado de juez o ministro sea depositario de bienes de difuntos, ni se le cometa su cobranza" ". Ningún pariente criado ni allegado de virrey, presidente, oidor, fiscal de audiencia y oficiales reales pos consanguinidad ó afinidad dentro del cuarto grado, sea puesto por depositario de bienes de difuntos, ni se cometa ninguna cobranza de ellos, como está prohibido por la regla general de que no tenga comisiones y de la ley“. Recopilación de los Reinos de las Indias" tomo II, quinta edición, 1841, Ed.Roix, pp.7.
} 
en las zonas cercanas a la muralla que ya se encontraba deteriorada principalmente cerca a las portadas de las Maravillas y de Martinete (Ramón,1999:77). Así también, se continuó la construcción del Cementerio General el año 1808 (El Mercurio Peruano, 1791 a, 02 enero,:127). Con la creación del Colegio de Medicina el año 1808 (Ramón,1999:73) los temas de la ciudad dejaron ser de dominio de los cosmógrafos, proto médicos para dar paso a los higienistas o médicos que formalizaron su rol en la en la ciudad. Por ejemplo, el jueves 22 de octubre de 1812 se concretó el primer Reglamento de Higiene publicado (El Verdadero Peruano,1812 á, 22 octubre,:37) con este documento se dio a conocer la ciencia de higiene pública y privada a la población.

El Estado Virreinal con el objetivo de disminuir el poder de la Iglesia en un momento de apogeo económico de la ciudad el 26 de diciembre de 1804 ordeno el secuestro de los fondos píos en América y su envió a Europa. De esta manera, la Metrópoli se apropió de buena parte del capital acumulado por censo o hipotecas (Fisher, 2000:87). En el Perú, por este concepto, se recaudó 1.5 millones de pesos hasta 1808 (Fisher, 2000:87). Esta decisión del Estado Virreinal tuvo las siguientes consecuencias: desestabilizó la economía de la Iglesia, disminuyó sus inversiones en la ciudad, afectó sus rentas y la Iglesia dejó de apoyar al Estado en las decisiones relacionadas a la ciudad.

El año 1806, inició el último periodo de grandes obras en Lima a cargo del virrey José Fernando de Abascal y Sousa que continuó con la materialización del poder de la Casa Borbón en la ciudad. Durante este periodo de 1806 a 1816 se refaccionaron algunas de las construcciones edificadas los primeros años del apogeo de la ciudad. 


\section{Cuadro 1.5}

Obras durante el periodo del virrey Abascal (1806-1816)

\begin{tabular}{|c|c|c|}
\hline Año & Obra & Fuente \\
\hline 1806 & $\begin{array}{c}\text { Reparación la antigua fábrica de pólvora } \\
\text { de Santa Catalina }\end{array}$ & Ramón,1999:73 \\
\hline 1807 & Portada de la Maravillas & Ramón,1999:73 \\
\hline 1808 & Construcción del Colegio de Medicina & Ramón,1999:73 \\
\hline 1808 & Cementario General & Vargas Ugarte,1956:112 \\
\hline
\end{tabular}

Fuente: Elaboración propia en base a Ramón (1999), Vargas Ugarte (1958)

En este periodo se mejoró la infraestructura educativa y de salubridad que se encontraba deteriorada. Sin embargo, el año 1816 al retiro del virrey Abascal, el Estado virreinal se encontraba en mal estado económico debido a los excesivos gastos de armamentos en recuperar los territorios de Chile y Buenos Aires (Ophelan,2013:248) que terminaron por dejar al gobierno local sin economía para continuar materializando más obras. Fue por esta razón que el siguiente virrey Antonio de Pezuela asumió el gobierno con limitaciones económicas de 1816 a 1821 y buscó el libre comercio con Inglaterra para mejorar esta situación, pero los habitantes de Lima buscaban un cambio indicio que se aproximaba el fin del periodo colonial.

La ciudad durante el periodo de apogeo y "libre comercio" aumentó su población, se urbanizaron las zonas que rodeaban al centro, el Estado Virreinal logró un mejor control de la ciudad con la reconfiguración territorial y la Iglesia perdió control sobre la economía de la ciudad. No obstante, aunque se realizaron obras de envergadura estas no materializaron el poder de la casa Borbón en toda la ciudad, únicamente se intervino en el centro donde se concentró el poder político y la zona al otro lado del río residencia de los gobernantes de turno generando una urbanización desigual entre el centro y la periferia. Se producían las reformas a medida que se saneaba la ciudad. En este periodo se continúo la materialización de la modernidad urbana a partir de la institucionalización de la ciencia con la construcción de edificaciones con funciones principalmente de higiene y recreación. 


\subsection{La formación del discurso ilustrado peruano (1771-1821)}

A mediados del siglo XVIII, con las reformas de la Casa Borbón llegaron las ideas de la ilustración a la ciudad y sirvieron para que la clase criolla pudiera iniciar el proceso de construir una ideología política propia. Con esta finalidad, una cierta libertad de imprenta permitió la circulación de las ideas políticas para la construcción de un discurso político-social que sirviera para la construcción de la identidad de la nueva nación peruana, la construcción de programas públicos, dar una visión a los gobiernos de turno sobre las políticas públicas a seguir, construir las agendas de los gobiernos de turno y las obras publicas a seguir.

Los sucesos en el mundo y el cambio de siglo como: las guerras de los Siete Años entre España y Portugal (1756-1763) (Fisher,2000:58) las guerras de independencia de Estados Unidos (1776-1783), las guerras napoleónicas, la revolución francesa (1789-1799) (Fisher,2000:66-68) y las nuevas Leyes de la Corte de Cádiz 1812 (Rey de Castro,2004:157) aportaron ideas políticas al discurso peruano como: el bien común, el progreso, la felicidad pública, la razón, igualdad, fraternidad, libertad y la capitalización que fueron debatidas por los criollos e incorporadas al discurso político que se encontraba en proceso de construcción. Este proceso de maduración e incorporación de ideas externas muestra la capacidad de la sociedad organizada de confrontar sus posiciones frente a las ideas externas y construir un discurso con identidad propia con el apoyo de cambios en la educación y la libertad de imprenta.

\subsubsection{El discurso ilustrado peruano}

En el discurso ilustrado peruano se encuentran ideas que se incorporaron como leyes y formas de conducir el gobierno de la futura nación peruana, como: la reivindicación social, el capitalismo, el libre comercio, el bien común, la libertad de pensamiento sobre la libertad de prensa, en 1810, el periódico La Minerva Peruana publicó lo siguiente:

"Como los salvajes, nace de ser en los primeros fácil y continúa la comunicación de las ideas. Si examinamos (dice un político español) el Estado de la Europa antes del descubrimiento de la imprenta, y los progresos posteriores de algunas naciones mientras han retrogradado otras entonces más adelantadas, se halla la prueba de que la ignorancia y los errores crecen con las prohibiciones y obstáculos para imprimir. En Inglaterra y los Estado Unidos de América, donde 
se miran con santo respeto los derechos de ciudadano, la prensa es libre. En Francis Bonaparte la ha restringido como el mejor medio de consolidar su tiranía, hasta el punto del envilecimiento y degradación que vemos hoy los escritores franceses. Nada se permite escribir allí sino lo que acomoda al tirano. La expresión libre de los pensamientos o ideas políticas no se halla ya en los libros: escondida esta en los corazones por no ser victima los que la manifiestan de mil espías con que rodea a que gobierno las operaciones odiosas y funestas de su administración" (La Minerva Peruana, 1810 á,9 junio:296)

En un segundo grupo, se encuentra los ideales a seguir producto de la influencia europea especialmente España, Inglaterra y Francia como: la felicidad, la libertad, el progreso y desarrollo. A continuación desarrollaremos cada uno de ellos:

La justicia social, fue parte importante del discurso ilustrado. En el caso del Perú fueron "Las Cartas a los españoles Americanos" de Juan Pablo Vizcardo y Guzmán entre los años 1748-1798 que constituyeron el primer intento de reivindicación social de los indígenas a partir de una monarquía liderada por un príncipe inglés con el apoyo de los criollos (Simons,1983:33-34). Otro intento de reivindicación social, fue la rebelión de Túpac Amaru en 1780 que tuvo como principal objetivo lograr la justicia social de la casta indígena ante los excesivos impuestos y una integración de este grupo social a la población como parte del proyecto político de la nueva patria.

Como una respuesta a esta rebelión por parte de la Metrópoli el año 1787 se creó la Audiencia de Cusco (Fisher, 2000:71). Otro intento fue la rebelión de Huánuco Panatahuas el año 1812 (Rey de Castro, 2004:146-152) que buscó la reivindicación social de los indígenas ante los abusos del Estado Virreinal. Estas rebeliones permitieron reformas en las instituciones del Estado y lograron la reivindicación de derechos de los indígenas en la ciudad a partir de cambios en la administración tributaria.

Con el cambio de siglo después de la guerra de España la idea de la justicia social surgió como una respuesta del patriota contra el opresor de su libertad y violador de los derechos que no permitía el desarrollo de la comunidad en la ciudad (La Minerva Peruana á, 26 Mayo 1810:272). En los inicios de la nueva nación peruana la justicia social cumplió un nuevo rol social como la búsqueda de igualdad y respeto de las leyes que protegiera a los ciudadanos por ejemplo un artículo titulado "Reflexiones políticas sobre el origen de las Sociedades" (Diario Abeja Republicana á, 11 de agosto, 1822: 01) la justicia social era vista 
como un recurso para remediar los males de la sociedad, destruir la desigualdad, buscar la tranquilidad y seguridad de la población.

Otro ideal del discurso ilustrado peruano buscó que la nueva nación peruana alcanzara un desarrollo económico y que esta se viera materializada en la ciudad de Lima. La idea de capitalismo provino de los Estado Unidos a raíz de la independencia de Norte América el año 1776 de la Corona Británica (Boch, 2010:24-26) y estuvo relacionado a las actividades de comercio marítimo que se daban entre las Metrópoli y sus colonias. Con la guerra de los seis años la economía española se debilitó y esto implicó un proceso de reestructuración y sistematización de las finanzas públicas en las colonias. Con este objetivo el Estado Virreinal, para mejorar su economía, buscó sistematizar sus rentas públicas para lograr acumular riquezas como se describe en un artículo titulado "Circular" (La minerva peruana á, 3 de Julio, 1810305) cuyo texto dice:

"En el manifiesto publicado el 23 de octubre último queda señalado el primero de enero para su
convocación, y el día primero de marzo para su reunión y determinar el modo con que estas se
han de convocar, y preparar los trabajos que se han de ocupar, no solo se ha nombrado una
comisión de cortes compuestas de individuos del cuerpo soberano nacional, sino también
varias juntas subordinadas a la misma, una para cada ramo que entran en la administración de
un Estado. Examina una legislación para proponer los planes para las leyes fundamentales que
deben ser las bases de nuestra monarquía y asegurar la corona en deseando Fernando y sus
sucesores las reformas que deben de hacerse en nuestro derecho público y privado. Examina
el otro ramo de hacienda, nos solo para sistematizar las rentas públicas, de un modo que
siendo lo menos gravosas posible llene el cupo de las necesidades públicas, sino también para
establecer la verdadera base de fomento de la riqueza nacional "(La Minerva Peruana,181 á,
03 de julio 1810:311).

Con el cambio de siglo surgió la necesidad sistematizar las rentas de la nueva nación peruana y de capitalizarse para ejecutar los planes y proyectos por parte de los gobiernos de turno y generar una reserva económica para la nación.

El bien común, fue otra idea que se incorporó al discurso ilustrado peruano que invocaba a los ciudadanos dejar sus propios intereses en busca de la felicidad del resto y a los gobiernos pensar en el bien de los ciudadanos (El Triunfo de la Nación á, 12 junio,1821: 01-02). En la ciudad, el bien común se traduce en las intervenciones en los espacios públicos como proyectos de envergadura que beneficien a toda la ciudad como por ejemplo la demolición de la muralla. Con el cambio de siglo el bien común cumplió el rol de permitir la reunión de 
voluntades de los funcionarios públicos que estaban al servicio de la nueva nación para beneficiar a la ciudadanía realizando una buena gestión de los bienes comunes (El Verdadero Peruano á, 12 noviembre, 1812:68). También esta idea, formó parte del discurso político de los postulantes a la presidencia que ofrecieron posponer sus objetivos particulares por los de la patria para buscar la modernidad y el desarrollo de la ciudad que beneficien a todos los estratos socio económico.

La libertad mercantil se incorporó en la ciudad desde mediados del siglo XVIII debido a la necesidad de formalizar el contrabando que venía dando por el Cabo de Hornos como consecuencia que la Metrópoli perdía ingresos por el excesivo contrabando en esta ruta (Rey de Castro, 2004:40-45). Más adelante, esta idea se convirtió en la Ley de libre comercio el año 1778 (Fisher, 2000:102) que tuvo el objetivo de aumentar las exportaciones de América a España. Sin embargo, un factor que influyó en el fortalecimiento del libre comercio fue la Guerra de Independencia de Estados Unidos de 1776 a 1783 que permitió un mayor flujo comercial (Fisher, 2000:67) y un crecimiento económico de la ciudad y fue asociado a la prosperidad como una manera de alcanzar el progreso.

La felicidad llegó a la ciudad junto con las ideas de la ilustración y estaba relacionada a la idea de alcanzar un anhelo de bienestar del súbdito y el monarca que era el objetivo que debía hacer cumplir la policía en la ciudad. En la ciudad se tradujo en la ejecución de obras públicas para la felicidad de todos los ciudadanos. Para 1822 la felicidad pública fue resultado directo de cumplir con las leyes y el buen uso del poder de los gobernantes de la nueva nación para llevar a cabo sus programas, obras y proyectos (El Tribuno de la Republica Peruana á, 19 diciembre,1822:113).

Durante la guerra entre España y Francia con las llamadas "Guerras Napoleónicas" entre los años de 1808 a 1812 la invasión napoleónica en tierras del viejo Mundo provocó un debilitamiento del comercio entre las colonias y la Metrópoli (Meyer Cossío, 2003:68) y un deseo de libertad de las colonias. Estos sucesos fueron noticia en muchos diarios de circulación nacional e infundieron el deseo de libertad en la ciudad la idea de libertad a finales del 
periodo colonial se tradujo en el rompimiento del subordinamiento del territorio, social, político y económico de la Metrópoli. Sin embargo, como aun esta idea no había madurado en todo el territorio del virreinato del Perú entre los años de 1811 a 1813 Francisco Antonio de Zela, ante un deseo de libertad de la Metrópoli lideró en Tacna una revuelta que pedía la reivindicación de dependencia de este territorio con la Junta de Buenos Aires (Rey de Castro, 2004:145). Con este hecho, puso en evidencia que era necesario aun trabajar las ideas de unificación de la futura nación y el deseo de libertad.

La vuelta del absolutismo bajo el reinado de Fernando VII entre los años de 1814 a 1833 (Pegenaute,1974:10-12) produjo la revolución de Cuzco que pedía una vuelta a las Leyes de la constitución de Cádiz como un último intento de tratar de mantener el vínculo con la Metrópoli. Para 1818 la consolidación de la independencia de Chile (Rey de Castro: 2004,210-217) demostró que la ideas de libertad habían madurado en toda la región sur del continente y se convirtieron en un ideal a seguir. Entre los años 1821-1829 se produjo la independencia de los territorios virreinales, de intendencias y capitanías que provocó la reconfiguración de territorio que dio origen a los países de Sudamérica (Ávila, 2013:111-121). En el caso del Perú el discurso ilustrado peruano estaba listo para ser utilizado en la nueva nación peruana desde el día que se firmó su independencia el 28 de julio de 1821. En este caso, se dio un proceso de construcción de un discurso político para construir una nación con una identidad nacional (Larrain, 2004:58) con la que se identificó la población y un territorio que luego sirvió para construir la nación peruana. 


\section{Comentarios generales del capítulo}

En este capítulo hemos visto el proceso de urbanización de la ciudad del periodo colonial que comprende de 1535 a 1821. En este periodo, la urbanización de ciudad estuvo influenciada por las Leyes de Indias, el papel de la Iglesia en las decisiones locales y de las autoridades como el Virrey y el Cabildo. Como hemos visto, la decisión de construir la muralla constituyó un momento importante para la urbanización de la ciudad y su crecimiento. Los sismos de los años de 1687 y 1746 sirvieron para mostrarnos el desorden de la urbanización de la periferia y hasta qué punto las Leyes de Indias fueron tomadas en cuenta en el crecimiento de la ciudad. Así también, la transferencia de la administración Borbón significó para la ciudad, un cambio de demarcación, una mayor actividad comercial que trajo como consecuencia un crecimiento urbano hasta los límites de la muralla y una mejora de la infraestructura de la ciudad con obras de envergadura. Desde mediados del siglo XVIII, las ideas externas que llegaron de Europa y fueron difundidas a través los principales diarios a la ciudad de Lima e iniciaron un debate entre los intelectuales criollos que dio como resultado el discurso ilustrado peruano. En este capítulo, podemos concluir que el desenvolvimiento de la ciudad colonial de Lima se dio en los siguientes aspectos.

\section{Uso y distribución de tierras en el periodo colonial}

La demarcación religiosa en cinco parroquias debido a la necesidad de evangelización de los indígenas por parte de la Iglesia dio inició a la urbanización en la periferia. Mientras en el centro, se continuaba con el reparto de solares a los primeros conquistadores siguiendo el trazo de damero. La población indígena fue replegada a la periferia. En el año de 1570 el traslado de la población indígena al barrio de Santiago del Cercado produjo pugnas entre los españoles por la tenencia de las tierras que fueron ocupadas por los indígenas en la periferia. Este proceso trajo como resultado la redistribución de tierras en la periferia de la ciudad colonial.

El sismo de 1687 evidenció las características de este proceso de urbanización en la periferia donde resaltan: la existencia de urbanización espontanea cercana a las propiedades de las principales órdenes religiosas, mercado ilegal 
de suelo producto del abandono de las tierras por parte de la población indígena que su mudó a vivir al barrio Santiago del Cercado. Para ese entonces, no se estaba cumpliendo las Leyes de Indias respecto a la distribución de tierras.

El sismo de 1746 puso en evidencia el crecimiento poblacional en la periferia y la necesidad de un ensanche de calles con la finalidad de mejorar la salubridad en la ciudad. Para ese momento, los propietarios de tierras en la periferia eran comerciantes españoles, autoridades locales, descendientes de los primeros conquistadores y órdenes religiosas como se observa en el plano de Lima de 1750 quienes habían construido edificaciones de usos comerciales y de vivienda convirtiendo a la periferia de un espacio rural a un espacio urbanizado. Iniciando los problemas de aglomeración en la periferia que aumentaron cuando el virrey ordenó se ofrezcan rentas bajas para que la población afectada que vivía en el centro se mudará a la periferia.

En el año de 1778 con la aplicación de la Ley de libre comercio, la ciudad atravesó por un aumento de sus actividades comerciales que dio como resultado un incremento poblacional que inició los problemas de falta de servicios básicos en la periferia. Este hecho, generó que los alcaldes barriales implementaran estos servicios con el apoyo económico de los vecinos. Para utilizar algunos terrenos disponibles en la ciudad, las autoridades tuvieron que hacer uso de la Ley de manos muertas, con la finalidad que muchas propiedades que no tenían herederos pudieran ser vendidas y de esa manera satisfacer la demanda por terrenos y generar cierta redistribución de la propiedad. Para ese momento, podemos concluir que el control del mercado de tierras era de la Iglesia pero, ante la aplicación de la secularización del clero por parte de la administración Borbón, este poder fue disminuyendo en favor de los comerciantes.

\section{El papel de la muralla en la defensa de la ciudad}

La construcción de la muralla de Lima en el año 1683, significó un hito urbanístico para la ciudad. El artefacto muralla, a partir de ese momento delimitó el crecimiento de la ciudad de Lima. Así también, el trazado existente en la periferia tuvo una modificación como consecuencia del inicio del 
funcionamiento de las portadas de acceso a la ciudad. Este hecho también generó el aumento de la actividad comercial y el cambio de uso de suelo de muchas propiedades de vivienda a comercio o usos mixtos en especial cerca a las portadas. Este hecho, produjo modificaciones al trazado urbano existente. La forma casi triangular de la muralla definió el crecimiento de la ciudad hacía el este y oeste.

La muralla de Lima durante todo el periodo colonial cumplió el papel de servir de reguardo a la población indígena y española que vivió en la ciudad. Definió la forma física de la ciudad. Resguardo las riquezas que poseía la ciudad y en especial las órdenes religiosas. Brindó una sensación de resguardo confianza a la población de tener un espacio seguro en caso de ataques externos o conflictos por el territorio de los pueblos vecinos. Al incluir a la población indígena al interior de la muralla se formalizó su derecho de ciudadanía. Sin embargo, también fue un elemento de exclusión de la ciudad con su hinterland donde se encontraban otras poblaciones con las que tenía relaciones de intercambio y comercio.

\section{Urbanización en el periodo colonial}

La fundación de la Ciudad de los Reyes inició la urbanización de la ciudad desde el centro a la periferia con la repartición de las tierras a los primeros conquistadores que materializaron su dominio en este territorio en términos políticos, administrativos y sociales. Durante los primeros años, el establecimiento de las órdenes religiosas propició la urbanización en el centro y la periferia generando la configuración de la ciudad. Desde 1542 con la aplicación de la Leyes Toledanas se ordenó el crecimiento de la ciudad colonial en el centro para la élite mientras que en la periferia se inició con el reparto de tierras. En el año de 1570 con la creación del barrio de Santiago del Cercado se creó la primera reducción fuera de la ciudad generando así la primera urbanización para los indígenas que vivían en la ciudad colonial y se determinó su traslado a esta reducción. Se dio el primer proceso de exclusión de un grupo social de la ciudad.

A partir de 1681, el desarrollo de la urbanización de la ciudad de Lima estuvo reglamentado por Las Leyes de Indias. Esta reglamentación definió el espacio 
que debería existir entre la ciudad y este artefacto muralla con ello se puso de manifiesto el control de la Metrópoli en la ciudad de Lima. También, la reconstrucción de la ciudad después del sismo de 1687 siguió esta reglamentación durante su proceso de reconstrucción.

La reconstrucción del sismo de 1746 en la ciudad de Lima permitió la implementación de las reformas borbónicas que significó la materialización de las ideas de modernidad e ilustración en la ciudad que dio como resultado un control sobre el crecimiento urbano. Las propuestas de ciudadela amurallada y el Plan de Ensanche de Calles mostraron como las ideas de la ilustración eran puestas al servicio de la ciudad, pero que iban en contra de los intereses de la Iglesia por lo cual no se llegaron a materializar. Fue en este periodo de apogeo económico en la ciudad como consecuencia de una mayor actividad comercial por el Cabo de Hornos que fue posible un mayor crecimiento económico que trajo como resultado la densificación de la población en la periferia debido a un aumento poblacional. Así también, este apogeo económico generó la urbanización del otro lado del río Rímac que se convirtió en la zona más exclusiva de la ciudad llamada Nueva Triana.

\section{Demarcación territorial del periodo Borbón}

Como hemos visto desde los inicios de la ciudad colonial, esta se desarrollo en función de la demarcación parroquial que permitió un control de estos territorios por parte de la Iglesia. Sin embargo, desde la administración Borbón la ciudad fue dividida en cuarteles al interior de los cuales la población tuvo un proceso de redistribución social. Este cambio en la demarcación acentuó las desigualdades en la ciudad aunque para el Estado Virreinal significó la materialización de la modernización de la ciudad que tuvo por objetivo restarle poder a la Iglesia de manera paulatina.

\section{La modernización urbana}

La introducción de las nuevas ideas de la ilustración junto con la aplicación de las nuevas reformas borbónicas materializaron una primera oleada de modernidad en la ciudad, con obras de envergadura como: Alameda de los descalzos, La Quinta Presa, la construcción del Cementerio General y el Jardín 
Botánico. Las ideas de salubridad que llegaron de Europa y los diagnósticos de la primera generación de higienistas influenciaron en la reglamentación y con ello contribuyeron al proceso de modernización que se daba en ese momento en la ciudad.

\section{El discurso ilustrado peruano}

La construcción de la nueva ideología política en base a ideas externas que fueron confrontadas por la clase intelectual limeña criolla y que fueron difundidas por el semanario El Mercurio Peruano contribuyeron a la construcción de la identidad de la futura nación peruana, reafirmaron la necesidad de un cambio en la población limeña y en un futuro servirían para construir los discursos de los políticos liberales del siglo XIX que buscaron la presidencia de la nueva nación. 
En el primer momento, el de las modernizaciones "liberalconservadoras" de finales de siglo el flamante estado coloca en la ciudad el objeto por excelencia de la reforma: la ciudad real que se expande para ser reconducida a su ideal civilizador, porque su desarrollo sin límites lleva al caos y a la destrucción de los lazos sociales. Hay una idea de "ciudad moderna" que repele el desorden profundo que conduce la modernidad urbana y que preside los intentos de reforma pública en pos de "otra" modernización. (Adrian Gorelik,2003:16) 


\section{Capítulo II La nueva nación y la utopía de la modernización: La transformación de la ciudad con los ingresos de guano}

En este capítulo analizaremos las primeras acciones de la naciente república peruana para modernizar la ciudad de Lima. En particular observaremos el establecimiento del nuevo orden en la ciudad y el proceso de transición generando la aparición de las nuevas instituciones republicanas, las cuales iniciaron el reto de la construcción de la nación en medio de luchas por el poder protagonizadas por los caudillos militares, y por las fracciones conservadoras y los liberales. Adicionalmente, como parte de la transformación urbana, veremos el proceso redistribución de la población con la nueva demarcación territorial en cinco cuarteles y diez distritos, así como la proliferación de callejones en la ciudad, producto de la subdivisión de las manzanas debido a una mayor oferta de casas-habitación. También indagaremos los intentos de los gobiernos en turno por reglamentar las funciones de las instituciones para un mejor control del territorio, gestión de la ciudad, orden y desarrollo urbano de la ciudad como veremos en la implementación del Reglamento de Policía y las recomendaciones de la segunda generación de higienistas para solucionar los problemas de salubridad en una ciudad que transitaba hacia la modernidad.

En el año 1845, con los ingresos generados por la economía del guano, los gobernantes liberales en turno realizaron el primer intento modernizador de la ciudad, sin una planificación integral buscando complacer a la élite y a los empresarios que aportaron con inversiones en agricultura, bienes raíces e industria al progreso de la ciudad. Entre los años de 1868 a 1876 la ciudad ingresó a un segundo intento modernizador, pero esta vez, a cargo de gobiernos alternados de liberales y conservadores, los cuales intervinieron la ciudad con obras de envergadura, convirtiendo la ciudad en un laboratorio urbano. En esta oportunidad contaron con un Plan de Ensanche. En este segundo periodo modernizador, los proyectos a cargo del Estado y la inversión privada, no fueron concluidos, provocando un desorden en la periferia y convirtiendo la modernidad de la ciudad en una utopía. No obstante, algunos proyectos como el Plan de Ensanche fueron retomados en parte después de la guerra del Pacífico, por los gobiernos que decidieron nuevamente materializar 
el progreso y la modernidad con el apoyo del capital privado. Esta etapa termina con la demolición de la muralla.

\subsection{La construcción de la nueva nación peruana y la ciudad.}

A partir de la independencia, en 1821, Lima vivió condiciones de inseguridad y violenta, en el marco de las pugnas por la presidencia y el proceso de transición de las principales instituciones de la ciudad. Un ejemplo de ello fue el motín del 5 de julio de 1821 cuando, luego de la salida de las tropas realistas de la ciudad, los pocos militares encargados de la seguridad intramuros perdieron el control de las calles y los bandoleros saquearon tiendas y panaderías (Ramón,1999:41) debido a que los caudillos militares se encontraban combatiendo aún en las guerras de independencia. En este contexto, de violencia e inseguridad, la muralla de Lima se convirtió en una defensa contra el bandolerismo (Flores Galindo, 1984:140,) aunque se encontraba deteriorada y era un foco de insalubridad en algunas de sus portadas.

Como consecuencia del retiro de las autoridades coloniales de la ciudad el año 1821 (Basadre,2014,tomol:208) ${ }^{37}$ se produjo una fragmentación política y social que trajo como consecuencia la aparición de cuatro frentes ciudadanos que desestabilizaron al primer gobierno de la nueva república peruana. Fueron parte de esos grupos la plebe local, los bandoleros, los caudillos militares y la élite colonial. Estos grupos generaron tensiones entre el gobierno en turno y la población por el control de la ciudad. Fue así que el reto del primer gobierno

\footnotetext{
${ }^{37}$ Según Basadre, "Seis días después de la proclama de la independencia se ordenó que los españoles pacíficos que respetasen las leyes fueran amparados en sus personas y propiedades; los demás debían abandonar el Perú. Acusado de conspirar, poniendo su oro y sus servicios a disposición de los enemigos y corrompiendo al ejército, apareció contra ellos una serie de decretos cuya paternidad, otorgada por Monteagudo, levanto permanentes odiosidades. Se ordenó que todos los españoles residentes en Lima se presentaran ante la autoridad en plazo perentorio bajo la pena de ser pasados por las armas; se les prohibió salir de noche y se restringió el permiso que tenían para salir del país con el compromiso, antes de obtenerlo de acreditar que no debían nada al Estado; se secuestraron bienes de los españoles que estaban en España y los quienes habían emigrado para unirse con el enemigo estableciéndose un juzgado se secuestros; quienes se quedaban en el país estaban obligados a obtener una carta de ciudadanía y el fisco se apoderaba de los bienes de los que morían sin herederos forzosos. La orden de expulsión fue reiterada por decretos posteriores y llegaron a ser fijadas las condiciones para que obtuvieran cartas de ciudadanía" En: Historia de la república del Perú 1822-1933, Tomo I, Ed. El Comercio 2014 , p.208.
} 
de José Bernado Tagle (Basadre,2014,tomol:5) consistió en controlar los disturbios en los espacios públicos y mantener el orden en los establecimientos comerciales mientras se producía el restablecimiento de las instituciones encargadas del orden y la seguridad en la ciudad.

En aquellos años algunos de los miembros de la élite colonial lograron el objetivo de ser parte de la élite republicana en formación, como el del protomédico Hipólito Unanue, que después de haber sido una figura representativa a finales de la colonia pudo mantener sus bienes en la ciudad gracias a su prestigio académico (Basadre,2014,tomol:161-166). En general, el proceso de reestructuración social tuvo como consecuencia una redistribución de las propiedades de la élite colonial, la activación del mercado de suelo, la reorganización social al interior de los cuarteles, el inicio de la construcción de una nueva identidad y un cambio paulatino en las costumbres y formas de vida de la población.

La decisión política del libertador José de San Martín de lograr con su presencia mantener la paz, el orden y la estabilidad de la naciente república durante el primer gobierno peruano, buscó establecer una forma de gobernar con justicia, libertad. (Basadre, 2014, tomol: 36). Así se intentó la creación de un Estado fuerte frente a la nueva realidad de la ciudad de Lima, azotada por la inseguridad.

El 18 de noviembre de 1823, fue nombrado por el Congreso presidente del Perú don José Bernardo de Tagle (Basadre, 2014, Tomo I: 88). Una de sus principales acciones fue poner en vigencia la constitución de 1822, que tuvo como principal objetivo organizar las instituciones del Estado Peruano para tener un control del territorio. Por aquel entonces:

"El decreto del 17 de julio de 1823 dispuso que toda persona que tuviera, por cualquier título bienes de enemigos o emigrados, diese parte a la comisión de secuestros. Una Ley del Congreso promulgadas por Tagle el 10 de noviembre de 1825, ordeno que los bienes secuestrados a los españoles o americanos unidos al partido de España que tenían descendientes legítimos en el país fuesen dados a estos " (Basadre,2014,tomol:210).

Gracias a esta Ley fue posible que muchos de los descendientes de propietarios de bienes pudieran quedarse en la ciudad y contribuir a la 
economía local con inversiones que permitieron la subsistencia de los ciudadanos de Lima.

Entre 1823 y 1825 se dio la transferencia de la administración de la ciudad del Cabildo a la Municipalidad, lo que produjo una reorganización administrativa. A partir de entonces, esta institución se encargó de administrar la ciudad y la instrucción primaria. Los primeros años para cumplir estas funciones, mantuvo la estructura administrativa del antiguo Cabildo realizando actividades como: el arriendo a los comerciantes de los arcos de los portales que rodean la Plaza Mayor y el cobro de los impuestos de: sisa $^{38}$ al ganado lanar y vacuno, mojonazgo ${ }^{39}$ aguardiente, chicha, guarapo, las vivanderas, los billares y bochas (Córdova Urrutia, 1839:46). Sin embargo, estos ingresos, no fueron suficientes para realizar trabajos de remodelación de espacios públicos y mantenimiento de áreas verdes. Fue por este motivo, que el 22 de abril de 1825 se impuso el pago del impuesto predial en la ciudad con el 2 por ciento para fundos rústicos y el 3 por ciento para propiedades en la ciudad (Basadre,2014,tomol:195) produciéndose la mejora de los ingresos de esta institución. Con el dinero recaudado por la Municipalidad, las Juntas Departamentales, la Prefectura y la Intendencia de Policía iniciaron sus funciones en la ciudad.

La ruptura de las rutas comerciales por el Cabo de Hornos al desarticularse los territorios del virreinato del Perú, las Intendencias y capitanías con la independencia produjo un estancamiento del crecimiento económico de la ciudad que ocasionó un momento de transición debido al cambio de régimen: La aristocracia limeña se encontraba empobrecida (Basadre,2014,tomol:208). Esta situación inestabilizó económicamente la ciudad durante los primeros

\footnotetext{
38 Según Constanza Loreth Fajardo Calderón y Dora Cecilia Suarez Anaya "Sisa era el porcentaje y medida que el vendedor sustraía al comprador en las transacciones menores en beneficio de la Corona. "'Impuestos en la época de la independencia, su impacto social y evolución e implicaciones en el sistema tributario actual”. En: Revista criterio libre, Vol. 10, №16, enero-junio 2012,p. 293-316.

39 "Lima 6 de Mayo de 1840. No debiendo alterarse la tasa de impuestos municipales, por las autoridades locales, que deben sujetarse a lo que se ha observado constantemente en cuanto al monto y cobro de estas contribuciones, según las leyes y la práctica recibida sobre el particular se declara: que por el impuesto municipal denominado mojonazgo no se cobre otro derecho sobre los licores que a razón de cuatro reales por botija de aguardiente y dos reales por la de vino; y que este cobro se haga en el lugar del consumo, y no en el de la producción o procedencia". Rubrica Ferreyros. En: Colección de Leyes y Decretos y órdenes desde la independencia el año 1821, Tomo VI, Lima, Imprenta de José Masías año 1842 , p.600.
} 
años y fueron los grandes comerciantes quienes soportaron la economía en esos momentos dedicados a créditos comerciales y exportaciones. Fue, por esta razón, que los primeros años del periodo republicano no se observa una significativa actividad de adquisición de nuevas propiedades. El mercado de suelo aun seguía controlado por la Iglesia (Aparicio,1974:132-133), que apoyó a las fuerzas realistas para impedir la independencia.

Durante todo el periodo colonial la Iglesia controló el mercado de suelo de la ciudad dividida en los cinco curatos o parroquias: Santa Ana, San Sebastián, San Marcelo, San Lázaro y Santiago del Cercado (Córdova Urrutia, 1839:64). Su fuerza le permitió, antes y después de la independencia, otorgar empréstitos al Estado. Sin embargo, unos años después de iniciar el periodo republicano la aristocracia exigió el pago de sus indemnizaciones al Estado. Fue así, que para lograr este objetivo fue creada la Caja de Consolidación de Crédito Público.

"El decreto del 16 de octubre de 1824 y el Reglamento del 12 de noviembre de 1825 inician la depuración de la deuda interna y el 22 de setiembre de 1826 se Constituye por decreto una Caja de Consolidación de crédito público durante el gobierno del General Andrés de Santa Cruz. A través de esta caja el Estado logró créditos depurados con la emisión de billetes del crédito público que percibían nominalmente un crédito de $3 \%$ anual según el decreto del 1 de Abril de 1827. La deuda reconocida ese año la constituían los libramientos girados por el Congreso Nacional "(Quiroz, 1987:51).

Con esta acción fue posible iniciar el pago de los adeudos a los miembros de la aristocracia que colaboraron durante las batallas de la Independencia. Aunque esta caja sirvió para pagar gastos corrientes fue desactivada el 9 de marzo de 1935 (Quiroz, 1987:51). Para 1828 la nueva nación tenía una nueva estructura administrativa:

"Las dependencias de carácter fiscal incluían la contaduría General de Contribuciones, la Contaduría General de Valores, La Junta de Liquidación, la Tesorería General, la Casa de la Moneda la Aduana, la Caja de Administración “(Basadre:2014,tomolll:189).

Ubicados en el núcleo central, estos organismos mostraron la materialización de la institucionalidad de la nueva república peruana. No obstante, la nueva administración de la ciudad aun se encontraba en proceso de organización, principalmente en relación con las atribuciones de la Municipalidad, Intendencia y las Juntas Departamentales debido que aun no se reglamentaban sus funciones. 


\subsubsection{La subdivisión de las manzanas en casas de vecindad y la aparición de los primeros callejones en la ciudad republicana (1823-1828)}

La subdivisión de manzanas fue un proceso que inició desde la época colonial. Por aquel entonces, la ciudad contaba con 117 manzanas pero hacia el siglo XVIII, con el aumento poblacional y el crecimiento de la ciudad, contaba con 175 manzanas y luego 211(Ramón, 1999:134). Concretamente, las primeras subdivisiones de las manzanas en la periferia se dieron desde el terremoto del año 1746, cuando el virrey Manso de Velasco permitió que se rentaran viviendas para con ello satisfacer la demanda de las personas pobres que requerían una vivienda con lo cual aparecieron los callejones en la ciudad.

Durante los primeros años de la independencia la subdivisión continúo en la periferia, transformando la morfología interior de las manzanas ante un aumento de demanda por infraestructura de servicios básicos. Un ejemplo fue el barrio de San Lázaro, con callejones tugurizados, donde vivía la población negra de la ciudad desde finales del siglo XVIII (Flores Galindo, 1984:117). Para la primera mitad del siglo XIX el núcleo central siguió ese proceso de tugurización y hacinamiento, que en la periferia generó los primeros problemas de insalubridad, Esa condición fue estudiada por los higienistas Cosme Bueno (1759), Ambrosio Cerdán (1792) y Hipólito Unanue (1806) (Lossio,2001:149) ${ }^{40}$. Estos estudios sirvieron para la elaboración de un nuevo Reglamento de Policía el año 1839.

En el año de 1828 la población de la ciudad se calculaba en 50,000 habitantes (Diario El Mercurio Peruano, 1828 á, 19 setiembre: 03). Para entonces el proceso de subdivisión había llegado al núcleo central (Ramón, 1999:112). La ciudad se densificó como consecuencia de la migración del campo a la ciudad, la migración extranjera ${ }^{41}$ y el momento de transición económico por el que

\footnotetext{
40 La primera generación de higienistas del periodo republicano observaron los problemas de insalubridad en las calles causantes de las epidemias de tifus y fiebre amarilla, recomendando el cumplimiento del Reglamento de Policía vigente y la limpieza en los espacios públicos.
}

${ }^{41}$ Según Basadre, "el abandono del país voluntario o forzoso de cierto número de comerciantes o americanos contribuyó a la desnacionalización de las actividades mercantiles pues su posición paso a ser ocupada por 
atravesaron muchas familias de la élite colonial, las cuales se habían visto obligadas a arrendar sus casas para sobrevivir. Fue así, que aumentaron los problemas de insalubridad al interior de las manzanas en el núcleo central. Sin embargo, los altos costos de la renta en el núcleo central produjeron un desplazamiento de la población hacia los barrios de Santiago del Cercado y Cocharcas (Ramón, 1999:117-132) diversificándose el mercado de la renta según precios.

Durante los primeros años de la independencia, también la periferia había atravesado por un proceso de rediseño de su morfología. La subdivisión de las manzanas, que venía desde finales del periodo colonial, dio como resultado un desorden al interior de las manzanas y un mayor número de callejones. Un ejemplo de esta transformación fue el barrio de Santiago del Cercado que en el periodo colonial fue diseñado para la población indígena y que para el año de 1812 albergaba a indios, negros y blancos, transformándose en un espacio multiétnico que contaba con 34 callejones donde los cuartos de vecindad tenían de 7 a 11 habitantes en promedio, aumentando los problemas de insalubridad. (Ramón,1999:125).

La migración de los habitantes a la ciudad de Lima y la oferta de propiedades en renta produjo una variación de la forma urbana de la ciudad, debido principalmente a que cambió el patrón de ocupación de las edificaciones de vivienda, en espacios más pequeños, para dar origen al callejón limeño que se convirtió en una característica de la forma de vida en la ciudad. A esto se suma un cambio de grupos sociales al interior de estos espacios de vivienda en renta, así como un aumento de la densidad poblacional que, como hemos visto, dieron como resultado la variación de la estructura urbana. (Bejamin: 2017158159). ${ }^{42}$ Producto de estos cambios se iniciaron en el centro los problemas de insalubridad, deterioro de las edificaciones coloniales y demanda de una mayor infraestructura de servicios básicos. Estos cambios en la estructura urbana continuaron a lo largo del siglo XIX y sólo se mitigaron en la medida en que se

extranjeros sobre todo anglosajones" “Historia de la república del Perú 1821-1933, tomo I" Ed., El Comercio, Lima, 2014, pp.208.

42 Guillermo Benjamín Álvarez de la Torre "Morfología y estructura urbana en ciudades medias mexicanas" En: Revista Región y sociedad, Año XXIX, Núm.68 -2017 pp.153-191. 
produjeron cambios en las demarcaciones territoriales y mejoras en la infraestructura urbana y equipamiento en la ciudad.

\subsubsection{Los cambios en la ciudad a partir de la nueva demarcación (1828-1840)}

La constitución de 1828 estableció la nueva demarcación territorial de la ciudad. Fueron creados cinco cuarteles y diez distritos a cargo de un gobernador y un subprefecto (Laso,1839:10). El objetivo fue mostrar el poder del Estado Peruano, dejar atrás el pasado colonial, iniciar la materialización de la nueva república, controlar la subdivisión de manzanas y buscar el desarrollo urbano en la ciudad. A partir de entonces, se produjo la reconfiguración de la población en los nuevos distritos. Sin embargo, el terremoto que asoló la ciudad el 30 de marzo del mismo año y dañó muchas edificaciones (las torres de las iglesias de San Juan de Dios, Nazarenas, Merced y las iglesias parroquiales de San Lázaro y Copacabana) (Diario El Mercurio Peruano, 1828 á,6 abril:01) retrasó el proceso de reconfiguración del territorio con la nueva demarcación. Con el terremoto, muchas viviendas tuvieron que ser reconstruidas en medio de un proceso de demarcación territorial que generó conflictos en los límites por la pertenencia de una propiedad de un barrio a otro. Además, se generaron conflictos por el pago de impuestos con la nueva demarcación y la resistencia de algunas familias de seguir la nueva demarcación y perder privilegios de ubicación de sus propiedades, más la necesidad de reconstruir las vialidades en función de los nuevos límites para reforzar la nueva demarcación. (Ver plano 2.1 y cuadro 2.1) Con el tiempo, con la nueva demarcación se produjo una fragmentación socio-espacial, transformaciones en el mercado de renta de vivienda y el mercado de suelo. $\left(\right.$ Serna,2017:72) ${ }^{43}$. Hubo depreciación o aumento de valor de viviendas en zonas que pasaron a pertenecer a otro cuartel y generó una reorganización en el mercado de suelo. Además, la continuidad de la subdivisión de propiedades tanto en el centro como en la periferia generó una segregación residencial que contribuyó a acrecentar las desigualdades en la ciudad.

\footnotetext{
43 Miguel Pablo Serna y Francisco Gonzales Mora "Cambios hasta cierto punto segregación residencial y desigualdades económicas en Montevideo (1996-2015) Latin American Reseach Review ,2017, 52 (4) pp.571-588 DOI: https://doi.org/10.25222/larr. pp.59-76.
} 


\section{Plano 2.1 Plano de demarcación territorial de 1828 en cinco cuarteles}
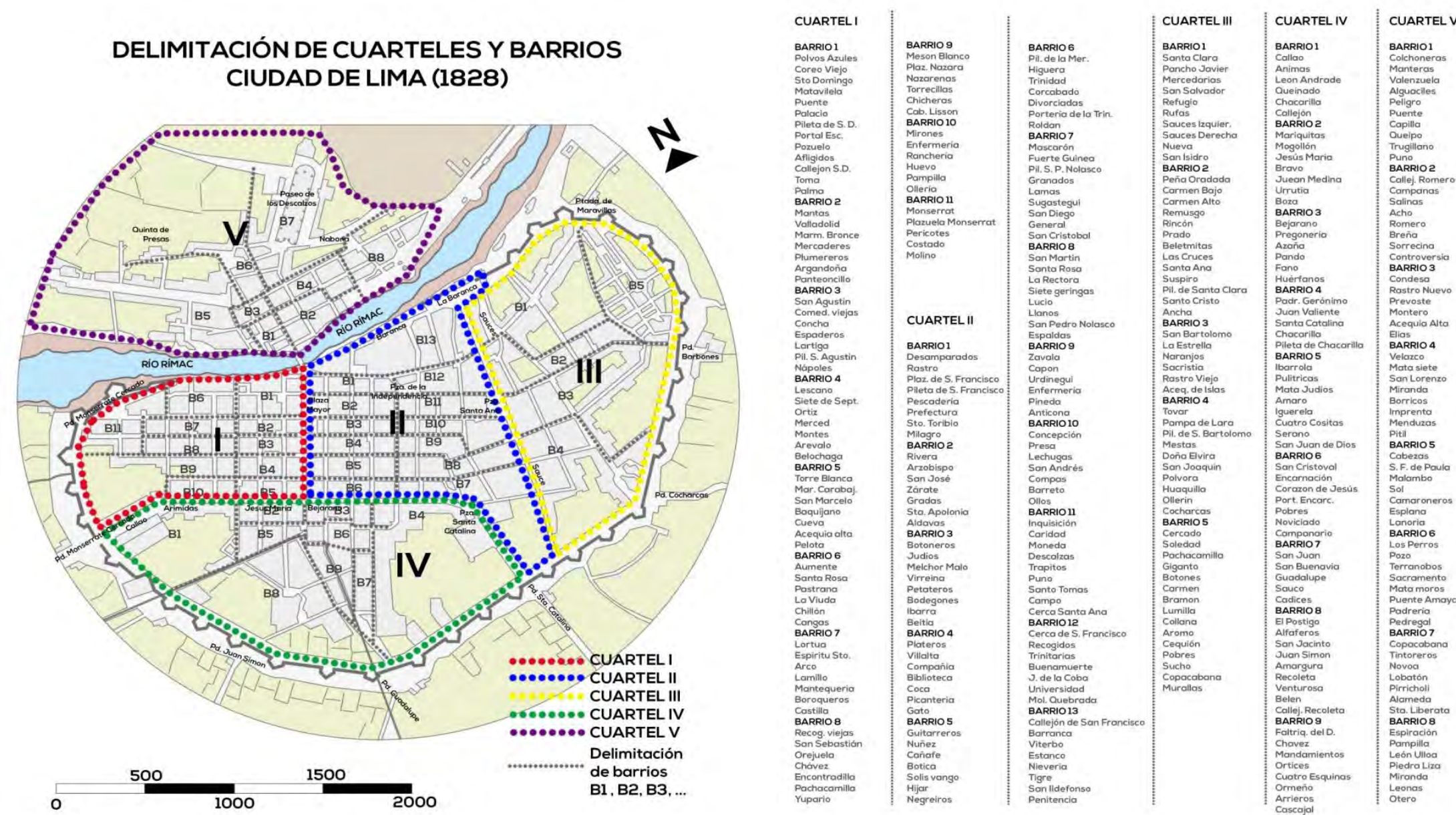

Fuente: Elaboración propia en base a fragmento del plano de Lima por Manuel Atanasio Fuentes de 1858 En: Estadística General de Lima y Córdova Urrutia (1839,p.31-32) 
Otro efecto de la nueva demarcación fue la reorganización de los distintos estratos socio económico al interior de las nuevas unidades administrativas y produjo la construcción de una nueva jerarquía social, con la posibilidad que las instituciones del Estado, como la Municipalidad, pusieran en marcha su plan de acción.

"El cuartel primero comprendió los barrios de Santo Domingo, San Agustín hasta Monserrate, que albergó a blancos y extranjeros con un total de 11 barrios. El cuartel segundo, comprendió los barrios de Desamparados, Plazuela de San Francisco, Casa de la Moneda, La Inquisición y albergó una población multirracial como blancos, mestizos y extranjeros con un total de 13 barrios. El cuartel tercero, dividido en dos espacios desde la plazuela de Santa Ana hasta la portada de Barbones dividido en cinco barrios desde Capuchinos hasta Guadalupe, constaba de cinco barrios donde vivían mulatos, negros, mestizos, indígenas. El cuartel cuarto comprendía los barrios bajo el puente como Malambo, Copacabana con ocho barrios donde vivían negros, pardos, mulatos y indígenas. El cuartel quinto, al otro lado del río, antes habitado por la élite colonial, fue la ubicación de los negros, mulatos y pardos" (Córdova Urrutia, 1839:33)

A pesar de la nueva demarcación, aun seguiría vigente la antigua debido a que no se reglamentaban las funciones de la Intendencia de Policía, la Municipalidad y la Prefectura para que la población cumpliera con los nuevos límites. Sin embargo, a pesar de la resistencia de la población de dejar la organización en cuarteles, de manera paulatina la población se organizó en diez distritos. (Ver cuadro 2.1) 


\section{Cuadro 2.1}

\section{Demarcación de los diez distritos según José María Córdova Urrutia el año 1828}

\begin{tabular}{|c|c|}
\hline Distrito & Comprende \\
\hline Primero & $\begin{array}{c}\text { Se compone de los barrios del } 6 \text { al } 10 \text { del cuartel primero, tomando } \\
\text { demarcación de la calle en línea recta calle la Toma hasta de la } \\
\text { Pelota o sacristía de San Marcelo }\end{array}$ \\
\hline Segundo & $\begin{array}{c}\text { Comprende los barrios } 1 \text { al } 5 \text { del cuartel primero y las principales } \\
\text { calles de los seis barrios del cuartel segundo, de Pescadería hasta } \\
\text { Divorciadas o antes calle de Correo. }\end{array}$ \\
\hline Tercero & $\begin{array}{c}\text { Parte del cuartel segundo, desde la calle San Diego hasta esquina } \\
\text { de Barranca o calle Tigre. }\end{array}$ \\
\hline Cuarto & Ultima calles del cuartel segundo. \\
\hline Quinto & $\begin{array}{l}\text { La mitad del cuartel tercero cuyas calles que quedan desde Peña } \\
\text { Oradada hasta Barbones. }\end{array}$ \\
\hline Sexto & La otra parte del cuartel tercero hasta Cocharcas. \\
\hline Sétimo & $\begin{array}{l}\text { La mitad del cuartel cuarto del lado de la portada del Callao } \\
\text { dividiendo la línea recta desde el Fano hasta la portada de } \\
\text { Guadalupe. }\end{array}$ \\
\hline Octavo & La otra parte del cuartel cuarto hasta la portada de Santa Catalina. \\
\hline Noveno & $\begin{array}{l}\text { Calles que quedan al lado de Malambo tirando un alinea recta desde } \\
\text { el puente hasta el Pedregal. }\end{array}$ \\
\hline Décimo & La parte de las alamedas. \\
\hline
\end{tabular}

Fuente: Córdova Urrutia (1839, pp.31-32) 
Para el año 1834 la nueva constitución permitió un mayor intervencionismo del Estado Peruano en las instituciones públicas como la Municipalidad, la Prefectura, la Intendencia de Policía y la Beneficencia, (Tarazona,1946:207208) lo que permitió la reglamentación de estas instituciones dando como resultado el cambio de la administración colonial a la de la república, con la posibilidad de generar proyectos para realizar obras públicas al interior de estas nuevas unidades administrativas según las necesidades de la población de los distritos. Aunque existió un conflicto territorial entre la demarcación en distritos y la demarcación de parroquias por el control de las actividades de la población, debido que las donaciones en dinero y propiedades ya no se hacían a la Iglesia sino a la Beneficencia, creada el 12 de junio de 1834 (Basadre:2014,tomoll,88). Estos conflictos se fueron solucionando a medida que las instituciones del Estado Peruano se fortalecieron. (Laso,1839). Sin embargo, a pesar de la nueva demarcación, las zonas residenciales al interior de estas nuevas unidades administrativas continuaron con la subdivisión de manzanas debido a la necesidad de vivienda. Fue así que para el año 1836:

"se registraron 247 callejones siendo el cuartel cuarto ubicado al otro lado del río el que tenía el mayor número de callejones en total 64 "(Diario El Telégrafo de Lima á, 18 febrero, 1836: $\mathrm{s} / \mathrm{n})$.

Otra característica de la vida en la ciudad en este periodo fue la convivencia de ricos y pobres en un mismo distrito donde existían residencias y casas de vecindad, (Ramón, 1999:130-131) demostrando que las zonas residenciales no eran homogéneas. Esta característica de la ciudad obligo a la élite mercantil a pensar en una posible reubicación de sus viviendas fuera de la ciudad o en los balnearios cercanos.

En la periferia continuó la subdivisión de propiedades para renta. Un ejemplo fue la aparición de grupos migrantes indígenas traídos desde la sierra para realizar servicios domésticos o trabajos para las tropas y los caudillos militares y que después de concluidas las campañas se quedaron a vivir en la ciudad, conformando una parte de la población que requería una vivienda económica en la periferia (Ramón, 1999:139). Esta forma de ocupar las propiedades generaría una reorganización de la población en casas-habitación que traería como consecuencia el deterioro de las casas coloniales por un sobre uso de su 
infraestructura existente y un cambio en la forma de vida al interior de las casas coloniales.

Para el año 1836 el mercado de suelo, después de las viviendas particulares, estaba dominado por la Iglesia. Un estudio de don José María Córdova y Urrutia sobre la distribución del mercado de suelo nos proporciona las siguientes cifras:

"De un total de 10,605 inmuebles 122 pertenecían al Estado, 8750 a particulares, 358 a la Beneficencia, 118 a Instrucción, Iglesia 382, Monasterios 539, Beaterios 84, Capillas 263 “ (Córdova Urrutia,1839:32a).

Según estos datos, la mayor parte de las propiedades de la ciudad se encontraban en manos privadas 8,750 , seguidas de las propiedades de la Iglesia 1,386 del Estado Peruano 122 y la Beneficencia 118. Además, muchas de las propiedades privadas, aun tenían una hipoteca a la Iglesia. Es decir, que de manera indirecta, aun existía un predominio de la Iglesia sobre el mercado de suelo que hubiera disminuido en los siguientes años mediante la implementación de una Ley para eliminar las hipotecas sobre las propiedades particulares y de esa manera lograr la redistribución de la propiedad en la ciudad y su inserción en el sistema financiero aun incipiente por esos años. Sin embargo, esta medida aun requería que el sistema mercantil se implementara y las ideas liberales sobre la activación del mercado de suelo tuvieran fuerza en los grupos de poder que acompañaban al gobernante de turno.

Un estudio del mercado de suelo en ese mismo año de don José María Córdova Urrutia nos describe el precio del valor de suelo en la ciudad. Según este estudio los valores más altos eran de 10 a 8 pesos el metro cuadrado en los cuarteles primero ubicado en la zona central. Mientras en los cuarteles tercero y quinto el valor del metro cuadrado estaba en 4 pesos en promedio (Córdova Urrutia, 1839:s/n) ${ }^{44}$ como una muestra de la materialización de la republica en la ciudad y su influencia en el mercado de suelo. No obstante, la estructura de precios en estos momentos aun pertenecía a una estructura colonial que benefició a la Iglesia donde los precios estaban en función a la

\footnotetext{
44 En el libro de Córdova de Urrutia el cuadro denominado División de la ciudad de Lima dispuesto con este orden para mejorar el servicio no tiene página. Sin embargo, se encuentra entre las páginas 31 y 32.
} 
cercanía o lejanía de la Plaza Mayor, Plazas parroquiales, conventos, monasterios o beaterios que cambiaría los próximos años.

En el año de 1839, cuando se encontraba en la presidencia el general Agustín Gamarra, entró en vigencia el nuevo Reglamento de Policía elaborado por don Benito Laso (Laso, 1839) con el objetivo de controlar a la población con la nueva demarcación, reglamentar sus actividades en la ciudad, mejorar la salubridad y el ornato en los espacios públicos, la limpieza de calles, acequias y recojo de basura por parte de los vecinos que tomo el nuevo orden social que se venía construyendo en la ciudad. Esa fue una forma de evitar la acumulación de desechos extramuros cerca a los baluartes de la muralla, lo que benefició a la salubridad de la ciudad. Además, debido a la creciente subdivisión de las propiedades en el centro y la periferia para uso de viviendas en renta, el nuevo Reglamento de Policía incluyó reglas para el control de las construcciones y la ubicación del desmonte proveniente de las demoliciones, en particular en el capítulo II “Del Ornato de la Población” (Laso,1839:31).

\subsection{El ciclo guanero y la transformación de la ciudad (1842- 1876)}

El reto de los nuevos gobiernos peruanos seguía siendo eliminar las instituciones del régimen colonial e introducir a la ciudad al sistema mercantil, permitiendo una mayor actividad económica. A partir del año de 1842 el guano de las islas se convirtió en la principal fuente económica del Estado Peruano lo que posibilitó la generación de un presupuesto para el funcionamiento de las instituciones del Estado y satisfacer a la élite y empresarios extranjeros con la ejecución de obras públicas en la ciudad. Inglaterra se convirtió en el más importante comprador de guano e inició su dominio comercial en la ciudad.

El guano era un fertilizante que era posible de ser recogido en las costas del Perú e islas cercanas. Provenía del escremento de las aves. La única inversión era la compra de bolsas para su recolección. "Este preciado fertilizante era de propiedad del Estado peruano. Sin embargo, por sus características había desplazado a otro fertilizantes en Inglaterra donde era comercializado por los 
contratistas" (Mathew,2009:113). La importancia para ese momento el gobierno del presidente Ramón Castilla:

"Pero los contratistas y los consignatarios no pueden ser separados por completo de esa manera, porque estos tenían mucho que ganar de cualquier éxito logrado por sus oficinas o socios comerciales en Lima, y como los principales proveedores de estas sucursales tenían mucho que perder si las cosas iban muy mal. Asimismo era de interés de los consignatarios asegurarle una buena ganancia al gobierno, para poder financiar los préstamos que ellos ayudaban a financiar y mantener la buena voluntad de personajes que de otra manera, podría buscar deshacerse de sus servicios. Debido a los préstamos, escribió Willian Gibbs y Myers en 1846, era el interés de los contratistas como del gobierno que tuviéramos un buen precio“" (Mathew,2009:113).

La venta a buen precio garantizaba recursos al Estado y de esa manera también se beneficiaban la élite que eran parte de los consignatarios. Otras veces el Estado en su necesidad de contar con dinero tenía que someterse a las condiciones de los contratistas. Esta cadena ${ }^{45}$ no solo permitía recursos al Estado sino a los inversionistas locales poder realizar inversiones en la ciudad. "Para el año 1849 el Perú era el mayor proveedor de fertilizante para el mercado británico sus importaciones sumabas 73 toneladas frente a sus competidores Chile, África del Oeste y la Patagonia cuyas importaciones estimaban en 4,311,2,345,1,945 toneladas de fertilizante"(Mathew,2009:137).

Según Jorge Basadre el periodo del auge del guano sería conocido como Prosperidad falaz y comprendería desde 1842 hasta 1866 (Basadre, 2014, tomolV: 5). Sin embargo, debido a lo inesperado de este tipo de comercio y la concentración de riqueza que generó en el país, desde 1850 hasta 1878 según Helen Hunt (Hunt, 1985:37), sería conocido como La edad madura del guano.

\footnotetext{
45 Según Willian Mathew "El establecimiento progresivo del guano como la mercancía más importante en el mercado de fertilizantes británicos fue el resultado de por lo menos cuatro factores: su evidencia física, las políticas y actividades de los consignatarios, la receptividad de los agricultores británicos y el comercio africano. El guano no solo era atractivo debido a su variedad de composición, sino también debido a que era un fertilizante concentrado de poco peso, capaz de ser llevado con bajos costos a los campos más remotos muchos de los cuales habían estado más allá del alcance de la carreta de estiércol. En: La firma inglesa Gibbs y el monopolio del guano en el Perú. Williann M. Mathew, Ed. Banco Central de Reserva, Lima, 2009. p.137-138.
} 
Desde entonces, con la aparición en la ciudad de una economía del guano existió en la población un anhelo de progreso y modernidad.

"La renta guanera posibilitó, en consecuencia, comprar la tregua política, estableciendo un relativo periodo de paz en el territorio nacional "(Mc Evoy, 1997:25).

Inglaterra se convirtió en el más importante comprador de guano e inició su dominio comercial en Lima. Además, gracias a la pacificación del territorio, las empresas inglesas comenzaron a instalarse en la ciudad, activando la economía y permitiendo un mayor circulante de dinero. Se inició así, un periodo de bonanza para el país que permitió a los gobiernos de turno planificar la materialización de la modernidad urbana en la ciudad.

\subsubsection{Un intento modernizador en la ciudad: El primer gobierno de Ramón Castilla (1845-1851)}

El primer gobierno del presidente Ramón Castilla de 1845 a 1851 buscó un consenso entre los grupos políticos, principalmente entre liberales, conservadores y los caudillos militares con el objetivo de materializar el ansiado progreso.

"En 1845, luego de derrocar al Directorio del gobierno encabezado por el general arequipeño Manuel Ignacio de Vivanco, asumió, finalmente, la presidencia de la República. Durante su primer gobierno, 1845-1851, Ilamado apaciguamiento nacional, Castilla logró aquietar temporalmente a las facciones, que habían venido asolando con sus enfrentamientos la inestabilidad política del país “(Mc Evoy,1997:26).

Gracias a estas acciones, fue posible, difundir un discurso cohesionador, para recuperar la legitimidad política, el respeto a la autoridad y la vuelta a la unidad nacional que se convirtieron en los principios que siguió el gobierno. Al iniciar el gobierno del presidente Castilla sus principales objetivos fueron:

1.- Lograr la pacificación de la nación y utilizar los ingresos de la venta del guano para emprender la materialización del proyecto modernizador (Diario oficial El Peruano á, 20 abril, 1845:01).

2.- Liberar de la esclavitud a los negros y de esa manera dar un paso en la justicia social. Además, abolió el tributo indígena (Basadre, 2014, tomolV: 46). $Y$ mejorar la infraestructura de las escuelas primarias como la base para alcanzar el desarrollo. 
"Castilla inició la construcción de un Estado central y estable, que desde el punto de vista económico, postuló las tesis liberales. El desarrollo de las mismas trascendió el ámbito de la economía y alcanzó la esfera social e ideológica en un proceso reformista que, dada la oposición de los sectores proteccionistas en lo económico y el rechazo de los católicos más conservadores a todo cambio en el ámbito de las creencias, calificó en su momento de tímido (García Jordán, 1991:105). La integración del Perú a la economía de libre intercambio pareció exigir la vertebración de un Estado-Nación moderno incompatible con la existencia de los fueros personales y corporativos, esclavitud, tributo indígena, y de todas las cargas que pesaban sobre la tierra en forma de diezmos, capellanías, censos y vinculaciones "(Mc Evoy: 2004,198).

Además, en este periodo de gobierno, la decisión política de introducir al país en el sistema mercantil tuvo las siguientes consecuencias: la eliminación paulatina de los sistemas de administración coloniales y eclesiásticas, eliminación del fuero eclesiástico, la organización de las finanzas públicas, la búsqueda de un orden público, la seguridad en la ciudad, el respeto de las tierras de los indígenas como un paso en la justicia social de las castas que vivían en la ciudad, un mejor control de territorio y la eliminación paulatina de las hipotecas de propiedades hechas a la Iglesia en el periodo colonial que permitirían en un siguiente periodo la activación del mercado de suelo.

La visión a futuro de la ciudad de este gobierno fue la materialización de la modernidad, lograr que todas las castas que habitaban la ciudad tuvieran los mismos derechos de ciudadanía y buscar el crecimiento de la industria como una formar de alcanzar el progreso. Para lograr este objetivo se reglamentaron las principales instituciones del Estado Peruano y emprendieron una serie de obras públicas, pero sin una planificación integral y un sesgo que satisfacía a la élite mercantil y industrial que lo acompañaba en el poder.

Una política urbana de este gobierno fue que gran parte de las obras públicas fueron sometidas a subastas para su ejecución convirtiendo al Estado en el administrador de obras en la ciudad como fue el caso de la construcción del nuevo mercado de la Concepción (Diario El Interprete, 1852 á, 27 abril: 01). 


\section{Cuadro 2.2}

\section{Obras públicas durante el primer gobierno del presidente Ramón Castilla (1845-1851)}

\begin{tabular}{|c|c|c|c|}
\hline Año & Obras Públicas & Institución ejecutora & Fuente \\
\hline 1847 & Plazuela 7 de setiembre & $\begin{array}{c}\text { Dirección de Obras } \\
\text { Públicas Municipalidad } \\
\text { de Lima. }\end{array}$ & Ramón,2007:19 \\
\hline 1847 & $\begin{array}{c}\text { Ensayo de colocación de } \\
\text { lajas de piedra en las calles } \\
\text { de Lima }\end{array}$ & $\begin{array}{c}\text { Dirección de Obras } \\
\text { Públicas Municipalidad } \\
\text { de Lima. }\end{array}$ & $\begin{array}{c}\text { Basadre,2014,tomo } \\
\text { IV:58 }\end{array}$ \\
\hline 1849 & $\begin{array}{c}\text { Reparación de la Alameda } \\
\text { de Acho }\end{array}$ & $\begin{array}{c}\text { Dirección de Obras } \\
\text { Públicas Municipalidad } \\
\text { de Lima. }\end{array}$ & $\begin{array}{c}\text { Basadre,2014,tomo } \\
\text { IV:58 }\end{array}$ \\
\hline 1851 & Terminal de ferrocarril & $\begin{array}{c}\text { Dirección de Obras } \\
\text { Públicas Municipalidad } \\
\text { de Lima. }\end{array}$ & $\begin{array}{c}\text { Basadre,2014,tomo } \\
\text { IV:58 }\end{array}$ \\
\hline 1851 & $\begin{array}{l}\text { Servicio de agua potable } \\
\text { para el puerto del Callao }\end{array}$ & $\begin{array}{c}\text { Dirección de Obras } \\
\text { Públicas Municipalidad } \\
\text { de Lima. }\end{array}$ & $\begin{array}{c}\text { Basadre,2014,tomo } \\
\text { IV:58 }\end{array}$ \\
\hline 1851 & $\begin{array}{c}\text { Finalización del ferrocarril } \\
\text { Tacna y Arica }\end{array}$ & Gobierno Central & $\begin{array}{c}\text { Basadre,2014,tomo } \\
\text { IV:58 }\end{array}$ \\
\hline 1851 & $\begin{array}{c}\text { Embellecimiento de Lima: } \\
\text { Estatuas de Colón y Simón } \\
\text { Bolívar en la alameda de los } \\
\text { Descalzos }\end{array}$ & Gobierno Central & $\begin{array}{c}\text { Basadre,2014,tomo } \\
\text { IV:58 }\end{array}$ \\
\hline 1852 & Mercado Central & Gobierno Central & $\begin{array}{c}\text { Basadre,2014,tomo } \\
\text { IV:58 }\end{array}$ \\
\hline
\end{tabular}

Fuente: Elaboración propia en base a: Ramón (2007, pp.19), Basadre tomo IV (2014, pp.58). 
Durante este periodo el Estado Peruano buscó la profesionalización de la construcción y que las obras contaran con estándares de calidad y tuvieran un control en su ejecución. Fue así que el presidente Castilla creó la Comisión Central de Ingenieros y estableció la Escuela de Ingenieros Civiles el 30 de diciembre de 1852 (Basadre, 2014,tomo VI: 64). Con estas acciones el presidente buscó que en un futuro los mejores profesionales egresados de la Escuela de Ingenieros formaran parte del grupo de ingenieros del Estado, dejando atrás a los profesionales de la construcción de la colonia como los agrimensores, alarifes y maestros mayores. La idea era modernizar la actividad de la construcción y mejorar la forma de construir las viviendas debido a la frecuencia de temblores en la ciudad.

La obra pública en la ciudad tuvo cierta continuidad durante el periodo de gobierno del presidente Rufino Echenique de 1851 a 1854 (Basadre, 2014, tomoVl:64). Se avanzó en la creación de la primera Escuela Central de Ingenieros Civiles (Diario Registro Oficial, 1853 á, 5 julio: 1) y en La Comisión Central de Ingenieros Civiles. Los ingenieros que salieron de esta institución se convertirían en profesionales destacados en el rubro de la construcción como: Emilio Chevalier, Carlos Faraguet, Ernesto Malinoski (Diario Registro Oficial, 1853 á, 08 enero: 13).

Durante su gobierno Rufino Echenique promulgó una nueva constitución en 1856, de corte liberal, que no entro en vigencia pero que refleja cómo estos acontecimientos influenciaron en las decisiones del gobierno de turno como la implementación de una nueva Ley Orgánica de Municipalidades el 01 de diciembre de 1856 donde se adicionaron funciones a esta institución como: el del Registro Civil y el Censo de las poblaciones y fueron transferidos a la Municipalidad el ramo de agua y educación (Castilla,1857:1-27). Estas nuevas funciones, fortalecieron la imagen de la Municipalidad y la convirtieron en la administradora de la ciudad con una autonomía capaz de reglamentar instituciones en su interior y administrar sus propios ingresos. Sin embargo, según el historiador Jorge Basadre, la posibilidad que las Municipalidades pudieran administrar sus propios bienes produjo despilfarros.

"La facultad dada a los consejos de administrar "exclusivamente" los fondos municipales produjo despilfarros "(Basadre, 2014, tomoVI: 71). 
El gobierno de turno esperaba que con la aplicación de la nueva Ley de Municipalidades esta institución pudiera ejecutar las obras en su jurisdicción, tener una mejor administración de sus rentas sin la intervención del Estado Peruano y mejorar la administración de los servicios básicos y la educación. Sin embargo, el Reglamento de Policía de 1839 fue ratificado el año 1857 y continuó en vigencia como una muestra de que la autonomía de la Municipalidad no se cumplió y que la ciudad aun seguía administrada por la Intendencia y la Prefectura (Castilla, 1857:15). 


\section{Cuadro 2.3}

\section{Obras públicas en el segundo periodo de gobierno del presidente Ramón Castilla (1855-1862)}

\begin{tabular}{|c|c|c|c|}
\hline Año & Obra Pública & $\begin{array}{l}\text { Institución } \\
\text { ejecutora }\end{array}$ & Fuente \\
\hline 1855 & Matadero General & DOPLM $^{46}$ & Ramón,2007:19 \\
\hline 1855 & Instalación del alumbrado a gas de Lima & DOPLM & $\begin{array}{l}\text { Basadre,2014, } \\
\text { tomo IV:58 }\end{array}$ \\
\hline 1885 & $\begin{array}{l}\text { Contrato para la provisión de cañería de } \\
\text { fierro }\end{array}$ & DOPLM & $\begin{array}{l}\text { Basadre,2014, } \\
\text { tomo IV:58 }\end{array}$ \\
\hline 1856 & Ferrocarril Lima-Chorrillos & DOPLM & $\begin{array}{l}\text { Basadre,2014, } \\
\text { tomo IV:58 }\end{array}$ \\
\hline 1857 & Escuela Normal Central & DOPLM & Ramón,2006:19 \\
\hline 1857 & $\begin{array}{l}\text { Inauguración de faroles de la Plaza de } \\
\text { Armas }\end{array}$ & DOPLM & $\begin{array}{l}\text { Basadre,2014, } \\
\text { tomo IV:58 }\end{array}$ \\
\hline 1857 & Inauguración de agua potable de Lima & DOPLM & $\begin{array}{l}\text { Basadre,2014, } \\
\text { tomo IV:58 }\end{array}$ \\
\hline 1859 & $\begin{array}{l}\text { Renovación de las plazas: De Armas, } \\
\text { Bolívar, Santa Ana y muelle Chorrillos }\end{array}$ & DOPLM & $\begin{array}{l}\text { Basadre,2014, } \\
\text { tomo IV:57 }\end{array}$ \\
\hline 1860 & Penitenciaria & DOPLM & $\begin{array}{l}\text { Basadre,2014, } \\
\text { tomo IV:58 }\end{array}$ \\
\hline 1861 & $\begin{array}{l}\text { Refacción del Colegio San Carlos y } \\
\text { Casa de Correos }\end{array}$ & DOPLM & $\begin{array}{l}\text { Basadre,2014, } \\
\text { tomo IV:58 }\end{array}$ \\
\hline 1862 & $\begin{array}{c}\text { Fábricas de Gas, Plaza de } \\
\text { Penitenciaria, construcción del } \\
\text { Ministerio de Hacienda, refacción del } \\
\text { Ovalo de Acho y Muelle }\end{array}$ & DOPLM & $\begin{array}{l}\text { Basadre,2014, } \\
\text { tomo IV:57 }\end{array}$ \\
\hline 1863 & $\begin{array}{c}\text { Puente sobre el río Rímac a la altura de } \\
\text { Santo Domingo (Puente de Piedra), } \\
\text { Palacio de Justicia. }\end{array}$ & DOPLM & $\begin{array}{l}\text { Basadre, } 2014 \\
\text { tomo IV:58 }\end{array}$ \\
\hline
\end{tabular}

Fuente: Elaboración propia en base a: Ramón (2007, pp.19), Basadre tomo IV (2014, pp.57-58)

46 (DOPLM) Dirección de Obras Públicas de la Municipalidad de Lima. 


\subsubsection{El segundo periodo de gobierno del presidente Ramón Castilla de rasgos dictatoriales $(1855-1862)$}

\subsubsection{La urbanización de la periferia a cargo de la inversión privada: La urbanización "La Chacrita”}

Durante el segundo periodo de Castilla (1855-1862) las nuevas edificaciones públicas de equipamiento urbano como el mercado, el matadero, la cárcel dieron aires de modernidad a la ciudad. Sin embargo, la inauguración de otras edificaciones como la Penitenciaria el 24 de julio de 1862 generó horror en la población según describe el médico Casimiro Ulloa ${ }^{47}$ (Ulloa, 1862:119). Aunque no se tienen datos sobre como los habitantes de Lima veían el resto de edificaciones modernas estas habían cambiado el rostro de la ciudad e introducido a los habitantes de Lima a la modernidad y a una pérdida de la identidad limeña como describe Ricardo Palma:

"Lima con las construcciones modernas, ha perdido por completo su fisonomía entre cristiana y morisca. Ya el viajero no sospecha una misteriosa verdad tras las rejillas ni la fantasía encuentra campo para poetizar las citas y aventuras amorosas. Enamorarse hoy de Lima, es lo mismo que haberse enamorado de cualquiera de las ciudades de Europa "(Palma,1968:124).

Hasta ese momento la ubicación de los edificios públicos fueron decisión de los gobiernos dictatoriales y aprobados por La Junta Central. El centro de la ciudad se había modernizado con edificaciones públicas de equipamiento como: La Penitenciaria, La Casa de Gobierno, La Cámara de Diputados, La Casa de la Moneda, La Escuela de Medicina, el Mercado, el Teatro, la Cárcel (Dupard,1859). Sin embargo en la periferia eran pocas las obras de infraestructura haciendo notorias las desigualdades en el centro y la periferia. Este hecho, junto con el despilfarro del dinero de guano para materializar un proyecto modernizador para la élite terrateniente y comercial, la excesiva burocracia y el mal uso del presupuesto público por parte de los funcionarios del Estado Peruano daban indicios de un desborde popular y la búsqueda de la población de una nueva forma de gobernar.

El proyecto de modernización de la ciudad en un contexto liberal ejecutado por los gobiernos de los presidentes Ramón Castilla y Rufino Echenique había

\footnotetext{
47 Casimiro Ulloa fue un médico profesor de la Facultad de Medicina de la Universidad Mayor de San Marcos, coeditor de la Gaceta Médica de Lima entre los años 1856-1858 y escritor de la sección quincenal de la Revista Lima.
} 
generado una burocracia en las instituciones del Estado debido a un intento por reglamentar las actividades en la ciudad. No obstante, con la materialización de edificaciones públicas en la ciudad, habían intentado materializar la modernidad. Así también, con la introducción del mercantilismo se había hecho realidad la dependencia económica con Inglaterra a partir del comercio del guano, generando una urbanización dependiente (Almandoz, 2018:47). Los gobiernos liberales habían cumplido los deseos de la élite de modernizar la ciudad con las obras públicas. La élite pensaba que era "moderno" lo de fuera (Almandoz, 2018:47) y el resultado fue la modernización con obras en espacios públicos en el centro y con la construcción de edificaciones que mostraran el poder del Estado. Sin embargo, estas acciones solo contribuyeron a aumentar las desigualdades y trajeron como consecuencia un rechazo al gobierno de turno y una búsqueda de cambio.

El problema de la población que vivía en casas de vecindad y el aumento del número de callejones continuaban. Las rentas en la ciudad eran altas y seguían los problemas de insalubridad al interior de las casas-habitación. Estos problemas fueron analizados por el médico Mariano Arosemena que propuso una posible solución en un artículo titulado " $L a$ autoridad ilustrada por la ciencia- Artículo cuarto de las habitaciones" (Arosemena, 1857:08-09). "En el extenso artículo se describe la existencia de terrenos vacíos en la periferia de la ciudad que podrían ser utilizados para la construcción de viviendas, con el dinero producto del guano que el gobierno podría disponer y que constituiría una inversión recuperable mediante pagos mensuales por parte de los propietarios. De esa manera, se evitaría el abuso de los propietarios a los arrendatarios" (Arosemena, 1857:08-09). "Como otra opción, propuso que los propietarios de huertas rentaran los terrenos vacíos de la ciudad que se encontraban en la periferia cercanos a la muralla hacia las portadas Santa Catalina, Cocharcas y Callao" (Arosamena, 1856:10-11).

Aunque las ideas de Arosamena no encontraron una respuesta por parte del gobierno en turno, sí tuvieron una respuesta por parte de los inversionistas privados como: el ingeniero Felipe Paz Soldán ${ }^{48}$, don Mariano Álvarez y don 
Pedro Sayán quienes compraron terrenos cerca de la muralla, convirtiéndose en la primera propuesta de viviendas privadas en la ciudad. Fue así como en el año 1857 se materializó la empresa urbanizadora "La Chacrita". En los terrenos ubicados al borde sur-este de la muralla de Lima en la zona conocida como Huertas del Noviciado y Huerta Perdida que fueron comprados por la empresa urbanizadora "La Chacrita" en 42,000 pesos (Eguiguren,1945:229). Posteriormente, el abogado Mariano Álvarez compró la Huerta Guadalupe para ampliar la urbanización (Eguiguren, 1945:229). El proyecto conocido como la urbanización "La Chacrita", constaba de 24 manzanas (Ludeña: 2004,33) como se ve en boceto que hizo el ingeniero Felipe Paz Soldán. Este proyecto, significó el primer trazado aporte de la inversión privada en la ciudad (ver Plano 2.2). El abogado Mariano Sayán se encargó de la venta. Sin embargo, la sociedad no tuvo éxito a pesar que se encontraba cerca edificaciones públicas como: el Auspicio, los colegios de San Carlos y Guadalupe y la estación LimaChorrillos (Dupard, 1859) porque aún no existía una plataforma financiera por parte de los bancos que permitiera a la población adquirir una vivienda vía préstamo hipotecario y debido que este proyecto de viviendas estaba ubicado en una zona despoblada y sin servicios básicos donde aun no llegaba el transporte público.

El 1872 el ingeniero Felipe Paz Soldán ${ }^{49}$ después de años de disuelta la compañía vendió al empresario Enrique Meiggs dos manzanas que equivalen a 7,467 varas cuadradas ubicados entre huerta Perdida y la calle Zepita (Eguiguren,1945:229). El año siguiente, el 11 de enero de 1873 se publicó en el diario oficial El Peruano la colocación del alumbrado público a gas en la zona (Diario oficial El Peruano, 1873 á, 11 enero: 16) que generó una expectativa en la población. Unos años más tarde, la incorporación de este trazado como parte del proyecto del Plan de Ensanche hizo más atractiva la zona para vivir pero esta vez la oferta inmobiliaria estaba diseñada para viviendas para los inmigrantes. Según los planes de fraccionador Meiggs los lotes ofrecidos tenían

\footnotetext{
49 Felipe Mariano Paz Soldán fue un historiador y geógrafo peruano. Considerado como el fundador de la historiografía peruana. El año 1857, fue Ministro de Relaciones Exteriores del presidente Ramón Castilla. Posteriormente, fue Ministro de Justicia e Instrucción entre los años 1869-1870 del presidente José Balta.
} 
precios asequibles y facilidades de pago para que la población con poder adquisitivo decidiera comprar un lote en esta zona.

La urbanización "La Chacrita" nos muestra como las ideas de liberalismo económico habían sido puestas en práctica por miembros de la élite limeña con la idea de generar riqueza y pensar que las cosas tienen un valor mientras son rentables (Berman, 1989:108). De esta manera avanzaba el esquema de la modernidad. Junto a las actividades industriales, aun incipientes en la ciudad o la producción de azúcar en las haciendas azucareras del norte, la idea urbanística de modernidad buscó el objetivo de generar un producto inmobiliario a partir de la división del suelo. En este caso la urbanización privada significó la materialización de las ideas modernas que habían llegado de Europa y la influencia de los comerciantes ingleses que vivían en la ciudad de Lima. Este proyecto de urbanización, significó la puesta en práctica de ideas como: el poder del mercado y la libertad económica de ofrecer, promocionar, vender un producto inmobiliario y atraer clientes de la élite a vivir en un espacio periférico de la ciudad fuera de la insalubridad del centro. Sin embargo, la falta de infraestructura vial y de servicios lo hizo poco atractivo. Este primer intento de urbanización privada en la periferia no se concretó por una falta de sincronización entre las ideas de los inversionistas privados con las del gobierno de turno, que por esos años, estaba preocupado en la institucionalización del Estado y satisfacer a los grupos de poder que lo acompañaban con la ejecución de obras públicas. 
Plano 2.2 Plano del borde sur de la ciudad entre los años (1857-1859)

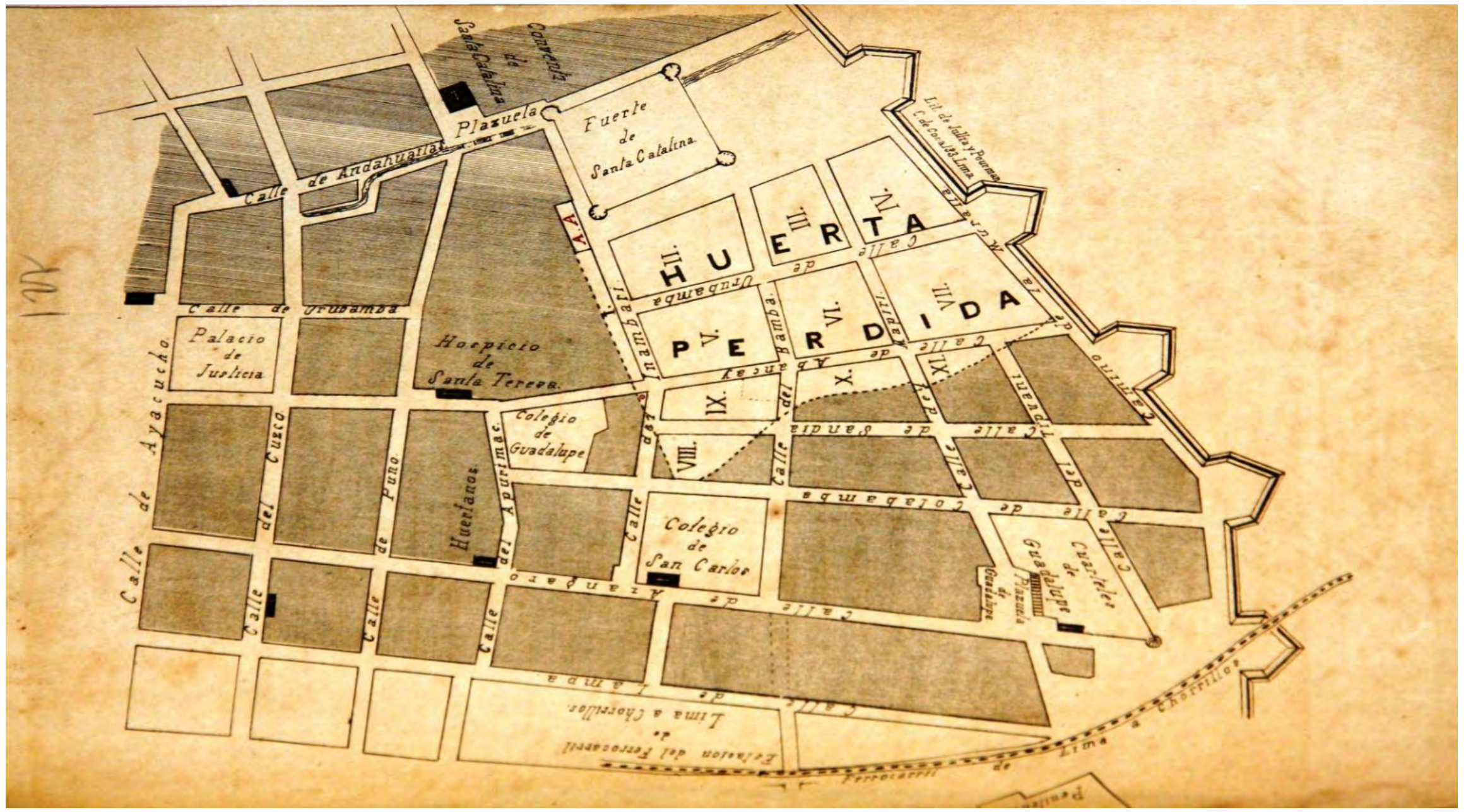

Fuente: Selaya J. (1857) 


\section{Plano 2.3}

Plano de la urbanización "La Chacrita” el año 1859

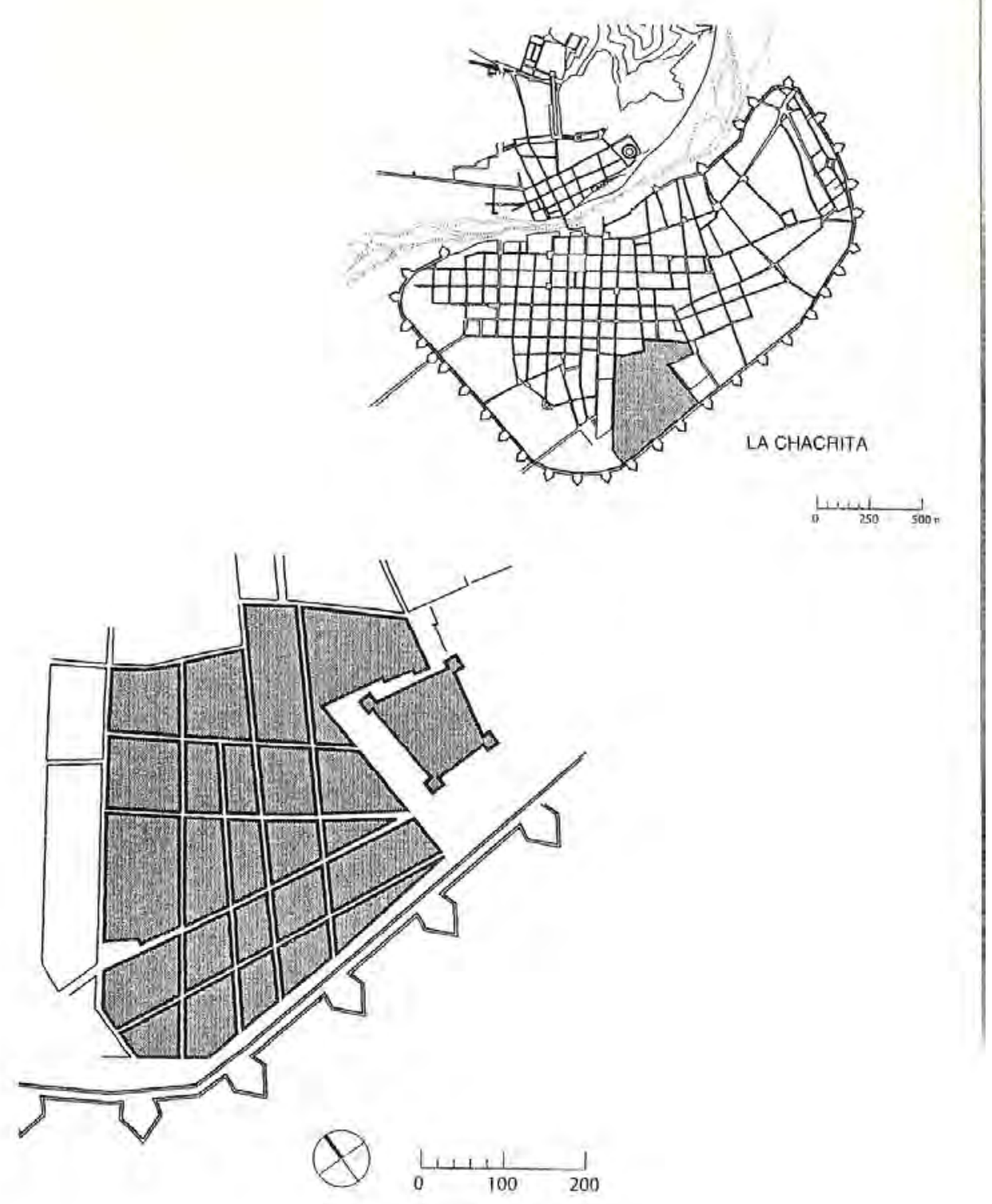

Ludeña (2004, pp.33) 


\subsubsection{La cartografía, la estadística, la continuación de obras y el nuevo financiamiento urbano (1851-1861)}

Como un signo del positivismo científico de esos años, los presidentes José Rufino Echenique (1851-1855) y Ramón Castilla (1856-1861) apoyaron la cartografía y la estadística como herramientas para analizar la demografía. El objetivo fue tener un mayor control de la administración de la ciudad, un mejor control del territorio, mejorar las rentas, desarrollar la industria, tener un control de la población, mejorar la seguridad y la mejorar la calidad de la instrucción pública.

Durante el gobierno del presidente José Rufino Echenique se creó la Sección de Estadística al interior del Ministerio de Gobierno (Diario oficial El Peruano, á 24 de junio, 1854: 164-166) principalmente para mejorar las rentas del Estado Peruano y hacer más eficiente la gestión para recaudar el impuesto predial y contribuciones y apoyar los gastos públicos. Un aporte particular, se produjo el año 1858, con la publicación del libro "Estadística General de Lima" por el higienista Manuel Atanasio Fuentes. La ciudad contó con un documento especializado elaborado que permitió conocer datos como: la población de Lima, que para ese entonces era 94,185 habitantes (Fuentes,1858:40) y otros datos como: el área de terreno ocupado por las casas de la ciudad que era de $7,692,658$ varas castellanas y el área ocupada por la muralla, 8,095,080 varas castellanas (Fuentes,1858:631-632). Con esta información los ingenieros del Estado Peruano tendrían una herramienta para lograr mejores proyectos y los empresarios privados podrían definir nuevas inversiones y, de esa manera, continuar la modernización en la ciudad.

Durante el segundo gobierno el presidente Castilla se mandó a elaborar el plano de Lima al ingeniero José María Dupard. Este documento gráfico muestra las obras realizadas por el Estado Peruano durante estos años como: La Penitenciaria, el Mercado y el Teatro (Dupard, 1859) para que la población pudiera tener un panorama de la obra pública en la ciudad y fuera posible continuar planificando más obras en el centro y la periferia. 


\section{Plano 2.4}

\section{Plano de Lima elaborado por el ingeniero José María Dupard el año 1859}

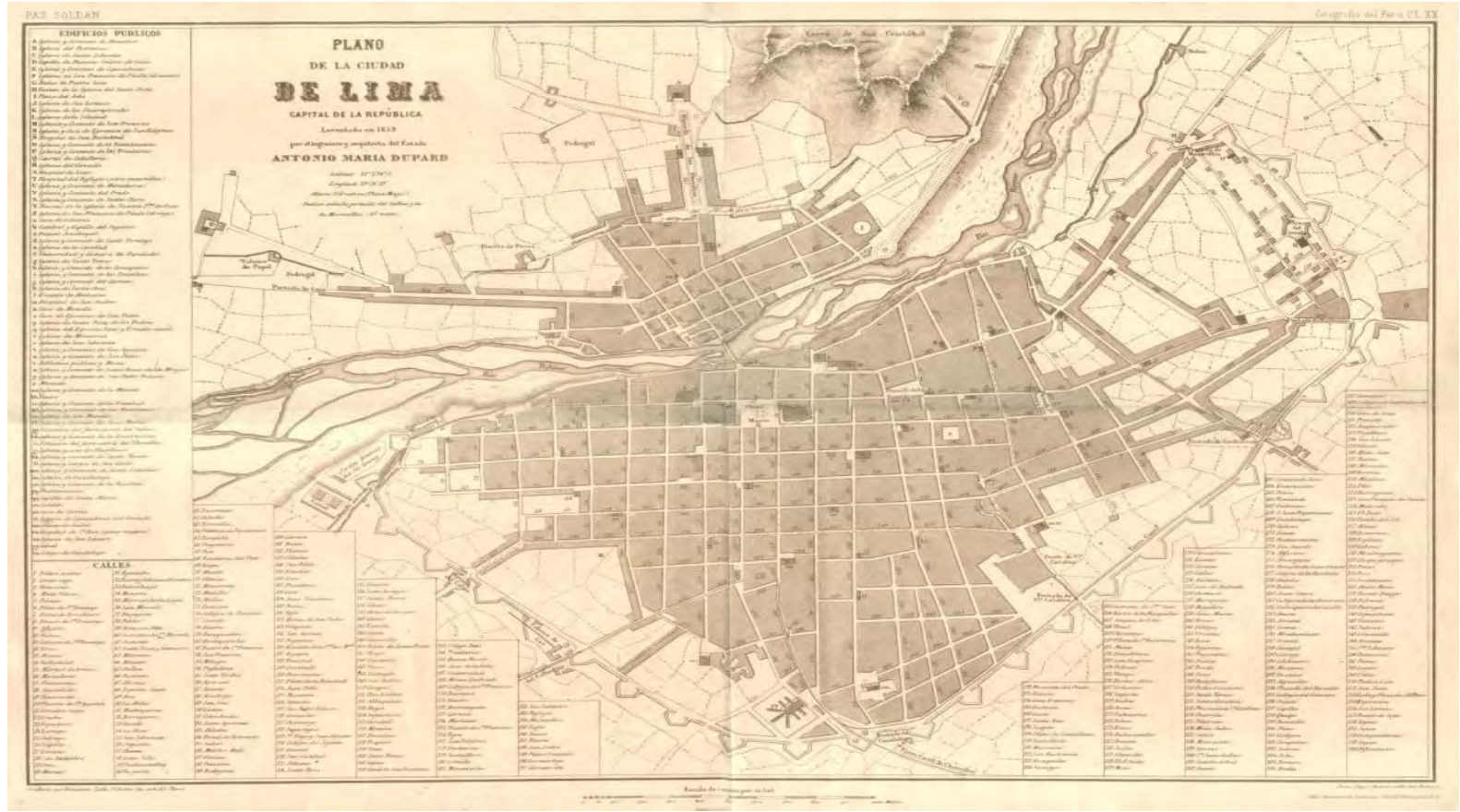

Fuente: Gunther, J. (1983).

Estos dos instrumentos permitieron a los gobiernos en turno planificar mejor el desarrollo urbano, el crecimiento a futuro de la ciudad y planificar proyectos dirigidos a un determinado barrio y distrito. En este documento observamos los primeros intentos de zoning para la ciudad.

Para el año 1862 el plano elaborado por Mariano Bolognesi nos daba un panorama de la materialización de la modernidad en la ciudad durante los dos periodos de gobierno del presidente Ramón Castilla. Para ese entonces, aun la ciudad se encontraba dividida en cinco cuarteles y diez distritos. La Plaza Mayor (Dupard,1859) era denominada Plaza de la Independencia (Bolognesi, 1862). La Plaza de la Inquisición (Dupard,1859) cerca a la Plaza Mayor también conocida como Plaza de Bolívar (Bolognesi,1862). El equipamiento que aparece en el plano fue: el Hospital de Santa Ana y la Escuela de Medicina en el distrito sexto del cuartel cuarto. La Penitenciaria y los colegios San Carlos y Guadalupe en el distrito siete del cuartel cuarto. El Cuartel de Artillería en el cuartel segundo, cerca de la muralla. El Edificio de Diputados cerca de la Plaza 
Bolívar o San Francisco en el cuartel segundo. El único puente que cruzaba el río Rímac llamado de Piedra. El edificio de la Municipalidad, el Teatro Segura, el Tribunal del Consulado y la Oficina de Correos cerca al centro (Bolognesi, 1862). La ciudad se había transformado en este segundo periodo y se había materializado el poder de la nueva república en la ciudad.

\section{Plano 2.5}

\section{Plano de Lima elaborado por Mariano Bolognesi el año 1862}

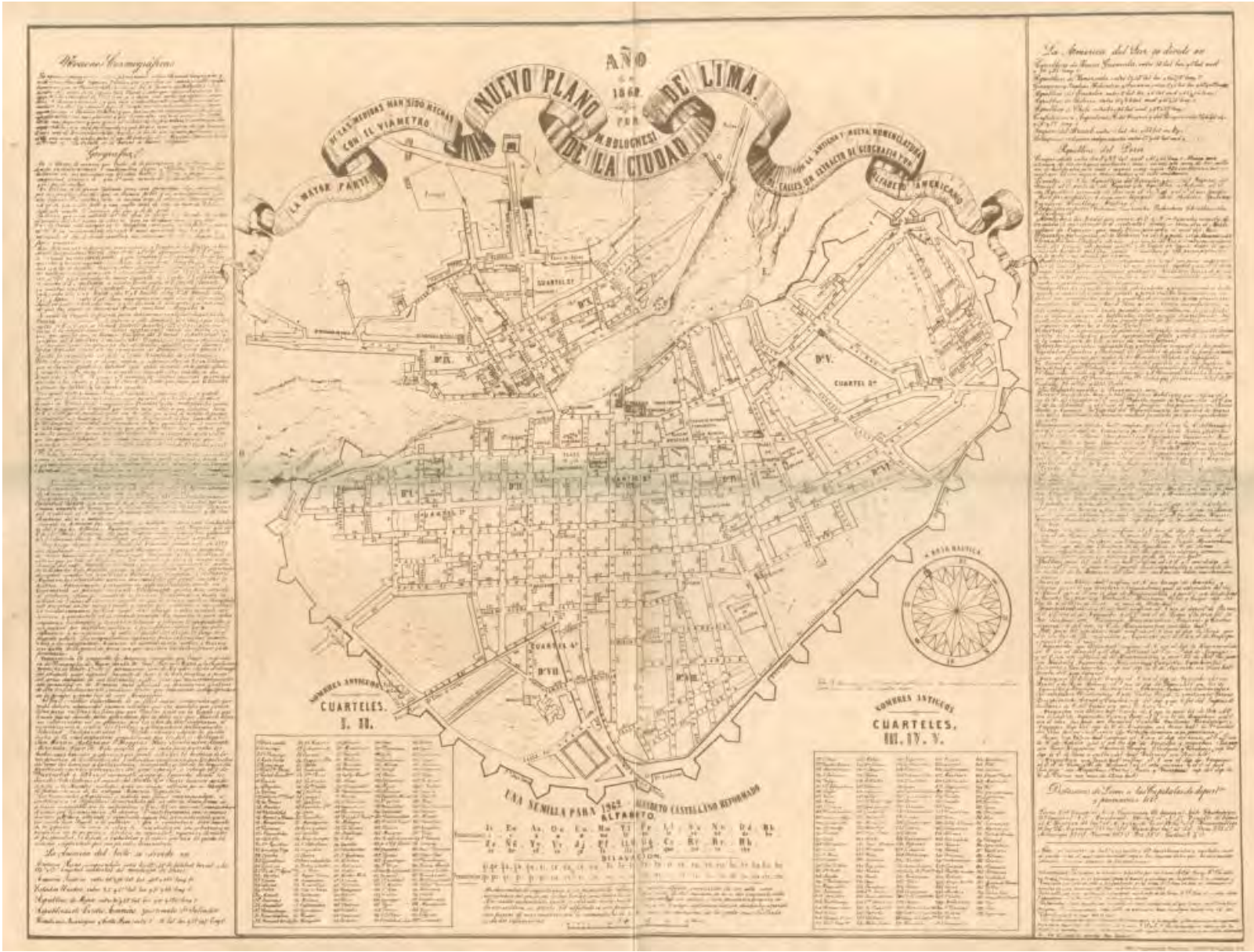

Fuente: Gunther, J. (1983)

El año 1863, en la presidencia del general José Antonio de Pezet, las obras públicas que se venían ejecutando fueron culminadas. Durante este periodo la agenda del gobierno sirvió para satisfacer a los grupos de los industriales ${ }^{50}$ que

\footnotetext{
50 Según Basadre "para 1864 existían en Lima las siguientes industrias: las fábricas de papel y seda; la fábrica de tejidos y algodón de Cagigago y Casanova (esta última duró de 1848 a 1852). La empresa más basta llegó a ser la de Carlos López Aldana que reabrió fábricas anteriormente mencionadas en Vitarte, la fábrica de galletas y chocolates de Álvaro Field, la de cigarros puros de Antonio Pouchan, la de mosaicos de Pedro Rosello, la fábrica de cerveza de
} 
aportaban al progreso del país, a la élite y clase política pero los malos manejos de dinero público y las desigualdades en la distribución de la obra pública en la ciudad generaron un descontento en la población que buscó un cambio.

El año 1866 asumió la presidencia don Mariano Ignacio Prado cuyo gobierno tuvo rasgos dictatoriales. El principal objetivo de este corto periodo de gobierno fue introducir a la ciudad al sistema financiero y mejorar la administración de la ciudad. Fue así que se implementó un nuevo Reglamento de Municipalidades (Diario El Comercio, 1866 á, 18 enero:1-7) y un nuevo Reglamento de Policía promulgado el 20 de marzo de 1866 (Diario El Comercio, 1866 á,21 junio:1-6). Para ese entonces, la obra pública estaba a cargo del Ministerio de Gobierno Policía y Obra Pública (Diario oficial El Peruano, 1867 á, 29 agosto: 51) que solo culminaron las obras que se venían ejecutando. Sin embargo, estos cambios en la reglamentación solo perjudicaron la administración de la ciudad causando desorden y retrasos en la ejecución de las obras.

Un aporte de este gobierno a la ciudad fue el primer intento de introducir el sistema financiero con el objetivo de aumentar las inversiones y permitir las hipotecas de los fundos rústicos urbanos con la creación del Banco Territorial Hipotecario el 31 de mayo de 1866 (García Calderón, 1868:2-3). Para el jurista Francisco García Calderón ${ }^{51}$ de tendencia ultra liberal, la creación de esta institución, significó la puesta en práctica de la libertad económica.

"Como abogado experto y confiable en bancos hipotecarios que se habían fundado por primera vez en el Perú hacia 1866, García Calderón elaboró un estudio de la incipiente normativa hipotecaria, con el título de Estudios sobre los Banco de Crédito Hipotecario y las leyes de Hipotecas (García Calderón,1868). El trabajo había sido pensado como un documento de consulta útil para los directores del Banco de Crédito Hipotecario del Perú acerca del banco y otras cuestiones jurídico-económicas acerca de las operaciones de la institución financiera,

Gustavo Sprinckmoller, la Internacional Smith y Cía. y la Nacional A Kieffer establecida en 1863. La fábrica del Águila de fundidores de bronce y especialistas en construcción y importación de maquinas para haciendas y minas, Ludovico Isola para obras de mármoles, la de manteca de Aparicio hermanos, y la de vapor para elaborar chocolate de Vignolo y Compañía y la fábrica de chocolates "El Tigre" de Rabetino. Fábricas de jabón, aceite, hielo y cristales “. "Introducción a las fuentes documentales para la historia de la republica del Perú con algunas reflexiones" 1971,Ed.P.L.V, Lima, pp.411-412

51 Según Mc Evoy “Francisco García Calderón Nació en Arequipa en 1834. Como abogado, patrocino a las casas comerciales, bancarias y financieras más encumbradas de su época. Fue consultor legal del Banco del Perú y del Banco de la Providencia, que fundó el magnate de los ferrocarriles Henry Meiggs y asesoro a los acaudalados consignatarios de guano, como Shutte y Witt. El año 1875 fue nombrado decano del Colegio de Abogados de Lima. Su principal obra fue Diccionario de la Legislación Peruana"."La experiencia burguesa en el Perú 1846-1946" Ed. Textos coloniales, Lima, 2004.pp.107-108. 
entre las que se halla la más importante de todas, la hipoteca inmobiliaria " (Mc Evoy:2004,129141).

Sin embargo, este trabajo, que no pudo ser implementado, constituye un intento de introducir el sistema hipotecario en la ciudad en un momento que hubiera permitido mayores inversiones a cargo de los industriales extranjeros.

Al final de este periodo la ciudad se había modernizado pero el beneficio no había sido para todos. La población reclamaba un cambio, la mejor utilización del recurso guano y la disminución de la burocracia en la administración de la ciudad. No obstante, los constantes cambios en la reglamentación en el afán de los gobiernos en turno por establecer una forma propia de gestionar la ciudad habían perjudicado el desarrollo y la administración de la ciudad que aun se encontraba a cargo de la Intendencia de Policía, la Municipalidad, la Prefectura y las Juntas Departamentales que compartían la gestión y administración de la ciudad. En este contexto, se hacía necesario que los próximos gobiernos pusieran en práctica la autonomía administrativa y reafirmaran a la Municipalidad como la principal institución de gestión de la ciudad, para de esa manera, hacer más eficiente la administración de los recursos destinados a obras públicas.

\subsubsection{La labor de los higienistas (1845-1868).}

A mediados del siglo XIX Lima tenía problemas de insalubridad a pesar de la ambiciosa reglamentación de orden e higiene que los gobiernos de este periodo habían implementado como parte del Reglamento de Policía de 1866 elaborado por J.M. Quimper (Quimper, 1866).

\footnotetext{
"Las inmundicias eran arrojadas a las calles, a las acequias y al río Rímac desde los mercados, "las partes más sucias de la ciudad, instalados en las principales plazas, como la Plaza Mayor y la Plaza de la Inquisición, o en el atrio de San Francisco; igualmente desde los mataderos, curtiembres, fondas y pulperías; también arrojaban desperdicios los numerosos vendedores ambulantes que recorrían a diario toda la ciudad; e incluso los vecinos que "desde puertas, ventanas y tragaluces", formando una cascada de inmundicias de toda clase". En las orillas del río Rímac y las portadas de Martinete y el Tajamar y, en general, alrededor de las murallas que rodeaban la ciudad fue donde se formaron los mayores basurales "(Lossio, 2001:142- 143).
} 
Así también, la contaminación del agua por falta de canalización de las acequias de la ciudad y las malas condiciones en las que vivían las familias al interior de las casas habitación hacia que las enfermedades se expandieran con mayor facilidad.

Ante este panorama de insalubridad en la ciudad los médicos de la Facultad de Medicina de la Universidad Mayor de San Marcos fundada el 9 de septiembre de 1856 (Basadre, 2014, tomoVI:128) decidieron iniciar la publicación de La Gaceta Médica de Lima entre los años de 1856 a 1858 para analizar esta problemática y proponer soluciones. Esa fue la segunda generación de higienistas preocupados por los problemas de la ciudad. De esta manera, los médicos Agustín de la Rosa Toro, Cayetano Heredia, Mariano Arosemena Quesada, José Casimiro Ulloa y Manuel Asencio Segura tuvieron la oportunidad de dar a conocer la ciencia de la salud pública, educar a los pobladores en hábitos de higiene, exhortarlos a cumplir la reglamentación existente y analizar los problemas de salubridad en la ciudad.

Unos de los problemas que les preocupaba era la limpieza en las calles y la salubridad en los espacios públicos. Ellos veían como los pobladores de Lima botaban la basura en los lugares no establecidos y echaban agua sucia a la vía pública desde sus casas (Lossio,2001:142-143) a pesar de la existencia de una reglamentación. Ante esta situación, el médico Agustín de la Rosa Toro dio a conocer los beneficios de la higiene pública a la población en un artículo titulado "La importancia de la higiene pública" (1856). Pensaba que era necesario educar a la población antes que elaborar reglamentos. En el artículo decía:

"La grandísima influencia que ejerce la higiénica pública sobre la salubridad de las poblaciones y la multitud de elementos de bienestar y desarrollo, que la aplicación de sus principios engendra en el seno de las sociedades, no puede verse sin asombro la indiferencia que con hasta aquí ha sido mirada por nosotros esta ciencia, y la ignorancia absoluta aun de sus más sencillos principios, en que viven nuestras masas sino también nuestras autoridades encargadas de dirigirlas. El ánimo se abate al contemplar el estado de miseria y abandono que se encuentran nuestros pueblos; el mayor de todos ellos el más civilizado, el más poderoso y el más civilizado de la familia peruana, considerando desde el punto de vista higiénico no es más que una cloaca donde fermentan todos los agentes de las enfermedades y la muerte "(De la Rosa Toro, 1856:11). 
La higiene pública, se convertía en un instrumento para que la ciudad mejorara su calidad de vida. Había que educar a la población en hábitos de higiene y así alcanzar el progreso y la modernidad. Fue así como el discurso de los médicos influenció la nueva Ley Orgánica de Municipalidades del año 1857 donde se estableció que la Municipalidad se ocuparía de mejorar las condiciones de salubridad (Castilla, 1857:8-15), de esta manera, el gobierno local asumió esta función en la ciudad.

A partir de entonces, gracias a las publicaciones en la revista La Gaceta Médica. El médico no solo era visto como un profesional de la salud, sino también, como el científico y intelectual capaz de recomendar y analizar los problemas urbanos (Sánchez, 1857:01-02). Este fue un momento de transición entre el rol que cumplió el protomédico colonial y el rol que cumplía el profesional de la medicina en la sociedad de ese momento, que a pesar de la labor de la primera generación de higienistas, aun no había logrado consolidar su rol en la población.

Por esos años, un higienista particular como don Manuel Atanasio Fuentes también observó que la difusión de la ciencia de la salud era importante para evitar la propagación de las enfermedades y para que la población pudiera detectar los problemas de la salud sin necesidad de recurrir a un médico. Fue por esta razón, que publicó el manual de bolsillo "Elementos de Higiene Privada, Extracto de diversos autores" (Fuentes, 1859:1-4) donde se describe los principales síntomas de las enfermedades, los cuidados que se debía tener en casa con la higiene de la habitación y conocimientos básicos de anatomía.

Los médicos de esta generación además de difundir la ciencia de la salud en la población se pronunciaron a favor y en contra de las acciones de la Municipalidad y del Estado Peruano en los espacios públicos de la ciudad, convirtiéndose en los principales defensores de las mejoras de la infraestructura básica en la ciudad. Por ejemplo en el artículo titulado "El alumbrado por gas" "escrito por el médico Francisco Rosas, se advirtió sobre la necesidad que el alumbrado a gas solo fuera para uso público" (Rosas, 1858:08-09) evitando así muertes en la población por el mal uso de esta 
tecnología al interior de las casas y recomendando a la Municipalidad la prohibición de la distribución de gas para uso doméstico.

"Otro problema que observó don Manuel Atanasio Fuentes en la ciudad fueron los problemas de la contaminación que provocaba el río Rímac en los barrios cercanos y el centro de la ciudad debido a que las personas arrojaban la basura en las riberas, las cuales seguían siendo utilizadas como el basurero de la ciudad ante la vista de la Municipalidad. Por esta razón, reclamó una mayor intervención de las autoridades para rescatar este espacio para la ciudad canalizando el río y de esa manera ganar terrenos para la ciudad que serian utilizados para las construcciones de vivienda de manera privada" (Fuentes, 1858:71-72). "Esta idea nos muestra el interés por ampliar el área urbanizable cerca al centro de la ciudad para ofertar lotes de terrenos para vivienda y de esa manera mejorar la calidad de vida de la población de estas zonas cercanas al río Rímac. Acerca de este problema, los médicos de la universidad de San Marcos, tenían otra visión acerca de este espacio de la ciudad, pensaban que era necesario, intervenir el río Rímac para volverlo navegable y ser utilizado como un espacio de recreación cerca de la ciudad" (Arosemena, 1857:11-12). Ambas propuestas hubieran mejorado la salubridad y la calidad de vida de la ciudad desde distintas perspectivas.

"Los médicos de esta generación también se pronunciaron respecto a la calidad de los servicios básicos y analizaron los problemas de salubridad por falta de una red de agua que provocaba la contaminación y era la principal causante de enfermedades como la fiebre amarilla, tifus y viruela". (Arosemena,1856:10-11). Al respecto, los médicos analizaron este problema y propusieron soluciones a la Municipalidad. En el artículo titulado "Una ojeada al estado higiénico de Lima" "el médico Francisco Rosas propuso cubrir las acequias de la ciudad a la Municipalidad y evaluó la propuesta del señor Basagoitia para proporcionar agua potable a la población" (Rosas, 1857:19-20).

En este caso, el médico Rosas recomendó que "era necesario el uso de la red de agua para llevarla a los domicilios y prescindir del recojo de agua de las piletas públicas y de servicio de los aguadores cuyo uso estaba reglamentado en el Art 192 del Reglamento de Policía del año 1866" (Quimper, 1866:29). 
"Según este profesional, el servicio debía modernizarse y quedar en manos privadas para mejorar la calidad del servicio. En el caso del alcantarillado, el análisis del médico Arosemena mostró el mal estado de las acequias y la necesidad de canalizarlas"_en un artículo titulado "La autoridad ilustrada por la ciencia- Artículo III las Aguas" (Revista La Gaceta Médica de Lima á 8 noviembre, 1856:11-12). La canalización de las acequias era una obra que requería una gran inversión y solo era posible a partir del aporte de los vecinos o de la empresa privada, fue por esta razón, que siguió en espera unos años más. Sin embargo este estudio permitió que la población y la Municipalidad se pusieran de acuerdo para lograr canalizar las acequias de la ciudad de manera conjunta.

Los estudios publicados por los médicos en la revista La Gaceta Médica, aportaron a una mejor administración de los servicios básicos de la ciudad y sirvieron para que la Municipalidad decidiera entregar estos a las empresas privadas para mejorar el servicio. Por ejemplo, la Municipalidad firmó el contrato para suministrar agua a domicilio el 29 de octubre de 1856 con el señor Francisco Basagoitia (Basadre: 2014, tomoVI: 78). Con la mejora de los servicios se controlaron mejor las enfermedades por contaminación y la ciudad se modernizó.

Ante los buenos resultados obtenidos en la administración de los servicios por las empresas privadas gracias a los estudios de los médicos, la Municipalidad decidió el año 1869 crear La Junta de Sanidad que estaría compuesta por el prefecto, varios médicos, algunas personas notables dedicadas a ver los temas de salubridad e higiene de la ciudad (Fuentes,1869:334-335). El rol que cumplió esta institución fue supervisar las obras de infraestructura y reportar los problemas de insalubridad en la ciudad mediante los denominados informes administrativos (Fuentes,1869:335) aportando a la mejora de la calidad de la ciudad, la detección de las enfermedades en lugares específicos de la ciudad como manzanas, barrios y distritos. A partir de entonces, el tema de la salubridad de la ciudad era discutido por todos los sectores de la sociedad, los intelectuales y los médicos que intercambiaron experiencias, brindaron sus conocimientos para solucionar los problemas de la ciudad con un presupuesto destinado a solucionar estos problemas por parte de la Municipalidad. 
En este periodo los médicos al igual que en el caso de México impulsaron proyectos urbanos ${ }^{52}$ y la mejora en la implementación de los servicios básicos en la ciudad y con ello buscaron mejorar las condiciones de la ciudad en el centro y la periferia (Sánchez, 2013:253). De esta manera, contribuyeron con el proceso de modernización a partir de propuestas en el espacio público que fue una forma de modernización (Gorelik,2003:17). En el caso de Lima, las propuestas de los higienistas tuvieron un efecto en la reglamentación que venía elaborando el Estado. Al organizar la Junta de Sanidad formaron parte del gobierno local compartiendo roles de gestión y de esta manera el papel de los higienistas en la ciudad se institucionalizó.

De 1845 a 1868 la ciudad se había transformado en el afán de los gobiernos de turno por modernizarla, teniendo como antecedente el discurso ilustrado peruano que buscaba introducir a la ciudad a una economía mercantilista y un discurso higiénico institucionalizado que buscaba las mejoras para la población. La ciudad se había transformado pero el progreso con el dinero del guano no había beneficiado a toda la población, solo a los grupos vinculados con el poder. Las casas de vecindad a pesar de los esfuerzos y recomendaciones de los higienistas y de la Junta de Sanidad tenían problemas de salubridad.

\subsubsection{La utopía de la modernización. Lima: un laboratorio urbano de obras de envergadura (1869-1876)}

Durante este periodo se produjo otro intento modernizador en la ciudad, pero a diferencia del anterior, estuvo a cargo de los gobiernos civilistas ${ }^{53}$ que realizaron obras públicas ${ }^{54}$ de envergadura, transformando la periferia y

\footnotetext{
52 Según Sánchez "la visión de algunos profesionales que impulsaban los proyectos buscando gestar nuevas condiciones en la ciudad se apegaban a las políticas estatales y hasta empresarios, pese a ello, estos en su momento denominados o auto denominados "higienistas" clamaban por perspectivas de conjunto en los arreglos de la ciudad, la agrupación de tareas de diversas oficinas públicas y la vinculación de las obras para de ese modo "cotrarrestar las terribles plagas que acometían a los habitantes de las ciudades"; entonces por sus aportes a la atención de las ciudades y por los sustentos utilizados de una disciplina que germinaba, debe otorgárseles el carácter de precursores del urbanismo de México. En:"Precursores del urbanismo en México" Ed. Trillas 2013, México. pp.253.

53 Según Basadre "Torres Paz llamo oligarquía a la clase social con dinero a una clase social con dinero ganado sobre todo con el negocio del guano cuyo auge constataba con el abatimiento y la degradación del pueblo y que pretendía elevarse políticamente sobre la ruinas del detestable caudillaje militar, los enemigos del partido civil acuñaron otra frase "argolla "."Introducción a las bases documentales de la historia del Perú con algunas reflexiones", Lima, 1971, Ed. P.V.L, pp. 403-407.

${ }^{54}$ Según Conolly "La presencia de obras de construcción grandes y chicas, es quizás el indicador más inmediato del grado de desarrollo de un lugar. Las grandes civilizaciones antiguas se conocen por sus monumentos. Las construcciones visibles, además de cumplir con construcciones concretas, siempre proyectan valores simbólicos. La
} 
mostrando hasta qué punto se estaba materializando la modernización urbana en la ciudad. (Conolly,1997:21). Así también, el ejercicio político del gobierno de ejecutarlas formó parte de una modernización política (Conolly,1997:22). Sin embargo, debido a que no se realizaron estudios previos sobre el proceso de ejecución y el presupuesto requerido por el Estado Peruano, estos ofrecimientos políticos a la población se convirtieron en pruebas de experimentación que convirtieron a la ciudad en un laboratorio urbano de 1868 a 1876. Al final de este periodo, muchas obras no se realizaron y otras no fueron culminadas, fue por esta razón, que la materialización de la modernización de la ciudad se convirtió en una utopía.

Al iniciar este periodo, la ciudad seguía dividida en cinco cuarteles y diez distritos y existían siete parroquias en la ciudad (Jouanny, 1872). Hacia el sur en el distrito octavo parte del trazado de la urbanización "La Chacrita" sería reutilizado como parte del Plan de Ensanche. Hacía el este, cerca a las portadas del Callao y Monserrate existían huertas y terrenos cercanos a las murallas que aun no se habían urbanizado. El ferrocarril del sur Lima-Chorrillos ingresaba por la portada de Guadalupe y el ferrocarril Lima-La Magdalena ingresaba por la portada de San Jacinto (Jouanny, 1872). Cerca de ambas estaciones se generó una actividad comercial que provocó urbanización espontanea. La población proyectada por don Mariano Felipe Paz Soldán para el año 1877 era de 89,434 habitantes (Paz Soldán, 1877:512) que significó que la población en la ciudad continuaba en aumento a pesar de las enfermedades y que la concentración poblacional en el centro continuaba.

obras cultas las entrañas y los subterráneos o lejanos son también parámetros de modernidad" En: El contratista Don Porfirio obras públicas, deuda y desarrollo desigual” Ed. Fondo de Cultura Económica. México, 1997, pp.21-22. 


\section{Plano 2.6 Plano de Lima por .P. V Jouanny 1872}

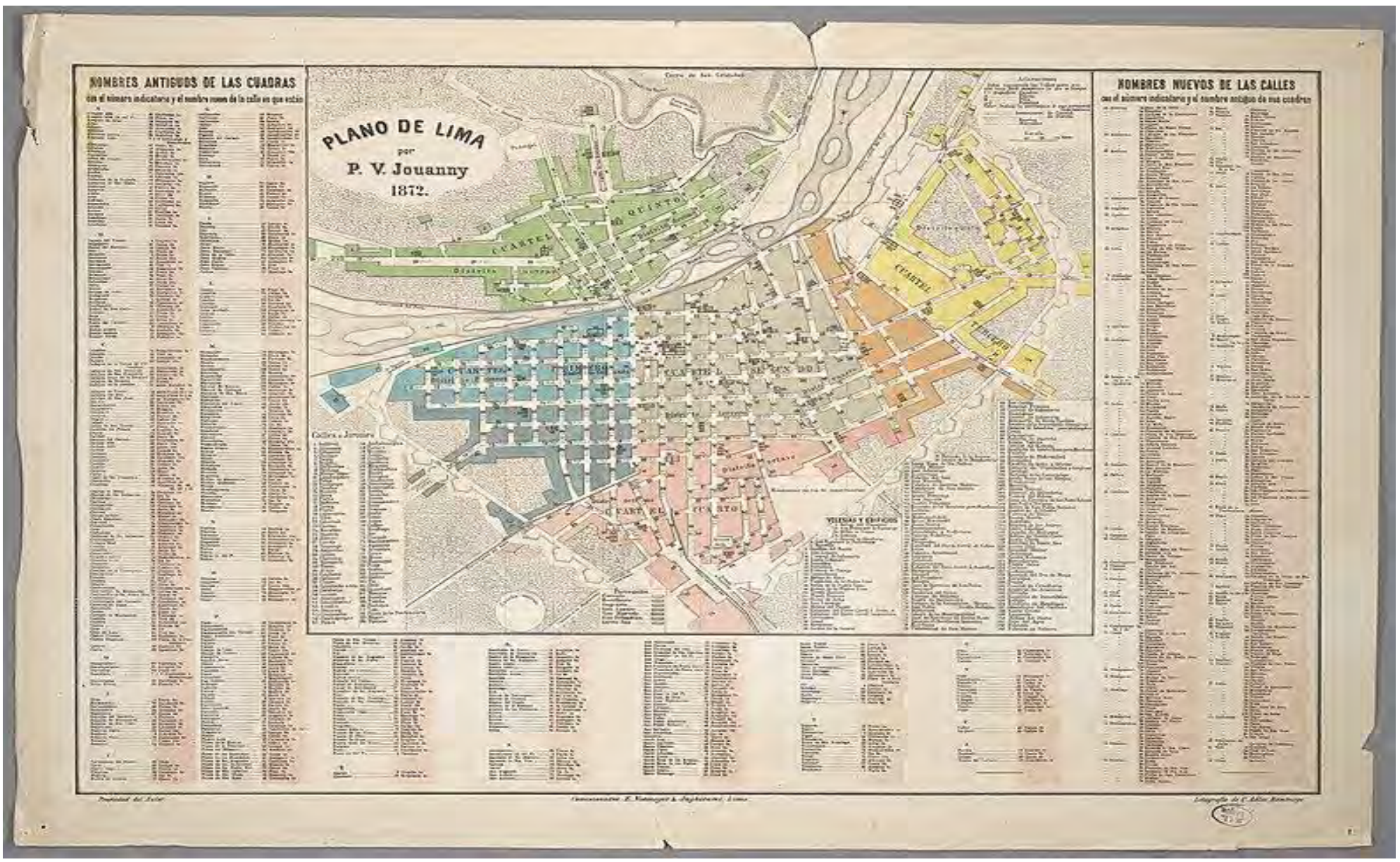

Fuente: Plano de Lima por P.V Jouanny (1872)

https://www.google.com.pe/search?q=Plano+de+Lima+Jouany+1872\&tbm=isch\&ved=2ahUKEwixyYaG0-inAhUInaOKHfQwAGgQ2-

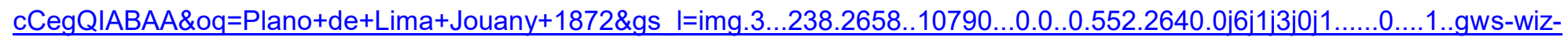
img.xyrTYD9SX8g\&ei=w JSXvHbBoi6tgX04YDABg\&bih=632\&biw=1280\#imgrc=-0rZRmitq-vgSM 
Durante estos años, los planes de gobierno de los presidentes en turno estuvieron orientados a mejorar las condiciones de la población y modernizar la ciudad con obras de envergadura para satisfacer la necesidad de vivienda, tener más propietarios y menos inquilinos y expandirla para permitir su crecimiento. Para lograr este objetivo, se propuso demoler la muralla de Lima. Sin embargo, en este momento, la situación financiera del Perú era desastrosa debido que el dinero del guano se había agotado, dejando un déficit presupuestal en el gobierno (Bonilla,1994:64-68). Por esta razón buscaron el apoyo de la inversión privada para lograr materializar este objetivo.

\subsubsection{El gobierno del presidente José Balta: la ejecución de obras de envergadura en medio de la crisis fiscal (1868-1872)}

Los objetivos del plan de gobierno del presidente Balta fueron, según Basadre: En lo económico este gobierno "buscó un equilibrio entre ingresos mediante una reforma del sistema aduanero y un control en los gastos destinados para la construcción de los ferrocarriles" (Basadre, 2014, tomo VI: 296). En lo social "se buscó mejorar la calidad de vida de la población mediante una oferta de viviendas en la periferia para los estratos socio-económico bajos y se implementó una red de transporte con las obras de los ferrocarriles LimaChorrillos, Lima-La Magdalena y Lima-Callao" (Basadre: 2014, tomoVII: 48) que permitieran la movilidad hacia los distintos puntos de la ciudad.

Uno de los principales problemas de este gobierno fue superar la crisis fiscal y la disminución de los ingresos por el recurso guano. Con este objetivo se implementó una serie de medidas como una contribución predial:

"El Ministro de Hacienda Don Nicolás de Piérola, reforzó el viejo sistema de impuestos, organizando el de timbres, con el fin de crear un registro de propiedad que permitiera más tarde crear un impuesto territorial. Reforzó la contribución predial y redujo el sistema tributario a un pequeño número de renglones con el fin de simplificar el cuadro y reeducar al país en el habito de tributar "(Romero, 2006:350).

Gracias a estas acciones el Estado comenzó a tener un control del territorio y de las rentas producto de los impuestos, buscando permitir una mayor cantidad de obras públicas. 
En este momento como una manera de evitar la especulación producida por la actividad del guano en la ciudad, lo que generó la proliferación de bancos con dinero barato, se establecieron bancos en Lima y su buscó el desarrollo del crédito hipotecario (Basadre, 2014, tomoVII: 84-88). Sin embargo, la obra pública era ejecutada por el Estado Peruano, fue por esa razón que se convirtió en el Supremo Gobierno aquel que decidía y ejecutaba en la ciudad dejando a la Municipalidad las obras menores, demostrando una vez más el centralismo existente en la administración de los recursos. Era un legado de los liberales que esta vez se habían convertido en el partido civilista. 


\section{Cuadro 2.4 Obras públicas durante el gobierno el presidente José Balta (1869-1871)}

\begin{tabular}{|c|c|c|c|}
\hline Año & Obra & Ejecución & Fuente \\
\hline 1869 & $\begin{array}{l}\text { Construcción el puente sobre el Río } \\
\text { Rímac a cargo de Don Enrique Armero } \\
\text { contratistas de las obras siendo } \\
\text { evaluada por los ingenieros del Estado } \\
\text { Backus y Systrom por un valor de } \\
\text { trecientosmil soles (Puente Balta) }\end{array}$ & Contratista & $\begin{array}{c}\text { Diario oficial, } \\
\text { El Peruano: } 1869,217\end{array}$ \\
\hline 1869 & Construcción de un malecón & Contratista & $\begin{array}{c}\text { Diario oficial, } \\
\text { El Peruano: } 1869,217\end{array}$ \\
\hline 1869 & $\begin{array}{l}\text { Creación de una Comisión Central para } \\
\text { la organización de La Feria Internacional } \\
\text { de la Exposición a realizarse en Lima }\end{array}$ & Contratista & $\begin{array}{l}\text { Diario oficial, } \\
\text { El Peruano:1869,99 }\end{array}$ \\
\hline 1869 & $\begin{array}{c}\text { Ampliación del Jardín Botánico hacia los } \\
\text { terrenos de la huerta del Monasterio de } \\
\text { la Encarnación con este motivo se } \\
\text { ensancho la calle Huanta hasta la } \\
\text { muralla }\end{array}$ & Contratista & $\begin{array}{c}\text { Diario oficial, } \\
\text { El Peruano: } 1869,136\end{array}$ \\
\hline 1869 & $\begin{array}{l}\text { Inicio de los trabajos de canalización de } \\
\text { las acequias de ciudad, con el aporte de } \\
\text { los vecinos de diez soles por vara lineal } \\
\text { frente a cada propiedad }\end{array}$ & Municipalidad & $\begin{array}{c}\text { Diario oficial, } \\
\text { El Peruano: } 1869,199\end{array}$ \\
\hline $\begin{array}{l}1869- \\
1870\end{array}$ & Demolición de la muralla de Lima & Supremo Gobierno & $\begin{array}{c}\text { Diario oficial, } \\
\text { El Peruano:1869:451 }\end{array}$ \\
\hline 1871 & $\begin{array}{c}\text { Dotación de agua a las edificaciones } \\
\text { públicas por parte de la empresa de } \\
\text { agua } \\
\end{array}$ & Supremo Gobierno & $\begin{array}{c}\text { Diario oficial, } \\
\text { El Peruano, 1871:399 }\end{array}$ \\
\hline 1871 & $\begin{array}{l}\text { Construcción del Palacio de la } \\
\text { Exposición para la Exposición } \\
\text { Internacional de Lima el año } 1872\end{array}$ & Supremo Gobierno & $\begin{array}{c}\text { Diario oficial. } \\
\text { El Peruano, 1871:23-24 }\end{array}$ \\
\hline 1871 & $\begin{array}{l}\text { Mensura de los terrenos que quedaron } \\
\text { vacantes a ambos lados del río Rímac } \\
\text { como consecuencia de las líneas del } \\
\text { ferrocarril Lima-Huacho y Callao-Oroya }\end{array}$ & Supremo Gobierno & $\begin{array}{c}\text { Diario oficial } \\
\text { El Peruano, 1871:463 }\end{array}$ \\
\hline 1871 & $\begin{array}{c}\text { Venta de los terrenos de propiedad del } \\
\text { Estado cerca a la portada de Guadalupe } \\
\text { para urbanización }\end{array}$ & Supremo Gobierno & $\begin{array}{c}\text { Diario oficial } \\
\text { El Peruano, 1871:578 }\end{array}$ \\
\hline 1871 & $\begin{array}{c}\text { Contrata y pago de alumbrado público } \\
\text { de Lima a la empresa de Don Ricardo } \\
\text { Martí }\end{array}$ & Municipalidad & $\begin{array}{c}\text { Diario oficial } \\
\text { El Peruano, 1871: } 229 .\end{array}$ \\
\hline
\end{tabular}

Fuente: Elaboración propia en base a: Diario oficial El Peruano (1869), (1871) 
Como vemos en el cuadro 2.4 en este periodo el Supremo Gobierno se encargó de las obras de envergadura y obras dirigidas a mejorar espacios de la ciudad que requerían de infraestructura y la Municipalidad se encargó de obras menores como la canalización de acequias con el apoyo económico de los vecinos (Diario oficial El Peruano, 1869 á, 12 abril,233). El intento de fortalecer la Municipalidad con una mejor recaudación predial no era utilizado en esta gestión debido a la intervención directa del Estado que convirtió a la Municipalidad en la administradora de la ciudad.

\subsubsection{El discurso de demolición de la muralla de Lima (1869-}

\section{7)}

La decisión política del presidente José Balta para demoler la muralla se sustenta en razones sociales, políticas, económicas, salubridad y crecimiento urbano que reflejan las ideas de progreso y modernidad vigentes en ese momento en la ciudad. Además, las experiencias de ensanche en otros países habían llegado a la ciudad por medio de los diarios e influenciado en la decisión del gobierno de turno. En un documento publicado el 01 de diciembre de 1869 el presidente dio una justificación ante el país de por qué era necesaria la demolición de la muralla, señalando seis razones y nueve incisos (Diario oficial El Peruano, 1869, á 02 diciembre:451). En este documento el Estado Peruano trató de justificar la demolición de la muralla de Lima. Este hecho constituye un precedente urbanístico para la futura expansión de la ciudad y establece su papel ante la búsqueda de la materialización de la modernidad.

"Primera razón. - Que el subido precio de los arrendamientos que en la actualidad se exige por los fundos urbanos ubicados en esta capital, coloca a una porción considerable de sus habitantes, en la dificultad de poderse proporcionar la localidad que necesitan, por una módica pensión conductiva "(El Peruano,1869 á:02 de diciembre, 451).

Esta primera razón estaba sustentada en el alto precio de los alquileres de las viviendas debido a la concentración en el núcleo central. Este problema decía el documento, afectaba a "una porción" considerable de sus habitantes. Puede además inferirse que el Estado Peruano trató que la ciudad tuviera más propietarios y menos inquilinos, motivo por el cual, los terrenos ocupados por la muralla serían ofertados para la venta de lotes con precios asequibles. Aunque 
en ese momento, había terrenos disponibles cerca de la muralla según la visión del Estado estos no eran suficientes para satisfacer la demanda existente.

\begin{abstract}
"Segunda razón. -Que la constante tendencia al alza del arrendamiento de dichos fundos, proviene entre dos causas de la necesidad que se encuentra la población de vivir concentrada en el reducido espacio al interior de las murallas, que impide la construcción de nuevos edificios y el ensanche al que esta llamada la capital "(Diario oficial El Peruano, 1869 á:02 de diciembre, 451).
\end{abstract}

Esta razón fue sustentada ante la realidad principalmente del aumento poblacional. La ciudad en ese momento tenía una alta concentración poblacional en el núcleo central, debido que se requería en lugar de la muralla construir nuevos edificios. Así también muestra la visión del gobierno de turno de expandir la ciudad para permitir su crecimiento como un hecho que sucedería inevitablemente por ser Lima la capital del Perú.

"Tercera razón. -Que es un deber del Gobierno remover todos los obstáculos que se opongan al desarrollo y bienestar de la capital de la República, poniendo al alcance de todos sus habitantes la satisfacción de las necesidades más importantes de la vida, en proporción a sus recursos "(Diario oficial El Peruano, 1869 á, 02 de diciembre:451).

Esta razón muestra el objetivo del Estado Peruano de arribar a la modernidad poniendo al alcance de todos sus habitantes, materializar el progreso y desarrollo satisfacer las necesidades de la población. La decisión de demoler la muralla significaba "remover obstáculos" para alcanzar el desarrollo y dejar atrás el pasado colonial. Por otro lado, muestra la jerarquía de Lima en su papel de "capital de la República" como la primera ciudad que debía ser modernizada para servir del modelo para el resto de ciudades.

"Cuarta razón. - Que habiéndose aumentado considerablemente el censo de la capital, con motivo de la inmigración extranjera y la afluencia de diferentes puntos de la República, se hace indispensable ensanchar los límites de su extensión, ya para dar comodidad a sus moradores, como para evitar que la aglomeración de ellos en los centros de la población comprometa la salubridad pública, ocasionando el desarrollo de epidemias violentas o de enfermedades endémicas "(Diario oficial El Peruano,1869 á,02 de diciembre:451).

Esta razón, justifica la demolición mediante el uso de los datos estadísticos poblacionales de la época que demuestran el crecimiento poblacional producto de la migración. Por ejemplo don Manuel Atanasio Fuentes estableció que para el año 1859 la población era de 94,195 habitantes y para 1862 la población seria de 195,167 habitantes (Fuentes, 1859:42). Otro estudio poblacional de esos años nos ofrece el ingeniero Mariano Felipe Paz Soldán en su libro “Diccionario Geográfico Estadístico del Perú" publicado el año 1877 donde 
proyectó una población de 89,434 habitantes para ese año (Paz Soldán, 1877:512). Las cifras de ambos estudios demuestran un aumento poblacional significativo que ocasionaría problemas de salubridad, tugurización y hacinamiento en las viviendas del centro corroborando la necesidad de expandir la ciudad. Por otro lado, la decisión del Estado Peruano fue apoyada por los médicos Mariano Arosemena y Casimiro Ulloa que reclamaban en sus artículos la mejora de la calidad de vida en las casas de vecindad de Lima. El crecimiento y el problema de salubridad obligaban al ensanche de la ciudad.

"Quinta razón. -Que el movimiento y el rápido adelanto que se siente en todos los ramos de la industria pública, no permiten que la capital de la República permanezca encerrada en tan reducido espacio sin que el Gobierno proporcione los medios de su acrecentamiento, consultando a la vez su ornato y embellecimiento "(Diario oficial El peruano,1869 á,02 de diciembre: 451).

Esta razón está referida a la preocupación del Estado Peruano por el desarrollo de la "industria pública" en la ciudad como uno de los principales impulsores para alcanzar el tan ansiado desarrollo y la modernidad. Si bien, los sectores más liberales de los anteriores gobiernos incentivaron a la industria desde la constitución de 1857 de manera tangible no existía una industria significativa en la ciudad como se observa en el plano del año 1859 elaborado por el ingeniero José María Dupard.

\footnotetext{
"Sexta razón.-Que para lograr este propósito conviene destruir las murallas que circundan la ciudad, las cuales se hallan en estado ruinoso, y cuya existencia carece de objetivo, desde que han desaparecido las causas que tuvo en la mira el Gobierno español, para construir los baluartes, convertidos en la actualidad, en focos infección de desagradable aspecto, notablemente dañosos a la salubridad pública y que dificulta la aprehensión de los malhechores "(Diario oficial El Peruano,1869 á,02 de diciembre:451).
}

Desde el año 1860 los informes de la Municipalidad de Lima describían una muralla deteriorada y derrumbes en muchos tramos que permitían el acceso de los malhechores por las noches (Municipalidad de Lima, 1860). De igual manera, las inundaciones de las acequias pertenecientes a las huertas cercanas afectaban a la muralla. Los médicos de la Facultad de Medicina de la universidad San Marcos veían la muralla como un elemento que iba en contra de la salubridad de la ciudad por encontrarse deteriorada que la convertía en un foco de insalubridad sobre todo en los lugares donde la población echaba basura. 
Con este discurso, el gobierno del presidente Balta buscó cumplir las expectativas de los ciudadanos de Lima en aspectos de desarrollo, mercado, libertad económica y democracia, bajo el principio de alcanzar una modernidad que en ese momento era lograr la civilización de un pueblo (Pineo,1998:155156). Ese proyecto mostró una forma de gobernar de manera conjunta con el empresariado privado debido la imposibilidad de solventar las obras de envergadura y cumplir el objetivo de satisfacer a la población que vivía en el centro con vivienda social ante la posibilidad de un desborde social debido a las desigualdades económicas. 


\section{Cuadro 2.5}

\section{Acciones ejecutadas para la demolición de la muralla}

(1868-1876)

\begin{tabular}{|c|c|c|}
\hline Año & Acciones ejecutadas & Fuente \\
\hline 1868 & $\begin{array}{l}\text { Demolición parcial para construir el Palacio de la } \\
\text { Exposición }\end{array}$ & Sifuentes,2004:230 \\
\hline 1871 & $\begin{array}{l}\text { El } 13 \text { de julio de } 1871 \text { el Supremo Gobierno dispone se } \\
\text { proceda a la enajenación con arreglo a las leyes de los } \\
\text { terrenos de las murallas de Guadalupe propiedad del } \\
\text { Estado comprendido en el plano del Ing. Sada se } \\
\text { convoca a subasta pública para demolición. }\end{array}$ & $\begin{array}{l}\text { Diario oficial } \\
\text { El Peruano, } 1871 \text { a' }^{\prime} 13 \\
\text { junio: } 578 .\end{array}$ \\
\hline 1871 & $\begin{array}{l}\text { Inicio de obras de demolición El } 24 \text { de noviembre de } \\
1871 \text { se publicó el resultado del remate de los terrenos } \\
\text { ocupados por la muralla de Lima ante la Junta de } \\
\text { Almoneda resultando el único postor y ganador del } \\
\text { remate el fraccionador Enrique Meiggs por la cantidad } \\
\text { de } 210,990 \text { soles con } 16 \text { centavos que era los dos } \\
\text { tercios del precio tasado por los terrenos ocupados por } \\
\text { la muralla. Firmado el contrato entre el Estado y el } \\
\text { ganador de la subasta se procedió a entregar la } \\
\text { escritura de compra-venta de los terrenos ocupados por } \\
\text { la muralla. }\end{array}$ & $\begin{array}{l}\text { Diario oficial } \\
\text { El Peruano, } 1872 \text { á } 20 \\
\text { agosto::65. }\end{array}$ \\
\hline $\begin{array}{l}1871- \\
1876\end{array}$ & $\begin{array}{l}\text { Continúa el proceso de demolición de la muralla a } \\
\text { medida que se ejecutaba el Plan de Ensanche a cargo } \\
\text { del fraccionador Enrique Meiggs. }\end{array}$ & $\begin{array}{c}\text { Diario oficial } \\
\text { El Peruano,1871: } 390\end{array}$ \\
\hline
\end{tabular}

Fuente: Elaboración propia en base a Diario oficial El Peruano (1871, pp.390, 578), (1871, pp.390).

En el cuadro 2.5 muestra como el Estado Peruano realizó demoliciones parciales. En primer lugar para la construcción del Palacio de la Exposición obra a cargo del fraccionador Enrique Meiggs (Pineo,1998:154). En segundo lugar, vender terrenos de la portada de Guadalupe para iniciar la demolición. Sin embargo, debido a la falta de recursos económicos el Estado Peruano 
realizó un cambio de planes subastando los terrenos de la muralla para que el ganador continuara con la demolición y El Consejo de Ministros avaló al ejecutivo para que los terrenos fueran rematados ante la Junta de Almoneda en treinta días (Diario oficial El Peruano á, 1871, 4 octubre:389).

\begin{abstract}
"Teniendo en consideración que los bienes nacionales deben enajenarse en remate público: que son muy crecidos los gastos de alineación y nivelación de las calles que han de formarse en los terrenos de las antiguas murallas y sus adyacentes que el Gobierno no se halla autorizado para ese desembolso extraordinario, ni para que los que exijan las demás obras precisas para dejar expeditas dichas calles y consultar la salubridad, comodidad y ornato de la nueva población: que la cesión de aquellos terrenos hecha indistintamente a cuantos los soliciten, sin más condición que el pago de los lotes que en el reconocimiento de un censo no asegura ni el reembolso de aquellos grandes valores, ni que los edificios se construyan en número suficiente, para que los individuos y familias obtengan el beneficio de habitación barata único fin del Gobierno se ha propuesto enajenar esos terrenos (Diario oficial El Peruano á, 1871, 4 octubre:389)."
\end{abstract}

Esta decisión tuvo las siguientes consecuencias: la periferia ingresó a un mercado de suelo de monopolio, la urbanización de la periferia a partir de entonces se realizó con fondos privados bajo la vigilancia de la Municipalidad y el proyecto de intereses social se convirtió en un proyecto inmobiliario privado.

Para finales del siglo XIX, el proceso especulativo inmobiliario no era un delito, era considerado una práctica digna como cualquier otra. "Especular era comprar a diez y vender a cien, en el mejor tiempo posible o incorporándole muy poco esfuerzo o mejorar el bien" (Longino,2003:07) ${ }^{55}$. En este entender, la práctica especulativa de Meiggs buscó activar la economía en un momento en el que el Estado Peruano se encontraba en una bancarrota fiscal. Esta práctica de urbanizar la periferia dejó un precedente para los próximos urbanizadores que decidieron invertir en la periferia y en otras áreas de la ciudad. Se compraron terrenos rurales a precio de expropiación y estos fueron incorporados a la ciudad aun mayor precio, obteniendo así, una mayor ganancia que sí se tratará de un terreno rural.

Este proceso de mercantilización del suelo tuvo un costo en la población que vivía en el centro en malas condiciones y era afectada por las epidemias (Pineo, 1998:158). Para activar la economía a partir de este proceso y generar

\footnotetext{
55 Longino,"Pueblos Imaginarios, la especulación urbana en la campaña bonaerense de 1870-1880" Revista Mundo Agrario Vol.3 N 6 primer semestre 2003. Universidad de La Plata. Facultad de Ciencias de la Educación. Centro de Estudios Histórico Rurales.
} 
una demanda de vivienda. El Estado Peruano impulsó la banca hipotecaria como una forma de apoyar a los empresarios privados siguiendo el espíritu de libertad económica que permitió generar préstamos para comprar propiedades y favorecer las inversiones inmobiliarias de la élite "Bajo la creencia que la propiedad aportaba el mayor beneficio económico para todos" (Fernández,2014:44) ${ }^{56}$. Con estas acciones el Estado Peruano, visualizó una activación económica con una mayor oferta de propiedad privada que fue una forma de incentivar el capitalismo local y el progreso.

Siguiendo este pensamiento, Enrique Meiggs hipotecó y compró más propiedades para capitalizarse en un futuro, dejando por un tiempo propiedades sin lotizar para vivienda, comercio o industria, lo que en términos actuales hubiera significado una "retención especulativa" (Fernández, 2014:44). Sin embargo aun con estas acciones, la periferia ingresó a un proceso de mercantilización del suelo, es decir, "una forma de producir riqueza a costa del territorio y sus habitantes" (Blanco, 2014:191) ${ }^{57}$. Pero como esto acrecentaba aun más las desigualdades en la ciudad, las élites apoyaron a la Beneficencia aumentando su capital vía Caja de Ahorros Mutuos para que los obreros y clase media pudieran adquirir una vivienda en la periferia o contar con un pequeño capital y de esta forma de favorecer al pueblo como una política mixta público-privada (Borja,2016:05) de acceder a la vivienda como una forma de subsidio a la vivienda en compra y alquiler.

El Estado peruano decidió que el empresario privado Meiggs ejecutara la obra pública más importante de Lima, dándole en recompensa por sus servicios la donación de las tierras ocupadas por la muralla mediante la figura legal del remate público. Por ejemplo en el inciso sexto del contrato, el rematista quedaba obligado a ejecutar la construcción de las alamedas, plazas así como su cuidado y arborización sin recibir una indemnización por el trabajo de estas obras por parte del Supremo Gobierno y la Municipalidad. En el inciso diez del contrato las obras de infraestructura básica serían cubiertas por el urbanizador

\footnotetext{
${ }^{56}$ Raúl E. Fernández Wagner "La construcción social de la propiedad privada en la evolución reciente del país y la región En: "La vivienda entre el derecho y la mercancía- Las formas de propiedad en América Latina", Ed. Trilce, 2014, Montevideo Uruguay.pp.1-248.

${ }^{57}$ Claudia Blanco "Vale rectificar varios siglos después" En: "La vivienda entre el derecho y la mercancía- Las formas de propiedad en América Latina", Ed. Trilce, 2014, Montevideo Uruguay.pp.1-248.
} 
privado en un plazo de noventa días para la ejecución del trazado de calles y tres años para la construcción de las casas desde la expedición de la escritura de venta del terreno (Diario oficial El Peruano, 1871 á, 7 octubre: 389-390). Con esta decisión, el Supremo Gobierno muestra la incapacidad económica para continuar asumiendo las obras de envergadura que se venían ejecutando en la ciudad y el interés porque el objetivo de modernizar la ciudad continuara a partir de la inversión privada. Convirtiendo su ofrecimiento de vivienda en la periferia en un producto de vivienda-mercancía (Borja, 2016:8) ${ }^{58}$.

El 24 de noviembre de 1871 se publicó el resultado del remate de los terrenos ocupados por la muralla de Lima ante la Junta de Almoneda quedando como único postor y ganador del remate el fraccionador Enrique Meiggs por la cantidad de 210,990 soles con 16 centavos que era los dos tercios del precio tasado por los terrenos ocupados por la muralla. Fue así que, firmado el contrato entre el Estado Peruano y el ganador de la subasta se procedió a entregar la escritura de compra-venta de los terrenos ocupados por la muralla (Diario oficial El Peruano, 1872 á 20 enero: 65). De esta manera, la periferia de Lima pasó a manos privadas y a partir de este momento se realizaron de manera paralela las obras de demolición de la muralla y la ejecución del Plan de Ensanche. La periferia pasaba a manos privadas en un hecho sin precedentes en la ciudad con el aval del Estado Peruano. En este caso, el Estado Peruano le confirió el poder de acumulación de propiedades a Meiggs con el propósito de generar riqueza y activar la economía en la ciudad. Por su parte, Meiggs, aportó ingresando al mercado de suelo de la periferia propiedades sin gravámenes, contribuyendo de esta manera con la libertad comercial de propiedades.

Para finales del año 1871 el Supremo Gobierno se encontraba realizando las rectificaciones al Plano de Ensanche que se encontraba en ejecución por el fraccionador Meiggs. Sin embargo, la acumulación de la deuda externa hizo insoportable al gobierno del presidente José Balta continuar su agenda y no pudo lograr el objetivo de aumentar la recaudación tributaria que hizo que la

\footnotetext{
58 Jordi Borja, "La vivienda popular, de la marginalidad a la ciudadanía" En: Geograficando, vol 12 n 02, 2,e009, diciembre 2016 Universidad Nacional de la Plata. Facultad de Humanidades y Ciencias de la Educación. Departamento de Geografía.
} 
población votara por el civilista Manuel Pardo para el próximo periodo dejando en proceso la ejecución de las obras de envergadura.

\subsubsection{El gobierno del presidente Manuel Pardo y la república práctica (1872-1876)}

En julio de 1872 asumió la presidencia don Manuel Pardo y La Valle. El ofreció tratar de solucionar algunos problemas de la ciudad, que reflejaban en parte lo que vivía el país. También señala al respecto:

"Las élites intelectuales peruanas fueron testigos al igual que los artesanos, de la "gangrena social", que desde mediados de la década de los cincuenta carcomía al país. El desempleo el galopante proceso inflacionario, la polarización social, la inestabilidad institucional, la vagancia, el crecimiento demográfico en medio de un desordenado proceso de urbanización y las rebeliones en provincias eran los efectos visibles, a inicios de 1870, de un modelo político y económico agotado. Este, con la finalidad de legitimarse, a más de ejercer un patronazgo desmedido, había colaborado en incorporar a las "plebes" en el diseño de la cultura electoral urbana. Lo depravado del proceso anterior, responsable de un endémico proceso inflacionario y de siete gobierno militares en la inestable década de los setenta, determinó la auto marginación de las élites económicas e intelectuales urbanas de la esfera política"(Lumbreras: 2003,380).

Se trataba de dar un orden a la administración del país y generar un progreso sostenido en base a la realidad ya sin discursos sino solucionando problemas tangibles, fue por esta razón, que a este periodo se le denominó La República Práctica con dos corrientes conservadora elitista y democrática popular (Lumbreras:2003,379).

Sus objetivos de gobierno fueron: En lo social, eliminar el alto índice de vagancia hubiera posibilitado un desborde social que hubiera llevado a una crisis del sistema (Lumbreras, 2003:381). Tratar de disminuir las desigualdades en la ciudad ofreciendo obras que beneficien a toda la población. Para ese momento, Mc Evoy describe el rostro urbano de la ciudad de la siguiente manera:

\footnotetext{
"Para la década de los setenta Lima cambiaba su rostro rápidamente. Ello se debía a que la "prosperidad falaz", generada por la consolidación y la exportación guanera, había determinado una serie de aceleradas transformaciones sociales que se manifestaron no solo en la emergencia de nuevos grupos económicos, constructores de magnificas casas de veraneo en el Chorrillos, fundadores de bancos y empresas financieras asiduas al teatro y la opera visitantes regulares del viejo continente, así como importadores y consumidores de la última moda parisién; sino que hicieron evidentes en el nuevo aumento de la población, los problemas de alojamiento, la carestía de alimentos y la aparición de conflictos sociales, la cara menos feliz de la expansión económica" (Mc Evoy,1997:79).
} 
Los empresarios y banqueros vivían con el dinero de un Estado Peruano rico, mientras que la población demandaba vivienda y tenía carestía de alimentos por falta de trabajo. En la ciudad coexistían de manera desigual pobres y ricos.

En lo político, reorganizar las instituciones del Estado Peruano para que exista un fuerte orden institucional, fue por esa razón, que los planes de gobierno en este periodo estuvieron enfocados a demostrar su poder materializado en las obras de envergadura. Esta razón llevó a que el Estado Peruano continuara con la modernización iniciada por el anterior, pero esta vez, con un fuerte componente de participantes de la sociedad civil, a diferencia del modelo del presidente Balta que tenía el apoyo del ejército. En lo económico lograr una eficiente administración del Estado para no llegar a la bancarrota fiscal.

La agenda de gobierno estaba diseñada para satisfacer las necesidades de la mayoría sin aumentar el gasto fiscal y buscando realizar los gastos únicamente necesarios. En esta oportunidad las obras públicas de envergadura estuvieron a cargo la inversión privada y las obras en los cuarteles a cargo de la Municipalidad mediante la modalidad de subasta. Debido a que las obras eran encargadas a terceros, se fijaron las reglas a las que debían sujetarse los empresarios que licitasen obras públicas con el Estado desde el punto de vista técnico (Diario oficial El Peruano, 1872 á 14 diciembre: 376-377). Estas medidas se tomaron para garantizar la calidad de las obras y un control sobre la administración de los recursos.

Uno de los aportes de su gestión fue la profesionalización de la construcción y la creación del Reglamento para el servicio de los ingenieros civiles y arquitectos del Estado según Resolución Suprema del 21 de octubre de 1872 (Diario oficial El Peruano: 1872 á, 02 noviembre: 278-281). Durante su gestión se reorganizó la Junta Central para supervisar la obra pública en ciudad compuesta por cinco ingenieros bajo la dependencia del Ministerio de Gobierno y Policía. Bajo esta modalidad de gestión se construyó el Palacio de la Exposición para la realización de la Feria Internacional de la Exposición de Lima el año 1872 (Diario oficial El Peruano, 1872 á, 6 julio: 4) que convirtió a esta edificación en el símbolo de la modernidad. A diferencia del periodo presidencial anterior, la Municipalidad se convirtió en la administradora de la 
ciudad y principal ejecutora de obra. Pero en este proceso La Junta Central realizó la función de evaluar, elaborar y supervisar los proyectos como veremos en el Cuadro 2.6. Al final de este periodo, las instituciones coloniales como la Intendencia ya no compartía funciones con la Municipalidad, esta había asumido la función de ser la gestora de la ciudad.

Al iniciar el gobierno del presidente Manuel Pardo, la Municipalidad realizó obras para mejorar los espacios públicos y calles de la ciudad e intervino en la canalización de las calles de la ciudad. Eso se hizo con dinero recaudado por los vecinos ante la imposibilidad de cubrir los gastos como una muestra de su capacidad de gestión para solucionar los problemas de la ciudad y ejecutar las obras a pesar de no tener recursos suficientes. Todas estas obras ejecutadas al interior de los diez distritos, se orientaron a modernizar Lima. 


\section{Cuadro 2.6}

\section{Obras públicas ejecutadas durante el gobierno del presidente Manuel Pardo (1872)}

\begin{tabular}{|c|c|c|c|}
\hline Año & Obra Pública & $\begin{array}{l}\text { Institución } \\
\text { ejecutora }\end{array}$ & Fuente \\
\hline 1872 & $\begin{array}{c}\text { Colocar piedras en un puente de } \\
\text { la calle Malambo }\end{array}$ & Municipalidad & $\begin{array}{c}\text { Diario oficial, El Peruano, } \\
\text { 1872: 336-339. }\end{array}$ \\
\hline 1872 & $\begin{array}{c}\text { Construcción de un banqueta y } \\
\text { empedrado de la calle Malambo y } \\
\text { en la plaza y boca calle de } \\
\text { Malambito }\end{array}$ & Municipalidad & $\begin{array}{c}\text { Diario oficial, } \\
\text { El Peruano,1872: } 336-339\end{array}$ \\
\hline 1872 & $\begin{array}{l}\text { Reparación del puente que } \\
\text { atraviesa de las calles Boza y } \\
\text { Matajudios empedrado }\end{array}$ & Municipalidad & $\begin{array}{c}\text { Diario oficial, El Peruano, } \\
\text { 1872: 336-339. }\end{array}$ \\
\hline 1872 & $\begin{array}{l}\text { Limpieza de la acequia cubierta } \\
\text { en el portal de escribanos }\end{array}$ & Municipalidad & $\begin{array}{c}\text { Diario oficial, } \\
\text { El Peruano,1872: 336- } \\
339 . \\
\end{array}$ \\
\hline 1872 & $\begin{array}{l}\text { Arboles para una alameda en } \\
\text { Malambo }\end{array}$ & Municipalidad & $\begin{array}{c}\text { Diario oficial, } \\
\text { El Peruano, 1872: 336- } \\
339 . \\
\end{array}$ \\
\hline 1872 & $\begin{array}{l}\text { Pavimento para el Mercado de la } \\
\text { Concepción }\end{array}$ & Municipalidad & $\begin{array}{c}\text { Diario oficial, } \\
\text { El Peruano, 1872: 336- } \\
\text { 339. }\end{array}$ \\
\hline 1872 & $\begin{array}{c}\text { Canalización de las calles } 6 \text { y } 7 \\
\text { de Carabaya }\end{array}$ & Municipalidad & $\begin{array}{l}\text { Diario oficial, } \\
\text { El Peruano, 1872: 336- } \\
\text { 339. }\end{array}$ \\
\hline 1872 & $\begin{array}{c}\text { Canalización de la ciudad debido } \\
\text { a que los vecinos pagaron la } \\
\text { cuota para los trabajos }\end{array}$ & Municipalidad & $\begin{array}{c}\text { Diario oficial El Peruano, } \\
\text { 1872: 339-340. }\end{array}$ \\
\hline 1872 & $\begin{array}{c}\text { Colocación de las estatua de } \\
\text { Colon frente al Palacio de la } \\
\text { Exposición }\end{array}$ & Municipalidad & $\begin{array}{c}\text { Diario oficial, } \\
\text { El Peruano, } 1872: 10\end{array}$ \\
\hline 1872 & $\begin{array}{l}\text { Ejecución del proyecto de la } \\
\text { cárcel por el Ing. Teodoro Elmore }\end{array}$ & Junta Central & $\begin{array}{c}\text { Diario oficial, El Peruano, } \\
\text { Lima sábado } 15 \text { de Junio } \\
\text { de } 1872,661 .\end{array}$ \\
\hline 1872 & $\begin{array}{l}\text { Elaboración de los planos de los } \\
\text { nuevos edificios de Gobierno y } \\
\text { Justicia }\end{array}$ & Junta Central & $\begin{array}{l}\text { Diario oficial, } \\
\text { El Peruano: } 1872 \text { á,27 } \\
\text { setiembre: } 411\end{array}$ \\
\hline 1872 & $\begin{array}{c}\text { Traslado de la estatua de Colón a } \\
\text { la plaza de Guadalupe frente al } \\
\text { Palacio de la Exposición }\end{array}$ & Municipalidad & $\begin{array}{c}\text { Diario oficial, } \\
\text { El Peruano, 1872:10. }\end{array}$ \\
\hline 1872 & $\begin{array}{c}\text { Alumbrado Público para la bajada } \\
\text { de los baños de Chorrillos }\end{array}$ & Municipalidad & $\begin{array}{c}\text { Diario oficial, } \\
\text { El Peruano, } 1872: 371 .\end{array}$ \\
\hline 1872 & $\begin{array}{c}\text { Alameda Lima-Callao a cargo de } \\
\text { Meiggs }\end{array}$ & Contratista & $\begin{array}{l}\text { Diario oficial, } \\
\text { El Peruano, } 1872: 12\end{array}$ \\
\hline
\end{tabular}

Fuente: Elaboración propia en base al Diario oficial El Peruano (1872). 


\section{Comentarios generales del capítulo}

En este capítulo concluimos que los gobiernos liberales (intervencionistas, dictatoriales, populistas) de turno decidieron intervenir la ciudad con los recursos provenientes de guano siguiendo la ideología del discurso ilustrado peruano. En este periodo, el discurso de la demolición de la muralla y su posterior demolición constituyen un momento importante para la ciudad, a partir del cual, la periferia inició su transformación con la aplicación del ensanche que permitió el crecimiento de la ciudad y la materialización de la modernidad. El desenvolvimiento de la ciudad republicana, se dio en los siguientes aspectos

La nueva demarcación territorial en el año de 1828 buscó dejar atrás el pasado colonial. La subdivisión de las manzanas se convirtió en un obstáculo para aplicar la nueva demarcación. La Iglesia perdió el control de estos espacios barriales. Los nuevos cuarteles requirieron de infraestructura y espacios públicos. Se produjo un aumentó en los costos de la renta de vivienda en los barrios ubicados en el centro. La subdivisión de las casas coloniales en departamentos o casas de vecindad provocó una mayor demanda infraestructura de servicios básicos.

El impulso de los gobiernos liberales de turno al sistema mercantil dio como resultado que la Iglesia perdiera el control del mercado de suelo en la ciudad de manera paulatina. Así también, la activación del mercado de suelo, produjo la desaparición del mercado ilegal de suelo que surgió durante los primeros años del periodo republicano como consecuencia de una mayor inversión privada que participó en la ejecución de las obras públicas por contrato con la Municipalidad y el Estado. Con la bonanza del guano a partir del año de 1842 aumentó la actividad económica en la ciudad y por consiguiente el mercado de suelo registró una mayor actividad que llevó a este mercado a una mayor actividad. Fue en ese momento, que la aparición de los bancos permitió inversiones en la ciudad generando el aumento de la renta y el valor de las propiedades en la ciudad. Se dio una sobrevaluación de precios.

Los gobiernos liberales de turno de 1842 a 1866 intentaron modernizar la ciudad con el recurso guano sin un plan previo con el objetivo de satisfacer a la élite, grupos de poder y los empresarios en su ideal de materializar el progreso. 
También, buscaron la modernidad urbana en la ciudad con la aplicación de reglamentación en las instituciones de Estado, la Municipalidad, la Intendencia generando un gasto público innecesario que hubiera servido para la ejecución la obra pública. El centralismo del Estado Peruano no permitió que la Municipalidad asumiera el rol de gestora de la obras en la ciudad generando un retraso en la materialización de la modernidad. Así también, el centralismo excluyó a la población que vivía en la periferia de la modernización, debido a que sólo ejecutó obras en el centro de la ciudad.

Ante los problemas de insalubridad del centro y la periferia los higienistas de la segunda generación decidieron intervenir con propuestas de intervención y mejora en la ciudad aportando al proceso de urbanización de Lima. Así también, estos estudios sirvieron para que las autoridades incluyeran lineamientos para la mejora de los barrios y evitar los problemas de insalubridad en el centro. Los higienistas elaboraron propuestas públicas y privadas para la ejecución de proyectos que mejorarían la salubridad en el centro como fue el caso del proyecto de don Manuel Atanasio Fuentes, los médicos de la universidad Mayor de San Marcos y de la Escuela Libre de Medicina de San Fernando. La obra pública realizada durante los gobiernos de los presidentes José Balta y Manuel Prado se convertiría en un indicador de modernidad de la segunda mitad del siglo XIX.

La necesidad económica por parte de la élite colonial generó la subdivisión de las manzanas en el centro de la ciudad y en la periferia. La falta de una reglamentación adecuada, trajo como consecuencia el desorden de la urbanización. El aumento de la subdivisión de las casas coloniales inició los problemas de insalubridad, tugurización y hacinamiento en el centro a falta de un control del Estado y la Municipalidad.

La construcción de edificaciones públicas en el centro, la subdivisión de propiedades en las manzanas cercanas y una redistribución de la población al interior de los barrios cercanos generó la necesidad de una mayor infraestructura pública. Sin embargo, ante la falta de obras públicas de infraestructura aumentaron los problemas de insalubridad en la ciudad. 
El discurso de la demolición definió los objetivos que tendrían los gobiernos liberales de turno para materializar el progreso. Fue un momento importante de la ciudad que inició su transformación con la ejecución de obras de envergadura. Este discurso sustentado en seis razones mostraría los indicadores de modernidad que seguiría la ciudad los próximos periodos de gobierno hasta inicios del siglo XX como: crecimiento urbano, renta urbana, salubridad, industria pública, destruir la muralla y remover obstáculos para el progreso y bienestar de la población. Estos objetivos fueron materializados con la ejecución del Plan de Ensanche por los gobiernos de los presidentes José Balta y Manuel Pardo que dieron paso a la transformación irreversible de la periferia. 


\section{CAPITULO} III
Los miembros de la burguesía han luchado para restringir, manipular y controlar sus mercados. De hecho buena parte de su energía creativa a través de los siglos, se ha gastado en acuerdo en este sentido, monopolios escriturados, holdings, trust, carteles y empresas, aranceles proteccionistas, fijación de precios, subvenciones estatales abiertas o encubiertas, todos ellos acompañados de himnos de alabanzas a los mercados libres. (Berman,1989:110) 


\section{Capítulo III.-La urbanización en la periferia: Modernización inmobiliaria y bancaria (1872- 1876)}

En este capítulo trataremos de explicar cómo la periferia de Lima ingresó a un proceso de estructuración urbana mediante un Plan de Ensanche y un mercado de suelo impulsado por el remate de los terrenos de la muralla. Para complementar este objetivo, las huertas de las órdenes religiosas y particulares fueron anexadas a la periferia mediante la transferencia de los gravámenes por parte de los bancos y la expropiación de propiedades y procesos de compraventa para materializar el Plan de Ensanche. De esta manera, el Estado Peruano buscó eliminar el poder de la Iglesia en la periferia para incentivar la adquisición de propiedades privadas y activar la economía. El fraccionador Enrique Meiggs, quien, como hemos visto, fue el principal beneficiario de la desaparición de la muralla, inició la ejecución de obras públicas y emprendió la urbanización privada de la zona. También abordaremos como el Estado Peruano modernizó el sistema financiero mediante la introducción del sistema hipotecario para favorecer la inversión urbana privada y ampliar la oferta de vivienda. Sin embargo, las dificultades del nuevo sistema hicieron surgir en el mercado alternativas como ventas y retroventas. Así también, veremos cómo se implementó la Ley de expropiación para materializar el Plan de Ensanche, pero debido a que las expropiaciones no ofrecieron una retribución justa al propietario se generó un proceso de enajenaciones forzosas y permutas. En un tercer punto analizaremos la estructura de precios en el centro de la ciudad influenciado por las nuevas transacciones bancarias, la actividad inmobiliaria, la construcción de proyectos de envergadura, la puesta en marcha del Plan de Ensanche y la introducción de servicios básicos. Por último, analizaremos las características del proceso urbano del fraccionador Enrique Meiggs, quien dividió la periferia en cinco secciones y ejecutó obras del Plan de Ensanche para concretar su proyecto privado. 


\subsection{El Plan de Ensanche de Lima (1869-1973)}

El Plan de Ensanche fue un proyecto que se inició durante el gobierno del presidente José Balta. La ejecución del plan fue puesta a subasta, quedando encargado el fraccionador Enrique Meiggs. Dicho Plan continuó durante el periodo del presidente Manuel Pardo de 1872 a 1876, debido a que también compartía la misma estrategia inmobiliaria.

El Plan de Ensanche de Lima fue diseñado por el ingeniero Luis Sada entre los años de 1870 a 1873 con el nombre de Plano Topográfico de la Ciudad de Lima ó Primer Plano Regulador de Lima (Sada,1872). Ver plano 3.1 Este proyecto buscó urbanizar la periferia para solucionar el problema de insalubridad y disminuir la densidad en el centro con una nueva oferta de vivienda. También se esperaba que con este Plan disminuyera la subdivisión de casas en el centro, las cuales habían generado un deterioro de la infraestructura de vivienda y que disminuyera la aparición de callejones, mejorando también la higiene con la baja en la densidad poblacional del centro. Una vez "ganada" la subasta por el fraccionador Meiggs (como único postor de los terrenos de la muralla) se abrió la oferta de lotes bajo un modelo monopólico de mercado de suelo, que seguiría los lineamientos del Plan de Ensanche para su urbanización. Por esa razón, don Pablo Macera denomina al trazo cuadriculado La Parrilla Mercantilista (Ludeña, 2004:42). 


\section{Plano 3.1}

Plano topográfico de Lima en 1872 elaborado por Luis Carlo di Sada

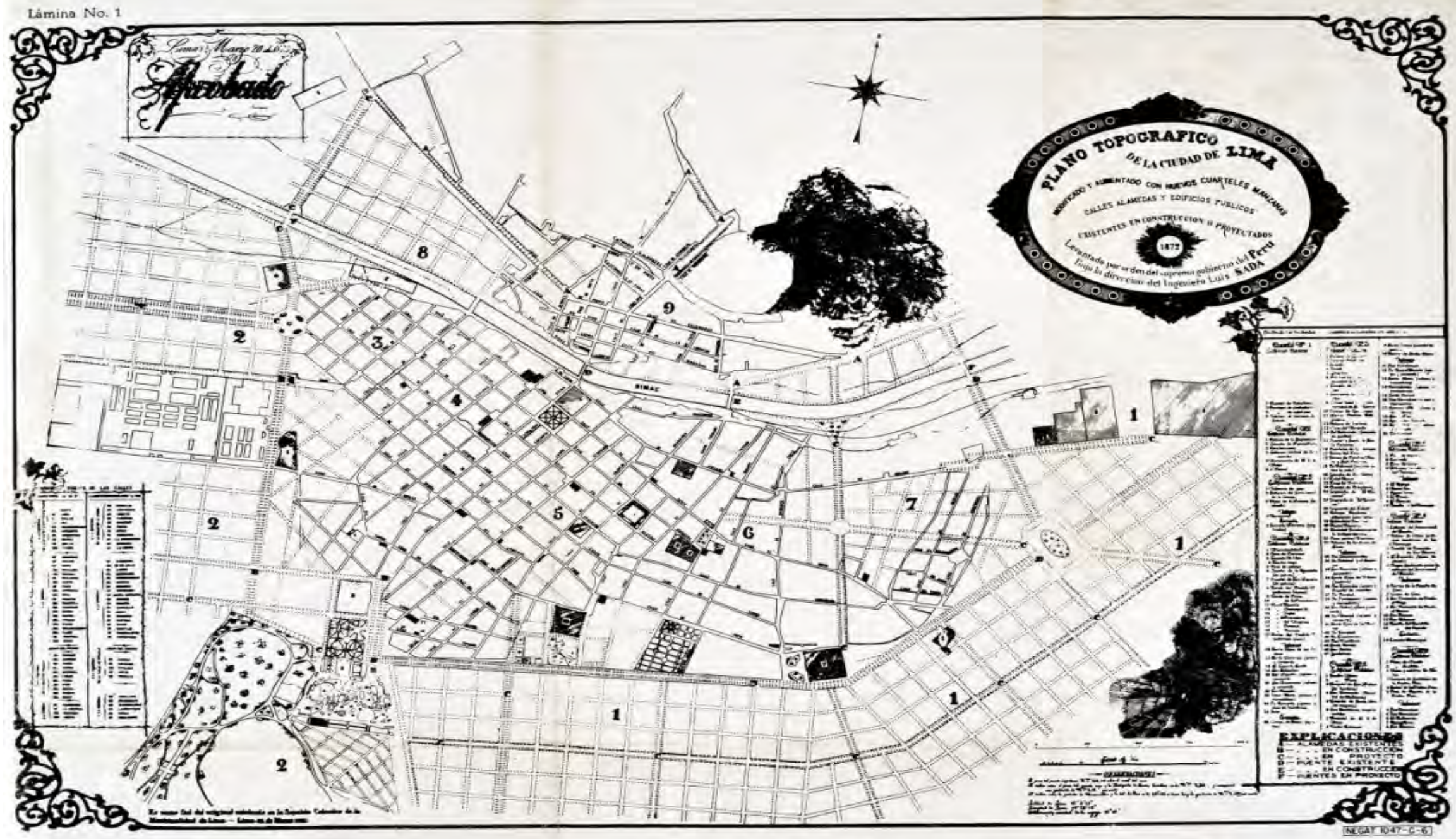

PRIMER PLANO REGULAdOR DE LiMA, por el Ing. Don Luia Sada di Carlo, siendo Presidente de la Repáblica. Don José Balta.- Aprobado por R. S. de 20 de 
El Plan de Ensanche incluyó una propuesta de demarcación de la ciudad en nueve cuarteles (ver plano de Ensanche número $3.1^{59}$ que no se llegó a ejecutar. El proyecto tenía como avenida principal la alameda de Circunvalación cuya función era unir el nuevo trazado de parrilla con el existente. Así también, consideró hacia el sur-oeste la construcción de dos óvalos de interconexión entre la ciudad, la nueva periferia y el Callao, denominados Unión y Dos de Mayo. Por el lado oeste, La Plaza de la Guardia Nacional permitiría una mejor conexión entre el este de la ciudad y el barrio del Santiago del Cercado, la zona de Barrios Altos y el otro lado del río. Cerca a este espacio se proyectó un pequeño óvalo en la zona central del cuartel cuarto donde aun existían terrenos de cultivo, para permitir la circulación desde el centro hacia la Plaza de la Guardia Nacional. El proyecto incluyó la construcción de un nuevo centro político y administrativo cerca al Palacio de la Exposición donde se reubicarían el Palacio de Justicia y Legislativo alrededor de una nueva plaza. En el siguiente cuadro vemos a detalle las obras a ejecutar:

${ }^{59}$ No se tienen datos si se realizó la nueva demarcación de la ciudad en nueve cuarteles en esos años. 
Cuadro $3.1^{\mathrm{a}}$

Obras a ejecutar para materializar el Plan de Ensanche

(1871-1876)

\begin{tabular}{|c|c|}
\hline Ubicación & Obra a ejecutar \\
\hline $\begin{array}{l}\text { Hacia la ribera } \\
\text { del río Rímac }\end{array}$ & $\begin{array}{l}\text { Construcción de una alameda al otro lado del río. } \\
\text { Puente en el río Rímac de conexión entre la alameda de Circunvalación } \\
\text { y el otro lado del río. } \\
\text { Trazado y construcción de calles y avenidas al otro lado del río entre el } \\
\text { puente Balta (en construcción) y el puente de piedra. } \\
\text { Puente en para conectar la alameda Circunvalación con el otro lado del } \\
\text { río a la altura de la Estación de Monserrate. }\end{array}$ \\
\hline $\begin{array}{c}\text { Hacia el oeste } \\
\text { de la ciudad }\end{array}$ & $\begin{array}{l}\text { Construcción de la alameda de Circunvalación } \\
\text { Construcción de la avenida Unión } \\
\text { Trazado y construcción de calles desde la avenida Unión hasta el borde } \\
\text { ribereño y desde la avenida Unión hacia el sur dos hileras de } \\
\text { manzanas. } \\
\text { Construcción del ovalo Dos de Mayo } \\
\text { Trazado y construcción de calles desde la alameda Circunvalación } \\
\text { hasta las calle Huancavelica. } \\
\text { Trazado y construcción de calles cerca al Palacio de la Exposición } \\
\text { Trazado y construcción de calles cerca a la Escuela de Agricultura de } \\
\text { Santa Beatriz. }\end{array}$ \\
\hline
\end{tabular}

Fuente: Elaboración propia en base a Sada (1872), M. Bolognesi (1862) 


\section{Cuadro 3.1b}

\section{Obras a ejecutar para materializar el Plan de Ensanche (1871-1876)}

\begin{tabular}{|c|l|}
\hline Ubicación & \multicolumn{1}{c|}{ Obra a ejecutar } \\
\hline la ciudad & $\begin{array}{l}\text { Construcción de la alameda de Circunvalación } \\
\text { Construcción de avenidas secundarias transversales y paralelas a la alameda } \\
\text { Circunvalación. } \\
\text { Trazado y construcción de avenidas para unir el trazado colonial con el nuevo } \\
\text { calles Bogotá, Tipiani y Maipiri. } \\
\text { Trazado de calles cerca a la Escuela de Medicina }\end{array}$ \\
\hline lacia el este de & $\begin{array}{l}\text { Construcción de la alameda de Circunvalación } \\
\text { Construcción de la Plaza de la Guardia Nacional } \\
\text { la Guardia Nacional siguiendo el trazo de la calle Junín y trazado y } \\
\text { construcción de calles cercanas. } \\
\text { Construcción de una avenida del ovalo a la ribera del río Rímac. } \\
\text { Construcción de una avenida desde la alameda Circunvalación al Cercado. } \\
\text { Construcción de una avenida de la Plaza de Guardia Nacional hacia la } \\
\text { exportada de Barbones. }\end{array}$ \\
\hline
\end{tabular}

Fuente: Elaboración propia en base a Sada (1872), Bolognesi (1862)

En este cuadro vemos que las obras tenían el objetivo de materializar la alameda de Circunvalación, lo que permitiría la conexión de toda la periferia. Para esos años, la alameda de Circunvalación era un espacio paseo arbolado concebido para socializar, ventilar e higienizar. (García Calderón, 1864:100). Con la ejecución del Plan de Ensanche, sería posible la materialización de la modernidad urbana entre plazas, circunvalaciones y avenidas arboladas que buscaron mostrar una ciudad de vanguardia, la desaparición paulatina del 
pasado y la construcción de la modernidad. Los espacios públicos se fueron convirtiendo en los intermediarios de las élites con el pueblo. Por ejemplo, dice Gorelik: "El Boulevard de circunvalación, significó la búsqueda de un freno y control para la expansión urbana, pero al mismo tiempo como un modelo de distribución idealmente equivalente al territorio urbanizado y como disparador de un nuevo ciclo de especulación que terminaría por superarlo una y otra vez" (Gorelik,2003:17). Sin embargo, debido a la guerra con Chile, solo se llegó a materializar una parte de este Plan, si bien la idea sería retomada por los gobiernos posteriores, como una muestra la continuidad del proyecto de modernización impulsado por la élite.

En el siguiente cuadro podemos observar el proceso que siguió el Plano de Ensanche desde su elaboración por el ingeniero Sada, en 1869, hasta la intervención directa de Enrique Meiggs, culminando en 1876. Incluye, su rectificación y ejecución en ese periodo. Un año después, en 1877, sobrevendría el fallecimiento del fraccionador Meiggs principal ejecutor de esta obra. 


\section{Cuadro 3.2}

\section{Proceso general del Plan de Ensanche (1869-1876)}

\begin{tabular}{|c|c|c|}
\hline Año & Acciones de elaboración y ejecución & Fuente \\
\hline 1869 & $\begin{array}{l}4 \text { de agosto. Contrato celebrado entre el Supremo Gobierno y el ingeniero Luis Sada } \\
\text { para elaboración del Plano de Ensanche }\end{array}$ & Tizón y Bueno,1916:43 \\
\hline 1869 & $\begin{array}{l}\text { El Gobierno decidió fijar el valor del metro cuadrado de acuerdo al precio de } \\
\text { mercado. }\end{array}$ & $\begin{array}{l}\text { Diario oficial El Peruano, } \\
1869 \text { á: } 02 \text { de } \\
\text { diciembre, } 01 .\end{array}$ \\
\hline 1871 & $\begin{array}{l}\text { El } 11 \text { de septiembre expedición de una Resolución Suprema para vender lotes de } \\
\text { terreno de interés social }\end{array}$ & $\begin{array}{ll}\text { Diario } & \text { Oficial } \\
\text { Peruano, } 1871 \text { á, } 16 \\
\text { setiembre: } 229 .\end{array}$ \\
\hline 1871 & $\begin{array}{l}\text { El } 13 \text { de septiembre. Inicia venta de lotes y el Estado instruye supervisar que los } \\
\text { compradores de los lotes cumplan la nivelación de sus construcciones según el } \\
\text { Plano de Ensanche. }\end{array}$ & $\begin{array}{l}\text { Diario oficial El Peruano, } \\
1871 \text { á, } 30 \text { setiebre: } 301 .\end{array}$ \\
\hline 1871 & $\begin{array}{l}\text { Nueva Resolución Suprema, con fecha } 04 \text { de octubre de 1871: rematar los terrenos } \\
\text { de la muralla fijando las bases a las que se sometió el ganador de la subasta } \\
\text { (Meiggs). }\end{array}$ & $\begin{array}{l}\text { Diario oficial El Peruano, } \\
1871 \text { á, } 7 \text { octubre: } 389 .\end{array}$ \\
\hline $\mid 872$ & 13 de mayo. Aprobación del Plano Topográfico por el presidente Pardo & $\begin{array}{lll}\text { Diario } & \text { Oficial } & \text { El } \\
\text { Peruano, } & 1872 \text { á, } & 15 \\
\text { junio: } 660 & \end{array}$ \\
\hline 1873 & El 20 de marzo. Aprobación de las rectificaciones del Plano de Ensanche & $\begin{array}{l}\text { Diario oficial El Peruano, } \\
1873 \text { á, } 19 \text { abril: } 460- \\
461 .\end{array}$ \\
\hline 1873 & $\begin{array}{l}\text { El } 23 \text { de marzo el gobierno pidió a la Junta Central la ubicación definitiva de los } \\
\text { palacios Legislativo y de Gobierno, cerca al Palacio de la Exposición. construcciones } \\
\text { y se inició el proceso de expropiación. }\end{array}$ & $\begin{array}{l}\text { Diario oficial } \quad \text { El } \\
\begin{array}{l}\text { Peruano, } 1873 \text { á, } 13 \\
\text { julio: } 461\end{array}\end{array}$ \\
\hline 1872 & $\begin{array}{l}\text { Un año más tarde el } 17 \text { de diciembre el gobierno dio permiso al rector de la } \\
\text { universidad de San Marcos para expropiar 10,089 varas cuadradas de la huerta } \\
\text { Matute, }\end{array}$ & $\begin{array}{l}\text { Diario oficial } \\
\begin{array}{l}\text { Peruano, } 1874 \\
\text { diciembre: } 01\end{array}\end{array}$ \\
\hline $\begin{array}{l}1872- \\
1876\end{array}$ & El Plan de Ensanche fue ejecutado por el fraccionador Meiggs. & $\begin{array}{l}\text { Diario oficial El Peruano } \\
1873 \text { á, } 19 \text { abril :08 }\end{array}$ \\
\hline
\end{tabular}

Fuente: Elaboración propia en base a Diario oficial El Peruano (1869),(1871),(1872)(1973)(1874),Tizón y Bueno (1916) 
El Plan de Ensanche se ejecutó desde 1871 cuando se le encargó al fraccionador Meiggs esta tarea,, pero solo fue posible materializar el trazado de las manzanas al sur hacia la avenida Circunvalación y los óvalos de Unión y Dos de Mayo quedando inconclusas las acciones, esperando ser retomado en los próximos gobiernos.

\subsection{El Plano Topográfico de 1875 elaborado por Enrique Meiggs.}

El plano topográfico elaborado por el fraccionador Enrique Meiggs encargado de ejecutar el Plan de Ensanche (Barbagelata,1945:87-88) muestra algunas variantes en relación con el mismo Plan de Ensanche, elaborado por Sada. Este documento gráfico muestra detalles que incluyó cuando se encontraba en el proceso de intervención de la obra, como la ubicación de los edificios, las áreas verdes existentes en la ciudad y la nomenclatura de calles, constituyendo el aporte de este documento gráfico a la cartografía del periodo. (Ver plano 3.2 y cuadro 3.3). 


\section{Plano 3.2 Plano topográfico de Lima versión Enrique Meiggs año 1875}

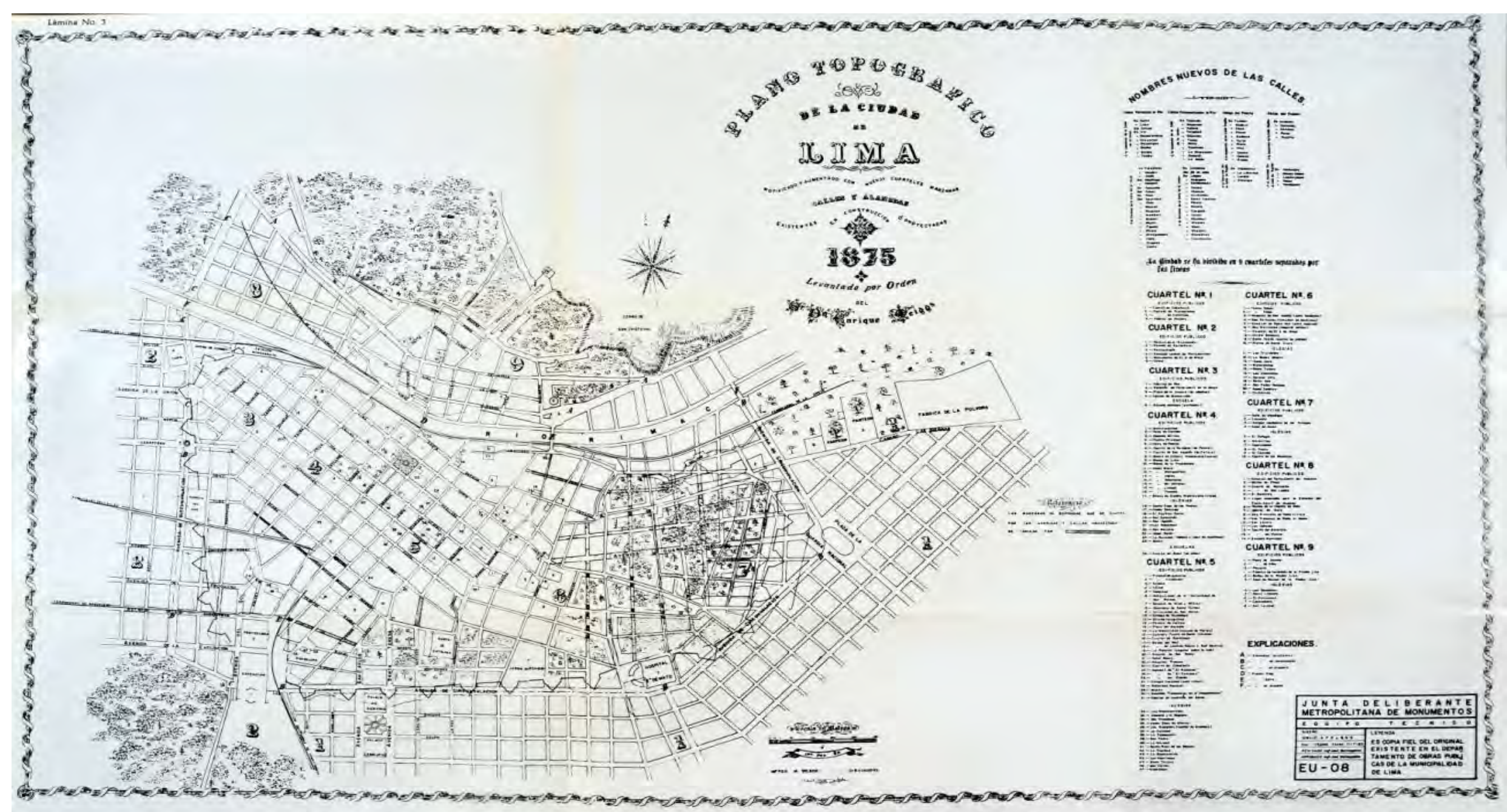

Fuente: Barbagelata J. (1945) 


\section{Cuadro 3.3}

\section{Variantes propuestas en el plano topográfico al}

Plano de Ensanche (1872- 1875)

\begin{tabular}{|c|c|c|}
\hline Ubicación & Variante & Fuente \\
\hline Borde ribereño & $\begin{array}{c}\text { Convertir los malecones de las dos riberas del río } \\
\text { Rímac en una línea con muros de encauzamiento } \\
\text { haciendo pasar el malecón por debajo de los } \\
\text { puentes }\end{array}$ & Barbagelata,1945:87-88 \\
\hline $\begin{array}{l}\text { Alameda de } \\
\text { Circunvalación }\end{array}$ & $\begin{array}{c}\text { Aumentar el ancho de la Alameda Circunvalación } \\
\text { a } 50 \text { metros para aumentar las hileras de árboles } \\
\text { de la Alameda }\end{array}$ & $\begin{array}{l}\text { Diario oficial El } \\
\text { Peruano, } 1872 \text { á } 15 \\
\text { junio: } 660\end{array}$ \\
\hline $\begin{array}{l}\text { Sección sur de la } \\
\text { alameda de } \\
\text { Circunvalación }\end{array}$ & $\begin{array}{c}\text { Variantes al trazado de las calles Santa Teresa y } \\
\text { San Carlos. }\end{array}$ & $\begin{array}{l}\text { Sada,(1872), } \\
\text { Meiggs(1875) }\end{array}$ \\
\hline
\end{tabular}

Fuente: Elaboración propia en base Sada (1872), Meiggs (1875), Diario oficial El Peruano (1872), Barbagelata (1845)

Las variantes realizadas por el fraccionador Meiggs mientras ejecutaba el Plan de Ensanche buscaron mejorar el proyecto según la visión moderna de las ciudades. Fue el caso del ensanche de la alameda de Circunvalación para convertirla en un paseo arbolado. Otro aporte fue la ubicación, en el documento gráfico, de las edificaciones construidas por esos años a lo largo de la avenida Circunvalación como: el Hospital Dos de Mayo, La Escuela de Medicina de San Marcos, el Jardín Botánico, la Penitenciaria, la fábrica de Gas, los jardines Conroy y las edificaciones que se construirían en el nuevo centro, como el Palacio de la Exposición y los edificios de Gobierno proyectados por la Junta Central. Con la ubicación de estas edificaciones fue posible elaborar planos parciales para planificar la urbanización de la periferia. 


\subsection{El proyecto de la Avenida Unión 1876}

El 1876 el fraccionador Enrique Meiggs se encontraba en plena ejecución y venta de lotes de terrenos en la periferia de manera privada. Entonces vio la oportunidad inmobiliaria de diseñar una vía que conectase Lima con el Callao para darle continuidad al trazado de parrilla del Plan de Ensanche con usos comercial y residencial. Entonces denominó a su proyecto pensando en la nueva ampliación: Plano topográfico de Lima al Callao y sus alrededores (Meiggs, 1876). Este proyecto contempló la urbanización del Callao y una carretera ${ }^{60}$ de 80 kilómetros de largo denominada avenida Unión (Barbagelata, 1971:3). Este ambicioso proyecto permitiría mejorar el flujo vehicular y peatonal entre estas dos ciudades y planificar un crecimiento urbano entre el puerto del Callao y la periferia oeste de Lima. Con la construcción de esta vía se favorecería la conexión entre Lima y el Callao para un transporte masivo de personas, mercaderías y para impulsar la urbanización existente en esta zona de periferia. El proyecto iniciaba en el Ovalo Unión y culminaba en el puerto del Callao. Comprendía un trazo de parrilla que llegaba hasta el río Rímac por el norte y hasta el ferrocarril Lima y Callao por el este. Fueron planeadas cinco hileras de manzanas aproximadamente a ambos lados de la vía principal. Las manzanas hacia la vía principal serían destinadas a uso comercial y servicios mientras que el resto a uso residencial. El proyecto fue aprobado por el gobierno del presidente Balta el año 1872 (Diario oficial El Peruano,1872 á, 13 julio:12). Y se realizó el proyecto a detalle como parte de la sección quinta que no se llegó a materializar debido a que el fraccionador Meiggs se encontraba ejecutando otras secciones del Plan de Ensanche. Sin embargo, este proyecto fue retomado para la primera mitad del siglo XX y en la actualidad la avenida Unión es la vía que conecta Lima con el aeropuerto Internacional Jorge Chávez conocida como avenida Argentina. El fraccionador Meiggs entregó a la ciudad una completa cartografía de este espacio entre dos ciudades, lo cual que constituye un aporte en materia de planeación urbana ligada al desarrollo inmobiliario. El proyecto coincidiría también con la teoría de los caminos del Dr.

\footnotetext{
60 ."Lima, julio 3 de 1869. Vista esta solicitud y considerando: que Don José Feliz Tiravantti pide que no se lleve a cabo que con él estaba a punto de celebrarse: que siendo de notoria necesidad la construcción de un camino carretera al Callao, por el malísimo estado en el que se encuentra el actual y por las ventajas que proporcionará no solo al comercio sino muy especialmente a las clases menesterosas, que deben ser atendidas de preferencia, facilitándoles los medios de comunicación asegurándoles el trabajo y con ello la subsistencia" Diario oficial El Peruano, Lima, jueves 15 de julio de 1869, p.51.
} 
Terrazas, pues sería ejemplo de la manera en que los caminos impulsan la urbanización 


\section{Plano 3.3}

\section{Plano topográfico de Lima Callao y sus alrededores 1876}

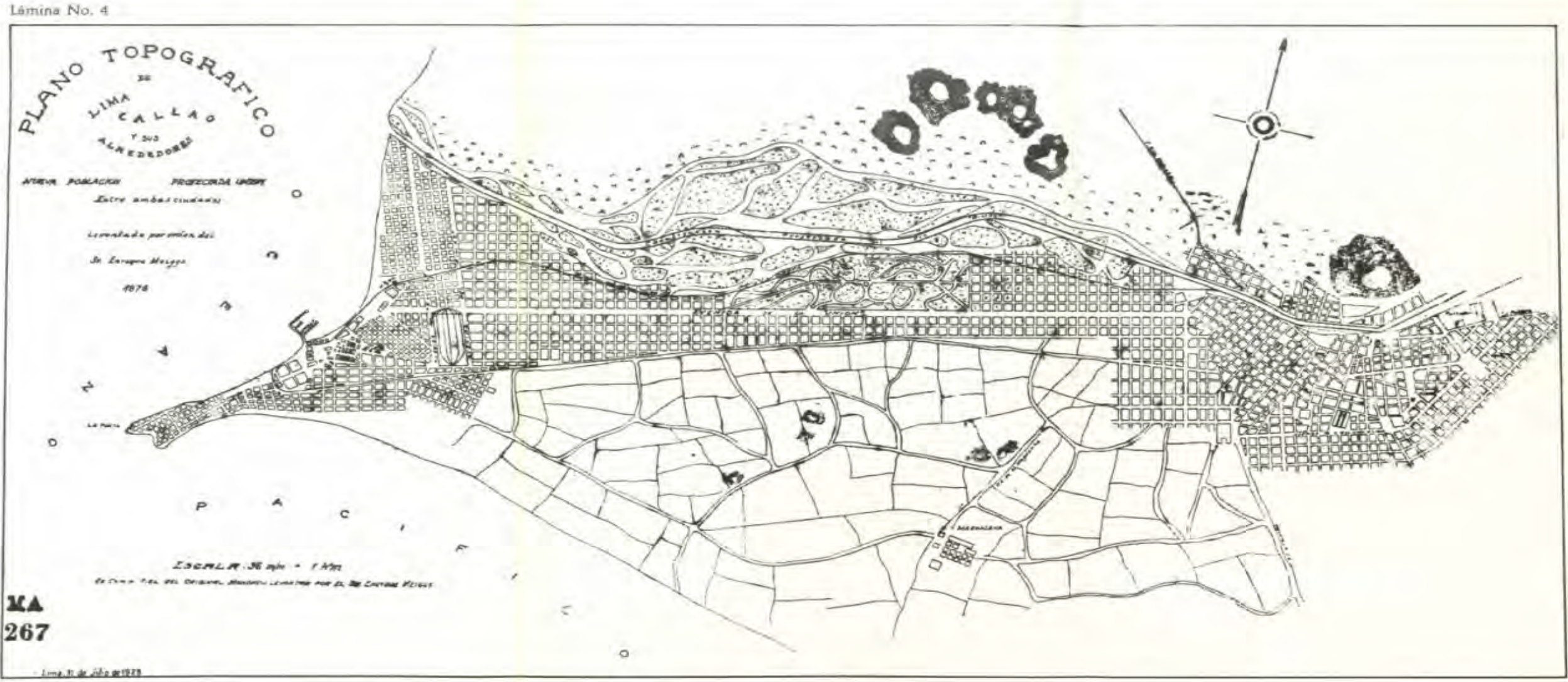

Plano de D. Enrigue Meiggs.-1876

Fuente: Barbagelata J.(1945) 
En el siguiente cuadro vemos los proyectos y las obras que se ejecutaron en esta vía que era un camino principal a la ciudad desde tiempo colonial.

\section{Cuadro 3.4}

\section{Proyectos y obras ejecutados en la vía de Lima al Callao} (1869-1872)

\begin{tabular}{|c|c|c|}
\hline Año & Proyecto y obra & Fuente \\
\hline $\begin{array}{l}\text { Periodo } \\
\text { colonial }\end{array}$ & $\begin{array}{l}\text { Proyecto de vía para unir Lima con el } \\
\text { Callao }\end{array}$ & Sáenz,2015:124 \\
\hline 1869 & $\begin{array}{c}\text { Don José Feliz Tiravanti pidió al Gobierno } \\
\text { se construya un camino carretero entre } \\
\text { Lima y Callao por } 80,000 \text { soles. Pero no } \\
\text { tuvo una respuesta positiva. }\end{array}$ & $\begin{array}{l}\text { Diario oficial El Peruano,1869 á, } \\
15 \text { julio:51 }\end{array}$ \\
\hline $1871-1872$ & $\begin{array}{l}\text { El año } 1871 \text { las Municipalidades del } \\
\text { Callao y Lima manifestaron los } \\
\text { inconvenientes de contratar en común a } \\
\text { una empresa para la construcción del } \\
\text { camino carretero al Callao y propusieron } \\
\text { construcciones separadas. El proyecto } \\
\text { sería realizado por la Municipalidad y el } \\
\text { Gobierno. }\end{array}$ & $\begin{array}{c}\text { Diario oficial El Peruano,1871 } \\
\text { á, } 29 \text { abril:01. }\end{array}$ \\
\hline 1872 & $\begin{array}{l}\text { El gobierno aprobó la construcción de la } \\
\text { Alameda Lima-Callao a cargo de Enrique } \\
\text { Meiggs. }\end{array}$ & $\begin{array}{c}\text { Diario oficial El Peruano, } 1872 \\
\text { á, } 13 \text { julio: } 12 .\end{array}$ \\
\hline
\end{tabular}

Fuente: Elaboración propia en base a: Diario oficial El Peruano (1869), (1871),(1872) y Sáenz (2015).

Al culminar su mandato el presidente Manuel Pardo el año 1876 los problemas en la ciudad de Lima eran agudos. El país estaba en una bancarrota fiscal y ninguna de las obras de envergadura que se iniciaron durante el anterior gobierno fueron culminadas. Aunque se habían realizado obras específicas en algunos cuarteles, pero la canalización de las calles no mostraba avance en toda la ciudad. En la periferia de Lima el Estado Peruano buscó materializar el Plan de Ensanche, otorgando a la inversión privada la autorización para 
urbanizar la periferia, lo que dio como resultado la construcción de un mercado de suelo de monopolio a cargo del fraccionador Meiggs, ocasionando el perjuicio para muchos propietarios que perdieron sus propiedades en procesos de expropiación para la construcción de las calles y avenidas. La modernidad se había materializado en áreas nuevas de la ciudad. Paz Soldán describe ese proceso de la siguiente manera:

"Las calles en general son tiradas á cordel y se cortan casi en ángulo recto formando cuadros que se llaman manzanas. Se ha cuidado de darles tal dirección que en los meses de verano siempre hay sombra en algún lado de la calle, exceptuando los días en el que el sol está en el zenit; y como rara vez falta la brisa del S.E no sé experimenta un fuerte calor. El mayor largo de las calles es de 125 metros y el menor de 90 metros, y el ancho en lo general de 100 metros y el menor de 90 metros muy pocas exceden de estas dimensiones; todas las calles tienen acequias o albañales cubiertos que pasan por medio recibiendo en su trayecto los desagües de las casas; hace poco esas acequias estaban al descubierto, con poco fondo, lo que presentaba una vista asquerosa y ocasionaba epidemias por la continua evaporación de materias en estado de putrefacción. Recientemente se ha introducido para pavimentar las calles una especie de macadam de piedra de Oroya que contiene arcilla glutinosa y forma una arcilla casi tersa, sí su duración corresponde á la comodidad y buena vista, Lima será una de las ciudades mejor y más económicamente pavimentadas" (Paz Soldán, 1877:514-515).

A pesar de los cambios señalados, era claro que los gobiernos de turno habían mal utilizado el dinero del guano. Al final de este periodo los recursos se habían agotado y continuaban los problemas de salubridad y la necesidad de vivienda para descongestionar el centro. La ciudad se había modernizado de acuerdo a los discursos de los presidentes en turno, que habían emprendido obras que, al no ser concluidas, convirtieron la materialización de la modernidad en un proyecto incierto.

\subsection{El mercado de suelo y la oferta de vivienda en la periferia al demolerse la muralla de Lima}

A partir de la demolición de la muralla de Lima, en 1871, inició el proceso de reestructuración del mercado de suelo de la periferia con ventajas privadas excepcionales. El beneficiario central fue Enrique Meiggs, ganador de un remate en el que sería el único contrincante, el remate público del 24 de noviembre de 1871 (Diario oficial El Peruano,1872 á, enero: 65). A partir de entonces, la configuración del mercado de suelo de periferia pasó a manos privadas con el aval del Estado Peruano. Esta decisión política, tuvo las siguientes consecuencias: el precio del mercado de suelo en la periferia quedó en manos de un solo inversionista privado, la oferta de vivienda estuvo a cargo 
de la inversión privada, las subvenciones económicas por parte de la Caja de Ahorros Mutuos fueron utilizadas para acceder a una vivienda en la periferia, la urbanización de la periferia se dio con dinero privado con el aval del gobierno de turno, los terrenos rurales cercanos a la muralla de Lima fueron anexados a la ciudad, los trabajos de ejecución del Plan de Ensanche quedaron en manos de la inversión privada. Es claro que el proceso de venta de lotes para vivienda tuvo rasgos especulativos, ${ }^{61}$ en un momento de mercantilización del suelo donde la vivienda se convirtió en vivienda-mercancía producto de la necesidad del Estado Peruano de cumplir con el ofrecimiento de vivienda al pueblo.

La decisión política del Estado Peruano, también afectó a los inversionistas privados, a quienes solo les quedó la posibilidad de invertir en desarrollos inmobiliarios fuera de la ciudad y en algunos espacios disponibles en el centro. Sin embargo, contribuyeron con la activación económica que buscó el Estado. Esa oferta complementaria de vivienda estuvo dirigida a comerciantes, obreros y extranjeros con posibilidades de adquirir una vivienda vía crédito hipotecario o préstamo bancario. Sin embargo, estas inversiones no fueron significativas y no pudieron competir con el monopolio que venía construyendo el fraccionador Enrique Meiggs en la periferia inmediata de la ciudad, lo que muestra que la modernización del mercado financiero que impulsó el Estado Peruano y activó las inversiones inmobiliarias en la ciudad quedó sesgada de manera monopólica. Fue así que como una alternativa ante el monopolio que estaba construyendo el fraccionador Enrique Meiggs fue el surgimiento de otros desarrollos inmobiliarios, aunque también participaría Meiggs en uno de ellos. Estos serían Marbella-Magdalena, que fue una sociedad de los empresarios Dibos Rutte y Rey Basadre el año 1872 (Ludeña, 2004:143) ubicado al oeste a las afueras de la ciudad en la población de La Magdalena; La Unión asociación de los empresarios Meiggs y Larco el año 1876 (Ludeña, 2004:143) cercano a los terrenos de la Exposición y por último La Victoria por la Compañía La Victoria y Nacional La Cerámica (Ludeña, 2004:143) ubicado al

\footnotetext{
${ }^{61}$ Según Jorge Jiménez para el caso de México “La inestable situación política de la capital de la república mexicana desde su origen como Distrito Federal fue de gran utilidad para los fines de la febril especulación inmobiliaria; en primer lugar por la endeble federación que generó el México independiente y en segundo lugar por la vacilante hasta la indeterminación___ estructura interna de la capital de la república” En: La traza del poder: historia de la política y los negocios urbanos en el Distrito Federal de sus orígenes a la desaparición del Ayuntamiento (18241928). 1993, Ed. Codex, México, pp.2.
} 
sur de la ciudad que no significaban una competencia ante el desarrollo inmobiliario que venía construyendo Enrique Meiggs en la periferia.

En el año 1871, un año después que el fraccionador Enrique Meiggs firmó el contrato con el Estado Peruano, se inició el proceso de urbanización mixto estatal-privado de la periferia con la anexión de las huertas cercanas a la muralla. Para lograr este objetivo, el Estado Peruano expidió la Ley de Expropiación por Decreto Supremo del 17 de mayo de 1872 (Diario oficial El Peruano,1872 á, junio: 661) para iniciar con el trazado según el Plan de Ensanche y encargó su ejecución al fraccionador Enrique Meiggs. En este caso, la doble función de Meiggs fue vista como corrupta por la población. A partir de entonces, se inició una dependencia del proyecto público sobre el privado que no benefició a los propietarios de los terrenos expropiados ni a la población que ocupaba la periferia que fueron afectados durante el proceso de urbanización con ventas forzadas de sus propiedades. En este proceso de urbanización, los principales afectados fueron las órdenes religiosas y particulares cuyas propiedades fueron anexadas a la periferia entre los años de 1872 a 1876, justificando el proceso con la subordinación de la tierra a las necesidades de crecimiento de la población, su necesidad de vivienda y activar su economía (Blanco,2014:191-192). De esta manera, fueron anexadas 24 huertas ${ }^{62}$ mediante la modalidad de expropiación, compra, enajenación forzosa y permuta. No obstante, como consecuencia de esta actividad, la Iglesia disminuyó sus propiedades y muchos de sus gravámenes fueron transferidos a los bancos y terceros durante el proceso de expropiación y venta de propiedades. De esta manera, se produjo una reestructuración del tejido social con nuevos propietarios y un cambio en las actividades económicas de algunos barrios producto de la ejecución de las obras del nuevo trazado. Las huertas que desaparecieron en este proceso abastecían a la ciudad de frutas, flores y cultivos de maíz, habas, lenteja y quínoa, frejoles, calabazas, coles, nabos, berenjenas, lechugas, rábanos y cardos para abastecer a la ciudad (Bromley y Barbagelata, 1945:39). Fue eliminando así el intercambio comercial entre la periferia rural y la ciudad, generando propiedades privadas e iniciar el proceso

\footnotetext{
62 Según Aldo Panfichi "Las huertas y chacras son terrenos donde se cultivaban legumbres y hortalizas, ubicados en la periferia de la ciudad". "Mundos Interiores", Lima, 2004 Ed. Universidad del Pacífico pp.56.
} 
de dividir la tierra para crear riqueza, especialmente a favor de Meiggs. Para finales del siglo XIX José Barbagelata describió el proceso de anexión de algunas huertas a la ciudad por el lado sur y sur-este.

"Al sur se encontraba la llamada Huerta Perdida y el Olivar de las monjas de la Encarnación de propiedad de don Antonio de Ribera y su mujer doña Inés Muñoz... estas dos huertas se hallaban en el lugar que hasta fines del siglo XIX se denominaba las Chacritas y que hoy forma parte de los barrios constituidos por los jirones de Cotabambas, Sandia, Maipiri e Inambari. Lindando con la ciudad a la altura de la actual calle Mascaron, estaba la huerta de doña María de Escobar, que luego fue urbanizada... dentro de la ciudad, en la extensión del terrenos que ocupó el convento de San Francisco, se hallaba la huerta de Francisco Pizarro, denominada del Marqués, que, con sus arbolados y estanque, fue el mejor de la incipiente población "(Bromley y Barbagelata, 1945:38).

Además, la anexión de las huertas provocó una disminución de los bosques, espacios verdes y la anexión de los estanques a la red de riachuelos de la ciudad, poniendo en marcha un mercado monopólico de suelo en la periferia. 


\section{Cuadro 3.5}

\section{Huertas ubicadas en la periferia de Lima a finales del siglo XIX}

\begin{tabular}{|c|c|c|c|c|}
\hline $\mathbf{N}^{\circ}$ & Huertas & $\begin{array}{c}\text { Propietario o } \\
\text { arrendatario } \\
\text { del predio }\end{array}$ & Ubicación & Fuente \\
\hline 1 & Platanal & Sin dato & $\begin{array}{l}\text { Al lado de la Avenida } \\
\text { Circunvalación al sur }\end{array}$ & Basurco,1904:Lamina 01 \\
\hline 2 & Pozo & Sin dato & $\begin{array}{l}\text { Al lado de la Avenida } \\
\text { Circunvalación al sur }\end{array}$ & Basurco,1904:Lamina 01 \\
\hline 3 & Pellejo & Sin dato & $\begin{array}{l}\text { Al lado de la Avenida } \\
\text { Circunvalación al sur }\end{array}$ & Basurco,1904:Lamina 01 \\
\hline 4 & Rendón & Sin dato & $\begin{array}{l}\text { Al lado de la Avenida } \\
\text { Circunvalación al sur }\end{array}$ & Basurco,1904:Lamina 01 \\
\hline 5 & Manzanilla & Sin dato & $\begin{array}{c}\text { Frente al Hospital } 02 \text { de } \\
\text { Mayo }\end{array}$ & Basurco,1904:Lamina 01 \\
\hline 6 & El Agustino & $\begin{array}{l}\text { Orden de los } \\
\text { Agustinos }\end{array}$ & Limite con el Agustino & Basurco,1904:Lamina 01 \\
\hline 7 & Raggada & Sin dato & $\begin{array}{l}\text { Al lado de la Avenida } \\
\text { Circunvalación al sur }\end{array}$ & Basurco,1904:Lamina 01 \\
\hline 8 & Virreina & $\begin{array}{l}\text { Álvarez Pinillos } \\
\text { (dueño) }\end{array}$ & $\begin{array}{c}\text { Por la Magdalena al sur } \\
\text { de la ciudad }\end{array}$ & $\begin{array}{c}\text { Junta } \\
\text { Departamental,1897:10-11 }\end{array}$ \\
\hline 9 & Recoleta & $\begin{array}{l}\text { Álvarez Pinillos } \\
\text { (dueño) }\end{array}$ & $\begin{array}{c}\text { Por la Magdalena al sur } \\
\text { de la ciudad }\end{array}$ & $\begin{array}{c}\text { Junta } \\
\text { Departamental,1897:10-11 }\end{array}$ \\
\hline 10 & Loja & Miguel Windor & $\begin{array}{l}\text { Al sur de Lima- La } \\
\text { Magdalena }\end{array}$ & $\begin{array}{c}\text { Junta } \\
\text { Departamental,1897:10-12 }\end{array}$ \\
\hline 11 & $\begin{array}{l}\text { Chacra } \\
\text { Colorada }\end{array}$ & Gustavo Batt & $\begin{array}{l}\text { Al este cerca al Palacio } \\
\text { de la Exposición }\end{array}$ & $\begin{array}{c}\text { Junta } \\
\text { Departamental,1897:10-11 }\end{array}$ \\
\hline 12 & Chimba & $\begin{array}{c}\text { Marthell } \\
\text { (Arrendatario) }\end{array}$ & $\begin{array}{l}\text { Por el río Huatica- } \\
\text { Orrantia }\end{array}$ & $\begin{array}{c}\text { Junta } \\
\text { Departamental,1897:11 }\end{array}$ \\
\hline 13 & Matalechucita & García Irigoyen & Por la Magdalena al sur & $\begin{array}{c}\text { Junta } \\
\text { Departamental,1897:11 }\end{array}$ \\
\hline
\end{tabular}

Fuente: Elaboración propia en base a Basurco (1904), Junta Departamental

(1897) 


\begin{tabular}{|c|c|c|c|c|}
\hline Nun & Huertas & $\begin{array}{l}\text { Propietario o } \\
\text { arrendatario } \\
\text { del predio }\end{array}$ & Ubicación & Fuente \\
\hline 14 & Salvi & Sin dato & $\begin{array}{l}\text { Entre Carretera al Callao y } \\
\text { Avenida Unión }\end{array}$ & $\begin{array}{c}\text { Notario Selaya,1874:597- } \\
\text { 598v }\end{array}$ \\
\hline 15 & $\begin{array}{c}\text { Del } \\
\text { Noviciado }\end{array}$ & $\begin{array}{l}\text { Convento de la } \\
\text { Concepción }\end{array}$ & $\begin{array}{l}\text { Al lado de la Huerta Perdida } \\
\text { por el antiguo camino a la } \\
\text { muralla }\end{array}$ & Notario Suarez, 1874:79. \\
\hline 16 & Particular & $\begin{array}{l}\text { Huerta de } \\
\text { María Gómez } \\
\text { y Francisco } \\
\text { Cerdeña (4) }\end{array}$ & Sin dato & $\begin{array}{c}\text { Junta } \\
\text { Departamental,1897:s/d. }\end{array}$ \\
\hline 17 & $\begin{array}{l}\text { Conde de } \\
\text { la Vega }\end{array}$ & Sin dato & $\begin{array}{l}\text { Entre Carretera al Callao y } \\
\text { Avenida Unión }\end{array}$ & $\begin{array}{c}\text { Notario Selaya, 1874:597- } \\
\text { 598v. }\end{array}$ \\
\hline 18 & Lazo & $\begin{array}{l}\text { Álvarez } \\
\text { Pinillos }\end{array}$ & $\begin{array}{l}\text { Entre Carretera al Callao y } \\
\text { Avenida Unión }\end{array}$ & $\begin{array}{c}\text { Junta Departamental, } \\
1897: 11 .\end{array}$ \\
\hline 19 & $\begin{array}{l}\text { Aranibar } \\
\text { (Arenibar) }\end{array}$ & Araníbar & $\begin{array}{l}\text { Entre Carretera al Callao y } \\
\text { Avenida Unión }\end{array}$ & $\begin{array}{c}\text { Notario Selaya, 1874:597- } \\
\text { 598v. }\end{array}$ \\
\hline 20 & De la Cruz & Sin dato & $\begin{array}{l}\text { Al este de la ciudad, colinda } \\
\text { con Chacra Mosquito }\end{array}$ & $\begin{array}{l}\text { Bromley y Barbagelata,1945: } \\
\text { Lámina 04 }\end{array}$ \\
\hline 21 & $\begin{array}{l}\text { Huerta } \\
\text { Perdida }\end{array}$ & Emilio Althaus & $\begin{array}{l}\text { Entre las huertas del } \\
\text { Noviciado y Guadalupe, el } \\
\text { cuartel de Santa Catalina y } \\
\text { el Antiguo camino a la } \\
\text { muralla }\end{array}$ & Notario Suarez,1874:79-80v \\
\hline 22 & $\begin{array}{c}\text { San } \\
\text { Francisco }\end{array}$ & $\begin{array}{l}\text { Convento de } \\
\text { san Francisco }\end{array}$ & Convento de san Francisco & $\begin{array}{c}\text { Tizón y Bueno,1904:Lamina } \\
01\end{array}$ \\
\hline 23 & Raimondi & Sin dato & Al sur de la ciudad & $\begin{array}{l}\text { Tizón y Bueno,1904:Lamina } \\
01\end{array}$ \\
\hline 24 & Mosquito & Sin dato & $\begin{array}{l}\text { Al este de la ciudad colinda } \\
\text { con Chacra Colorada }\end{array}$ & $\begin{array}{c}\text { Bromley y Barbagelata,1945: } \\
\text { Lám.04 }\end{array}$ \\
\hline
\end{tabular}

Fuente: Elaboración propia en base a: Selaya (1874), Suarez (1874) Bromley (1945), Junta Departamental (1897), Basurco (1904), Tizón y Bueno (1904). 


\section{Plano 3. 4}

\section{Huertas ubicadas en la periferia de Lima para finales del siglo XIX y principios del siglo XX}

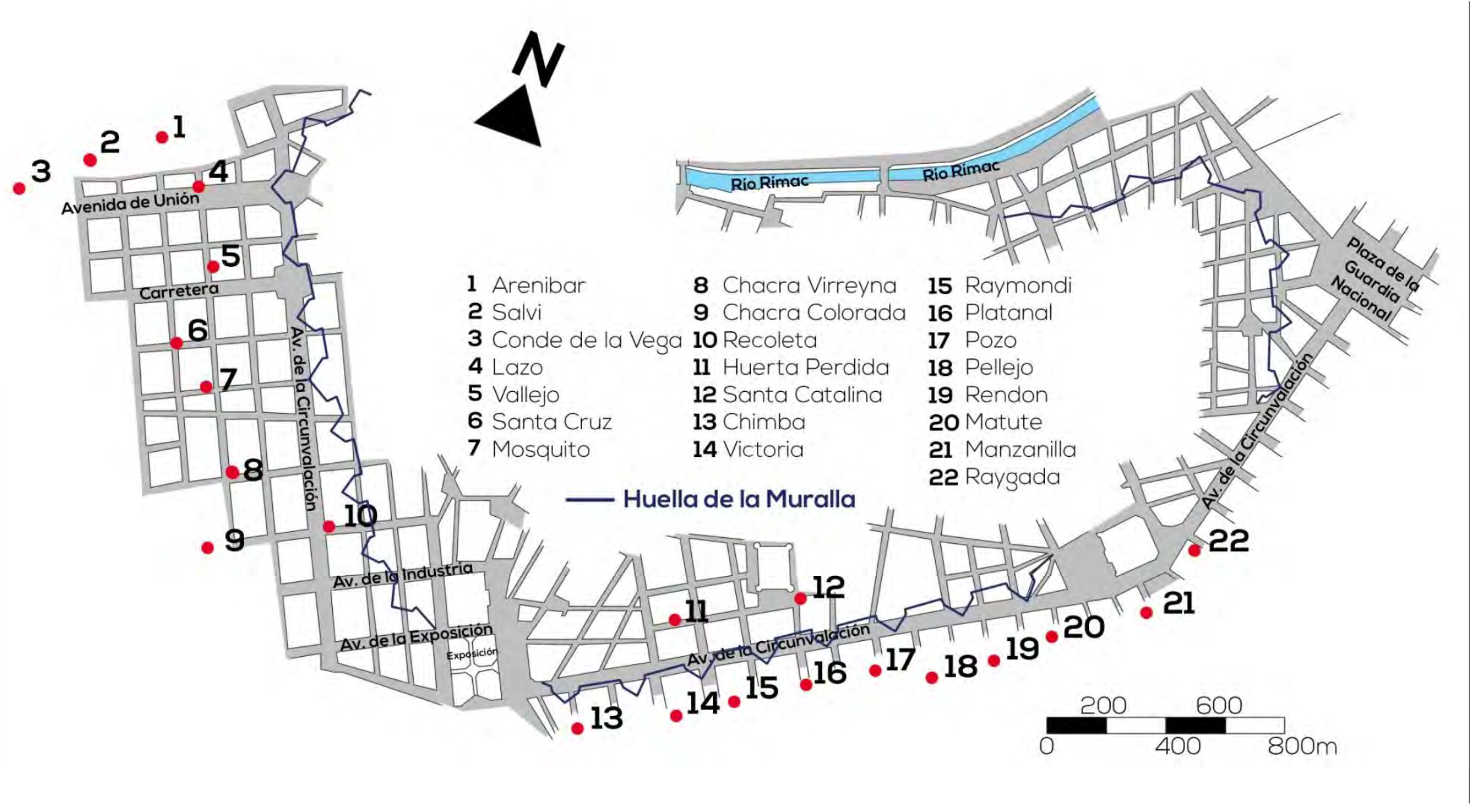

Fuente: Elaboración propia en base a Notario Selaya (1874), Notario Suarez (1875), Junta Departamental (1897), Basurco (1904), Tizón Bueno (1908), Bromley y Barbagelata (1945), 
El cuadro 3.5 nos muestra que la mayoría de las huertas y terrenos rurales cercanos a la muralla que abastecían a la ciudad eran de propiedad particular, lo que nos indica que el impacto esperado por el Estado para restarle poder a la Iglesia no fue significativo. Sn embargo, fue un intento por convertir a la periferia "en un espacio más laico, más libre; y es que al romperse la posición territorial de la Iglesia, también se encontró con una posición de más apertura en distintos ámbitos y así la población se liberó de las ataduras religiosas, lo que modificó y atrajo nuevas formas de vida y pensamiento"(Sánchez, 2013:76).

En el proceso de ejecución del Plan de Ensanche muchas de las propiedades que tenían una hipoteca con la Iglesia fueron transferidas a la banca comercial para permitir su venta o permuta y de esa manera se produjo la redistribución de la propiedad. Con esta acción se promovió la libertad mercantil como un hecho que sucedía en la periferia como consecuencia demolición de la muralla, pero que podía suceder en el centro de la ciudad a partir de las inversiones de compra de propiedades a la Iglesia de las familias de la élite e instituciones como la Beneficencia.

\subsection{Los Bancos Hipotecarios y la Ley de Expropiación en apoyo a los fraccionadores privados}

Entre los años de 1870 a 1875 la ciudad tuvo una repentina actividad económica producto del dinero que el Estado Peruano gastaba principalmente en la construcción de los ferrocarriles y que forzaba a la población a un mayor consumo (Basadre: 2014,tomoVII,84-85). A esta situación, se adicionó un crecimiento económico producto del apoyo del Estado Peruano a los empresarios privados extranjeros y nacionales que contribuyeron a la actividad económica en la ciudad, aportando capital para la realización de inversiones inmobiliarias y financieras. De esta manera, fue posible el desarrollo del mercado de consumo de productos y servicios que permitió el acceso a los créditos hipotecarios, favoreció el crecimiento económico en la ciudad, permitió a parte de la población a la compra de una propiedad e impulsó la expansión de la ciudad hacia la periferia. 


\subsubsection{Créditos hipotecarios y redistribución de la propiedad}

A partir de 1870 el sistema financiero, mediante hipotecas, absorbió los gravámenes provenientes de la Iglesia como censos63: reservativo64, consignativ065, enfitéutico66 y capellanías 67 con el objetivo de mejorar la redistribución de la propiedad en la ciudad. De esta manera, los bancos recibieron las primeras hipotecas o gravámenes (García Calderón, 1868:2326). Sin embargo, debido a falta de un registro de las hipotecas que ingresaban al sistema financiero en un padrón, se produjeron fraudes que generaron la desconfianza por parte de muchos propietarios ante el temor de perder sus bienes. Al respecto, el jurista Francisco García Calderón reclamó una mejor sistematización en el proceso de registro de una hipoteca a nivel nacional para tener un mayor control de este proceso y evitar fraudes (García Calderón, 1868:34-36). En este contexto, se hizo necesaria la aparición de un Registro Único de Hipotecas y una Ley para su funcionamiento que hubiera permitido un aumento de los créditos hipotecarios para la población con recursos económicos y una mayor inversión en bienes de la élite que hubiera acelerado el proceso de urbanización que no se dio en ese momento. Con los años, los bancos lograron una cierta confianza de los propietarios e inversionistas y de manera paulatina los prestamistas del mercado ilegal de hipotecas fueron desapareciendo y el mercado de hipotecas ingresó a un proceso de consolidación. Para ese entonces, los bancos hipotecarios cumplieron la función promover la actividad de bienes raíces, absorbieron las hipotecas de la

\footnotetext{
${ }^{63}$ Según Ricardo Tizón y Bueno "Censo en general se llama censo a un contrato en virtud del cual se adquiere el derecho a percibir una pensión mediante la entrega de alguna cosa "Agrimensura Legal Peruana", Ricardo, Tizón y Bueno, Ed. Imprenta Centro Editorial, Lima, 1913, p.44.

${ }^{64}$ Según Ricardo Tizón y Bueno "Censo Reservativo consiste en el mismo derecho de cobrar el canon, pero en virtud de la sesión de un fundo, hecha con esta condición”. Agrimensura Legal Peruana, Tizón y Bueno, 1913, pp. 45.

${ }^{65}$ Según Ricardo Tizón y Bueno "Censo Consignativo consiste en el derecho de cobrar por un tiempo indeterminado, cierto rédito o canon anual; en virtud de haberse impuesto el capital respectivo sobre un fundo, cuyo poseedor no está obligado a redimirlo ". "Agrimensura Legal Peruana", Ricardo Tizón y Bueno, Lima, Ed. Imprenta Centro Editorial, 1913, pp.44-45.

${ }^{66}$ Según Ricardo Tizón y Bueno "Censo enfitéutico o enfiteusis como impropiamente se le llama "Es un contrato por el cual una persona transfiere a otra el dominio útil de un fundo por cierto rédito o canon anual, conservando el dominio directo (Art.1886 de Código Civil).La duración de este contrato se cuenta por años o por vidas sin designar la persona o personas en cuyas cabezas se constituye cada vida equivale a 50 años (Art. 1890 Código Civil)" "Agrimensura Legal Peruana", Ricardo Tizón y Bueno, Lima, Ed. Imprenta Centro Editorial, 1907,pp.51.

67 Según Ricardo Tizón y Bueno "Capellanías es una fundación de una renta que debe gozar una persona con la obligación de celebrar un número de misas o desempeñar ciertos cargos (Art.1189 Código Civil)" ."Agrimensura Legal Peruana", Ricardo Tizón y Bueno, Lima, Ed. Imprenta Centro Editorial, 1907, pp.51.
} 
Iglesia y permitieron un mayor acceso de la población con poder adquisitivo a un bien. Uno de los bancos en cumplir estos objetivos fue el Banco de Crédito Hipotecario68 que estableció mecanismos para transferir un censo enfitéutico a una hipoteca (Banco de Crédito Hipotecario, 1873:04). Al respecto nos explica Ricardo Tizón y Bueno:

"Artículo 7.-El dueño del dominio directo ó del dominio útil que resulte obligado á abonar a otro el importe en dinero de sus derechos en la enfiteusis, podrá realizar ese abono dentro de dos años de plazo contados desde el día en que se celebre la escritura. En garantía de ese abono quedará la finca hipotecada á la otra parte durante dos años, en los mismos términos y condiciones de los contratos de los bancos hipotecarios (4). En todo caso, el dueño del dominio útil seguirá en posesión mientras no se realice el pago en dinero en efectivo. Estas hipotecas por dos años, podrán ser transferidas al banco, sustituyéndose este, al acreedor y extendiendo el plazo y las condiciones a lo que es usual en los contratos hipotecarios, sin que sea necesaria la previa cancelación y nuevo contrato que prescribe la ley de contratos hipotecarios "(Ricardo Tizón y Bueno, 1917:4-5).

En ese momento las hipotecas de propiedades a favor de la Iglesia fueron disminuyendo y se incorporaron al sistema financiero, generando una mayor actividad de bienes raíces en la ciudad. Los bancos tuvieron que implementar reglamentos internos para realizar esta tarea y no tener pedidas económicas como crear contratos de dos años para poder recibir un censo como hipoteca. Esta fue una muestra de las libertades que tenían para operar en el mercado debido de una falta de control del Estado Peruano, que buscó que la ciudad tuviera menos inquilinos y más propietarios. La oferta de créditos hipotecarios por parte de los bancos, generó una expectativa en la población y los inversionistas. Al respecto, publicó el Diario El Nacional:

"Dilatar, dar proporciones mayores al crédito territorial, es poner hasta cierto punto en movimiento una gran parte del valor que los fundos representan, valores estancados y que no entran en circulación de la riqueza, en proporción en que estaban llamadas a entrar. Es en cierto modo duplicar ese valor, desde el titulo que representa la hipoteca es un nuevo capital que se arroja a la circulación, garantizado por el fundo y por el banco, y que lejos de embarazar, impulsa movimiento de la propiedad gravada. El establecimiento del Banco Territorial del Perú revela que el espíritu de iniciativa se va extendiendo y en consecuencia que se irán aumentando las condiciones del último caso, la riqueza de los Estados "(El Nacional, 1870:01).

La aparición de los créditos hipotecarios no solo buscó generar una redistribución de la propiedad sino permitió a los propietarios de bienes en la ciudad la posibilidad de contar con un capital para invertir en otras actividades

\footnotetext{
68 Según los Estatutos del Banco de Crédito Hipotecario "El interés de la anualidad era del diez por ciento por un tiempo de veinte años Las hipotecas no podían exceder la mitad del valor de bien inmueble. El valor del inmueble hipotecado no será menor de dos mil soles y el préstamo no será menor de quinientos soles "Estatutos del Banco de Crédito Hipotecario aprobados por Supremos Decreto del 16 de agosto de 1866, Lima, 1873, Ed. Imprenta de Francisco Solís Plazuela de Santo Tomas N²55, pp.6-7.
} 
como la industria y el comercio, beneficiando con oferta laboral a la población y con una mayor recaudación de impuestos al Estado Peruano. En este momento la ciudad, tenía una actividad económica que permitió una mayor oferta de propiedades en venta y en alquiler, lo que propició una diversificación del mercado de suelo en el centro de la ciudad.

Debido a que las Leyes sobre hipotecas aun no se habían implementado para prestar garantías a los propietarios y a los inversionistas generaron pérdidas a los inversionistas privados y particulares, aumentaron los litigios de propiedades en la ciudad, muchos de los inversionistas decidieron no ingresar al mercado financiero, la población dudaba sobre hipotecar su propiedad. Sin embargo, a pesar de la falta de una legislación, la hipoteca69 era vista como una forma de acceder a la posesión de una propiedad para el arrendamiento de vivienda y para el Estado Peruano se convirtió en un instrumento para alcanzar el progreso.

\footnotetext{
${ }^{69}$ Según Francisco García Calderón "la palabra hipoteca designa un contrato accesorio que tiene por objeto asegurar una obligación principal; y consiste en que el que toma dinero prestado conceda al acreedor el derecho de hacer vender una finca determinada sino se paga la deuda en el plazo convenido. También se llama hipoteca, el gravamen mismo que la finca soporta y el derecho que sobre ella tiene el acreedor". "Diccionario de la Legislación Peruana", Lima, 1 vol., ed. Paris Librarie, 2003, pp.1072.
} 
Cuadro 3.6

Hipotecas en la ciudad de Lima entre los años (1873-1875)

\begin{tabular}{|c|c|c|c|c|c|c|c|}
\hline $\begin{array}{c}\text { Tipo de } \\
\text { transacción }\end{array}$ & Propiedad & ubicación & Monto & $\begin{array}{c}\text { Compra } \\
\text { dor }\end{array}$ & Vendedor & Banco & Fuente \\
\hline $\begin{array}{l}\text { Hipoteca } \\
\text { 3/agosto/1875 }\end{array}$ & Finca & $\begin{array}{l}\text { Calle del } \\
\text { Espíritu } \\
\text { Santo } \\
\text { (periferia) }\end{array}$ & $\begin{array}{c}\mathrm{s} / .10,000 \\
\text { ó } \\
500 \text { pesos }\end{array}$ & $\begin{array}{l}\text { Don. } \\
\text { Bernardo } \\
\text { Prus }\end{array}$ & $\begin{array}{l}\text { Paulo } \\
\text { Gómez } \\
\text { Sánchez } \\
\text { Hidalgo }\end{array}$ & $\begin{array}{l}\text { Banco } \\
\text { Territorial } \\
\text { Hipotecario }\end{array}$ & $\begin{array}{l}\text { Notario } \\
\text { Palacios, } 187 \\
\text { 5:1251v1252 }\end{array}$ \\
\hline $\begin{array}{l}\text { Cancelación } \\
\text { de hipoteca }\end{array}$ & Casa & $\begin{array}{l}\text { Calle } \\
\text { Mariquitas } \\
\text { Núm. } 76 \\
\text { (periferia) }\end{array}$ & $\begin{array}{c}\text { s/.1000 } \\
\text { ó } \\
50 \text { pesos }\end{array}$ & $\begin{array}{l}\text { Don. } \\
\text { Fidel } \\
\text { Sosa }\end{array}$ & $\begin{array}{l}\text { Doña } \\
\text { Juana } \\
\text { Lazo de } \\
\text { Elespuru }\end{array}$ & Sin dato & $\begin{array}{l}\text { Notario } \\
\text { Palacios, } 187 \\
5: 1278 v- \\
1279\end{array}$ \\
\hline $\begin{array}{l}\text { Hipoteca } \\
\text { Cancelación }\end{array}$ & Finca & $\begin{array}{l}\text { Calle la } \\
\text { Libertad } \\
\text { segunda } \\
\text { cuadra } \\
\text { Núm.40(p } \\
\text { eriferia) }\end{array}$ & $\begin{array}{c}\mathrm{s} / 17,600 \\
\text { ó } \\
800 \text { pesos }\end{array}$ & $\begin{array}{l}\text { Don. } \\
\text { Melitón } \\
\text { Porras }\end{array}$ & $\begin{array}{l}\text { Antonieta } \\
\text { Rodríguez } \\
\text { de la Peña }\end{array}$ & $\begin{array}{l}\text { Banco } \\
\text { Territorial } \\
\text { Hipotecario }\end{array}$ & $\begin{array}{l}\text { Notario } \\
\text { Palacios } \\
\text {,1875:1297 }\end{array}$ \\
\hline Venta & $\begin{array}{l}\text { Terreno } \\
672 \text { varas } \\
\text { A } 4 \text { soles la } \\
\text { vara } \\
\text { cuadrada }\end{array}$ & $\begin{array}{l}\text { Calle de la } \\
\text { Pampilla } \\
\text { (periferia) }\end{array}$ & $\begin{array}{c}\text { s/.2688 } \\
\text { ó } \\
134,4 \\
\text { pesos }\end{array}$ & $\begin{array}{l}\text { José } \\
\text { García } \\
\text { Maldona } \\
\text { do }\end{array}$ & $\begin{array}{l}\text { José } \\
\text { Elguera }\end{array}$ & Sin dato & $\begin{array}{l}\text { Colección } \\
\text { Terán } \\
\text { Tomo25,187 } \\
4: 341 \mathrm{v}\end{array}$ \\
\hline Cancelación & $\mathrm{s} / \mathrm{d}$ & Sin dato & $\begin{array}{c}\text { s/197333 } \\
\text { ó } \\
9866 \\
\text { pesos }\end{array}$ & $\begin{array}{l}\text { Banco } \\
\text { "El Perú" }\end{array}$ & $\begin{array}{l}\text { Enrique } \\
\text { Meiggs }\end{array}$ & $\begin{array}{l}\text { Banco El } \\
\text { Perú }\end{array}$ & $\begin{array}{l}\text { Notario } \\
\text { Palacios, } 187 \\
5: 1317 \mathrm{v}- \\
1318\end{array}$ \\
\hline Venta & $\begin{array}{l}\text { Terrenos } \\
\text { hacienda } \\
\text { Lusisitico }\end{array}$ & Sin dato & $\begin{array}{c}\text { s/300000 } \\
\text { ó } \\
15,000 \\
\text { pesos }\end{array}$ & $\begin{array}{l}\text { Federico } \\
\text { Ford }\end{array}$ & $\begin{array}{l}\text { Enrique } \\
\text { Meiggs }\end{array}$ & Sin dato & $\begin{array}{l}\text { Colección } \\
\text { Terán Tomo } \\
251874: 352\end{array}$ \\
\hline Cancelación & Finca & $\begin{array}{l}\text { Calle } \\
\text { Espíritu } \\
\text { Santo } \\
\text { (periferia) }\end{array}$ & $\begin{array}{c}\mathrm{s} / 10000 \\
\text { ó } \\
500 \text { pesos }\end{array}$ & $\begin{array}{l}\text { Manuel y } \\
\text { Santiago } \\
\text { Basuera }\end{array}$ & $\begin{array}{l}\text { Felipe } \\
\text { Santiago } \\
\text { Hidalgo }\end{array}$ & $\begin{array}{l}\text { Banco } \\
\text { Territorial } \\
\text { Hipotecario }\end{array}$ & $\begin{array}{l}\text { Notario } \\
\text { Palacios } \\
\text {,1875:1255 }\end{array}$ \\
\hline $\begin{array}{l}\text { Hipoteca } \\
\text { (Plazo de un } \\
\text { año) }\end{array}$ & Casa & $\begin{array}{l}\text { Calle } \\
\text { Polvos } \\
\text { Azules } \\
\text { Núm.04 } \\
\text { (periferia } \\
\text { río Rímac) }\end{array}$ & $\begin{array}{c}\text { s/10000 } \\
\text { ó } \\
500 \text { pesos }\end{array}$ & $\begin{array}{l}\text { Doña } \\
\text { Balbina } \\
\text { Castillos }\end{array}$ & $\begin{array}{l}\text { Doña } \\
\text { Faustina } \\
\text { de } \\
\text { González } \\
\text { y Doña } \\
\text { Enriqueta } \\
\text { Hercelles }\end{array}$ & Sin dato & $\begin{array}{l}\text { Notario } \\
\text { Palacios, } 187 \\
5 \\
: 1260\end{array}$ \\
\hline $\begin{array}{l}\text { Traspaso de } \\
\text { enfiteusis } \\
\text { Monasterio } \\
\text { Encarnación }\end{array}$ & Casa & $\begin{array}{l}\text { Calle } \\
\text { Belén } \\
\text { (centro) }\end{array}$ & $\begin{array}{c}15,000 \\
\text { pesos } \\
\text { Ó } \\
\mathrm{s} / .300,000\end{array}$ & $\begin{array}{l}\text { Don } \\
\text { Pedro } \\
\text { Gallague } \\
r\end{array}$ & $\begin{array}{l}\text { Don } \\
\text { Adolfo } \\
\text { Lachavier } \\
\text { e }\end{array}$ & Sin dato & $\begin{array}{l}\text { Colección } \\
\text { Terán Tomo } \\
25,1873 \\
: 330 \mathrm{v}\end{array}$ \\
\hline
\end{tabular}

Fuentes: Elaboración propia en base a documentos del Archivo General de la Nación del Perú: Notario Colección Terán (1873) y (1874) y Palacios (1875). 
En ese momento los bancos recibían a los inversionistas y las Cajas de Ahorro eran utilizadas por las clases obrera, media y extranjera para ahorrar su dinero y poder acceder a un crédito hipotecario en un mediano y corto plazo (Diario El Nacional, 1870 á, 18 de febrero:01).

El cuadro 3.6 nos muestra que el Banco Territorial Hipotecario era el que tenía una mayor actividad en la ciudad debido a que recibió las propiedades transferidas de la Iglesia y facilitó préstamos a largo plazo, pagaderos en anualidades al seis por ciento del interés hasta en veinte años (Banco Hipotecario, 1873:4). Los valores de los predios hipotecados no eran menores a 2,000 soles (Banco Hipotecario, 1873:7). También podemos observar, que los montos de las hipotecas tenían un rango de 10,000 a 30,000 soles aproximadamente que era el valor del $30 \%$ del valor del predio. Este dinero, sirvió a la élite comercial y terrateniente para acceder a comprar otros terrenos en la ciudad, comprar casas más pequeñas en la periferia, refaccionar otras propiedades y de esta manera incrementar su patrimonio inmobiliario. Así también las hipotecas, en su mayor parte, se realizaban sobre terrenos ocupados en la periferia, lo que nos muestra una mayor actividad de redistribución del mercado de suelo en esta zona que el centro de la ciudad. Esa fue una consecuencia de las obras del Plan de Ensanche

\subsubsection{Expropiación, permutas, enajenaciones forzadas y expropiaciones de propiedades}

Para la ejecución del Plan de Ensanche el Estado Peruano decidió poner en vigencia la de Ley de Expropiación, el mecanismo que legitimaría el nuevo uso del suelo. Según Decreto supremo publicado el 08 de marzo de 1870 (Diario oficial El Peruano,1870 á, 11 marzo:207) la Ley de Expropiación entró en vigencia en esa fecha. Este hecho, generó la expectativa, en parte de la población que vivía en la periferia, de que mejoraría su calidad de vida y, para la población del centro, que terminarían los problemas de salubridad y el pago de rentas altas. Sin embargo, la decisión de aplicar la Ley de Expropiación en la periferia para ejecutar la urbanización tuvo consecuencias contradictorias. Por un lado reorganizó el trazado de la periferia, regularizó la tenencia donde 
se ejecutó la obra pública y mejoró el pago de impuestos prediales. Por otro lado, generó la pérdida de espacios verdes y, sobre todo, no permitió una retribución justa a los propietarios de los bienes expropiados. Frente a esa amenaza se generaron otras alternativas que compensaran de mejor manera al propietario y que permitieran el avance de las obras en la periferia. Estas fueron la permuta70 y enajenación forzosa71. No obstante, la expropiación72 siguió siendo aplicada en algunos casos cuando fue necesario mostrar el poder del Estado Peruano para la ejecución de una obra pública, como en la ejecución de las obras de ferrocarriles y en casos especiales en la ciudad. Dentro de las alternativas que surgieron producto de la necesidad de los propietarios de obtener un mejor precio por su bien en caso de expropiación, estuvo la permuta, la que por su versatilidad de transformarse en una venta y porque la transacción solo requirió de un simple contrato y ante la posibilidad de disolver la transacción de mutuo acuerdo sin llegar a un litigio se convirtió en la más utilizada (García Calderón, 2003:1516). El cuadro siguiente muestra algunos ejemplos.

\footnotetext{
${ }^{70}$ Según Francisco García Calderón "Permuta es un contrato entre dos o más personas se transfiere el dominio legal de una cosa por otra. En la permuta cada uno de los contratantes es comprador y vendedor, y cada una de las cosas permutadas es cosa vendida y precio de la otra. Cuando no se toma en consideración el valor de las cosas, la permuta es simple. Si se hace comparación de valores es estimada. Son permutables todas las cosas que puedan ser enajenadas, y puede permutar el que puede enajenar. El administrador no puede hacer permuta, sino estimada, previo avaluó de la cosa y demás requisitos prescritos en el código civil. Para validez de las permutas no es necesario inspeccionar ni tener a la vista las cosas permutadas; bastas que sean conocidas por los permutantes. El contrato de permuta se constituye por solo el convenio de las partes; la entrega es su cumplimiento ", "Diccionario de la Legislación Peruana", Francisco García Calderón, Lima, 1 vol., ed. Paris Librarie, 2003, pp.1316.

${ }^{71}$ Según Francisco García Calderón “ Enajenación forzosa la cesión o venta que una persona o cuerpo tiene que hacer de una cosa de su propiedad, por motivos de utilidad pública...para que se acredite que un bien es de utilidad pública se requiere: 1.-Que se acredite de un modo indudable la necesidad de tomarla y la utilidad que la Nación o el pueblo deberán reportar; 2.- Que se indemnice previamente al dueño del valor de su propiedad, proporcionando no solo al que realmente tiene sino a las ventajas que le produce. Antes de proceder al juicio, debe formarse un expediente sobre la necesidad de la obra pública que exige la expropiación forzada; y en él se manifiesta con operaciones de perito la posibilidad y medio de ejecución, y cuanto produzca aprobar los dos extremos dichos, que son la necesidad de tomar la propiedad privada y la utilidad que la Nación o el pueblo deben reportar de este hecho "Diccionario de la Legislación Peruana", Francisco García Calderón, Lima, 1 vol., ed. Jurídica Grijley, Lima,2003, pp.832.
}

\footnotetext{
${ }^{72}$ Según Francisco García Calderón "Expropiaciones es el acto de quitar a uno de su propiedad para emplearla en otra utilidad pública. En el artículo enajenación forzada hemos tratado los casos y el modo en que puede hacerse la expropiación". "Diccionario de la Legislación Peruana", Francisco García Calderón, Lima, 1 vol. ed. Jurídica Grijley, 2003, pp.931.
} 


\section{Cuadro 3.7}

\section{Expropiaciones, ventas forzosas y permutas en Lima \\ Entre (1872-1876)}

\begin{tabular}{|c|c|c|c|c|c|c|c|}
\hline $\begin{array}{c}\text { Tipo de } \\
\text { transacción }\end{array}$ & De & A & Motivo & $\begin{array}{l}\text { Precio } \\
\text { V2 } \\
\text { soles }\end{array}$ & Área & Ubicación & Fuente \\
\hline Permuta & $\begin{array}{l}\text { Enrique } \\
\text { Meiggs }\end{array}$ & $\begin{array}{l}\text { Miguel } \\
\text { Trefogli }\end{array}$ & $\begin{array}{l}\text { Apertura de } \\
\text { la Av. De } \\
\text { Santa Teresa }\end{array}$ & $\begin{array}{c}\text { s/. } 1 \\
\text { ó } \\
20 \\
\text { pesos }\end{array}$ & $\begin{array}{c}\text { Meiggs } \\
\text { cede } 2 \\
\text { terrenos } \\
\text { de } 884 \mathrm{v}^{2} \mathrm{y} \\
662 \mathrm{v}^{2} \mathrm{y} \\
\text { Trefogli } \\
\text { cede un } \\
\text { terreno de } \\
85 \mathrm{v}^{2}\end{array}$ & $\begin{array}{l}\text { Huerta } \\
\text { Perdida }\end{array}$ & $\begin{array}{l}\text { Notario } \\
\text { Suarez,1874:36 } \\
\text { 8-369 }\end{array}$ \\
\hline Permuta & $\begin{array}{c}\text { Compañía } \\
\text { de Obras } \\
\text { Públicas y } \\
\text { Fomento } \\
\text { de Lima }\end{array}$ & $\begin{array}{c}\text { Tomas } \\
\text { Gómez } \\
\text { Villabaz } \\
0\end{array}$ & $\begin{array}{l}\text { Lotes de las } \\
\text { murallas para } \\
\text { el dominio } \\
\text { útil de la } \\
\text { Huerta } \\
\text { Virreina }\end{array}$ & $\begin{array}{l}\text { Sin } \\
\text { dato }\end{array}$ & $\begin{array}{c}\text { La } \\
\text { Compañía } \\
\text { de Obras } \\
\text { Públicas y } \\
\text { Fomento } \\
\text { cede } \\
365 v^{2}\end{array}$ & Sin dato & $\begin{array}{c}\text { Colección Terán } \\
\text { Tomo 25,1876: } \\
387 v-388\end{array}$ \\
\hline Permuta & $\begin{array}{l}\text { Leonor } \\
\text { Llona de } \\
\text { López }\end{array}$ & $\begin{array}{c}\text { Julio } \\
\text { Laporte }\end{array}$ & $\begin{array}{c}\text { Terrenos de } \\
\text { la Calle } \\
\text { Tayacaja }\end{array}$ & $\begin{array}{l}\text { Sin } \\
\text { dato }\end{array}$ & $\begin{array}{c}\text { Llona } \\
\text { cede } \\
149 v^{2} y \\
\text { Laporte } \\
\text { cede } \\
116 v^{2} \\
\end{array}$ & $\begin{array}{c}\text { Terrenos de } \\
\text { la Calle } \\
\text { Tayacaja } \\
\text { (intermedio) }\end{array}$ & $\begin{array}{c}\text { Colección Terán } \\
\text { Tomo 25,1875: } \\
368\end{array}$ \\
\hline Permuta & $\begin{array}{l}\text { Enrique } \\
\text { Meiggs }\end{array}$ & $\begin{array}{l}\text { Gregori } \\
\text { o N. } \\
\text { Real }\end{array}$ & $\begin{array}{c}\text { Hacienda } \\
\text { Miranaves } \\
\text { que compró } \\
\text { de Sada }\end{array}$ & $\begin{array}{c}20 \text { sol } \\
\text { centavo } \\
\text { s la } \\
\text { vara } \\
4 \text { pesos }\end{array}$ & $\begin{array}{c}\text { N. Real } \\
\text { cede } 14 \\
590 v^{2}\end{array}$ & & $\begin{array}{c}\text { Notario Suarez, } \\
1874: 542 v-544\end{array}$ \\
\hline
\end{tabular}




\begin{tabular}{|c|c|c|c|c|c|c|c|}
\hline $\begin{array}{c}\text { Tipo de } \\
\text { transacción }\end{array}$ & De & A & Motivo & $\begin{array}{l}\text { Precio } \\
\text { V2 soles }\end{array}$ & Área & Ubicación & Fuente \\
\hline Expropiación & $\begin{array}{c}\text { María } \\
\text { Herrera, } \\
\text { Mercedes } \\
\text { Herrera, } \\
\text { Josefa } \\
\text { Herrera, } \\
\text { Cesar } \\
\text { Lazo y } \\
\text { Flores. }\end{array}$ & $\begin{array}{l}\text { Enrique } \\
\text { Meiggs }\end{array}$ & $\begin{array}{l}\text { Alameda } \\
\text { de } \\
\text { Circunvala } \\
\text { ción }\end{array}$ & $\begin{array}{c}25 \\
\text { centavos } \\
\text { sol x m2 } \\
\text { ó } \\
5 \text { pesos }\end{array}$ & $\begin{array}{c}148.66 \\
0 m^{2}\end{array}$ & $\begin{array}{c}\text { Terrenos de } \\
\text { Chacra } \\
\text { Colorada } \\
\text { (periferia) }\end{array}$ & $\begin{array}{c}\text { Notario } \\
\text { Palacios } \\
1875: 1342- \\
1344\end{array}$ \\
\hline $\begin{array}{c}\text { Cesión y } \\
\text { expropiación }\end{array}$ & $\begin{array}{l}\text { Augusto } \\
\text { Althaus }\end{array}$ & $\begin{array}{l}\text { Enrique } \\
\text { Meiggs }\end{array}$ & $\begin{array}{c}\text { Por la } \\
\text { Sociedad } \\
\text { "La } \\
\text { Construct } \\
\text { ora" }\end{array}$ & $\begin{array}{l}40000 \\
\text { pesos }\end{array}$ & $\begin{array}{l}\text { Sin } \\
\text { dato }\end{array}$ & $\begin{array}{l}\text { Huerta San } \\
\text { Jacinto } \\
\text { propiedad de } \\
\text { La } \\
\text { Beneficencia } \\
\text { inmediata s } \\
\text { la fábrica de } \\
\text { gas y fábrica } \\
\text { hecha en } \\
\text { ella. }\end{array}$ & $\begin{array}{c}\text { Colección } \\
\text { Terán Tomo } \\
06 \text { Año } 1875 \\
\text { fol. } 172 v\end{array}$ \\
\hline $\begin{array}{c}\text { Compra-Venta } \\
\text { forzada o } \\
\text { enajenación } \\
\text { forzada } \\
\end{array}$ & $\begin{array}{l}\text { Francisco } \\
\text { Delgado } \\
\text { de la Flor }\end{array}$ & $\begin{array}{l}\text { Enrique } \\
\text { Meiggs }\end{array}$ & $\begin{array}{l}\text { Ferrocarril } \\
\text { de llo a } \\
\text { Moquegua }\end{array}$ & $\begin{array}{c}s / .1626 \\
81.6 \\
\text { pesos }\end{array}$ & $\begin{array}{l}\text { Sin } \\
\text { dato }\end{array}$ & $\begin{array}{c}\text { Villa en } \\
\text { Moquegua, } \\
\text { Arequipa }\end{array}$ & $\begin{array}{c}\text { Notario Suarez } \\
, 1874: 46-47\end{array}$ \\
\hline $\begin{array}{c}\text { Venta por } \\
\text { expropiación }\end{array}$ & $\begin{array}{c}\text { Don José } \\
\text { Equisquiz } \\
\text { a }\end{array}$ & $\begin{array}{l}\text { Enrique } \\
\text { Meiggs }\end{array}$ & $\begin{array}{c}\text { Ferrocarril } \\
\text { de } \\
\text { Pacasmay } \\
0\end{array}$ & $\begin{array}{c}3000 \\
\text { pesos } \\
60,000 . \mathrm{s} /\end{array}$ & $\begin{array}{l}\text { Sin } \\
\text { dato }\end{array}$ & $\begin{array}{c}\text { Calle } \\
\text { Cajamarca } \\
\text { (centro) }\end{array}$ & $\begin{array}{c}\text { Notario Suarez } \\
1874: 252-255\end{array}$ \\
\hline $\begin{array}{l}\text { Convenio y } \\
\text { expropiación }\end{array}$ & $\begin{array}{l}\text { Paula } \\
\text { Cortes de } \\
\text { Muente }\end{array}$ & $\begin{array}{c}\text { Empresa } \\
\text { Ferrocaril } \\
\text { La } \\
\text { Magdalen } \\
\text { a } \\
\end{array}$ & $\begin{array}{c}\text { Ferrocarril } \\
\text { Magdalen } \\
\text { a }\end{array}$ & Sin dato & $\begin{array}{l}\text { Sin } \\
\text { dato }\end{array}$ & $\begin{array}{c}\text { Población de } \\
\text { La } \\
\text { Magdalena }\end{array}$ & $\begin{array}{c}\text { Colección } \\
\text { Terán Tomo } \\
\text { 02, 1872: } 829\end{array}$ \\
\hline
\end{tabular}

Fuente: Elaboración propia en base Colección Terán (1872),(1875), Suarez (1874), Palacios (1875).

Como una segunda alternativa ante una expropiación, la enajenación forzosa permitió al propietario negociar el monto de su indemnización por el predio expropiado. (García Calderón, 2003:832). Esto beneficiaba al propietario y, especialmente, al Estado Peruano y a los urbanizadores, pues permitía que la 
expropiación fuera ejecutada en el menor tiempo sin necesidad de litigios y procedimientos como trámites administrativos y valuaciones. Como vemos en el los cuadro 3.3, las permutas se utilizaron principalmente para la apertura de las calles como Santa Teresa, Tayacaja y alameda de Circunvalación según el Plan de Ensanche entre los años de 1874 a 1875. Las enajenaciones forzosas fueron poco frecuentes y las expropiaciones fueron aplicadas en su mayoría para la ejecución de las obras de ferrocarriles. Puede verse también que un actor central en estas negociaciones, a menudo como beneficiario, fue Enrique Meiggs. En consecuencia, la decisión política del Estado para que el fraccionador Meiggs cumpliera la doble función pública-privada contribuyó a la agudización del monopolio de suelo en la periferia con el uso de estas transacciones. Además, el modelo permitió que Meiggs hiciera uso de su cargo para adquirir propiedades a precio de expropiación y generó el descontento de los propietarios que vivían en la periferia. Los terrenos que adquirió fueron los mejor ubicados, los que en un futuro, al culminar los trabajos del Plan de Ensanche, subirían de precio. Este fue el caso de los terrenos de la huerta Virreina permutados por terrenos de la muralla de propiedad de Meiggs, Archivo General de la Nación, Colección Terán, Tomo, Año,1876 fol.387v-388.

\subsection{La actividad de renta en la ciudad (1872-1876)}

La actividad de renta caracterizó a la ciudad desde el periodo colonial tanto Gabriel Ramón (Ramón,1999:110-119) como J. Parker (Parker,1998:156-158) describen las malas condiciones higiénicas en que vivían las familias y el alto costo de los alquileres que llevó a muchos inquilinos de clase media y clase baja a decidir por buscar comprar una vivienda en la periferia. Durante la colonia y principios del siglo XIX, los grandes propietarios de la ciudad eran la Iglesia, el Estado, la Municipalidad y la Beneficencia que tenían el mayor número de inquilinos y decidían acerca de los precios de la renta. Sin embargo, los contratos de arrendamiento estaban controlados por el Estado a través del código civil (García Calderón, 2003:162) para evitar la especulación de la renta y que además garantizaba que las transacciones beneficiaran a ambas partes. 
Las propiedades podían ser arrendadas por un tiempo máximo de diez años para evitar el deterioro y estancamiento de la redistribución de la renta en la ciudad. Gracias al control por parte del Estado Peruano fue posible realizar los traspasos73 que favorecieron a los propietarios a realizar prestamos con los bancos para refaccionar los inmuebles y a los inquilinos tener la posibilidad de contar con una vivienda y refaccionar el inmueble deteriorado a cuenta de alquileres. Esta modalidad contribuyó a la mejora de muchas casas deterioradas ocupadas por los inquilinos por el tiempo máximo de diez años. En el siguiente cuadro vemos algunas características de la actividad de renta en la ciudad.

\footnotetext{
73 Según Francisco García Calderón "Cesión de traspaso es la renuncia de aquello que se tiene o posee dando y entregando a otro el dominio. Regularmente es lo que se tiene arrendado o alquilado. Entre nosotros se tiene I costumbre de llamar traspasos a las mejorar que un arrendatario ha hecho de la finca arrendada que se deben ser abonadas por el dueño o por el nuevo arrendatario, al terminar la locación. En esta materia prevalece la costumbre del convenio del primero y el segundo arrendatarios sobre las disposiciones". "Diccionario de la Legislación Peruana", Francisco García Calderón, Lima, 1 vol. ed. Jurídica Grijley, 2003, Lima, pp.1785.
} 


\section{Cuadro 3.8}

\section{Arrendamientos en la ciudad entre los años de (1874-1875)}

\begin{tabular}{|c|c|c|c|c|c|}
\hline Arrendador & Arrendatario & $\begin{array}{l}\text { Precio } \\
\text { mensual }\end{array}$ & Plazo & Propiedad & Fuente \\
\hline $\begin{array}{l}\text { Monasterio Santa } \\
\quad \text { Clara }\end{array}$ & $\begin{array}{l}\text { José F. } \\
\text { Castañeda }\end{array}$ & $\begin{array}{l}\text { s/. } 74 \mathrm{~s} 4 \text { años } \\
\text { s/. } 70 \times 6 \text { años } \\
\text { restantes }\end{array}$ & 10 años & $\begin{array}{c}\text { Casa alta y baja con sus } 2 \\
\text { tiendas accesorias en calle } \\
\text { de Las Descalzas. }\end{array}$ & $\begin{array}{c}\text { Notario } \\
\text { Suarez,1874:261- } \\
261 \mathrm{v} \\
\end{array}$ \\
\hline $\begin{array}{l}\text { Francisco } \\
\text { Casimiro }\end{array}$ & $\begin{array}{l}\text { Placido } \\
\text { Somates }\end{array}$ & $\mathrm{s} / .20$ & 8 años & $\begin{array}{l}\text { Pulpería situada al costado } \\
\text { del monasterio del Prado } \\
\text { frente a la Huerta que fue } \\
\text { de Esteban Jiménez }\end{array}$ & $\begin{array}{c}\text { Notario } \\
\text { Suarez,1874:266v }\end{array}$ \\
\hline Juan Roldad & $\begin{array}{l}\text { Rafael } \\
\text { Gallegos }\end{array}$ & $\begin{array}{l}\text { s/. } 16 \times 3 \text { años } \\
\text { s/. } 20 \times 2 \\
\text { restantes }\end{array}$ & 5 años & $\begin{array}{l}\text { Casita y fábrica Ollería } \\
\text { situadas en Calle Malambo }\end{array}$ & $\begin{array}{c}\text { Notario } \\
\text { Suarez,1874: } 271 \mathrm{v}- \\
272 \\
\end{array}$ \\
\hline $\begin{array}{l}\text { Melchor } \\
\text { Velasquez }\end{array}$ & $\begin{array}{c}\text { José } \\
\text { Monteverde }\end{array}$ & $\begin{array}{l}\text { s/. } 12 \times 5 \text { años } \\
\text { s/. } 20 \times 5 \\
\text { restantes }\end{array}$ & 10 años & $\begin{array}{c}\text { Tienda compuesta de } 2 \\
\text { piezas y } 1 \text { corral situada en } \\
\text { la Calle Pandra }\end{array}$ & $\begin{array}{c}\text { Notario } \\
\text { Suarez,1874:276 }\end{array}$ \\
\hline $\begin{array}{l}\text { María Luisa } \\
\text { Rueda }\end{array}$ & Florentino Lira & $\begin{array}{l}\text { s/. } 800 \times 5 \text { años } \\
\text { s/. } 100 \times 5 \\
\text { restantes }\end{array}$ & 10 años & $\begin{array}{c}\text { Casa ubicada en la Calle } \\
\text { del Hospital de San Lázaro } \\
N^{0} 107 \\
\end{array}$ & $\begin{array}{c}\text { Notario } \\
\text { Suarez,1874:381v }\end{array}$ \\
\hline $\begin{array}{l}\text { Manuela } \\
\text { Espichan }\end{array}$ & Manuel Peña & $\begin{array}{c}50 \text { pesos } x 1 \\
\text { año o } 2.5 \text { soles } \\
60 \text { pesos } x \\
\text { 1resto o } 3 \text { soles }\end{array}$ & 9 años & $\begin{array}{l}\text { Casita solar en Calle Los } \\
\text { Gallinasitos } N^{\circ} 6\end{array}$ & $\begin{array}{c}\text { Notario } \\
\text { Palacios,1874: } \\
116 \mathrm{v}-117 \mathrm{v}\end{array}$ \\
\hline José Bianchi & $\begin{array}{l}\text { José Felipe } \\
\text { Choino }\end{array}$ & $\mathrm{s} / .800$ & 20 años & $\begin{array}{l}\text { Almacén de la propiedad } \\
\text { situada en calle de } \\
\text { Espaderos } N^{\circ} 198 \text { y } 200\end{array}$ & $\begin{array}{c}\text { Notario } \\
\text { Palacios, } 1875: 356- \\
357 \\
\end{array}$ \\
\hline $\begin{array}{l}\text { Diario La Opinión } \\
\text { Nacional }\end{array}$ & Sin dato & $\begin{array}{l}80 \text { soles } \\
\text { mensuales }\end{array}$ & 10 años & $\begin{array}{c}\text { Altos situados en la Calle } \\
\text { del Pezuelo de Santo } \\
\text { Domingo } N^{\circ} 57\end{array}$ & $\begin{array}{l}\text { Diario La Opinión } \\
\text { Nacional, 1875:01. }\end{array}$ \\
\hline $\begin{array}{l}\text { Cesión y traspaso } \\
\text { Terreno }\end{array}$ & $\begin{array}{l}\text { Domingo Boza } \\
\text { A } \\
\text { Compañía de } \\
\text { Ferrocarril } \\
\text { Lima Chancay }\end{array}$ & $\begin{array}{l}\mathrm{s} / 2100 \\
\mathrm{~s} / 2 \text { por v2 de } \\
4200 \mathrm{v} 2\end{array}$ & Sin dato & $\begin{array}{l}\text { Terrenos forma parte de la } \\
\text { huerta Arrieta }\end{array}$ & $\begin{array}{l}\text { Colección Terán, } \\
\text { tomo } 25 \text {, tomo } \\
\text { S,1875: } T 25 \text {,fol305 }\end{array}$ \\
\hline
\end{tabular}

Fuentes: Elaboración propia en base a Suarez (1874), Notario Palacios (1874),(1875), Colección Terán (1875), Hemeroteca Biblioteca Nacional del Perú Diario La Opinión Nacional $(1875)^{74}$.

\footnotetext{
74 "Beneficencia.- Se convoca postores para el remate de arrendamiento escriturario, por diez años de unos altos situados en la calle de Pezuelo de Santo Domingo signado con el número 57 . Sobre la base de 80 soles mensuales; cuyo acto se verificará el día 7 de abril próximo. A las dos de la tarde. Advirtiendo que sólo se admitirán postores hasta la misma hora de la víspera. Las bases del remate pueden verse en secretaria de doce a cuatro de la tarde. El Secretario. Lima, marzo 16 de 1875." La Opinión Nacional, sábado, 27 de marzo de 1875,p.01.
} 
Según el cuadro vemos que las rentas mensuales iban desde 80 soles por una casita en la calle Pezuelo de Santo Domingo a una cuadra de la Plaza Mayor; mientras en los barrios periféricos las rentas iban desde 16 soles una casa en el barrio de Malambo y 2,50 a 3 soles una casita en la calle Gallinazitos. Sin embargo, por esos años los salarios promedio se encontraban en un rango de 105 soles mensual ${ }^{75}$. Que era el sueldo que ganaba el administrador de una empresa o institución públicas, contra los 83,2 pesos mensuales que ganaba el conserje de la misma institución (Diario oficial El Peruano, 1869 á, 4 mayo: 299). Sí, suponemos que la tercera parte era destinado para el pago de la renta el promedio estas iban desde 25 soles hasta 100 soles $^{76}$ en promedio. Esta cifra nos demuestran que los inquilinos no podían acceder a créditos hipotecarios directamente con los bancos porque no podían pagar ahorrar y no podían alcanzar los montos sino que primero debían ahorrar en las Cajas de Ahorros a un interés de seis por ciento anual (Caja de Ahorros,1894:3-8) para luego trasladar el monto a un banco hipotecario para ser evaluados para un préstamo.

Estas condiciones, no permitían que la mayor parte de la población accediera a una vivienda a pesar de la intensa actividad económica de estos años, producto de recurso guano y nos demuestra que la élite era la que se benefició de esta economía. En consecuencia, la poblacional asalariada debía ahorrar un tiempo promedio de veinte años ${ }^{77}$ para poder adquirir una propiedad en la periferia vía crédito hipotecario y otro tiempo para construir una pequeña casa sin tener que adeudarse demasiado con los bancos. Bajo estas condiciones, se estructuraron los precios en la ciudad.

\footnotetext{
${ }^{75}$ Según el Presupuesto General de la República para el año 1869 se tenían el pago anual de sueldos de la siguiente manera: "Para un agente fiscal 1,200 soles anuales, para un fiscal 2,400 soles anuales, para un relator 1,200 soles anuales, para un amanuense 320 soles anuales, para un secretario de cámara 1,200 mensuales". Diario El oficial El Peruano, Lima miércoles 26 de mayo de 1869, Tomo 56, Núm. 120.p.01

${ }^{76}$ Según Francisco García Calderón "según el código civil habitación es el derecho de uso aplicado a una casa en todo o en parte. Esta definición podemos decir que habitación es el derecho que una persona tiene a servirse del todo o parte de una casa ajena, ó de aprovecharse de los frutos de ella, en cuanto basten para sus necesidades y de su familia”, “Diccionario de la Legislación" Peruana, Lima, 1 vol. ed. Jurídica Grijley, 2003, Lima, pp.1057.
}

\footnotetext{
77 ..Articulo 12 Los deudores del Banco podrán amortizar la deuda primitiva aun antes del plazo establecido de 20 años, pagando en dinero o en cedulas por su valor nominal, el tanto por ciento del capital que tomaron primitivamente conforme se ha fijado en la tabla adjunta y según la época que se verifique la amortización. Se admiten amortizaciones que no bajen de la cuarta parte del capital vigente en la época de amortización "Estatutos del Banco Hipotecario del Perú a probados por decreto supremo de 1866", Ed. Imprenta de Francisco J. Solís, plazuela de Santo Tomas, Lima, 1872, p.6
} 


\subsection{Estructura de precios en el centro y la periferia (1872-1876)}

El comportamiento del mercado de suelo ante los programas del Estado produjo una reestructuración de precios en el núcleo central y en toda la ciudad. En el caso del núcleo central, el Estado Peruano, la Beneficencia, la Facultad de Medicina, las Juntas Departamentales, la Municipalidad acumularon propiedades producto de transferencias de particulares y de la Iglesia, lo que cambió paulatinamente la estructura interna del mercado de suelo, convirtiendo a estas Instituciones, en los grandes propietarios de la ciudad. Mientras que en la periferia, las obras del Plan de Ensanche provocaron una reestructuración del mercado de suelo, beneficiando a quien estuvo a cargo de la ejecución del Plan, el fraccionador Enrique Meiggs. A su muerte en el año 1877 las obras quedaron paralizadas, produciéndose un desorden en la tenencia, lo que provocó que la reestructuración del mercado de suelo quedara trunca y se generara un mercado ilegal de suelo sobre todo al oeste de la ciudad. En el cuadro 3.9 vemos la actividad de compra-venta de propiedades en la ciudad, lo que nos proporciona una idea de las características de las transacciones. Aquí aparece, todavía, una transacción a favor de Meiggs. 


\section{Cuadro 3.9}

\section{Compra ventas en la ciudad entre los años de (1872-1873)}

\begin{tabular}{|c|c|c|c|c|c|c|c|}
\hline $\begin{array}{c}\text { Tipo de } \\
\text { transacción }\end{array}$ & Vendedor & Comprador & Precio & $\begin{array}{l}\text { Precio } \\
\text { V2 }\end{array}$ & Área & Ubicación & Fuente \\
\hline $\begin{array}{l}\text { Venta } \\
\text { Terreno }\end{array}$ & Arenibar & $\begin{array}{l}\text { Emilio del } \\
\text { Solar }\end{array}$ & $\begin{array}{c}\text { s/.3,652. } \\
80 \\
70,056 \\
\text { pesos }\end{array}$ & $\mathrm{S} / .2$ & $\begin{array}{c}1,82 \\
6.4 \mathrm{v} \\
2\end{array}$ & $\begin{array}{l}\text { Calle bajando de } \\
\text { las Nazarenas, } \\
\text { paralela a } \\
\text { Tayacaja } \\
\text { (centro) }\end{array}$ & $\begin{array}{c}\text { Notario } \\
\text { Selaya, } 1873: 1198 \\
\text { V. }\end{array}$ \\
\hline Venta terreno & Mates & $\begin{array}{l}\text { Enrique } \\
\text { Meiggs }\end{array}$ & $\begin{array}{c}\text { s/.37,182 } \\
\text { ó } \\
470,640\end{array}$ & $\mathrm{~s} / 2$ & $\begin{array}{l}74,3 \\
64 \mathrm{v} 2\end{array}$ & $\begin{array}{l}\text { Martinete } \\
\text { (periferia) }\end{array}$ & $\begin{array}{c}\text { Colección Terán - } \\
\text { tomo2-tomoA } \\
\text {,1872:825-825v. }\end{array}$ \\
\hline $\begin{array}{l}\text { Venta } \\
\text { Casita }\end{array}$ & $\begin{array}{l}\text { Daniel de la } \\
\text { Torre }\end{array}$ & $\begin{array}{l}\text { Fernando } \\
\text { Mugues }\end{array}$ & $\begin{array}{c}\text { s/2495 } \\
\text { ó } \\
49,900 \\
\text { pesos }\end{array}$ & $\begin{array}{l}\text { Sin } \\
\text { dato }\end{array}$ & $\begin{array}{l}\text { s/d } \\
3 / 4 \\
\text { del } \\
\text { lote }\end{array}$ & $\begin{array}{l}\text { Calle Belén } 431 \\
\text { (periferia) }\end{array}$ & $\begin{array}{c}\text { Colección Terán } \\
\text { tomo2-tomoA } \\
, 1872: 820\end{array}$ \\
\hline $\begin{array}{c}\text { Venta } \\
\text { Casa Alta }\end{array}$ & $\begin{array}{l}\text { Fabricio } \\
\text { Cáceres }\end{array}$ & $\begin{array}{l}\text { Manuel } \\
\text { Freyre }\end{array}$ & $\begin{array}{l}\text { s/.10000 } \\
\text { ó } \\
200,000 p \\
\text { esos }\end{array}$ & $\begin{array}{l}\text { Sin } \\
\text { dato }\end{array}$ & $\mathrm{s} / \mathrm{d}$ & $\begin{array}{c}\text { Calle de } \\
\text { Sacristía de San } \\
\text { Marcelo } \\
\text { (centro) }\end{array}$ & $\begin{array}{c}\text { Colección Terán - } \\
\text { tomo2-tomoA } \\
, 1872: 825\end{array}$ \\
\hline $\begin{array}{l}\text { Venta } \\
\text { Huerta }\end{array}$ & $\begin{array}{c}\text { María } \\
\text { Grass de } \\
\text { Carrillo }\end{array}$ & $\begin{array}{l}\text { Don } \\
\text { Sebastián } \\
\text { Carrillo }\end{array}$ & $\begin{array}{c}500 \\
{ }^{78} \text { (Pesos) } \\
\text { ó } \\
25 \text { soles }\end{array}$ & $\begin{array}{l}\text { Sin } \\
\text { dato }\end{array}$ & $\begin{array}{l}\text { Sin } \\
\text { dato }\end{array}$ & $\begin{array}{c}\text { Copacabana } \\
\text { (centro) }\end{array}$ & $\begin{array}{c}\text { Colección Terán - } \\
\text { tomo2-tomoA } \\
, 1872: 352 v\end{array}$ \\
\hline $\begin{array}{l}\text { Venta } \\
\text { Casa }\end{array}$ & $\begin{array}{l}\text { María } \\
\text { Zapata }\end{array}$ & $\begin{array}{l}\text { José } \\
\text { Aparicio y } \\
\text { Rosas }\end{array}$ & $\begin{array}{l}12,660 \\
\text { pesos } \\
\text { ó } \\
\text { s/.633 }\end{array}$ & $\mathrm{s} / .0 .5$ & $\begin{array}{c}1266 \\
\text { v2 }\end{array}$ & $\begin{array}{l}\text { Calle Huaylas } \\
\text { (centro) }\end{array}$ & $\begin{array}{c}\text { Colección Terán - } \\
\text { tomo2- tomoA año } \\
1873 \\
\text { Fol.830v-831 }\end{array}$ \\
\hline $\begin{array}{l}\text { Venta } \\
\text { Casa }\end{array}$ & $\begin{array}{l}\text { Josefa y } \\
\text { Sebastián } \\
\text { Gonzales } \\
\text { de Oviedo }\end{array}$ & $\begin{array}{c}\text { José Miguel } \\
\text { Torres }\end{array}$ & $\begin{array}{l}\text { s/.20000 } \\
\text { ó } \\
400,000 \\
\text { pesos }\end{array}$ & $\begin{array}{l}\text { Sin } \\
\text { dato }\end{array}$ & $\begin{array}{l}\text { Sin } \\
\text { dato }\end{array}$ & $\begin{array}{c}\text { Calle } \\
\text { Divorciadas } \\
\text { (Carabaya) } \\
\text { N¹83-185 } \\
\text { (centro) }\end{array}$ & $\begin{array}{c}\text { Colección Terán - } \\
\text { tomo25-tomo5, } \\
1872 \\
: 306\end{array}$ \\
\hline
\end{tabular}

Fuentes: Elaboración propia en base Selaya (1873), Colección Terán (1872),(1873).

\footnotetext{
${ }^{78}$ Conversión de pesos a soles "Según la ley de 1857 se establece que las monedas de oro en la República tendrán la ley de nueve decimos de fino y serán de cinco clase. La primera y la de mayor denominación se llamará la primera Sol, la segunda medio Sol, la tercera doblón y la cuarta Escudo .. El sol corresponderá a veinte pesos de plata, el medio sol a diez pesos, el doblón a cinco pesos, el escudo a dos pesos y el medio escudo a un peso" Villa García M (2013) “La transformación en 150 años del Sol al Nuevo Sol”. En: Revista Moneda N 154, pp.43-49.
} 
En todo este proceso podemos ver terrenos, casas, fincas, departamentos, huertas y terrenos en venta. Las propiedades con el más alto valor se encontraban en el núcleo central con precios que iban de 12,000 pesos (600 soles) a 200,000 pesos $(10,000$ soles $)$ mientras en parroquias cercanas a la periferia el precio variaba de 500 pesos ( 25 soles) a 7,000 pesos ( 350 soles) que nos demuestra que cuanto más cerca a la Plaza Mayor era más alto el precio. Sin embargo, en la periferia existían casitas pequeñas, huertas y terrenos cuyos precios eran de 500 pesos ( 25 soles) a 45,000 pesos $(2,500$ soles) por ejemplo el cuadro nos muestra un terreno en Martinette con un precio de 470,640 pesos (37,186 soles) que nos muestra como las obras del Plan de Ensanche comenzaron a influenciar en los precios de las propiedades en la periferia.

Aunque no existen datos de valores de metro cuadrado para los cuarteles en estos años el cuadro de valores arancelarios para la ciudad de 1839 a 1944 nos proporcionan una idea de la jerarquía de precios desde la Plaza Mayor hasta la alameda de Circunvalación (Avenida Miguel Grau o avenida Alfonso Ugarte).

\section{Foto 3.1}

\section{Precios arancelarios de la ciudad de Lima entre (1839-1944)}

PRECIOS ARANCELARIOS DE ALGUNAS CALLES DE LIMA

\begin{tabular}{|c|c|c|c|c|c|c|c|c|c|c|c|c|c|c|c|c|c|}
\hline Calles & $\begin{array}{c}1839 \\
\text { Pesos } \\
\text { por } \mathrm{v}^{2} .\end{array}$ & $\begin{array}{c}1896 \\
\text { Soles } \\
\text { por } \mathrm{m}^{2} \text {. }\end{array}$ & $\begin{array}{l}1505 \\
\text { Soles } \\
\text { por m? }\end{array}$ & $\begin{array}{c}1907 \\
\text { Soles } \\
\text { por } \mathrm{m}^{2} \text {. }\end{array}$ & $\begin{array}{c}1508 \\
\text { Soles } \\
\text { por } \mathrm{m}^{2} \text {. }\end{array}$ & $\begin{array}{l}1911 \\
\text { Sules } \\
\text { por } \mathrm{m}^{2} \text {. }\end{array}$ & $\begin{array}{l}1913 \\
\text { Soles } \\
\text { por } \mathrm{m}^{2}=\end{array}$ & $\begin{array}{c}1914 \\
\text { Soles } \\
\text { por } \mathrm{m}^{2} \text {. }\end{array}$ & $\begin{array}{c}1916 \\
\text { Soles } \\
\text { por } \mathrm{m}^{2} \text {. }\end{array}$ & $\begin{array}{c}1917 \\
\text { Soles } \\
\text { por } \mathrm{m}^{2} \text {. }\end{array}$ & $\begin{array}{c}1920 \\
\text { Soles } \\
\text { por } \mathrm{m}^{2} \text {. }\end{array}$ & $\begin{array}{c}1921 \\
\text { Soles } \\
\text { por } \mathrm{m}^{2} \text {. }\end{array}$ & $\begin{array}{c}1923 \\
\text { Soles } \\
\text { por m². }\end{array}$ & $\begin{array}{c}1924 \\
\text { Soles } \\
\text { por } \mathrm{m}^{2} \text {. }\end{array}$ & $\begin{array}{c}1927 \\
\text { Soles } \\
\text { por } \mathrm{m}^{2} \text {. }\end{array}$ & $\begin{array}{c}1935 \\
\text { Soles } \\
\text { por } \mathrm{m}^{2} \text {. }\end{array}$ & $\begin{array}{c}1044 \\
\text { Soles } \\
\text { por } \mathrm{m}^{2} \text {. }\end{array}$ \\
\hline Plaza de Armas & 10.00 & 20.00 & 50.00 & 100.00 & 300.00 & 250.00 & 300.00 & 300.00 & 300.00 & 300.00 & 30000 & 500.00 & 500.00 & 500.20 & $500 . .00$ & 35000 & 500.00 \\
\hline Palacio . . . . . . & 9.00 & 20.00 & 30.00 & 80.00 & 13000 & 130.00 & 150.00 & 150.00 & 150.00 & 150.00 & 150.00 & 300.00 & 300.00 & 30000 & 300.00 & 250.00 & 400.00 \\
\hline Mercaderes ........ & 9.00 & 20.00 & 50.00 & 100.00 & 300.00 & 250.00 & 300.00 & 300.00 & 30000 & 300.00 & 300.20 & 500.00 & 500.00 & 500.00 & 500.00 & 330.00 & 500.90 \\
\hline Espaderos . . . . . . & 8.90 & 20.00 & 50.00 & 10000 & 280.00 & 250.00 & 300.00 & 300.00 & 300.00 & 30000 & 300.00 & 500.00 & 500.00 & 500.00 & 50000 & 325.00 & 500.00 \\
\hline La Merced . . . . & 7.20 & 16.00 & 40.00 & 90.00 & 180.00 & 180.00 & 200.30 & 200.00 & 200.00 & 20000 & 20000 & +00.00 & 450.00 & 450.00 & 450.00 & 275.00 & 450.00 \\
\hline Av, Alf. Ugarte . . . & - & 1.00 & - & $\begin{array}{c}10.00 \\
10 . \text { cuadra }\end{array}$ & $\begin{array}{c}10.00 \\
11 . \text { cuadra }\end{array}$ & $\begin{array}{c}10.00 \\
1 \% \text { cuadra }\end{array}$ & $\begin{array}{c}10.00 \\
11 \text { cuadra }\end{array}$ & $\begin{array}{c}10.00 \\
10 . \text { ceadra }\end{array}$ & $\begin{array}{c}10.00 \\
1 \% \text { cuadra }\end{array}$ & $\begin{array}{l}10.00 \\
\text { hasta Col. } \\
\text { Guadalupe }\end{array}$ & $\begin{array}{c}10.00 \\
\text { hasta Col. } \\
\text { Guadalupe }\end{array}$ & $\begin{array}{l}1500 \\
\text { hasta } \\
\text { Quilca }\end{array}$ & $\begin{array}{l}18.00 \\
\text { hasta } \\
\text { Quilca }\end{array}$ & $\begin{array}{l}18.00 \\
\text { hasta } \\
\text { Quilca }\end{array}$ & $\begin{array}{l}40.00 \\
\text { hasta } \\
\text { Quilca }\end{array}$ & 38.00 & 70.00 \\
\hline Av. Grau . . . . . & - & 1.00 & $\begin{array}{l}6.00 \\
1 \text { 1. cuadra }\end{array}$ & $\begin{array}{c}10.00 \\
11 \text { cuadra }\end{array}$ & $\begin{array}{l}10.00 \\
1 \text { c cuadra }\end{array}$ & $\begin{array}{c}20.00 \\
1+\text { cuadra }\end{array}$ & $\begin{array}{l}20.00 \\
11 . \text { cuadra }\end{array}$ & $\begin{array}{c}2000 \\
1+\text { cuadra }\end{array}$ & $\begin{array}{l}20,00 \\
\text { hasta Co- } \\
\text { tabambas }\end{array}$ & $\begin{array}{c}20.00 \\
\text { hasta } \mathrm{Co}_{0} \\
\text { tabambas }\end{array}$ & $\begin{array}{c}25.00 \\
\text { hasta Co- } \\
\text { tabambas }\end{array}$ & $\begin{array}{l}30.00 \\
\text { hasta } C_{0}- \\
\text { tabambas }\end{array}$ & $\begin{array}{l}30.00 \\
\text { hasta Co- } \\
\text { tabambas }\end{array}$ & $\begin{array}{c}30.00 \\
\text { hasta Co. } \\
\text { tabambas }\end{array}$ & $\begin{array}{c}45.00 \\
1 . \text { cuadra }\end{array}$ & $\begin{array}{c}60.00 \\
1+\text { cuadra }\end{array}$ & $\begin{array}{l}100.00 \\
1 \% \text { cuadra }\end{array}$ \\
\hline
\end{tabular}

Fuente: "Bromley y Barbagelata, (1945). 
Según el cuadro, la jerarquía de precios era escalonada. Partía de la Plaza Mayor hasta la Merced. Por ejemplo, en 1896, existió un mismo valor de la Plaza Mayor hasta la calle Espaderos variando de la Merced hasta notarse una gran diferencia cerca a las avenidas de Alfonso Ugarte y Grau (Circunvalación) que para ese periodo era la periferia de Lima. Esto nos indica, que el centro mantenía una dinámica propia y la periferia se encontraban en proceso de reestructuración de precios. Gracias a la información y lo visto en los anteriores ítems podemos decir que los principales factores que influyeron en la estructura de precios en la ciudad fueron: La actividad bancaria a través de los créditos hipotecarios, la erradicación de los sistemas coloniales de gravámenes, la construcción de proyectos de envergadura en la ciudad, la puesta en marcha del Plan de Ensanche, la introducción de servicios de agua, desagüe y luz en los distintos cuarteles de la ciudad y la ejecución de edificaciones públicas en el núcleo central y zonas aledañas. Pese a todo, no contamos con un padrón de propietarios de la ciudad de estos años, indispensable para conocer el índice de concentración de las propiedades, que nos hubiera permitido conocer tres aspectos básicos de la estructura de la propiedad en la ciudad como: 1) La composición de valores de las fincas ${ }^{79}$ 2) La distribución de estos valores en relación a los propietarios para obtener el índice de concentración y 3) La distribución de los valores en la ciudad (Morales,2011:26-27) ${ }^{80}$. Sin embargo, la información recopilada nos permite mostrar la estructura de precios en la ciudad utilizando la información de cuadro de valores arancelarios y los documentos de archivos de la actividad de renta, hipoteca y compra-ventas en distintos puntos de la ciudad.

\footnotetext{
79 Según Francisco García Calderón finca es la heredad o posesión en que alguno tiene derecho de cobrar su renta, ó una cantidad determinada de Bienes corporales. "Diccionario de la Legislación Peruana”, Lima, 1 vol. ed. Jurídica Grijley, 2003, pp. 982.
}

\footnotetext{
80 Según María Dolores Morales "El conocimiento de la distribución de los valores en el espacio ciudad es fundamental para entender como estaban jerarquizadas las zonas de la ciudad, cuáles eran los valores altos bajos y en cuales predominaban las propiedades de cada sector analizado" En: "Antologías Ensayos Urbanos La ciudad de México en el siglo XIX". Ed. UAM- Xochimilco, 2011, México. pp.49
} 
Plano 3.5

\section{Estructura de precios en la ciudad (1870-1876)}

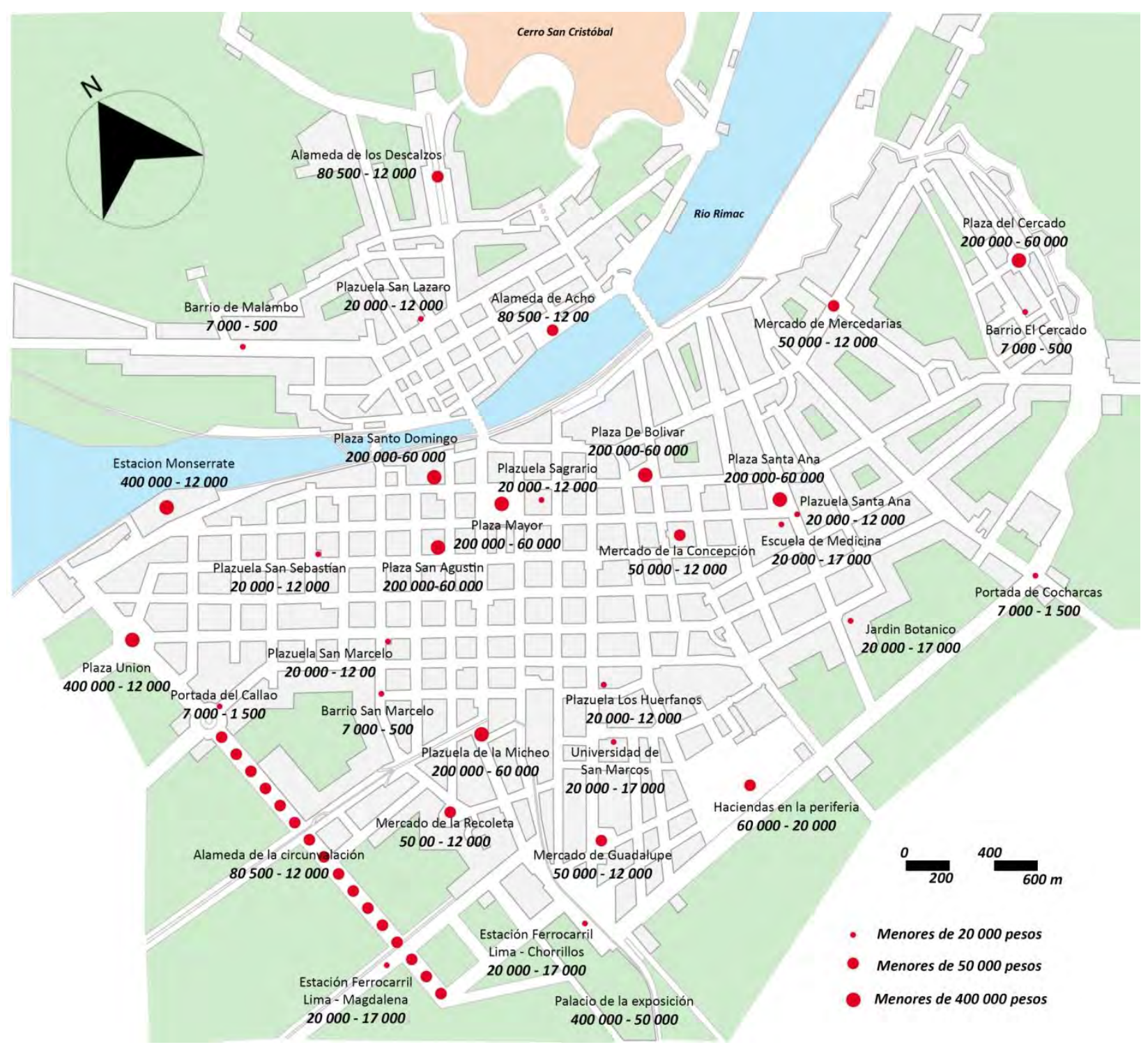

Fuente: Elaboración propia en base a plano de Lima de 1880 (Gunther, 1983) 
Cuadro 3.10

Estructura de precios en la ciudad de Lima (1870-1876)

\begin{tabular}{|c|c|c|}
\hline Ubicación & $\begin{array}{l}\text { Uso de } \\
\text { suelo }\end{array}$ & $\begin{array}{l}\text { Rango de precios } \\
\text { (en pesos) }\end{array}$ \\
\hline Palacio de la Exposición & $\begin{array}{l}\text { vivienda- } \\
\text { comercio }\end{array}$ & $400,000-50,000$ \\
\hline Estación de Monserrate Plaza Unión & industrial & $400,000-12,000$ \\
\hline $\begin{array}{c}\text { Alamedas de: Circunvalación, Acho y } \\
\text { Descalzos }\end{array}$ & vivienda & $80,500-12,500$ \\
\hline $\begin{array}{c}\text { Plazas en el núcleo central: Plaza Mayor, } \\
\text { Santo Domingo, Santa Ana, San Agustín, } \\
\text { Santo Oficio, de Micheo, de Bolívar, Santiago } \\
\text { del Cercado }\end{array}$ & $\begin{array}{l}\text { vivienda- } \\
\text { comercio }\end{array}$ & $200,000-60,000$ \\
\hline $\begin{array}{c}\text { Mercados de la Concepción, Guadalupe, } \\
\text { Mercedarias, la Recoleta }\end{array}$ & comercio & $50,000-12,000$ \\
\hline $\begin{array}{c}\text { Plazas parroquiales de Huérfanos, Sagrario, } \\
\text { San Lázaro, San Marcelo, San Sebastián y } \\
\text { Santa Ana y Plazas de la Guardia Nacional y } \\
\text { Santiago del Cercado }\end{array}$ & $\begin{array}{l}\text { vivienda- } \\
\text { comercio }\end{array}$ & $20,000-12,000$ \\
\hline $\begin{array}{c}\text { Jardines Conroy, Jardín Botánico, Facultad } \\
\text { de Medicina, Universidad de San Marcos, } \\
\text { estaciones de ferrocarriles Lima-Chorrillos y } \\
\text { Lima-La Magdalena }\end{array}$ & $\begin{array}{l}\text { servicios de la } \\
\quad \text { ciudad }\end{array}$ & $20,000-, 17,000$ \\
\hline $\begin{array}{c}\text { Río Rímac, portadas de: Callao, Cocharcas y } \\
\text { Cementerio General }\end{array}$ & vivienda & $7,000-1,500$ \\
\hline $\begin{array}{c}\text { Barrios periféricos: Santiago del Cercado, } \\
\text { Malambo, San Marcelo }\end{array}$ & $\begin{array}{l}\text { vivienda- } \\
\text { comercio }\end{array}$ & $7,000-500$ \\
\hline Huertas de la periferia & rural & $20,000-2,500$ \\
\hline Haciendas en la periferia & rural & $60,000-20,000$ \\
\hline
\end{tabular}

Fuente: Elaboración propia en base a cuadros de renta, hipotecas, compra-ventas y expropiación años (1872),(1873)(1874)(1875), cuadro de precios arancelarios de algunas calles de Lima 1839-1944 y plano de Jouanny (1872) 
Puede verse que la Plaza Mayor, concentradora del poder político, económico y religioso, además de ser el centro administrativo (Ludeña, 2002:74), impactaba las propiedades cercanas, que eran las más caras. Sin embargo, desde la demolición de la muralla el centro inició "un proceso centrífugo debido a que la élite comenzó su retirada a los balnearios del sur por los problemas de salubridad" (Ludeña, 2002:53) lo que influenció en la baja de los precios. A medida que se materializó el Plan de Ensanche los precios de mayor valor eran los terrenos industriales cerca a la Estación de Monserrate donde se ubicaron las fábricas y curtiembres por la existencia de manantes y las propiedades que se encontraban cerca al Palacio de la Exposición debido las expectativas que generó la Feria Internacional de la Exposición de Lima el año 1872.

En el grupo de propiedades de precios intermedios se encontraban las propiedades ubicadas cerca de las Plazas de Santa Ana, Santo Oficio, de Micheo, de Bolívar y el Cercado debido a aparición de edificaciones públicas de equipamiento y servicios como El Mercado de la Concepción, El Palacio de Justicia, La Cámara de Senadores, El Cuartel de Infantería y La Casa de la Moneda (Jouanny, 1872). También en este rango se encontraban las plazas parroquiales que tenían alguna actividad comercial y en su cercanía se encontraban la hospicios de huérfanos, hospitales y lazaretos (Jouanny, 1872). Los precios cerca a las alamedas y jardines botánicos, ferrocarriles de LimaCallao y Lima-Chorrillos también se mantuvieron en rangos medios debido a que concentraban comercios y servicios.

El borde ribereño y la periferia tenían el valor más bajo excepto cerca a los puentes de Viterbo, Piedra, Desamparados y el nuevo llamado Balta (Jouanny, 1872) porque concentraron una actividad de vivienda, hospedaje y comercio. Por último, los barrios periféricos como Malambo, Santiago del Cercado y Bajo el Puente tenían los precios más bajos con algunas excepciones ante la expectativa de la ejecución de la alameda de Circunvalación y la cercanía a alguna de las portadas como Martinette, Callao o Cocharcas que concentraron actividad comercial y de hospedaje. En el caso de las huertas, de acuerdo a su ubicación en función de las obras públicas subieron de precio. Por otro lado, las haciendas que se encontraban en la periferia mantuvieron su valor por ser unidades de producción así como los terrenos industriales. 
A medida que se ejecutaba el Plan de Ensanche en la periferia y el fraccionador Meiggs materializó su proyecto inmobiliario y se produjo una reestructuración del mercado de suelo. Este proceso, interrumpido en 1977, al morir Meiggs, fue retomado en parte, años después de la Guerra del Pacífico, cuando la ciudad se recuperó económicamente con el apoyo de los gobiernos de turno y los inversionistas privados buscaron urbanizar nuevamente la periferia.

\subsection{El diseño del mercado de suelo para la periferia de Lima según Enrique Meiggs (1872-1876)}

El diseño del mercado de suelo que elaboró el fraccionador Meiggs para la periferia, estuvo dividida en cinco secciones o sub-mercados, lo que generó una nueva estructura de precios y obedeció estrictamente al tipo de mercado al que se dirigió. No obstante, por ser un monopolio inmobiliario concentró toda la oferta producto de las hipotecas que los bancos podían dar a los miembros de las clases asalariada y los ahorros concentrados en las Cajas de Ahorros y lo que los prestamistas podían ofrecer a la población para acceder a una propiedad en la periferia. Siguiendo la lógica capitalista, abiertamente monopólica y especulativa, y teniendo en cuenta que el crecimiento

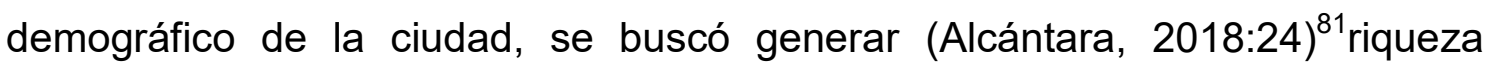
económica y activar la economía en la ciudad, alcanzar el progreso y la modernización urbana.

El diseño de las cinco secciones buscó la mayor rentabilidad. El 1870 un estudio de don Manuel Atanasio Fuentes titulado "La población de Lima" dio como resultado para el año 1862 una población de 105,267 habitantes de los cuales 23,714 eran limeños, 30,030 forasteros y 39,597 extranjeros82 (Diario

\footnotetext{
81 Según Érica Alcántara "El fraccionamiento se idea desde una lógica capitalista. El crecimiento demográfico y económico demandan también su crecimiento en superficie, por lo que la primera y más lógica solución fue hacer crecer las ciudades en numerosas hectáreas fuera de las problemáticas urbes...La lógica misma estaba asociada a la estructura de fraccionar las tierras era la forma de dividir para producir, la cual era la misma lógica de la industria" En: Tesis de Maestría UNAM. "Fraccionadores y fraccionamiento: una historia del desarrollo inmobiliario en la ciudad de México a través de ciudad Satélite y Villa Coapa (1952-1980)", UNAN, México. pp.24-25

${ }^{82}$ Según Francisco García Calderón "Llamamos extranjero al que habiendo nacido en otro país vive en el Perú, sin haberse naturalizado en el... por esto luego que se proclamo la independencia, se concedió entrada libre en el Perú a todos los extranjeros, se les ofreció la misma protección que a los ciudadanos, y se les dio amplia libertad para el ejercicio de la industria (dic.17 de 1821)", "Diccionario de la Legislación Peruana”, Lima, 1 vol. ed. Jurídica Grijley, 2003, pp.931-932.
} 
El Nacional,1870 á, 04 febrero:01). Estos fueron los grupos poblacionales a los que dirigió el fraccionador Meiggs su oferta de viviendas, pero solo una parte podía acceder a créditos hipotecarios, tenían una capacidad de ahorro o podían ser sujetos a créditos con la Compañía del fraccionador Meiggs. De esta manera, la urbanización de la periferia se convirtió en un mercado de suelo segmentado y de segregación social al que solo podía acceder la población que se encontraba en condiciones de pagar el precio del lote o un crédito hipotecario. Por ejemplo, hacia las zonas cercanas a la Alameda de Circunvalación, el mercado de suelo estaba orientado a captar a la élite mercantil y terrateniente que no deseaba migrar hacia los balnearios del sur. Por otro lado, el fraccionador Meiggs diseñó una oferta para los inmigrantes extranjeros de carácter mixto, comercial y de vivienda, cerca a los óvalos Unión, Dos de Mayo Bolognesi. Esto nos demuestra que los precios de los lotes de cada sección fueron decisión del fraccionador, quien buscó obtener la mayor rentabilidad del desarrollo inmobiliario en la periferia siguiendo el modelo: dividir y producir más riqueza. Por ejemplo la sección primera y cuarta cerca al Palacio de la Exposición tuvo una oferta de viviendas para la élite y los extranjeros inversionistas y banqueros debido a la expectativa que se tenía de la construcción de un nuevo centro moderno; mientras que el resto de secciones, fueron dejadas para una segunda etapa. El monopolio de la periferia se convirtió en el único que podía satisfacer la demanda de vivienda en la ciudad, avalado por el Estado Peruano, estableciendo que la asociación con el capital privado era la única forma de urbanizar la periferia y mostrar a la población la materialización de la modernidad con el Plan de Ensanche.

Aunque la propuesta completa del Plan de Ensanche no se llevó a cabo, la decisión de Meiggs de urbanizar la periferia, en cinco secciones, aportó con una nueva demarcación territorial basada en la especulación del suelo de la 
periferia (Beltrán, 2010:102-103) ${ }^{83}$ con la posibilidad de generar una conexión con el centro mediante óvalos bajó la lógica de la mercantilización del suelo. El diseño de Meiggs de la periferia definió una nueva dinámica económica de trabajar en la ciudad y vivir en la periferia como una alternativa ante la insalubridad del centro. Este diseño de la urbanización de la periferia significó una reorganización del territorio y la creación de nuevas unidades barriales impulsadas por el fraccionador Meiggs, mediante el diseño de lotización, el cual incluyó a una parte de los grupos sociales que se encontraban viviendo en el centro. Producto de este diseño, se impulsó la segregación residencial que afectó las relaciones entre los futuros habitantes de la periferia. La construcción de una comunidad compacta, debido a la diversidad económica de cada una de las secciones en las que dividió la periferia. El proyecto dividido en secciones, estuvo diseñado para evitar la cohesión social debido a la diversidad de grupos sociales a los que iba dirigido (Ruiz,2016:03-05) ${ }^{84}$.

Las cinco secciones tenían los siguientes límites: Primera sección, desde el Parque de la Exposición y la Penitenciaria hasta el cuartel de Santa Catalina; Segunda sección, desde el cuartel del Santa Catalina hasta la plaza de la Guardia Nacional; Tercera sección, desde la Plaza de la Guardia Nacional hasta los Jardines Conroy todo el borde ribereño. Cuarta sección, desde la carretera al Callao hasta el Parque de la Exposición. Quinta sección, desde la carretera al Callao hasta el Camal (ver plano 3.2) (Bromley y Barbagelata, 1945: $\mathrm{s} / \mathrm{n}$ )

\footnotetext{
83 Constanza Beltrán Beltrán “Colonización y consolidación del territorio en el siglo XIX: las nuevas naciones americanas" En: Revista Apuntes, Bogotá, julio-diciembre 2010, Vol 23. Núm.02 pp.102-103.

${ }^{84}$ Ruiz Tagle Javier "La persistencia de la segregación y la desigualdad en barrios socialmente diversos: Un estudio de caso en La Florida, Santiago. En: Revista EURE Tomo 42, Nㅜ 125, jan 2016. pp. 81-107
} 


\section{Plano 3.6}

\section{Limites de las cinco secciones según Enrique Meiggs}

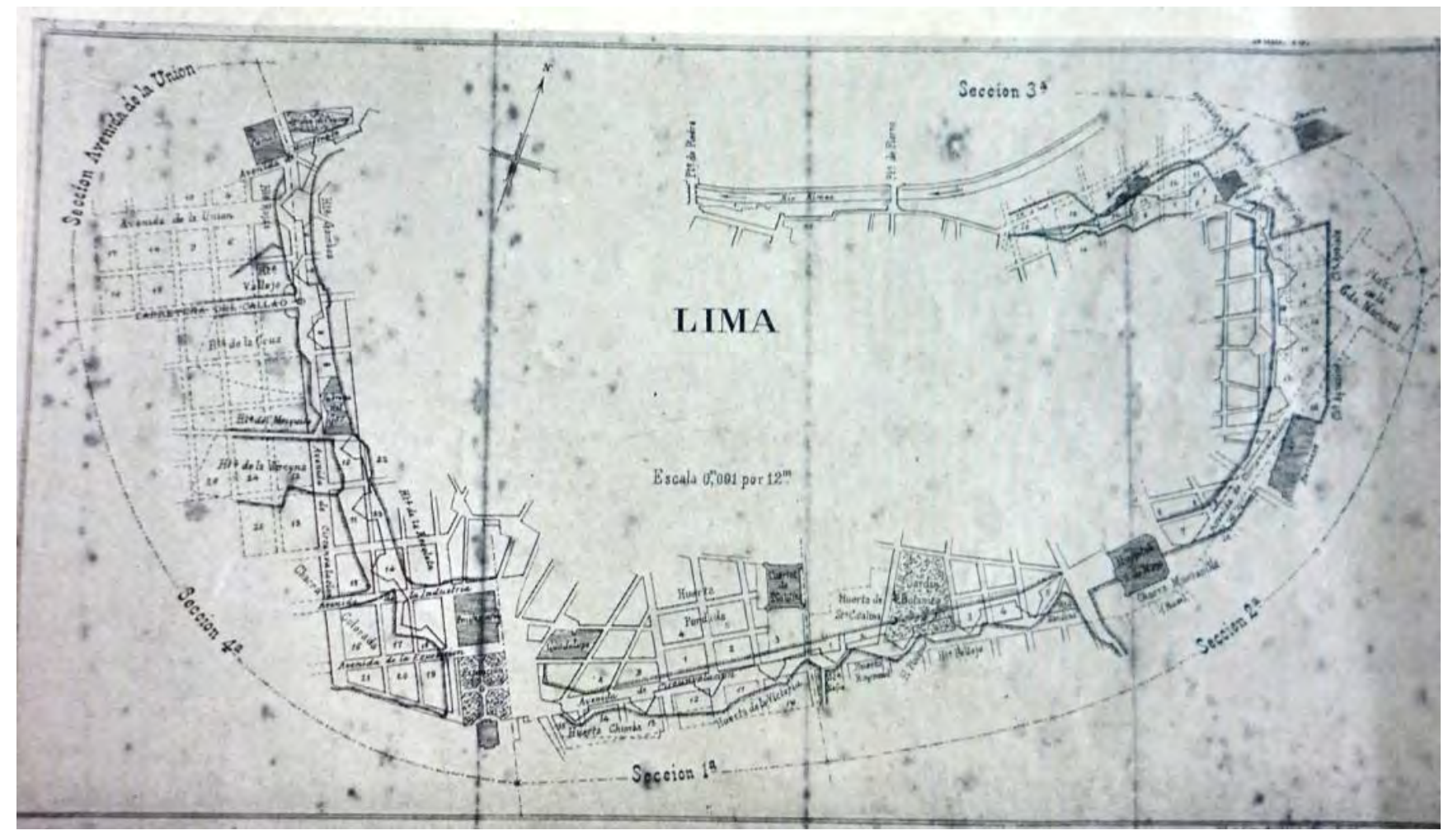

Fuente: Bromley, J. \& Barbagelata, J. (1945).

El nuevo proceso urbanizador tuvo un primer paso en 1872, con la construcción del Palacio de la Exposición, a cargo del fraccionador Enrique Meiggs. Ahí se celebró la Feria Internacional de la Exposición de Lima (García Bryce,2004:95) a la que acudieron visitantes extranjeros de Chile, Ecuador, Bolivia, El Salvador, Inglaterra, Francia, Bélgica, Alemania, Suiza, Estados Unidos, Japón y Persia, generando la posibilidad de mayores inversiones. Además, es necesario destacar que la decisión del Estado Peruano, de permitir la intervención monopólica del fraccionador Enrique Meiggs, evitó que existieran más inversiones, ocasionando la pérdida de oportunidad de la construcción de más desarrollos inmobiliarios en la ciudad que hubiera beneficiado a la población que buscaba una vivienda en la ciudad. 
La intervención en la periferia a cargo del fraccionador Enrique Meiggs se dio en dos periodos: El primero entre 1872 a 1874 que se caracterizó por un proceso de capitalización con la compra de lotes a terceros de forma directa o vía expropiación y un segundo periodo entre 1875 a 1877 que se caracterizó por la venta de terrenos mediante la Compañía de Obras Públicas y Fomento del Perú que ofreció lotes para viviendas, comercio y terrenos industriales.

\subsubsection{Urbanización al sur y la unión del tejido colonial con la periferia}

Una sección del proyecto Meiggs corresponde a la zona sur de la ciudad, desde el Palacio de la Exposición hasta el cuartel de Santa Catalina. Ver plano 3.7. El proyecto de urbanización contó con quince manzanas en las cuales ocho manzanas correspondieron a la Huerta Perdida (Notario Suarez, 1874:368-369) y seis manzanas a Chacha Victoria. Por otro lado, hacia el norte lotizó la manzana primera a la novena y hacia el sur las manzanas diez a la quince, esta última ocupada por el colegio Santa Sofía. A ambos lados de la avenida de Circunvalación que sería la alameda moderna se planteó una oferta de viviendas dirigida a la élite mercantil, terrateniente, banqueros e industriales. En el proceso de urbanización de esta sección fueron afectadas las huertas ubicadas a ambos lados de la avenida de Circunvalación como: Chimba, Victoria, Raimondi, El Pellejo, huerta Pérdida, Santa Catalina y Matute (Bromley, 1945) que cambiaron de uso de suelo a vivienda e ingresaron a un proceso de expropiación con el Estado Peruano y en otros casos fueron compradas por el fraccionador Meiggs para la ejecución de su proyecto inmobiliario privado. 


\section{Plano 3.7}

\section{Sección primera lado norte}

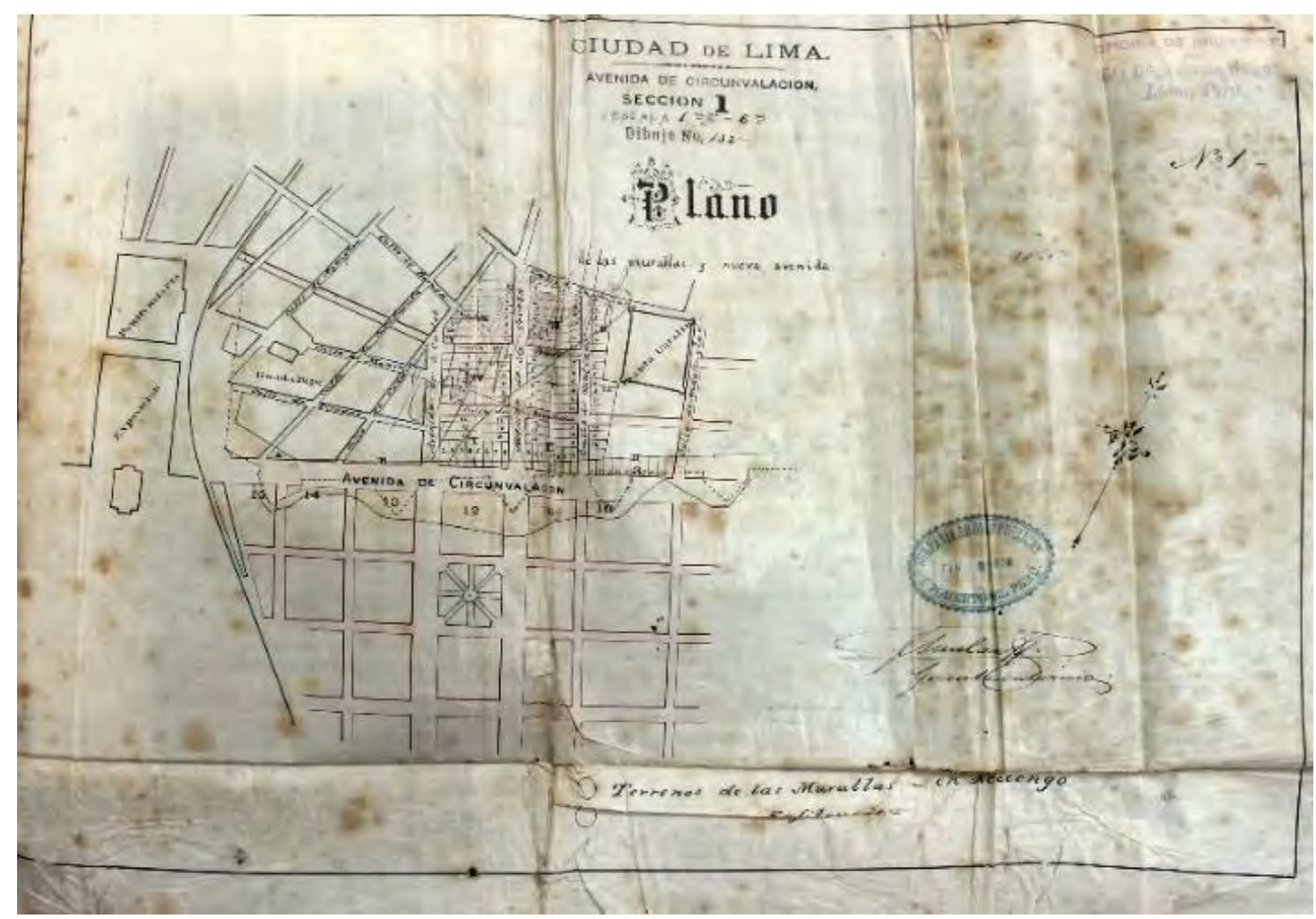

Fuente: Archivo General de la Nación, Notario Selaya (1876)

\section{Plano 3. 8}

\section{Sección primera lado sur}

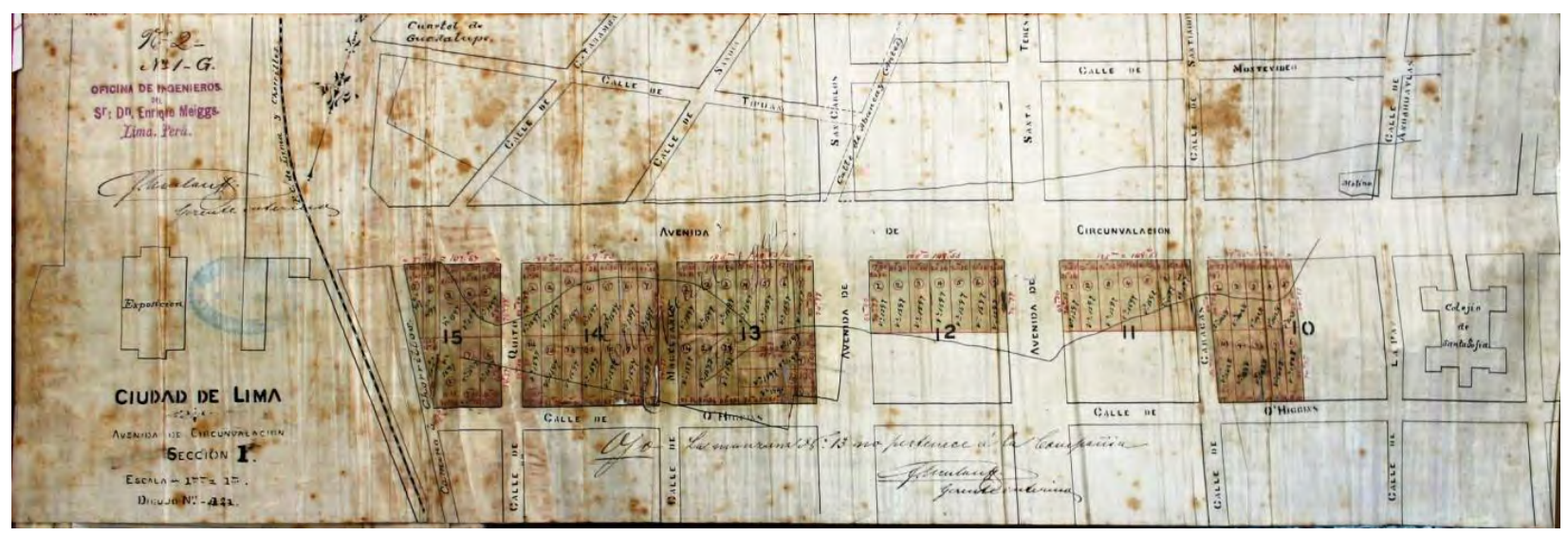

Fuente: Archivo General de la Nación Notario Selaya (1876). 
En esta primera sección se realizó la unión de tejido colonial con el propuesto por el Plan de Ensanche mediante una recomposición morfológica (Capel, 2002:203) para permitir la conexión con la nueva periferia cambiando el sentido del trazado a ortogonal. Este trabajo de cirugía urbana se realizó para unir tres calles Maipiri, Bogotá ${ }^{85}$ y Montevideo que pertenecían al trazado antiguo con la avenida de San Carlos (ver Plano 3.5) que permitió la integración del tejido urbano y social centro-periferia, una mejor conexión de los barrios ubicados en esta zona con el centro de la ciudad y el aumento de valor de los predios a estas calles.

\section{Plano 3.9 \\ Fragmento propuesto en la primera sección entre las calles Maipiri, Bogotá y Montevideo}

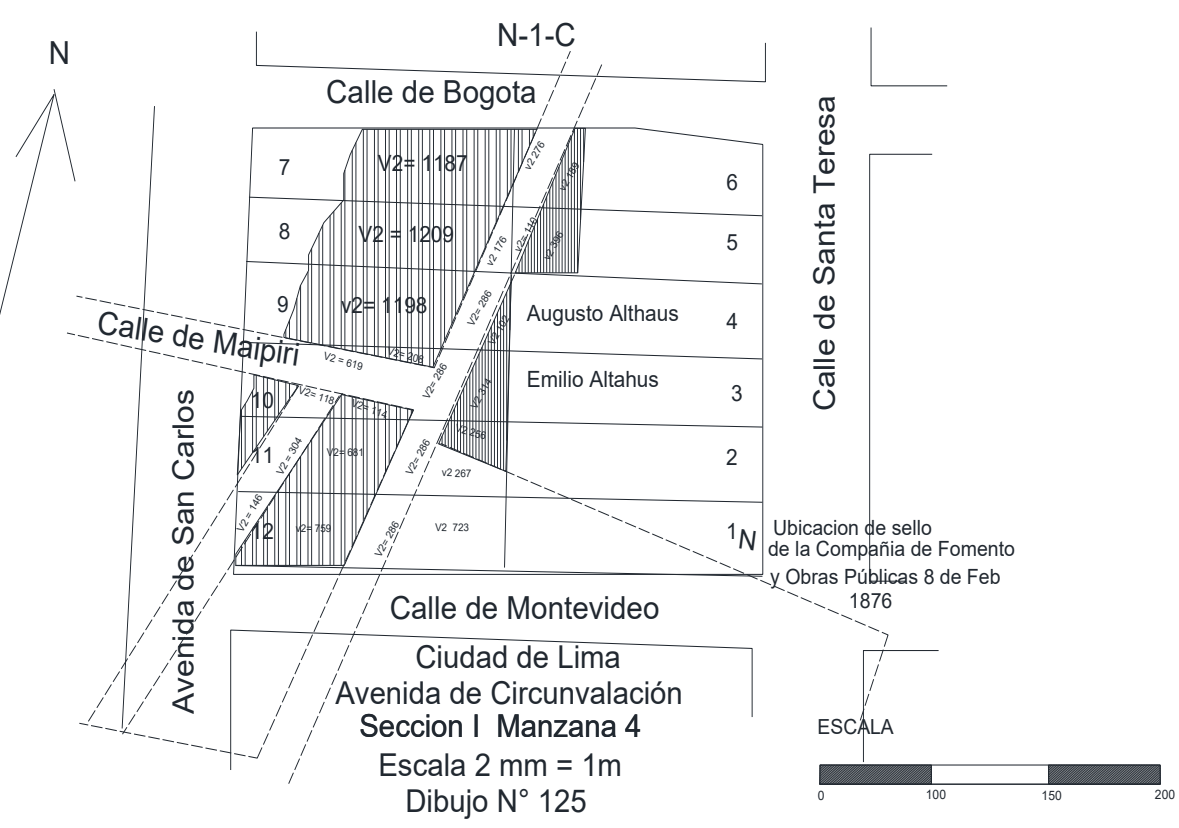

Fuente: Archivo General de la Nación del Perú, Notario Selaya (1876)

\footnotetext{
85 Para el año 1892 fueron rematados 10 lotes de terrenos en las calles Sandia, Bogotá y San Carlos por la Municipalidad, Diario Judicial, 1892 á, Lunes 09 mayo, (Núm. 538) pp.2207.
} 
En este caso, el fraccionador Enrique Meiggs decidió que la calle Maipiri llegará hasta la avenida Santa Teresa y la avenida San Carlos tomó el nombre de Azángaro y la calle Montevideo tomó el nombre de Bamba (Jouanny,1880). Con esta propuesta el fraccionador Meiggs priorizó el negocio inmobiliario sobre la obra pública y se produjo una recomposición del tejido social y la unión del tejido colonial con el de la periferia, lo que permitió una conexión centroperiferia.

\subsubsection{La oferta inmobiliaria para la élite que se quedó a vivir en la ciudad}

La oferta inmobiliaria en esta sección estuvo dirigida principalmente a la élite que tuvo dos alternativas para vivir: contar con un lote de terreno hacia la alameda de Circunvalación o mudarse a vivir a los balnearios del sur. El precio promedio de la vara cuadrada fue de S/. 2,88 y la dimensión promedio de los lotes de 600 a 1,200 metros cuadrados. Los lotes de mayor área se encontraban cerca a la calle Montevideo (Notario Selaya, 1876:77). No obstante, debido al crecimiento del negocio inmobiliario del fraccionador don Enrique Meiggs, en el año 1876, este cedió a la Cía. de Obras Públicas y Fomento trece manzanas de la sección primera cuyo valor de mercado fue S/.341, 683 (Notario Selaya, 1876:75-78). Con esta acción insertó de manera formal en el negocio inmobiliario de la periferia a su Compañía. En esta sección, el fraccionador Meiggs logró vender algunos lotes de terreno debido al poco interés de la élite por la falta la de servicios básicos. De esta manera, contribuyó a la consolidación de la urbanización de periferia. El principal aporte a la ciudad fue el trazado de la alameda de Circunvalación que permitió al Estado Peruano mostrar que las obras del Plan de Ensanche se estaban ejecutando y que la modernización de la ciudad se hacía realidad.

\subsubsection{El trazado al este de la ciudad y la Plaza de la Guardia Nacional}

El principal efecto de esta sección en la ciudad fue el registro de las propiedades para la Municipalidad y el trazado de manzanas cerca al Hospital Dos de Mayo, para continuar con la división de lotes en un siguiente periodo 
urbanizador que no se llegó a concretar. Sin embargo este trazado años más tarde sirvió para que la Compañía urbanizadora Cocharcas86 decidiera vender terrenos en esta sección usando este trazado, y continuara con la urbanización de este lado de la ciudad. Por otro lado, no se llegó a concretar el diseño de la Plaza de la Guardia Nacional que hubiera conectado este sector con el centro y el otro lado del río, pero que además, hubiera permitido un crecimiento urbano del lado este de la ciudad.

\section{Plano 3.10 \\ Sección segunda}

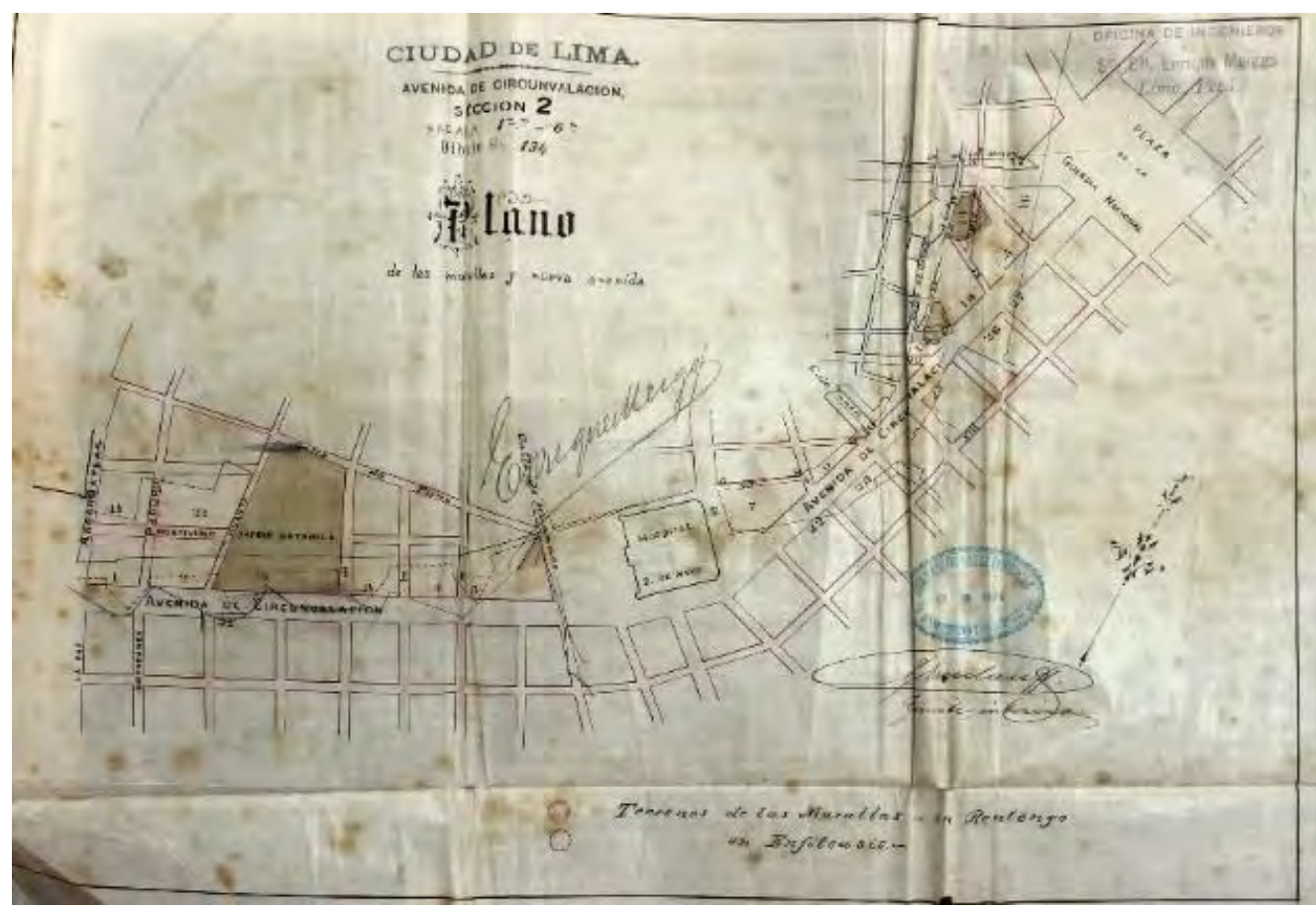

Fuente: Archivo General de la Nación del Perú, Notario Selaya (1877)

\subsubsection{El registro de tenencia de propiedades en la tercera sección}

La sección tercera correspondió desde la Plaza de la Guardia Nacional hasta el puente Viterbo y desde este puente hasta el Camal, margen izquierda del río Rímac. En esta sección el fraccionador Enrique Meiggs tampoco pudo lotizar ni

\footnotetext{
${ }^{86}$ La Compañía urbanizadora Cocharcas urbanizó las manzanas cercanas al Jardín Botánico que corresponden a la sección segunda el año 1908. En: Diario El comercio de Lima, domingo 2 febrero de 1908, (Núm. 31,897), pp.7 “La Compañía urbanizadora Cocharcas".
} 
vender terrenos debido a que el borde ribereño se encontraba urbanizado de manera espontánea y tenía problemas de saneamiento legal, según se registró en el documento Terrenos de la Ribera del Rímac escrito por el abogado Samuel Samudio. (Patiño, 1891:33-48) Por esta razón Meiggs únicamente se dedicó a realizar un registro de la tenencia de las propiedades. Con esta acción, contribuyó a que la Municipalidad iniciara el saneamiento legal del borde ribereño en los años posteriores. Además, realizó un registro de los terrenos de su propiedad y de realengo que sirvió para la transferencia de propiedades a Bienes Nacionales ${ }^{87}$ años después de su fallecimiento. Vale decir que el patrimonio que llegó a acumular el fraccionador Meiggs en esta sección tercera constaba de veintidós manzanas que en promedio tenían 6,213 varas cuadradas valorizadas en S/. 152,254 soles (Notario Selaya, 1876:8082).

Es necesario decir que en esta sección existía un mercado de suelo constituido espontáneamente y la expectativa de Meiggs era que cuando ingresó a realizar la ejecución de las obras del Plan de Ensanche ese mercado fuera formalizado. En consecuencia, según Jaramillo, los precios existentes en el borde ribereño hubieran sufrido una mutación como consecuencia de los precios propuestos por el monopolio planteado por Meiggs, generando un desplazamiento del mercado, una formalización de la tenencia y un despliegue socio-espacial (Jaramillo,2009:221) Ello hubiera beneficiado a la Municipalidad con ingresos por impuestos prediales, sobre propiedades cuyo precio hubiera aumentado $y$, en teoría, se hubieran mejorado las condiciones de salubridad de esta ribera del río Rímac.

\footnotetext{
87 Según Francisco García Calderón "Bienes nacionales se llaman a las cosas cuya propiedad pertenecen a la nación. En las relaciones internacionales se señala como bien de una nación a todos los que se encuentran en el territorio de ella, aunque pertenezcan a particulares; pero en el derecho constitucional solo se consideran como nacionales los bienes cuya propiedad pertenecen al Estado, aunque sean de uso común". "Diccionario de la Legislación Peruana", Lima, 1 vol. ed. Jurídica Grijley, 2003, Lima, pp.272.
} 


\section{Plano 3.11}

\section{Sección tercera}

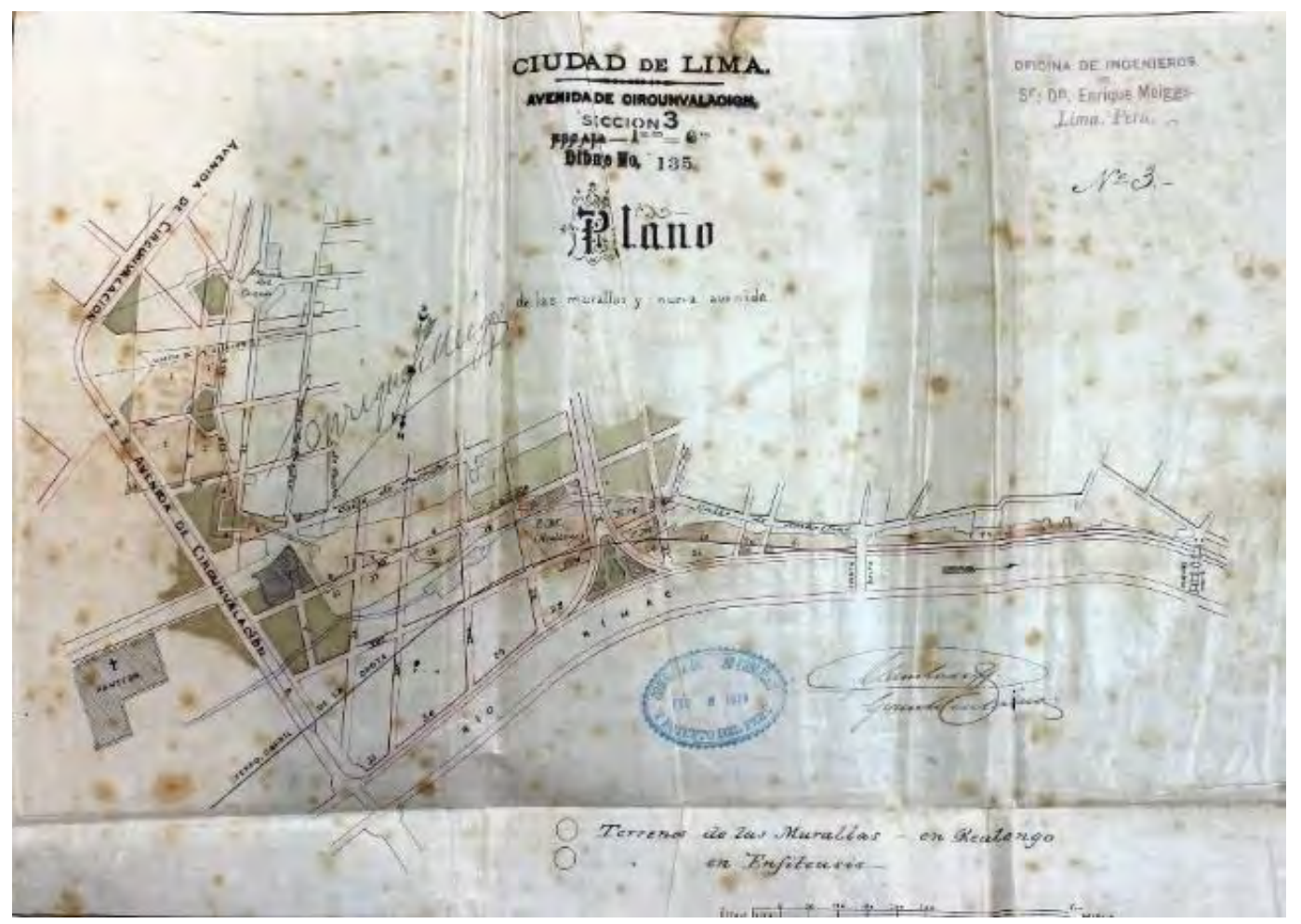

Fuente: Archivo General de la Nación del Perú, Notario Selaya (1876)

\section{Foto 3.2}

\section{Baluarte $\mathrm{N}^{\circ} 2$, de la antigua muralla, ubicado en Barrios Altos}

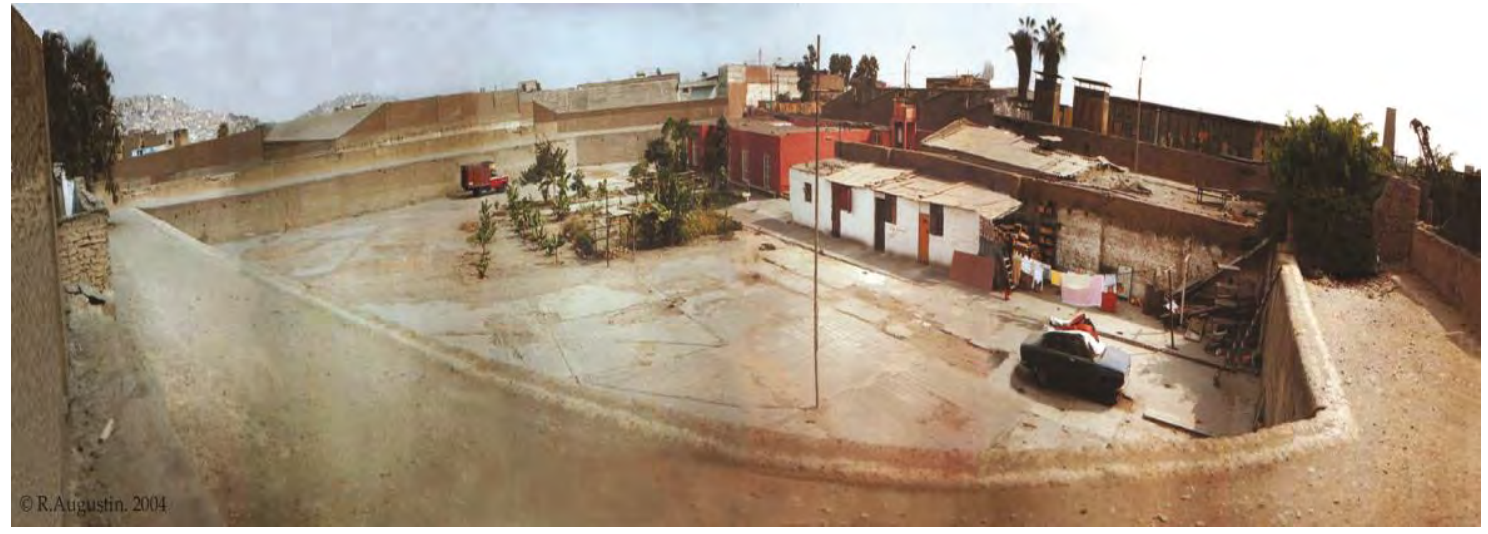

Fuente: Augustín (2011) 
Según la propuesta original del ingeniero Luis Sada, se pensó construir malecones a ambos lados del río Rímac, razón por la cual, el Estado Peruano cedió los terrenos cercanos al puente Balta años para la Municipalidad (Patiño,1891), Con estas acciones se benefició la población de los lugares ribereños en su calidad de vida. Además, con estos trabajos fue posible que la Municipalidad retomara el proyecto de renovación urbana que inició el año 1866, que incluyó la reestructuración de las vialidades y construcción de los malecones a ambas lados el borde ribereño (Barbagelata y Bromley, 1945), pero esta vez según el planteamiento del Plan de Ensanche. Sin embargo, debido a los problemas de tenencia de las propiedades esta sección continúo en proceso de deterioro. No fue posible la ejecución total del proyecto público ni privado y el mercado informal continuó operando.

\subsubsection{La urbanización cerca a los óvalos Dos de Mayo y Unión}

La sección cuarta comprende desde la carretera al Callao hasta el Palacio de la Exposición. En esta sección Meiggs realizó obra pública y privada con la Compañía de Obras Públicas y Fomento del Perú que formalizó en este periodo. En esta sección, Meiggs compró huertas que anexaría a su monopolio inmobiliario cerca al Palacio de la Exposición, como: Mosquito, De la Cruz parte de la huerta Virreina, Coloinda y Chacra Colorada (Notario Selaya, 1877:871) Además, ejecutó obra pública, lotizó y vendió terrenos cercanos a las Plazas Unión, Dos de Mayo y a La Estación de Monserrate donde se encontraban terrenos industriales, comerciales y de vivienda.

Cuando se encontraba expropiando terrenos para realizar el trazado de calles cerca a la estación de Monserrate, tuvo que realizar obras menores como resolver el paso del ferrocarril Lima-Callao y canalizar riachuelos que atravesaban calles. Nuevamente antepuso la obra privada sobre la pública como se observa en el documento de compra venta del año 1875 titulado "Expropiación de los terrenos del señor Herrera a favor del fisco" (Notario Palacios, 1875:1343) Ahí se registra que Enrique Meiggs compró los terrenos de hacienda Chacra Colorada, que median 142,193 varas cuadradas, a 26 centavos la vara cuadrada cuyo precio total fue de S/. 37,165 (Notario 
Palacios, 1875:1343). Meiggs compró a precio de expropiación, anexando esos terrenos a su monopolio e ingresándolos a un proceso de espera para ser lotizados, lo que nunca sucedió. No obstante, estas acciones trajeron como consecuencia el cambio de suelo rural a urbano repentino y el desplazamiento de la población hacia otras zonas de la ciudad. Nuevamente el proyecto privado se imponía al interés público. Las huertas compradas que no fueron lotizadas iniciaron su deterioro y convirtieron a la zona insegura, generando urbanización espontánea.

Figura 3.12

Sección cuarta

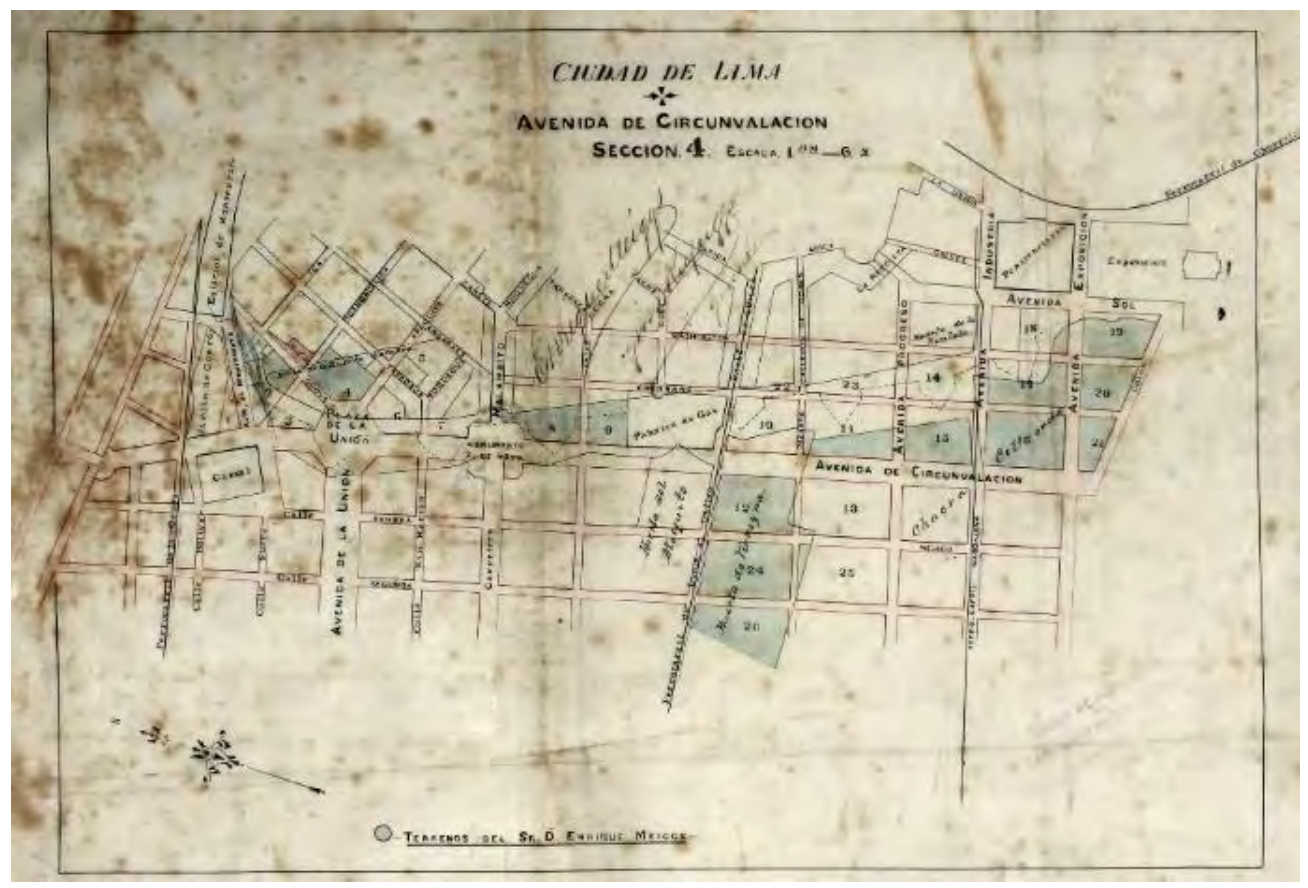

Fuente: Archivo General de la Nación del Perú, Notario Selaya (1876)

\subsubsection{Oferta de lotes de vivienda y comercio para inmigrantes.}

En la cuarta Sección Meiggs realizó el negocio de bienes raíces e hipotecó sus propiedades para aumentar su capital y seguir invirtiendo en la compra de terrenos. En el caso de esta sección la oferta de suelo estuvo principalmente dirigida a los extranjeros con capacidad adquisitiva, entre comerciantes y trabajadores asalariados, los cuales buscarían un lote pequeño pero bien ubicado frente a una plaza, para establecer un negocio-vivienda. Por otro lado, 
debido a la necesidad de contar con un mayor capital para la adquisición de más huertas cerca al Palacio de la Exposición, el fraccionador Enrique Meiggs hipotecó las propiedades ya existentes para pedir préstamo al Banco Hipotecario y así ampliar su monopolio inmobiliario (Notario Selaya, 1877:775v783).

En este momento el patrimonio que había acumulado comprando terrenos en las secciones se dividió en dos: patrimonio familiar y de la Compañía de Obras Públicas y Fomento del Perú. Por esta razón que el 09 de febrero de 1877, posiblemente meses antes de su fallecimiento, protocolizó el documento titulado "Pago de acciones del Gerente de la Compañía de Fomento y Obras Públicas a Enrique Meiggs", donde recibió propiedades de la sección cuarta y algunas manzanas de la sección primera (Notario Selaya ,1877:775v-783), dejando así dividido su patrimonio y el de la empresa. También con esta acción decidió compartir las ganancias con sus socios en la Compañía de Fomento y Obras Públicas con el objetivo de tener un crecimiento económico a través de su empresa y diversificarla con una mayor oferta de servicios, como venta de materiales de construcción. La idea era convertirse también en dueño de un Banco Hipotecario (José Selaya,1877:732-753) y aumentar su acumulación de riqueza.

En esta sección la oferta inmobiliaria fue de nueve manzanas, las cuales tenían como promedio 9,497 varas cuadradas. Las manzanas más grandes fueron la manzana once de Chacra Colorada con 24,349 varas cuadradas y la manzana catorce con 20,551 varas cuadradas (Notario Selaya,1877:82v-84). En el siguiente cuadro veremos las ventas que realizó cerca a los óvalos Unión y Dos de Mayo. 


\section{Cuadro 3. 11}

\section{Lotes vendidos en la sección cuarta. (1874-1876)}

\begin{tabular}{|c|c|c|c|c|}
\hline $\begin{array}{l}\text { Nro. de } \\
\text { Manzana }\end{array}$ & Propietarios & Calles aledañas & Lote & Fuente \\
\hline Sin Numero & José María León & $\begin{array}{c}\text { Plaza Unión, Avenida de } \\
\text { Circunvalación, calle Arequipa, } \\
\text { calle Tayacaja }\end{array}$ & 9,8 & $\begin{array}{c}\text { Notario José Selaya,1874- } \\
75: 894\end{array}$ \\
\hline Sin Numero & $\begin{array}{l}\text { Nicholas Richmon, } \\
\text { Raños Rendetti }\end{array}$ & $\begin{array}{c}\text { Plaza Unión, Avenida de } \\
\text { Circunvalación, calle Arequipa, } \\
\text { calle Tayacaja }\end{array}$ & 14,13 & $\begin{array}{l}\text { Notario José Selaya,1874-75: } \\
894\end{array}$ \\
\hline Sin Numero & $\begin{array}{l}\text { Carmen Vásquez, } \\
\text { Enrique Ridoul }\end{array}$ & $\begin{array}{c}\text { Plaza Unión, Avenida de } \\
\text { Circunvalación, calle Arequipa, } \\
\text { calle Tayacaja }\end{array}$ & 15,16 & $\begin{array}{l}\text { Notario José Selaya, 1876: } \\
894\end{array}$ \\
\hline Sin Numero & $\begin{array}{l}\text { Man Murchios, José } \\
\text { Padilla }\end{array}$ & $\begin{array}{c}\text { Plaza Unión, Avenida de } \\
\text { Circunvalación, calle Arequipa, } \\
\text { calle Tayacaja }\end{array}$ & 19,20 & $\begin{array}{l}\text { Notario José Selaya, 1874-75: } \\
894\end{array}$ \\
\hline Sin Numero & $\begin{array}{l}\text { Ramón Gallego, } \\
\text { Rosendo Gallego }\end{array}$ & $\begin{array}{c}\text { Plaza Unión, Avenida de } \\
\text { Circunvalación, calle Arequipa, } \\
\text { calle Tayacaja }\end{array}$ & 6 & $\begin{array}{l}\text { Notario José Selaya,1874-75: } \\
\qquad 894\end{array}$ \\
\hline $\begin{array}{l}\text { Sección } 4 \\
\text { Manzana } 5\end{array}$ & Juan Terre, & $\begin{array}{l}\text { calle San Martin, calle Moquegua, } \\
\text { calle Angaraes, calle Arequipa }\end{array}$ & 1,2 & $\begin{array}{c}\text { Notario José Selaya,1874-75: } \\
868\end{array}$ \\
\hline $\begin{array}{l}\text { Sección } 4 \\
\text { Manzana } 5\end{array}$ & $\begin{array}{l}\text { Augusto Pautrat, } \\
\text { Francisco Corteaux }\end{array}$ & $\begin{array}{l}\text { calle San Martin, calle Moquegua, } \\
\text { calle Angaraes, calle Arequipa }\end{array}$ & $3,4,5$ & $\begin{array}{c}\text { Notario José Selaya,1874-75: } \\
868\end{array}$ \\
\hline $\begin{array}{l}\text { Sección } 4 \\
\text { Manzana } 5\end{array}$ & $\begin{array}{c}\text { Celinda de Varia de } \\
\text { Velásquez, Ricardo } \\
\text { I.G. Varea, María Urue } \\
\text { de Varea } \\
\end{array}$ & $\begin{array}{l}\text { calle San Martin, calle Moquegua, } \\
\text { calle Angaraes, calle Arequipa }\end{array}$ & $7,8,9$ & $\begin{array}{l}\text { Notario José Selaya,1874-75: } \\
\qquad 688\end{array}$ \\
\hline $\begin{array}{l}\text { Sección } 4 \\
\text { Manzana } 5\end{array}$ & $\begin{array}{l}\text { Angel Cavassa,Diego } \\
\text { López Aliaga, } \\
\text { Guillermo Knudsen }\end{array}$ & $\begin{array}{l}\text { calle San Martin, calle Moquegua, } \\
\text { calle Angaraes, calle Arequipa }\end{array}$ & $\begin{array}{l}10,11 \\
12\end{array}$ & $\begin{array}{l}\text { Notario José Selaya,1874-75: } \\
\qquad 868\end{array}$ \\
\hline $\begin{array}{l}\text { Sección } 4 \\
\text { Manzana } 5\end{array}$ & $\begin{array}{c}\text { María Uribe de Varea, } \\
\text { Ángel Cavassa, } \\
\text { Domingo Sánchez, } \\
\text { Proper Cheraliex }\end{array}$ & $\begin{array}{l}\text { calle San Martin, calle Moquegua, } \\
\text { calle Angaraes, calle Arequipa }\end{array}$ & $\begin{array}{l}13,14 \\
15\end{array}$ & $\begin{array}{l}\text { Notario José Selaya,1874-75: } \\
\qquad 868\end{array}$ \\
\hline $\begin{array}{c}\text { Sección } 4 \\
\text { manzana } \\
\text { sin numero }\end{array}$ & M. Avelino Lazo & Calle Tayacaja, calle Angaraes & 3 & $\begin{array}{c}\text { Notario José Selaya,1874-75: } \\
902\end{array}$ \\
\hline $\begin{array}{l}\text { Sección } 4, \\
\text { Sin numero }\end{array}$ & $\begin{array}{l}\text { Diego López Aliaga, } \\
\text { Guillermo Thounsend, } \\
\text { Guillermo Knudsen }\end{array}$ & $\begin{array}{c}\text { Calle de Arequipa, calle } \\
\text { Angaraes, calle Moquegua, calle } \\
\text { Tayacaja }\end{array}$ & $\begin{array}{c}9,10,1 \\
1,12\end{array}$ & $\begin{array}{l}\text { Notario José Selaya,1874-75: } \\
\qquad 902\end{array}$ \\
\hline $\begin{array}{l}\text { Sección } 1 \\
\text { Sin numero }\end{array}$ & $\begin{array}{l}\text { Tasa de Tunsing, Nam } \\
\text { lang, Basilia Mena, } \\
\text { Pablo Costa }\end{array}$ & $\begin{array}{l}\text { Calle Bogotá, Santiago, Santa } \\
\text { Teresa, calle Inambari }\end{array}$ & $\begin{array}{c}1,2,10 \\
, 11,12 \\
, 7\end{array}$ & $\begin{array}{l}\text { Notario José Selaya, 1874-75: } \\
\qquad 902\end{array}$ \\
\hline
\end{tabular}

Fuentes: Elaboración propia en base Selaya (1874),(1875),(1876). 
En total, la oferta de suelo consistió en setenta y cuatro lotes en las manzanas 1,2,3,5,6,7 que fueron los que daban a las Plazas Unión y Dos de Mayo vendiéndose un total de treintainueve y dos terrenos industriales obteniendo un monto de $\mathrm{S} / .187,642$ a un promedio de $\mathrm{S} / .4,75$ soles la vara cuadradas entre los años 1874 a 1875. Las ventas se hicieron en su mayoría a inmigrantes chinos y europeos (Notario Selaya, 1876:82v-84).

La transformación urbana que produjo esta sección en la ciudad fue: el trazado de la Plaza Dos de Mayo el año 1872 que se convertiría en un hito para la ciudad moderna, la materialización de la zona industrial de la ciudad cerca a la estación de Monserrate y el trazado de la alameda de Circunvalación. Con estas obras, Meiggs consolidó la urbanización de la periferia en la zona sur poniente de Lima, con las consecuentes ganancias especulativas.

\subsubsection{El diseño de la Avenida Unión en la quinta sección}

Esta sección comprende desde el camino al Callao hasta el Camal. El fraccionador Enrique Meiggs diseñó el trazado que no estaba incluido en el Plan de Ensanche, buscando unir Lima con el Callao a través de la avenida Unión cuyo proyecto hemos descrito en el capítulo segundo. Con este propósito, inició la expropiación de las huertas: Lazo, limeña, Salvi, La Chalaca y Arenibar Lazo y Conde de Vega (Notario Selaya, 1874:597-598v) y paralelamente compró terrenos que tuvo que ceder para permitir que se concretara el trazado de la avenida Unión. También negoció con los dueños la permuta de fragmentos de terrenos a ambos lados de la avenida Unión (Notario Suarez, 1872:321v-322) de un total de seis manzanas. Así, el fraccionador Meiggs acumuló una vez más su patrimonio. (Notario Selaya, 1876:84).

El diseño de la avenida Unión siguió un trazado reticulado que le dio continuidad al Plan de Ensanche desde la Plaza Unión hasta el Callao. En esta sección lotizó veinticuatro manzanas a ambos lados de la Avenida Unión. Los trabajos de expropiación se hicieron entre los años de 1874 a 1876, cuando realizó la compra de terrenos para su Compañía. Con este diseño permitió la conexión de Lima con el Callao e hizo un registro gráfico de la 
ubicación de riachuelos, caminos de herradura, edificaciones y límites de las huertas existentes.

\section{Plano 3.13}

\section{Sección quinta}

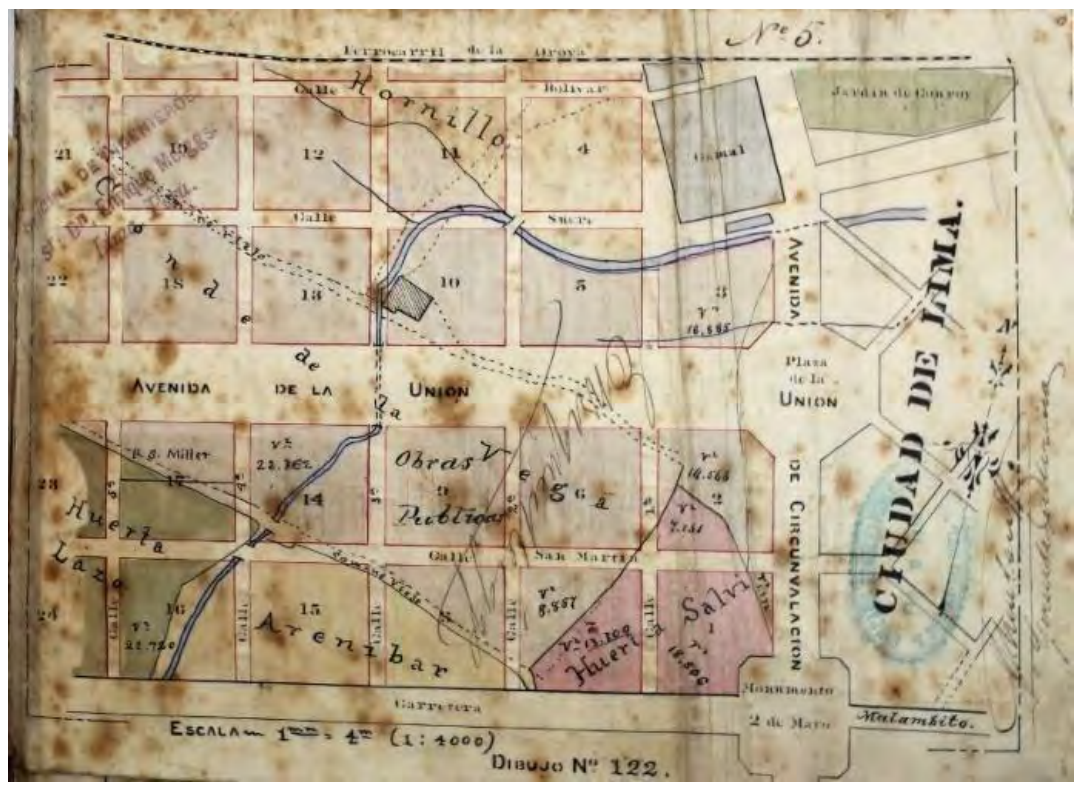

Fuente: Archivo General de la Nación, Notario Selaya, (1876)

\section{Plano 3.14}

\section{Fragmento de la sección quinta según el Sr. Aranibar}

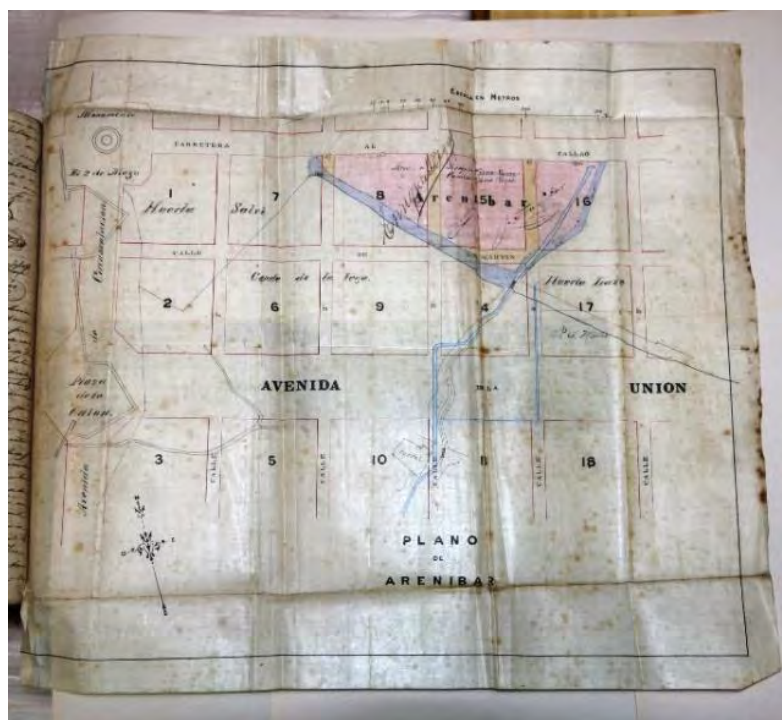

Fuente: Aranibar (1874) Fragmento de la avenida Unión, Selaya (1874). 
El documento gráfico fue elaborado por su propietario el señor Aranibar por el conflicto de los límites con las huertas cercanas Salvi, Conde de Vega y Lazo (Notario Selaya,1874:597-598v). El aporte de la sección quinta a la ciudad fue permitir la conexión de Lima con el puerto del Callao, lo que generó un mejor flujo de personas y mercancías entre estas dos ciudades, beneficiando a la actividad económica, generando una mayor oferta de propiedades e impulsando el crecimiento urbano hacia el lado poniente de la ciudad.

\subsection{Los trabajos que ejecutó Enrique Meiggs del Plan de Ensanche (1872-1876)}

Al ser el único postor e inevitable ganador de la licitación del remate de los terrenos de la muralla y de la ejecución del Plan de Ensanche, el fraccionador Enrique Meiggs, realizó los trabajos de crecimiento y transformación urbana bajo un sistema que le beneficiaba en detrimento de la ciudad. Así emprendió las expropiaciones, la elaboración de planos de la periferia, propuestas de apertura de calles y avenidas, la construcción de la Alameda de Circunvalación, la construcción de la Plaza de la Guardia Nacional, algunas mejoras en el borde ribereño y obras menores como canalización y demoliciones.

En el siguiente cuadro vemos las obras que comprendía la ejecución del Plan de Ensanche y en qué medida entre los años 1872 a 1876 fueron ejecutadas. 


\section{Cuadro 3. 12}

\section{Obras a ejecutar del Plan de Ensanche primera sección (1872-1876)}

\begin{tabular}{|c|c|c|}
\hline Obra a ejecutar & Porcentaje ejecutado & Fuente \\
\hline $\begin{array}{c}\text { Construcción de la alameda de } \\
\text { Circunvalación }\end{array}$ & $\begin{array}{c}\text { Se ejecutó } 80 \% \text { hasta el } \\
\text { hospital Dos de mayo }\end{array}$ & Plano de Lima 1896 \\
\hline $\begin{array}{c}\text { Construcción de avenidas } \\
\text { secundarias transversales y } \\
\text { paralelas a la alameda } \\
\text { Circunvalación. }\end{array}$ & $\begin{array}{c}\text { Se ejecuto } 50 \% \text { la } \\
\text { avenida Santa Teresa y } \\
\text { posteriormente se } \\
\text { aperturó la avenida San } \\
\text { Carlos }\end{array}$ & Plano de Lima 1896 \\
\hline $\begin{array}{c}\text { Trazado y construcción de } \\
\text { avenidas para unir el trazado } \\
\text { colonial con las nuevas calles } \\
\text { Bogotá, Tipiani y Maipiri. }\end{array}$ & $\begin{array}{c}\text { Se ejecutó al 60\% } \\
\text { a cargo de la Compañía } \\
\text { de Meiggs }\end{array}$ & $\begin{array}{c}\text { Plano de Lima 1896, } \\
\text { Plano de Lima 1896 } 1876),\end{array}$ \\
\hline $\begin{array}{c}\text { Trazado de calles cerca a la } \\
\text { Escuela de Medicina }\end{array}$ & No se ejecutó & Plano de Lima 1896 \\
\hline
\end{tabular}

Fuente: Elaboración propia en base a Plano de Lima elaborado por el Cuerpo de Tasaciones (1896), Selaya (1876)

En esta primera sección debido a que el fraccionador Enrique Meiggs lotizó quince manzanas paralelamente no ejecutó gran parte de los trabajos del Plan de Ensanche. En realidad, su principal preocupación fue materializar el trazado para de inmediato ofrecer en venta su proyecto inmobiliario. Por esta razón, muchas obras quedaron sin realizar cerca a la sección segunda y porque en estos años culminó el gobierno del presidente Manuel Pardo, que generó una paralización por el cambio de gobierno. En esta sección el fraccionador Enrique Meiggs utilizó el dinero de la venta de los lotes en otras secciones para continuar adquiriendo terrenos. Pero continuó con la ejecución de obras menores para poder concretar el trazado de la lotización como la demolición de muros al interior de terrenos que expropió. Con estas acciones trazó las avenidas y calles planteadas en el Plan de Ensanche. 


\section{Plano 3.15 \\ Detalle de demolición de muro en la primera sección en la Avenida Circunvalación}

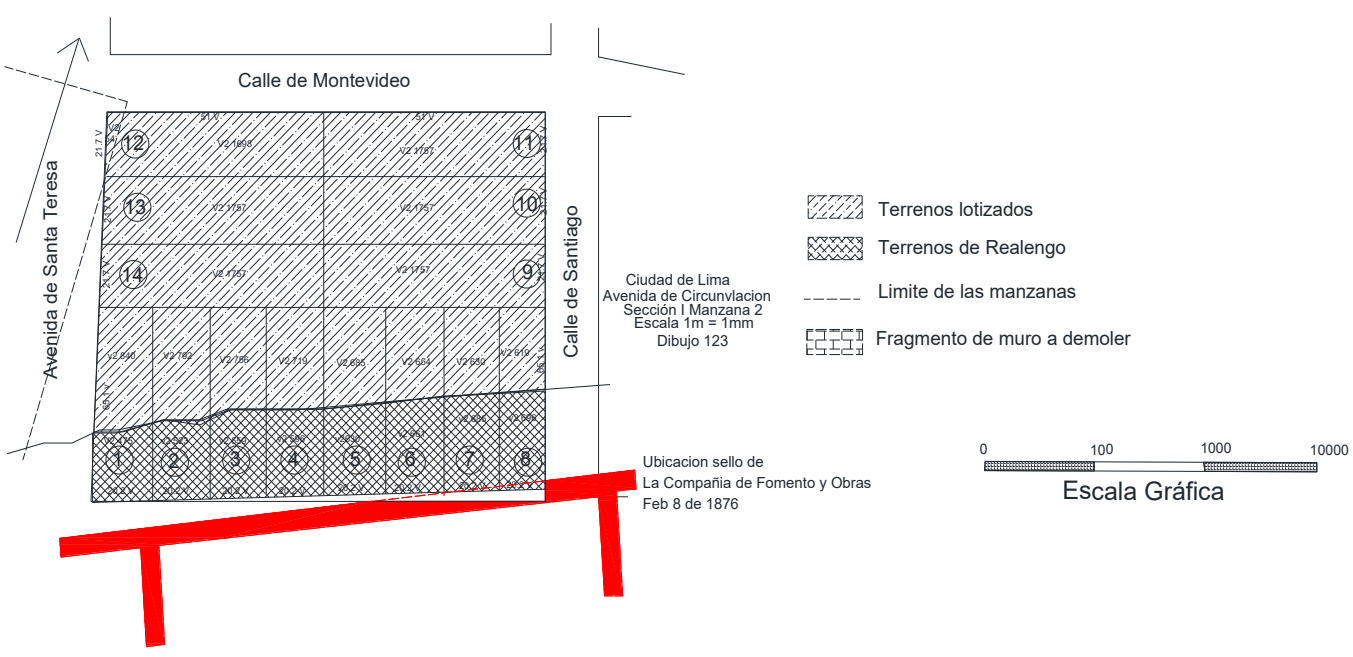

Fuente: Archivo General de la Nación del Perú, Notario Selaya (1876)

\section{Cuadro 3. 13 Obras a ejecutar del Plan de Ensanche segunda sección (1872-1876)}

\begin{tabular}{|c|c|l|}
\hline Obra a ejecutar & $\begin{array}{c}\text { Porcentaje } \\
\text { ejecutado }\end{array}$ & Fuente \\
\hline Construcción de la alameda de Circunvalación & No se ejecutó & Plano de Lima 1896 \\
\hline Construcción de la Plaza de la Guardia Nacional & No se ejecutó & Plano de Lima 1896 \\
\hline $\begin{array}{c}\text { Construcción de un óvalo de conexión por el este entre el } \\
\text { centro y la plaza de la Guardia Nacional siguiendo el trazo } \\
\text { de la calle Junín y trazado y construcción de calles } \\
\text { cercanas. }\end{array}$ & No se ejecutó & Plano de Lima 1896 \\
\hline $\begin{array}{c}\text { Construcción de una avenida del ovalo a la ribera del río } \\
\text { Rímac. }\end{array}$ & No se ejecutó & Plano de Lima 1896 \\
\hline $\begin{array}{c}\text { Construcción de una avenida desde la alameda } \\
\text { Circunvalación al Cercado. }\end{array}$ & No se ejecutó & Plano de Lima 1896 \\
\hline $\begin{array}{c}\text { Construcción de una avenida de la Plaza de Guardia } \\
\text { Nacional hacia la exportada de Barbones. }\end{array}$ & $\begin{array}{c}\text { Se ejecutó una } \\
\text { parte de la } \\
\text { avenida de la } \\
\text { Guardia Nacional }\end{array}$ & Plano de Lima 1896 \\
\hline
\end{tabular}

Fuente: Elaboración propia en base a Plano de Lima elaborado por el Cuerpo de Tasaciones (1896) 
En la sección tercera no se realizaron obras del Plan de Ensanche debido a que en la zona este de la ciudad existía urbanización espontanea que hacían necesario un proceso de saneamiento legal por parte de la Municipalidad.

\section{Cuadro 3.14 Obras a ejecutar del Plan de Ensanche tercera sección (1872-1877)}

\begin{tabular}{|c|c|c|}
\hline Obra a ejecutar & $\begin{array}{c}\text { Porcentaje } \\
\text { ejecutado }\end{array}$ & Fuente \\
\hline $\begin{array}{c}\text { Construcción de una alameda al otro lado } \\
\text { del río }\end{array}$ & No se ejecutó & $\begin{array}{c}\text { Plano de Lima } \\
1896\end{array}$ \\
\hline $\begin{array}{c}\text { Construcción de un puente en el río Rímac } \\
\text { de conexión entre la alameda de } \\
\begin{array}{c}\text { Circunvalación y el otro lado del río a la } \\
\text { altura de Huerta Perdida. }\end{array}\end{array}$ & No se ejecutó & $\begin{array}{c}\text { Plano de Lima } \\
1896\end{array}$ \\
\hline $\begin{array}{c}\text { Trazado y construcción de calles y avenidas } \\
\text { al otro lado del río entre el puente Balta y el } \\
\text { puente de Piedra. }\end{array}$ & $\begin{array}{c}\text { Solo se ejecutó } \\
\text { el Tajamar del } \\
\text { Alguacil }\end{array}$ & $\begin{array}{c}\text { Plano de Lima } \\
1896, \text { Notario } \\
\text { Selaya (1877) }\end{array}$ \\
\hline $\begin{array}{c}\text { Construcción de un puente para conectar la } \\
\text { alameda Circunvalación con el otro lado del } \\
\text { río a la altura de la Estación de Monserrate. }\end{array}$ & No se ejecutó & $\begin{array}{c}\text { Plano de Lima } \\
1896\end{array}$ \\
\hline
\end{tabular}

Fuente: Elaboración propia en base a Plano de Lima elaborado por el Cuerpo de Tasaciones (1896), Notario Selaya (1877).

Debido a los problemas de tenencia no fue posible al fraccionador Meiggs intervenir los terrenos cerca al borde ribereño. A pesar de que la Municipalidad y el Ministerio de Gobierno Policía y Obras Públicas el año 1866 había ejecutado un plan de intervención para reconocer los terrenos del fisco, mejorar las vialidades, reconocer el trazo existente, los terrenos para demoler y trazado de manzanas en proyecto. El objetivo era ordenar la urbanización en el borde ribereño con un plan de intervención integra denominado Encauzamiento del río Rímac y construcción de malecones en ambas riberas ${ }^{88}$. Sin embargo,

\footnotetext{
88 Encauzamiento del río Rímac y construcción de malecones a ambas riberas. Plano ubicado En: Anales de Obras Públicas del Ministerio de Gobierno y Policía el año 1866.pp.s/n.
} 
este proyecto no se llegó a ejecutar y este espacio continuó su proceso de deterioro hasta después de la guerra del Pacífico

\section{Cuadro 3.15}

\section{Obras a ejecutar del Plan de Ensanche cuarta sección}

(1872-1877)

\begin{tabular}{|c|c|c|}
\hline Obra a ejecutar & $\begin{array}{l}\text { Porcentaje } \\
\text { ejecutado }\end{array}$ & Fuente \\
\hline $\begin{array}{l}\text { Construcción de la alameda } \\
\text { de Circunvalación }\end{array}$ & $\begin{array}{l}\text { Se ejecutó en un } 30 \% \\
\text { y fue culminada por } \\
\text { los gobiernos } \\
\text { posteriores a la guerra }\end{array}$ & Plano de Lima 1896 \\
\hline $\begin{array}{c}\text { Construcción de la avenida } \\
\text { Unión }\end{array}$ & $\begin{array}{l}\text { Solo se ejecutó la } \\
\text { expropiación }\end{array}$ & Plano de Lima 1896 \\
\hline $\begin{array}{c}\text { Trazado y construcción de } \\
\text { calles desde la avenida Unión } \\
\text { hasta el borde ribereño y } \\
\text { desde la avenida Unión hacia } \\
\text { el sur dos hileras de } \\
\text { manzanas. }\end{array}$ & $\begin{array}{l}\text { Se ejecutó en un } 80 \% \text {, } \\
\text { además se } \\
\text { canalizaron los } \\
\text { riachuelos en esta } \\
\text { zona }\end{array}$ & $\begin{array}{c}\text { Plano de Lima 1896, Notario } \\
\text { Selaya, } 1877\end{array}$ \\
\hline $\begin{array}{c}\text { Construcción del ovalo Dos } \\
\text { de Mayo }\end{array}$ & Se ejecutó $100 \%$ & Plano de Lima 1896 \\
\hline $\begin{array}{c}\text { Trazado y construcción de } \\
\text { calles desde la alameda } \\
\text { Circunvalación hasta la calle } \\
\text { Huancavelica. }\end{array}$ & Se ejecutó $100 \%$ & $\begin{array}{l}\text { Plano de la sección cuarta, } \\
\text { Plano de Lima } 1896\end{array}$ \\
\hline $\begin{array}{c}\text { Trazado y construcción de } \\
\text { calles cerca al Palacio de la } \\
\text { Exposición }\end{array}$ & No se ejecutó & $\begin{array}{c}\text { Plano de la sección cuarta } \\
\text { según Meiggs, Plano de } \\
\text { Lima } 1896\end{array}$ \\
\hline $\begin{array}{l}\text { Trazado y construcción de } \\
\text { calles cerca a la Escuela de } \\
\text { Agricultura de Santa Beatriz }\end{array}$ & No se ejecutó & $\begin{array}{c}\text { Plano de la sección cuarta } \\
\text { según Meiggs, Plano de } \\
\text { Lima } 1896\end{array}$ \\
\hline
\end{tabular}

Fuente: Elaboración propia en base a Plano de Lima elaborado por el Cuerpo de Tasaciones (1896), Notario Selaya (1877), Plano de la sección cuarta 
La sección cuarta fue en buena medida ejecutada según el Plan de Ensanche. El fraccionador Enrique Meiggs lotizó la totalidad de las manzanas cerca a los óvalos Unión para vivienda, comercio e industria. Sin embargo, no pudo concretar el trazado cerca al Palacio de la Exposición porque se encontraba comprando terrenos de la huerta Virreina y Chacra Colorada para en una segunda etapa lotizar y vender. El trabajo ejecutado por Meiggs consistió en realizar obras menores como: canalizar riachuelos que atravesaban las calles y avenidas, redimensionar algunas manzanas. Por ejemplo a la altura de la calle Cochrane tuvo que demoler un fragmento de muralla y resolver el paso del ferrocarril Lima-Callao. Con estas obras consolidó la urbanización de la periferia y materializó la zona industrial al nor-oeste de la ciudad, cerca a la Estación de Monserrate que es utilizada hasta la actualidad (Una de las principales avenidas de esta zona industrial lleva su nombre).

\section{Plano 3.16}

\section{Demolición de muro en la calle Santiago}

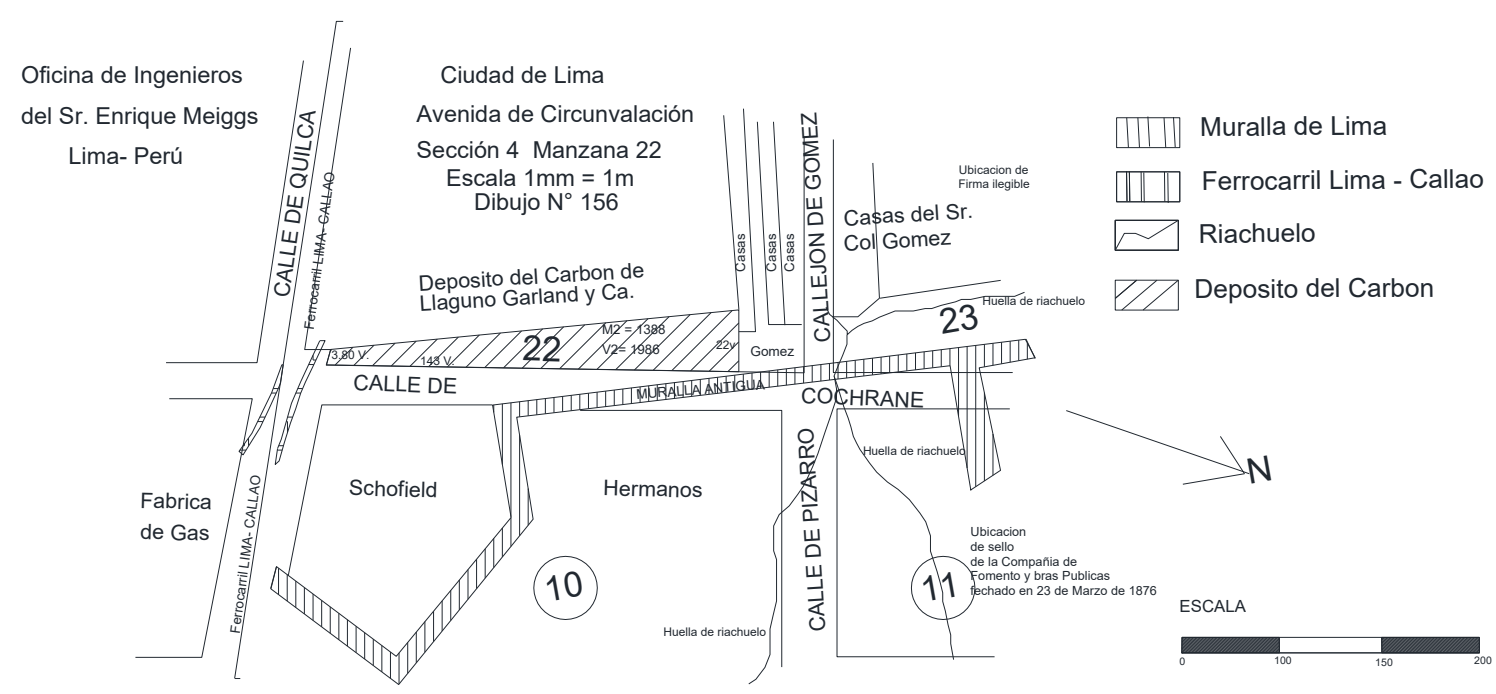

Fuente: Archivo General de la Nación del Perú, Notario Selaya (1876) 
Como se ve en los cuadros anteriores, Meiggs solo ejecutó obras del Plan de Ensanche en la sección primera y cuarta, altamente rentables. La falta de ejecución del Plan de Ensanche en algunas secciones tuvo las siguientes consecuencias: generó desorden en la urbanización de la periferia, propició la apropiación ilícita de terrenos propiedad del Estado, hubo descontento de los vecinos de las secciones que no fueron intervenidas, ocasionó la migración de las familias que vivían en estas secciones a otros espacios de la ciudad. Además, en donde no se ejecutaron las obras las propiedades se devaluaron, se generaron islas de urbanización que provocó más urbanización espontanea en los siguientes años. Hubo deterioro de los espacios públicos cercanos, aumento en la inseguridad ciudadana, problemas de insalubridad ante la falta de servicios básicos.

\subsection{La urbanización de la periferia a la ciudad}

El fraccionador Enrique Meiggs falleció en 1877, en un momento intenso de su negocio inmobiliario y cuando se encontraba realizando obra pública y privada. (Steward,1946: 336-337). Aunque las obras estaban a cargo de la Compañía de Obras y Fomento del Perú, no fue posible continuar con los trabajos porque solo el fraccionador conocía los detalles de diseño, financieros y legales del proyecto inmobiliario y del Plan de Ensanche. Los trabajos quedaron paralizados y un año más tarde la Compañía fue cerrada. Lo cierto fue que en aquel momento Meiggs había logrado reunir una cuantiosa fortuna gracias al monopolio urbanístico que le había cedido el Estado peruano. En el siguiente cuadro vemos el patrimonio acumulado por Meiggs en cada una de las secciones entre los años 1872 a 1877. 


\section{Cuadro 3.16}

\section{Resumen económico del negocio inmobiliario de Enrique Meiggs en la periferia de Lima (1872-1877)}

\begin{tabular}{|c|c|c|c|c|c|}
\hline \multicolumn{5}{|c|}{ Propiedades Enrique Meiggs } \\
\hline Sección & Manzanas & $\begin{array}{c}\text { Área } \\
\text { promedio } \\
\text { de manzana } \\
\text { varas }\end{array}$ & $\begin{array}{c}\text { P.U. } \\
\text { promedio } \\
\text { S/. }\end{array}$ & $\begin{array}{c}\text { Área } \\
\text { Varas }^{2}\end{array}$ & $\begin{array}{c}\text { Monto } \\
\text { Acumulado S/. }\end{array}$ \\
\hline 01 & 13 & 11,815 & 2.88 & 119,557 & 341,683 \\
\hline 02 & 14 & 8,602 & 1.94 & 101,525 & 196,920 \\
\hline 03 & 22 & 6,213 & 1.00 & 137,503 & 152,254 \\
\hline 04 & 09 & 9,497 & 2.38 & 85,551 & 187,782 \\
\hline 05 & 6 & 19,789 & 2.50 & 126,116 & 268,290 \\
\hline Totales & $\mathbf{6 4}$ & $\mathbf{5 5 , 9 1 6}$ & $\mathbf{2 . 1 4}$ & $\mathbf{5 7 0 , 2 5 2}$ & $\mathbf{1 , 1 4 6 , 9 2 9 . 5 0}$ \\
\hline
\end{tabular}

Fuente: Elaboración propia en base a documentos del Archivo General de la Nación, Selaya (1876)

En sólo cinco años Meiggs había acumulado más de un millón de soles de la época, habiendo partido casi de cero. El único capital con el que contaba cuando decidió proyectar su monopolio inmobiliario en la periferia fueron los honorarios por la construcción de ferrocarriles y el pago como constructor de la obra pública en la periferia. Sin embargo, en base a hipotecas de sus propiedades y compras a precio de expropiación aumentó espectacularmente su patrimonio, llegando a urbanizar 55,916 varas cuadradas, lo que equivale a un veinte por ciento del total de la periferia (Notario Selaya,1876:775-783). Podemos ver geográficamente sus acciones en el plano 3.17 , de la testamentaria.

La ejecución de la urbanización de la periferia realizada por Meiggs generó una metamorfosis urbana donde el negocio inmobiliario fue el eje, la actividad que movería la economía de la ciudad hacia su interés personal. (De Mattos, $2016,30)^{89}$. Además, puede decirse que de todo el diseño solo se pudo materializar parte de la sección cuarta que luego tendría una continuidad a

89 "La lógica financiera de la financiación y crecimiento urbano mercantilizado" Carlos De Mattos En: "Urbanización planetaria y la reconstrucción de la ciudad”, Arturo Orellana y otros Ed. Ril editores, Universidad Católica de Chile, Santiago. 2016 pp.29-57. 
principios del siglo $\mathrm{XX}$ por su cercanía al nuevo centro moderno que se construyó para complacer a la élite. $\mathrm{Y}$ muchos de los espacios que se urbanizaron fueron absorbidos por el mercado ilegal de suelo debido la intempestiva paralización a causa de la Guerra con Chile, lo que no permitió al Estado tomar medidas para evitar la apropiación ilícita de propiedades. En lo social, generó una expectativa en la población que vivía en el centro de mudarse a la periferia hecho que no se concretó. Al no concretarse la urbanización de la periferia se demostró que los negocios de minas y agricultura seguían siendo los más rentables, lo que hizo que después de la guerra los inversionistas priorizaran sus inversiones en estos negocios por sobre los inmobiliarios, ocasionando que el Estado implementara leyes para atraerlos nuevamente al negocio inmobiliario.

\section{Plano 3.17}

\section{Plano de la testamentaria de Enrique Meiggs el año 1879}

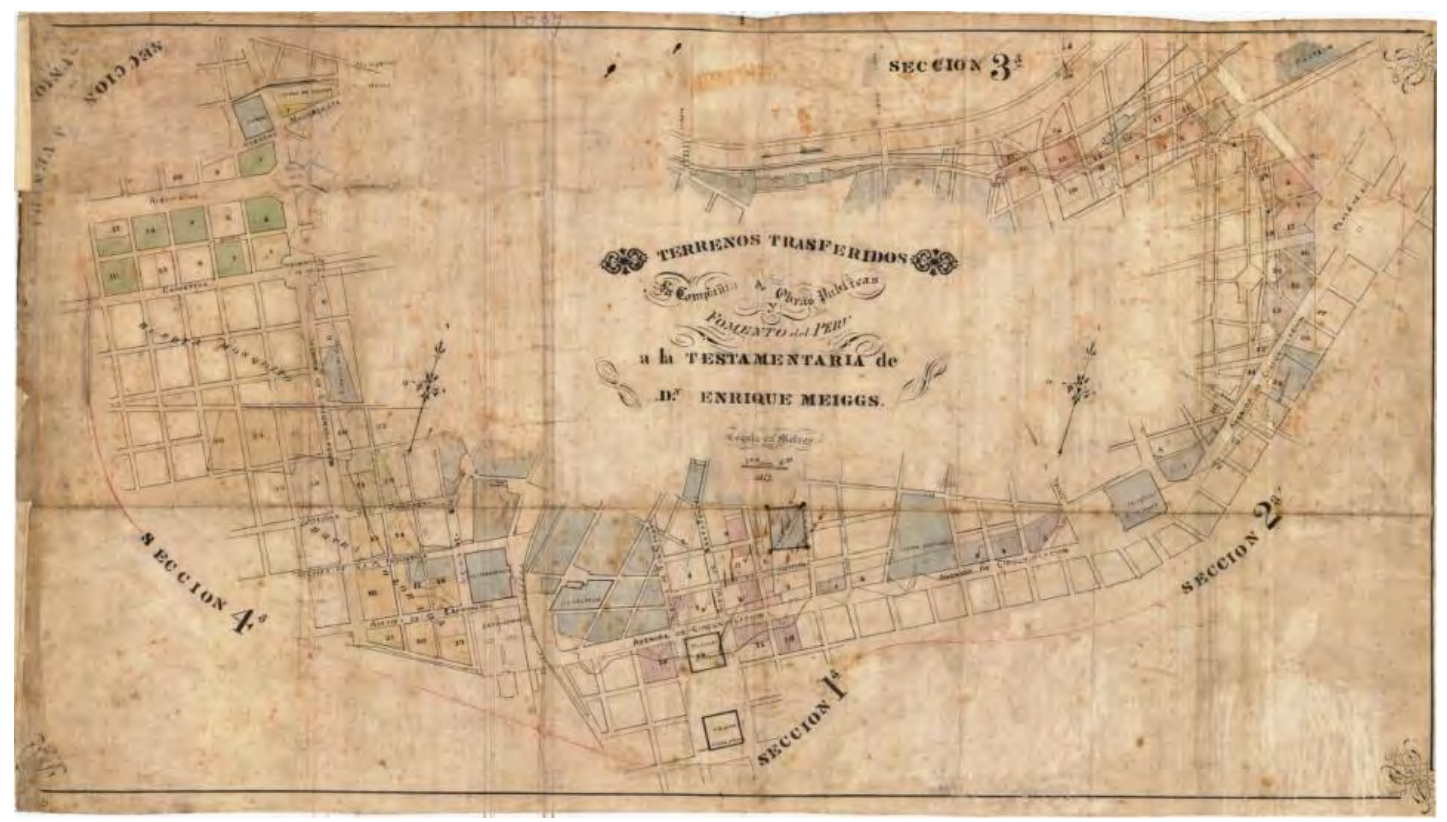

Fuente: Archivo General de la Nación del Perú, Notario Palacios (1879)

Años más tarde de la muerte de Meiggs sus herederos se repartieron los terrenos y las acciones que correspondían a la Compañía de Fomento y Obras Públicas del Perú, para posteriormente venderlos a particulares, desapareciendo la mayor parte del patrimonio que acumuló durante los años que intervino la periferia. 
En general, la paralización de las obras del Plan de Ensanche y el proyecto inmobiliario del fraccionador Enrique Meiggs tuvieron las siguientes consecuencias: La interrupción del proceso de urbanización dejó vacíos urbanos en cada una de las secciones, lo que provocó un desorden urbano, los terrenos pertenecientes a Bienes Nacionales fueron ocupados ilegalmente, el crecimiento ordenado de la periferia no se concretó, muy pocas personas se interesaron en comprar lotes en la periferia ${ }^{90}$ por falta de servicios. Sin embargo, los que compraron lotes al fraccionador Enrique Meiggs dejaron de pagar sus préstamos hipotecarios generando que los bancos tuvieran problemas para recuperar su capital. Así también, los propietarios de la periferia se vieron obligados a vender sus propiedades ante el proceso de deterioro y abandono en el que ingresaron muchas zonas de la periferia. La reestructuración del mercado de suelo de la periferia se paralizó y las propiedades atravesaron por una desvalorización de los precios. Al no existir una oferta de vivienda en la periferia la población nuevamente buscó un alquiler en la ciudad, lo que significó un aumento de precios de las rentas en el centro debido a una mayor demanda, la aparición de un mercado ilegal de suelo en la periferia, la especulación de las rentas de algunos propietarios de casas en el centro y el descenso de la actividad hipotecaria de los bancos fueron los problemas que tuvieron que solucionar los gobiernos de turno luego del periodo de reconstrucción de la ciudad La nueva ciudad que provocó el Plan de Ensanche sería moderna en el sentido caótico.

Ante la situación de desastre de la periferia el Estado Peruano no realizó ninguna acción, debido a que se encontraba en una bancarrota fiscal, proceso claro al final del periodo presidencial de Manuel Pardo. Además, se acercaba la guerra del Pacífico con Chile. Tampoco la Municipalidad pudo intervenir en la ejecución de las obras del Plan de Ensanche por falta de fondos para afrontar las obras públicas. Por último, ningún inversionista privado se interesó en rescatar el proyecto inmobiliario de Meiggs debido que era visto como un negocio de poco interés debido a la paralización de las obras del Plan de

\footnotetext{
90 Según Basadre Meiggs derribo las murallas sin cobrar a cambio de una concesión de terrenos en donde planeo la construcción de bulevares rodeados por árboles, soñaba con la urbanización de Lima y el Callao idea que se ha convertido el realidad después del año de 1920. Pero nadie compro estos terrenos y los arboles se secaron. También quiso Meiggs construir casas decorosas para empleados y obreros "Historia General del Perú tomo VIII", Lima, Ed. El Comercio, 2014 pp.51-52.
} 
Ensanche. Tampoco a los bancos o a la élite comercial les interesó acudir al rescate del negocio inmobiliario. Además, se decía que el fraccionador Meiggs había sido una persona relacionada al Estado Peruano corrupto.

\section{Comentarios generales del capítulo.}

La demolición de la muralla de Lima, en el año 1870 dio paso a la intervención en la periferia con la finalidad de materializar el progreso y modernizar la ciudad con proyectos de envergadura a partir del Plan de Ensanche. E programa incluía la Avenida Unión y una serie de obras que no fueron concluidas, generándose desorden en la urbanización y convirtiendo la modernización de la ciudad en una utopía. Las grandes extensiones de terrenos en la periferia que quedaron sin urbanizar contribuyeron al incremento de los problemas de salubridad y precariedad urbana.

La reglamentación de las transacciones bancarias por parte del Estado permitió la activación de las inversiones en la ciudad por parte de la burguesía guanera. Ante este hecho, el Estado y la elite propiciaron la aparición de las Cajas de Ahorros con el objetivo que la clase obrera, media e inmigrante que vivía en malas condiciones en el centro pudiera acceder a la compra de una vivienda en la periferia. Sin embargo, cuando los terrenos de la periferia se convirtieron en un proyecto inmobiliario privado, únicamente los que contaban con ahorros pudieron acceder a comprar una vivienda en la periferia.

El mercado de suelo especulativo que realizó el fraccionador Meiggs en la periferia afectó la ejecución del Plan de Ensanche, generando desorden de la urbanización. Los precios de los terrenos para vivienda ofrecidos por el fraccionador Meiggs estuvieron dirigidos a segmentos socio-económicos específicos, como limeños con poder adquisitivo, comerciantes, terratenientes, empresarios, banqueros, migrantes y empleados públicos, convirtiendo el mercado de suelo de la periferia en segmentado y de segregación. Al fallecer el fraccionador Meiggs y quedar trunca la urbanización de la periferia hizo su aparición un mercado de suelo ilegal.

El Estado Peruano buscó materializar la modernidad en la periferia con la construcción de alamedas arboladas como el caso de la avenida de 
Circunvalación y la plaza de la Guardia Nacional, espacios para que la población tuviera una experiencia moderna. Pero al no ser concluidas los terrenos fueron ocupados ilegalmente generando desorden en la urbanización.

El apoyo del Estado Peruano a la actividad inmobiliaria que venía realizando el fraccionador Meiggs fue absoluto y el mismo Estado se desligó del proceso, dejando al desarrollador un enorme poder de decisión urbana y acumulación personal de recursos.

La paralización del Plan de Ensanche tuvo efectos medio ambientales en la periferia como: afectó espacios verdes, terrenos de cultivo, riachuelos que fueron ocupados de manera ilegal al verse paralizadas las obras en la periferia. Así también muchos de los espacios abandonados por la paralización de las obras de ensanche fueron utilizados como basureros generando espacios insalubres en la periferia. 
La noción de progreso con el fin último de cimentar y legitimar el arraigo y profundización del capitalismo, sus relaciones sociales de producción, las instituciones y los códigos y simbolismos que le son consustanciales; al tiempo que se definió con dicha noción el perfil, los rasgos e identidad del Estado procreado en medio de la decimonónica convulsión social y política.

Isaac Enrique Pérez $(2018,93)$ 


\section{Capítulo IV El proyecto modernizador civilista, la reubicación del centro y la expansión de la ciudad al sur-oeste (1878-1908)}

El presente capítulo intenta explicar la construcción del proceso modernizador en Lima a partir de la guerra con Chile y la política urbana de los gobiernos civilistas. Estos gobiernos buscaron la materialización de la modernidad retomando en buena medida el proyecto de Luis Sada Di Carlo, el Plan de Ensanche, el mismo que Enrique Meiggs había puesto en marcha para urbanizar la periferia, aunque esta vez haciendo uso de la Ley de Expropiación de 1900 y 1903 . Además, la construcción del centro moderno y continuaron con proyectos de envergadura como la canalización del río Rímac, la construcción de las avenidas centrales (La Magdalena, La Colmena y la Interior) de manera conjunta con la inversión privada. Fue así que, nuevamente, las urbanizadoras privadas, a falta de un control de la Municipalidad, intervinieron abiertamente en la urbanización y muchos de los fraccionamientos que promovieron, hacia el poniente de la ciudad, quedaron sin equipamiento ni servicios.

Al iniciar el siglo XX, la periferia de la ciudad se había expandido hacia el sur poniente con la intervención de las empresas privadas. El Estado Peruano materializó una nueva propuesta de demarcación territorial que buscó incluir estas nacientes urbanizaciones para que la Municipalidad pudiera atender las necesidades básicas de las poblaciones, ahora agrupadas en distritos. Por otro lado, los cuarteles cerca del centro tenían problemas de salubridad que aun no habían sido resueltos. Por esa razón, se nombró una Comisión para estudiar la problemática, lo que trajo como resultado una serie de recomendaciones que fueron puestas en práctica para mejorar la salubridad en la ciudad. Para el año 1908, la ciudad había crecido logrando una conurbación con La Magdalena hacia el sur poniente y Santa Beatriz o Escuela de Agricultura hacia el sur por el sur, producto de la migración de las élites a estos balnearios. Eso favoreció la expansión urbana al sur, anticipando un proceso de metropolización de las próximas décadas. 


\subsection{La ciudad durante la ocupación de las tropas chilenas y el periodo de reconstrucción (1878-1894)}

En el año de 1878 el presidente Mariano Ignacio Prado ante la negativa de comandar un gabinete de conciliación ante la fragmentación de las fuerzas políticas, se quedó finalmente solo y terminaría saliendo del país. Eso creó un vacío de poder que permitió a Nicolás de Piérola diera un golpe de estado y asumiera la presidencia del Perú en el año 1879. Carmen Mc Evoy nos describe ese momento:

"El 19 de diciembre el país amaneció con la noticia que Mariano Ignacio Prado, Comandante General del ejército y Presidente de la República había iniciado un viaje "secreto" a Europa con la finalidad de adquirir armamento para el Perú. Viaje que dejó en acefalia la conducción política y militar peruana justificada por el mandatario en un par de documentos publicados en el extranjero. A pesar de los frágiles argumentos, la decisión apresurada del presidente de emprender el viaje, delegando el mando supremo al anciano vice-presidente, el general cuzqueño Luis La Puerta, fue un gravísimo error político-militar que el país hubo de pagar. La estéril "gira" presidencial en pos de los elusivos blindados, complicó, aún más el ya difícil escenario político nacional creando un vacío de poder que fue llenado rápidamente por Nicolás de Piérola" (Mc Evoy, 1997:209-210).

El inicio de este periodo dictatorial y la bancarrota fiscal tuvieron las siguientes consecuencias: paralización de las actividades económicas, estancamiento de las inversiones, muchos negocios se arruinaron, destrucción de la banca comercial, falta de oportunidades de empleo en la población y aparición de un mercado ilegal ante la crisis económica que vivía la población. En este contexto se inició la guerra con Chile, bajo la disputa por el control de los depósitos de salitre en Antofagasta y Tarapacá. Las élites peruanas buscaron seguir manteniendo su economía como en la época del guano y pensaron que la única manera era estatizando el salitre, dejando fuera de este lucrativo negocio a los empresarios chilenos e ingleses. Esta fue la principal razón para iniciar la guerra. El 5 de abril de 1879 el gobierno chileno le declaró la guerra al gobierno del Perú (Basadre, 2014, tomoVIII: 247).

"Al estallar la guerra se produjo la paralización de la obra pública, la agudización de la crisis económica, el racionamiento en el abastecimiento de los servicios básicos, la paralización de la actividad comercial, la disminución del abastecimiento de alimentos a la ciudad, el aumento de la delincuencia y la inseguridad ciudadana" (Guerra,1991:141-142). 
En el año 1881 se produjo la ocupación de Lima por el ejército chileno. Estaba en funciones el presidente golpista Nicolás de Piérola, quien tuvo que salir de la capital para reorganizarse en la sierra del Perú. Las tropas chilenas buscaron controlar la ciudad mediante las siguientes acciones: un bloqueo del litoral y las carreteras con la finalidad de restringir el ingreso de productos de primera necesidad y comercio a la ciudad (Rosario, 2014:209), decretaron el toque de queda a las ocho de la noche (Guerra, 1991:142) restringiendo de esta manera las actividades en los espacios públicos, controlaron los accesos a la ciudad como: la estaciones de los ferrocarriles (Lima-Callao, Lima-La Magdalena, Lima-Ancón y Lima_La Oroya) y las carreteras Lima-Callao, Lima-Chorrillos, Lima-Matucana y caminos vecinales para tener un control militar del territorio. Además, se decretó el funcionamiento de la policía de seguridad a cargo de las tropas chilenas, se estableció la jefatura de policía militar para imponer castigos por faltas menores debido al aumento del pandillaje. Sin embargo, las tropas chilenas permitieron a la Municipalidad que el Cuerpo de Celadores del Estado protegiera los comercios como una manera de evitar que fueran saqueados ante la falta de vigilancia y la violencia en las calles (Consejo Municipal de Lima, 1881:118). No obstante, con estas medidas, la inseguridad ciudadana continuó a pesar de algunas acciones para controlarla como explica Mc Evoy:

"La creación de una guardia urbana también ocurrió en Lima, donde un grupo de comerciantes extranjeros domiciliados en el barrio de Malambo solicitó al intendente permiso para constituirse en milicia armada. El argumento era que sus vidas e intereses estaban en peligro debido a los "malhechores" que dominaban las calles por falta de policía y tropa"(Mc Evoy, 2016:348-349).

Como parte del control de la ciudad, las tropas chilenas iniciaron la ocupación de las edificaciones públicas como los cuarteles, la Biblioteca Nacional, la Escuela de Ingenieros y el Palacio de la Exposición (Guerra, 1991:118) Los cuartes fueron utilizados como almacén, como una forma de hacer sentir a la población el control que tenían sobre la ciudad e iniciar el saqueo en las instituciones del Estado Peruano. Otro efecto fue la aparición del comercio ambulante cerca de las edificaciones ocupadas por el ejército chileno, producto de la necesidad económica de la población ante la situación existente. (Guerra, 1991:120) 
En medio del conflicto, existió la necesidad por parte de la élite peruana de contar con un gobierno provisional, con legitimidad suficiente, con el cual negociar los temas de la administración de la ciudad y el final del conflicto. Por esta razón las autoridades chilenas permitieron el funcionamiento de un gobierno provisional el 12 de marzo de 1881. Este se ubicó al oeste, en la población balneario de La Magdalena que era zona neutral (Guerra,1991:198 y Mc Evoy, 1997:216). Entonces el abogado Francisco García Calderón fue nombrado presidente provisional del Perú (Mc Evoy,1997:216). Las consecuencias que tuvo en la ciudad esta decisión política fueron: Lima dejó de ser el centro administrativo y político para cumplir únicamente una función religiosa, la administración de la ciudad paso operó por autoridades locales bajo el control de las autoridades chilenas, las relaciones entre las tropas chilenas y la población fueron menos conflictivas, se restablecieron las actividades de gobierno local y de las principales instituciones públicas. En términos urbanísticos se fortaleció la relación entre la ciudad de Lima y los balnearios del sur, aumentó el tráfico por el sur-oeste vía ferrocarriles Lima-La Magdalena ${ }^{91}$ y Lima-Chorrillos, se produjo un crecimiento urbano inesperado en los balnearios, hizo su aparición una urbanización espontanea en las zonas periféricas de los balnearios, la reubicación del Ejecutivo y el Congreso en estos balnearios ${ }^{92}$ ocasionó la reubicación de la élites en estos espacios, las edificaciones públicas existentes en estos balnearios fueron reacondicionadas para ser utilizadas por el gobierno provisional, se dio el cambio repentino de suelo de rural a urbano y se generaron problemas de abastecimiento de servicios básicos ${ }^{93}$.

\footnotetext{
91 Según Basadre "El ferrocarril Lima Chorrillos fue inaugurado en 1858 y el ferrocarril Lima-Magdalena el año 1875."Historia del Perú Republicano -Tomo VI", 2014, Ed. El Comercio, Lima pp.78.

92 Según Guerra "La Municipalidad de La Magdalena para Casa de Gobierno y la Escuela de Chorrillos para el funcionamiento del Congreso de la Nación”, “La ocupación de Lima 1881-1883 el gobierno de García Calderón” Ed. PUCP, Lima, 1991. pp.199.

${ }^{93}$ Según Herrera "Los problemas de servicios básicos de Barranco serían solucionados en los años posteriores con la creación de la Empresa de Agua de Barranco el año de 1891". "Anales de Obras Públicas del Perú" año 1891 pp.194197.
} 


\section{Plano 4.1}

\section{Ferrocarriles eléctricos de Lima, Callao, La Magdalena y Chorrillos por el ingeniero Enrique Silgado}

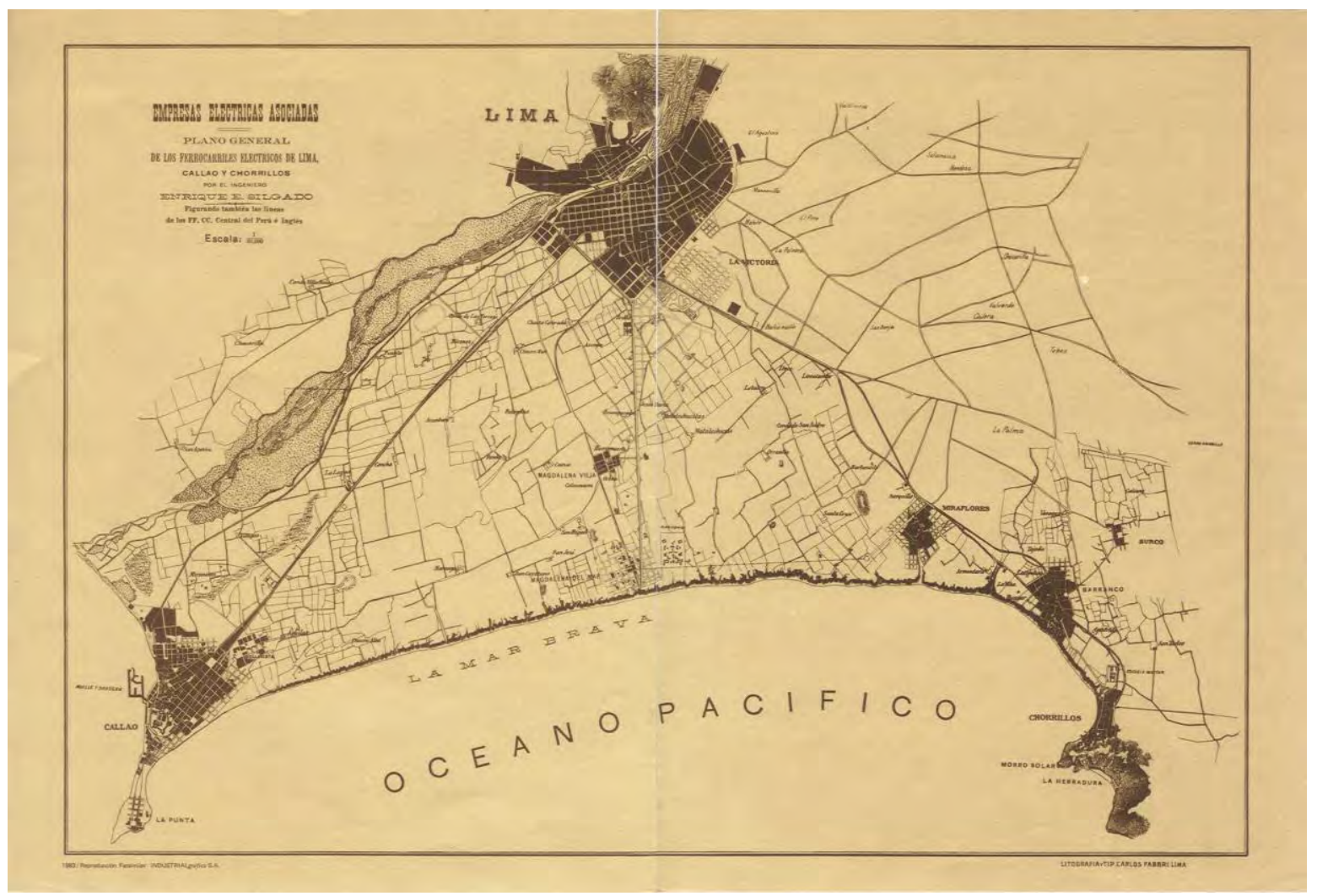

Gunther, J. (1983), Plano General de los Ferrocarriles eléctricos de Lima, Callao y Chorrillos por el ingeniero Enrique Silgado en 1908.

Por su parte, el alcalde de Lima, Rufino Torrico, antes de ser reemplazado por un intendente chileno, buscó mantener en funcionamiento las edificaciones públicas que no habían sido ocupadas por el enemigo, especialmente los hospitales. En las actas de sesión de la Municipalidad de Lima del 24 de enero de 1881 se describe lo siguiente:

"El señor alcalde dijo que por ahora el más importante asunto, que preocupa a la Alcaldía, es el sostenimiento de las Cárceles de Guadalupe y Penitenciaria, de los hospitales de Sangre y Penitenciaria, San Bartolomé y el fundado por la Municipalidad, así como también el del Palacio de la Exposición, que, como había ya manifestado a la junta, el gasto que demandan gravita en las rentas Municipales" (Consejo Municipal de Lima, 1881:82).

Para el funcionamiento de las edificaciones públicas fue necesario el mejoramiento de las rentas municipales que en esos momentos de crisis económica se convirtió en una tarea difícil para la administración local. Sin embargo, recurrieron a donaciones para restablecer el funcionamiento de los 
Hospitales y tratar de realizar el levantamiento de los cadáveres de soldados caídos en distintos puntos de la ciudad, pues podrían ocasionar epidemias en la población.

\section{Cuadro 4.1}

\section{Obras públicas durante el gobierno municipal del alcalde Rufino Torrico el año 1881}

\begin{tabular}{|c|c|}
\hline Acciones & Fuente \\
\hline $\begin{array}{c}\text { Creación del Hospital de Sangre el } 6 \text { de enero de } \\
1881\end{array}$ & $\begin{array}{c}\text { Actas de Consejo Municipal de } \\
\text { Lima,1881:79 }\end{array}$ \\
\hline Escoba para los cuarteles de la tropa chilena & $\begin{array}{c}\text { Actas del Consejo Municipal de } \\
\text { Lima,1881:81 }\end{array}$ \\
\hline $\begin{array}{c}\text { Contrato de administración de los ingresos por el } \\
\text { pago de pontazgo del puente Balta }\end{array}$ & $\begin{array}{c}\text { Actas del Consejo Municipal de } \\
\text { Lima:1881:115 }\end{array}$ \\
\hline $\begin{array}{c}\text { Inhumación de los cadáveres que se encontraban } \\
\text { en los campos de batalla de San Juan, Chorrillos y } \\
\text { Miraflores }\end{array}$ & $\begin{array}{c}\text { Actas del Consejo Municipal de } \\
\text { Lima,1881:84 }\end{array}$ \\
\hline $\begin{array}{c}\text { Pago a la Empresa de Agua Potable para continuar } \\
\text { asegurando el abastecimiento sobre todo en el } \\
\text { hospital de sangre }\end{array}$ & $\begin{array}{c}\text { Actas del Consejo Municipal de } \\
\text { Lima,1881:116 }\end{array}$ \\
\hline $\begin{array}{c}\text { Nombramiento para la administración del mercado } \\
\text { de La Concepción al Sr. Bresani }\end{array}$ & $\begin{array}{c}\text { Actas del Consejo Municipal de } \\
\text { Lima,1881:79 }\end{array}$ \\
\hline
\end{tabular}

\section{Fuente: Elaboración propia en base a: Actas del Consejo Municipal de Lima} (1881)

Ante la necesidad de una mejor administración de las rentas municipales el gobierno provisional, según decreto del 8 de enero de 1881, delegó la administración de la ciudad a la Prefectura, la cual asumió el cargo unos meses después (Consejo Municipal de Lima, 1881:78). Este repentino cambio de administración afectó aun más los ingresos de la Municipalidad que ya se habían visto disminuidos desde el conflicto, generó un desgobierno en la ciudad, motivó el reclamo de los vecinos ante la apresurada decisión del gobierno provisional y generó un conflicto de intereses en el gobierno provisional y las autoridades chilenas, especialmente por el cobro del cupo de 
guerra a través de la Municipalidad ${ }^{94}$ en las ciudades de Lima y el Callao (Guerra, 1991:229).

Al retiro de las tropas chilenas, la ciudad se encontraba en una mayor crisis económica y existía un desgobierno ante la incertidumbre de quien asumiría la administración. El vacío de poder provocó que las edificaciones públicas y los espacios en la ciudad continuaran su deterioro ante la falta de recursos para su mantenimiento. A este problema se añadió la inseguridad ciudadana, el aumento de la insalubridad en las calles, el desempleo de gran parte de la población, la falta de acceso a los servicios básicos y el fortalecimiento del mercado especulativo.

\subsubsection{El gobierno del presidente Miguel Iglesias y los inicios de la reconstrucción de la ciudad (1882-1885)}

En el año 1883 el general Miguel Iglesias, quien dirigía el gobierno peruano desde un año antes, negoció el fin del conflicto con el gobierno chileno. Las fuerzas chilenas desocuparon la ciudad de Lima, pero en el proceso de retirada se llevaron bienes muebles como describe Mc Evoy:

"Los ejércitos chilenos al abandonar el territorio peruano no solo se llevaron consigo el riquísimo "botín salitrero". Junto con el mismo se embarcaron hacia Santiago los tesoros culturales más preciados de los limeños. Centenares de libros de la Biblioteca Nacional; invalorables obras de arte como el cuadro de "Los funerales de Athuallapa", pintado por Montero; el original reloj que decoraba el Palacio de la Exposición de Lima, construido por Pedro Ruíz Gallo; la moderna imprenta del Estado, donde el gobierno civilista imprimió decenas de obras de difusión popular; las rejas coloniales que resguardaban la catedral capitalina y la activa fundición de Bellavista donde se realizaron los primeros tímidos intentos de industrialización urbana, fueron algunas de la otras riquezas nacionales arbitrariamente tomadas por las fuerzas invasoras" (Mc Evoy,1997:253-254).

Las primeras acciones del gobierno de Iglesias estuvieron orientadas para que la ciudad recuperara sus actividades con normalidad, especialmente el restablecimiento de los servicios básicos, la apertura de las vías de comunicación con los balnearios cercanos para permitir el abastecimiento de alimentos a la ciudad y el restablecimiento del servicios de los ferrocarriles y el tranvía, para que de esta manera, la población pudiera continuar con sus

\footnotetext{
94 Según las actas de la Municipalidad el año1881 quedaba pendiente la administración del Palacio de la Exposición y el Palacio de Gobierno que se encontraban abandonados. En Actas del Consejo Municipal de Lima año 1881 p. 80.Otro pendiente, era el cobro de alumbrado público que era administrado por la Municipalidad directamente. En actas del Consejo Municipal de Lima año 1881 pp.80.
} 
actividades con normalidad y las familias retornaran a sus barrios. Así, el presidente Iglesias nombró al Ministro Mariano Saldivar para realizar las primeras acciones e iniciar la reconstrucción de la ciudad entre los años de 1883 a 1884. En este último año la población de Lima era de 101,488 habitantes (González, 1885:47) ${ }^{95}$. En tal contexto, el nuevo ministro identificó los principales objetivos a seguir para reconstruir la ciudad, según la visión del presidente Iglesias, como: mantener la seguridad en la ciudad y la convivencia pacífica de la población (Diario oficial El Peruano, 1884 á, 13 de marzo: 315), iniciar la reconstrucción de las edificaciones públicas ${ }^{96}$ y controlar la especulación que realizaban los empresarios que se encontraban a cargo de la administración de las líneas férreas ${ }^{97}$ como se describe:

"Por otra parte como el espíritu de especulación domino por completo, no hubo estudio previo, plan general, ni sistema alguno en la construcción de la red que debía dar movimiento y animación á la vida material de la República" (Diario oficial El Peruano, 1884 á, 9 de marzo:317).

El Estado Peruano, con el objetivo de iniciar la reconstrucción de la ciudad, procedió a la reorganización de los ministerios sobre todo La sección de obras públicas del Ministerio de Gobierno y Policía. Esta sección retomó lo contratos de concesiones, adjudicaciones y administración de obras públicas de la ciudad (Diario oficial El Peruano, 1884 á, 23 febrero: 204) ${ }^{98}$. Continuaría entonces el mecanismo de intervención del Estado y de la empresa privada. Ambos emprenderían la reconstrucción de la ciudad. ${ }^{99}$ Como resultado, en el año 1884

\footnotetext{
95 Demografía de Lima en1884, José González Clavero, Imprenta J.F. Solís 1885

96 " vista la solicitud de D.R Protolongo se resuelve suprimir en el local de la biblioteca nacional todo servicio de agua en el interior de las habitaciones; debiendo debiendo establecerse este servicio como se propone por el arquitecto informante. 2.- Pase este expediente al encargado de los trabajos de la Biblioteca nacional para que considere en el proyecto que se le ha encomendado las reparaciones necesarias a la seguridad del edificio en la parte dañada por los desagües". Diario oficial El Peruano 1884, 23 de febrero, (Núm.8).pp. 203.

${ }^{97}$ Producto de este análisis de la situación ferrocarrilera nacional se presentó un proyecto de Ley de Obras Públicas el 5 de diciembre de 1884, para recuperar las líneas férreas a favor del Estado hacerlas productivas y lograr una mejor conexión de Lima con las poblaciones cercanas Diario oficial El Peruano, 1884,29 marzo, (Núm.13), pp.319.
}

\footnotetext{
${ }^{98}$ El 5 de julio de 1884 se publicó el Reglamento General de Obras Públicas en el cual se clasificaban las obras en: fiscales, municipales, corporativas, particulares y en el vecindario En: Diario oficial El peruano, Sábado 5 julio, 1884 (Núm. 1), pp.4-12. De manera complementaria, el 15 de octubre de 1884 se publicaron los procedimientos técnicos para la presentación del expediente técnico de las obras públicas con el nombre de Prescripciones Reglamentarias sobre Proyectos de Obras Públicas En: Diario oficial El peruano, 1884 ,15 octubre, (Núm.11) pp.186-188.

${ }^{99}$ Este año la sección de Obras Públicas del Ministerio de Gobierno y Policía reorganizó a su personal administrativo y técnico para iniciar el proceso de reconstrucción de los edificios en la ciudad y reacondicionar espacios públicos destruidos por la guerra. Fue así que se consideraron nuevas partidas presupuestarias que incluían los salarios de los arquitectos e ingenieros del Estado que en promedio ganarían de 2,000 a 4,000 soles mensuales, Diario oficial EI peruano, 1884,15 de marzo, (Núm.11), pp.265.
} 
se venía construyendo el Lawm Tenis y el Club Regatas Lima, ambos ubicados al sur de la ciudad (Basadre: 2014,tomoX, 65) que mostraban un signo de reconstrucción y modernidad de la ciudad.

Como una necesidad de mejorar la salubridad de la ciudad desatendida durante la ocupación chilena el Estado puso en vigencia El Reglamento General de Sanidad ${ }^{100}$ (Diario oficial El Peruano, 1884 á, 18 octubre:205-214). De esta manera, se restableció La Junta de Sanidad en la ciudad bajo la nueva normativa con las siguientes funciones: se encargó de aprobar las reformas de higiene y velar por la higiene pública realizando inspecciones de salubridad en mercados, establecimientos industriales, mataderos, cementerios y evitar epidemias con la construcción de lazaretos. Además, el Estado restableció la función de la Municipalidad y nombró alcalde de Lima a don Luis Rocca y Boloña, quien al asumir funciones inició la mejora en la recaudación de las rentas municipales para fortalecer a esta institución y poder realizar las obras públicas en la ciudad. Para lograr este objetivo, revisó las concesiones de: alumbrado público, serenazgo, licencias, ferrocarril urbano, pensiones por calles enrieladas, arrendamientos de inmuebles y multas (Consejo Municipal de Lima, 1884:26-27) Además, el alcalde decidió continuar con la política de concesiones de los principales servicios de la ciudad, buscando recuperar el monto de la recaudación que se tenía antes del conflicto. Poco se haría en realidad, tal como se puede ver el cuadro siguiente:

\footnotetext{
100 En el Reglamento general de sanidad ${ }^{100}$ se dividió el servicio sanitario en marítimo y terrestre a nivel nacional y se creó la Junta Central para vigilar el cumplimiento del reglamento. De inmediato, esta Junta se encargó de aprobar las reformas de higiene y velar por la higiene pública en las distintas ciudades a nivel nacional En: Diario oficial EI peruano, 1884, 18 octubre, (Núm.12) pp.205-214.
} 


\section{Cuadro 4.2}

\section{Políticas urbanas y obras públicas durante el periodo del presidente Miguel Iglesias (1884-1885)}

\begin{tabular}{|c|c|c|c|}
\hline Año & Obras & Ejecutor & Fuente \\
\hline 1884 & $\begin{array}{l}\text { Contratación de personal para la } \\
\text { Cárcel de Guadalupe }\end{array}$ & Municipalidad & $\begin{array}{c}\text { Consejo Municipal de } \\
\text { Lima,1884:7 }\end{array}$ \\
\hline 1884 & Refacciones en la Biblioteca Nacional & $\begin{array}{l}\text { Ministerio de } \\
\text { Gobierno Policía y } \\
\text { Obras Públicas }\end{array}$ & $\begin{array}{l}\text { Diario oficial El Peruano á, } \\
23 \text { febrero, } 1884: 203\end{array}$ \\
\hline 1884 & $\begin{array}{c}\text { Refacción del local de la Exposición } \\
\text { Nacional }\end{array}$ & $\begin{array}{l}\text { Ministerio de } \\
\text { Gobierno Policía y } \\
\text { Obras Públicas }\end{array}$ & $\begin{array}{l}\text { Diario oficial El Peruano á, } \\
29 \text { marzo,1884:319-320 }\end{array}$ \\
\hline 1884 & $\begin{array}{l}\text { El Paseo de la Aguas fue arrendado } \\
\text { para uso de la empresa de transportes }\end{array}$ & Municipalidad & Junta Municipal,1884:7-8 \\
\hline 1884 & $\begin{array}{c}\text { Cobró el peaje de la carretera Lima- } \\
\text { Callao }\end{array}$ & Municipalidad & Junta Municipal,1884:7-8 \\
\hline 1884 & $\begin{array}{l}\text { Los servicios de baja policía de la } \\
\text { ciudad fueron rematados a un nuevo } \\
\text { concesionario }\end{array}$ & Municipalidad & $\begin{array}{l}\text { Consejo Municipal de } \\
\text { Lima,1884:10 }\end{array}$ \\
\hline 1884 & $\begin{array}{l}\text { La Municipalidad retomó el control de la } \\
\text { señalización de las calles y numeración } \\
\text { de casas }\end{array}$ & Municipalidad & $\begin{array}{l}\text { Consejo Municipal de } \\
\text { Lima,1884:23 }\end{array}$ \\
\hline 1884 & $\begin{array}{l}\text { subasta de la construcción de la nueva } \\
\text { carretera Lima-Miraflores }\end{array}$ & Municipalidad & $\begin{array}{c}\text { Consejo Municipal de } \\
\text { Lima, 1884:24 }\end{array}$ \\
\hline 1885 & Proyecto de la casa de correos & $\begin{array}{l}\text { Ministerio de } \\
\text { Gobierno Policía y } \\
\text { Obras Públicas }\end{array}$ & $\begin{array}{c}\text { Diario oficial El Peruano á, } \\
11 \text { marzo, } 1885: 179\end{array}$ \\
\hline 1885 & $\begin{array}{c}\text { Construcción del colegio del Sagrado } \\
\text { Corazón en la Venturosa de propiedad } \\
\text { de la Beneficencia }\end{array}$ & $\begin{array}{l}\text { Ministerio de } \\
\text { Gobierno Policía y } \\
\text { Obras Públicas }\end{array}$ & $\begin{array}{c}\text { Diario oficial El peruano á, } \\
18 \text { marzo, } 1885: 196\end{array}$ \\
\hline 1885 & $\begin{array}{l}\text { Reconstrucción de paredes de la Casa } \\
\text { de Gobierno }\end{array}$ & $\begin{array}{l}\text { Ministerio de } \\
\text { Gobierno Policía y } \\
\text { Obras Públicas }\end{array}$ & $\begin{array}{c}\text { Diario oficial El Peruano á, } \\
13 \text { junio, } 1885: 198\end{array}$ \\
\hline
\end{tabular}

Fuente: Elaboración propia en base a Consejo Municipal de Lima (1884), Junta Municipal (1884) y Diario oficial El Peruano (1884), (1885).

En materia urbanística se restablecieron las vialidades en la ciudad y se construyeron nuevas para continuar mejorando la conexión con los balnearios del sur, como fue el caso de la construcción de la carretera Lima-Miraflores (Diario oficial El Peruano, 1884 á, 18 octubre: 205-214). Con estas acciones, estos balnearios, ubicados al sur-oeste, continuaron su proceso de crecimiento urbano y consolidaron su relación con la ciudad. Al final de este periodo de 
gobierno la ciudad había recuperado su habitual actividad pero aun quedaba pendiente la reconstrucción de las viviendas.

\subsubsection{El primer gobierno del general Andrés Avelino Cáceres y la recuperación económica de la ciudad (1886-1890)}

La reconstrucción, sin embargo, tuvo que esperar. Entre los años de 1884 a 1885 la ciudad fue escenario de una guerra civil. Un ejemplo de la situación de guerra en la ciudad puede verse en el siguiente fragmento:

"Los combates en Lima en noviembre de 1885. Por vencido y deshecho dieron a Cáceres las informaciones del Gobierno de Lima, cuando el legendario caudillo apareció a las puertas de la Capital el 28 de noviembre. El escenario de combate fue la zona de San Bartolomé y luego las calles de la capital durante los días 29 y 30 . Los Caceristas entraron por las portadas de las Maravillas y Barbones y se adueñaron del puente Balta; y luego de una corta refriega apoyados por algunos entusiastas jóvenes de la capital, de las iglesias de San Francisco y San Pedro. En algunas calles hubo barricadas. Las tropas defensoras de Iglesias comenzaron a replegarse para concentrarse en el Palacio de Gobierno que fue rodeado por los Caceristas. El vecindario dio esta vez inequívocas muestras de entusiasmo por el héroe de la campaña de la resistencia" (Basadre: 2004, tomoX, 25).

Al terminar el conflicto, entre 1886 y 1890 ejerció el gobierno el general Andrés Avelino Cáceres con características dictatoriales. Los objetivos de este periodo de gobierno fueron: En lo económico, generar una economía exportadora minera para lograr la reconstrucción del país ${ }^{101}$ (Mc Evoy, 1997:277) y el impulso de la actividad económica. Con esta finalidad, se reactivó la banca hipotecaria en la ciudad, aumentó la recaudación de impuestos para aumentar los ingresos fiscales y ejecutar la obra pública. Inició una cierta recuperación de la actividad de la ciudad y, en particular, de las arcas públicas. Para fortalecer este objetivo, se aplicaron impuestos a los siguientes productos: el tabaco, el papel sellado y el alcohol (Basadre: 2014, tomoX: 219). En lo económico se presentaba la necesidad de construir sociedades y empresas, ${ }^{102}$ (Mc Evoy, 1997:273) lo que llevó al Estado a apoyar la industria, la que se consideró el soporte económico y social de la nación y la base para la reconstrucción del país. En lo administrativo, se buscó la centralización fiscal y la reorganización de las instituciones públicas, tratando de hacerlas más

\footnotetext{
101 Según Mc Evoy “Los aportes más importantes de la industria azucarera al crecimiento económico del país fueron el avance tecnológico y la formación del capital durante la crucial década de 1890". "La utopía republicana ideales y realidades en formación”, 1997, Lima, Ed. PUCP, pp.278.

102 Según Mc Evoy El “La tendencia al asociacionismo no se circunscribió. Los años de la reconstrucción fueron años de intensa actividad cultural y social "tan solo a los grupos laborales "La utopía republicana ideales y realidades en formación", 1997, Lima,Ed. PUCP, pp.281.
} 
eficientes. Por ejemplo dejó a cargo de La Junta Departamental la recaudación de las rentas de la Municipalidad ${ }^{103}$. Esta decisión fue negativa para la administración de la ciudad y se convirtió en un obstáculo para la ejecución de la obra pública. Otro objetivo fue mejorar la seguridad de la población para ello se reorganizó la policía (Diario oficial El Peruano 1886 á, 6 de agosto:117). En lo educativo, se reconstruyeron los colegios en la ciudad y se puso en vigencia El Reglamento General de Instrucción Pública (Diario oficial El Peruano, 1886 á,6 de noviembre:377-382).

Durante este periodo la gran mayoría de las casas en la ciudad se encontraban deterioradas y requerían una remodelación. Pesaban los años de ocupación que llevaron el gobierno provisional a los balnearios del sur, en donde se produciría la construcción de viviendas para la élite (Dávalos y Lisson: 1922, tomoll, 202). Ante el deterioro de gran parte de las propiedades de la ciudad, el Estado Peruano buscó reactivar el mercado financiero para que los propietarios pudieran acceder a créditos y reconstruir sus viviendas para dar legalidad a las transacciones sobre las propiedades, estableciendo El registro de propiedad inmueble publicado 28 de enero de 1888 (Diario oficial El Peruano, 1888 á, enero: $5-6)^{104}$. Esta medida tuvo las siguientes consecuencias: inició la activación del mercado financiero, aumentó las inversiones en vivienda por parte del capital privado, logró el crecimiento económico en la ciudad, permitió una oferta laboral en el rubro construcción, mejoró las condiciones de salubridad de las viviendas ubicadas en el centro y reactivó los negocios inmobiliarios en la ciudad.

Otra medida que buscó la activación del mercado de suelo y que las transacciones tuvieran un impulso por parte del Estado Peruano, en favor de los bancos y las empresas inmobiliarias, fue la Ley Payán de garantías

\footnotetext{
103 como una manera de buscar una descentralización fiscal se emitió la "Ley de Descentralización Fiscal" del 13 de noviembre de 1886 Diario Oficial El peruano, 1886 a, 20 noviembre,(Num.55), pp.435-436 de esta manera, se dividió la administración de los gastos del Estado y de los Departamentos. Años después el Coronel Daniel Zapatel en la "Memorias del prefecto del departamento" del año 1891, reclamaba los pocos ingresos de esta institución que no permitían realizar mayores obras para la ciudad y sus alrededores. Fue así que solicitó al gobierno la separación del Apoderado Fiscal Zapatel, Memorias del prefecto del departamento, Año 1891, p.85 como recaudador de impuestos que no permitía la recaudación directa por parte de la Junta de: Alcabalas, patentes y matriculas de predios rústicos y urbanos.

${ }^{104}$ De manera complementaria a partir de esta fecha se debían inscribir los títulos de dominio como: enfiteusis, hipotecas legales, hipotecas judiciales, anticresis, censos, servidumbres, contratos de arrendamiento, quedando exceptuados los créditos privilegiados. Diario oficial El Peruano, 1888, enero, Num.1 Edición Complementaria.pp.1720.
} 
hipotecarias ${ }^{105}$ puesta en ejecución desde el 2 enero de 1889 (Diario oficial El peruano,1889 á, enero 1889:4-6). Con esta medida se produjo la formalización del procedimiento de remate de propiedades por parte de los bancos por incumplimiento de los propietarios. Con ello claramente se favoreció a los inversionistas inmobiliarios y a los bancos, los cuales en ese momento apoyaban al gobierno a la reconstrucción, garantizando la seguridad de las transacciones realizadas por el sistema financiero e hipotecario en la ciudad, lo que permitió el aumento de las inversiones privadas extranjeras y la reactivación económica interrumpida por la guerra. Este fenómeno de crecimiento económico también se registró en Buenos Aires, Santiago y Rio de Janeiro (Pineo,1998:155).

El 4 de enero de 1889 se instituyó un nuevo Reglamento Sanitario para la provincia de Lima (La Crónica Médica, 1889 á, 31 enero:6-7). Con este reglamento el Estado Peruano trató de atender las necesidades de la población de Lima de manera conjunta con las instituciones públicas locales, buscando evitar la propagación de las enfermedades, mejorar las condiciones de salubridad en los espacios públicos y la calidad de los servicios básicos. Sería una muestra de la búsqueda del Estado por el bienestar social, apoyándose en el gobierno local. (Pérez, 2018:101). Sin embargo, aun quedó pendiente para la Municipalidad y el Estado central la necesidad de mejorar las condiciones de salubridad de las casas de vecindad y cuantificar el problema para tomar las acciones correspondientes.

\footnotetext{
105 Según Basadre se llama Ley Payan en reconocimiento a los esfuerzo de don José Payán un ciudadano cubano uno de los fundadores de la Bolsa de Valores de Lima. "Historia del Perú Republicano", Jorge Basadre tomo X, 2014, Lima, Ed. El Comercio, p.129-130. De manera complementaria, para finales de este año el gobierno estableció la verificación de los prestamos con garantías hipotecarias por parte de los bancos dentro de un régimen especial con un plazo de 10 a 50 años promulgó, Diario oficial El Peruano,1889 á, enero 1889, (Núm.1),pp.4-6.
} 


\section{Cuadro 4.3}

Obras públicas durante el primer gobierno del presidente Andrés Avelino Cáceres (1886-1887)

\begin{tabular}{|c|c|c|c|}
\hline Año & Obra & Ejecutor & Fuente \\
\hline 1886 & $\begin{array}{c}\text { Obras del ferrocarril Lima- } \\
\text { Chancay }\end{array}$ & $\begin{array}{l}\text { Ministerio de } \\
\text { Gobierno Policía y } \\
\text { Obras Públicas }\end{array}$ & $\begin{array}{l}\text { Diario oficial, El Peruano, } \\
1886 \text { á,14 de julio:44 }\end{array}$ \\
\hline 1886 & $\begin{array}{c}\text { Construcción de la } \\
\text { fachada de Palacio de } \\
\text { gobierno }\end{array}$ & $\begin{array}{l}\text { Ministerio de } \\
\text { Gobierno Policía y } \\
\text { Obras Públicas }\end{array}$ & $\begin{array}{c}\text { Diario oficial, El } \\
\text { Peruano, } 1886 \text { á, } 16 \text { de } \\
\text { julio: } 51\end{array}$ \\
\hline 1886 & $\begin{array}{c}\text { Obras en la Casa de } \\
\text { Correos }\end{array}$ & $\begin{array}{l}\text { Ministerio de } \\
\text { Gobierno Policía y } \\
\text { Obras Públicas }\end{array}$ & $\begin{array}{c}\text { Diario oficial El } \\
\text { Peruano, } 1886 \text { á, } 16 \text { de } \\
\text { julio: } 51\end{array}$ \\
\hline 1886 & $\begin{array}{l}\text { Alumbrado del Palacio de } \\
\text { Gobierno }\end{array}$ & $\begin{array}{c}\text { Ministerio de } \\
\text { Gobierno Policía y } \\
\text { Obras Públicas }\end{array}$ & $\begin{array}{c}\text { Diario oficial El } \\
\text { Peruano, } 1886 \text { á, } 6 \text { de } \\
\text { agosto: } 117\end{array}$ \\
\hline 1886 & $\begin{array}{c}\text { Construcción de la Casa } \\
\text { de Correos }\end{array}$ & $\begin{array}{l}\text { Ministerio de } \\
\text { Gobierno Policía y } \\
\text { Obras Públicas }\end{array}$ & $\begin{array}{c}\text { Diario oficial El } \\
\text { Peruano, } 1886 \text { á,6 de } \\
\text { agosto:117 }\end{array}$ \\
\hline 1886 & $\begin{array}{l}\text { Construcción de la línea } \\
\text { férrea Lima-Pisco }\end{array}$ & $\begin{array}{l}\text { Ministerio de } \\
\text { Gobierno Policía y } \\
\text { Obras Públicas }\end{array}$ & $\begin{array}{c}\text { Diario oficial El } \\
\text { Peruano,1886 á,16 de } \\
\text { Noviembre:1 }\end{array}$ \\
\hline 1887 & $\begin{array}{l}\text { Instalación del servicio } \\
\text { telefónico en Lima }\end{array}$ & $\begin{array}{l}\text { Ministerio de } \\
\text { Gobierno Policía y } \\
\text { Obras Públicas }\end{array}$ & $\begin{array}{c}\text { Basadre:2014,tomo } \\
\text { X,138-139 }\end{array}$ \\
\hline 1887 & $\begin{array}{l}\text { Instalación del alumbrado } \\
\text { eléctrico en Lima }\end{array}$ & Municipalidad & $\begin{array}{c}\text { Basadre:2014,tomo } \\
\text { X,139-140 }\end{array}$ \\
\hline
\end{tabular}

Fuente: Elaboración propia en base a Diario oficial El Peruano (1886), (1887), Basadre (2014).

Como observamos en el cuadro las obras de este periodo estuvieron enfocadas a la reconstrucción de los edificios públicos y la modernización de los servicios en la ciudad. Se continuó con la construcción de las líneas férreas que pudieran abastecer de alimentos a la ciudad y mejorar la conexión en las 
distintas zonas de la ciudad. Así también, en este periodo se retomaron las obras de envergadura que significó para la población una muestra de recuperación de la ciudad ante la guerra del Pacifico. La edificación de obras públicas y la instalación del alumbrado eléctrico en la ciudad materializó un nuevo periodo en la ciudad: el fin del periodo de reconstrucción y el inició de un nuevo periodo modernizador.

Con estas acciones el Estado continuó con "la ecuación industrialización, urbanización, modernización -para utilizar el paradigma vigente hasta mediados de los setenta- era una suerte de secuencia causal derivada de los exitosos casos de los países industrializados y urbanizados a lo largo del siglo XIX" (Almandoz,2008:01) ${ }^{106}$. La continuidad de la reactivación económica y su crecimiento económico tuvo como objetivo continuar la materialización del progreso a partir de la activación de la banca y su formalización "con base en el "espíritu de empresa" y el fomento gubernamental" (Pérez, 2018:99) ${ }^{107}$.

\subsubsection{El proyecto de canalización del río Rímac del ingeniero Felipe Arancivia (1886)}

El proyecto de canalización fue elaborado por el ingeniero Felipe Arancivia con la finalidad de mejorar la salubridad en el centro, lograr el ensanche de la ciudad sin necesidad de urbanizar la periferia, mejorar las condiciones de vida de los pobladores de bajo el puente y contribuir a mejorar las condiciones de salubridad del otro lado del río Rímac. (Arancivia,1886:06). Ante la imposibilidad del Estado Peruano de asumir la ejecución de tales obras el ingeniero Arancivia buscó que algún inversionista privado se interesara en llevar a cabo este proyecto, motivo por el cual, incluyó una oferta de vivienda en seis manzanas, muy cerca del Centro que serían el espacio ganado al rio con la canalización y, que a su vez, contribuiría a la mejora de la salubridad de la ciudad. No obstante, no obtuvo el interés de los inversionistas privados porque en este momento el negocio minero era mucho más rentable que el inmobiliario.

\footnotetext{
${ }^{106}$ Arturo Almandoz "Despegues sin madurez. Urbanización industrialización y desarrollo en la Latinoamérica del siglo XX" En: Revista EURE Tomo 34, N 102 agoso-2008 pp.1-13.

${ }^{107}$ Isaac Enrique Pérez "Las concepciones del progreso y la construcción de un proyecto nación: hacia una historia de las ideas en el entendido siglo XIX mexicano (1821-1910) En: Revista Histórica XLII.2 , Lima, (2018) pp.89-139.
} 
El proyecto comprendía dos etapas. En una primera etapa la canalización del río Rímac entre el tramo del puente de Piedra y puente Balta, con un total de 400 metros de ancho. En una segunda etapa, la edificación de viviendas en seis manzanas en un área de 65,794 metros cuadrados. Las seis manzanas estarían repartidas en cinco calles transversales, de un ancho de 12 metros, y 3 calles longitudinales del mismo ancho que permitirían la ventilación de las viviendas (Arancivia, 1886:21-25).

\section{Plano 4.2}

\section{Proyecto de Canalización del río Rímac}

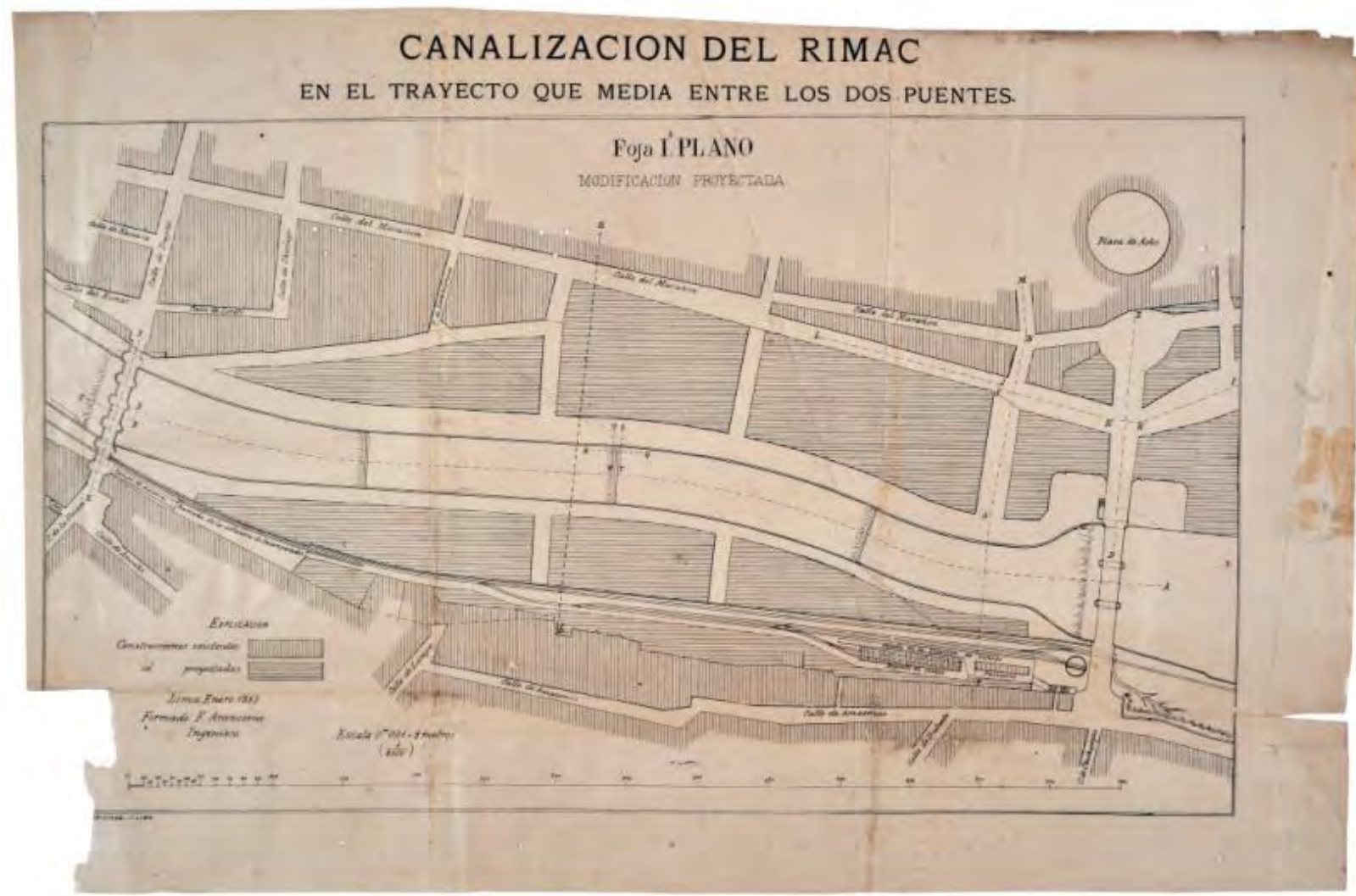

Arancivia (1886, pp.22-23).

El proyecto no se concretó debido a que ningún inversionista privado se interesó en ejecutarlo, pero quedó para en que un futuro fuera ejecutado. De haberse realizado esta obra hubiera generado una mayor concentración poblacional en el centro de la ciudad, revalorizando los terrenos de los tajamares del río Rímac y hubiera existido un mayor vínculo entre ambas 
riberas del río aumentando el flujo de personas y mercaderías. Hubiera unificado la ciudad de Lima con la otra ribera.

Esta propuesta nos muestra una vez más la intención de canalizar el río Rímac para continuar el proceso de mercantilización del suelo ante la reactivación económica de la ciudad lograda por el gobierno del presidente Cáceres. Sin embargo, el poco interés de los inversionistas privados, motivo por el cual no se ejecutó la obra, se debió principalmente al factor ubicación. Cerca a este proyecto se encontraban barrios marginales como Bajo el puente, el Chirimoyo entre otros que hacían poco atractiva la oferta de viviendas para sectores medios y la élite que podían comprar terrenos muy cerca al centro. También, evidencia el poco interés por parte de los inversionistas privados de invertir en el negocio inmobiliario de viviendas sociales ante el negocio agrícola y de minas debido a que aun la ciudad se encontraba en inestabilidad económica.

Al finalizar el mandato del presidente Andrés Avelino Cáceres, en el año 1890, el Estado Peruano mantuvo una recaudación estable por concepto de impuestos, lo que le permitió distribuir el presupuesto de la nación para las distintas instituciones como salud, hacienda y obra pública. Se había cumplido la tarea de reconstruir las instituciones públicas y el sistema financiero, lo que permitiría a los inversionistas y el Estado emprender una cierta reconstrucción de la ciudad, de manera conjunta. (Diario oficial El Peruano, 1890 á,11 agosto:105).

\subsubsection{El gobierno de Remigio Morales Bermúdez y la mejora de los servicios básicos en la ciudad (1890-1894)}

El presidente Remigio Morales Bermúdez buscó hacer más eficiente los ingresos del Estado para continuar la obra pública y lograr una mejor administración de la ciudad. En el caso de Lima La Junta Departamental de Lima seguiría administrando las rentas de la Municipalidad con la aprobación del gobierno. Esa era una muestra de la continuidad del modelo centralista en la administración apoyada por los políticos liberales. Sin embargo, mejoró la 
infraestructura de los colegios y universidades (Diario oficial El Peruano, 1892 á,2 abril:317).

En este momento, la ciudad se encontraba en proceso de activación de la economía y las obras tenían por finalidad mostrar un ambiente de progreso y modernidad urbana, para continuar modificando las condicionantes de índole social, económica y territorial (Sánchez, 2013:91-92). Esto significó, mejorar la infraestructura vial, la construcción de edificaciones públicas, mejorar las vialidades, el alumbrado eléctrico y que las casas tuvieran servicio telefónico para que de esa manera la población tuviera una experiencia moderna en la ciudad, que mostrará que el Estado intentaba continuar la modernización urbana. En este proceso, el Ministerio de Gobierno Policía y Obras Públicas, bajo el modelo centralista, sería la principal institución encargada de la ejecución de las obras, por sobre las demás instituciones de la ciudad. 


\section{Cuadro 4.4 Obras públicas durante el gobierno del presidente Remigio Morales Bermúdez (1890-1893)}

\begin{tabular}{|c|c|c|c|}
\hline Año & Obra & Ejecutor & Fuente \\
\hline 1890 & $\begin{array}{l}\text { Contrato de servicio telefónico con la } \\
\text { Peruvian Telephone Company } \\
\text { Lima,Callao y Chorrillos }\end{array}$ & $\begin{array}{l}\text { Ministerio de } \\
\text { Gobierno Policía y } \\
\text { Obras Públicas }\end{array}$ & $\begin{array}{l}\text { Diario oficial El Peruano,1890 } \\
\text { á,19 setiembre:241 }\end{array}$ \\
\hline 1891 & $\begin{array}{l}\text { Construcción de las cripta para los } \\
\text { héroes de la guerra con Chile }\end{array}$ & $\begin{array}{l}\text { Ministerio de } \\
\text { Gobierno Policía y } \\
\text { Obras Públicas }\end{array}$ & $\begin{array}{c}\text { Diario oficial El Peruano,1891 } \\
\text { á,17 julio:53 }\end{array}$ \\
\hline 1891 & $\begin{array}{l}\text { Licitación para el alumbrado a gas o } \\
\text { gasolina de la Casa de Gobierno }\end{array}$ & $\begin{array}{l}\text { Ministerio de } \\
\text { Gobierno Policía y } \\
\text { Obras Públicas }\end{array}$ & $\begin{array}{l}\text { Diario oficial El Peruano,1891 } \\
\text { á,25 noviembre:484 }\end{array}$ \\
\hline 1891 & $\begin{array}{c}\text { Mejora de los servicios de agua, luz y } \\
\text { transporte a Barranco }\end{array}$ & $\begin{array}{l}\text { Ministerio de } \\
\text { Gobierno Policía y } \\
\text { Obras Públicas }\end{array}$ & $\begin{array}{c}\text { Diario oficial El Peruano,1891 á,4 } \\
\text { octubre:382 }\end{array}$ \\
\hline 1891 & Construcción de la Oficina de Correos & $\begin{array}{l}\text { Ministerio de } \\
\text { Gobierno Policía y } \\
\text { Obras Públicas }\end{array}$ & $\begin{array}{c}\text { Anales de Obras Públicas del } \\
\text { Perú 1891:187 }\end{array}$ \\
\hline 1891 & $\begin{array}{c}\text { El alumbrado eléctrico para Lima a } \\
\text { cargo de los señores Wildlund y } \\
\text { Laguno }\end{array}$ & $\begin{array}{l}\text { Ministerio de } \\
\text { Gobierno Policía y } \\
\text { Obras Públicas }\end{array}$ & $\begin{array}{c}\text { Anales de Obras Públicas del } \\
\text { Perú 1891:216-219 }\end{array}$ \\
\hline 1891 & $\begin{array}{c}\text { Inspección de obras del ferrocarril Lima } \\
- \text { - Chorrillos }\end{array}$ & $\begin{array}{l}\text { Ministerio de } \\
\text { Gobierno Policía y } \\
\text { Obras Públicas } \\
\end{array}$ & $\begin{array}{c}\text { Anales de Obras Públicas del } \\
\text { Perú 1891:233-234 }\end{array}$ \\
\hline 1892 & $\begin{array}{c}\text { Abono de los fondos de la Prefectura } \\
\text { de Lima a la Caja de Policía para pago } \\
\text { a las comisarias de la ciudad y } \\
\text { Columnas de la Guardia Civil }\end{array}$ & $\begin{array}{l}\text { Ministerio de } \\
\text { Gobierno Policía y } \\
\text { Obras Públicas }\end{array}$ & $\begin{array}{c}\text { Diario oficial El Peruano,1892 } \\
\text { á,21 mayo:475 }\end{array}$ \\
\hline 1893 & $\begin{array}{l}\text { Llamado para el empadronamiento de } \\
\text { los terrenos ocupados por las Murallas }\end{array}$ & $\begin{array}{l}\text { Ministerio de } \\
\text { Gobierno Policía y } \\
\text { Obras Públicas }\end{array}$ & $\begin{array}{c}\text { Diario oficial El Peruano,1893 } \\
\text { á,28 agosto: } 223\end{array}$ \\
\hline 1893 & $\begin{array}{l}\text { Obras de refacción y pintura del } \\
\text { Palacio de Gobierno }\end{array}$ & $\begin{array}{l}\text { Ministerio de } \\
\text { Gobierno Policía y } \\
\text { Obras Públicas }\end{array}$ & $\begin{array}{c}\text { Diario oficial El Peruano,1893 á,7 } \\
\text { noviembre:443 }\end{array}$ \\
\hline
\end{tabular}

Fuente: Elaboración propia en base a Diario oficial El Peruano (1891),(1892), Anales de Obras Públicas del Perú (1891) 
En este periodo, se continuó la mejora de la conexión con los balnearios del sur de La Magdalena, Chorrillos y el Callao con obras de mejoramiento de transporte y la instalación de la telefonía. Se construyeron Comisarias en toda la ciudad para mejorar la seguridad. También, se dio el primer intento de regularizar la tenencia de la propiedad en la periferia por parte del Estado Peruano. Se continuó con la política de construir ferrocarriles para interconectar la ciudad con los balnearios del sur. Con estas acciones por parte del gobierno en turno la actividad económica en la ciudad mejoró.

\subsubsection{Intervención en la margen izquierda del río Rímac (1890)}

El año 1890 el Gobierno cedió los terrenos comprendidos entre el puente de Piedra y el puente Balta a la Municipalidad para que a su vez esta realizará una permuta con terrenos de su propiedad con los Tenedores de Bonos de la Deuda Externa del Perú, propietarios de la "Empresa de Ferrocarriles del Perú". La idea era realizar obras para el mejoramiento en el borde ribereño. Según "Contrato de permuta de terrenos fiscales y municipales ubicados a una ribera del río dentro de la población" se permutaron tres terrenos ${ }^{108}$ de la Municipalidad situados en el muladar del Tajamar, a la derecha e izquierda de la estación de Palma y terrenos de la estación de Ancón de propiedad de los Tenedores de Bonos (Patiño:1891,37-38).

A diferencia del proyecto anterior propuesto para este mismo espacio ribereño para ser ejecutado por la inversión privada, el proyecto de canalización del río Rímac del ingeniero Felipe Arancivia el año 1886 la idea ahora era mejorar la salubridad y la infraestructura del borde ribereño de manera conjunta, entre la empresa privada y el Estado mediante la figura legal de sesión de uso y permuta de terrenos con la finalidad de buscar el bienestar social de la población que vivía en los barrios cercanos al frente ribereño. En este espacio se programaron las siguientes intervenciones.

\footnotetext{
108 Según Patiño Samudio "se permutaron los siguientes terrenos: terreno situado en el Muladar del Tajamar 11,780 metros cuadrados a 0.20 centavos cada uno a precio 2,374 soles; terreno situado a la derecha de la Estación de Palma 3,910 metros cuadrados a un sol 3,910 soles; Terrenos situado a la izquierda de la misma 835 metros cuadrados a un sol cada uno 835 soles; Terreno de los Tenedores de Bonos de la Estación del Ferrocarril de Ancón 6,040 metros a un sol cada uno 6,040 soles". "Terrenos de la Ribera del Río Rímac", Año 1891.Imprenta del Centro Militar del Perú, Lima,pp-37-38.
} 


\section{Cuadro 4.5}

\section{Obras a ejecutar por la Empresa de ferrocarriles del Perú en la margen izquierda del río Rímac}

\begin{tabular}{|c|c|c|c|}
\hline Obra a ejecutar & Ubicación & Propietario & Estado \\
\hline $\begin{array}{c}\text { Demolición de la Estación de } \\
\text { Ferrocarril Lima-Chancay y } \\
\text { construcción de edificios en los } \\
\text { muladares continuos }\end{array}$ & $\begin{array}{c}\text { Puente de } \\
\text { Piedra-Estación } \\
\text { de Monserrate }\end{array}$ & Estado & $\begin{array}{c}\text { Ejecutado } \\
\text { (Basurco,1904) }\end{array}$ \\
\hline $\begin{array}{l}\text { Mejoramiento de la Estación de } \\
\text { La Palma del ferrocarril Lima- } \\
\text { Ancón }\end{array}$ & $\begin{array}{l}\text { Puente de Los } \\
\text { Ferrocarriles }\end{array}$ & Estado & $\begin{array}{c}\text { Ejecutado } \\
\text { (Jouanny,1880) }\end{array}$ \\
\hline $\begin{array}{c}\text { Construcción de un puente de } \\
\text { comunicación en el río Rímac } \\
\text { para uso público }\end{array}$ & $\begin{array}{l}\text { Desde la toma } \\
\text { de La } \\
\text { Magdalena } \\
\text { hasta el otro } \\
\text { lado }\end{array}$ & La Empresa & $\begin{array}{c}\text { Ejecutado } \\
\text { (Basurco,1904) }\end{array}$ \\
\hline $\begin{array}{c}\text { La Empresa cedió a la } \\
\text { Municipalidad lo terrenos de la } \\
\text { Estación de Tajamar hasta el } \\
\text { Puente de Piedra }\end{array}$ & $\begin{array}{l}\text { Entre el puente } \\
\text { Balta y el } \\
\text { puente de } \\
\text { Piedra }\end{array}$ & $\begin{array}{c}\text { Cedió la } \\
\text { Empresa a la } \\
\text { Municipalidad }\end{array}$ & $\begin{array}{c}\text { Ejecutado } \\
\text { (Basurco,1904) }\end{array}$ \\
\hline $\begin{array}{c}\text { Construcción de un puente } \\
\text { desde el ferrocarril de Ancón } \\
\text { hasta la Oroya }\end{array}$ & $\begin{array}{l}\text { Puente de } \\
\text { Piedra }\end{array}$ & $\begin{array}{c}\text { Cedió el } \\
\text { Estado a la } \\
\text { Municipalidad }\end{array}$ & $\begin{array}{c}\text { Ejecutado } \\
\text { (Basurco,1904) }\end{array}$ \\
\hline $\begin{array}{c}\text { Trámite para adquisición del } \\
\text { puente Arana la comunicación } \\
\text { de los barrios bajos de la ciudad }\end{array}$ & $\begin{array}{l}\text { Estación del } \\
\text { Tajamar }\end{array}$ & Estado & Sin dato \\
\hline $\begin{array}{l}\text { La construcción de una plaza } \\
\text { pública en los terrenos de la } \\
\text { Estación de Ancón y los terrenos } \\
\text { ribereños para la construcción } \\
\text { de un paseo público }\end{array}$ & $\begin{array}{l}\text { Entre el puente } \\
\text { Balta y el } \\
\text { Puente de } \\
\text { Piedra }\end{array}$ & $\begin{array}{l}\text { Cedió el } \\
\text { Estado a la } \\
\text { Municipalidad }\end{array}$ & $\begin{array}{c}\text { Ejecutado } \\
\text { plaza } \\
\text { Monserrate } \\
\text { (Basurco,1904) }\end{array}$ \\
\hline $\begin{array}{l}\text { Construcción de doble vía por el } \\
\text { ojo del puente de piedra }\end{array}$ & $\begin{array}{l}\text { Puente de } \\
\text { Piedra }\end{array}$ & Estado & Sin dato \\
\hline $\begin{array}{l}\text { Mejoramiento del las vías del } \\
\text { ferrocarril Lima-Oroya }\end{array}$ & $\begin{array}{l}\text { Desde el puente } \\
\text { Balta hasta la } \\
\text { toma de río } \\
\text { Magdalena }\end{array}$ & $\begin{array}{c}\text { Cedió la } \\
\text { Municipalidad } \\
\text { a los } \\
\text { Tenedores de } \\
\text { Bonos } \\
\end{array}$ & $\begin{array}{c}\text { Ejecutado } \\
\text { (Basurco,1904) }\end{array}$ \\
\hline
\end{tabular}


La intervención en la margen del río Rímac trajo las siguientes consecuencias: un mejor servicio de las estaciones Lima- La Oroya, Lima-Ancón y la Estación de la Palma, la mejora de la limpieza de la zona de los tajamares a cargo de la Municipalidad, un mejor flujo peatonal a los barrios ubicados bajo el puente, el aumento de los precios de los terrenos ubicados cerca de la margen izquierda del río Rímac y la mejora de las condiciones de salubridad de este lado de la ciudad.

El fallecimiento del presidente Morales Bermúdez, en el año 1894, generó disputas por el poder. Fue así, que nuevamente el país ingresó entre los años de 1894 a 1895 a una guerra civil. Durante un breve periodo de tiempo asumió la presidencia don Justiniano Borgoño (Basadre: 2014, tomoXI, 15) Nicolás de Piérola lo derrocó y asumió el gobierno el 8 de setiembre de 1895 (Basadre: 2014, tomoXI,38). Para entonces, la ciudad se había recuperado del conflicto del Pacífico e iniciaría un nuevo periodo modernizador. En este corto periodo se ejecutaron las siguientes obras:

\section{Cuadro 4.6}

\section{Obras públicas durante la guerra civil año 1895}

\begin{tabular}{|c|c|c|c|}
\hline Año & Obra & Ejecutor & Fuente \\
\hline 1895 & Construcción de la Casa de Correos & Gobierno & $\begin{array}{l}\text { Anales de Obras Públicas del } \\
\text { Perú,1895:124 }\end{array}$ \\
\hline 1895 & Construcción del Teatro de Lima & Municipalidad & $\begin{array}{c}\text { Anales de Obras Públicas del } \\
\text { Perú,1895:125 }\end{array}$ \\
\hline 1895 & $\begin{array}{l}\text { Reparaciones del Panóptico }{ }^{109} \\
\text { ubicado cerca al Palacio de la } \\
\text { Exposición }\end{array}$ & Gobierno & $\begin{array}{l}\text { Anales de Obras Públicas del Perú:125- } \\
\qquad 126\end{array}$ \\
\hline 1895 & $\begin{array}{c}\text { Cruzamiento de la línea férrea a } \\
\text { Chorrillos por la del tranvía al mismo } \\
\text { lugar }\end{array}$ & Gobierno & $\begin{array}{c}\text { Anales de Obras Públicas del } \\
\text { Perú,1895:134 }\end{array}$ \\
\hline 1895 & $\begin{array}{l}\text { Cruzamiento de la línea inglesa por } \\
\text { el tranvía de la Punta y por el de } \\
\text { Miraflores }\end{array}$ & Gobierno & $\begin{array}{l}\text { Anales de Obras Públicas del } \\
\text { Perú,1895:135-136 }\end{array}$ \\
\hline 1895 & $\begin{array}{c}\text { Solución del contrato de construcción } \\
\text { de la Cárcel de Lima en los terrenos } \\
\text { de "Huerta Perdida" }\end{array}$ & Gobierno & $\begin{array}{l}\text { Anales de Obras Públicas del } \\
\text { Perú,1895:126-127 }\end{array}$ \\
\hline
\end{tabular}

Fuente: Elaboración propia en base a Anales de Obras Públicas del Perú (1895)

${ }^{109}$ El Panóptico fue construido durante el gobierno del presidente Ramón Castilla entre los años de 1856 a 1860. 


\subsection{La materialización del discurso civilista de modernidad y progreso urbano (1896-1908)}

El civilismo ${ }^{110}$ surgió como un partido político hacia inicios de la década de 1870 su fundador fue Manuel Pardo y la Valle, que representaba la aristocracia peruana. Después de la guerra con Chile el partido civilista atravesó por un proceso de reformulación de su ideología y se convirtió en un movimiento de élite (Mc Evoy,1997:377-378). Los presidentes que asumieron el poder en este periodo (1896-1908) buscaron la materialización de la modernidad en la ciudad de Lima. Puede decirse que hubo un proceso civilista de modernidad urbana, durante el cual la oligarquía buscó transformar la ciudad para complacer a la aristocracia limeña. Este partido tuvo una continuidad de cinco periodos presidenciales entre los años de 1896 a 1908.

Los civilistas Manuel Pardo y la Valle, Mariano Ignacio Prado, Eduardo López de Romaña, Serapio Calderón, Manuel Candamo, José Pardo y Barrera y Augusto B. Leguía dejaron a cargo de la inversión privada la urbanización de la periferia de Lima, como se había hecho durante el gobierno del presidente José Balta. Ellos ejecutaron la obra pública mediante la aplicación de La ley de Expropiación que fue rectificada en dos oportunidades por los gobiernos de turno. De esta manera, una vez más se produjo la urbanización de la periferia. La oferta estuvo dirigida a la élite, clase media, obrera e inmigrante, la cual buscó salir del centro de la ciudad hacia la periferia debido a los problemas de insalubridad. La aristocracia vio la oportunidad de invertir en la ciudad con la compra de propiedades en un segundo proceso especulativo y vivir en los balnearios del sur y así protegerse de la insalubridad ${ }^{111}$. Mientras que el Estado oligárquico retomó la construcción del centro moderno, evitando los espacios insalubres de la ciudad.

\footnotetext{
${ }^{110}$ Según Mc Evoy “Los miembros del partido coalicionista exhibieron cierta autonomía en relación al frente que conformaban especialmente en el proceso de designación de candidatos en las elecciones de 1894, el comando de coalición recayó en manos del líder del partido Demócrata Nicolás de Piérola. Cabe subrayar como en una hábil jugada política los miembros de la flamante asociación civilista solicitaron al gobierno el nombramiento de un ministerio compuesto de los tres partidos coalicionalistas. "La utopía republicana: ideales y realidades en la formación de la cultura política peruana 1871-1919" Ed. PUCP, Lima, 1997, pp.322.

${ }^{111}$ Según Alcántara "La aristocracia se mantenía de las rentas de la tierra, de los campos e iba a la ciudad a ejercitar sus relaciones políticas y sociales. Por otro lado, la burguesía establecía su residencia en la ciudad donde trabajaba y buscaba alejarse de ella por medio de una residencia de campo". Tesis de Maestría UNAM". "Fraccionadores y fraccionamientos una historia de desarrollo inmobiliario en la ciudad de México a través de ciudad satélite y Villa Coapa (1952-1980)", UNAM, México. pp.24
} 


\subsubsection{El segundo gobierno del presidente Nicolás de Piérola Retomando la materialización de la modernidad (1896-1990)}

El año 1896 asumió la presidencia el civilista don Nicolás de Piérola en medio de una inestabilidad política y reclamos sociales por el alto costo de vida, ante la crisis económica por la que nuevamente atravesó la ciudad. Sus principales objetivos fueron: La búsqueda de la salud fiscal, mejorar los ingresos del Estado Peruano y un control del presupuesto de la Nación y de los impuestos (Basadre: 2014, tomoXI: 102-104). Además, trató de continuar el proyecto de modernidad de los gobiernos antes de la guerra del Pacifico, pero esta vez, con un fuerte componente de la inversión privada. En lo social, buscó aumentar la oferta de empleo en la ciudad incentivando la industria. En lo administrativo, se creó el Ministerio de Fomento, en cuyo interior se encontraban las secciones de: Obras públicas, Industrias y Beneficencia (Ministerio de Fomento, 1896:5-6) buscando impulsar el desarrollo y modernización del país ${ }^{112}$. En el texto de Pineo señala al respecto:

"Con una política recuperada y una estabilidad económica restaurada se retomaron los proyectos modernizadores con un especial interés en la modernización y el embellecimiento de Lima. Entre 1895 a 1899 emitió algunas leyes facilitando la expansión urbana, el desarrollo inmobiliario y las construcciones elegantes a lo largo de las grandes avenidas como La Colmena" (Pineo, 1998:155) ${ }^{113}$.

El alcalde de la ciudad en este periodo fue Juan Martín Echenique, quien trabajó de manera conjunta con el Estado Peruano el proyecto modernizador mediante la realización de proyectos para la ciudad desde la Sección de obras de la Municipalidad, la cual estaba a cargo de los ingenieros municipales: Felipe Arancivia, José Castaños, Pedro Combe, Julio Fernad, Miguel Trefogli, Pedro Antonio Varela (Consejo Municipal de Lima, 1898:362). El ingeniero Felipe Arancivia culminó el proyecto de la canalización del río Rímac (Cuadros,

\footnotetext{
112 El primer Ministro en asumir el cargo fue don Eduardo López de Romaña el año 1896. Registro Oficial de Fomento, Minas y Beneficencia, Año 1896, pp.6.

113 Traducción del libro "Cities of Hope" Ron Pineo y James A. Baer. No existe versión en español del libro. Traducción de algunos párrafos. Jéssica Esquivel.
} 
1896:17) con la finalidad de mejorar las condiciones de salubridad de este lado de la ciudad y ganar terrenos al río cerca a la Plaza Mayor.

\section{Cuadro 4.7}

\section{Obras públicas durante el segundo gobierno del presidente Nicolás de Piérola (1896-1899)}

\begin{tabular}{|c|c|c|c|}
\hline Año & Obra & Ejecutor & Fuente \\
\hline 1895 & $\begin{array}{l}\text { Alumbrado a gas del Palacio de } \\
\text { Gobierno }\end{array}$ & $\begin{array}{l}\text { Dirección de } \\
\text { Gobierno y Policía y } \\
\text { Obras Públicas }\end{array}$ & $\begin{array}{c}\text { Anales de Obras } \\
\text { Públicas 1895. p.196 }\end{array}$ \\
\hline 1895 & Construcción del teatro de Lima & $\begin{array}{c}\text { Dirección de } \\
\text { Gobierno y Policía y } \\
\text { Obras Públicas }\end{array}$ & $\begin{array}{c}\text { Anales de Obras } \\
\text { Públicas 1896.p.125 }\end{array}$ \\
\hline 1896 & $\begin{array}{l}\text { Canalización del Río Rímac entre el } \\
\text { puente de Piedra y el Puente Balta }\end{array}$ & $\begin{array}{c}\text { Dirección de } \\
\text { Gobierno y Policía y } \\
\text { Obras Públicas }\end{array}$ & $\begin{array}{c}\text { Anales de Obras } \\
\text { Públicas 1896,p.606- } \\
607\end{array}$ \\
\hline 1896 & $\begin{array}{l}\text { Contrato con la Empresa de Tranvía } \\
\text { línea Cementerio General Santa } \\
\text { Clara, portada Guía, Malambo y San } \\
\text { Lázaro, Plaza de Acho, Santa } \\
\text { Apolonia, Santo Domingo }\end{array}$ & $\begin{array}{l}\text { Municipalidad y } \\
\text { Gobierno }\end{array}$ & $\begin{array}{l}\text { Diario oficial El } \\
\text { Peruano, } 1896,4 \\
\text { febrero: } 75\end{array}$ \\
\hline 1897 & $\begin{array}{l}\text { Proyecto de la Cárcel de Lima en los } \\
\text { terrenos de "Huerta Perdida" }\end{array}$ & $\begin{array}{c}\text { Dirección de } \\
\text { Gobierno y Policía y } \\
\text { Obras Públicas }\end{array}$ & $\begin{array}{c}\text { Diario oficial El } \\
\text { Peruano, } 1897,21 \\
\text { enero: } 74\end{array}$ \\
\hline 1899 & Morgue de Lima & $\begin{array}{c}\text { Dirección de } \\
\text { Gobierno y Policía y } \\
\text { Obras Públicas }\end{array}$ & $\begin{array}{c}\text { Anales de Obras } \\
\text { Públicas 1899,p.211- } \\
212 \\
\end{array}$ \\
\hline 1899 & $\begin{array}{l}\text { Corte en el Palacio de la Exposición } \\
\text { para la continuación de la avenida de } \\
\text { Circunvalación entre el Instituto de } \\
\text { Vacuna y la Exposición de Marquina }\end{array}$ & $\begin{array}{l}\text { Dirección de } \\
\text { Gobierno y Policía y } \\
\text { Obras Públicas }\end{array}$ & $\begin{array}{c}\text { Anales de Obras } \\
\text { Públicas 1899.p.300- } \\
301\end{array}$ \\
\hline 1899 & $\begin{array}{c}\text { El proyecto del nuevo colegio de } \\
\text { Guadalupe }\end{array}$ & $\begin{array}{c}\text { Dirección de } \\
\text { Gobierno y Policía y } \\
\text { Obras Públicas }\end{array}$ & $\begin{array}{c}\text { Diario oficial } \\
\text { El Peruano á,12 } \\
\text { mayo, } 1899: 413\end{array}$ \\
\hline 1899 & $\begin{array}{l}\text { Construcción de la cárcel de mujeres } \\
\text { de Lima }\end{array}$ & $\begin{array}{c}\text { Dirección de } \\
\text { Gobierno y Policía y } \\
\text { Obras Públicas } \\
\end{array}$ & $\begin{array}{l}\text { Diario oficial } \\
\text { El Peruano á,24 } \\
\text { junio, 1899:583 }\end{array}$ \\
\hline 1899 & $\begin{array}{c}\text { Construcción de la escuela de } \\
\text { Medicina a cargo del ingeniero } \\
\text { Basurco }\end{array}$ & $\begin{array}{l}\text { Dirección de } \\
\text { Gobierno y Policía y } \\
\text { Obras Públicas }\end{array}$ & $\begin{array}{l}\text { Diario oficial } \\
\text { El Peruano á,14 } \\
\text { julio, } 1899: 50\end{array}$ \\
\hline
\end{tabular}

Fuente: Elaboración propia en base a El peruano Diario oficial El Peruano (1896)(1897)(1899) y Anales de Obras Públicas (1895),(1896),(1898) 
Sobre este tipo de acciones señala Sánchez:

"Con la introducción de esos servicios iba más allá de su simple dotación, ya que mejorar las deficiencias de las ciudades y sus periferias, implicaba acciones más integrales como organizar y proveer a las ciudades de un adecuado nivel de equipamiento infraestructura y vivienda pero además inducir niveles de organización y buen habitar" (Sánchez,2013:31).

Siguiendo este pensamiento podemos decir que en este periodo el gobierno del presidente Piérola intentó estas mejoras en la ciudad con el objetivo de mejorar la calidad de vida en la ciudad y buen habitar, con énfasis en la ejecución de avenidas centrales que permitiera comunicar mejor el centro con la zona de expansión, con la perspectiva futura de permitir el acceso al centro a la población de clase media que comenzaban a mudarse a las nuevas urbanizaciones.

En este periodo se buscó solucionar los problemas de tenencia de la periferia de Lima, ocasionados por la paralización de los trabajos del Plan de Ensanche que estuvieron a cargo del empresario Enrique Meiggs, para poder retomar la urbanización de la periferia. Sin embargo, esto no fue posible debido a la negativa de los pobladores y los herederos de Meiggs de colaborar con el Estado en esta tarea. No obstante, se realizaron proyectos de envergadura como la apertura de las avenidas centrales de: Magdalena del Mar o Central, Interior, Alfonso Ugarte y Paseo Colón con las que materializó la conexión con el nuevo centro y de manera paralela se continuó con la edificación y remodelación de las edificaciones públicas que junto con la mejora de los servicios materializaron la modernidad en la ciudad.

\subsubsection{Regularización de la propiedad en la periferia (1896- 1897).}

El gobierno del presidente Nicolás de Piérola decidió impulsar la intervención de la inversión privada en la urbanización de la periferia, retomando para ello las obras del Plan de Ensanche. No obstante, el proceso tuvo el problema de la tenencia legal de predios. Espacialmente existieron dudas con muchas de las propiedades vendidas por Meiggs y otras ocupadas de manera ilegal que 
pertenecían al Estado. Las dudas se presentaban debido a la no existencia de un padrón de propietarios de la periferia debidamente asentado en los Registros Públicos, Por otro lado, no estaba claro hasta qué punto el fraccionador Enrique Meiggs había realizado los trabajos del Plan de Ensanche que se había comprometido a realizar con el Estado bajo contrato. Ante esta situación, el 18 de junio de 1896 el Estado encargó a Teodorico Terry la realización de una valuación de la obra ejecutada por el fraccionador Enrique Meiggs por contrato con el Gobierno, firmado el 8 de enero de 1872 (Terry, 1896:20-25). De manera paralela, se realizó el empadronamiento de los lotes, concretamente los de particulares, los expropiados por Enrique Meiggs, los terrenos edificados, los que pertenecen al fisco y por último los que pertenecían a Meiggs y sus herederos ${ }^{114}$. Este proceso de saneamiento legal que se realizó en la periferia puso en evidencia la responsabilidad de la Municipalidad y el Gobierno por el control de la urbanización de esa zona, sujeta desde la muerte de Meiggs a un desorden urbano y a la apropiación de terrenos de Estado Peruano por parte de los herederos de Meiggs y otros. En concreto, la regularización de propiedades trajo las siguientes consecuencias: dejó sin efecto cualquier contrato sobre los terrenos de Enrique Meiggs en adelante, legalizó los terrenos de propiedad de particulares que demostraron su autenticidad, algunos terrenos expropiados para el trazo de calles y avenidas fueron devueltos al fisco, nuevamente se activó el mercado de suelo urbano en la periferia en las zonas donde se pudo materializar la intervención y se amplió la oferta de vivienda en la periferia por parte de los inversionistas privados ${ }^{115}$ al sur-poniente de la ciudad. En este momento los inversionistas se interesaron por el negocio inmobiliario de la periferia y la ciudad experimentó un crecimiento en ese sentido, donde se ubicó el Palacio de la Exposición, a lo

\footnotetext{
114 En el caso de los herederos de Meiggs y la testamentaria estaban obligados a indemnizar al Estado la suma 131, 170,173 soles por incumplimiento de contrato de Meiggs con el Gobierno "Anales de las Obras Públicas del Perú" Ed. Torres Aguirre, Año1896, pp.20-25. Un segundo paso después del proceso de saneamiento legal de los lotes en la periferia el gobierno encargó al arquitecto San Martín la elaboración de un plano de catastro de los terrenos ocupados por la antiguas murallas para conocer el estado actual de las cuatro secciones urbanizadas por Meiggs con la finalidad de evaluar las obras ejecutadas, los terrenos expropiados y otros detalles que ayuden a tener una idea del estado actual de la periferia "Anales de las Obras Públicas del Perú" Ed. Torres Aguirre, Año1896,pp.26-28.
} 
que se sumó la inversión del Estado en líneas de ferrocarril para conectar ese lado de la ciudad con el nuevo centro. En la práctica, se trató de la reinserción de parte de este territorio de la periferia al proceso de mercantilización de la vivienda. Al final de este proceso, el resultado fue la regularización de propiedades al oeste cerca a los óvalos Dos de Mayo y Unión, lo que, junto con terrenos del fisco, permitiría el crecimiento económico a partir de la división de la tierra realizada por los inversionistas privados, quienes retomaron nuevamente procesos especulativos de suelo con el aval del Estado.

\section{Cuadro 4.8 Acciones para el saneamiento legal en la periferia (1896-1897) a cargo del Estado}

\begin{tabular}{|c|c|}
\hline Obra & Fuente \\
\hline $\begin{array}{c}\text { Verificación de los espacios colindantes con lo } \\
\text { vendido por Meiggs }\end{array}$ & $\begin{array}{c}\text { Anales de Obras Públicas del } \\
\text { Perú,1896:27 }\end{array}$ \\
\hline $\begin{array}{c}\text { Revisión de las adquisiciones hechas por Meiggs y la } \\
\text { Municipalidad }\end{array}$ & Anales de Obras Públicas del \\
Perú,1896:27
\end{tabular}

Fuente: Elaboración propia en base a Anales de Obras Públicas del Perú (1896), El Peruano (1896, pp.26-27),(1897,pp.64) 


\section{Plano 4.3}

\section{Lima el año 1896}

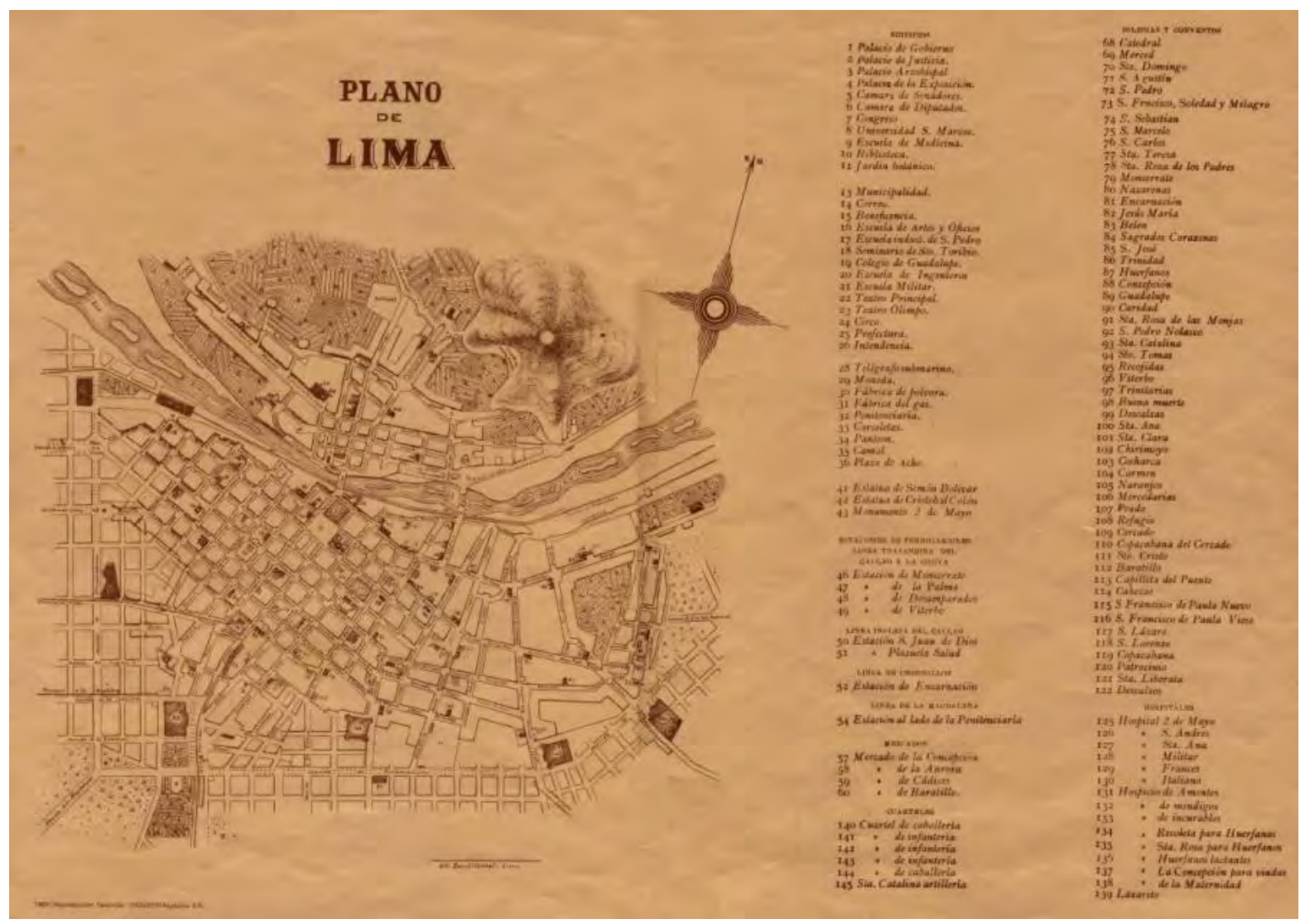

Gunther, J. (1983), Plano preparado por el Cuerpo de Tasaciones para el avaluó de las áreas urbanas de Lima. (Lámina 13)

Al culminar las verificaciones de los trabajos ejecutados por Enrique Meiggs, así como la tenencia de las propiedades y apropiaciones, se procedió al registro de las propiedades el 12 de diciembre de 1896 (Director de Obras Públicas, 1896:31). Con esta acción, se culminó el proceso de saneamiento legal de la periferia a cargo de la Dirección de Obras Públicas. En adelante se pudo realizar un balance del estado actual de lo realizado por Meiggs y reiniciar obra pública en parte de la periferia. De la misma manera, quedó establecido el monto que Meiggs debía al Estado s/.131170 $73^{116}$ (Terry, 1896:22-23) que era el monto que debían de pagar sus herederos. Gracias a este empadronamiento

\footnotetext{
116 "Presupuesto del costo que ha de ocasionar el levantamiento del plano catastral de los terrenos de las murallas, adjudicadas por el Gobierno a D. Enrique Meiggs en concepto de tres meses de trabajo para los técnicos y de 78 días útiles para los peones. Por ayudante encargado del croquis del plano a 120 soles por mes, para un ayudante de medidas de las bases distancias y deslindes al mes 80 soles". Diario oficial el Peruano, Lima sábado 03 de octubre de 1896, Tomo II, Núm. 34, p.239. El monto de s/.131170 73 es 109 308,94 veces el sueldo de un ayudante.
} 
se registraron 106 títulos que correspondían a 141 lotes de terrenos comprados a Meiggs, (Terry, 1896:24) lo que significaba el diez por ciento del total de los terrenos de la periferia que pertenecían a Meiggs, de un total de quinientos cincuenta tres, tal como se observa en el plano de la testamentaria de Meiggs del año 1879 (Ver plano en el capítulo III plano 3.17). Al culminar este proceso aun quedó pendiente el saneamiento de muchos terrenos que pertenecían al Estado Peruano, ocupados ilegalmente, principalmente al este de la ciudad. No obstante, hacia el lado este y sur los terrenos saneados se incorporaron al mercado de suelo de la ciudad iniciando así un nuevo periodo urbanizador con la intervención de los inversionistas privados.

\subsubsection{La matrícula de predios rústicos y la distribución de las propiedades en el año de 1896}

El Estado peruano estableció, desde el año 1893, el padrón de propietarios en la ciudad de Lima que para el año 1896 ya contaba con 4117 propiedades que pagarían un impuesto predial de diez por ciento del valor de sus predios ${ }^{117}$. La mejora del catastro de la ciudad tuvo las siguientes consecuencias: aumentó la recaudación predial por parte de La Junta departamental de Lima, la ciudad a partir de entonces contó con un registro actualizado de los propietarios, se dio la posibilidad de establecer acciones para el desarrollo de la ciudad, se abrió la posibilidad de una mejor planeación en los barrios, con un control sobre las transacciones en el sistema financiero y el mercado de suelo.

El padrón comprendió la ciudad de Lima que ese año llegaba hasta la avenida 28 de Julio (Junta Departamental, 1897:1-95). Sin embargo, no se consideraron las propiedades de la periferia debido a que estas se encontraban en proceso de empadronamiento y las propiedades recientemente adquiridas no pagaban impuesto el primer año. Para conocer el panorama de los registros en el padrón

\footnotetext{
117 El 20 de diciembre de 1896 la Junta Departamental encargada de la administración de la rentas de la Municipalidad publicó el padrón de propietarios de la ciudad de Lima y las poblaciones cercanas de Magdalena, Huatica, Surco, Carabayllo Alto y Bajo, Bocanegra, Lurigancho, La Legua, Lurín, Pachacamac. Todo el padrón comprende un total de 4117 propiedades que pagarían un impuesto predial de diez por ciento del valor de su predio. A demás, se incorporaron a este documento registros anteriores de los años 1893 y 1894 que en total sumaron 98 propiedades como consta en el documento titulado "Matricula de predios Rústicos y Urbanos 1897" elaborado por la Junta Departamental, Año 1897,Lima,pp. 92-95.
} 
en el centro de la ciudad podemos ver el siguiente cuadro, el cual registra propietarios particulares, la Iglesia118, la Junta Departamental, la Municipalidad, la Beneficencia y las empresas privadas 119.

\section{Cuadro 4.9}

\section{Catastro de Lima y poblaciones cercanas el año 1896}

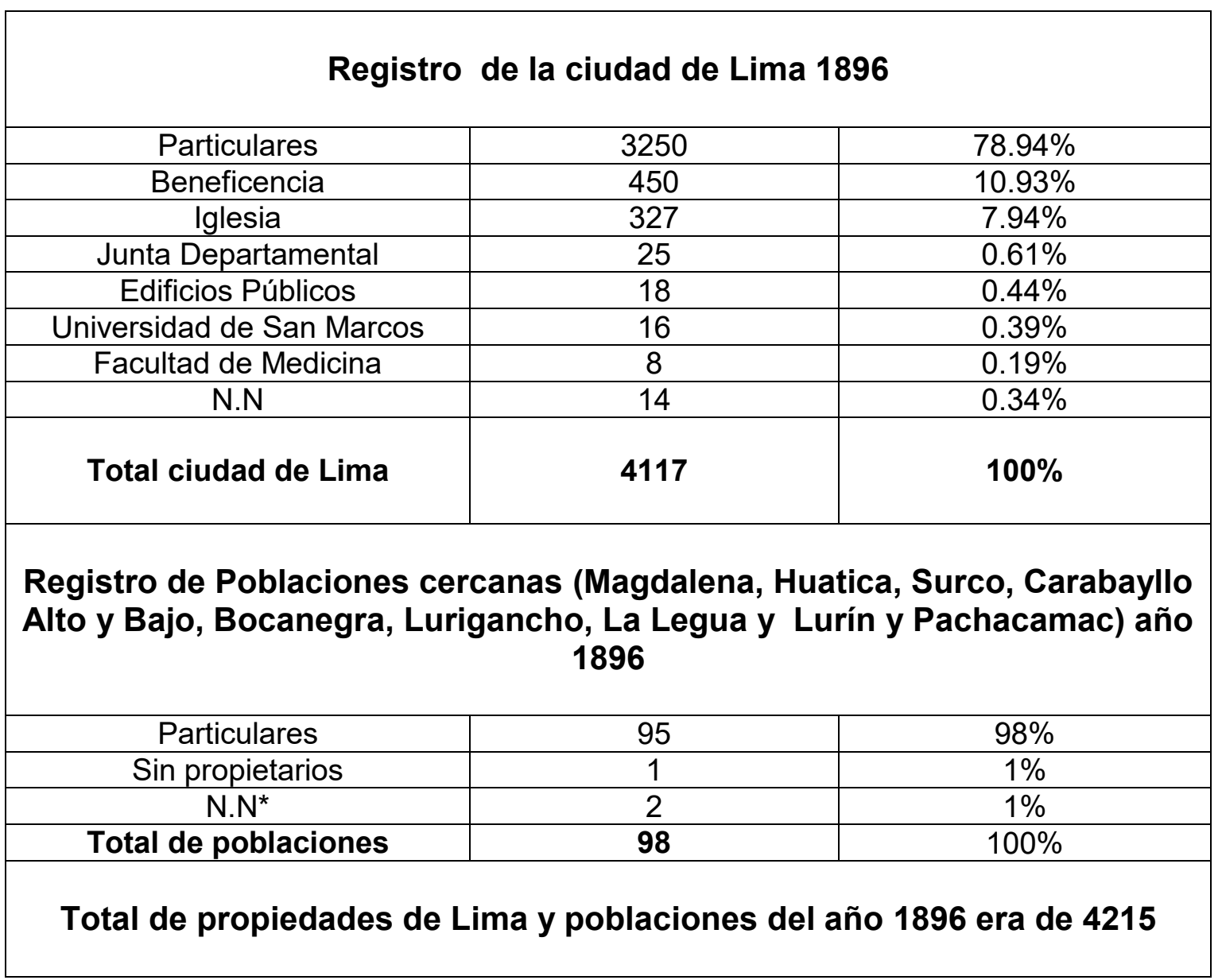

Elaboración propia. En base a Matricula de predios rústicos y urbanos de Lima (1897-pp.1-96).

*NN.- Significa propiedad abandonada en la ciudad de Lima o no se conoce el propietario del predio.

\footnotetext{
118 La Iglesia conformada por: conventos, monasterios, órdenes religiosas, parroquias y beaterios; las instituciones públicas como: la Facultad de Medicina, la Universidad de San Marcos. En: "Matricula de predios Rústicos y Urbanos 1897" elaborado por la Junta Departamental, Año 1897, Lima.

119 Por último instituciones privadas como: el Colegio Belén, la Fábrica de Gas, la Empresa de Luz eléctrica, el Club Nacional, el Banco del Callao y el Molino de Piedra Liza. En: "Matricula de predios Rústicos y Urbanos 1897" elaborado por la Junta Departamental, Año 1897, Lima.
} 
Según los datos catastro de Lima señalados, había predominio de la propiedad particular sobre la propiedad de la Iglesia, lo que se debió a los siguientes factores: la activación del mercado de suelo desde 1888 gracias a la legalización de las transacciones de hipotecas en la ciudad, la existencia del Registro de Propiedad, el crecimiento económico y la oferta de créditos hipotecarios, préstamos por parte de los bancos para adquirir propiedades y el apoyo a los inversionista privados. Todas estas acciones por parte de los gobiernos en turno permitieron una mayor redistribución de la propiedad y la acumulación de propiedades de particulares, provocando la disminución de las propiedades de la Iglesia y una mayor actividad de compra- venta en la ciudad.

\subsubsection{Retomando el proyecto del nuevo centro en la ciudad (1896-1999)}

En el periodo del presidente Nicolás de Piérola se decidió retomar el Plan de Ensanche proyectado por el ingeniero Luis Sada para urbanizar la periferia, impulsando la construcción de un nuevo centro y de esa manera retomando la modernización de la ciudad. Este proceso surgía en buena medida por la necesidad de la élite de replicar en ese espacio de la ciudad el modelo europeo de ciudad, el cual representaría el progreso y la materialización de la modernidad. Además, se trataba de un espacio para que la aristocracia limeña pudiera desarrollar sus actividades mercantiles.

La forma física que adquirió esta centralidad fue triangular. Ver plano 4.4. Esa zona contó con una vía para unir el balneario de La Magdalena con el nuevo centro, es decir, se construyó la avenida Central o avenida de La Magdalena y se mejoró la avenida 09 de noviembre ó paseo Colón, uniendo el ovalo Bolognesi con la avenida Grau (parte de la avenida Circunvalación) (Basurco,1904). Esta vía, al unirse a la avenida Alfonso Ugarte (parte de la avenida Circunvalación) llegaba hasta el óvalo Dos de Mayo, desde donde inició la avenida Interior. Estas tres avenidas formaron un triángulo que definió el nuevo centro propuesto por el gobierno del presidente Nicolás de Piérola que incluía al Palacio de la Exposición ${ }^{120}$. Así se produjo la refuncionalización de las

\footnotetext{
${ }^{120}$ Según Sánchez "Es aquí donde se reinvidica el carácter transformador de un espacio, de un ambiente de una urbe y en la manera de pensar de una sociedad, más si se considera que ese impulso transformador proviene de lo analizado, visualizado y ejecutado por los gobiernos y profesionales quienes impulsaban el proyecto" En: Precursores del urbanismo en México. 2013, Ed. Trillas, México, pp. 221.
} 
calles y la aparición de avenida centrales. De manera complementaria, para llegar a esta centralidad, fue necesario un diseño caminero (Terrazas, 2010:18$25)^{121}$ que permitiera la conexión desde distintos puntos de la ciudad a este nuevo centro. El siguiente cuadro muestra las avenidas que se aperturaron a cargo del ingeniero Enrique Silgado.

\section{Cuadro 4.10}

Avenidas y calles aperturadas (1896-1899)

\begin{tabular}{|c|c|c|}
\hline Avenida & Tramo & Fuente \\
\hline $\begin{array}{l}\text { Avenida de } \\
\quad \text { la } \\
\text { Exposición }\end{array}$ & $\begin{array}{l}\text { Desde la avenida Alfonso } \\
\text { Ugarte hasta el edificio de la } \\
\text { Exposición }\end{array}$ & Basurco,1904 \\
\hline $\begin{array}{l}\text { Avenida } \\
\text { Interior }\end{array}$ & $\begin{array}{l}\text { Desde hasta la avenida La } \\
\text { Colmena desde la plazuela del } \\
\text { Monumento Dos de Mayo hasta } \\
\text { la plazuela de Santa Catalina }\end{array}$ & $\begin{array}{c}\text { Tizón y } \\
\text { Bueno,1906:11 }\end{array}$ \\
\hline $\begin{array}{l}\text { Avenida } \\
\text { Alfonso } \\
\text { Ugarte }^{122}\end{array}$ & $\begin{array}{l}\text { Desde el ovalo Bolognesi hasta } \\
\text { el ovalo de Dos de Mayo }\end{array}$ & $\begin{array}{c}\text { Basurco, } 1904, \mathrm{El} \\
\text { Peruano, } 1898,22 \\
\text { enero: } 70\end{array}$ \\
\hline $\begin{array}{c}\text { Avenida } 09 \\
\text { de } \\
\text { Diciembre o } \\
\text { Paseo } \\
\text { Colón }\end{array}$ & $\begin{array}{c}\text { Desde la avenida Grau hasta el } \\
\text { ovalo Bolognesi }\end{array}$ & Basurco,1904 \\
\hline $\begin{array}{l}\text { Avenida } 28 \\
\text { de Julio }\end{array}$ & $\begin{array}{c}\text { Desde la avenida La } \\
\text { Magdalena (Nicolás de Piérola) } \\
\text { a la avenida San Carlos hasta } \\
\text { terrenos sembrados }\end{array}$ & Basurco,1904 \\
\hline $\begin{array}{l}\text { Avenida } \\
\text { Bolognesi }\end{array}$ & $\begin{array}{c}\text { Desde del ovalo Dos de Mayo } \\
\text { al ovalo Unión }\end{array}$ & Basurco,1904 \\
\hline
\end{tabular}

Fuente: Elaboración propia en base a Basurco (1904), Tizón y Bueno (1906) y Diario oficial El Peruano (1898)

\footnotetext{
${ }^{121}$ Según Terrazas "Para acceder a la centralidad, los habitantes de la ciudad y quien la visitan deben trasladarse a los ámbitos que la concentran, que como hemos visto estos se agrupan siguiendo un esquema de caminos urbanos" En: "La ciudad que hoy es centro", 2010, Ed. UAM-A, México pp.22.

122. En el documento del Ministerio de Fomento se observa la compra hecha a Doña Lucia Collazos de Aguirre un área de terrenos $351 \mathrm{~m} 2$ con el fin de prolongar la avenida Alfonso Ugarte adyacente a la antigua Escuela de clases de Chorrillos. Diario oficial El peruano, sábado 22 de enero de 1898, (Núm. 9),pp.70.

${ }^{123}$ Ver En la Matricula de Predios Rústicos y Urbanos de Lima de 1897 está registrada la avenida 28 de Julio a pesar que no aparece en los planos de Lima de 1904 y 1908. Sin embargo aparece en el plano de Lima elaborado por el Cuerpo General de Tasaciones de 1927.
} 
Para permitir el acceso al nuevo centro se utilizaron las líneas férreas que se habían construido en gobiernos anteriores. De esta manera, estas líneas férreas, unidas a las nuevas avenidas aperturadas fueron utilizadas por la población para movilizarse a este nuevo centro. Fue así como se definieron los siguientes caminos.

-Por el Norte: El ferrocarril Lima-Ancón, el jirón de la Unión, la Colmena (Nicolás de Piérola) ó la avenida Interior, avenida Central.

-Por el sur: El tren Lima-Chorrillos ó la carretera Lima-Miraflores, la avenida y la avenida Central.

-Por el este: El ferrocarril Lima-La Oroya, la carretera Lima-Matucana y la Avenida Grau.

- Por el oeste: La carretera Lima-Callao ó Ferrocarril Lima-Callao, la avenida Alfonso Ugarte y El tren Lima- La Magdalena, (antigua Penitenciaria) y la avenida Central o de la Magdalena. Diario oficial El Peruano á,8 febrero, 1899:104.

Con la materialización de la red vial que conectaba el centro con la periferia y los balnearios del sur fue posible un mayor vínculo urbano entre Lima y las localidades ubicadas al sur que ya concentraba comercios, servicios y recreación. Además, con esta nueva estructura vial, se desarrollaron algunas zonas en la ciudad, como el centro financiero a lo largo de la avenida La Colmena; la zona residencial a lo largo de la avenida La Magdalena; la zona industrial al sur y norte donde se ubicaron las fábricas textiles, cervecerías y curtiembres, entre otras industrias pequeñas. "De esta manera, aunque no se contaba con un reglamento de usos de suelo, la materialización de la nueva infraestructura vial posibilitó un nuevo orden en el establecimiento de las funciones de la ciudad, lo que significó un avance en la planificación de la ciudad, un mayor desarrollo del capitalismo, un cambio social y económico tratando de alcanzar la modernidad". (Sánchez, 2013:36). 


\section{Plano 4.4 \\ Proyecto del nuevo centro de Lima. 1898}

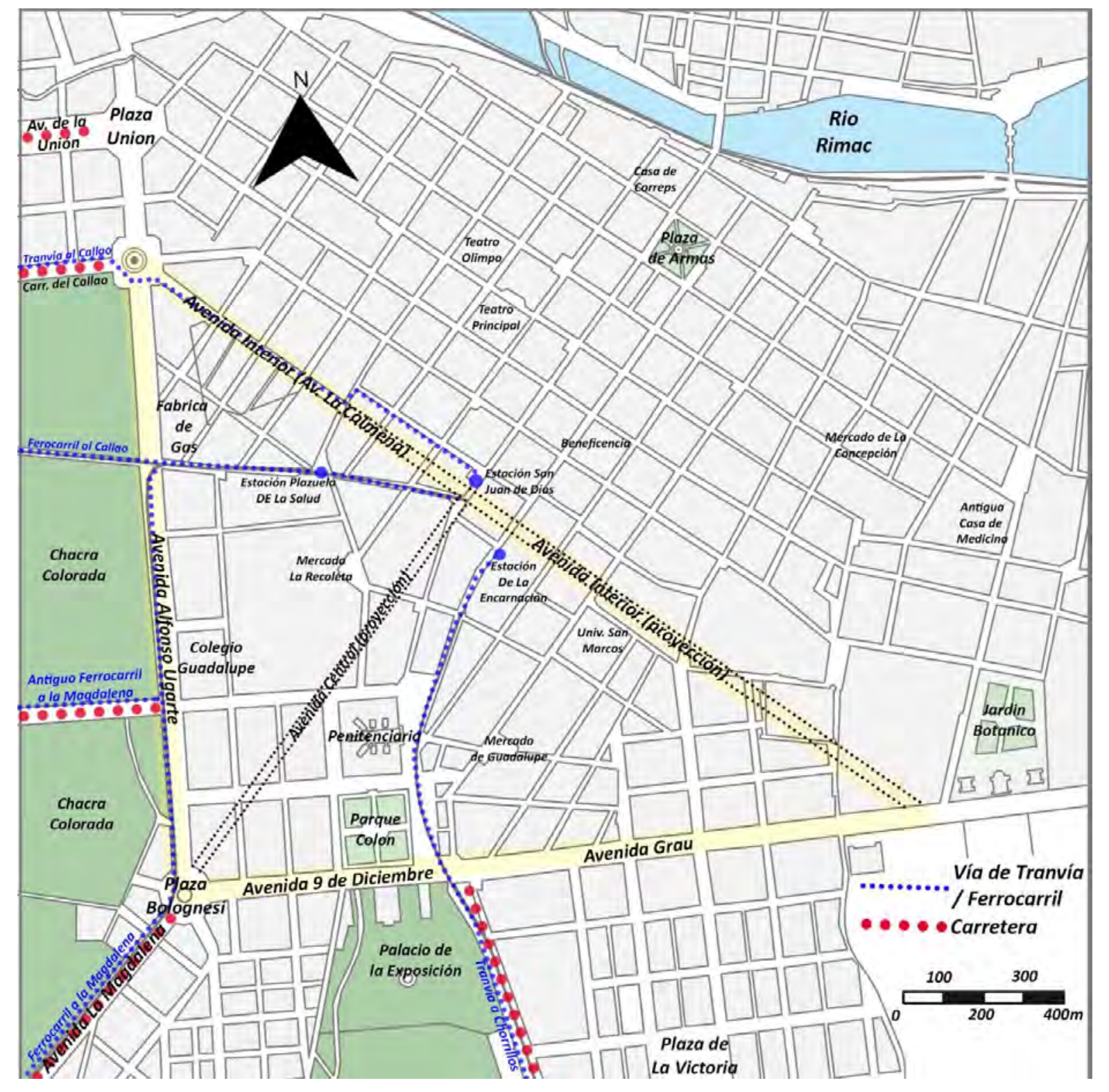

Elaboración propia. En base al plano a Gunther J. (1983), plano de Lima Basurco S.

(1904). (Lamina 14) 


\subsubsection{El proyecto de la Avenida de La Magdalena (1899)}

El proyecto de modernización del presidente Nicolás de Piérola planteó la apertura de varias avenidas centrales hacia la periferia, lo que continuaron los siguientes gobiernos. La principal fue la Avenida Central o Avenida de La Magdalena, que buscó unir la ciudad de Lima con el balneario de La Magdalena. Durante el gobierno de Piérola, solo fue ejecutado el tramo hasta la Plaza Bolognesi, por problemas de presupuesto y porque ocasionó un conflicto con los concesionarios de las líneas del tranvía a lo largo en la intersección ubicada en el óvalo Bolognesi (Diario oficial El Peruano á, 13 abril, 1901:305).

Desde la guerra del Pacífico el balneario La Magdalena continúo su proceso de urbanización y se reforzó el vínculo con la ciudad de Lima a través del ferrocarril Lima-La Magdalena. A finales del siglo XIX la élite acentuó su éxodo a los balnearios como La Magdalena, huyendo de las malas condiciones de salubridad en el centro de Lima. Eso hizo necesario una vía que permitiera que la élite se movilizara a la ciudad durante el día, para luego regresar al balneario por la noche, sin pasar por los espacios insalubres de la ciudad. Esta fue la principal razón para que el gobierno del presidente Nicolás de Piérola decidiera elaborar el proyecto, el cual fue culminado en el periodo del presidente Eduardo López de Romaña de 1899 a 1903.

El proyecto de la avenida Magdalena inició en la intersección de la avenida Grau, que pasa delante del Palacio de la Exposición, con la avenida Bolognesi, que viene del Monumento Dos de Mayo ${ }^{124}$ (Silgado,1898:302-305). La propuesta inicial contempló que iniciara en el mar y continuara en línea recta y pasara por la Plaza de Micheo, la Estación de San Juan de Dios y la Merced hasta el puente de Piedra, tramo que no se ejecutó. La avenida fue proyectada con veinticinco metros de ancho, de los cuales, catorce metros fueron para banquetas a ambos lados, con hileras de árboles y un espacio para el tranvía que también sería construido por el Estado y concesionado (Diario oficial El

\footnotetext{
${ }^{124}$ Según el ingeniero Enrique Silgado, "el trayecto de la Avenida seria: San Martin, Breña (de los padres Salesianos), Desamparados, Oyague, Potrero Asin, Orbea, en una extensión total de 4,747.10 de longitud"."Proyecto de la Avenida la Magdalena" En:"Anales de Obras Públicas del año 1898",Imprenta Torres Aguirre,Lima,p.301-305. En los próximos años la avenida la Magdalena tomó el nombre de avenida Nicolás de Piérola ver plano de Lima elaborado por el ingeniero Santiago Basurco el año 1904.
} 
Peruano, 1899 á, 9 febrero: 104). Con esta obra el Estado Peruano buscaría mejorar la salubridad, el tráfico y el ornato de la ciudad con un eje ampliado.

\section{Plano 4.5}

\section{Avenida La Magdalena en el año de 1899}

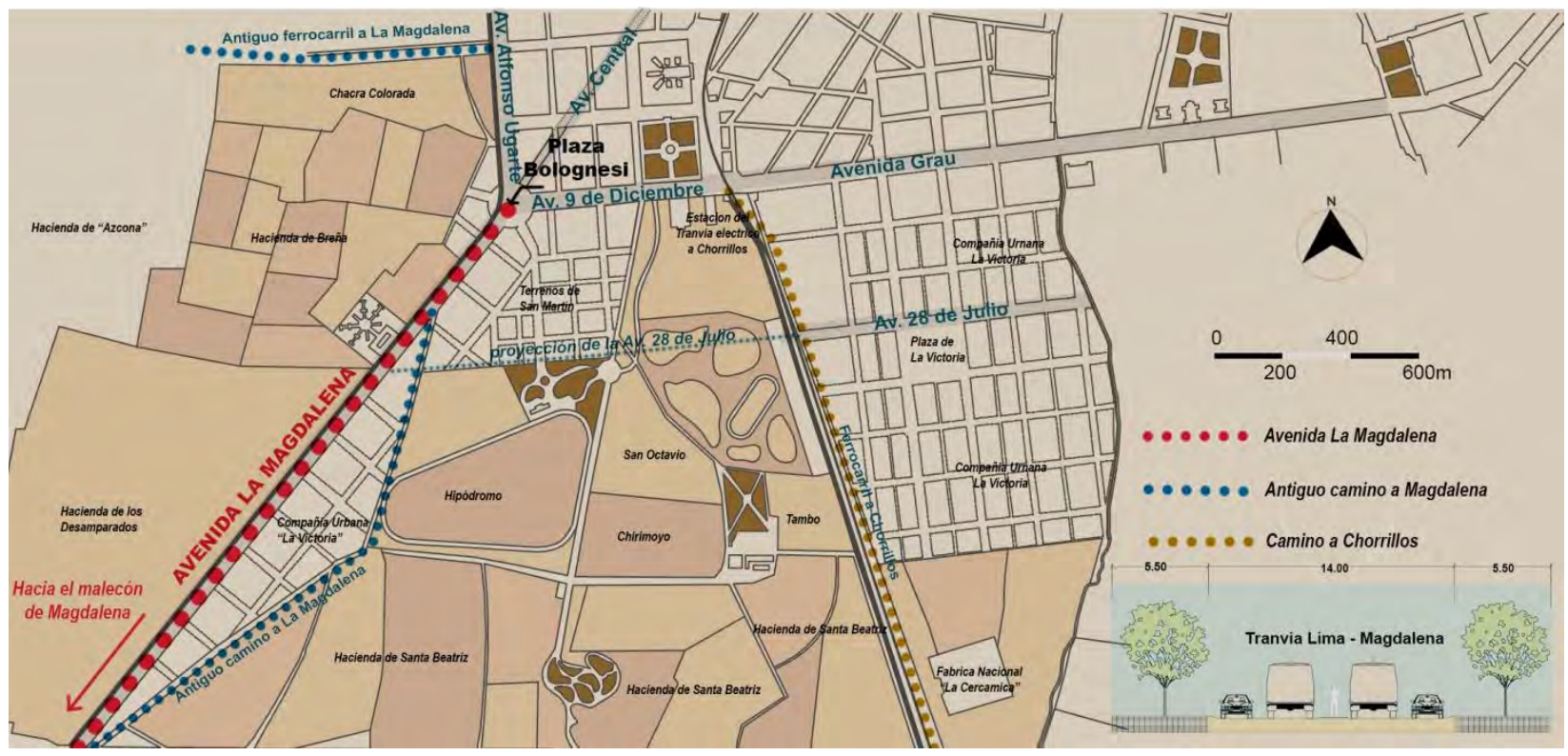

Fuente: Elaboración propia en base a

(Basurco, 1904), (Diario oficial El Peruano,1899: 106)

Mientras se construyó esta obra, de manera paralela, el Estado recibió propuestas para la concesión del tranvía Lima-La Magdalena. (Diario oficial El Peruano, 1899 á, 15 febrero:119) La intención fue culminar la obra e implementar inmediatamente el servicio de ferrocarril. Finalmente se construyó desde el óvalo Bolognesi hasta el malecón de La Magdalena (Plano de Lima del año de 1935 elaborado por el sistema de fotogrametría por el Servicio del Ejercito) (Gunther, 1983, Lamina25). Para ese año la avenida la Magdalena tomó el nombre de avenida Brasil. Esta obra fue presupuestada por el Gobierno con dinero proveniente del "Presupuesto Departamental de Lima" emitido a través del Ministerio de Fomento. (Diario oficial El Peruano á, 24 junio: 582). Durante el proceso de ejecución se realizaron expropiaciones a los fundos ubicados en el trazo de la avenida (Basurco,1904). Los permisos para la ejecución de la obra fueron expedidos por la Municipalidad. Los trabajos de canalización y pavimentación estuvieron a cargo del ingeniero Enrique Silgado (Diario oficial El Peruano, 1899 á, 10 febrero:112). 


\section{Cuadro 4.11}

\section{Acciones ejecutadas durante la obra de la Avenida de La Magdalena (1899-1901)}

\begin{tabular}{|c|c|c|}
\hline Año & Acciones realizadas & Fuente \\
\hline 1899 & Trabajos de apertura de la avenida La Magdalena & $\begin{array}{l}\text { Diario oficial El Peruano á,8 } \\
\text { febrero,1899:104 }\end{array}$ \\
\hline 1899 & $\begin{array}{l}\text { Canalización de las acequias y pavimentación de la avenida } \\
\qquad \text { La Magdalena }\end{array}$ & $\begin{array}{l}\text { Diario oficial El Peruano á,10 } \\
\text { febrero,1899:112 }\end{array}$ \\
\hline 1899 & Propuesta para la concesión del tranvía Lima-La Magdalena & $\begin{array}{l}\text { Diario oficial El Peruano á,15 } \\
\text { febrero,1899:119 }\end{array}$ \\
\hline 1899 & $\begin{array}{l}\text { Extracción de piedra para el pavimento de la avenida de la } \\
\text { Magdalena }\end{array}$ & $\begin{array}{c}\text { Diario oficial El Peruano á,24 } \\
\text { junio, 1899:582 }\end{array}$ \\
\hline 1899 & Permiso para la construcción del tranvía Lima- La Magdalena & $\begin{array}{c}\text { Diario oficial El Peruano á,30 } \\
\text { junio, 1899:601 }\end{array}$ \\
\hline 1899 & $\begin{array}{l}\text { Trabajo de la avenida la Magdalena con presupuesto } \\
\text { aprobado de } 3,102 \text { soles }\end{array}$ & $\begin{array}{l}\text { Diario oficial El Peruano á,11 } \\
\text { diciembre,1899:628 }\end{array}$ \\
\hline 1900 & $\begin{array}{l}\text { Reconocimiento del Sr. Carlos Watson como contratista de la } \\
\text { construcción del tranvía Lima-Magdalena }\end{array}$ & $\begin{array}{l}\text { Diario oficial El Peruano á,29 } \\
\text { enero, } 1900: 116\end{array}$ \\
\hline 1900 & $\begin{array}{l}\text { Asignación de recursos para el mantenimiento de la avenida } \\
\text { de La Magdalena de } 600 \text { soles. }\end{array}$ & $\begin{array}{l}\text { Diario oficial El Peruano á,12 } \\
\text { mayo,1900:480 }\end{array}$ \\
\hline 1900 & $\begin{array}{l}\text { Asignación de recursos a José Luis Torres por parte de la } \\
\text { Dirección de Obras Públicas para cuidado y conservación de } \\
\text { la avenida de La Magdalena } 28 \text { soles semanales }\end{array}$ & $\begin{array}{l}\text { Diario oficial El Peruano á,15 } \\
\text { junio, 1900:615 }\end{array}$ \\
\hline 1900 & $\begin{array}{l}\text { Reparación de los canales transversales de la avenida de la } \\
\text { Magdalena Ing. Silgado }\end{array}$ & $\begin{array}{l}\text { Diario oficial El Peruano á,20 } \\
\text { junio, 1900:654 }\end{array}$ \\
\hline 1901 & $\begin{array}{l}\text { Utilización de la Estación de San Juan de Dios como paradero } \\
\text { del tranvía Lima-Magdalena y de los trenes que vienen de la } \\
\text { avenida Alfonso Ugarte }\end{array}$ & $\begin{array}{l}\text { Diario oficial El Peruano á,13 } \\
\text { abril,1901:305 }\end{array}$ \\
\hline
\end{tabular}

Fuente: Elaboración propia en base a Diario oficial El Peruano (1899),(1900),(1901) 
La realización de la avenida de La Magdalena tuvo las siguientes consecuencias: generó la reconfiguración del tejido urbano existente a lo largo de la avenida, activó el mercado de suelo en la zona, materializó la modernidad en este espacio de la ciudad, contribuyó a mejorar al tráfico entre los balnearios y la ciudad, inició el proceso de metropolización, aumentó el flujo vehicular y peatonal a los balnearios, aumentó el precio de los terrenos a ambos lados de esta vía, se produjo un ensanche de la ciudad hasta la avenida 28 de Julio con la urbanización de La Victoria ${ }^{125}$ la cual se convirtió en la nueva periferia. Además, al finalizar el gobierno del presidente Piérola, se encontraban en ejecución la apertura de las avenidas centrales y la construcción de nuevas edificaciones públicas como el colegio Guadalupe, el nuevo Teatro de Lima, que mostraron la materialización de la modernidad urbana en la ciudad. Sin embargo, aunque la ciudad se había recuperado económicamente, era necesario atender otros problemas como la salubridad que afectaba a la población que vivía en el centro.

\subsubsection{El gobierno de Eduardo López de Romaña y la inversión privada en la urbanización de la periferia (1899-1903)}

En el año 1899 asumió la presidencia el ingeniero Eduardo López de Romaña Alvizuri. ${ }^{126}$ Sus principales objetivos fueron: Consolidar la economía con una política de exportación, la estabilización del gasto público, buscar mayores rentas para el Estado Peruano e incentivar a las empresas privadas para invertir en Lima (Basadre: 2014, tomoXI: 276). En lo administrativo buscó mejorar el control de las rentas del Estado para estabilizar la moneda (Basadre: 2014, tomoXI:276). En lo educativo: "apoyar a la instrucción primaria y mejorar

\footnotetext{
${ }^{125}$ Según Tizón y Bueno "El año 1898 se realizó un corte en el Paseo Colón cuya primitiva idea, justo es que conste alguna vez, se debió al señor Guevara, ingeniero Municipal entonces; que realizó parte del plan de Sada, uniendo las dos grandes ramas de la avenida de Circunvalación en la que después fue titulada la plaza Bolognesi, y la apertura de la avenida Piérola por iniciativa del mandatario del mismo nombre, abrieron verdaderamente la segunda era del ensanche de Lima. Casi simultáneamente la compañía anónima La Victoria urbanizaba la Chácara de ese nombre con $747,318 \mathrm{~m} 2$. De los que 268.513 se destinaron a calles y el resto ósea 478.805 se vendió a particulares para su urbanización. Puede decirse que fue la primera vez que salía del perímetro de las antiguas murallas que mando construir el duque de Palata", “El Ensanche de Lima”, Tizón y Bueno, Lima, 1906, pp.08-09.
}

126 Jorge Basadre dice, "Eduardo de Romaña Alvizuri.- El primer presidente del Perú de profesión ingeniero. Se educó en Stoneyhurts Inglaterra y ostentaba un título en el King College de Londres. Profesional distinguido encontrado trabajo en Inglaterra y el Brasil". "Historia de la Republica del Perú 1822-1933-tomo XI", Ed. El Comercio, Lima, pp.230 
la salubridad en la escuela pública. En lo social, apoyo a la inmigración extranjera como un elemento transformador de la población" (Diario oficial El Peruano á, 9 setiembre, 1899:277-278). Durante este periodo el gobierno realizó las obras públicas conjuntando la intervención de la Municipalidad, entonces a cargo del alcalde Federico Elguera, la Dirección de Obras del Ministerio de Fomento y la Junta Departamental. 
Cuadro 4.12

Obras públicas durante el periodo del presidente Eduardo López de Romaña (1899-1901)

\begin{tabular}{|c|c|c|c|}
\hline Año & Obra & Ejecutor & Fuente \\
\hline 1899 & $\begin{array}{c}\text { Trabajos de canalización de las } \\
\text { acequias transversales de la avenida } \\
\text { de La Magdalena }\end{array}$ & $\begin{array}{l}\text { Dirección de Obras } \\
\text { Públicas e Irrigación }\end{array}$ & $\begin{array}{c}\text { Diario oficial } \\
\text { El Peruano á,16 } \\
\text { setiembre,1899:323 }\end{array}$ \\
\hline 1899 & $\begin{array}{l}\text { Obras de construcción del colegio de } \\
\text { Nuestra Señora de Guadalupe }\end{array}$ & $\begin{array}{l}\text { Dirección de Obras } \\
\text { Públicas e Irrigación }\end{array}$ & $\begin{array}{c}\text { Diario oficial } \\
\text { El Peruano á,16 } \\
\text { setiembre,1899:323 }\end{array}$ \\
\hline 1899 & $\begin{array}{l}\text { Contrato para el alumbrado eléctrico de } \\
\text { la ciudad de Lima con el señor Forbes }\end{array}$ & Municipalidad & $\begin{array}{c}\text { Diario oficial } \\
\text { El Peruano á,16 } \\
\text { diciembre, } 1899: 658-660\end{array}$ \\
\hline 1900 & $\begin{array}{l}\text { Dotación de agua para la Cárcel de } \\
\text { Guadalupe y el Palacio de Justicia }\end{array}$ & $\begin{array}{l}\text { Dirección de Obras } \\
\text { Públicas e Irrigación }\end{array}$ & $\begin{array}{l}\text { Diario oficial } \\
\text { El Peruano á, } 20 \\
\text { abril,1900:400 }\end{array}$ \\
\hline 1900 & $\begin{array}{l}\text { La empresa de ferrocarril Lima- } \\
\text { Chorrillos y al Callao cobro de dinero al } \\
\text { Estado por servicios prestados }\end{array}$ & $\begin{array}{l}\text { Dirección de Obras } \\
\text { Públicas e Irrigación }\end{array}$ & $\begin{array}{l}\text { Diario oficial El peruano } \\
\text { á,20 junio, } 1900: 654\end{array}$ \\
\hline 1901 & $\begin{array}{l}\text { Proyecto para el nuevo Hospital de } \\
\text { Insanos }\end{array}$ & $\begin{array}{l}\text { Dirección de Obras } \\
\text { Públicas e Irrigación }\end{array}$ & $\begin{array}{l}\text { Diario oficial } \\
\text { El Peruano á,13 } \\
\text { abril,1901:306 }\end{array}$ \\
\hline 1901 & $\begin{array}{l}\text { Colocación de la estatua de Bolognesi } \\
\text { en el ovalo del mismo nombre }\end{array}$ & $\begin{array}{l}\text { Dirección de Obras } \\
\text { Públicas e Irrigación }\end{array}$ & $\begin{array}{c}\text { Diario oficial } \\
\text { El Peruano á,17 } \\
\text { mayo,1901:531 }\end{array}$ \\
\hline 1901 & $\begin{array}{l}\text { Construcción de la Escuela de } \\
\text { Medicina }\end{array}$ & $\begin{array}{l}\text { Dirección de Obras } \\
\text { Públicas e Irrigación }\end{array}$ & $\begin{array}{l}\text { Diario oficial } \\
\text { El Peruano á,10 } \\
\text { junio, } 1901: 675\end{array}$ \\
\hline 1901 & Plazuelas de Recoleta y Bolognesi & Municipalidad & $\begin{array}{c}\text { Basadre,2014:tomoXII, } \\
\text { 100-101 }\end{array}$ \\
\hline 1901 & Intervino el Tajamar & Municipalidad & $\begin{array}{c}\text { Basadre,2014:tomoXII, } \\
\text { 100-101 }\end{array}$ \\
\hline 1902 & Agua potable para el Callao & $\begin{array}{l}\text { Dirección de Obras } \\
\text { Públicas e Irrigación }\end{array}$ & $\begin{array}{l}\text { Diario oficial } \\
\text { El peruano á,08 } \\
\text { julio, } 1902: 55\end{array}$ \\
\hline 1903 & $\begin{array}{l}\text { Trazo del tranvía de tracción eléctrica } \\
\text { Lima-Chorrillos }\end{array}$ & $\begin{array}{l}\text { Dirección de Obras } \\
\text { Públicas e Irrigación }\end{array}$ & $\begin{array}{l}\text { Diario oficial El peruano } \\
\text { á,30 enero, } 1903: 190\end{array}$ \\
\hline
\end{tabular}




\begin{tabular}{|c|c|c|c|}
\hline Año & Obra & Ejecutor & Fuente \\
\hline 1903 & $\begin{array}{l}\text { Alineación de la nueva avenida "La } \\
\text { Industria" }\end{array}$ & $\begin{array}{l}\text { Dirección de } \\
\text { Obras Públicas e } \\
\text { Irrigación }\end{array}$ & $\begin{array}{c}\text { Diario oficial } \\
\text { El Peruano á,2 } \\
\text { marzo,1903:375 }\end{array}$ \\
\hline 1903 & $\begin{array}{l}\text { Expropiación del fundo "Barboncito" de } \\
\text { propiedad de Antonio Dapello para la } \\
\text { construcción del tranvía Lima-Chorrillos }\end{array}$ & $\begin{array}{l}\text { Dirección de } \\
\text { Obras Públicas e } \\
\text { Irrigación }\end{array}$ & $\begin{array}{c}\text { Diario oficial } \\
\text { El Peruano á,20 } \\
\text { junio,1903:1078 }\end{array}$ \\
\hline 1903 & $\begin{array}{c}\text { Expropiación del Fundo "Surquillo" del } \\
\text { Convento de la Merced Dominicos para } \\
\text { la construcción de tranvía eléctrico } \\
\text { Lima-Chorrillos }\end{array}$ & $\begin{array}{l}\text { Dirección de } \\
\text { Obras Públicas e } \\
\text { Irrigación }\end{array}$ & $\begin{array}{l}\text { Diario oficial } \\
\text { El Peruano á,23 } \\
\text { junio,1903:1095 }\end{array}$ \\
\hline 1903 & $\begin{array}{c}\text { Concesión otorgada por la } \\
\text { Municipalidad del Callao al sindicato } \\
\text { para la explotación de tranvía Lima- } \\
\text { Callao } \\
\end{array}$ & $\begin{array}{l}\text { Dirección de } \\
\text { Obras Públicas e } \\
\text { Irrigación }\end{array}$ & $\begin{array}{l}\text { Diario oficial } \\
\text { El Peruano á,26 } \\
\text { junio,1903:1118 }\end{array}$ \\
\hline 1903 & $\begin{array}{c}\text { Agua potable para la Magdalena Vieja } \\
\text { y Magdalena del Mar }\end{array}$ & $\begin{array}{l}\text { Dirección de } \\
\text { Obras Públicas e } \\
\text { Irrigación }\end{array}$ & $\begin{array}{l}\text { Diario oficial } \\
\text { El Peruano á,20 } \\
\text { julio,1903:131 }\end{array}$ \\
\hline 1903 & $\begin{array}{c}\text { Elaboración del Plano de Ensanche } \\
\text { comprendidas entre el Palacio de la } \\
\text { Exposición, la Plaza Bolognesi y la } \\
\text { cancha de carreras }\end{array}$ & Municipalidad & $\begin{array}{c}\text { Actas del Consejo Municipal } \\
\text { de Lima,1903:69 }\end{array}$ \\
\hline 1903 & $\begin{array}{l}\text { Canalización de la acequia de de Santa } \\
\text { Beatriz }\end{array}$ & Municipalidad & $\begin{array}{c}\text { Actas del Consejo Municipal } \\
\text { de Lima,1903:01 }\end{array}$ \\
\hline 1903 & Canalización de la avenida Grau & $\begin{array}{l}\text { Municipalidad y el } \\
\text { Gobierno }\end{array}$ & $\begin{array}{c}\text { Actas del Consejo Municipal } \\
\text { de Lima,1903:20 }\end{array}$ \\
\hline 1903 & Tranvía eléctrico de Lima a Chorrillos & Municipalidad & $\begin{array}{c}\text { Actas del Consejo Municipal } \\
\text { de Lima,1903:24 }\end{array}$ \\
\hline 1903 & $\begin{array}{l}\text { Prohibición de construcciones en la } \\
\text { calle Chota }\end{array}$ & Municipalidad & $\begin{array}{c}\text { Actas del Consejo Municipal } \\
\text { de Lima,1903:51 }\end{array}$ \\
\hline 1903 & Alumbrado en la plaza Bolognesi & Municipalidad & $\begin{array}{c}\text { Actas del Consejo Municipal } \\
\text { de Lima,1903:40 }\end{array}$ \\
\hline 1903 & Canalización del barrio La Colmena & Municipalidad & $\begin{array}{c}\text { Actas del Consejo Municipal } \\
\text { de Lima,1903:284 }\end{array}$ \\
\hline 1903 & Ensanche del antiguo teatro principal & Municipalidad & $\begin{array}{l}\text { Actas del (Consejo Municipal } \\
\text { de Lima,1903:60 }\end{array}$ \\
\hline
\end{tabular}

Fuente: Elaboración propia en base a Diario oficial El Peruano (1899),(1900),(1901),(1902) (1903) y Actas del Consejo Municipal de Lima (1903), Basadre (2014, p. 100-101) 
El presidente López de Romaña se preocupó por mejorar la infraestructura de la ciudad, como la construcción de las líneas del tranvía que conectaran la ciudad. Para ello expropió una serie de terrenos en la ciudad. También se preocupó de la mejora y construcción de edificios públicos continuando la obra de su predecesor. La obra pública realizada por el alcalde Federico Elguera ${ }^{127}$ fue posible gracias al manejo de las rentas municipales y a las donaciones de las Instituciones de la ciudad, como el Jockey Club $^{128}$ (Actas del Consejo Municipal, 1903:499). Gracias a estos fondos se mejoró el equipamiento urbano de la ciudad. Por su parte, el gobierno realizó obras de infraestructura básica y mejoró la conexión de Lima-Chorrillos, Lima-La Magdalena y LimaCallao mediante los ferrocarriles, lo que permitiría un mayor flujo vehicular entre Lima y los balnearios. El año 1902 se emitió el Decreto Supremo de Nuevas Poblaciones donde se establecieron los lineamientos para el ensanche de los balnearios y el trazo de las nuevas calles, las edificaciones, públicas, plazas. También se autorizó a la Municipalidad la expropiación para la apertura de calles fijadas en los proyectos (Diario oficial El Peruano á, 17 setiembre, 1902) facultando a la Municipalidad el control del crecimiento urbano en los balnearios.

En esa época aumentó la actividad comercial y para evitar fraudes y especulación, permitiendo el aumento de las inversiones en la ciudad, se implementó El Registro Mercantil (Diario oficial El Peruano á, 24 Abril, 1902:754-756) el cual legalizó los bienes de las empresas nacionales y extranjeras que se encontraban operando en la ciudad. Así también buscó garantizar la legalidad de las transacciones y seguridad de los inversionistas, permitiendo el crecimiento del mercado de suelo y el mercado financiero.

Aunque durante el gobierno del presidente Piérola se realizó el proceso de saneamiento legal de la periferia, aun quedaron pendientes de regularización terrenos que pertenecían al Estado Peruano que no habían sido recuperados. Por este motivo, el Estado nombró al abogado Juan Francisco Pazos para la

\footnotetext{
127 Según Basadre don Federico Elguera nació en Lima el 1 de julio de 1860 educado en Paris y más tarde en la Universidad de San Marcos, se inició como periodista de la Opinión Nación. "Historia General del Perú 1821-1933" tomo XII, Ed. El Comercio 2014, Lima.pp.100.

128 Según las actas del Consejo Municipal "Para la obra de canalización de la acequia cerca del Palacio de la Exposición la Municipalidad aportó con dos mil soles, la Junta Departamental con dos mil soles y los trabajos estaban a cargo del Jockey Club", Actas de la Municipalidad de Lima, Año 1903, pp.499.
} 
recuperación de dichos terrenos por un tiempo de cuatro años, debiéndose seguir juicios con las personas particulares que se apropiaron ilícitamente de los terrenos del fisco (Diario oficial El Peruano á, 13 abril,1901:305). El objetivo era que los terrenos recuperados fueran vendidos o reservados para el Estado para futuros proyectos. Sin embargo, según la Ley del 22 de diciembre de 1888 era necesario que pasaran diez años para que un bien o renta del fisco fuera denunciado. Fue por esta razón que desde el 1882 se reclamó el cumplimiento del contrato que se firmó con Enrique Meiggs. Sin embargo, no se logró ningún resultado (Diario oficial El Peruano á, 10 junio, 1901:676). Para ese momento, los problemas legales sobre la tenencia de los terrenos de la muralla tuvieron las siguientes consecuencias: no fue posible seguir con el Plan de Ensanche del Ingeniero Sada, los inversionistas no pudieron intervenir al este de la ciudad, se generó un desbalance en la urbanización del poniente y oriente de la periferia y el desorden en la urbanización al este de la ciudad se consolidó, se produjo un crecimiento urbano desigual y los espacios ocupados de manera informal ingresaron en un proceso de deterioro. (Tizón y Bueno, 1906:15).

Desde una mirada antropológica "los asentamientos pueden ser definidos por "la ocupación de tierras de un modo considerado ilegal y protagonizados por aquellos habitantes que quedaron al margen del mercado de tierras y de toda política social" (Carcedo, 2013:39) ${ }^{129}$. En Lima aunque es necesaria una mejor profundización al respecto, los pobladores que ocuparon la periferia de manera ilegal fueron aquellos que buscaron una mejor calidad de vida fuera de las inmundicias del centro de la ciudad, aunque tenían poder adquisitivo para comprar al mercado ilegal de suelo.

\footnotetext{
${ }^{129}$ Carcedo, "La ocupación informal del suelo urbano como estrategia de supervivencia: un estudio de caso en la ciudad de Santa Rosa La Pampa". En: Huellas N 17, 2013, Ed. Facultad de Ciencias Humanas Universidad de la Pampa, Argentina, pp.35-53.
} 


\subsubsection{La Ley de Expropiación de 1900 y la inversión privada en la urbanización de la periferia.}

En el año 1900 el presidente Eduardo López de Romaña expidió la Ley General de Expropiaciones del 12 de noviembre de $1900^{130}$ (Diario oficial El Peruano á,17 noviembre:298) para permitir la apertura de las avenidas, y de esa manera, lograr la expansión de la ciudad, reiniciar la urbanización ${ }^{131}$ en la periferia y continuar la obra del presidente anterior. "Sin embargo, esta vez el proceso estuvo a cargo de los inversionistas privados, quienes fueron beneficiados por el Estado Peruano con la aplicación de esta Ley, ya que facultaba a una corporación, empresa o concesionario, la expropiación de una propiedad con la autorización del Estado previa revisión del expediente del proyecto a realizar" (Diario oficial El Peruano á,17 noviembre:298).

En este momento el estado decidió aplicar una Ley para que la inversión privada pudiera intervenir la periferia, algo similar a las leyes de expropiación de tiempos del fraccionador Meiggs, quien buscó lograr un crecimiento empresarial con la mercantilización de la tierra y el apoyo del Estado. En este segundo momento el proceso especulativo fue más salvaje, debido a que estaba avalado por la clase social dominante y porque en esta oportunidad ya no se trató de un proyecto mixto de vivienda público-privado, sino más bien, la oferta de vivienda mercancía le dio el protagonismo al capital privado basado en una dinámica de acumulación de capital legitimado por el Estado Peruano y la élite dominante (De Mattos,2016:28). Los gobiernos buscaron recuperar los territorios de la periferia ocupados ilegalmente con la idea de remercantilizarlos y retomar los procesos de urbanización, especialmente del espacio más cercano al nuevo centro propuesto por el Plan de Ensanche, que se convirtió

\footnotetext{
${ }^{130}$ La Ley de expropiación en los art.2 y 4 dice“.- Art 2.-Se considera obra pública toda obra decretada, según el caso por el Congreso o el ejecutivo. Art.4.-Se consideran también de utilidad pública, aquellas para que el Poder Ejecutivo autoriza a una Corporación Nacional a una empresa o a un Concesionario". Diario Oficial El Peruano, 17 de noviembre de 1900,(Num.54), pp. 298-300.

${ }^{131}$ Al respecto de la Ley de Expropiación de 1903 el ingeniero Ricardo Tizón y Bueno dice: "Esa ley contiene en su totalidad disposiciones atentatorias al derecho privado. Abrevia trámites niega ciertos derechos a los propietarios y reduce a limites estrechísimos la indemnización que les corresponde. La política comunal al apoyar la dación de esa Ley a creído facilitar el ensanche de la ciudad y lo que ha hecho es desprestigiarlo haciendo ver un peligro para una clase social en lo que es un beneficio para todos". "El Ensanche de Lima", Ricardo Tizón y Bueno, Año 1906, Memoria II En: Ensanche de Lima. Conferencia dada por el Socio Ricardo Tizón y Bueno En: Boletín de la Sociedad de Ingenieros del Perú. Imprenta. Sociedad de Ing. Del Perú, pp.19.
} 
en el centro del poder social en proceso de materialización. Se trató de una reafirmación del capitalismo en la ciudad mediante la intervención de la propiedad privada como la alternativa más segura, lo que llevaría al crecimiento económico y a la modernidad urbana en la ciudad.

La Ley de Expropiación, fue una ley que dio el poder del Estado a los intereses privados, produciéndose una forma muy lucrativa de comercialización de suelo, nuevamente en la periferia (Jiménez, 1993:03) ${ }^{132}$. En la práctica se afectaba al propietario, debido a que el monto de las indemnizaciones estaba a cargo del urbanizador. Además, no existió un control de la Municipalidad sobre la urbanización propuesta por las empresas, lo que ocasionó un desorden en la periferia. Por ejemplo los terrenos cercanos al ovalo Bolognesi, que estaban reservados para el fisco y que fueron encargados al ingeniero Felipe Arancivia para su urbanización, tal como lo señala Tizón y Bueno:

\footnotetext{
"Vino después la venta que el gobierno del Sr. Romaña hizo de los terrenos que en las vecindades de la Plaza Bolognesi se había reservado anteriormente el fisco para diversas dependencias oficiales; y con esa oportunidad el ingeniero de estado Sr. Felipe Arancivia levantó el plano de esos terrenos y formuló el Plan correspondiente. Con la respectiva división de estos terrenos en lotes y división de calles" (Tizón y Bueno, 1906:9).
}

Los terrenos en cuestión finalmente fueron urbanizados por la inversión privada, debido a la sesión de uso de estos terrenos por parte del Estado Peruano, a cambio de la ejecución de la obra de las avenidas centrales. Además, en este momento el negocio inmobiliario era muy atractivo debido a que los inversionistas se adjudicaban grandes cantidades de terreno a precio de expropiación, poniendo en práctica una especulación urbana que significaría un negocio superior a cualquier ese momento. La aplicación de la Ley tuvo las siguientes consecuencias: abuso de los inversionistas privados por el pago de las indemnizaciones de los terrenos expropiados a particulares, proyectos de urbanización sin la aprobación de la Municipalidad, urbanizaciones sin equipamiento ni servicios básicos, desplazamiento de la población afectada a otras zonas, mal uso de los inversionistas sobre la distribución del suelo en la periferia y la reestructuración social de la población que vivía en esta zona. Fue

\footnotetext{
132 Según Jiménez "En la primera década del siglo XX se dieron en México los más avanzados mecanismos inmobiliarios para desarrollar la ciudad en beneficio de los anteriores mencionados. Sin embargo, la desenvoltura de la promoción descontrolada y altamente lucrativa de la comercialización del suelo fue interrumpida por la revolución mexicana" La traza del poder historia y política de los negocios urbanos en el Distrito Federal: de sus orígenes a la desaparición del Ayuntamiento (1824-1928). Ed.Codex, 1993, México.pp.3.
} 
a ley de la selva. "Sin embargo, en este caso sí existió una intervención de regulación por parte de la Municipalidad, como consecuencia de la mala práctica urbana por parte de los inversionistas privados, si bien no se pudo solucionar el desorden de la urbanización debido a que ya se había concretado en gran parte en la periferia". (Tizón y Bueno, 1906:15).

\subsubsection{El caso de la Avenida Interior o La Colmena (1901)}

Un ejemplo de la aplicación de la Ley de Expropiación fue la construcción de la avenida Interior, retomada por el gobierno del presidente Eduardo López de Romaña con el nombre de avenida La Colmena ó Nicolás de Piérola (Basurco, 1904). La obra estuvo a cargo de la empresa privada Sociedad Anónima La Colmena, la cual procedió de inicio a expropiar los terrenos a particulares.

La nueva avenida tuvo 2,260 metros de largo por veinticinco de ancho e iniciaba en el óvalo Dos de Mayo y terminaba en la avenida Grau (Diario oficial El Peruano á, 27 agosto,1901:339). Sin embargo, solo se ejecutó hasta el empalme con el Jirón de la Unión. A lo largo de esta avenida se ubicaron los bancos: Banco Perú Londres, Banco Providencia. También se instalaron ahí viviendas para la élite que no se mudó a vivir a los balnearios del sur." ${ }^{\text {"133 }}$ (Estatutos de La Colmena, 1902:3-8). Su apertura fue aprobada según Resolución de Alcadia del 17 de abril de 1901 (Diario oficial El Peruano, 1901 a, agosto: 339).

Para el gobierno del presidente don Eduardo López de Romaña esta avenida materializó la modernidad que vivía la ciudad. En la práctica, fue un espacio ocupado por los miembros de la élite durante la mañana y luego, en la noche, volvían a su residencias ubicadas en los balnearios del sur, usando la nueva avenida de La Magdalena o la carretera Lima-Miraflores. De esta manera, se legalizó un espacio de segregación espacial diseñado para la aristocracia de la época. Las casas en este caso eran de estilo ecléctico de dos niveles contaban con varias recamaras en la planta alta y un enorme sala para los eventos sociales de la élite en la planta baja. La zona de servicio por lo general estaba

\footnotetext{
${ }^{133}$ La Compañía Urbanizadoras La Colmena ofreció lotes de terrenos para vivienda pagaderos en 5 a 20 años vía préstamo hipotecario, “Estatutos de La Colmena” Ed. Librería Imprenta Gil, Lima, Año,1902, pp.3-8.
} 
en el sótano o en la parte posterior de la planta baja. Contaban con un jardín interior.

\section{Foto 4.1}

\section{Avenida La Colmena en el año 1920}

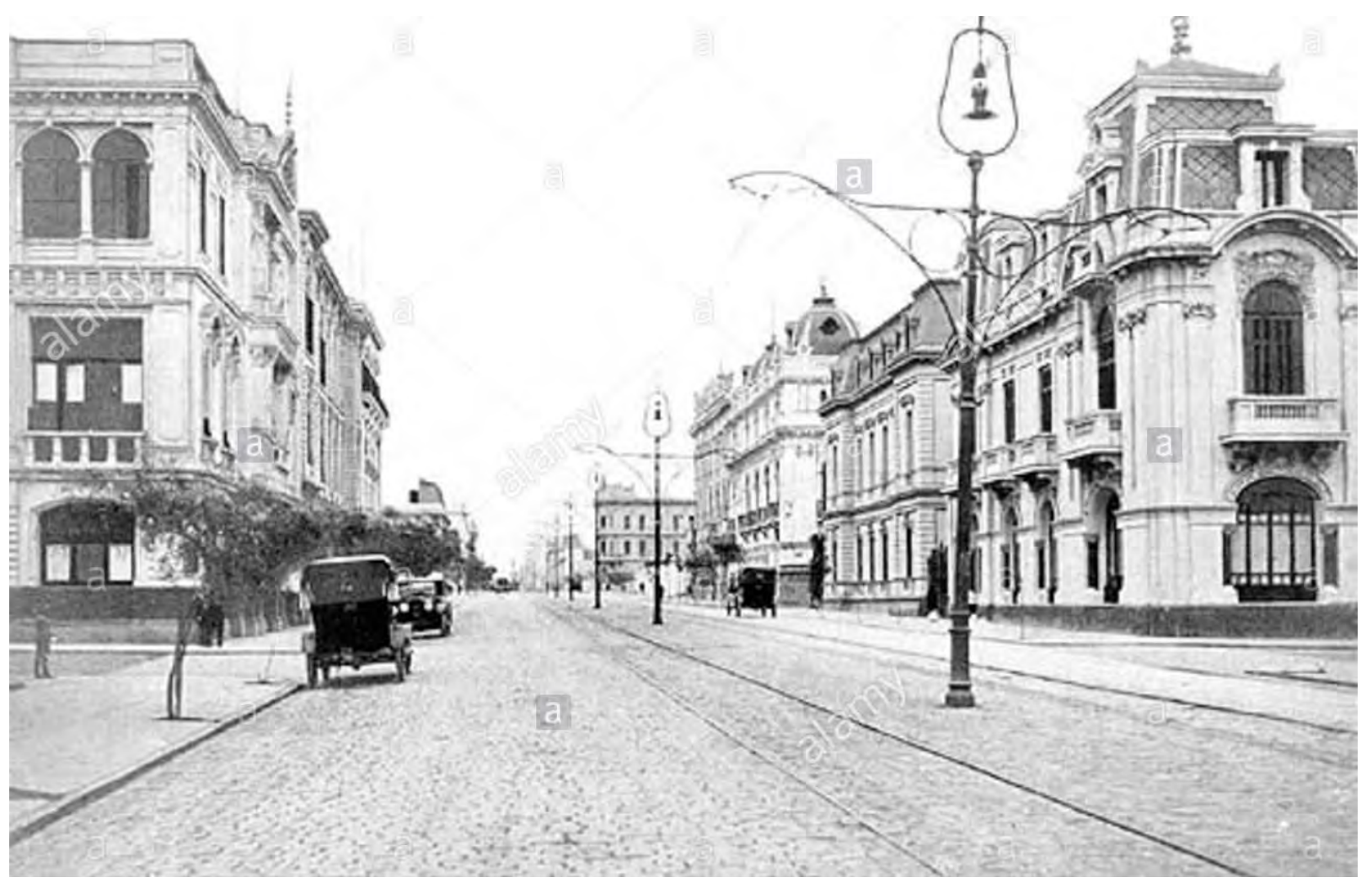

Fuente: La Avenida La Colmena o Nicolás de Piérola el año 1920

lalimaquesefue.blogspot.com/2011/02/foto-ano-1920-avenida-la-colmena.html.

Al final de este periodo la ciudad registró una intensa actividad en materia de inversión privada, específicamente con la consolidación de los caminos que llegaban a este nuevo centro a través del servicio de tranvía y ferrocarril. Para el año 1902 la aplicación de la Ley de Expropiación había generado tal desorden en la urbanización en la periferia que hizo necesaria la intervención de la Municipalidad y el Estado Peruano para controlarlo. Por este motivo el gobierno emitió el Decreto Supremo del 26 de setiembre de 1902 donde se ordenó lo siguiente:

"Las municipalidades de la república harán levantar el plano de sus jurisdicciones, en el que deben quedar bien determinadas por colores y signos convencionales, la parte cubierta por techo, el ensanche, prolongación o nueva delineación de calles, la parte que sea conveniente cortar para regularizarla, mejorarlas, abrir comunicación, establecer, plazas, edificios públicos,etc,etc" (Tizón y Bueno,1906:4). 
Levantar el plano de esta zona, como lo indicaba la instrucción, hubiera posibilitado tener un documento gráfico que permitiera conocer la magnitud del desorden en la periferia. Sin embargo, plano no lo realizó la Municipalidad de Lima (Tizón y Bueno, 1906:4-5).

El desorden en la urbanización de la periferia ocasionó los siguientes problemas: calles estrechas entre manzanas, falta de servicios básicos y equipamiento, islas urbanas que generaron más urbanización informal a la ya existente del periodo de Meiggs, apropiación de espacios comunes en las urbanizaciones, falta de espacios públicos, áreas verdes y falta de títulos de propiedad de los nuevos propietarios, lo que provocó enfrentamientos entre los propietarios y las empresas urbanizadoras. Ante esta problemática el Estado Peruano expidió la Ley de Registro de Predios el 04 de octubre de 1902 (Diario oficial El Peruano, 1902 a, octubre: 689-690) y creó la Junta de Vigilancia de Registro de Predios buscando un mejor control de las propiedades que poseían las urbanizadoras y las que ofrecían a la venta.

\subsubsection{El gobierno del presidente Manuel Candamo y la nueva Ley de Expropiación (1903-1904)}

En el año 1903 asumió la presidencia el presidente Manuel Candamo (Basadre, 2014, tomoXII: 22). En lo social, buscó incrementar la seguridad en la ciudad aumentando el número de policías y mediante la construcción del cuartel de gendarmería en la calle Sacramento de Santa Ana ubicado en el centro (Diario oficial El peruano á, 31 julio, 1903:163). "En lo administrativo, buscó la reorganización del Ministerio de Gobierno en asuntos de orden político, policial y administrativo para hacerla más eficiente. En lo económico, apoyó el cobró de los censos y capellanías para la subsistencia de la Iglesia, realizó reformas arancelarias para una mayor recaudación, apoyó a la agricultura y a la minería para aumentar los ingresos del Estado Peruano" (Diario oficial El Peruano á, 31 julio, 1903:162-168). 


\section{Cuadro 4.13}

\section{Obras públicas durante el periodo del presidente Manuel Candamo y del gobierno provisional a cargo de presidente Serapio Calderón (1903-1904)}

\begin{tabular}{|c|c|c|c|}
\hline Año & Obra & Ejecutor & \multicolumn{1}{c|}{ Fuente } \\
\hline 1903 & $\begin{array}{c}\text { Expropiación de terrenos de la } \\
\text { hacienda "Mirones" para la } \\
\text { construcción del tranvía } \\
\text { eléctrico Lima-Callao }\end{array}$ & $\begin{array}{c}\text { Dirección de Obras } \\
\text { Públicas e Irrigación }\end{array}$ & $\begin{array}{l}\text { Diario oficial El Peruano } \\
\text { á,16 diciembre,1903:908 }\end{array}$ \\
\hline 1903 & $\begin{array}{c}\text { Derechos de la empresa de } \\
\text { agua potable y desagüe de } \\
\text { Barranco }\end{array}$ & $\begin{array}{c}\text { Dirección de Obras } \\
\text { Públicas e Irrigación }\end{array}$ & $\begin{array}{l}\text { Diario oficial El Peruano } \\
\text { á,16 diciembre,1903:908 }\end{array}$ \\
\hline 1904 & $\begin{array}{c}\text { Monumento a Bolognesi } \\
\text { Dirección de Obras } \\
\text { Públicas e Irrigación }\end{array}$ & $\begin{array}{l}\text { Diario oficial El Peruano } \\
\text { á,8 enero,1904:40 }\end{array}$ \\
\hline 1904 & $\begin{array}{c}\text { Reglamento de la Escuela } \\
\text { Normal de Mujeres de Lima } \\
\text { Cruzamiento de líneas férreas de Obras } \\
\text { entre Lima y Miraflores con } \\
\text { líneas existentes en su trayecto }\end{array}$ & $\begin{array}{c}\text { Dirección de Obras } \\
\text { Públicas e Irrigación }\end{array}$ & $\begin{array}{l}\text { Diario oficial El Peruano } \\
\text { á,26 marzo,1904:524 }\end{array}$ \\
\hline $\begin{array}{c}\text { Diario oficial El Peruano } \\
\text { á,29 marzo,1904:541 }\end{array}$ & \\
\hline
\end{tabular}

Fuente: Elaboración propia en base a Diario oficial EI Peruano (1903), (1904)

En este periodo se continuó la obra de infraestructura y equipamiento en la ciudad y mejoró la conexión con los balnearios y el Callao con la construcción de más ferrocarriles.

La nueva Ley de Expropiación de 1903 (Diario oficial El Peruano, 1903 á, noviembre: 679$)^{134}$ permitió mayores atribuciones a los inversionistas privados que urbanizaban la periferia y pudieron expropiar un mayor número de terrenos y acelerar la urbanización al sur-este de la ciudad. Esta Ley buscó implementar un procedimiento más rápido para la expropiación de las propiedades a cargo de las urbanizadoras, con el aval del Estado, con la finalidad de ejecutar la obra

\footnotetext{
${ }^{134}$ La Ley de Expropiación del 23 de octubre de 1903 en el Art 9. dice “Tienen personería para expropiar, el Estado, la Municipalidad de Lima o la empresa autorizada para la apertura de las avenidas o calles conexas, según fuese el sujeto que los haga por su cuenta". Diario Oficial El peruano, sábado 7 de noviembre de 1903, (Núm.103), pp.679.
} 
pública, continuar con la urbanización en la periferia a cargo de la inversión privada y continuar con la apertura de más avenidas centrales en el menor tiempo posible, materializando la modernidad a favor de las empresas inmobiliarias.

Según esta Ley, el Estado Peruano, la Municipalidad y las empresas urbanizadoras estaban autorizadas para expropiar terrenos y podían fijar el precio sin valuación previa. Este procedimiento trajo como consecuencia, como era de esperar, el enfrentamiento legal entre las urbanizadoras y los propietarios, principalmente por el monto de las expropiaciones. Además, generó retrasos en la ejecución de las avenidas y, por consiguiente, retrasos en la urbanización de la periferia. Muchos propietarios se vieron perjudicados por los precios de expropiación que pagaron los urbanizadores. Lo cierto es que las empresas se enriquecieron adquiriendo extensiones de terrenos a precio de expropiación que luego urbanizaron, produciéndose un proceso especulativo de compra de suelo con el aval del Estado. Al respecto el ingeniero Tizón y Bueno expresó su opinión:

"¿Ya es tiempo de que la Municipalidad intervenga, cuando menos para dar unidad a esos proyectos y relacionarlos con los múltiples problemas de vida urbana á que se hallan afectos, como canalización de agua, alumbrado, pavimentación, etc,etc?¿Es posible dejar por más tiempo que la iniciativa gubernativa de un lado, la municipal de otro y la de los particulares en tercer término, campeen libremente, sin que haya quien se tome el trabajo de encausarlas y darles el rumbo más provechoso para los intereses de la comunidad?" (Tizón y Bueno, 1906:15).

Más aun, con la apertura de calles al interior de la urbanización se ocasionó un desorden urbano. Fue el caso de la urbanizadoras "La Victoria" (Basurco, 1904). Para tratar de controlar el desorden y la especulación en la periferia, en el año 1903 la Municipalidad, a cargo del alcalde Federico Elguera, emitió la Ordenanza de Avenidas Interiores el 23 de octubre de 1903. En ella se prohibieron las construcciones en dos niveles, el uso de adobe y las construcciones nuevas sobre las avenidas estaban obligadas a contar con la aprobación de la Municipalidad, la fachadas exteriores debían ser de menos de 12 metros (Calle, 1906:265-266). Con la nueva ordenanza se esperaba que fuera posible controlar la apertura de calles interiores, la fragmentación de las manzanas y evitar el desorden en la urbanización. Sin embargo, el desorden continuó. Entre los años de 1898 a 1903 la siguientes empresas se 
encontraban urbanizando la periferia del sur-poniente de la ciudad: La Magdalena, Cocharcas, La Victoria, Huerta del Prado, la Colmena, Chacra Colorada, el Progreso (Urrea, 1923:164), y San Martín-Paseo Colón (Ludeña, 2005:34). Podemos advertir que los detalles del proceso de urbanización que siguieron estos fraccionamientos requieren un trabajo a profundidad con el uso de las fuentes primarias.

La ratificación de la Ley de Expropiación nos demuestra la urgencia que tenía el Estado por demostrar el progreso en la ciudad (Sánchez,2013:230) en la zona en expansión, con el objetivo que el proyecto modernizador del partido civilista tuviera una continuidad en los próximos gobiernos. Fue una muestra de que la mercantilización del suelo era el mejor camino para el crecimiento económico del país y demostrar que existía una oferta de viviendas en la zona de expansión para las clases media, conformada por comerciantes y extranjeros, empleados públicos y privados, que pudieran acceder a comprar una vivienda vía crédito hipotecario o venta directa. Parecía abrirse la oportunidad, para la población con poder adquisitivo, de mudarse del centro y mejorar su calidad de vida. Para el Estado significó poner en uso la superestructura que se venía construyendo desde el ingreso al poder del partido civilista.

Otro problema que aun no estaba solucionado por los gobiernos de turno era la salubridad en la ciudad. En el año 1904, de manera lenta, se construía el Instituto Municipal de Higiene, ubicado cerca al Palacio de la Exposición, (Consejo Municipal de Lima, 1904:295) con la finalidad de ocuparse de los problemas de salubridad en la ciudad y poder cuantificar las viviendas insalubres, controlar las epidemias y poder difundir investigaciones.

\subsubsection{El gobierno del presidente José Pardo y Barreda y el problema de la salubridad en la ciudad (1904-1908)}

De 1904 a 1908 asumió la presidencia el civilista don José Pardo y Barrera que continuó con la política de modernización de la ciudad. "En lo educativo, mejoró el equipamiento de las escuelas. Buscó apoyar los derechos laborales de la clase obrera. En obras de infraestructura, continuó con el proyecto de mejorar las vialidades mediante las obras de ferrocarriles y caminos. En lo económico, 
fomentó la industria, agricultura, minería, manufactura y comercio para aumentar la recaudación fiscal" (Diario oficial El Peruano á, 27 setiembre: 465467). 


\section{Cuadro 4.14}

\section{Obras durante el periodo del presidente José Pardo y Barrera (1904-1908)}

\begin{tabular}{|c|c|c|c|}
\hline Año & Obra & Ejecutor & Fuente \\
\hline 1904 & Refacción de la calle San Jacinto & Municipalidad & Actas de la Municipalidad,1904:447 \\
\hline 1905 & $\begin{array}{l}\text { Expropiación de terreno en el } \\
\text { distrito de Miraflores para el } \\
\text { tranvía Lima-Chorrillos }\end{array}$ & D.O.P.I & $\begin{array}{c}\text { Diario oficial El Peruano á,15 } \\
\text { junio, 1905:311-312 }\end{array}$ \\
\hline 1905 & $\begin{array}{l}\text { Entrega del segundo piso del } \\
\text { mercado de La Concepción }\end{array}$ & D.O.P.I & $\begin{array}{c}\text { Diario oficial El Peruano á,24 } \\
\text { agosto,1905:190 }\end{array}$ \\
\hline 1905 & $\begin{array}{c}\text { Aprobación del presupuesto para } \\
\text { las obras de agua potable y } \\
\text { desagüe y desecación del puerto } \\
\text { del Callao }\end{array}$ & D.O.P.I & $\begin{array}{c}\text { Diario oficial El Peruano á,30 } \\
\text { noviembre, } 1905: 511\end{array}$ \\
\hline 1905 & $\begin{array}{c}\text { Ampliación del tranvía en el } \\
\text { centro }\end{array}$ & $\begin{array}{l}\text { Ministerio de } \\
\text { Fomento }\end{array}$ & $\begin{array}{c}\text { Diario oficial El Peruano á,9 } \\
\text { agosto, 1906:60 }\end{array}$ \\
\hline 1906 & $\begin{array}{c}\text { Línea C del tranvía del Camal } \\
\text { hasta calle Santa Rosa }\end{array}$ & D.O.P.I & $\begin{array}{c}\text { Diario El Peruano } 1906 \text { á, } 31 \\
\text { agosto:87 }\end{array}$ \\
\hline 1906 & $\begin{array}{c}\text { Línea de tranvía al centro desde } \\
\text { Chorrillos hasta la calle Carrera } \\
\text { en el Jirón Lampa }\end{array}$ & D.O.P.I & $\begin{array}{l}\text { Diario oficial El Peruano } 1906 \text { á, } 9 \\
\text { agosto:60 }\end{array}$ \\
\hline 1906 & $\begin{array}{c}\text { Entrega de la línea E del tranvía } \\
\text { de Lima del Monumento Dos de } \\
\text { Mayo a la calle Buenos Aires }\end{array}$ & D.O.P.I & $\begin{array}{c}\text { Diario oficial El Peruano á,5 } \\
\text { julio, } 1906: 5\end{array}$ \\
\hline 1907 & $\begin{array}{c}\text { Modificación del trazado primitivo } \\
\text { de la segunda sección de la } \\
\text { avenida Miraflores a la } \\
\text { Magdalena }\end{array}$ & D.O.P.I & $\begin{array}{c}\text { Diario El Peruano } 1907 \text { á, } 5 \\
\text { agosto:318 }\end{array}$ \\
\hline 1907 & $\begin{array}{c}\text { Ensanche y apertura de calles } \\
\text { que aparecen en el plano de la } \\
\text { villa de Miraflores }\end{array}$ & D.O.P.I ${ }^{135}$ & $\begin{array}{c}\text { Diario El Peruano } 1907 \text { á, } 6 \\
\text { setiembre :632 }\end{array}$ \\
\hline 1908 & $\begin{array}{c}\text { Ampliación del tranvía hasta "La } \\
\text { Herradura" }\end{array}$ & $\begin{array}{c}\text { Dirección de Obras } \\
\text { Públicas e } \\
\text { Irrigación-sección } \\
\text { vías de } \\
\text { comunicación }\end{array}$ & $\begin{array}{c}\text { Diario El Peruano } 1908 \text { á, } 13 \text { marzo } \\
: 462\end{array}$ \\
\hline 1908 & $\begin{array}{l}\text { Mejoras en la penitenciaría de } \\
\text { Lima }\end{array}$ & $\begin{array}{l}\text { Ministerio de } \\
\text { Fomento }\end{array}$ & $\begin{array}{c}\text { Diario El Peruano } 1908 \text { á, } 01 \text { agosto } \\
: 222\end{array}$ \\
\hline
\end{tabular}

Elaboración propia en base a Diario oficial El Peruano,(1905),(1906),(1907) y Actas

Municipales (1904)

\footnotetext{
${ }^{135}$ D.O.P.I es Dirección de Obras Públicas e Irrigación.
} 
En este periodo se continuó con la construcción de infraestructura, servicios básicos y construcción de edificaciones, lo que significó la materialización de la modernidad urbana. De la misma manera se articularon mejor los barrios de la ciudad con la construcción de las distintas líneas del tranvía. La nueva organización de la administración al interior de los Ministerios, junto con La Nueva Ley de Expropiación contribuyó a acelerar la urbanización al sur de la ciudad y de los balnearios cercanos como Chorrillos y Miraflores.

El año 1906 el abogado Juan José Calle publicó el Diccionario de la Legislación Municipal del Perú en dos tomos. Este completo documento solo comparado con el Diccionario de la Legislación Peruana del año 1879, escrito por el abogado Francisco García Calderón, permitió que la población pudiera utilizar la reglamentación existente y que la Municipalidad tuviera un mejor control de la ciudad. Sin embargo, los urbanizadores ya habían iniciado con la lotización y venta de lotes cerca a los óvalos Dos de Mayo y Unión y solo pudo ser posible controlar el crecimiento urbano hacia el sur y sur-este y en los balnearios de Chorrillos y La Magdalena. El acelerado proceso de urbanización hacía necesaria una nueva demarcación territorial.

\subsubsection{La nueva demarcación territorial del año 1906}

El 18 de marzo de 1904 el gobierno del presidente José Pardo y Barrera implementó una nueva demarcación territorial (Portella, 1923:264-266) debido a la necesidad de brindar seguridad a las industrias ubicadas el sur de la ciudad y que estas contribuyeran con el pago de impuestos para la implementación de servicios básicos, ya que muchas de las urbanizadoras no habían cumplido con la implementación de estos, aumentando el problema de salubridad en la ciudad. La nueva demarcación se hizo efectiva según Ley 391 del 01 de diciembre de 1906 (Portella, 1923:262-263). Sin embargo, el proceso de implementación de servicios fue lento. El año 1908 los vecinos del barrio de La Victoria al sur de la ciudad esperaban acceder a los servicios básicos al ser incluidos en la nueva demarcación en los próximos años (Diario La Prensa,1908 á: 12 julio,01). A partir de entonces la ciudad quedó dividida en seis distritos, como se puede observar en el siguiente cuadro. 


\section{Cuadro 4.15}

\section{Demarcación territorial el año de 1906}

\begin{tabular}{|c|c|}
\hline Distrito & Demarcación \\
\hline A (1) & $\begin{array}{l}\text { "Puente de Piedra, esquina Desamparados, por el jirón de la Unión hasta la esquina de } \\
\text { la Merced de allí a la derecha por la avenida Monserrate hasta el río y por su orilla hasta } \\
\text { el puente de Desamparados". }\end{array}$ \\
\hline B (2) & $\begin{array}{l}\text { "Desde la esquina de Desamparados hasta la de la Merced limítrofe con el distrito A, de } \\
\text { allí por el jirón Cusco hasta la calle de Granados; y continuando por la izquierda con el } \\
\text { jirón Huanta hasta el río y por su orilla hasta Desamparados". }\end{array}$ \\
\hline C (3) & $\begin{array}{l}\text { "La esquina de siete pecados por el jirón Huanta, hasta la esquina de Granados, } \\
\text { limítrofe con el distrito } 2 \text {, y las calles de Mestas con doña Elvira hasta el } 4 \text { y de la } \\
\text { esquina de Martinette, a la derecha por la orilla del río hasta la portada de Maravillas, } \\
\text { todo el cercado por la avenida de Circunvalación hasta el Hospital Dos de Mayo". }\end{array}$ \\
\hline $\mathrm{D}(4)$ & $\begin{array}{l}\text { "Comprenderá desde la Merced por el jirón Cusco, hasta la esquina Granados limítrofe } \\
\text { con el distrito } 2 \text { y de la esquina de Mestas hasta doña Elvira jirón Huanta con el } 3 \text { y el } \\
\text { Hospital Dos de Mayo toda la avenida Grau y barrios de la Victoria hasta la esquina de } \\
\text { Sanguineti Dasso en la Plaza de la Exposición continuando a la derecha con el jirón } \\
\text { Azángaro hasta la esquina de Higuera limítrofe con el distrito 6". }\end{array}$ \\
\hline$E(5)$ & $\begin{array}{l}\text { "Este distrito conservará los límites que actualmente tiene a la derecha por el río Rímac, } \\
\text { desde Piedra Lisa hasta la portada Guía". }\end{array}$ \\
\hline$F(6)$ & $\begin{array}{l}\text { "Desde la plaza de la Unión, por el jirón Arequipa hasta la esquina de la calle Higuera; } \\
\text { continuando a la derecha por el jirón Azángaro, hasta la esquina de la avenida Grau, } \\
\text { siguiendo a la derecha por la avenida Nueve de diciembre, Paseo Colon hasta plaza } \\
\text { Bolognesi, y siempre a la derecha por la avenida Bolognesi y Alfonso Ugarte hasta la } \\
\text { plaza de la Unión". }\end{array}$ \\
\hline $\mathrm{G}(7)^{*}$ & $\begin{array}{l}\text { "Posteriormente el barrio de La Victoria con la esquina de Sanguineti y Dasso } \\
\text { conformaría el distrito siete". }\end{array}$ \\
\hline
\end{tabular}

Fuente: Elaboración propia en base a Portella (1923, pp.264-266)

La nueva demarcación territorial puso en evidencia que la expansión acelerada a cargo de las empresas urbanizadoras había generado un desbalance del proceso de urbanización entre el oriente y el poniente de la periferia de la 
ciudad, lo que hizo necesario la implementación de infraestructura básica y equipamiento. Así también, los urbanizadores privados habían expandido la ciudad hacia el sur, siendo necesario ejecutar el levantamiento de un plano catastral de la ciudad, mismo que no se había realizado a pesar del decreto supremo del año 1902 como reclamó el ingeniero Tizón y Bueno (Tizón y Bueno, 1906:5-12). El plan catastral permitiría nuevamente la elaboración de un plan integral de ensanche o la actualización del Plan de Ensanche elaborado por ingeniero Sada. Por ejemplo, por esos años, se sabía que existían terrenos disponibles al este como las huertas de los Recoletos, del Prado, Besan, y Naranjos (Tizón y Bueno, 1906:5-12) que podían ser anexadas a la ciudad.

La nueva demarcación permitió una mejor administración, ya que la ciudad se había vuelto muy compleja. La demarcación permitió transferir recursos y competencias, redistribuir recursos como infraestructura y servicios básicos de forma equitativa para mejorar la calidad de vida en la ciudad. Así se trató de insertar, en el proyecto de modernidad urbana civilista, los espacios producto de una expansión promovida por el Estado con la mercantilización del suelo. Sirvió como una base para preparar la ciudad ante la próxima división en municipalidades distritales en los próximos años y de esa manera buscar una descentralización administrativa y una mayor participación ciudadana en los procesos de construcción del tejido social (Salas, 2016: 97) (136 $^{136}$

136 María Andreina Salas Borgouin “Dinámica territorial del poder político en Venezuela contemporánea (19612013) En: Cuadernos de geografía Revista Colombiana de Geografía Vol. 25 núm. ene-junio 2016 Bogotá, pp.95109. 


\section{Plano 4.6}

\section{La demarcación territorial de Lima elaborada por Carlos Fabbri}

(1908)

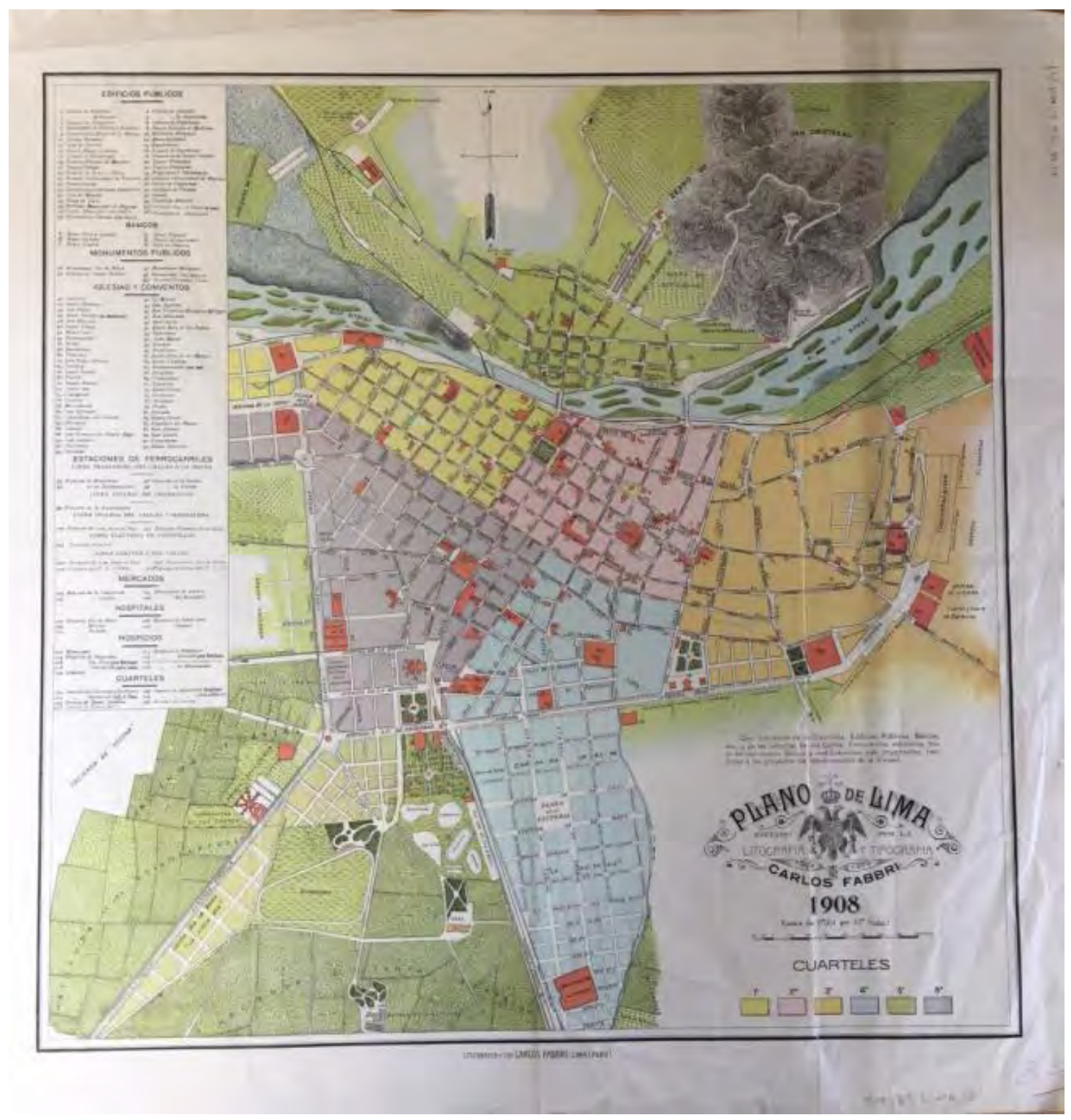

Fuente: El plano de Lima de 1908. Fuente digital: $h$ ttps://www.rsgs.org/blog/collectionscorner-the-1908-plano-

lima?fbclid=IwAROyG44LVJ5JBe3f8ZNkhnKSeWKaMVwvJZpwDeCtkYglocn1ATWIpkbBLrO

La nueva demarcación territorial, ver plano 4.6, tuvo las siguientes consecuencias: mejoró la seguridad ciudadana al sur de la ciudad, se produjo la identificación de estos espacios con la ciudad, muchas de estas urbanizaciones pudieron acceder a servicios básicos con el apoyo de la 
Municipalidad y el Estado, gracias a la recaudación de impuestos. Además, un mayor número de industrias se instalaron al sur de la ciudad.

\subsubsection{El problema de la salubridad (1904-1908)}

El problema de la salubridad no se había podido solucionar por la falta de un diagnóstico adecuado del control de las enfermedades, la falta de un presupuesto para este objetivo, la falta de una adecuada difusión sobre prácticas diarias de higiene, la construcción de más hospitales para atender a los enfermos y la poca preocupación de los gobiernos en turno para solucionar este problema, que afectaba a la población que vivía en el Centro. ${ }^{137}$ Por ejemplo, la peste bubónica que asoló a la ciudad afectó a más del sesenta seis por ciento de la población en el año 1905 (Diario La Prensa, 1905 á,17 diciembre: 02). Ante esta alarmante situación, el Instituto de Higiene cumplió la función elaborar un diagnóstico de la ciudad para buscar una solución. El diagnostico surgió de un grupo de higienistas de Lima del siglo XX que estaba compuesto por los médicos: Antonio Portella, Leónidas Avendaño, Enrique León García, Ricardo Izaguirre, Manuel O. Tamayo, Enrique Pardo Figueroa y Nieto, Carlos Alberto García y Felipe Salazar y Alarco y el ingeniero Santiago Basurco. Ellos publicaron sus inspecciones y caracterizaron el problema que veían en el Boletín Demográfico Sanitario de la ciudad de Lima y La crónica Médica. Gracias a estas publicaciones fue posible detectar los principales problemas como: las malas condiciones de vivienda en los callejones de vecindad en los cuarteles de la ciudad, la necesidad de contar con un manual de hábitos de higiene, la prohibición para los arrendatarios de ofrecer casas habitación en mal estado y cuantificar el problema en toda la ciudad mediante la elaboración de un catastro de higiene de la ciudad ${ }^{138}$. No obstante, no se llegó a concretar un "código sanitario" como en el caso de México, (Sánchez,

\footnotetext{
${ }^{137}$ La población había aumentado y se hacía necesaria la reubicación del hospital de Santa Ana ubicado en el barrio chino colindante con la parroquia del mismo nombre. Para ello se presentaron dos proyectos: el primero por la Sociedad de Beneficencia para la construcción del nuevo hospital de Santa Ana, "Proyecto de traslación del Hospital de Santa Ana" En: Crónica Médica, Núm. 323. Lima, Imprenta San Pedro, p.161-173; El segundo, un proyecto para un nuevo hospital de mujeres elaborado por los señores Pedro Paulet y Manuel O. Tamayo "proyecto para el nuevo Hospital de mujeres de Lima" En. Crónica medica, Nun.414, Imprenta San Pedro, pp.82-93.

138 Las inspecciones realizadas por los médicos de la municipalidad publicadas en el Boletín Demográfico Sanitario de Lima de los años 1906 a 1907 nos muestran las malas condiciones de vida de la población en los cuarteles.
} 
2013:138) ${ }^{139}$ porque en Lima el tema de la salud se encontraba en proceso de ser espacializado, realizando geografía médica con la aplicación de inspecciones para tener un registro cuantificado del problema. Con tal información sería posible encontrar una solución y elaborar una normativa de salubridad ${ }^{140}$. Por ejemplo, en la carta dirigida al inspector de higiene de Consejo Provincial, el 6 de julio de 1906 el médico Manuel Morante informó la situación de parte del cuartel tercero:

"Cumpliendo lo ordenado por VS he visitado el callejón N41 de la calle San Isidro conocido como "Callejón del Pueblo Nuevo" este callejón pertenece a la señora Carmen viuda de Rivera; de construcción muy antigua ocupa un inmenso área de terreno. Tiene un solo piso sin habitaciones subterráneas. Está compuesto de tres solares unidos llamados Solar de D. Juan con 52 cuartos. Solar de los Milagros con 68id y Solar de la Resurrección con 26 id. Total 146 cuartos compuestos cada uno de una habitación a la que esta anexo un corralito. Las condiciones generales higiénicas del edificio son inaceptables" (Morante,1907:21-22).

Este párrafo nos confirma las condiciones de tugurización y hacinamiento en las que vivía la población en los cuarteles cerca al centro, lo que junto con la propagación de la peste Bubónica, ocasionaban problemas de salud al interior de muchas manzanas de la ciudad. Ante esta problemática, el alcalde de Lima decidió intervenir en los callejones cerca del centro, como Petateros. El ingeniero Ricardo Tizón y Bueno comenta la intervención de la siguiente manera:

"El actual alcalde Sr. Elguera, que trajo según pudo verse desde el principio de su actuación en el ayuntamiento, decidido propósito de contribuir al establecimiento de Lima; pensó a penas asumió la alcaldía llevar a su realización el ensanche del callejón de Petateros, inmundo pasaje situado, para bochorno del vecindario, en el centro mismo de Lima. Pero tan hermoso proyecto degeneró en una avenida que se bautizó con el nombre de 28 de julio y que continuando el callejón de Petateros cuando se ensanchara, seguiría por el interior de las manzanas hasta terminar hasta la actual estación de San Juan de Dios"(Tizón y Bueno, 1906:12).

También se realizó una intervención en el callejón Otaiza a cargo del ingeniero Hohagen. Al respecto, el ingeniero Tizón y Bueno comenta de la siguiente manera:

\footnotetext{
"Hay dos proyectos parciales de nuevas calles: uno antiguo debido al ingeniero Hohagen para comunicar a través de la manzana del Colegio Real, las calles de San Idelfonso y Santo Tomas; y otro cuyo autor precisamente no conocemos, para poner en relación la calle

139 Según Sánchez" Así surgieron estudios que los médico llamaron la geografía médica, en ellos se mostraba la manera en que se extendían las enfermedades y epidemias que causaban estragos en la población" En: "Precursores del urbanismo en México". México, Ed. Trillas, 2013, pp.253.

140 Por ejemplo en articulo "Inspección de Higiene" se dice que el 13 de abril de 1907 se aplicó la Ordenanza Municipal para mejorar los comercios tuvo como resultado 1503 comercios notificados de los cuales 1014 cumplieron con las mejoras. Diario La Prensa 1908, viernes 10 enero,(Núm./d) pp.04.
} 
Albaquitas con la de San Pedro Nolasco, destruyendo ese foco de inmoralidad e inmundicia llamado callejón Otaiza" (Tizón y Bueno, 1906:13).

Durante los años de 1907 a 1908 se intervinieron esas manzanas, lo que incluyó el ensanchamiento de las vías, la limpieza de las casas habitaciones infectadas y demoliciones de habitaciones (Ver figura 4.1). Las intervenciones fueron una medida aplicada ante las urgencias de la situación de la ciudad tanto en el espacio público como al interior de las manzanas y de las viviendas donde se realizaron algunas demoliciones para aperturar un pasaje principal (Ver figura 4.1). Estas experiencias permitieron a los especialistas elaborar un documento de diagnóstico, no solo basado en las estadísticas, sino también en las soluciones puestas a prueba con las intervenciones realizadas. Este hecho, permitió una mejor implementación de soluciones para la mejorar de las viviendas en el centro y las que estaban por construir en la zona de expansión. 


\section{Figura 4.1}

\section{Intervención en el callejón de Petateros (1906)}

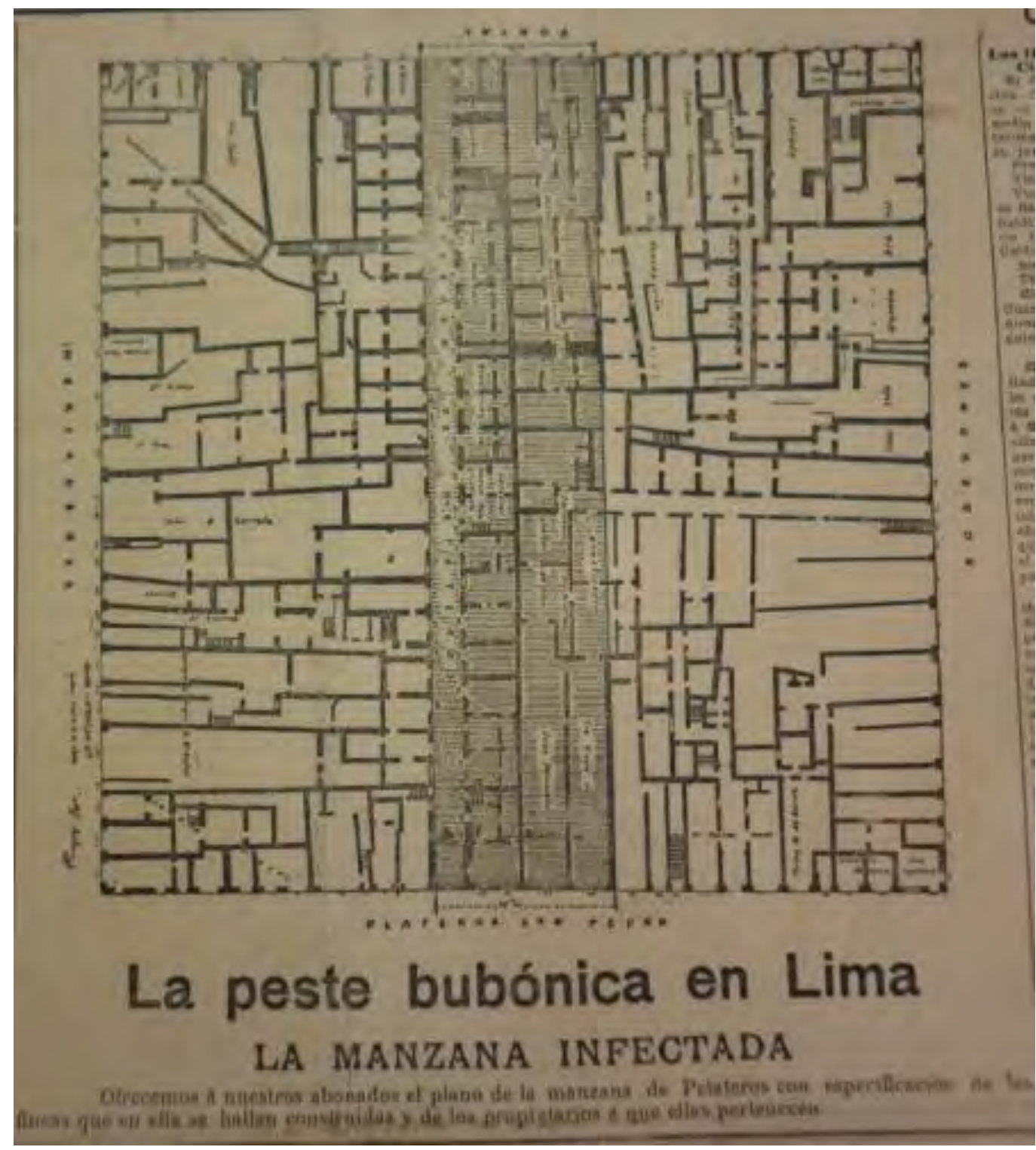

La Prensa (1908), Lima, "La recrudescencia de la bubónica en Lima- El ensanche de Petateros lo acordado ayer por la Beneficencia" En: La Prensa, jueves 8 de marzo de 1908, (Núm., 2704).pp./d.

** Apertura de la vía central y demolición de las viviendas.

Los resultados de los estudios de salubridad en la ciudad fueron publicados con el nombre de "Higiene en la habitación-Informe emitido por la comisión nombrada por el gobierno para estudiar las condiciones sanitarias de las casas de vecindad de Lima" elaborado por el ingeniero Santiago Basurco y el médico Leónidas Avendaño. (Basurco, 1907:54-83). El informe mostró las deplorables condiciones que vivía la población en los cuarteles que rodeaban al centro de 
la ciudad. Al respecto, se recomendó a las urbanizadoras los parámetros mínimos de áreas para las viviendas y el uso de los materiales más adecuados. En una segunda parte, se dieron algunas recomendaciones sobre las prácticas de higiene en las viviendas. Con todas estas recomendaciones se esperaba que los propietarios, antes de alquilar, mejoraran las condiciones de las viviendas y que los nuevos inquilinos tuvieran adecuadas prácticas de higiene para mejorar su calidad de vida y evitar la propagación de epidemias.

"El 20 de Junio de 1908 se realizó el censo de la ciudad de Lima que dio como resultado una población de 142,997 habitantes" (Diario La Prensa: 1908 á, 27 octubre,03). "La ciudad llegaba hasta la Escuela de Agricultura y para el alcalde Federico Elguera la ciudad se había vuelto inmanejable, debido a la rápida urbanización a cargo de las urbanizadoras privadas". En un artículo titulado "El saneamiento de la ciudad de Lima" (Diario La Prensa,1908 á, 22 abril:01) el ingeniero municipal H.G. Binghan Powell "puso en evidencia los problemas de salubridad pública que a futuro tendría la ciudad, como el problema de la canalización de las acequias, un adecuado sistema de abastecimiento de agua con tuberías madre. Todo ello debido al aumento poblacional ocasionado por los urbanizadores, la necesidad de pensar en un reservorio de agua para la ciudad, el tratamiento de la basura debido al aumento de la población, el tipo de pavimento más adecuado para el tráfico que soportaría la ciudad, la contaminación de aire ocasionado por la tierra y la ventilación de las casas. Sin embargo, para instalar infraestructura de agua, desagüe y demás servicios en la periferia se requería de una inversión fuerte por parte del Estado Peruano. Por tanto, este sería el principal problema que enfrentarían los gobiernos en turno en las próximas décadas". 


\section{Conclusiones del capítulo}

Las obras urbanísticas iniciadas por el fraccionador Meiggs quedaron paralizadas a su fallecimiento. Además, la ciudad ingresó en un periodo de estancamiento con el inicio de la guerra con Chile. Sin embargo, con la retirada de las tropas chilenas, inició un periodo de reconstrucción económica y de infraestructura que llevó nuevamente a los presidentes en turno buscar materializar la modernidad siguiendo del discurso civilista, es decir, con el apoyo de la inversión privada, lo que generó un proceso especulativo de suelo en la ciudad. El resultado de la aplicación de estas leyes fue el desorden de la urbanización al poniente y un acelerado proceso de crecimiento urbano al sur. También apareció la necesidad de enfrentar los problemas de infraestructura del centro, lo que llevó a los gobernantes en turno a decidir retomar en parte la construcción del centro moderno con la construcción de avenidas centrales que conectaran la ciudad con los balnearios. La acelerada urbanización, a cargo de los inversionistas privados, hacia el sur, hizo necesaria una nueva demarcación territorial en el año 1906, misma que sirvió de base para implementar infraestructura básica en los nuevos fraccionamientos.

En los años de reconstrucción, después de la guerra una de las primeras tareas del gobierno de turno fue desaparecer el mercado de suelo informal mediante la aparición del Registro de Predios de la ciudad, lo que ayudó a generar confianza en los inversionistas para que volvieran a intervenir y de esa manera mejorar la economía de la ciudad. Así también la Ley de Garantías Hipotecarias que implementó el Estado permitió la reactivación del mercado del suelo. El principal problema fue que, a partir de 1900, con la aplicación de la Ley de Expropiación, las urbanizadoras pudieron comprar en la periferia extensas áreas de terrenos a precio de expropiación, las cuales destinaron a lotizar y vender. El negocio inmobiliario se volvió más rentable que nunca. Requería un mínimo de inversión, era de rápida recuperación, no requería de inversión en infraestructura y equipamiento y permitía una fuerte especulación. En este contexto, el mercado de suelo de la periferia se activó, produciéndose una nueva redistribución de mercado de suelo en la periferia la que, desde los tiempos del fraccionador Meiggs, había quedado paralizada. 
Con la apertura de las avenidas centrales, la mejora de los servicios de transporte y el equipamiento urbano, el mercado de suelo se reactivó en función de avenidas como La Magdalena y La Colmena, convirtiéndose en un mercado segmentado en función de una población especifica como: clase media, inmigrantes y élite que se mudaron paulatinamente a vivir hacia estos fraccionamientos.

La posibilidad de retomar la urbanización de la periferia, que quedó trunca a la muerte del fraccionador Meiggs, activo el proceso especulativo en esa zona, si bien condicionado a la regularización de las propiedades. A partir de ahí los gobiernos de turno dieron poder a los inversionistas privados para urbanizar la periferia, pero debido a que la urbanización espontanea se había consolidado hacia el este, ésta solo fue posible al lado oeste y sur, donde el fisco tenia terrenos en reserva y donde la tenencia de suelo había sido saneada. No obstante, la Ley de Expropiación de 1900 aceleró el proceso de urbanización en la periferia sur poniente de la ciudad produciéndose, ante la falta del control del Estado Peruano y la Municipalidad, un desorden y un proceso especulativo (comprar barato, vender caro) lo que generó no sólo acumulación de recursos en las empresas, sino también falta de espacios públicos y áreas verdes, calles interiores estrechas, falta de servicios básicos, equipamiento y accesibilidad en las nuevas urbanizaciones

La decisión política de continuar la construcción del centro moderno cerca al Palacio de la Exposición mostró la continuidad de la materialización de la modernidad en la ciudad para satisfacer a la élite. Por su parte, la población en general pudo acceder a una cierta modernidad debido a que el Estado Peruano implementó la red de tranvías, la cual llegaba al centro desde distintas partes de la ciudad y desde los balnearios del sur. Fue posible entonces que la población se conectara más fácil con el centro moderno que se venía construyendo. Otro aporte a la modernización fue la apertura de las avenidas centrales como La Magdalena y La Colmena. Todo ello permitió la aparición del tráfico entre la ciudad y los balnearios, aunque a la larga ese fue uno de los problemas que trajo la modernidad a la ciudad. 
Los gobiernos de turno después de la reconstrucción de la ciudad, no se preocuparon por la salubridad y esta problemática se agravó a inicios del siglo $\mathrm{XX}$, con la acelerada urbanización hacia el sur y este. Muchas urbanizaciones no contaban con servicios básicos, generando problemas de salubridad. Ante esta problemática, los higienistas aportaron documentos que informaban a los propietarios y fraccionadores las medidas a tomar en cuenta para la mejora de la infraestructura de las casas habitación en Lima. Por su parte, la Municipalidad, decidió intervenir en las manzanas donde se presentaron los casos más críticos, dando pautas a los inversionistas de cómo intervenir en los fraccionamientos privados. 


\section{Conclusiones}

El presente trabajo ha tratado de demostrar la manera como se produjo el proceso de modernización urbana en la ciudad de Lima, proceso en el que destaca la demolición de la muralla, en el año de 1870, y las prácticas inmobiliarias que establecieron. Siguiendo a Gorelik podemos decir que Lima siguió, como en general sucedió en América Latina, "un camino para la modernización e intentó preservar la voluntad ideológica de una cultura para producir un determinado tipo de transformación estructural" (Gorelik, 2013:15). En Lima, las transformaciones de la ciudad buscaron una modernidad capitalista avalada por el Estado que, en su afán por alcanzar el crecimiento económico, apoyó ampliamente a los inversionistas privados, convirtiendo a estos en poderosos ejecutores de las transformaciones de la ciudad, siguiendo el discurso liberal ilustrado. Este discurso hacia finales del siglo XIX, se convirtió en el discurso civilista de modernidad urbana. En todo momento el Estado peruano siguió la idea de que, la única manera de lograr el tan ansiado progreso, era insertando a la ciudad en procesos de mercantilización de suelo, lo que dio como resultado procesos especulativos, los cuales, a su vez, caracterizaron el proceso de modernización urbana de Lima de finales del siglo XIX y principios del siglo XX. "La idea de progreso", como señala Pérez, "se presenta como un referente conceptual en torno al cual se desplegaron distintas perspectivas" (Pérez,2018:92). Para el caso de Lima, se tradujo en el deseo de insertar en la ciudad la llamada "industria pública", buscando mejoras en el habitar, la construcción de infraestructura y el equipamiento, para materializar la superestructura de la modernización en la ciudad y en las zonas de expansión (Sánchez, 2013:207).

Con este trabajo se ha tratado de cumplir el objetivo de conocer los procesos de urbanización que tuvo la ciudad de Lima en el siglo XIX, aunque para ello ha sido necesario abordar procesos que van desde inicios del periodo colonial, a fin de esclarecer los significados del cambio histórico de la modernidad. En el 
capítulo primero se muestra la manera como la construcción de la muralla de Lima tuvo el sentido de protección física de los bienes y, a futuro, influenció la urbanización y el crecimiento de la ciudad. Para mediados del siglo XVIII, el binomio modernidad-ilustración generó propuestas de intervención después del sismo del año 1746 como: El plan de ensanche de calles y el proyecto de construcción de una ciudadela amurallada; que si bien, no se llegaron a materializar permitieron mostrar hasta qué punto estas ideas fueron aceptadas por las autoridades locales y la población. A esto se suma, la visión del Estado Virreinal sobre la primera modernidad urbana en la ciudad, que se tradujo en reformas administrativas, nueva demarcación territorial, construcción de infraestructura y equipamiento, siempre con el objetivo de mostrar el poder del Estado y de la Iglesia. El discurso liberal ilustrado "estuvo presente (con) la necesidad de generar una conciencia o un sentimiento nacional identitario" (Pérez,2013:119) capaz de generar un cambio moderno en el país y en la ciudad. Ese discurso estuvo presente al inicio de la república independiente.

En el capítulo segundo observamos que, desde mediados del siglo XIX, los gobiernos liberales decidieron comprometerse con la aventura de la modernización, (Berman,1989:252) utilizando en forma especial el dinero del guano. A partir de este periodo, se realizaron transformaciones en la ciudad. En estos procesos de cambio influyeron las ideas, la teorización, el estudio y las propuestas de los higienistas que tuvieron influencia en la reglamentación y la gestión local. De esa manera, encaminaron la ciudad hacia el lado reivindicativo de la modernidad (Sánchez,2013:252). Los primeros gobiernos buscaron el progreso con la implementación de la obra pública para satisfacer las necesidades de la élite limeña por alcanzar la modernización urbana. En un segundo intento, a partir de la demolición de la muralla, fue posible utilizar los instrumentos de planificación para la expansión urbana de la ciudad mediante la ejecución del Plan de Ensanche, lo que dio como resultado una especulativa "parrilla mercantilista" de vivienda en la zona de expansión, así como la construcción del espacio público que "sería un nuevo tipo de espacio social, un entorno arquetípicamente moderno que podría reunir todos los estratos sociales, fragmentados y opuestos" (Berman, 1989:255). Antes de iniciada la guerra del Pacífico, la modernidad urbana únicamente se llegó a concretar en 
fragmentos de la periferia como un intento planificado e inconcluso producto de la mercantilización del suelo.

En el capítulo tercero presentamos la búsqueda del progreso con el inicio de la materialización de la infraestructura de la modernidad urbana, (Sánchez, 2013:207) a cargo de los gobiernos liberales, con obras de envergadura como: la demolición de la muralla de Lima, el Plan de Ensanche, el proyecto de la Avenida Unión y el plano Topográfico de Lima. La ejecución de estas obras tuvo repercusiones sociales y económicas en la ciudad, entre las que destacan: la redistribución de la población en la periferia, la expansión especulativa de la ciudad y el enriquecimiento de algunos empresarios inmobiliarios, entre los que destaca Enrique Meiggs. En este capítulo observamos, como el Estado ante la inminente bancarrota fiscal por malos manejos del dinero proveniente del recurso guano, intentó activar la economía siguiendo el pensamiento de la libertad comercial. Para ello, encontró que la única alternativa era mercantilizar el suelo de la periferia y fue la manera en la que el Estado impulso las sociedades capitalistas (De Mattos,2015:41). Con el modelo del fraccionador Meiggs puede decirse, siguiendo a Berman, que "Las antiguas formas de honor y dignidad no mueren son incorporadas al mercado, se les añade una etiqueta de precio, adquieren una nueva vida como mercancías" (Berman, 1988:108). En la práctica, el proceso especulativo de suelo significó expropiar con precios castigados, dividir el suelo y vender a precios altos, con el argumento de activar la economía y progresar. El resultado de esta decisión, asumida por el Estado, fue una profunda metamorfosis urbana (De Mattos,2015:38). En lugar de una oferta de vivienda social se construyó un monopolio inmobiliario, con un solo inversionista privado, generando una especial riqueza inmobiliaria. "La subordinación del espacio al dinero y al capital acarrea una cuantificación que se extiende desde una valuación monetaria y la comercialización del lote hasta el espacio entero" (De Mattos,2015:25) ${ }^{141}$. En la ciudad el fraccionador Meiggs ejecutó su proyecto con este pensamiento, siempre con el apoyo del Estado, poniendo en implementación la Ley de Expropiación. Con el acceso a la banca

\footnotetext{
141 “La burguesía y el Espacio" Carlos A. De Mattos y Enrique Link En: "Lefvebre revisitado: capitalismo, vida cotidiana y el derecho a la ciudad" Ed. Ril. Santiago de Chile, 2015. pp.19-37
} 
hipotecaria fue posible la materialización de la comercialización del suelo. El proyecto del fraccionador Meiggs quedó inconcluso a su muerte.

En el capítulo cuarto, después de la ocupación chilena de la ciudad, el Estado buscó nuevamente la reactivación del binomio industrialización-mercantilización como la única manera de lograr el progreso. Fue así, que a partir de los gobiernos de los presidentes Miguel Iglesias y Andrés Avelino Cáceres, se buscó la reactivación de la banca especialmente del sector hipotecario, con la finalidad de reactivar la actividad del mercado de suelo y de esta manera retomar la mercantilización de suelo. Sin embargo, para alcanzar el objetivo de reactivar el mercado de suelo de la periferia, el Estado realizó un proceso de saneamiento legal, cuyo resultado fue la regularización parcial de algunas propiedades ubicadas al oeste de la ciudad. De manera paralela, se continúo con el proceso de materialización de la infraestructura y el equipamiento a través de la ejecución de la obra pública.

Durante el gobierno del presidente Nicolás de Piérola de 1890 a 1896 se ejecutó el discurso de modernización urbana civilista. Continuaron las obras de infraestructura, construcción de edificaciones públicas y embellecimiento, con el objetivo de alcanzar la modernidad urbana, principalmente para satisfacer a la elite aristocrática. Retomando el Plan de Ensanche se refuncionalizó la ciudad con una nueva red vial, con la apertura de avenidas centrales que mostraran un nuevo rostro de la ciudad. Esta vez, la idea era materializar el centro moderno como una centralidad y facilitar el tránsito de la población, es decir, la modernidad urbana a la vista de toda la población. En este periodo, buscando un mayor crecimiento económico de la ciudad, el Estado decidió la remercantilización del suelo en la periferia, reafirmándose en la idea que el libre comercio era la única manera de alcanzar el progreso. Fue así que puso en vigencia las Leyes de Expropiación de los años 1900 y 1903, beneficiando a las empresas inmobiliarias. El resultado fue: nueva especulación del suelo, desarrollo desordenado de la urbanización en la periferia, falta de servicios, la aparición de problemas de salubridad en estas nuevas urbanizaciones y la continuidad de los problemas de salubridad en el centro. 
En este trabajo ha quedado claro que la principal causa de la construcción de la muralla en los años de 1684 a 1687 fue delimitar el crecimiento de la ciudad, el resguardo de la población y de las riquezas que esta poseía. Hacia 1750, la implantación de las reformas borbónicas significó el primer intento de modernización urbana por parte de Estado Virreinal en un contexto de ideas de ilustración. Como en muchas capitales de Latinoamérica, las reformas borbónicas fueron buscar restarle poder a la Iglesia en términos políticos, económicos y administrativos. En Lima, la nueva demarcación territorial del año 1769 dejó sin efecto las delimitaciones parroquiales, lo que generó una redistribución de la población, la población indígena tuvo desde entonces derecho de ciudadanía en la ciudad, se generó resistencia por parte de la élite que perdió privilegios ante la nueva demarcación y los nuevos cuarteles iniciaron el proceso de construcción de su identidad. Hacia el último periodo de la administración colonial, el Estado Virreinal se preocupó por construir edificaciones públicas que cambiaran el rostro de la ciudad como: el Jardín Botánico, el Cementerio General, Plaza de toros de Acho, que materializaran una cierta modernización de la ciudad. El resultado fue una pre-modernidad ejecutada por el Estado Virreinal para mostrar su poder, por lo cual la élite tuvo una experiencia moderna en el espacio público.

En el capítulo segundo concluimos que los proyectos que ejecutaron los distintos gobiernos, entre dictatoriales, intervencionistas y populistas, con el dinero del guano a partir de mediados del siglo XIX, buscaron materializar la modernización urbana en la ciudad, pero al no concluir las obras básicas convirtieron la modernización en una utopía. A partir de la decisión de demoler la muralla de Lima, el año 1870 se establecieron los objetivos de los gobiernos de turno para alcanzar la modernidad urbana como: impulsar la "industria pública”, mejorar la salubridad, mercantilizar especulativamente el suelo, dejar atrás el pasado colonial y establecer un precedente de planificación moderna. Hacia finales del siglo XIX, la idea de planificar el crecimiento de la ciudad y ofrecer vivienda a la población, mediante un modelo especulativo, se concretó en la elaboración del Plan de Ensanche. El Perú, al igual que los países de la región, buscó una expansión urbana para alcanzar el progreso, teniendo como eje el mercado inmobiliario. Aunque en un principio la intención formal del 
Estado fue favorecer con vivienda de interés social a la población que vivía en malas condiciones en el centro, su principal necesidad fue activar la economía en el menor tiempo posible, por esta razón, entregó al fraccionador Meiggs la ejecución del proyecto de vivienda, recibiendo el programa general en exclusiva, como pago por los servicios de la demolición. Este hecho, generó un precedente en la forma de mercantilizar el suelo y producir riqueza por el Estado Peruano que sería replicado en el futuro con el mismo objetivo. Sin embargo, para apoyar a la población que vivía en el centro, el Estado y la élite decidió impulsar las Cajas de Ahorro Mutuo a cargo de la Beneficencia y facilitar el ahorro de la población para que de esa manera fuera posible adquirir viviendas en la periferia en el proyecto privado. El resultado, fue una oferta de vivienda público-privada (Borja,2016:05) con un subsidio a la vivienda. Aunque el proceso de mercantilización de suelo de periferia tuvo un costo para la población que vivía en el centro que fue afectada por epidemias, la gran mayoría continúo viviendo en el centro. La intención del Estado Peruano con esta decisión siguiendo el espíritu de libertad económica y "Bajo la creencia que la propiedad aportaba el mayor beneficio económico para todos" (Fernández, 2014:44) ${ }^{142}$ fue la activación económica como una forma de incentivar el capitalismo local. A la muerte del fraccionador Meiggs el Plan de Ensanche quedó inconcluso y la población en la periferia ingresó a la informalidad del mercado de suelo. A largo plazo, puede decirse que las lotizaciones ejecutadas por el fraccionador Meiggs contribuyeron al proceso de construcción de la morfología urbana, sobre todo cerca al Palacio de la Exposición y hacia el sur, lo que fue retomado por la siguiente generación de inversionistas inmobiliarios de la periferia.

En esta investigación se pone en evidencia el proceso especulativo en la periferia, cuando el fraccionador Meiggs ejecutó el Plan de Ensanche y el proyecto privado paralelamente. Sin embargo, este conocimiento cabal de este proceso requiere el acceso a fuentes primarias que permitan mostrar los detalles de compra de los terrenos por parte de Meiggs a otros fraccionadores que también se encontraban urbanizando espacios cercanos a la periferia,

\footnotetext{
${ }^{142}$ Raúl E. Fernández Wagner "La construcción social de la propiedad privada en la evolución reciente del país y la región En: "La vivienda entre el derecho y la mercancía- Las formas de propiedad en América Latina”, Ed. Trilce, 2014, Montevideo Uruguay.pp.1-248.
} 
datos de los precios con los que expropió los terrenos de la periferia para ejecutar el Plan de Ensanche y los precios con los que compraron terrenos otros inversionistas cerca a la periferia. Con esta información, sería posible conocer el tamaño del mercado especulativo en la periferia a finales del siglo XIX y otras características como las transacciones de propiedades, tamaño de lotes y venta de espacios públicos, que nos lleven a detallar, aspectos de la urbanización en la periferia. Este nuevo estudio es materia de un nuevo proyecto de investigación sobre procesos especulativos de suelo en la periferia de Lima en el siglo XIX.

Concluimos que la expansión y la redistribución de la propiedad en la periferia de Lima fue resultado de la demolición de la muralla, guiada teóricamente por la necesidad de satisfacer a la población que vivía en malas condiciones en el centro, lo que luego se convirtió en un proyecto privado especulativo. En este trabajo hicimos los siguientes hallazgos: El apoyo al sistema financiero por parte del Estado Peruano tuvo el objetivo de la activación del mercado de suelo y su reestructuración en la ciudad y en la periferia, el apoyo a la banca hipotecaria por parte de la élite posibilitó un mayor número de inversiones, la activación de la actividad hipotecaria operó en condiciones altamente especulativas, con costos sociales y ganancias propias.

En el capítulo cuarto concluimos que al finalizar la guerra con Chile la ciudad inició un periodo de reconstrucción de la infraestructura pública y mejoras en las condiciones de habitar. Para ello, contó con el apoyo de la sociedad organizada y los empresarios que buscaron nuevamente invertir en la ciudad con el apoyo del gobierno de turno. Esto se logró con la aparición del Registro de Propiedad Inmueble y el Registro Mercantil y con la Ley de Hipotecas. Después de este periodo asumieron el Gobierno de manera consecutiva los miembros del partido civilista que materializaron una modernidad urbana civilista, la que buscó satisfacer las necesidades de progreso de la aristocracia, dando a la población un cierto ingreso a la experiencia moderna, principalmente con la infraestructura. Sin embargo, el principal programa inmobiliario fue nuevamente el Plan de Ensanche, por lo que refuncionalizaron las principales vías, generando una centralidad de donde partirían avenidas hacia los balnearios ubicados al sur, mejorando la conexión del centro con 
estos espacios, a donde se mudó a vivir la aristocracia. La preocupación por mejorar la infraestructura vial que permitiera el acceso a esta centralidad desde cualquier punto de la ciudad buscó aminorar las desigualdades en la ciudad. A diferencia del primer proceso especulativo, en este caso la intención del Estado fue remercantilizar el suelo de la periferia recuperado durante el proceso de saneamiento legal para generar un crecimiento económico, pensando que este aportaría al desarrollo (Mattos,2015:23) en el menor tiempo posible y demostrar que los gobiernos civilistas se encontraban materializando el progreso y era necesario que continuaran en el poder en los siguientes periodos de gobierno. No obstante, en este segundo proceso especulativo tuvo los rasgos señalados por Mattos: "el Estado atendiendo las exigencias, demandas e intereses de la clase social que detenta el poder político,... la misma era utilizada como un instrumento para activar la acumulación del capital y para promover el crecimiento económico" (De Mattos,2015:41) Con este pensamiento, los miembros de la élite limeña fueron los favorecidos por el Estado con el establecimiento de las Leyes de Expropiación de 1900 y 1903, las cuales les dieron el poder absoluto a los inversionistas privados para expropiar grandes extensiones de terreno en la periferia, dando como resultado un proceso especulativo de suelo que hizo que muchos miembros de la élite se enriquecieran. En este caso, también el gobierno y la élite apoyaron con subsidios mediante la Caja de Ahorros Mutualista de la Beneficencia para que una mayor población tuviera acceso a la vivienda y mejoraran las condiciones de la vivienda en el centro y las zonas de expansión, con un subsidio a la vivienda. Los estudios de caso de la construcción de las avenidas La Magdalena y La Colmena, nos muestran como fueron los procesos especulativos de suelo que ejecutaron los inversionistas privados con el aval del Estado. En este caso, también es necesario a recurrir a fuentes primarias para conocer el tamaño del mercado especulativo que se formó al este y sur de la ciudad a cargo de varias empresas urbanizadoras. Saber los precios que se pagaron por las expropiaciones permitiría conocer a detalle este segundo proceso especulativo de suelo a principios del siglo XX.

El resultado de esta política del Estado fue el desorden de la urbanización, con una intervención tardía de la Municipalidad en un intento por resolver el 
problema que habían provocado las urbanizadoras. Para inicios del siglo XX la modernización urbana se había materializado en el centro y el gobierno continuaba ejecutando obra pública para seguir construyendo la infraestructura de la modernidad. Sin embargo, debido a las epidemias en el centro, la Municipalidad tuvo que intervenir los callejones de Petateros y Otaiza antes que los médicos culminaran el catastro sobre las condiciones de salubridad de las casas habitación de Lima. Esta experiencia, les permitió implementar de mejor manera las recomendaciones para mejorar la calidad de vida de las casas habitación de Lima y aportar así al proceso de modernización que se estaba dando.

La modernidad urbana que ejecutaba el Estado para satisfacer a la élite había creado enormes desigualdades urbanas en el centro y en la periferia, un desarrollo desigual de la urbanización, un proceso especulativo de suelo en la periferia y un crecimiento de la ciudad al sur que había hecho inmanejable satisfacer con servicios y infraestructura a las nuevas urbanizaciones. Estos problemas de la ciudad llevaron al Estado a establecer una nueva demarcación territorial, como una muestra de la necesidad de proveer a cada uno de estos espacios recursos y infraestructura de manera equitativa, con el cobro de arbitrios y aportaciones de la élite para mitigar los problemas de salubridad que se estaban dando.

Aunque el tema de la modernización urbana de la ciudad en el siglo XIX es un tema muy amplio, esperamos que con esta investigación se haya aportado un material para el conocimiento del proceso de este tema desde su fundación, en el año 1535, hasta principios del siglo XX, cuando se sentaron las bases para la metropolización que vendría durante las siguientes décadas. Creemos que uno de los principales aportes de esta investigación ha sido demostrar la importancia de los procesos especulativos de producción del espacio en la periferia, con dos momentos: Primero, durante la gestión de gobiernos liberales, como fueron los casos de los gobiernos de Balta y Pardo durante los años 1870 a 1876 cuando Enrique Meiggs urbanizó la periferia de forma privada y ejecutó el Plan de Ensanche. Segundo durante 1900 a 1908, cuando los gobiernos civilistas decidieron implementar las Leyes de Expropiación de 1900 y 1903, dando poder a los urbanistas para urbanizar grandes extensiones 
de terrenos, generando desorden en la urbanización de periferia. Pero este tema aun debe ser profundizado para conocer más a detalle los procesos especulativos en la ciudad.

El año 1908 la modernidad urbana se había materializado en fragmentos de la ciudad como el nuevo centro cerca al Palacio de la Exposición, a lo largo de las avenidas centrales y en algunos espacios de la periferia cerca a los óvalos Unión y Dos de Mayo, demostrando una modernización fragmentada y desigual. Si bien la infraestructura vial permitía que la población pudiera recorrer los espacios públicos modernos ubicados en el centro, las condiciones del buen habitar no habían mejorado cerca a la Plaza Mayor y los espacios cercanos. La idea de civilizar a la población tampoco se concretó por las malas prácticas de salubridad, seguían generando problemas en las casas de vecindad de Lima.

\section{ALGUNAS APORTACIONES DE PROCESOS SIMILARES QUE AYUDAN A ENTENDER LA MODERNIZACION DE LIMA}

Creemos que es importante realizar una reflexión sobre los grandes temas tratados en esta investigación por los teóricos latinoamericanos que han abordado el estudio de procesos similares que permiten mostrar hasta qué punto se realizan aportaciones a los procesos más importantes de intervención de la ciudad como: especulación, centralidad, ejecución de obras públicas.

Uno de las características de la modernización urbana de Lima fue la idea de progreso, la cual impulso los cambios en la ciudad desde el Estado y los grupos de poder, con la ausencia o debilidad de la sociedad civil. A respecto dice Larrain:

"Un fenómeno significativo, que diferencia la modernidad latinoamericana de otras, es la falta de autonomía y desarrollo de la sociedad civil (la esfera privada de individuos, clases y organizaciones regulada por el derecho civil), en América Latina la sociedad civil es débil, insuficientemente desarrollada y muy dependiente de los Estados y la política" (Larrain,2004:237). 
En el caso de Lima el progreso estuvo relacionado con el crecimiento económico y la extrema liberalidad de los procesos concretos de inversión (Pérez,2018:91) lo que se apoyó en la fe de los gobernantes de que esa liberalización era la clave para alcanzar la modernidad urbana. Estos pensamientos aplican para entender porque la modernidad urbana de Lima fue en gran medida el resultado de las decisiones del Estado para satisfacer a la élite. Así también, como la búsqueda de progreso de estos grupos llevó a mercantilizar el suelo para materializar la modernidad urbana en la ciudad. Sobre esta idea particular de modernizar, México, a finales del siglo XIX, también tuvo el proyecto arraigado de alcanzar el progreso. Por esta razón existen algunas similitudes y diferencias con Lima, lo que nos permite mostrar que la construcción de la modernidad urbana tuvo puntos en común. En el caso de México el progreso fue concebido como una reforma (Pérez,2018: 99). En México fue un "proceso que tendía a modernizar actividades, elevar las condiciones sociales, hacer uso de nuevas tecnologías y modificar territorios. En este proceso, "fue importante la aparición de un grupo de profesionales preocupados por los problemas de la ciudad, quienes analizaron, teorizar y elaborar propuestas coadyuvaron a encaminar a la capital a la modernidad que despuntaba en el mundo" (Sánchez ,2013:252). En el caso de Lima en el siglo $\mathrm{XIX}$, los higienistas contribuyeron diagnosticar y cuantificar el problema de salubridad en el centro, pero además, incorporaron normativas para mejorar la calidad de vida en la ciudad y generaron una nueva demarcación territorial para proveer de manera equitativa recursos y construir infraestructura.

La mercantilización de suelo a partir de las reglas emitidas por el Estado también fue una característica en el proceso de urbanización de la ciudad de México. Al producirse la expansión del territorio de la capital, iniciado en 1854, surgió la mercantilización del suelo con la aparición de los primeros fraccionadores y la primera sociedad inmobiliaria de la ciudad de México, para producir riqueza adquiriendo toda clase de terrenos agrícolas para lotificarlos y venderlos como lotes urbanos"(Jiménez,1993:6). En todo ello se restó poder a los monopolios religiosos mediante la confiscación de bienes. Para Lima la mercantilización del suelo de periferia inició cuando se decidió demoler la muralla. Entonces apareció el fraccionador Meiggs, quien adquirió con el aval 
del Estado, los terrenos de la periferia, siendo este un caso de un monopolio inmobiliario. Por su parte, la actividad inmobiliaria en México se dio para consolidar las colonias donde "surgió otro tipo de especulador inmobiliario, que aprovechará, por un lado, las ventajas de una ley de colonización y, por otro lado el interés gubernamental por atraer capitales externos, permitiendo así la entrada de la primera inmobiliaria extranjera, con la promulgación en 1883 con la Ley sobre terrenos baldios" (Jimenez1993). "Esta ley no solo permitió a las compañías encubrir sus proyectos de urbanización sino sentar jurisprudencia para que los extranjeros no residentes en el país pudieran tener propiedades en México"(Jiménez,1993:10). En Lima este precedente de expropiación del Estado y especulación inmobiliaria ya se había sentado cuando se inició la demolición de la muralla. En ambos casos, el resultado fue la especulación de suelo avalado por los respectivos gobiernos de turno, con el objetivo de aumentar la oferta de vivienda en las ciudades y mejorar la calidad de vida de la población. En Lima el proceso de mercantilización de suelo trajo consigo desorden en la urbanización y la falta de implementación de servicios básicos por parte de las urbanizadoras provocando problemas de salubridad. En México los inversionistas extranjeros implementaron servicios básicos producto de la competencia existente. Además, existía una normativa para la apertura de calles y la construcción de casas y en ambos casos el control de la salubridad quedó a cargo del gobierno local.

En Lima, el ingeniero Tizón y Bueno reclamaba un catastro para la ciudad, para conocer el estado de la urbanización de la periferia el año 1906. En México Antonio Torres Torrija elaboró el primer informe sobre las colonias del Distrito Federal (Jiménez,1993:24). En ambos casos, la materialización de la modernización urbana continuaría en función de los intereses de la élite con el aval de los gobiernos de turno.

Uno de los indicadores de la materialización de la modernidad urbana, es la obra pública, que nos permite conocer "¿Hasta qué punto la modernización de las obras públicas en México permitió un sistema eficaz para el aprovisionamiento de la infraestructura? Se trata de una especie de costo beneficio, no del costo de las obras en sí, sino de las políticas que las promovió y de su forma de producción" (Connolly, 1997:390-391). 
El contratismo, se inició en el periodo de Ramón Castilla el año 1855 en el primer intentó modernizador y continuó entre los años de 1870 a 1876. En el capítulo segundo, vemos contratos de obras por parte de la Municipalidad para refaccionar edificaciones, canalizar y ejecutar tendido de redes para agua y desagüe en los barrios cerca al centro con el objetivo de mejorar la calidad en el centro. A partir de 1869, el gobierno delegó la demolición de la muralla al fraccionador Meiggs. A partir de entonces los empresarios extranjeros fueron los grandes contratistas de la obra pública en Lima. Estas obras de envergadura que se proyectaron dan muestra de una construcción especulativa en la construcción de la infraestructura (Connolly, 1997:393) porque estaban sobre valoradas por los inversionistas que las ejecutaron como el fraccionador Meiggs. En ambos casos la obra pública tuvo el objetivo de modernizar la infraestructura de la ciudad como una urgencia de los gobiernos de turno de demostrar la materialización de la modernidad urbana. En ambos casos existió un gran contratista de obras de envergadura en la ciudad y obras de ferrocarriles. Para México fue Pearson y para Lima Meiggs, estos personajes fueron para ambos gobiernos de turno piezas claves para alcanzar el progreso y activar la económica en la ciudad. 


\section{Bibliografía General}




\section{Bibliografía General}

Acta de fundación de Lima (1535). Lima, Municipalidad Metropolitana de Lima.

Alcántara, E.(2018) Fraccionadores y fraccionamiento. Una historia de la ciudad del desarrollo inmobiliario en México a través de Ciudad Satélite y Villa Coapa (1952-1980). Tesis de Maestría.UNAM.

Almandoz, A. (2008) Despegues sin madurez: urbanización industrialización y desarrollo en la Latinoamérica del siglo XX. En: Revista EURE Tomo 34, N 102 agoso-2008 pp.1-13.

Almandoz, A. (2018) Modernización urbana en América Latina de las grandes aldeas a las metrópolis masificadas. Santiago de Chile, Ed. Ril.

Almandoz, A. (2020) Reconsideraciones epistemológicas y conceptuales sobre el urbanismo, En: Revista EURE, vol. 46 Núm. 137, enero 2020, Santiago de Chile, pp. 282-283.

Álvarez, M. (1898). Apertura de Calles de Lima, En: Anales de Obras Públicas del Perú, Año 1898, Imprenta Torres Aguirre, 1999, p. 53-54

Aparicio, M. (1974). "El clero patriota en la revolución de 1814".

Angulo, D. (1939). Información que se hizo por el cabildo, justicia y reximiento desta ciudad de los reyes, y por ante mi Diego Fernández Montaño, theniente del cabildo, de la rruyna que padeció esta ciudad con el Terremoto de 20 de octubre de 1687. En: Revista del Archivo Nacional del Perú. Tomo XII. Lima, pp.7-164.

Arosemena, M. (1856) Lima, 30 de diciembre. La autoridad ilustrada por la ciencia: De las habitaciones. En: Gaceta Médica de Lima. Tomo 01, (Núm. 10), pp. 08-09.

Arosemena, M. (1856) Lima, 30 de noviembre. La autoridad ilustrada por la ciencia: 
De las aguas. En: Gaceta Médica de Lima. Tomo 01, (Núm. 08),pp. 10-11.

Arosemena, M. (1857) Lima, 15 de enero. La autoridad ilustrada por la ciencia: De las Habitaciones. En: Gaceta Médica de Lima. Tomo 01, (Núm.11), p. 8-9.

Augustín, B. (2011) Las murallas coloniales de Lima y Callao: Arquitectura defensiva y su influencia en la evolución urbana de la capital. Lima, Universidad Ricardo Palma, Editorial Universitaria.

Augustín, R. (2016) Ceques y dameros. La reducción indígena de Santiago del Cercado. Lima, Universidad Ricardo Palma, Editorial Universitaria.

Arancivia, F. (1886) Enunciado de problema general de canalización del Rímac y Sus subdivisiones a que se presta el proyecto. Lima, Imprenta Torres Aguirre.

Avila, A.(2013) Las declaraciones de independencia. Los textos fundamentales de las Independencias americanas. México. Ed. COLMEX.

Banco De Crédito Hipotecario (1873) Estatutos reformados del Banco de Crédito Hipotecario. Lima, Imprenta J.Francisco Solis.

Blanco C.(2014) Vale rectificar varios siglos después. En: La vivienda entre el derecho y la mercancía- Las formas de propiedad en América Latina, Ed. Trilce, 2014, Montevideo Uruguay.pp.1-248.

Barbagelata, J. (1971). Un siglo del acontecimiento histórico, precursor del desarrollo Urbano de Lima moderna. Lima, Instituto De Urbanismo Y Planificación del Perú.

Barbagelata, J., \& Bromley, J. (1945) Evolución urbana de la provincia de Lima. Lima, Imprenta Lumen.

Barreiro J. (2001) Ilustración y modernidad los avatares de la razón, Ed. Universidad 
de Santiago de Compostela.

Barros, M. (1970) Historia diplomática de Chile (1541-1938).Barcelona, Ed. Ariel.

Barreiro, J(2001) Ilustración y modernidad los avatares de la razón, Ed. Universidad de Santiago de Compostela.

Barrios, M. (1902). Proyecto de traslación del Hospital de Santa Ana, En: Crónica medica, Núm. 323.Imprenta San Pedro, p.161-172.

Basadre, J. (1971) Introducción a las bases documentales para la historia de la República del Perú con algunas reflexiones (Vol. 1). Lima, Ediciones PLV.

Basadre, J., (2004) Historia de la República del Perú. 1821-1933 Tomo I. Lima, El Comercio.

Basadre, J., (2004). Historia de la República del Perú 1821-1933. Tomo II. Lima, El Comercio.

Basadre, J., (2004). Historia de la República del Perú 1821-1933. Tomo III. Lima, El Comercio.

Basadre, J., (2004). Historia de la República del Perú 1821-1933. Tomo IV. Lima, El Comercio.

Basadre, J., (2004). Historia de la República del Perú 1821-1933. Tomo V. Lima, El Comercio.

Basadre, J., (2004). Historia de la República del Perú. Tomo VI 1821-1933. Lima, El Comercio.

Basadre, J., (2004). Historia de la República del Perú. Tomo VII 1821-1933. Lima, El Comercio.

Basadre, J., (2004). Historia de la República del Perú. Tomo VIII 1821-1933. Lima, El Comercio. 
Basadre, J., (2004). Historia de la República del Perú 1821-1933. Tomo IX. Lima, El Comercio.

Basadre, J., (2004). Historia de la República del Perú 1821-1933. Tomo X. Lima, El Comercio.

Basadre, J., (2004). Historia de la República del Perú 1821-1933. Tomo XI. Lima, El Comercio.

Basurco, J. (1907). Higiene en la habitación-informe emitido por la comisión nombrada Por el gobierno para estudiar las condiciones sanitarias de las Casa de vecindad de Lima, En: Boletín del Ministerio de Fomento. Año 3, N 4 Lima, 30 de abril de 1907, p.54-83.

Basurco, S. (1983). Planos de Lima de 1904. En: Colección Juan Gunther.Lima, Municipalidad de Lima Metropolitana, Petróleos del Perú, 1983.

Beltrán C.(2010) Colonización y consolidación del territorio en el siglo XIX: las nuevas naciones americanas En: Revista Apuntes, Bogota, juliodiciembre 2010, Vol 23. Núm.02 pp.102-103.

Bello, A. (1954). Principios de derecho internacional. Caracas, Ministerio de Educación.

Beneficencia Pública de Lima (1894) Estatutos de la Caja de Ahorros. Lima, Imprenta. Torres de Aguirre.

Benjamín G. (2017) Morfología y estructura urbana en ciudades medias mexicanas En: Revista Región y sociedad, Año XXIX, Núm.68 -2017 pp.153-191.

Bernales, J. (1972). Lima: La ciudad y sus monumentos. Sevilla, Escuela de Estudios Hispano-Americanos.

Berman, M. (1989) Lo sólido se desvanece en el aire, México, Ed. siglo XXI.

Bolognesi (1862). Plano de Lima 1862. En: Colección Juan Gunther. Lima, Municipalidad de Lima Metropolitana, Petróleos del Perú, 1983.

Bonialian, M. (2017) Plano de Red Marítima por el Cabo de Hornos en el siglo XVIII Recuperado de: http/historiamexicana.colmex.mx/index.php/ 
RHM/article/view/3441/3354.

Bonilla, E (1994) Guano y burguesía en el Perú. Quito, Flacso sede Ecuador.

Beltrán C.(2010) Colonización y consolidación del territorio en el siglo XIX: las nuevas naciones americanas. En: Revista Apuntes, Bogotá, julio-diciembre 2010, Vol 23. Núm.02 pp.102-103.

Borja J.(2016) La vivienda popular, de la marginalidad a la ciudadanía.

En: Geograficando, vol 12 n 02, 2,e009, diciembre 2016 Universidad Nacional de la Plata. Facultad de Humanidades y Ciencias de la Educación. Departamento de Geografía.

Bosch, A. (2005) Historia de los Estados Unidos 1776-1945.

Barcelona, Critica Barcelona.

Boza B. (1895). Panóptico. En: Anales de las Obras Públicas del Perú, Año 1985, Lima, Imprenta Torres Aguirre, p.125-126.

Boza B. (1895). Teatro de Lima, En: Anales de las Obras Públicas del Perú, Año 1900, pág.125.

Bromley J. (1945). Planos de Lima de 1613. En: Colección Juan Gunther. Lima, Municipalidad de Lima Metropolitana, Petróleos del Perú, 1983.

Butler, A. (1898). Corte en los parques de la exposición, En: Anales de las Obras Públicas del Perú, Año, 1898 p.300-301..

Butler, A. (1898). Colegio Guadalupe, En: Anales de las Obras Públicas del Perú, Año, 1898 p.212-213.

Calle, J. (1906). Diccionario de la legislación municipal del Perú. Imprenta Torres Aguirre.

Capel, H. (2002). La morfología de las ciudades. Tomo I: Sociedad, cultura y paisaje urbano (Vol. 37). Madrid, Ediciones del Serbal, SA.

Capelo,J. (1896). Canalización del Río Rímac, En: Anales de Obras Públicas del Ministerio de Gobierno y Policía y Obras Públicas, Año,1896, Imprenta Torres Aguirre p. 607-608.

Carcedo F. (2013) La ocupación informal del suelo urbano como estrategia de supervivencia: un estudio de caso en la ciudad de Santa Rosa La 
Pampa. En: Huellas № 17, 2013, Ed. Facultad de Ciencias

Humanas Universidad de la Pampa, Argentina, pp.35-53.

Castilla, R. (1857) Ley Orgánica de Municipalidades del año 1856. Lima, Imprenta del estado por E. Aranda.

Cicutti, V. (2007) Registros urbanos de una modernidad periférica. Representaciones y transformaciones materiales en el frente costero de Rosario 1920 y 1940. Buenos Aires. Ed. Nobuko.

Coello, A. (2001). El cercado de Lima colonial (1568-1606). Lima, Fondo Editorial PUCP.

Conolly, P. (1997) El contratista Don Porfirio obras públicas, deuda y desarrollo Desigual, México, Fondo de Cultura Económica.

Córdova Urrutia, J.(1839).Estadistica,histórica,geográfica,industrial y comercial de los Pueblos que componen las provincias del departamento de Lima. Ed. Imprenta de Instrucción Primaria por Félix Moreno.

Crespo, M. (2005) Arquitectura doméstica de la Ciudad de los Reyes, Sevilla, Escuela De Estudios Hispano-Americanos.

Cruz, M. (2010). Razón e Historia en el pensamiento ilustrado de José Baquíjano y Carrillo, Lima, Ed. PUCP. Escuela de Posgrado. Mención en filosofía Cuadros (1896). Plano de Canalización del Río Rímac. En: Anales de Obras Públicas Del Ministerio de Gobierno y Policía y Obras Públicas, Año 1896, p. 17.

Cuadros, (1896). Plano catastral de los terrenos de las antiguas murallas.

En: Anales de Obras Públicas del Ministerio de Gobierno y Policía y Obras Públicas, Año 1896, p. 26-28.

Dávalos y Lissón, P. (1883). ¿Por qué hice fortuna?: relato inspirado en el recuerdo de Una vida dedicada a conseguir la independencia y la Tranquilidad de espíritu que da la posesión del dinero adquirido y no guardado con avaricia. Lima, Librería e 
Imprenta Gil.

Dávalos y Lissón, P. (1926). La primera centuria: causas geográficas, políticas y económicas que han detenido el progreso moral y material del Perú en el primer siglo de su vida Independiente. Tomo II, Lima, Librería e Imprenta Gil.

De la Puente, J. (2016). El estado en la sombra: el Perú durante la ocupación Chilena: Documentos administrativos (diciembre de 1881-julio de 1882). Lima, Fondo Editorial, PUCP.

De Mattos, C. (2015. La burguesía y el Espacio. Carlos A. De Mattos y Enrique Link En: Lefvebre revisitado: capitalismo, vida cotidiana y el derecho a la ciudad. Ed. Ril. Santiago de Chile, 2015. pp.19-37

De Mattos,C. (2016). La lógica financiera de la financiación y crecimiento urbano Mercantilizado. En:Urbanización planetaria y la reconstrucción de la ciudad. Arturo Orellana y otros Ed. Ril editores, Universidad Católica de Chile, Santiago. 2016 pp.29-57.

Director O. Públicas del Perú, (1896). Terrenos de las antiguas murallas y demás expropiaciones por D. Enrique Meiggs para la Alameda de circunvalación, En: Anales de Obras Públicas del Ministerio de Gobierno y Policía y Obras Públicas, año,1896, p. 31

Dupard J.(1859). Plano de Lima 1859, En: Juan Gunther Doering, Municipalidad Metropolitana de Lima, Petróleos del Perú, 1983.

Eguiguren, L., (1966). Lima Inexpugnable: Un libro desconocido del polígrafo Pedro de Peralta Barrionuevo. Lima, Lurimsa.

Eguiguren, L. (1945). Las calles de Lima. (Vol. 1).

Elmore, (1891). Alumbrado eléctrico para Lima. En: Anales de Obras Públicas del Ministerio de Gobierno y Policía y Obras Públicas, año 1891, p.216.

Escobedo, J. (1785). La División de quarteles y barrios, e instrucción para el establecimiento de alcaldes de barrio en la capital de Lima. Lima 
Espagne. (1841). Recopilación de leyes de los reinos de las Indias, mandada [s] imprimir y publicar por la Majestad católica del rey don Carlos II, nuestro señor: Va dividida en cuatro tomos, con el índice general, y al principio de cada tomo el especial de los títulos que contiene.

Boix, Editor.

Fernandez R.(2014) La construcción social de la propiedad privada en la evolución reciente del país y la región. En:La vivienda entre el derecho y la mercancía- Las formas de propiedad en América Latina, Ed. Trilce, 2014, Montevideo Uruguay.pp.1-248.

Ferreyros, G. (1888). Memorias del prefecto del departamento de Lima. Lima. Imprenta De Torres Aguirre

Fisher, J. (2000). El Perú borbónico (1750-1824). Lima, Ed. IEP.

Flórez. G. (1984). Aristocracia y plebe. Lima 1760-1830. Lima, Ed. Mosca Azul.

Flórez (1898). Cárcel para mujeres para Lima, En: Anales de las Obras Públicas del Perú, Año1898, p. 211.

Flórez (1898). Morgue de Lima, En: Anales de las Obras Públicas del Perú, Año, 1898, p. 211-212.

Fuentes, M. (1859). Elementos de higiene privada: extractos de diversos autores. Lima, Tip. Nacional de M.N. Corpancho.

Fuentes, M. (1869). Manual práctico de medicina legal. Lima, Imprenta del Estado.

Fuentes, M. (1858). Estadística General de Lima (Volumen I). Lima, Perú: Tip. Nacional

García Calderón, F. (2003). Diccionario de la legislación peruana, 2 vols. Lima: Editorial Jurídica Grijley.

Garcia-Bryce, I.(2004). Crafting the republic: Lima's artisans and nation-building in Perú, 1821-1879, Universidad de Nuevo México.

García-Calderón, F. (1868). Estudios sobre el Banco de Crédito Hipotecario y las Leyes de Hipotecas. Lima, Imprenta dirigida por José M. Noriega. 
Gascón, M. (2005). Vientos, terremotos, tsunamis y otras catástrofes naturalesHistoria y casos latinoamericanos. Buenos Aires, Argentina: Editorial Biblos.

Gorelik A. (2013) Ciudad, modernidad y modernización. En: Revista Universitas Humanística, Núm. 56 junio 2003, Universidad Javeriana,

Bogotá, pp.11-27.

Guerra, M. (1991). La ocupación de Lima, 1881-1883.Lima, PUCP, Dirección Académica de Investigación, Instituto Riva-Agüero.

Gunther (1983). Plano de Lima de 1896. Plano preparado por el Cuerpo de

Tasaciones para el avaluó de las áreas urbanas de Lima.

Municipalidad Metropolitana de Lima, Lima, Petróleos del Perú, 1983.

Gutiérrez, R. (2005). Fortificaciones en Iberoamérica. Madrid, Ed. Fundación Ibedrola Gutiérrez, R., \& Esteras, C. (1993). Pueblos de indios. Otro urbanismo en la región Andina, Quito, Abya-Yala.

Herrera (1891) Agua potable para el Barranco, En: Anales de las Obras Públicas del Perú, Año, 1891, p.194-197.

Herrera, (1891) Embellecimiento de la Plaza Grau en el Callao. En: Anales de las Obras Públicas del Perú, Año,1891, p.189.

Hidalgo, L. (1908) Principios generales que deben servir de base a los proyectos de nuevas poblaciones. Lima, Imprenta del Centro Editorial.

Hoolhaas R.(2004) Delirio de Nueva York, Barcelona, Ed. Gustavo Gili.

Hunt, S. J. (1973). Growth and guano in nineteenth century Peru (No. 34). Research Program in Economic Development, Woodrow Wilson School, Princeton University.

Jaramillo, S. (2009). Hacia una teoría de la renta del suelo urbano. Ediciones Uní Andes, Universidad de los Andes.

Jiménez, J.(1993). La traza del poder: historia y política de los negocios urbanos en el 
Distrito Federal de sus orígenes a la aparición del Ayuntamiento (1824-1928). México. Ed.Codex.

Jouanny P.V (1983) Planos de Lima de 1880. En: Colección Juan Gunther.Lima, Municipalidad de Lima Metropolitana, Petróleos del Perú, 1983. Junta Departamental (1897). Matrícula de Predios Rústicos y Urbanos de 1897. Lima

Quimper, J.M.(1866) Reglamento de policía de seguridad pública, Lima, Ministerio de Gobierno, Policía y Obras Públicas.

Landa, I, (2020) Una aproximación a la historiografía urbana: algunos aspectos epistemológicos y históricos. En Revista Eure Vol. 36 Núm. 139, setiembre 2020,.Santiago de Chile. pp.259-276

La Parra López, E. (1984). La libertad de prensa en las Cortes de Cádiz, Ed. NAU Libre.

Larraín, J.(2004) Identidad y modernidad en América Latina. México, Ed. Océano. Laso B. (1839) Reglamento de policía para la capital de Lima y su provincia Lima, Imprenta José Masías.

La Colmena (1902) Estatutos de la Colmena Asociación Anónima de construcción y Ahorros. Lima. Librería Imprenta Gil.

Lebfervre (1976) Espacio y política. Ed. Península.

Lossio, J. (2002). Acequias y gallinazos: salud ambiental en Lima del siglo XIX. Lima, Ed. IEP.

Ludeña, W. (2002). Lima: poder, centro y centralidad: Del centro nativo al centro neoliberal. En: Revistas EURE, Vol.8 N 83 mayo 2002, p.45-79.

Ludeña, W. (2004). Lima: historia y urbanismo en cifras 1821-1970. Lima, Universidad Nacional de Ingeniería.

Lumbreras, L. (2003) Historia de América Latina. Volumen 5 creación de las Repúblicas y Formación de la Nación, Quito, Ed. Universidad Andina Simón Bolívar.

Mathew, M. (2009) La firma inglesa Gibbs y el monopolio del guano en el Perú, 


\section{Ed Banco Central de Reserva del Perú.}

Martínez G. (2020) Derribar muros. De la historia urbana a los estudios urbanos con perspectiva histórica: propuestas teóricas metodológicas desde un dialogo interdisciplinar. En: Revista Eure Vol.46 № 137 Enero 2020, pp.23.

Mejia Pavony G.(1999) La pregunta por la existencia de la Historia Urbana. Conferencia de Germán Rodrigo Mejía Pavony. Universidad. Javeriana conferencia marzo 1999. Bogotá pp.1-14.

Mc Evoy, C. (1997). La utopía republicana: ideales y realidades en la formación de la cultura política peruana 1871-1919. Lima, Fondo Editorial PUCP.

Mc Evoy, C. (2004). La experiencia burguesa en el Perú, 1840-1940, Lima, Iberoamericana, Ed. Vervuet

Mc Evoy, C. (2011). Guerreros civilizadores. Política, sociedad y cultura en Chile durante la Guerra del Pacífico. Santiago, Ediciones UDP.

Meiggs, E. (1875) Plano topográfico de Lima. En: Evolución Urbana de Lima. Bromley y Barbagelata, Ed. Lumen, 1945.

Meiggs, E. (1876) Plano de la Avenida Unión. En: Evolución Urbana de Lima. Bromley y Barbagelata, Ed. Lumen, 1945.

Memorias. Municipalidad de Lima (1903) Fragmento del plano de la Canalización de Lima, Proyecto de Lima y sus alrededores, plano, Mapoteca de la B.N.P.

Meyer, R., Salazar, A., \& Gutiérrez, E. (2003). Los inmigrantes en el mundo de los negocios, siglos XIX y XX. México, Ed. Plaza y Valdés.

Ministerio de Fomento (1896) Registro oficial de Fomento, Minas y BeneficenciaSección Beneficencia, Año 1,1896,Lima, Imprenta de la Escuela de Ingenieros.

Morales, D. (2011). La ciudad de México en el siglo XIX. Ensayos urbanos. México, Universidad Autónoma Metropolitana 
Morante, M. (1907). Carta al Sr. Inspector de Higiene del H. Consejo Provincial

En: Boletín Demográfico Sanitario de Lima. Lima, Imprenta Liberal

Moreno, A. (1983). Relación y documentos de gobierno de Perú (1745-1761). Madrid,

Consejo Superior de Investigaciones Científicas, CSIC.

Nahoun,B.(2014), “Uno, dos o más formas de tenencia segura” pp.11-19 En: “La vivienda entre el derecho y la mercancía- Las formas de propiedad en América Latina" Montevideo, Ed. Trilce.

O'phelan, S. (2013). Perú Crisis Imperial e Independencia. Tomo 1 1808-1830,

Ed. Mapfre.

Odriozola, M. (1863). Terremotos. Colección de las relaciones de los más notables que ha sufrido esta capital y que la han arruinado. Lima, Tipografía de A. Alfaro

Orrego, J. (2005). La ilusión del progreso: los caminos hacia el estado-nación en el Perú y América Latina (1820-1860). Fondo Editorial PUCP.

Ortiz, J. (1997) Los cosmógrafos mayores del Perú en el siglo XVII. En: Boletín Instituto Riva Agüero, Nro. 24, Lima -Perú Ed. PUCP, 1997, p.383.

Páez.(2009) Teorías críticas de la modernidad Ensayos. Ed. UNAM.

Palma, R. (1968). Tradiciones peruanas, Lima, Ed.USP.

Paris, M. (2013). De los centros urbanos consolidados a los lugares de centralidad: una propuesta metodológica para su estudio. Ciudades, 16 (1) 47-69. Recuperado de: http://uvadoc.uva.es/.

Patiño, M. (1891) Terrenos de las riberas del Rímac. Lima, Impr. Centro Militar del Perú.

Paz Soldán, M. F. (1877). Diccionario geográfico estadístico del Perú. Lima, Imprenta Del Estado.

Pegenaute, P.(1974). Represión política en el gobierno de Fernando VII: Las Comisiones militares de 1824-1825. Navarra, Universidad de Navarra.

Pereyra. (1980) Historia, ¿para qué? México, Ed. Siglo XXI.

Pérez, I. (2018) Las concepciones del progreso y la construcción de un proyecto 
nación: hacia una historia de las ideas en el entendido siglo XIX mexicano (1821-1910). En: Revista Histórica XLII.2 , Lima, (2018) pp.89-139.

Pérez,I. (1891). Ferrocarril de Lima a La Magdalena, En: Anales de las Obras Públicas del Perú, Año,1891, p. 233-234.

Pérez, P. (1985). La población de Lima en el S. XVIII. España, Universidad Autónoma de Madrid.

Pineo, R., Baer, J. A., \& Baily, S. L. (1998). The Cities of Hope. People, Protest and Progress in Urbanizing Latin America, 1870-1930. Routledge

Portella, J. (1923) Manual del propietario: Recopilación de leyes y resoluciones Relativas a la propiedad, Lima, Imprenta Progreso.

Portocarrero, S., \& Panfichi, A. (2004). Mundos interiores, Lima 1850-1950.Lima: Ed. Universidad del Pacífico.

Quiroz, A. W. (1987). La deuda defraudada: consolidación de 1850 y dominio Económico en el Perú. Lima, Instituto Nacional de Cultura.

Ramón, G. (1999). La muralla y los callejones, intervención urbana y proyecto político en Lima durante la segunda mitad del siglo XIX. Lima, PomperúSidea.

Ramón G. (2007). El guion de la cirugía urbana: Lima, 1850-1940. Lima. San Marcos.

Ramírez R.(2007) Del suburbio, la periferia al borde: Modelo de crecimiento de la zona Metropolitana del Valle de México En: Revista Leirdinarie Latino Americain,2007, http://www.scielo.org.co/scielo.php?script=sci_nlinks\&ref=000282\& pid=S0121-215X201400010000300048\&Ing=es pp.69-89.

Rey De Castro, A. (2004). El pensamiento político y la formación de la nacionalidad peruana 1780-1820. Tesis de maestría. 
Pontificia Universidad Católica del Perú.

Roix (1841). Recopilación de Leyes de los Reynos de las Indias mandadas a imprimir y publicar por la magestad católica del Rey Carlos II nuestro señor. Tomo II, quinta edición, Impresión y Librero calle de Trinitas número 8.

Romero, E., \& Contreras, C. (2006). Historia económica del Perú, Lima, Ed. UNMSM. Romero, J. (1976). Latinoamérica, las ciudades y las ideas. Buenos Aires, Siglo XXI. Rosario, E. (2014). Parlamentos en conflicto: el Congreso de la República y la Guerra del Pacífico, 1879-1881. Seminario de Historia Rural Andina, Fondo Editorial, Universidad Nacional Mayor de San Marcos.

Rosa Toro, A. (1856) Importancia de la higiene pública. En: Revista Gaceta médica de Lima. Tomo 01, (Núm. 03), Lima, 15 de setiembre. p. 11.

Rosas, F. (1856) Alumbrado por gas. En: Revista Gaceta Médica de Lima. Tomo 01 Lima, (Núm. 09), 15 de diciembre. pp 08-09

Rosas, F. (1857) Una ojeada sobre el estado higiénico de Lima. En: Gaceta Médica de Lima. Tomo 02, (Núm. 26), Lima, 30 de agosto. 19-20

Rougemont, P. (1883) Una página de la dictadura de D. Nicolás de Piérola. Lima: Impr. Cosmopolita.

Rueda, L. (2016) "Hacia un estado del arte de la historia urbana en Colombia: el caso de Bogotá" En Revista Apuntes,Vol 29 Núm. 02, 2016, Bogotá, pp.56-67.

Ruiz J. (2016) La persistencia de la segregación y la desigualdad en barrio socialmente diversos: Un estudio de caso en La Florida, Santiago. En: Revista EURE Tomo 42, № 125 (jan 2016. pp. 81-107

Sada, L. (1872) Plano topográfico de la Ciudad de Lima. En: Evolución Urbana de Lima. Bromley y Barbagelata, Ed. Lumen,1945.

Sáenz, I. (2005). La urbe y el mar. Caletas y Puertos en Lima durante el siglo XVIII. En: Revista Derroteros de la Mar del Sur. N¹3. P.123-143.

Sáenz, I. D. (2015). El Damero en discusión. Prácticas espaciales y cartografía urbana en Lima tardo virreinal. Terra Brasilis (Nova Série). En: Revista da Rede Brasileira de Historia da Geografía e Geografía Histórica, 
San Martín, M. (1891). Distribución de agua entre varios edificios del Estado, Anales De Obras Públicas del Ministerio de Gobierno y Policía y Obras Públicas. Año, 1891, p. 220-223

San Martin, M. (1895). Alumbrado por gas del Palacio de Gobierno, En: Anales de las Obras Públicas del Perú, Año, 1895.p.196.

San Martín, M. (1895). Terrenos destinados a la nueva cárcel de Lima, En: Anales de las Obras Públicas del Perú, Año 1895. p.199-202.

Sánchez, A. (1857) Lo que es el médico en nuestra actual sociedad. En: Revista Gaceta Médica de Lima Tomo 02, (Núm. 25), Lima, 15 de agosto.p.1-2.

Sánchez G. (2013) Preculsores del urbanismo de México. México. Ed. Trillas.

Salas, M. (2016) Dinámica territorial del poder político en Venezuela contemporánea (1961-2013).En: Cuadernos de geografía Revista Colombiana de Geografía Vol 25 núm. ene-junio 2016 Bogotá, pp.95-109.

Serna, M. (2017) Cambios hasta cierto punto segregación residencial y desigualdades económicas en Montevideo (1996-2015) Latin American Reseach Review ,2017, 52 (4) pp.571-588

Sifuentes, L. (2004). Las murallas de Lima en el proceso histórico del Perú, Ensayo acerca de la historia y evolución urbana de la ciudad de Lima entre los siglos XVII y XIX. Lima, Ed. Concytec.

Silgado, E, (1898). Avenida La Magdalena-proyecto En: Anales de Obras Públicas del Perú Año, 1899, Imprenta Torres Aguirre. p.301-305.

Simmons, M. (1963). Los escritos de Juan Pablo Viscardo y Guzmán precursor de la Independencia hispanoamericana. Caracas, Universidad Católica Andrés Bello.

Sociedad Anónima de Constructores (1902). Estatutos de La Colmena. Lima: Librería e imprenta Gil, Lima, Torres Aguirre.

Stewart, W. (1946). Henry Meiggs, Yankee Pizarro. Duke University.

Suarez, F. (2002). Las Cortez de Cádiz. Madrid, España: Ed. Rialp. 
Tantaleán, J. (2011). La Gobernabilidad y el Leviatán Guanero. Desarrollo, crisis y guerra con Chile. Lima, BCRP-IEP.

Tarazona, J. M. (1946). Demarcación política del Perú, Recopilación de Leyes y Decretos (1821-1946). Lima, Ministerios de Hacienda y Comercio,

Dirección Nacional de Estadística.

Terrazas, O. (2010). La ciudad que hoy es centro. México, UAM Azcapotzalco.

Terry, T. (1896). Plano catastral de los terrenos de las antiguas murallas,

En: Anales de Obras Públicas del Ministerio de Gobierno y Policía y Obras Públicas de 1896. p. 25-27.

Terry, T. (1896). Terrenos de las antiguas murallas de Lima, En: Anales de Obras Públicas del Ministerio de Gobierno y Policía y Obras Públicas de 1896. p. $20-25$.

Tibersar, A. (1991). Comienzos de los franciscanos en el Perú (Vol. 1). CETA. Tizón y Bueno, R. (1906). Memoria 11 Ensanche de Lima. Conferencia dada por el Socio Ricardo Tizón y Bueno En: Boletín de la Sociedad de Ingenieros del Perú. Imprenta. Sociedad de Ing. Del Perú.

Tizón Y Bueno, R. (1913). Agrimensura legal: las leyes de expropiación, Lima, Tip. de El Perú.

Tizón y Bueno, R.(1913) . Agrimensura legal peruana, Lima, Ed. Centro Editorial. Tizón y Bueno, R. (1916) El plano de Lima. Apuntaciones Históricas y estadísticas, Lima, Imprenta del Centro Editorial.

Tizón Y Bueno, R. (1917). Consolidación de Enfiteusis, Lima, Tip. de El Perú Tizón y Bueno. (1983). Plano de Lima de 1907, En Colección Juan Gunther 16131983. Lima: Municipalidad de Lima Metropolitana, Petróleos del Perú.

Ulloa, J. (1862) Crónica de la Quincena. En: La Revista de Lima, Tomo VI, p. 115-120

Urrea, D. (1923) Tercer informe de la inspección fiscal de bancos, cajas de ahorros, Compañías de seguros, y empresas urbanizadoras correspondientes Al año de 1923. Lima, Inspección Fiscal de Bancos.

Valle, F. (2006). Teología, filosofía y derechos en el Perú de las XVIII-Dos reformas 
ilustradas en el Colegio de San Carlos de Lima (1771 y 1787).

En: Revista Teológica Límense. Vol XL - No. 3 - 2006 (pp. 337-382)

Vargas Ugarte R. (1941). Los jesuitas del Perú (1568-1767). Lima.

Vargas, Ugarte R. (1956). Historia del Perú Virreinato, siglo XVIII 1700-1790.

Librería Imprenta Gil.

Velasco A. (2015) Reseña de las Reformas Borbónicas 1750-1808 coordinado por

Clar García Aluardo. Memoria y sociedad 19 №38,pp.90-93.

Vigñas, (1891). Ferrocarril de Lima al Callao y Chorrillos, En: Anales de Obras

Públicas del Perú. Año, 1891,p.233-234

Villa-García, M. (2013). La transformación en 150 años, desde el" Sol" al" Nuevo Sol".

En: Revista Moneda, (154), p.43-49.

Walker, C. (2012). Colonialismo en ruinas: Lima frente al terremoto y tsunami de 1746. Lima: Instituto Francés de Estudios Andinos.

Waisman M.(1972) La estructura del entorno histórico. Buenos Aires, Ed. Nueva Visión.

Ward, T. (2010). El porvenir nos debe una victoria: La insólita modernidad de Manuel González Prada. Red para el desarrollo de las Ciencias Sociales en el Perú.

Zambrano I(1993) En: El poblamiento durante la colonia "Ciudad y territorio proceso Del territorio en Colombia. Ed. IFEA, Lima, Año 1993. p.25-61.

Zapatel, A. (1891). Memorias del prefecto del departamento de Lima. Lima: Imprenta Calle del Cuzco 124. 


\section{Bibliografía digital}

Goyas, R. (2013). Asentamientos y pueblos de indios desaparecidos en el alto Jalisco durante el virreinato. En: Revista Scielo Nro.30 Vol. 15 julio-dic.2013 recuperado de: http:/www.scielo.org/scielo.php?script=sci_arttext\&pid=S44202013000200002.

Plano topográfico 1787 copia de 1862. Colección del Museo de Historia y Antropología de Lima. Fotografía de Antonio Manrique. https://www.researchgate.net/figure/Figura1-Plano-Topografico-1787-Copia-de-1862-Coleccion-Museo-Nacionalde fig1 321129616

Plano de Lima por P.V Jouanny 1872

https://www.google.com.pe/search?q=Plano+de+Lima+Jouany+1872\&tbm=isch\&ved= 2ahUKEwixyYaG0-inAhUInaOKHfQwAGgQ2-

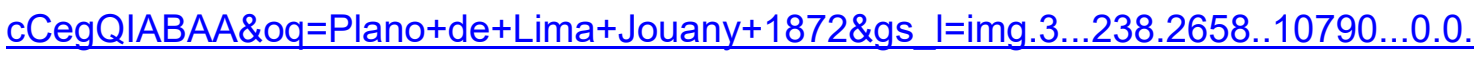
.0.552.2640.0j6j1j3j0j1 ..........1..gws-wizimg.xyrTYD9SX8g\&ei=w JSXvHbBoi6tgX04YDABg\&bih=632\&biw=1280\#imgrc=OrZRmitq-vgSM

Plano de Lima de 1908 por C. Fabbri

https://www.rsgs.org/blog/collections-corner-the-1908-plano-delima?fbclid=IwAR0yG44LVJ5JBe3f8ZNkhnKSeWKqMVwvJZpwDeCtkYglocn1ATWIpk bBLrO

La avenida la Colmena o Nicolás de Piérola el año 1920

lalimaquesefue.blogspot.com/2011/02/foto-ano-1920-avenida-la-colmena.html

Las murallas de Lima en un plano de 1750 https://medium.com/@culturaparalima/lasmurallas-ribere\%C3\%B1as-de-lima-1508decb9398

La nueva ruta por el Cabo de Hornos desde 1778. México de epicentro a periferia. La desintegración del modelo semi informal del comercio hispano americano (17501840) MarianoBonialian.https://www.google.com.pe/search?q=La+nueva+ruta+por+el+Cabo+ de+Hornos+desde+1778\&tbm=isch\&ved=2ahUKEwjl57DMnubnAhVJY60KHdWNDHo Q2-

Plano de Lima de 1858 por Manuel Atanasio Fuentes.

https://www.google.com.pe/search?sxsrf=ALeKk01oE0t5qlzY98hHrPkSVnFWdy8laQ:1 
582592385722\&q=PLano+de+la+ciudad+de+LIMA+RECTIFICADO+POR+mANUEL+a TANASIO+fUENTES\&tbm=isch\&source=univ\&sa=X\&ved=2ahUKEwjjmOaHwOvnAhX bUsOKHegeCMwQsAR6BAgKEAE\&biw=1280\&bih=632\#imgrc=MzRE5byco3dpOM $(1858$, p.)

Sáenz, I. (2008) Imaginaciones urbanísticas y proceso reconstructivo en Lima y Callao (17461761)http://www.esteticas.uanm.mx/revistas_imagenes/rastris/ras_isaenz01.html 


\section{Documentos de Archivo}

Libro de Cabildo Nº1 (1535) Acta de Fundación de Lima. Fol.23

Concejo Municipal de Lima, (1881). Actas de sesión sobre alumbrado y serenazgo, pág. 86.

Concejo Municipal de Lima, (1881). Actas de sesión sobre el acuerdo para el Puente Balta, pág. 118.

Concejo Municipal de Lima, (1881). Actas de sesión sobre el Hospital de Sangre de la exposición, pág. 69.

Concejo Municipal de Lima, (1881). Actas de sesión sobre el sostenimiento de las cárceles y hospitales de sangre, pág. 82.

Concejo Municipal de Lima, (1881). Actas de sesión sobre la cuenta del alcalde, pág. 80.

Concejo Municipal de Lima, (1881). Actas de sesión sobre la Inhumación de cadáveres insepultos en el campo de batalla, pág. 115.

Concejo Municipal de Lima, (1881). Actas de sesión sobre la proposición de un cupo de s/. 1 000, pág. 130-131.

Concejo Municipal de Lima, (1881). Actas de sesión sobre las facultades extraordinarias al alcalde, pág. 78.

Concejo Municipal de Lima, (1881). Actas de sesión sobre los pagos de la Caja Municipal, pág. 116.

Concejo Municipal de Lima, (1881). Actas de sesión sobre los pagos de la Caja Municipal, pág. 82.

Concejo Municipal de Lima, (1884). Actas de sesión respecto a la cuenta de la tesorería municipal del año 1883, pág. 26-27.

Concejo Municipal de Lima, (1884). Actas de sesión sobre acuerdos y bases con la Empresa de Transportes, pág. 07-10.

Concejo Municipal de Lima, (1884). Actas de sesión sobre el informe de la Municipalidad de Miraflores respecto a la construcción de la carretera de Lima, pág. 24.

Concejo Municipal de Lima, (1884). Actas de sesión sobre la Cárcel de Guadalupe, pág. 07.

Concejo Municipal de Lima, (1884). Actas de sesión sobre la numeración de las puertas a la calle, pág. 23. 
Concejo Municipal de Lima, (1884). Actas de sesión sobre los informes del Boletín Municipal, pág. 20.

Concejo Municipal de Lima, (1898). Actas de sesión sobre las comisiones delegadas para las diversas obras, pág. 362.

Concejo Municipal de Lima, (1903). Actas de sesión sobre el Jockey Club, pág. 499.

Concejo Municipal de Lima, (1903). Actas de sesión sobre gestión del agua potable, pág. 51.

Concejo Municipal de Lima, (1903). Actas de sesión sobre las obras del Instituto Municipal de Higiene, pág. 56.

Concejo Municipal de Lima, (1903). Actas de sesión sobre procedimientos antihigiénicos, pág. 38-40.

Concejo Municipal de Lima, (1903). Actas de sesión sobre reparación de pavimento, pág. 51.

Concejo Municipal de Lima, (1904). Actas de sesión sobre refacción de calle San Jacinto, pág. 447.

Documento de convenio y expropiación en terrenos de Magdalena (1872).Archivo General de la Nación (AGN) Colección Terán Tomo 02, fol. 829v.

Documento de venta de casa en Calle de Sacristía (1872).Archivo General de la Nación (AGN) Colección Terán Tomo 02, fol. 825.

Documento de venta de casa en Calle Huaylas (1872).Archivo General de la Nación (AGN) Colección Terán Tomo 02, fol. 830v-831.

Documento de venta de casita en Calle Belén (1872).Archivo General de la Nación (AGN) Colección Terán Tomo 02, fol. 820.

Documento de venta de Huerta en Calle Copacabana (1872).Archivo General de la Nación (AGN) Colección Terán Tomo 02, fol. 825v.

Documento de venta de terreno en Martinete (1872).Archivo General de la Nación (AGN) Colección Terán Tomo 02, fol. 825-825v.

Oficina de Obras Públicas y Fomento del Perú (1876) Plano de la Sección I. Manzana 2. Archivo General de la Nación (AGN) Protocolo Notarial 756, fol.86.

Oficina de Obras Públicas y Fomento del Perú (1876) Plano de la Sección I. Hacia el lado sur de la avenida de Circunvalación- Chacra Victoria. Archivo General de la Nación (AGN) Protocolo Notarial 757, fol.871.

Oficina de Obras Públicas y Fomento del Perú (1876) Plano de la Sección I. Trazado de las calles Maipiri, Bogotá y Montevideo. Archivo General de la Nación (AGN) Protocolo Notarial 756, fol.86. 
Oficina de Obras Públicas y Fomento del Perú (1876) Plano de la Sección II según el trazado realizado por Enrique Meiggs. Archivo General de la Nación (AGN) Protocolo Notarial 757 , fol.871.

Oficina de Obras Públicas y Fomento del Perú (1876) Plano de la Sección III del borde ribereño elaborado por Enrique Meiggs. Archivo General de la Nación (AGN) Protocolo Notarial 756 , fol. 86 .

Oficina de Obras Públicas y Fomento del Perú (1876) Plano de la Sección IV Trazado de la Manzana 22. Archivo General de la Nación (AGN) Protocolo Notarial 756, fol. 86.

Oficina de Obras Públicas y Fomento del Perú (1876) Plano de la Sección I. Archivo General de la Nación (AGN) Protocolo Notarial 756, fol.86.

Oficina de Obras Públicas y Fomento del Perú (1876) Plano de Sección V elaborado por Enrique Meiggs. Archivo General de la Nación (AGN) Protocolo Notarial 756, fol.86.

Oficina de Obras Públicas y Fomento del Perú (1876) Plano de Sección V elaborado por Sr. Aranibar. Archivo General de la Nación (AGN) Protocolo Notarial 754, fol.599.

Oficina de Obras Públicas y Fomento del Perú (1877) Plano de la Sección IV elaborado por Enrique Meiggs. Archivo General de la Nación (AGN) Protocolo Notarial 757 , fol. 871 .

\section{Notario Francisco Palacios (1875)}

Documento de Cancelación de hipoteca al Banco Hipotecario del Perú. Archivo General de la Nación (AGN) Protocolo Notarial 586, fol.1317v-1318.

Documento de Cancelación de hipoteca de casa en Calle Polvos Azules al Banco Hipotecario del Perú. Archivo General de la Nación (AGN) Protocolo Notarial 586, fol. 1260.

Documento de Cancelación de hipoteca en Calle Mariquitas al Banco Hipotecario del Perú. Archivo General de la Nación (AGN) Protocolo Notarial 586, fol. 1278v-1279.

Documento de Cancelación de hipoteca en Calle La Libertad al Banco Hipotecario del Perú. Archivo General de la Nación (AGN) Protocolo Notarial 586, fol. 1297.

Documento de Cancelación de hipoteca en Calle Espíritu Santo al Banco Hipotecario del Perú Archivo General de la Nación (AGN) Protocolo Notarial 586, fol. 1255.

Documento de cesión y expropiación en Huerta San Jacinto. Archivo General de la Nación (AGN) Colección Terán Tomo 06, fol. 172v.

Documento de expropiación de terrenos de Chacra Colorada. Archivo General de la Nación (AGN) Protocolo Notarial 586, fol. 1342v-1344.

Documento de Hipoteca de finca en Calle Espíritu Santo. Archivo General de la Nación (AGN) Protocolo Notarial 586, fol. 1251v-1252. 
Expropiación de los terrenos del señor Herrera a favor del fisco. Archivo General de la Nación (AGN) Protocolo Notarial 586, fol.1343.

\section{Notario José Selaya (1872)}

Documento de permuta de la huerta Virreina. Archivo General de la Nación (AGN) Colección Terán Tomo 25, fol. 387v-388.

Documento de venta de casa en Calle Divorciadas. Archivo General de la Nación (AGN) Colección Terán Tomo 25, fol. 306.

\section{Notario José Selaya (1873)}

Documento de Traspaso de enfiteusis de casa en Calle Belén. Archivo General de la Nación (AGN) Colección Terán Tomo 25, fol. 330v.

Documento de venta de terreno en Calle Tayacaja. Archivo General de la Nación (AGN) Protocolo Notarial 751, fol. 1198v.

\section{Notario José Selaya (1874)}

Documento de Cancelación de hipoteca en Calle La Libertad al Banco Hipotecario del Perú. Archivo General de la Nación (AGN) Colección Terán Tomo 25, fol. 341v.

Documento de cesión y permuta de las propiedades de huertas Salvi, Conde de la Vega y Lazo. Archivo General de la Nación (AGN) Protocolo Notarial 754, fol.597$598 \mathrm{v}$.

Documento de Hipoteca al Banco Hipotecario del Perú Hacienda Lusifico. Archivo General de la Nación (AGN) Colección Terán Tomo 25, fol. 352.

Documento y plano de cesión y permuta de Huertas Conde de la Vega y Arenibar. Archivo General de la Nación (AGN) Protocolo Notarial 754, fol.597-598v.

\section{Notario José Selaya (1875)}

Documento de venta del gerente de Obras Públicas y Fomento a diversos propietarios de manzana 5 Sección 4. Archivo General de la Nación (AGN) Protocolo Notarial 754, fol.868.

Documento de venta del gerente de Obras Públicas y Fomento a diversos Don Avelino Lazo y otros propietarios. Archivo General de la Nación (AGN) Protocolo Notarial 754, fol.902-902v.

Documento de compra de terrenos en Huerta Arrieta. Archivo General de la Nación (AGN) Colección Terán Tomo 25, fol. 305.

Documento de permuta de terrenos en Calle Tayacaja. Archivo General de la Nación (AGN) Colección Terán Tomo 25, fol. 368 
Documento de venta del gerente de Obras Públicas y Fomento a diversos propietarios de manzana entre Calle Arequipa, Tayacaja, San Martin y Avenida Central. Archivo General de la Nación (AGN) Protocolo Notarial 754, fol.894.

\section{Notario José Selaya (1876)}

Documento de Pago de acciones a la sociedad- El señor Enrique Meiggs a la Compañía de Obras Públicas y Fomento. Archivo General de la Nación (AGN) Protocolo Notarial 756, fol.76-85v.

Documento de Pago de acciones a la sociedad- El señor Enrique Meiggs a la Compañía de Obras Públicas y Fomento. Archivo General de la Nación (AGN) Protocolo Notarial 756 , fol.75-78.

Documento de Pago de acciones a la sociedad- El señor Enrique Meiggs a la Compañía de Obras Públicas y Fomento. Archivo General de la Nación (AGN) Protocolo Notarial 756, fol.76-85v.

Documento de permuta de terrenos en Huerta Virreina. Archivo General de la Nación (AGN) Colección Terán Tomo 25, fol. 387-388.

\section{Notario José Selaya (1877)}

Selaya, J. (1877) Documento de Pago de acciones del Gerente de la Compañía de Fomento y Obras Públicas a Enrique Meiggs. Archivo General de la Nación (AGN) Protocolo Notarial 757, fol.775v-783.

\section{Notario José Selaya (1879)}

Selaya, J. (1879) Plano de la testamentaria. Lima: Archivo General de la Nación (AGN) Protocolo Notarial 891.

\section{Notario C. Suarez (1874)}

Documento de arrendamiento de almacén en Calle de Espaderos. Archivo General de la Nación (AGN) Protocolo Notarial 901, fol. 356-357.

Documento de arrendamiento de casa en Calle del Hospital San Lázaro. Archivo General de la Nación (AGN) Protocolo Notarial 901, fol. 381v.

Documento de arrendamiento de casa en Calle Las Descalzas. Archivo General de la Nación (AGN) Protocolo Notarial 901, fol. 261-261v.

Documento de arrendamiento de casita solar en Calle los Gallinazitos. Archivo General de la Nación (AGN) Protocolo Notarial 901, fol. 116v-117v

Documento de arrendamiento de Casita y fábrica Ollería. Archivo General de la Nación (AGN) Protocolo Notarial 901, fol. 271v-272.

Documento de arrendamiento de pulpería frente a huerta que fue de Esteban Jiménez. Archivo General de la Nación (AGN) Protocolo Notarial 901, fol. 266v. 
Documento de arrendamiento de tienda en Calle Pandora. Archivo General de la Nación (AGN) Protocolo Notarial 901, fol. 276.

Documento de compra de terrenos. Archivo General de la Nación (AGN) Protocolo Notarial 898 , fol. $321 \mathrm{v}-322$.

Documento de compra-venta forzada de terrenos para el Ferrocarril de llo a Moquegua. Archivo General de la Nación (AGN) Protocolo Notarial 900, fol. 46-47.

Documento de permuta de terrenos de Huerta del Noviciado y Huerta Perdida. Archivo General de la Nación (AGN) Protocolo Notarial 900. fol. 79-80v.

Documento de permuta de terrenos de la Hacienda Miramares. Archivo General de la Nación (AGN) Protocolo Notarial 901, fol. 542v-544.

Documento de permuta de terrenos de la Huerta Perdida. Archivo General de la Nación (AGN) Protocolo Notarial 901, fol. 368v-369.

Documento de venta forzada por expropiación para el Ferrocarril de Pacasmayo. Archivo General de la Nación (AGN) Protocolo Notarial 901, fol. 252-255.

Plano de Huerta Perdida. Archivo General de la Nación (AGN) Protocolo Notarial 900. Adjunto al folio 79 . 


\section{Documentos de hemeroteca}

Boletín del Instituto Riva Agüero № 24 Ed. PUCP, 1997 p.383

El Mercurio Peruano (1791) Lima, 17 de febrero. Razones físicas que reprueban la costumbre de enterrar a los muertos en las iglesias. (Num.s/d) p.s/n.

El Mercurio Peruano (1791) Lima, 17 de febrero. Razones físicas que reprueban la costumbre de enterrar en Iglesias. (Núm. 14), fol 124

El Mercurio Peruano (1791) Lima, 2 de enero. Idea general del Perú. (Núm. 01), p. 01.

El Mercurio Peruano (1791) Lima, 3 de febrero. Reflexiones históricas políticas sobre el estado de la población de esta capital. (Núm. 10), p. 91-95.

El Mercurio Peruano (1828) Lima, 19 de setiembre. Cuadro estadístico de la población, riqueza y contribuciones de la provincia del Cercado del Departamento de Lima, (Núm. 331), pp. 03.

El Mercurio Peruano (1828) Lima, 26 de abril. Interior, respecto al terremoto del 30 de marzo, (Núm. 215), pp. 01.

El Mercurio Peruano (1871) Lima, 17 de noviembre. Proyectos literarios. (Núm. 91), pp. 196.

La Minerva Peruana (1810) Lima, 1 de julio. Circular. (Núm. 41), pp.305.

La Minerva Peruana (1810) Lima, 16 de noviembre. Bayona. (Núm. 40), pp. 295.

La Minerva Peruana (1810) Lima, 26 de mayo. Rasgo del Diario de Sevilla. (Núm. 35), pp.269.

La Minerva Peruana (1871) Lima, 10 de mayo. Libertad de la prensa. (Núm. 329), pp. 242-243.

La Minerva Peruana (1810) Lima, 9 de junio. Cartas. (Núm.40),p.296.

El Verdadero Peruano (1812) Lima, 12 de noviembre. Discurso político. (Núm. 08), pp. 61.

El Verdadero Peruano (1812) Lima, 22 de octubre. Salud pública. (Núm. 05), pp. 37.

El Triunfo de la Nación (1821) Lima, 12 de junio. Ensayo sobre el espíritu público de las naciones. (Núm. 35), pp. 01.

El Tribuno de la República Peruana (1822). Lima, 28 de noviembre. Apuntamientos sobre la libertad civil. (Núm. 01), pp. 01.

El Tribuno de la República Peruana (1822). Lima,19 diciembre. Política. (Núm./n)

La Abeja Republicana (1822) 11 de agosto. Reflexiones políticas sobre el origen de las sociedades y objeto de ellas. (Núm. 03), año 1822 pp. 26-27. 
El Telégrafo de Lima (1836) Lima, 30 de setiembre. Intendencia de policía, (Núm. 948) pp.s/p.

El intérprete del pueblo (1852). Lima. 27 de abril. Plaza del Mercado, (Núm. 75), pp. 0

Diario Registro oficial (1853). Lima 08 de enero. Tomo III, (Núm.02), p.13.

Diario Registro oficial (1853). Lima 5 de julio. Tomo III, (Núm.29).p.1

Diario El Comercio de Lima (1866), Lima, 18 de enero. Reglamento de Municipalidades (Núm, s/d), pp.1-7

Diario El Comercio de Lima (1866), Lima, 21 de junio. Reglamento de Policía pp.(Núm,s/d),pp.1-6.

Diario El Comercio de Lima (1908) Lima, 02 febrero. Compañía Urbanizadora Cocharcas, (Núm. 31,897), pp.07.

Diario El Nacional (1870) Lima, 04 de febrero. Población de Lima, (Núm. 1414), pp.01.

Diario El Nacional (1870) Lima, 18 de febrero. Nuevo Banco Hipotecario, (Núm.1427), pp.01.

La crónica médica, (1889). Lima, 31 de agosto. Sociedades Amantes de la Ciencia, (Núm./d), pp.182-183.

La crónica médica, (1889). Lima, 31 de enero. Reglamento Sanitario Provincial de Lima, (Núm./d), pp.6-7.

La crónica médica, (1890). Lima, 31 de julio. Nuestras víctimas en la última guerra con Chile, (Núm./d), pp.01.

Diario Judicial, (1892). Lima,09 de mayo. Lotes de terrenos en las calles Sandia, Bogotá y San Carlos por la Municipalidad, (Núm.538), pp.2207.

La crónica médica, (1906). Lima, 31 de marzo. Proyecto para el nuevo hospital de mujeres de Lima, (Núm.414), pp.82-93.

La Opinión Nacional (1875) Lima, 27 de marzo. Beneficencia, (Núm./d), pp.01.

Diario Oficial El Peruano (1845) Lima, 20 de abril. Discurso del presidente Ramón Castilla. Tomo 22, (Núm. 33), 01.

Diario Oficial El Peruano (1854) Lima, 24 de junio. Ley para el desarrollo de las estadísticas. Tomo 25 (Núm. 40), pp. 164-166.

Diario Oficial El Peruano (1867) Lima, 29 de agosto. Sobre la obra pública .Tomo 53 (Núm. 12), pp. 51.

Diario Oficial El Peruano (1868) Lima, 03 de agosto. Discurso del Presidente José Balta .Tomo 55 (Núm. 29), pp. 115.

Diario oficial El Peruano (1869) Lima, 04 de mayo. Presupuesto General de la República, Tomo 56, (Num.102), fol. 299. 
Diario Oficial El Peruano (1869) Lima, 01 de mayo. Funciones de los comisarios de policía .Tomo 52 (Núm. 161), pp. 295.

Diario Oficial El Peruano (1869) Lima, 01 de setiembre. Sobre la canalización de las acequias .Tomo 57 (Núm. 59), pp. 199.

Diario Oficial El Peruano (1869) Lima, 02 de agosto. Parque de la exposición .Tomo 57 (Núm. 25), pp. 99.

Diario Oficial El Peruano (1869) Lima, 02 de diciembre. Justificación ante el país de porque era necesaria la demolición de la muralla en seis razones y nueve incisos. Tomo 57, (Núm. 121), pp. 451.

Diario Oficial El Peruano (1869) Lima, 02 de diciembre. Decreto del Presidente José Balta. Tomo 57, (Núm. 121), pp. 451.

Diario Oficial El Peruano (1869) Lima, 06 de marzo. Propuestas para el puente del Río Rímac .Tomo 56 (Núm. 54), pp. 217.

Diario El oficial El Peruano (1869) Lima, 26 de mayo. Presupuesto General del la República. Tomo 56, (Núm. 120).p.01

Diario Oficial El Peruano (1869) Lima, 15 de julio. Respecto al camino carretero entre Lima y Callao. Tomo 57 (Núm. 31), pp.51.

Diario Oficial El Peruano (1869) Lima, 13 de agosto. Prolongación del Jardín Botánico Tomo 57 (Núm. 35), pp.136.

Diario oficial El Peruano (1870) Lima, 11 de marzo. Decreto supremo sobre Ley de Expropiación, Tomo 58, (Núm. 55), pág. 207.

Diario Oficial El Peruano (1871) Lima, 07 de octubre. Respecto a los terrenos de las murallas. Tomo 02, (Núm.13), pp. 389-390.

Diario Oficial El Peruano (1871) Lima, 11 de febrero. Sobre la construcción del Palacio de la Exposición. Tomo 01, (Núm. 02), pp. 23-24.

Diario Oficial El Peruano (1871) Lima, 12 de abril. Sobre los recursos de la Municipalidad de Lima. Tomo 56, (Núm. 84), pp. 233.

Diario Oficial El Peruano (1871) Lima, 16 de setiembre. Alumbrado público de Lima a la empresa de Don Ricardo Martí. Tomo 02, (Núm.10), pp. 229.

Diario Oficial El Peruano (1871) Lima, 16 de setiembre. Decreto respecto a la venta de los terrenos de las murallas. Tomo 02, (Núm. 10), pp. 229.

Diario Oficial El Peruano (1871) Lima, 17 de junio. Reglamento los procedimientos de venta y construcción de las edificaciones en la nueva periferia. Tomo 01, (Núm. 20), pp. 578.

Diario Oficial El Peruano (1871) Lima, 20 de mayo. Respecto a los terrenos al lado del Río Rímac. Tomo 01, (Núm. 16), pp. 463. 
Diario Oficial El Peruano (1871) Lima, 29 de abril. Clausula de contrato con empresa de agua. Tomo 01 (Núm. 23), pp. 399.

Diario Oficial El Peruano (1871) Lima, 29 de abril. Contrato con empresa de agua en la capital. Tomo 01, (Núm. 13), pp. 399.

Diario Oficial El Peruano (1871) Lima, 30 de setiembre. Nombramiento del arquitecto San Martín como administrador de los peticionarios de los terrenos de las murallas. Tomo 02, (Núm. 22), pp. 301.

Diario oficial El Peruano (1872) Lima, 20 de enero. Decreto sobre Meiggs como único postor sobre terrenos de la muralla. Tomo 1 (Núm.3), pp.65.

Diario Oficial El Peruano (1872) Lima, 23 de marzo. Manifiesto de los ingresos y egresos de la Tesorería Municipal. Tomo 01, (Núm.10), pp. 336-339

Diario oficial El Peruano (1872) Lima, 15 de junio. Expropiación de terrenos para abrir calles nuevas según plano de Sada. Tomo 1 (Núm. 22). pp.661.

Diario Oficial El Peruano (1872) Lima, 15 de junio. Modificaciones propuestas para la alameda. Sobre la alameda que une Lima y Callao. Tomo 1 (Núm. 22), pp. 660.

Diario Oficial El Peruano (1872) Lima, 15 de junio. Proyecto para la construcción de la nueva cárcel de la ciudad. Tomo 01, (Núm. 22), pp. 661.

Diario Oficial El Peruano (1872) Lima, 06 de julio. Sobre el Palacio de la Exposición. Tomo 02, (Núm. 01), pp.04

Diario Oficial El Peruano (1872) Lima, 13 de julio. Sobre la alameda que une Lima y Callao. Tomo 2 (Núm.2), pp.12

Diario Oficial El Peruano (1872) Lima, 13 de julio. Traslado de la estatua de Colón. Tomo 02, (Núm. 02), pp.10.

Diario Oficial El Peruano (1872) Lima, 06 de agosto. Enrique Meiggs como único postor a la compra de los terrenos de las murallas. Tomo 02, (Núm. 09), pp. 065.

Diario Oficial El Peruano (1872) Lima, 02 de noviembre. Reglamento para el servicio de los ingenieros civiles y arquitectos del Estado. Tomo 02, (Núm. 23), pp. 278-281.

Diario Oficial El Peruano (1872) Lima, 14 de diciembre. Alumbrado público traído para la bajada de Chorrillos. Tomo 02, (Núm. 30) pp. 371.

Diario Oficial El Peruano (1872) Lima, 14 de diciembre. Decreto respecto a reglas que deben sujetarse los empresarios que realizan obras con el Estado. Tomo 02, (Núm. 30), pp. 376-377.

Diario Oficial El Peruano (1873) Lima, 11 de enero. Alumbrado en Calle Malambo. Tomo 01, (Núm. 02), pp.13

Diario Oficial El Peruano (1873) Lima, 11 de enero. Alumbrado público en sitios despoblados. Tomo 01, (Núm. 02), pp.16. 
Diario Oficial El Peruano (1873) Lima, 25 de enero. Respecto al monumento del Dos de Mayo. Tomo 01 (Núm. 04), pp. 66.

Diario Oficial El Peruano (1873) Lima, 17 de mayo. Sobre Huerta de Miota. Tomo 01. (Núm. 20), pp. 561.

Diario Oficial El Peruano (1873) Lima, 19 de abril. Fijación de sitios para el palacio de Gobierno y Legislativo. Tomo 1 (Núm. 16), pp. 461.

Diario Oficial El Peruano (1873) Lima,, 19 de abril. Solicitud en la que Enrique Meiggs pide que se indique la manera como debe proceder en el juicio de expropiación de las cofradías, comunidades y municipios, que son necesarios para la ejecución de las obras. Tomo I (Núm.16), p.08.

Diario Oficial El Peruano (1873) Lima, 13 de julio. Sobre el plano de Luis Sada. Tomo 2 (Núm. 2), pp. 461.

Diario Oficial El Peruano (1873) Lima, 27 de setiembre. Arreglo del muro en la ribera del Tajamar. Tomo 02, (Núm. 13), pp. 321.

Diario Oficial El Peruano (1873) Lima, 27 de setiembre. Nombramiento a Don Manuel Antonio Viñas como ingeniero del Estado. Tomo 02, (Núm. 13), pp. 319.

Diario Oficial El Peruano (1873) Lima, 18 de octubre. Respecto al programa propuesto por la Junta Central de Ingenieros. Tomo 02, Núm. 16, pp 411

Diario Oficial El Peruano (1873) Lima, 25 de octubre. Solicitud de Don Cesar Saco respecto al decreto del 29 de agosto. Tomo 02, (Núm. 17), pp. 457.

Diario Oficial El Peruano (1874) Lima, 1 de julio. Obra en Plaza 02 de Mayo. Tomo 02, (Núm. 01), pp. 1.

Diario Oficial El Peruano (1874) Lima, 28 de diciembre. Autorización al rector de San Marcos. Tomo 2 (Núm. 140), pp. 557.

Diario Oficial El Peruano (1875) Lima, 030 de diciembre. Pago por canalización al costado del Jardín Botánico. Tomo 02, (Núm. 47), pp. 181.

Diario oficial El Peruano, (1884). Lima, 23 de febrero. Decreto sobre la restauración de la Biblioteca Nacional, (Núm.8) pp.203.

Diario oficial El Peruano, (1884). Lima, 23 de febrero. Preparación de proyecto de Ley para concesiones, adjudicaciones y administraciones de obras públicas, (Núm.8) pp.204.

Diario oficial El Peruano, (1884). Lima, 29 de marzo. Cuenta de su despacho del señor Ministro de Gobierno a la Asamblea Constituyente, (Núm.13), pp.315-321.

Diario oficial El Peruano, (1884). Lima, 29 de marzo. Local de la Exposición Nacional, (Núm.13),pp.319-331.

Diario oficial El Peruano, (1884). Lima, 29 de marzo. Orden Público, (Núm.13),pp.315 
Diario oficial El Peruano, (1884). Lima, 29 de marzo. Sección de gobierno, (Núm.13), pp.319-333.

Diario oficial El Peruano, (1884). Lima, 15 de marzo. Salarios de arquitectos e ingenieros del Estado, (Núm. 11), pp.s/n.

Diario oficial El Peruano (1884).Lima, 5 julio. Reglamento General de Obras Públicas en el cual se clasificaban las obras en: fiscales, municipales, corporativas, particulares y en el vecindario. (Núm. 1), p.s/n.

Diario oficial El Peruano, (1884). Lima, 15 de octubre. Prescripciones reglamentarias sobre proyectos de obras públicas, (Núm.11), pp.186-188.

Diario oficial El Peruano, (1884). Lima, 18 de octubre. Reglamento general de sanidad, (Núm.12) pp.205-214.

Diario oficial El Peruano, (1885). Lima, 15 de marzo. Resolución sobre la reconstrucción de la Casa de Correos, (Núm.11), pp.179.

Diario oficial El Peruano, (1885). Lima, 13 de marzo. Resolución sobre Construcción del colegio del Sagrado Corazón en la Venturosa de propiedad de la Beneficencia, (Núm.11), pp.196.

Diario oficial El Peruano, (1885). Lima, 13 de junio. Resolución referida a la reconstrucción de paredes de la Casa de Gobierno, (Núm.22), pp.337.

Diario oficial El Peruano, (1886). Lima, 14 de julio. Sobre el Ferrocarril de Lima a Chancay, (Núm.6), pp.44.

Diario oficial El Peruano, (1886). Lima, 16 de julio. Resolución sobre Fachada del Palacio de Gobierno, (Núm.7), pp.51.

Diario oficial El Peruano, (1886). Lima, 16 de julio. Resolución sobre la reorganización de la fuerza policial, (Núm.7), pp.49.

Diario oficial El Peruano, (1886). Lima, 16 de julio. Resolución sobre colocación de servicio telefónico, (Núm.7), pp.51.

Diario oficial El Peruano, (1886). Lima, 06 de agosto. Resolución sobre alumbrado del Palacio de Gobierno, (Núm./d), pp.117.

Diario oficial El Peruano, (1886). Lima, 06 de agosto. Resolución sobre construcción de la Casa de Correos, (Núm.15), pp.117.

Diario oficial El Peruano, (1886). Lima, 06 de noviembre. Reglamento General de Instrucción Pública, (Núm.48), pp. 49.

Diario oficial El Peruano, (1886). Lima, 16 de noviembre. Sobre la construcción de la Línea férrea Lima-Pisco, (Núm.52), pp.409.

Diario oficial El Peruano, (1886). Lima, 20 de noviembre. Ley de descentralización fiscal, (Núm.55), pp.435-436. 
Diario oficial El Peruano, (1888). Lima, enero. Registro de propiedad inmueble, (Núm.1) pp.5-6. Edición Complementaria.

Diario oficial El Peruano, (1889). Lima, viernes 4 enero. Ley Payán de garantías hipotecarias, (Núm.1), pp.04-06.

Diario oficial El Peruano, (1890). Lima, 11 de agosto. Transmisión del mando supremo, (Núm.s/d),pp.105.

Diario oficial El Peruano, (1890). Lima, 4 julio. Referente al contrato con Peruvian Telephone Company, (Núm.8), pp.241.

Diario oficial El Peruano, (1890). Lima, 17 de noviembre. Reglamento de licencias de comercios en la ciudad, (Núm.31), pp.458.

Diario oficial El Peruano, (1891). Lima, 24 de octubre. Resolución referente a los servicios de agua, luz y transporte a Barranco, (Núm.48), pp.382.

Diario oficial El Peruano, (1891). Lima, 17 de julio. Resolución referente a construcción de la cripta para los héroes de la guerra con Chile, (Núm.7), pp.53

Diario oficial El Peruano, (1891). Lima, 17 de setiembre. Resolución referente a la reparación del puente de Piedra, (Núm.32), pp.251.

Diario oficial El Peruano, (1892). Lima, 02 de abril. Consejo superior de instrucción pública, (Núm.40), pp.317.

Diario oficial El Peruano, (1892). Lima, 21 de mayo. Resolución referente al pago a las cinco comisarías de la ciudad, (Núm.60), pp.475.

Diario oficial El Peruano, (1892). Lima, 22 de octubre. Ley de municipalidades, (Núm.46), pp.364-370.

Diario oficial El Peruano, (1892). Lima, 22 de octubre. Ley de municipalidades, pp.364372

Diario oficial El Peruano, (1893). Lima, 07 de noviembre. Resolución sobre las obras en el Palacio de gobierno, (Núm.56), pp.443.

Diario oficial El Peruano, (1893). Lima, 11 de noviembre. Sobre la protesta de los herederos de Meiggs, (Núm.58), pp.459.

Diario oficial El Peruano, (1893). Lima, 28 de agosto. Sobre el empadronamiento de los terrenos de las murallas, (Núm.8), pp.223.

Diario oficial El Peruano, (1896). Lima, 04 de febrero. Contrato con Empresa del Tranvía, (Núm.10), pp.75.

Diario oficial El Peruano, (1896). Lima, 03 de octubre. Sobre el interdicto de los herederos de Meiggs, Tomo II (Núm,34.), pp.270. 
Diario oficial el Peruano, (1896), Lima sábado 03 de octubre. Presupuesto del costo que ha de ocasionar el levantamiento del plano catastral de los terrenos de las murallas, Tomo II, Núm. 34, p.239

Diario oficial El Peruano, (1897). Lima, 18 de enero. Terrenos de las antiguas murallas de Lima y los demás expropiados por D. Enrique Meiggs para la alameda de circunvalación, (Núm.s/d), pp.64.

Diario oficial El Peruano, (1897). Lima, 21 de enero. Resolución referida al proyecto de la Cárcel de Lima, (Núm.10), pp.74.

Diario oficial El Peruano, (1898). Lima, 22 de enero. Prolongación de avenida Alfonso Ugarte, (Núm.9), pp.70.

Diario oficial El Peruano, (1899). Lima, 08 de febrero. Sobre la Avenida La Magdalena, (Núm.25), pp.104.

Diario oficial El Peruano, (1899). Lima, 10 de febrero. Sobre el haber al Dr. Enrique

Silgado, (Núm.27), pp.112.

Diario oficial El Peruano, (1899). Lima, 15 de febrero. Resolución para solicitar propuestas para el Tranvía en La Magdalena, (Núm.29), pp.119.

Diario oficial El Peruano, (1899). Lima, 12 de mayo. Resolución referida al proyecto del Colegio Guadalupe, (Núm.96), pp.413.

Diario oficial El Peruano, (1899). Lima, 24 de junio. Sobre trabajos en la avenida La Magdalena, (Núm.132), pp.582

Diario oficial El Peruano, (1899). Lima, 24 de junio. Resolución referida a la construcción de la Cárcel de Mujeres, (Núm.132), pp.583

Diario oficial El Peruano, (1899). Lima, 30 de junio. Resolución sobre la construcción del tranvía Lima a La Magdalena, (Núm.136), pp.601.

Diario oficial El Peruano, (1899). Lima, 14 de julio. Resolución referida a la construcción de la Escuela de Medicina, (Núm.12), pp.50.

Diario oficial El Peruano, (1899). Lima, 16 de setiembre. Sobre obras de construcción del Colegio Guadalupe, (Núm.60),pp.323.

Diario oficial El Peruano, (1899). Lima, 16 de setiembre. Sobre trabajos de canalización en Avenida La Magdalena, (Núm.60), pp.323

Diario oficial El Peruano, (1899). Lima, 11 de diciembre. Resolución sobre el presupuesto de los trabajos en La Magdalena, (Núm.131), pp.628.

Diario oficial El Peruano, (1899). Lima, 11 de diciembre. Sobre obras en Avenida La

Magdalena, (Núm.131), pp.628. 
Diario oficial El Peruano, (1899). Lima, 16 de diciembre. Condiciones Higiénicas para las Casas Escuelas, (Núm.136), pp.649-655.

Diario oficial El Peruano, (1899). Lima, 16 de diciembre. Sobre contrato de alumbrado eléctrico, (Núm.136), pp.658-660.

Diario oficial El Peruano, (1900). Lima, 29 de enero. Reconocimiento a Carlos Watson como contratista del Tranvía Lima a La Magdalena, (Núm.22), pp.116.

Diario oficial El Peruano, (1900). Lima, 20 de abril. Sobre dotación de agua para la Cárcel de Guadalupe y el Palacio de Justicia, (Núm.67), pp.400.

Diario oficial El Peruano, (1900). Lima, 12 de mayo. Resolución referida a la asignación del presupuesto al proyecto de mejoramiento de Avenida La Magdalena, (Núm.77), pp.480.

Diario oficial El Peruano, (1900). Lima, 15 de junio. Resolución referida a la asignación semanal del proyecto de mejoramiento de Avenida La Magdalena, (Núm.94), pp.615.

Diario oficial El Peruano, (1900). Lima, 20 de junio. Respecto a la reparación de canales en la Avenida La Magdalena, (Núm.99), pp.654.

Diario oficial El Peruano, (1900). Lima, 20 de junio. Sobre cobro al estado de parte de la empresa de Ferrocarril Lima-Chorrillos, (Núm.99), pp.654.

Diario oficial El Peruano, (1900). Lima, 17 de noviembre. Ley general de expropiaciones, (Núm.54), pp.298-300.

Diario oficial El Peruano, (1901). Lima, 13 de abril. Resolución sobre el uso de la Estación de San Juan de Dios como paradero del tranvía Lima-Magdalena, (Núm.48), pp.305.

Diario oficial El Peruano, (1901). Lima, 13 de abril. Sobre el proyecto de Hospital de Insanos, (Núm.48), pp.306.

Diario oficial El Peruano, (1901). Lima, 13 de abril. Sobre la expropiación de terrenos de las murallas, (Núm.48), pp.305.

Diario oficial El Peruano, (1901). Lima, 13 de abril. Sobre las líneas del ferrocarril inglés por la Avenida Alfonso Ugarte, (Núm.48), pp.305.

Diario oficial El Peruano, (1901). Lima, 17 de mayo. Sobre estatua de Bolognesi en ovalo del mismo nombre, (Núm.76), pp.531.

Diario oficial El Peruano, (1901). Lima, 10 de junio. Sobre construcción de escuela de medicina, (Núm.95), pp.675.

Diario oficial El Peruano, (1901). Lima, 10 de junio. Sobre el contrato de Meiggs, (Núm.95), pp.675.

Diario oficial El Peruano, (1901). Lima, 16 de agosto. Respecto a los documentos de venta de terrenos de las murallas, (Núm.37), pp.288. 
Diario oficial El Peruano, (1901). Lima, 28 de agosto. Resolución suprema respecto a una nueva vía, (Núm.47), pp.339.

Diario oficial El Peruano, (1901). Lima, 09 de setiembre. Mensaje de Eduardo L. de Romaña, (Núm.s/d), pp.277-278.

Diario oficial El Peruano, (1902). Lima, 24 de abril. Sobre la creación del registro mercantil, (Núm.s/d), pp.754-756.

Diario oficial El Peruano, (1902). Lima, 08 de julio. Sobre dotación de agua en el Callao, (Núm.s/d), pp.55.

Diario oficial El Peruano, (1902). Lima, 28 de octubre. Ley de Registro de Predios, (Núm.95), pp.689-690.

Diario oficial El Peruano, (1902). Lima, 17 de diciembre. Decreto de nuevas poblaciones, pp.1021.

Diario oficial El Peruano, (1903). Lima, 30 de enero. Sobre el trazo del tranvía de Lima, (Núm.24), pp.190.

Diario oficial El Peruano, (1903). Lima, 02 de marzo. Sobre la alineación de avenida La Industria, (Núm.47), pp.375.

Diario oficial El Peruano, (1903). Lima, 20 de junio. Sobre expropiación del fundo Barboncito, (Núm.136), pp.1078.

Diario oficial El Peruano, (1903). Lima, 23 de junio. Sobre expropiación del fundo Limatambo, (Núm.138), pp.1095.

Diario oficial El Peruano, (1903). Lima, 26 de junio. Sobre concesión del tranvía LimaCallao, (Núm.141), pp.1118.

Diario oficial El Peruano, (1903). Lima, 20 de julio. Sobre dotación de agua potable en la Magdalena, (Núm.17), pp.131.

Diario oficial El Peruano, (1903). Lima, 31 de julio. Mensaje del presidente de la república en la instalación del Consejo Extraordinario, (Núm.23), pp.162-168.

Diario oficial El Peruano, (1903). Lima, 07 de noviembre. Ley de Expropiación, (Núm.103), pp.679.

Diario oficial El Peruano, (1903). Lima, 16 de diciembre. Resolución sobre expropiación de terrenos de Mirones, (Núm.132), pp.908.

Diario oficial El Peruano, (1903). Lima, 16 de diciembre. Resolución sobre contrato de agua potable, (Núm.132, pp.908.

Diario oficial El Peruano, (1904). Lima, 08 de enero. Resolución sobre la construcción del monumento a Bolognesi, (Núm.s/d), pp.40.

Diario oficial El Peruano, (1904). Lima, 26 de marzo. Reglamento de la Escuela Normal de Mujeres de Lima, (Núm.s/d),pp.524. 
Diario oficial El Peruano, (1904). Lima, 29 de marzo. Resolución referida a abastecimiento de tren por la empresa eléctrica Santa Rosa, (Núm.68), pp.541.

Diario oficial El Peruano, (1904). Lima, 27 de setiembre. Mensaje a la nación de José Pardo, (Núm.59),pp.466-467.

Diario oficial El Peruano, (1905). Lima, 15 de junio. Resolución referida a expropiación de terrenos en Miraflores por el tranvía Lima-Chorrillos, (Núm.72), pp.311-312.

Diario oficial El Peruano, (1905). Lima, 05 de julio. Entrega del tranvía Línea B, (Núm.s/d), pp.5.

Diario oficial El Peruano, (1905). Lima, 24 de agosto. Resolución referida a la construcción del segundo piso del mercado de La Concepción, (Núm.23), pp.190.

Diario oficial El Peruano, (1905). Lima, 30 de noviembre. Resolución referida a la dotación de agua potable en el Callao, (Núm.50), pp.511.

Diario oficial El Peruano, (1906). Lima, 05 de julio. Resolución referida al tranvía urbano de Lima, (Núm.01),pp.5-6.

Diario oficial El Peruano, (1906). Lima, 09 de agosto. Resolución referida ampliación del tranvía de Lima, (Núm.8),pp.60.

Diario oficial El Peruano, (1906). Lima, 09 de agosto. Resolución referente a la línea del tranvía al centro, (Núm.8), pp.60.

Diario oficial El Peruano, (1906). Lima, 31 de agosto. Resolución referente a la línea C del tranvía, (Núm.11), pp.87.

Diario oficial El Peruano, (1907). Lima, 05 de agosto. Resolución referente a la alameda de Miraflores, (Núm.29), pp.318.

Diario oficial El Peruano, (1907). Lima, 06 de setiembre. Resolución referente a obras de ensanche en Miraflores, (Núm.s/d), pp.632.

Diario oficial El Peruano, (1907). Lima, 12 de setiembre. Resolución referente a construcción de avenida Miraflores, (Núm.60), pp.689.

Diario oficial El Peruano, (1907). Lima, 06 de noviembre. Resolución referente a construcción de avenida Miraflores, (Núm.105), pp.1235.

Diario oficial El Peruano, (1907). Lima, 06 de noviembre. Resolución referente a avenida La Magdalena, (Núm.105), pp.1235.

Diario oficial El Peruano, (1908). Lima, 13 de marzo. Resolución referente a ampliación de línea del tranvía, (Núm.51), pp.462.

Diario oficial El Peruano, (1908). Lima, 01 de agosto. Resolución referente al proyecto de la cárcel de Lima, (Núm.19), pp.222.

Diario oficial El Peruano, (1908). Lima, 19 de octubre. Resolución referente al tranvía Lima-Chorrillos, (Núm.59), pp.707. 
Diario La Prensa, (1905). Lima, 17 de diciembre. Estadística municipal, (Núm.1291), pp.02.

Diario La Prensa, (1908). Lima, 10 de enero. Inspección de higiene, (Núm.s/d), pp.04.

Diario La Prensa (1908).Lima, 8 marzo. La recrudescencia de la bubónica en Lima- El ensanche de Petateros lo acordado ayer por la Beneficencia" - Imagen del callejón de Petateros, (Num, 2704).p.s/d.

Diario La Prensa, (1908). Lima, 22 de abril. El saneamiento de la ciudad de Lima, (Núm.2775), pp.01.

Diario La Prensa, (1908). Lima, 12 de julio. Por los barrios de La Victoria, (Núm.2923), pp.01.

Diario La Prensa, (1908). Lima, 27 de julio. El censo de Lima, (Núm.2951), pp.03.

Registro Oficial (1853) Lima, 05 de julio. Creación de la Escuela de Ingenieros. Tomo 03, (Núm. 29), pp. 217-220.

Registro Oficial (1853) Lima, 08 de enero. Informe respecto a los ingenieros civiles del estado. Tomo 03, (Núm. 02), pp. 13-14. 